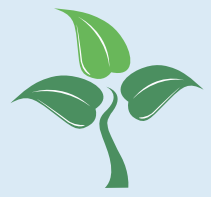

\title{
sustainability
}

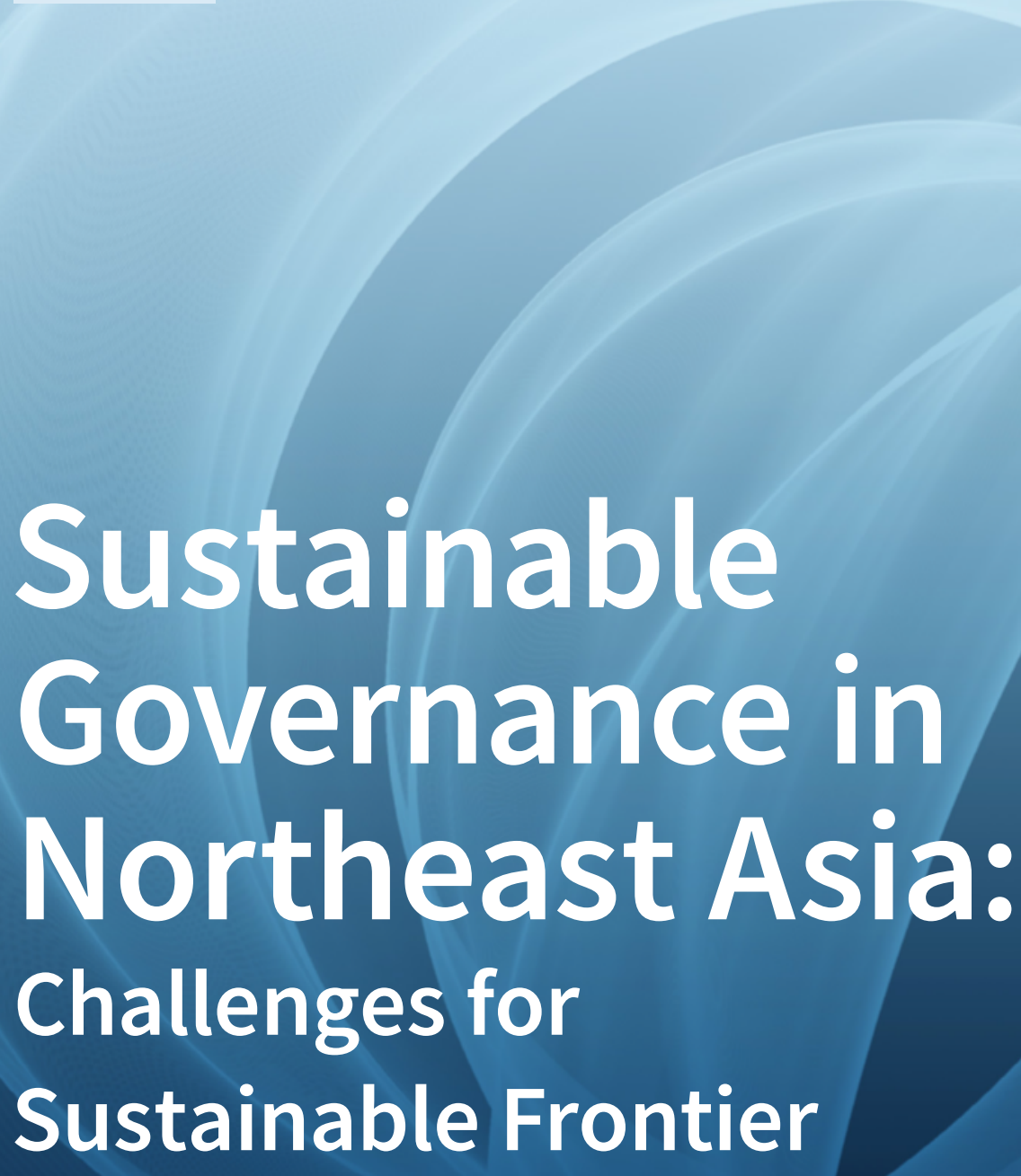

Edited by Yongrok Choi, Malin Song and Seunghwan Myeong Printed Edition of the Special Issue Published in Sustainability 
Sustainable Governance in

Northeast Asia: Challenges for Innovation Frontier 



\section{Sustainable Governance in Northeast Asia: Challenges for Innovation Frontier}

Special Issue Editors

Yongrok Choi

Malin Song

Seunghwan Myeong 
Special Issue Editors

Yongrok Choi

Inha University

Korea

Seunghwan Myeong

Inha University

Korea

\section{Editorial Office}

MDPI

St. Alban-Anlage 66

Basel, Switzerland

\section{Malin Song}

Longhu Scholar of Anhui University of Finance and Economics (AUFE)

China

This is a reprint of articles from the Special Issue published online in the open access journal Sustainability (ISSN 2071-1050) from 2015 to 2016 (available at: http://www.mdpi.com/journal/ sustainability/special_issues/innovation-frontier)

For citation purposes, cite each article independently as indicated on the article page online and as indicated below:

LastName, A.A.; LastName, B.B.; LastName, C.C. Article Title. Journal Name Year, Article Number, Page Range.

ISBN 978-3-03897-153-5 (Pbk)

ISBN 978-3-03897-154-2 (PDF)

Articles in this volume are Open Access and distributed under the Creative Commons Attribution (CC BY) license, which allows users to download, copy and build upon published articles even for commercial purposes, as long as the author and publisher are properly credited, which ensures maximum dissemination and a wider impact of our publications. The book taken as a whole is (C) 2018 MDPI, Basel, Switzerland, distributed under the terms and conditions of the Creative Commons license CC BY-NC-ND (http:/ / creativecommons.org/licenses/by-nc-nd/4.0/). 


\section{Contents}

About the Special Issue Editors $\ldots \ldots \ldots \ldots \ldots \ldots \ldots \ldots$ vii

Yongrok Choi, Malin Song and Seunghwan Myeong

Introduction to the Special Issue on the Sustainable Asia Conference 2015

Reprinted from: Sustainability 2016, 8, 266, doi: 10.3390/su8030266 . . . . . . . . . . . . . 1

Wen Guo, Tao Sun and Hongjun Dai

Effect of Population Structure Change on Carbon Emission in China

Reprinted from: Sustainability 2016, 8, 225, doi: 10.3390/su8030225 . . . . . . . . . . . . . 10

Bongjoon Kim and Taeyoung Kim

A Study on Estimation of Land Value Using Spatial Statistics: Focusing on Real Transaction

Land Prices in Korea

Reprinted from: Sustainability 2016, 8, 203, doi: 10.3390/su8030203 . . . . . . . . . . . . . 30

Huasheng Zhu, Xue Huang, Qingcan He, Jie Li and Lingzhi Ren

Sustaining Competitiveness: Moving Towards Upstream Manufacturing in Specialized-Market-Based

Clusters in the Chinese Toy Industry

Reprinted from: Sustainability 2016, 8, 176, doi: 10.3390/su8020176 . . . . . . . . . . . . . 44

Hongjun Dai, Tao Sun and Wen Guo

Brownfield Redevelopment Evaluation Based on Fuzzy Real Options

Reprinted from: Sustainability 2016, 8, 170, doi: 10.3390/su8020170 . . . . . . . . . . . . . 63

Shujing Yue, Yang Yang and Yaoyu Hu

Does Foreign Direct Investment Affect Green Growth? Evidence from China's Experience

Reprinted from: Sustainability 2016, 8, 158, doi: 10.3390/su8020158 . . . . . . . . . . . . 73

Fang Yang, Shiying Pan and Xin Yao

Regional Convergence and Sustainable Development in China

Reprinted from: Sustainability 2016, 8, 121, doi: 10.3390/su8020121 . . . . . . . . . . . . . . 87

Tong Fu, Hongzhang Chen and Yongrok Choi

Does the Sustainable PPI Investments Promote Financial Market's Sustainable Development?

Reprinted from: Sustainability 2016, 8, 120, doi: 10.3390/su8020120 . . . . . . . . . . . . . 102

Lei Li, Ting Chi, Meng Zhang and Shi Wang

Multi-Layered Capital Subsidy Policy for the PV Industry in China Considering

Regional Differences

Reprinted from: Sustainability 2016, 8, 45, doi: 10.3390/su8010045 . . . . . . . . . . . . . 121

Huiming Zhang, Yu Zheng, Dequn Zhou and Peifeng Zhu

Which Subsidy Mode Improves the Financial Performance of Renewable Energy Firms? A Panel

Data Analysis of Wind and Solar Energy Companies between 2009 and 2014

Reprinted from: Sustainability 2015, 7, , doi: 10.3390/su71215831 . . . . . . . . . . . . . . 136

Rui Zhao, Hualing He and Ning Zhang

Regional Water Footprint Assessment: A Case Study of Leshan City

Reprinted from: Sustainability 2015, 7, 16532-16547, doi: 10.3390/su71215829 . . . . . . . . . . 149 


\section{Zhengning Pu, Hui Wang, Haili Bian and Jiasha Fu}

Sustainable Lake Basin Water Resource Governance in China: The Case of Tai Lake

Reprinted from: Sustainability 2015, 7, 16422-16434, doi: 10.3390/su71215824 . . . . . . . . . . . . 165

\section{Gang Du and Chuanwang Sun}

Location Planning Problem of Service Centers for Sustainable Home Healthcare: Evidence from the Empirical Analysis of Shanghai

Reprinted from: Sustainability 2015, 7, 15812-15832, doi: 10.3390/su71215787 . . . . . . . . . . . 178

\section{Yuhuan Sun, Qian Li, Ting Chen and Xiaoai Jia}

Dynamic Factor Analysis of Trends in Temporal-Spatial Patterns of China's Coal Consumption

Reprinted from: Sustainability 2015, 7, 15119-15135, doi: 10.3390/su71115119 . . . . . . . . . . . 199

\section{Yongrok Choi}

Intermediary Propositions for Green Growth with Sustainable Governance

Reprinted from: Sustainability 2015, 7,14785-14801, doi: 10.3390/su71114785 . . . . . . . . . . . . 213

\section{Kejia Chu, Ning Zhang and Zhongfei Chen}

The Efficiency and Its Determinants for China's Medical Care System: Some Policy Implications for Northeast Asia

Reprinted from: Sustainability 2015, 7, 14092-14111, doi: 10.3390/su71014092 . .

\section{Hualin Xie and Wei Wang}

Exploring the Spatial-Temporal Disparities of Urban Land Use Economic Efficiency in China and Its Influencing Factors under Environmental Constraints Based on a Sequential Slacks-Based Model

Reprinted from: Sustainability 2015, 7, 10171-10190, doi: 10.3390/su70810171 . . . . . . . . . . . 246 


\section{About the Special Issue Editors}

Yongrok Choi, Ph.D. is a Distinguished Professor of Inha University (Inha Fellow Professor). He is the organizer of the Asia Business Forum, which has managed the Sustainable Asia Conference (SAC—http:/ / abf.inha.ac.kr/) since 2009. Every year the SAC conference publishes a special edition in Sustainability.

Malin Song is the Director of the Research Center of Statistics for Management, Anhui University of Finance and Economics. His primary research fields include Environmental Economics and System Modeling and Analysis.

Seunghwan Myeong is a professor in the Department of Public Administration, Inha University (Incheon, Korea). He received his Ph.D. from Syracuse University in 1996. His research interests are in electronic government and e-governance, information management in public organizations, and information and communication policy. He served as the President of the Korean Association for Policy Analysis and Evaluation (KAPAE) in 2016. He is the president for the Korean Association for Policy Studies (KAPS) in 2018. He currently serves as the Head Director of the Global e-Governance Institute (GeGRI) and is a Member of the Board of Directors at the Korean Customs UNI-PASS Association. His publications include Electronic Government (2006); Information Society and Modern Organization (2004); Effects of IT on Policy Decision-Making Processes: Some Evidences Beyond Rhetoric (2009); An Exploratory Study on the Relationship among Talent Characteristics, Information Capability, and Social Network (2011); Factors Influencing on Information Use Behavior of Different Generations (2012); Smart E-Governance 2015); Which Type of Social Capital Matters for Building Trust in Government? (2016). He has published in various journals, including Administration and Society, Korean Journal of Information Policy, Government Information Quarterly, Sustainability, among others (shmyeong@inha.ac.kr). 



\title{
Editorial
}

\section{Introduction to the Special Issue on the Sustainable Asia Conference 2015}

\author{
Yongrok Choi ${ }^{1, *}$, Malin Song ${ }^{2, *}$ and Seunghwan Myeong ${ }^{3, *}$ \\ 1 Department of International Trade and Regional Studies, Inha University, 100 Inha-ro, Nam-gu, \\ Incheon 402-751, Korea \\ 2 Research Center of Statistics for Management, Anhui University of Finance and Economics (AUFE), No. 962, \\ Caoshan Road, 233030, Bengbu, China \\ 3 Department of Public Administration, Inha University, Inharo 100, Nam-gu, Incheon 402-751, Korea \\ * Correspondence: yrchoi@inha.ac.kr (Y.C.); songml@mail.ustc.edu.cn (M.S.); shmyeong@inha.ac.kr (S.M.); \\ Tel.: +82-032-860-7760 (Y.C.); Fax: +82-32-876-9328 (Y.C.)
}

Academic Editor: Marc A. Rosen

Received: 7 March 2016; Accepted: 7 March 2016; Published: 12 March 2016

\begin{abstract}
Of late, Asian countries have been experiencing serious environmental disasters, such as the particulate matter (PM) smog in China, a yellow sand storm in Korea, and the Fukuyama nuclear power station shutdown in Japan. Since its inauguration in 2009, the Sustainable Asia Conference (SAC) has evolved into one of the leading international conferences for coping with these environmental challenges and presenting novel and fundamental advances in sustainable development for Asia. This editorial for SAC 2015 will highlight the contents and new methodologies put forth by selected papers, presenting diverse implications in sustainable policies and business strategies.
\end{abstract}

Keywords: Sustainable Asia Conference; innovation frontier; green growth; urbanization

\section{Background of the Special Issue}

This Special Issue consists of selected papers from the Sustainable Asia Conference (SAC) 2015, an international conference held in Lanzhou, China, on 20-21 September 2015. Since its inauguration in 2009, SAC has emerged as one of the leading international conferences for presenting novel and fundamental advances in sustainable development for Asia. The purpose of the conference is for scientists, scholars, engineers, and students from universities and research institutes around the world to present ongoing research activities and, thus, promote global research networking in the area of sustainable development. This conference provides opportunities for the delegates to come face-to-face, exchange new ideas and application experiences, establish research and business relationships, and find global partners for future collaborations. The scope of this special issue encompasses topics related to sustainable development and management at both the macro- and micro levels for Asian countries, as presented at the SAC 2015.

The majority of traditional economics and business management science is based on the argument of Adam Smith that individual competition could reveal the best solution, and this individual solution could maximize social welfare as a whole. This belief has driven rapid economic development for almost three hundred years of industrialization. This competitive optimal solution, however, has created too many undesirable byproducts of market failures, such as environmental pollution and the resultant global warming. Diverse efforts have been made to overcome this externality issue, and a new paradigm called collabonomics has evolved, involving a new paradigm in economics and business by sharing trust and values. The new paradigm is based on the synergy effect coming from 
the interdisciplinary, yet quite innovative, approach to handle the externality issues of undesirable outputs [1].

Especially, the most rapidly growing Asian countries have generated much attention worldwide due to their serious environmental situation as well as the resulting disasters. In view of these undesirable outcomes of the rapidly growing economies, the Chinese government argued that it was not ready to participate in international talks on environmental issues officially. Nonetheless, in its national policies since 2005, China has stressed more and more on the enhanced treatment of carbon dioxide emissions [2]. The approach in the SAC 2015 is quite different from those of traditional orthodox theories, where the role of the market is overemphasized and cooperation for value creation and sharing may result in worsened economic performance. Therefore, the SAC could be an important cornerstone for setting up a new platform for academic networking and discover outperforming governance in the most rapidly growing region in the world.

\section{Important Issues for a Sustainable Asia}

Sustainability science is composed of the three pillars of environment, economics, and social studies. Most of the papers in this issue are based on the harmonization of these three perspectives. Individual sustainability issues in this special edition range from the macro views of policy implications, such as urbanization and brownfield rehabilitation, to the micro views of practical suggestions, such as the social support of the home healthcare system and toy manufacturers' intermediation. Notably, the majority of the papers have focused on the social and environmentally sustainable issues in Asian countries, particularly in China, which is the largest greenhouse gas (GHG) emitter in the world. In recent times, the country's grave pollution problems have heightened the awareness of environmental issues for its government as well as the public. The Chinese government's response to this challenge should ideally be to assess the feasibility of economic growth against the constraints of resources and the environment. Compared with the SAC 2014, the papers have enlarged its sustainable content issues based on much wider applications of diverse methodologies.

Indeed, the core of the Special Issue is the sustainable governance of the policies. Considering the urgency, the Chinese and Korean governments introduced various pilot projects to promote green growth, which typically entailed more proactive policies to cope with the environmental challenges. Both countries promoted their respective pilot projects of carbon emission trading system (ETS) and diverse renewable energy development. Unfortunately, most of the policies did not perform sustainably, because of the moral hazard occurring in the participating private sector and the bureaucratic approach of the governments. In order to fill this missing link in the public private partnership (PPP) for sustainable green growth, the role of the intermediary is crucial; therefore, the intermediary propositions for green growth are proposed [1]. From the governance perspective, the PPP, as the harmonized third party, could not achieve successful governance due to internal bottlenecks, as well as external difficulties. In order to capitalize on the opportunities and strengths, and to overcome the threats and weaknesses, this paper suggests four propositions as the appropriate intermediary: facilitator proposition, network manager proposition, collaborator proposition, and service provider proposition [1].

Since coal consumption had caused the most serious environmental problems in China, it is necessary to examine the regional differences in temporal-spatial coal consumption and the factors influencing them. In an empirical test, the correlation between the level of economic development and coal consumption is shown to be positive and significant at the $1 \%$ level. This implies that the rapid economic growth across the country has dramatically increased the consumption of energy resources, particularly coal. In other words, China's economic development is happening at the expense of high energy costs, environmental pollution, and ecological imbalance. In the second stage of determining the governance factors related to coal consumption, the urbanization level is found to be negatively related to coal consumption. Thus, when the proportion of the urban population is increased by $1 \%$, coal consumption will reduce by 698,080 tons of standard coal [3]. Urbanization should be promoted with 
detailed fine-tuning, as it also triggers problems of social disparity and degradation of human health. Using a sequential slack-based measure (SSBM) model, another paper analyzed the spatiotemporal disparities of urban land use economic efficiency (ULUEE) under environmental constraints, and its influencing factors in 270 cities across China during the period 2003-2012 [4]. The empirical results show that most cities face urbanization problems, such as oversupply of labor, over-development, excessive pollutant discharge, and shortage of economic output. Especially, the unreasonable use of funds is termed as the most serious one, indicating that putting a stop to the relentless leasing of land to make up for the local government's financial deficit would be very helpful in improving the ULUEE of Chinese cities [4]. On similar lines, another paper examined a policy of attracting investments for Private Participation in Infrastructure (PPI) projects, especially in the urban areas. In terms of the environmental, social, and governance (ESG) criteria, the promotion effect of sustainable PPI investments was shown to be significant for the sustainable development of financial markets. Furthermore, it highlighted a mediation mechanism wherein the PPI investments help enlarge the size of the financial market and, thus, foster financial market liquidity as well [5]. Urbanization could reduce the consumption of coal, and the infrastructure development will foster financial markets as well. Nevertheless, one also needs to take into consideration the undesirable problems, such as the oversupply of labor and excessive pollutant discharge. Urbanization is inevitable in China, especially in the long term. However, it should mitigate the regional differences, especially in social welfare and the quality of human development. As the regional differences in human development limit the potential for sustainable development, the Chinese government urgently needs to cope with the challenges of social justice, i.e., how to achieve equal opportunities and capabilities for its huge population. Based on the convergence theory of economic growth, a paper conducted an empirical test in China for the period 1997 to 2006, involving the human development index and the three major dimensions of human development (income, health, and education) [6]. The paper concludes that the rates of return on investment in education and health decline with the increase in investment. Thus, the region with a low initial level of investment achieves a higher growth rate, and ultimately converges. This implies that urbanization helps in lowering social disparity. However, the speed for convergence is different, depending on the surrounding environment, especially with respect to government policies. When the population of the provinces is considered, the paper observes that the distribution of provincial social development in China has a tendency to converge as "twin peaks". Thus, provinces of Eastern China converge to the rich ones, while the West China converge to the poor ones, and Central China lags behind. This highlights the significance of the "rise of Central China" plan as it can play an important role in promoting an effective link between the developed Eastern China and underdeveloped Western China and harmonizing sustainable development nationwide [6].

Urbanization has presented another challenge of water pollution and shortage. With the development of urbanization, water scarcity has become more and more prominent. To promote water conservation, securing water efficiency corresponding to urban growth is an increasing challenge for policy makers. As a comprehensive indicator of water resources management, a paper utilized the water footprint to measure the total amount of freshwater used for consumption and examined the pollution issue [7]. As the variation of the water footprint in a specific region is difficult to investigate, the paper conducted a holistic assessment of the urban water footprint in Leshan City of the Sichuan Province and measured the freshwater consumption of various sectors during the period 1992-2012. The crop production sector accounts for the largest proportion of the water footprint, $41.53 \%$ on average, followed by animal products $(27.44 \%)$, indicating that the agricultural sector consumes excess freshwater recklessly and has great potential to enhance water efficiency through irrigation. Additionally, a number of policy instruments, such as pricing strategy, economic sanctions, and financial subsidies, may give rise to internalization of the external cost of water [7]. Water pollution is another severe problem in Asia. In order to handle the water pollution in a market-oriented manner, the Chinese government introduced the emissions trading system (ETS). Notably, the government controls the emission rights market. The "GDP Only" preference blocks equitable rules to address the 
externalities. To modify this distortion, a paper has developed a multi-objective primary distribution model that optimizes economic efficiency, environmental contribution, and fairness in the case of Tai lake [8]. This lake, located in the Jiangsu Province, is the third-largest freshwater lake in China with a water area of 2338 square kilometers. It experienced an explosive growth of algae in the early summer of 2007, seriously disrupting the tap water for over 10 million residents living in the six cities near the lake. This issue has raised concerns about the sustainable use and management of water resources in China. The Tai Lake problem forced the local government to improve sustainable water management. Using a non-linear programming distribution model for a water pollution, the paper confirms that the emission-rights distribution and trading in the market based on both the manufacturer's geographic location and the government's preference can help facilitate industrial structure optimization toward the local regulator's preference [8].

In order to promote sustainable development in mining of resources, such as coal and iron ore, it is necessary to rehabilitate brownfields. Brownfield, the opposite of "greenfield", generally refers to contaminated lands. These wastelands not only occupy precious land resources but also ruin the surrounding environment. Therefore, the redevelopment of wastelands can ease the land shortage crisis, create ideal conditions for transformation of cities, improve the ecological environment, improve the quality of the city, and ensure the successful implementation of a sustainable development strategy. Since the investment in a brownfield project is based on new funding, the evaluation is based on the discounted cash flow (DCF) analysis. Based on the uncertainty arising from the complicated nature of environmental recovery, the evaluation shall take into account the fuzzy real option theories as well. In the simulation model, without any time lag effect, the net present value becomes negative, which means the project is infeasible and should be surrendered. If the waiting option is considered, the investment value of this project becomes positive, which is far greater than zero, implying that this project is feasible and should be continued. Therefore, as the pollution factors in water management, making brownfield redevelopment projects full of risks and uncertainty, it is better to execute the waiting option two years later. Utilizing the fuzzy real option method, the paper highlights project management uncertainty and flexibility to evaluate the investment value accurately [9].

As mentioned earlier, the Chinese government has quite aggressively promoted policies for renewable energy, especially for the solar energy industry. Several subsidy policies have been initiated to boost the photovoltaic (PV) industry. However, to ensure sustainable governance of the policies, the subsidies for the PV industry should be considered mainly in terms of the following aspects: the provinces' and municipalities' economic condition, energy efficiency, and environmental responsibility [10]. Using 19 evaluation indicators of economic, environmental, and energy factors, along with the entropy weight method, in the 31 provinces of China, the paper carried out empirical tests to find out the optimal subsidy criteria layer. It deployed the Technique for Order of Preference by Similarity to the Ideal Solution (TOPSIS) method for sorting the assessment objects. The paper noted that the global PV industry is policy-driven and the simple Golden-Sun Project only provided two layers of capital subsidies - which are 50\% of the initial investment for distributed PV systems and $70 \%$ initial investment for remote, independent PV systems. This appealing policy made companies invest large amounts of money into the PV industry, which led to a high idle rate of PV capacity and a huge waste of money and installation resources. Compared to the two-layer capital subsidy policy, the paper proposed a 31-layer policy to differentiate subsidies for regions and controlled the upper limit of capital investment into each province accurately, leading to appropriate capital flow for sustainable PV development [10]. Subsidy modes in the renewable energy industry may affect corporate financial performance as well. Thus, the relationships between the subsidy modes and financial performance of these two types of companies are investigated using a panel data model [11]. The paper begins with the classification of the subsidy modes into four categories: direct subsidy, indirect subsidy, innovative subsidy, and non-innovative subsidy. As the subsidies might not be distributed effectively because of rent-seeking behavior, the paper emphasizes that under certain circumstances, which show that the market-based mechanism has not yet been fully established, direct subsidies may have a more 
conspicuous influence than indirect subsidies on corporate financial performance. Innovative capacity could result in an effective increase in the profitability of enterprises. Using 26 wind and 21 solar energy enterprises listed on the Shanghai and Shenzhen stock exchanges for the period 2009-2014, the paper found that both indirect and non-innovative subsidies have significant effects on the financial performance of renewable energy companies. In terms of sub-industries, the subsidy effect of wind energy companies is slightly better than that of solar energy companies. The paper concludes that the subsidy mode is crucial for its effective performance and, thus, market- and performance-oriented subsidy mechanisms are definitely needed [11].

Intermediary businesses connecting local manufacturers and the international market are considered an important factor in the development of clusters [12]. Therefore, the geographical distribution and location of small and medium sales agencies (SAs) that connect manufacturers to customers, and the specialized markets (SMs) as physical exchange platforms or spaces for SAs and their clients are extremely important for the sustainable performance of the industry clusters. SMs are trading locations where a specific kind of utility commodity (sometimes mixed with a small amount of other kinds of commodities) is sold in bulk for both domestic and global markets. SAs are, generally, local independent merchants or sales departments attached to local manufacturers or even external producers in other places. They connect the local manufacturers with external clients and even foreign markets, and act as an important channel of products and information. Yiwu City in the Zhejiang Province and Linyi City in the Shandong Province are two typical examples of "commodity markets", situated in the north and south of China, respectively. Using Linyi City as the case study, Zhu et al. (2016) [13] empirically tested the factors influencing the expansion of SAs from wholesale to manufacturing and on the scale of internal production with three kinds of determinants: individual motivations of entrepreneurial innovation, local agglomeration effects of SMs, and dynamic relationships with cross-cluster cooperation. The empirical results show that individual motivations of intra-firm coordination, regional inter-firm relationships, and cross-regional inter-firm relationships have a significant and positive impact on the upgrading of local industrial clusters to sustain local competitiveness.

Sustainable governance in the health and medical care system is another key factor for a sustainable society. The medical care system in China has experienced significant changes during three decades of reforms, and thus it needs to be re-investigated for ensuring sustainable governance of these reforms. Chu et al. (2015) [14] investigated the technical efficiency of Chinese hospitals in 31 provinces during the period from 2002 to 2013 by proposing a new global generalized directional distance function (GGDDF) approach, taking into account undesirable output, i.e., mortality. In spite of the technical innovation over time, the researchers concluded that most Chinese provinces are not performing well in terms of hospitals' technical efficiency and leave a large potential to improve. In order to find out the bottlenecks or determinants for governance, the researchers took the second stage of the Tobit model, and found that the medical insurance reforms have improved the performance of Chinese hospitals, while public subsidies have decreased it. The related policy implications for Northeast Asia were derived, which included encouraging the development of private hospitals, enlarging the coverage of medical services, and pursuing customized policies for the provinces with different levels of GDP per capita and population density [14]. The problems of a shortage of medical resources and an aging population have become increasingly prominent in China. The number of elderly people aged over 60 is more than 200 million, accounting for $14.9 \%$ of the total population in China. Korea and Japan face similar challenges when it comes to aging people's healthcare. In order to cope with these medical issues, home healthcare services could provide more efficient, flexible, and convenient solutions, which can effectively alleviate the problem of a shortage of medical resources. Especially, it can reduce medical costs and improve service quality at the same time [15]. Home healthcare is defined as home-visiting medical services provided by general practitioner service teams based on online and/or phone reservation systems. Since 2003, 11 pilot community health centers have been set up in Changning, Putuo, and other districts in Shanghai. As of 2014, the 
system of family doctors or nurse practitioners was established in all community health centers in Shanghai, and approximately $1 / 6$ th of the residents had signed home care nursing service contracts with family doctors. The training level of healthcare workers and the status of medical equipment affect service quality in home healthcare. Especially, the inappropriate location of service centers for home healthcare, which is a decisive factor influencing whether medical staff are able to provide timely and convenient services for patients, is the major determinant of patient satisfaction. To examine this location governance issue, Du and Sun (2015) [15] analyzed home healthcare in Shanghai under several realistic constraints to reduce medical costs and improve medical efficiency. The researchers used the following evaluation indexes: minimum total cost of building health centers, minimum investment cost for business startup, minimum labor cost, and the minimum transportation cost. They concluded that the appropriate location of the service centers for home healthcare could decrease investment costs, avoid redundant construction, and improve the degree of patient satisfaction, contributing to the sustainable development of home healthcare [15].

With regard to the rapidly-occurring green growth, we need to consider the performance of foreign direct investment (FDI) from the economic and environmental benefits perspective as well. In 2014, the amount of FDI that China introduced reached USD \$11.9562 trillion, which is 34 times that of the amount in 1990; this inflow of FDI has certainly contributed toward the economic growth of China. Yue et al., (2016) took 104 cities in China as research objectives, and built a comprehensive index reflecting the economic and environmental effects of FDI, exploring the economic effects and environmental effects of FDI on the host country. The researchers made three contributions to the studies on China's green growth. First, by using an SBM-DDF (which stands for slack-based measure directional distance function) model, they found that FDI is helpful for China's green economic growth. Second, when the green growth efficiency is broken into economic efficiency and environmental efficiency, FDI promotes China's green economic growth through the promotion of environmental effects and economic effects. Unfortunately, FDI's promotion of environmental efficiency through clean technology transfer and environmental technology spillover may not be obvious. Third, the researchers proposed effective countermeasures to improve the effect of FDI on China's green economic growth. The government should first consider the "quality" of FDI. A high-quality FDI is good for the economy and delivers environmental benefits and, thus, it should be actively encouraged [16].

\section{Methodologies of Sustainability Science}

All papers in this special issue focus on the common paradigm of value creation based on network management. Compared with the profits, value is invisible, but it is extremely important for sustainable development policies, as well as sustainable management strategies in business. It involves a harmonized partnership, such as higher eco-friendly efficiency, better quality of social life, and the equitable economic development, as shown in the papers in this special issue. As sustainability science is based on the harmonized partnership among interrelated entities or the activities of those entities, network management is crucial for harmonizing the relationship and creating value from the partnership network [17]. Of course, the optimal solutions for harmonizing conflicting interests are not easy to evaluate and, thus, the methodological approaches could be diverse, but with more emphasis on the importance of sustainable governance. Due to the multi-disciplinary character of sustainability science, diverse approaches could and should be imported and utilized for better understanding of multivariate complexity as well as for more systematic implications and suggestions.

Since most papers in this Special Issue handle conflicting interests as well as multi-inputs/outputs for their models, traditional regression analyses may not match with these purposes. Therefore, most papers handle the multi-input/output models, such as data envelope analysis (DEA) and structural equation modeling (SEM). DEA is especially important in the field of energy and environmental economics since it handles desirable outputs as well as undesirable outputs such as wastewater and land [4], mortality rate [14], and industrial sulfur dioxide [16]. SEM or similar stepwise approaches are other popular approaches to evaluate diverse survey-related issues as they clarify the role of 
intermediation or stepwise relationship resulting from the complexity among variables [3,5,11]. As the sustainability issues should examine the spatial and time dynamic effects, most DEA approaches are also based on the stepwise approach $[4,14]$.

The linear regression or linear transformation of multivariant variables is introduced as well. As coal consumption is strongly related to the distance of coal production sites, Sun et al. (2015) [3] used the center of gravity models. This is advantageous as the model can demonstrate development trajectories visually and quantitatively with the support of geographical information systems (ArcGIS) to study the spatial distribution of energy consumption and carbon emissions, and the spatial distribution of energy consumption intensity, respectively, for China's provinces and regions. Likewise, to examine the relationship between private participation in infra (PPI) investments and financial market development (FMD), Fu et al. (2016) [5] first controlled the country-fixed effect for unmeasurable country characteristics and the time-fixed effect for common shocks across countries. Then, to avoid the influence of heteroskedasticity and autocorrelation, the researchers ran a second round of estimations with robust standard errors and tested the mediator effect with the corresponding coefficients.

To determine the changing role of sales agencies (SAs) in the specialized market cluster (SMs), Zhu et al. (2016) [13] used binary logistic regression, which starts with all variables in the regression equation, and then removes the independent variables that have no significant effect on the dependent variable according to the probability value of statistics derived from the maximum likelihood estimation .

Linear programming is also used. A multi-objective mixed-integer programming model is introduced to solve the location problem for sustainable home healthcare centers [15]. Li et al. (2016) [10] introduced 19 evaluation indicators involving economic, environmental, and energy factors, allocated weight to each indicator using the entropy weight method, and sorted the 31 evaluation objects by using the TOPSIS method. To test the convergence theory with regard to the economic growth of different regions, Yang et al. (2016) [6] utilized the $\beta$-convergence method and $\sigma$-convergence method based on the fixed effects model. The former one mainly concentrates on the difference in growth rate among countries or regions, while the latter one focuses on the distribution difference in growth rate. In order to evaluate the regional water footprint in Leshan City, Zhao et al. (2015) [7] calculated all the sectors of industrial production process using the linear programming method and with the support of geographical information systems (ArcGIS) [7]. For this unique water footprint calculation, they cited 87 references, which is the largest citation in this Special Issue. A non-linear programming distribution model is introduced for water pollution emissions trading based on the local government's industrial preferences and enterprise location, along with the stepwise supplement of empirical emissions trading simulations using corporate data from the Tai Lake basin [8].

Lastly, the discounted cash flow (DCF) analysis is used to evaluate the brownfield rehabilitation projects. The fuzzy real option method is utilized for determining the uncertainty in project management [9]. The parameters in the DCF model are fixed values, such as the present value of future cash flows and investment costs. However, the present value of future cash flows and investment costs in the brownfield redevelopment project can only estimate the general scope because of pollution factors. In view of this situation, these parameters are represented by fuzzy numbers [9].

\section{Conclusions}

The research contents and methodologies examined in this Special Issue gave us greater insights and opened new frontiers to handle new challenges for sustainable governance. Most of the articles handled the multiple inputs and outputs, taking time and space into consideration. Sustainable governance should involve complicated, yet complex, procedural approaches to understand the workable mechanism and harmonize all interest groups with the cooperation network. It is not easy to clarify the causal relations on this network, but it is essential for the network manager or the agency to create and share all the challenges and values together. This is reflected in the catchphrase of the Sustainable Asia Conference (SAC): Once a friend, forever friends. 
Networking participants striving for a harmonized, sustainable performance will have to adopt a more field- and performance-oriented approach to create these invisible but precious values-this is sustainable governance [12] (p. 4115). In order to discover the sustainable governance-related factors in the rapidly evolving Asian model, sustainable issues, as well as their methodologies, should be highlighted. Especially, compared with the efficiency-oriented Western countries, the Northeast Asian countries emphasize more on the harmonized inter-relationship. This social relationship is quite crucial to create and share the values in these countries. Today, the world is shifting from the visible aspects of profits and efficiency toward the invisible values that are based on the sustainable cooperation network in the business, economy, and society as a whole. To further explore the oriental models of this sustainable cooperation network mechanism in detail, SAC 2016 shall call the papers at the end of June 2016 at Jeju Island, a paradise in the Orient.

Acknowledgments: The National Research Foundation of Korea grant funded by the Korean government (NRF-2014S1A5B1011422) supported this work.

Author Contributions: All authors made equal contributions to the work in this editorial paper.

Conflicts of Interest: The authors declare no conflict of interest.

\section{References}

1. Choi, Y. Intermediary Propositions for Green Growth with Sustainable Governance. Sustainability 2015, 7, 14785-14801. [CrossRef]

2. Yu, Y.; Choi, Y. Measuring Environmental Performance Under Regional Heterogeneity in China: A Metafrontier Efficiency Analysis. Comput. Econ. 2014. [CrossRef]

3. Sun, Y.; Li, Q.; Chen, T.; Jia, X. Dynamic Factor Analysis of Trends in Temporal-Spatial Patterns of China's Coal Consumption. Sustainability 2015, 11, 15119-15135. [CrossRef]

4. Xie, H.; Wang, W. Exploring the Spatial-Temporal Disparities of Urban Land Use Economic Efficiency in China and Its Influencing Factors under Environmental Constraints Based on a Sequential Slacks-Based Model. Sustainability 2015, 8, 10171-10190. [CrossRef]

5. Fu, T.; Chen, H.; Choi, Y. Does the Sustainable PPI Investments Promote Financial Market's Sustainable Development? Sustainability 2016, 8, 120. [CrossRef]

6. Yang, F.; Pan, S.; Yao, X. Regional Convergence and Sustainable Development in China. Sustainability 2016, 8, 121. [CrossRef]

7. Zhao, R.; He, H.; Zhang, N. Regional Water Footprint Assessment: A Case Study of Leshan City. Sustainability 2015, 7, 16532-16547. [CrossRef]

8. $\quad \mathrm{Pu}, \mathrm{Z}$.; Wang, H.; Bian, H.; Fu, J. Sustainable Lake Basin Water Resource Governance in China: The Case of Tai Lake. Sustainability 2015, 7, 16422-16434. [CrossRef]

9. Dai, H.; Sun, T.; Guo, W. Brownfield Redevelopment Evaluation Based on Fuzzy Real Options. Sustainability 2016, 8, 170. [CrossRef]

10. Li, L.; Chi, T.; Zhang, M.; Wang, S. Multi-Layered Capital Subsidy Policy for the PV Industry in China Considering Regional Differences. Sustainability 2016, 8, 45. [CrossRef]

11. Zhang, H.; Zheng, Y.; Zhou, D.; Zhu, P. Which Subsidy Mode Improves the Financial Performance of Renewable Energy Firms? A Panel Data Analysis of Wind and Solar Energy Companies between 2009 and 2014. Sustainability 2015, 7, 16548-16560. [CrossRef]

12. Choi, Y.; Gao, G. The Role of Intermediation in the Governance of Sustainable Chinese Web Marketing. Sustainability 2014, 6, 4102-4118. [CrossRef]

13. Zhu, H.; Huang, X.; He, Q.; Li, J.; Ren, L. Sustaining Competitiveness: Moving Towards Upstream Manufacturing in Specialized-Market-Based Clusters in the Chinese Toy Industry. Sustainability 2016, 8, 176. [CrossRef]

14. Chu, K.; Zhang, N.; Chen, Z. The Efficiency and Its Determinants for China's Medical Care System: Some Policy Implications for Northeast Asia. Sustainability 2015, 7, 14092-14111. [CrossRef]

15. Du, G.; Sun, C. Location Planning Problem of Service Centers for Sustainable Home Healthcare: Evidence from the Empirical Analysis of Shanghai. Sustainability 2015, 7, 15812-15832. [CrossRef] 
16. Yue, S.; Yang, Y.; Hu, Y. Does Foreign Direct Investment Affect Green Growth? Evidence from China's Experience. Sustainability 2016, 8, 158. [CrossRef]

17. Choi, Y.; Zhang, N. Introduction to the Special Issue on "the Sustainable Asia Conference 2014". Sustainability 2015, 7, 1595-1602. [CrossRef]

(C) 2016 by the authors. Licensee MDPI, Basel, Switzerland. This article is an open access article distributed under the terms and conditions of the Creative Commons Attribution (CC BY) license (http:/ / creativecommons.org/licenses/by/4.0/). 


\title{
Effect of Population Structure Change on Carbon Emission in China
}

\author{
Wen Guo ${ }^{1,2}, *$, Tao Sun ${ }^{2}$ and Hongjun Dai ${ }^{2,3}$ \\ 1 Accounting Department, College of Accounting, Nanjing University of Finance \& Economics, \\ Nanjing 210046, China \\ 2 College of Economics and Management, Research Institute of Financial Development, \\ Nanjing University of Aeronautics and Astronautics, Nanjing 211106, China; suntao@nuaa.edu.cn (T.S.); \\ dhj@hnnu.edu.cn (H.D.) \\ 3 College of Economics and Management, Huainan Normal University, Huainan 232038, China \\ * Correspondence: xsyjgw@nuaa.edu.cn; Tel.: +86-25-8489-3060 (ext. 925)
}

Academic Editors: Malin Song and Seunghwan Myeong Received: 25 October 2015; Accepted: 17 February 2016; Published: 4 March 2016

\begin{abstract}
This paper expanded the Logarithmic Mean Divisia Index (LMDI) model through the introduction of urbanization, residents' consumption, and other factors, and decomposed carbon emission changes in China into carbon emission factor effect, energy intensity effect, consumption inhibitory factor effect, urbanization effect, residents' consumption effect, and population scale effect, and then explored contribution rates and action mechanisms of the above six factors on change in carbon emissions in China. Then, the effect of population structure change on carbon emission was analyzed by taking 2003-2012 as a sample period, and combining this with the panel data of 30 provinces in China. Results showed that in 2003-2012, total carbon emission increased by 4.2117 billion tons in China. The consumption inhibitory factor effect, urbanization effect, residents' consumption effect, and population scale effect promoted the increase in carbon emissions, and their contribution ratios were $27.44 \%, 12.700 \%, 74.96 \%$, and $5.90 \%$, respectively. However, the influence of carbon emission factor effect $(-2.54 \%)$ and energy intensity effect $(-18.46 \%)$ on carbon emissions were negative. Population urbanization has become the main population factor which affects carbon emission in China. The "Eastern aggregation" phenomenon caused the population scale effect in the eastern area to be significantly higher than in the central and western regions, but the contribution rate of its energy intensity effect ( -11.10 million tons) was significantly smaller than in the central ( -21.61 million tons) and western regions ( -13.29 million tons), and the carbon emission factor effect in the central area ( -3.33 million tons) was significantly higher than that in the eastern $(-2.00$ million tons) and western regions ( -1.08 million tons). During the sample period, the change in population age structure, population education structure, and population occupation structure relieved growth of carbon emissions in China, but the effects of change of population, urban and rural structure, regional economic level, and population size generated increases in carbon emissions. Finally, the change of population sex structure had no significant influence on changes in carbon emissions.
\end{abstract}

Keywords: population structure; carbon emission; LMDI; urbanization; residents' consumption

\section{Introduction}

With the intensified change in the global climate, the problem of carbon emissions from burning fossil energy has become an important focus. The fourth assessment report of IPCC pointed out that human factors were the main reasons causing a dramatic increase of global carbon emission; therefore, the effect of expansion of the population scale and change in demographic structure has become an essential academic issue. Due to historical reasons, the one-child policy led to the current 
special population structure in China, and also provided typical sample data for research into the effect of change of demographic structure on carbon emission. The change of Chinese demographic structure (including population age structure, population sex structure, population education structure, population urban and rural structure and population occupation structure) is shown in Figure 1.

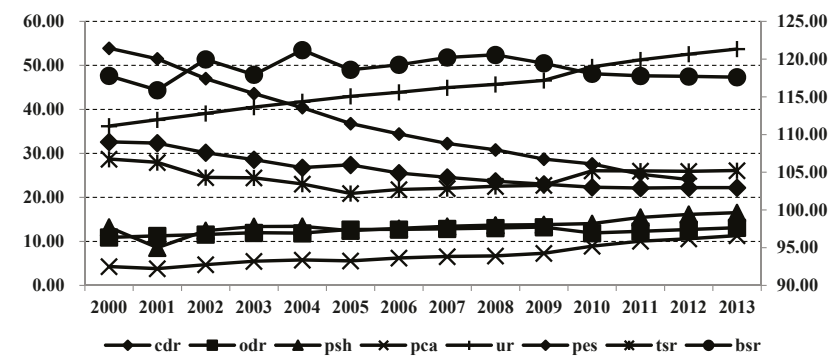

Figure 1. Change of Chinese population structure from 2000 to 2013. Data source: (1) Data of children dependency ratio (cdr), elderly dependency ratio (odr), proportion of the population in senior high school (psh), proportion of the population in college and above (pca), ratio of population urbanization (ur), sex ratio of total population (tsr), and sex ratio at birth (bsr) were collected from China Statistical Yearbook [1] for 2001-2014, while data of children dependency ratio and elderly dependency ratio in 2000-2001 were obtained from China Commonly Used Population Data Set Since 1990 [2]. (2) Data of the proportion of employees in state-owned units in total China urban employment (pes) were from the China Labour Statistical Yearbook [3] in 2001-2013.

At present, there are significant features regarding aspects of age structure, urban and rural structure, education structure, sex structure, and occupational structure in the Chinese population. Firstly, China began to carry out the one-child policy in the 1970s, which was officially designated as the basic national policy in 1982. This policy caused low birth rates over a long period. In addition, improved living standards, advances in medical technology, and other factors also caused a rapid decline in the death rate. The phenomenon of low birth rates and low death rates led to the main features of age structure in China as being "declining birthrates" and "aging populations". According to Figure 1, it was found that the child dependency ratio and the elderly dependency ratio continuously increased since 2010, and met the above characteristic of the population age structure. Secondly, China has entered a rapid development stage of population urbanization since the 1980s. In 2000-2013, the population urbanization ratio in China increased from $36.22 \%$ to $53.73 \%$ (see Figure 1 ), and maintained an average annual growth rate of more than 1\%. Wang [4] indicated that population urbanization in China is still in the middle stage, and exhibits disparity with the world's average level. We can expect that Chinese population urban and rural structure will change with the rapid development of population urbanization in China in the future. Thirdly, Figure 1 showed that the Chinese population education structure also changed greatly since the new century, the proportion of the population of senior high school and proportion of the population in college and above, respectively, rose from $13.20 \%$ and $4.28 \%$ to $16.52 \%$ and $11.32 \%$ in $2000-2013$, indicating the increase of population quality in China. Fourthly, Chinese population sex structure was in long-term imbalance due to the child-bearing viewpoint of "preference for sons over daughters". Figure 1 also showed that the Chinese total population sex ratio has been about 105 since 2000, significantly higher than the normal level. On the other hand, the sex ratio at birth in China was higher than 115 in 2000-2013; the cumulative effect will undoubtedly lead to more serious population gender imbalances in the future. Finally, due to historical reasons, the state-owned economic component played an important role in the Chinese economy, with the depth of market economic reform, and the proportion of the state-owned economy gradually reducing. The proportion of employees in state-owned units in total Chinese urban employment rapidly declined in recent years (see Figure 1), which confirmed changes of population occupational structure in China. 
Regarding the effect of population structure change on carbon emission, the conclusions of scholars are varied. Liddle [5] found that the effect of population age structure on carbon emission from transport energy consumption presented a change tendency as an inverted " $U$ " type, while Okada [6], and Menz et al. [7] believed that aging populations would reduce the overall carbon emission from energy consumption. Zhu et al. [8], Knight et al. [9], and many other scholars found that the level of urbanization significantly affected overall carbon emission. Katircioğlu [10] took energy consumption in Turkey as a case; his study showed that the development of high education level and improvement of population quality will promote growth of the power consumption and the petroleum consumption regardless of long term or short term timeframes. Obviously, population structure change significantly affected change of carbon emission; therefore, this paper examined change of carbon emission of 31 provinces in China during 2003-2012 as the research object, focusing on the analysis of the effect of China's population structure change on carbon emission from the perspectives of development of urbanization and residents' consumption, and attempted to explain the pattern of change in carbon emission in China from the perspective of population structure change.

The following content of this paper was organized as follows. In Section 2, we summarize the literature about this issue. Section 3 discusses the model, methodology, and the data which was used in this paper. Results were calculated and empirical results are summarized in Sections 4 and 5 respectively. Finally, Section 6 concludes this paper.

\section{Literature Review}

At present, structural decomposition analysis (SDA) and index decomposition method (IDA) are the two main decomposition methods to analyze carbon emission. Although the two methods are widely applied [11,12], Hoekstra et al. [13], and Ang [14] believed that the IDA method adapts to the empirical analysis at all levels as macro, regional, and industry based on a comparison of the above two methods. The IDA method also has advantage in data acquisition; therefore, it was more popular in academic study. The IDA method can be further subdivided into two types as the Laspeyres Index Decomposition Method and the Divisia Index Decomposition Method. Ang et al. [15] found that the Logarithmic Mean Divisia Index (LMDI) decomposition method has advantages of handling null, independent data paths compared with the Laspeyres Index Decomposition Method, and it was more applicable to empirical research. Therefore, the application of the LMDI method in the field of carbon emission measurement and decomposition was more extensive in recent years [16,17]. Many scholars also put forward many corresponding improved forms of LMDI on the basis of specific study objects [18-20].

Regarding the relationship between carbon emission and demographic factors, the early studies mostly focus on the influence of population scale on carbon emission. Rosa et al. [21] collected the cross-sectional data and found that the population elasticity was close to 1 . O'Neill et al. [22] also believed that the impact of population on carbon emission was only manifested by the scale effect, while controlling other influencing factors, with elasticity close to 1. Ping [23] also obtained a similar conclusion. However, Satterthwaite [24] found that the growth of population scale could promote the growth of carbon emission, while the contribution of consumption level and consumption scale, which grows with the growth of population scale, on promoting the growth of carbon emission was greater. Yao et al. [25], and Wang et al. [26] took time-series data at the national level in China as a sample; their studies found that growth of consumption scale and rising consumption levels were important factors influencing the growth of carbon emission.

In recent years, the influence of population structure change on carbon emission has drawn more and more attention. Firstly, change of population age structure (aging populations) is a kind of typical population structure change, and has significant impact on change of carbon emission. York [27] believed that population size and age structure affected carbon emission significantly through affecting total energy consumption. Liddle et al. [28] analyzed the effect of two age groups, 20-34 and 35-60, on carbon emission. The results showed that elasticity of carbon emissions in the two samples were 
contradictory; elasticity of the former group is positive, but the other is negative. Lugauer et al. [29] found that carbon emission increased rapidly with the increasing of the proportion of the population aged 35 to 49. Liddle [5] analyzed the impact of age structure on carbon emission from residents' electricity consumption and transportation energy consumption. He believed that the impact of age structure on carbon emission from transportation energy consumption appeared as an inverted " $U$ " type; namely, the influence coefficients of the minimum and maximum age groups were negative, and the influence coefficient of the age group of 20-34 is positive, while the influence direction of age structure on carbon emission from residents' electricity consumption was the inverse. Zagheni [30] argued that total carbon emission would decrease with the growth of the proportion of the population over the age of 60; namely, an increase of elderly population could reduce carbon emission, and the conclusion of the study of Okada [6], Menz et al. [7] was similar. In addition, Laureti et al. [31] took attention of the effect of population structure on nitrogen oxides; this study also supports the above view's conclusion.

Secondly, many scholars studied the impact of population urban and rural structure change (urbanization) on carbon emission, and there were two methods of research for this topic. The first assumed that there was a single causal relationship from urbanization to carbon emission, to explore the influence of urbanization on carbon emission. However, due to differences between their study samples and other factors, they did not reach the same conclusion. Jorgenson [32] took OECD countries as samples and found that the effect of urbanization on carbon emission in the national level was not significant, Liddle et al. [28] and Jorgenson [33] obtained a similar conclusion. Jorgenson et al. $[34,35]$ found that urbanization had a significant effect on carbon emission, while its effect coefficient is small based on a mixed sample with data of developed countries and developing countries. Studies by Poumanyvong et al. [36], Martinez et al. [37], Poumanyvong et al. [38], Zhu et al. [8], and Knight et al. [9] supported the above conclusion. Fang et al. [39] argued that urbanization did not have a significant effect on carbon emission in low-income countries, but it was able to significantly reduce carbon emission in high-income countries. The second tested the two-way causality relationship between urbanization and carbon emission. Mishra et al. [40] found that urbanization was a one-way Grainger reason to change carbon emission in Pacific island countries in the short-term. Hossain [41] believed that there was no causal relationship between urbanization and carbon emission in newly-industrialized countries in the short-term. Al-mulali [42] verified the two-way and long-term positive causal relationship between urbanization and carbon emission in the Middle East and North African countries.

Although some literature considered the effect of population scale change, population structure change, and change of population age structure on carbon emission [43,44], most literature still ignored the effect of population sex structure change and population education and occupation structure change mentioned previously. In addition, although the positive effect of increasing the size and level of consumption on carbon emission has become a consensus, there were few studies related to the effect of change of consumption structure on carbon emission. Finally, the early one-child policy caused China to face the transformation period of population structure change, as mentioned previously; population age structure, population sex structure, population education structure, population urban and rural structure, and population occupation structure significantly changed from 1997 to 2013, and it provided a typical sample for this study. Therefore, we attempted to expand the study of this topic via the following two aspects: (1) introducing factors of demographic urbanization and residents' consumption into Kaya identity, and decomposed change of carbon emission into six effects as carbon emission factor effect, energy intensity effect, consumption inhibitory factor effect, urbanization effect, residents' consumption effect, and population scale effect through using LMDI method; their contribution rate and action mechanism on change of carbon emission was then discussed; and (2) empirically analyzed effects of regional population structure change on carbon emission and its decomposition effects by using panel data of 29 provinces in China from 2003 to 2012. 


\section{Methodology and Data}

\subsection{LMDI Decomposed Method}

According to Kaya identity, the relationship between population, energy, economic, and carbon emission can be expressed as Equation (1):

$$
C=\frac{C}{E} \times \frac{E}{G} \times \frac{G}{P} \times P
$$

where $C, E, G$, and $P$ express total carbon emission, total energy consumption, GDP, and total population, respectively. We attempted to analyze the effect of population structure change on carbon emission from the perspectives of urbanization and residents' consumption based on Kaya identity, and used $R C$ to express residents' consumption, and Equation (1) can be further extended as:

$$
C=\frac{C}{E} \times \frac{E}{G} \times \frac{G}{R C} \times \frac{R C}{P} \times P
$$

In addition, $P_{u}$ and $P_{r}$ were used to express total population, $R C_{u}^{b}, R C_{r}^{b}$ to express basic living consumption of urban and rural residents, including five classes as consumption of food, clothing, housing, household appliances and services, transportation, and communication, $R C_{u}^{i b}, R C_{r}^{i b}$ to express non-basic living consumption, including three categories: health care, education and entertainment products and services, and other goods and services. Then, residents' consumption $R C$ can be converted as:

$$
R C=\left[\begin{array}{llll}
\frac{R C_{u}^{b}}{P_{u}} & \frac{R C_{u}^{i b}}{P_{u}} & \frac{R C_{r}^{b}}{P_{r}} & \frac{R C_{r}^{i b}}{P_{r}}
\end{array}\right] \times\left[\begin{array}{llll}
\frac{P_{u}}{P} & \frac{P_{u}}{P} & \frac{P_{r}}{P} & \frac{P_{r}}{P}
\end{array}\right]^{T} \times P
$$

We can deduce the expanded Kaya equation which is based on perspectives of urbanization and residents' consumption through substituting Equation (3) above into Equation (2):

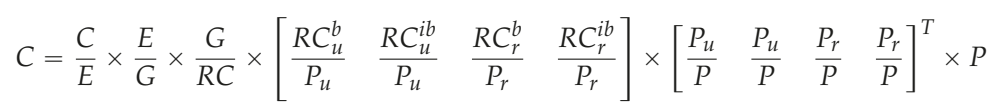

Assumed: $c i=\frac{C}{E}$ expresses carbon emission per unit of energy, namely carbon emission factor, $e i=\frac{E}{G}$ expresses energy consumption per unit of GDP, namely energy intensity, cif $=\frac{G}{R C}$ expresses the inverse of residents' consumption ratio, namely consumption inhibitory factor, $r c_{u}^{b}=\frac{R C_{u}^{b}}{P_{u}}, r c_{u}^{i b}=\frac{R C_{u}^{i b}}{P_{u}}, r c_{r}^{b}=\frac{R C_{r}^{b}}{P_{r}}, r c_{r}^{i b}=\frac{R C_{r}^{i b}}{P_{r}}$ expresses basic and non-basic living consumption per urban resident, basic and non-basic living consumption per rural resident, respectively. $p_{u}=\frac{P_{u}}{P}, p_{r}=\frac{P_{r}}{P}$ expresses the proportions of the urban and rural population, respectively. Then, Equation (4) can be translated to Equation (5):

$$
C=c i \times e i \times c i f \times\left[\begin{array}{llll}
r c_{u}^{b} & r c_{u}^{i b} & r c_{r}^{b} & r c_{r}^{i b}
\end{array}\right] \times\left[\begin{array}{llll}
p_{u} & p_{u} & p_{r} & p_{r}
\end{array}\right]^{T} \times P
$$

We can deduce Equation (6) through using the log and differential to Equation (5):

$$
d \ln C=d \ln c i+d \ln e i+d \ln c i f+\frac{d\left(r c_{u}^{b} p_{u}+r c_{u}^{i b} p_{u}+r c_{r}^{b} p_{r}+r c_{r}^{i b} p_{r}\right)}{r c_{u}^{b} p_{u}+r c_{u}^{i b} p_{u}+r c_{r}^{b} p_{r}+r c_{r}^{i b} p_{r}}+d \ln P
$$


Assumed: $\quad s_{u}^{b}=\frac{r c_{u}^{b} p_{u}}{r c_{u}^{b} p_{u}+r c_{u}^{i b} p_{u}+r c_{r}^{b} p_{r}+r c_{r}^{i b} p_{r}}$ expresses the proportion of basic living consumption in urban residents' total living consumption, $s_{u}^{i b}=\frac{r c_{u}^{i b} p_{u}}{r c_{u}^{b} p_{u}+r c_{u}^{i b} p_{u}+r c_{r}^{b} p_{r}+r c_{r}^{i b} p_{r}}$ expresses the proportion of non-basic living consumption in urban residents' total living consumption, $s_{r}^{b}=\frac{r c_{r}^{b} p_{r}}{r c_{u}^{b} p_{u}+r c_{u}^{i b} p_{u}+r c_{r}^{b} p_{r}+r c_{r}^{i b} p_{r}}$ expresses the proportion of basic living consumption in rural residents' total living consumption, $s_{u}^{i b}=\frac{r c_{u}^{i b} p_{u}}{r c_{u}^{b} p_{u}+r c_{u}^{i b} p_{u}+r c_{r}^{b} p_{r}+r c_{r}^{i b} p_{r}}$ expresses the proportion of non-basic living consumption in rural residents' total living consumption. We can deduce Equation (7) as:

$$
d \ln C=d \ln \left(c i \times e i \times c i f \times p_{u}^{s_{u}^{b}} \times p_{u}^{s_{u}^{s_{u}^{b}}} \times p_{r}^{s_{r}^{b}} \times p_{r}^{s_{r}^{i b}} \times\left(r c_{u}^{b}\right)^{s_{u}^{b}} \times\left(r c_{u}^{i d)^{s_{u}^{i b}}} \times\left(r c_{r}^{b}\right)^{s_{r}^{b}} \times\left(r c_{r}^{i b}\right)^{s_{r}^{i b}} \times P\right)\right.
$$

Equation (7) can be translated to Equation (8); Equation (8) is the multiplicative form of carbon emission based on factor decomposition:

$$
C=c i \times e i \times c i f \times p_{u} s_{u}^{b} \times p_{u}{ }^{s_{u}^{i b}} \times p_{r}{ }^{s_{r}^{b}} \times p_{r} s_{r}^{i b} \times\left(r c_{u}^{b}\right)^{s_{u}^{b}} \times\left(r c_{u}^{i b}\right)^{s_{u}^{i b}} \times\left(r c_{r}^{b}\right)^{s_{r}^{b}} \times\left(r c_{r}^{i b}\right)^{s_{r}^{i b}} \times P
$$

In order to measure the contribution value of carbon emission factor and other variables on carbon emission, we should decompose change of carbon emission into the sum or product of the above variables. This paper adopted the LMDI plus decomposition method to solve the above problem which was referred to by Ang [14]. The total effect of change of carbon emission $(\Delta C)$ from period 0 to period $T$ can be decomposed into six effects as carbon emission factor effect $\left(\Delta C_{c i}\right)$, energy intensity effect $\left(\Delta C_{e i}\right)$, consumption inhibitory factor effect $\left(\Delta C_{c i f}\right)$, urbanization effect $\left(\Delta C_{u-r}\right)$, residents' consumption effect $\left(\Delta C_{b-i b}\right)$, and population scale effect $\left(\Delta C_{P}\right)$. Their calculation formulas are as follows:

$$
\begin{aligned}
& \Delta C_{c i}=L\left(C^{T}, C^{0}\right) \times \ln \frac{c i^{T}}{c i^{0}} \\
& \Delta C_{e i}=L\left(C^{T}, C^{0}\right) \times \ln \frac{e i^{T}}{e i^{0}} \\
& \Delta C_{c i f}=L\left(C^{T}, C^{0}\right) \times \ln \frac{c i f^{T}}{c i f^{0}} \\
& \Delta C_{u-r}=L\left(C^{T}, C^{0}\right) \times\left\{\left[\left(s_{u}^{b^{T}}+s_{u}^{i b^{T}}\right) \ln p_{u}{ }^{T}-\left(s_{u}^{b^{0}}+s_{u}^{i 0^{0}}\right) \ln p_{u^{0}}\right]+\left[\left(s_{r}^{b^{T}}+s_{r}^{i b^{T}}\right) \ln p_{r}{ }^{T}-\left(s_{r}^{b^{0}}+s_{r}^{i b^{0}}\right) \ln p_{r}{ }^{0}\right]\right\} \\
& \Delta C_{b-i b}=L\left(C^{T}, C^{0}\right) \times\left\{\left[\left[_{u}^{s^{T}} \ln r c_{u}^{b^{T}}+s_{r}^{b^{T}} \ln r c_{r}^{b^{T}}-s_{u}^{b^{0}} \ln r c_{u}^{b^{0}}-s_{r}^{b^{0}} \ln r c_{r}^{b^{0}}\right]+\left[s_{u}^{i b^{T}} \ln r c_{u}^{i b^{T}}+s_{r}^{i T^{T}} \ln r c_{r}^{i b^{T}}-s_{u}^{i b^{0}} \ln r c_{u}^{i b^{0}}-s_{r}^{i b^{0}} \ln r c_{r}^{i b^{0}}\right]\right\}\right. \\
& \Delta C_{P}=L\left(C^{T}, C^{0}\right) \times \ln \frac{P^{T}}{P^{0}} \\
& \Delta C=\Delta C_{c i}+\Delta C_{e i}+\Delta C_{c i f}+\Delta C_{u-r}+\Delta C_{b-i b}+\Delta C_{P}
\end{aligned}
$$

where:

$$
L\left(C^{T}, C^{0}\right)=\left\{\begin{array}{l}
\left(C^{T}-C^{0}\right) /\left(\ln C^{T}-\ln C^{0}\right), C^{T} \neq C^{0} \\
C^{0}, C^{T}=C^{0} \\
0, C^{T}=C^{0}=0
\end{array}\right.
$$

\subsection{Variables and Data}

Our work focused on regional carbon emission and its decomposition effects of 31 provinces in China from 2003 to 2012. Due to the lack of data for Tibet, we took panel data of the other 30 provinces as the sample. We selected variables and collected data from two routes. Firstly, in the study of calculation 
and decomposition of regional carbon emission, we used 20 kinds of terminal energy consumption in various regions and a $\mathrm{CO}_{2}$ emission coefficient to determine regional total carbon emissions $(C)$; this method can overcome the defect of unjust allocations in regions compared with using the three kinds of primary energy. The above 20 kinds of terminal energy consumption in various regions was shown in China Energy Statistical Yearbook [45] to express regional total energy consumption, and was converted into standard coal equivalent. Data of regional total GDP $(G)$, regional total residents' consumption $(R C)$, regional total population $(P)$, the proportion of urban population $\left(p_{u}\right)$ and rural population $\left(p_{R}\right)$ were from the China Statistical Yearbook [1]. The used proportion of consumption on food, clothing, housing, household appliances and services, transportation, and communication of per person in residents' per capita total consumption to express the proportion of basic living consumption of rural residents $\left(s_{r}^{i b}\right)$ data was also from China Statistical Yearbook [1], and the proportion of non-basic living consumption of rural residents $\left(s_{r}^{b}\right)$ can be calculated by $1-s_{r}^{i b}$. The calculation of these two items of data for urban residents is the same for rural residents. Secondly, the empirical study used the children dependency ratio (children) and the elderly people dependency ratio (elderly) to refer to regional population age structure, used the sex ratio of total population (sex) to refer to regional population sex structure, and used proportion of the population of senior high school (senior) and proportion of the population in college and above (college) to refer to the regional population education structure. The data for the above variables are from the China Statistical Yearbook [1]. The used proportion of employees in state-owned units in total Chinese urban employment (occupation) refers to regional population occupation structure, its data is from the China Labour Statistical Yearbook [3], and used the proportion of urban population to refer to population of urban and rural (urban) structure. In addition, regional total GDP (GDP), regional total population (population) were selected as control variables. After the collection, sorting, and screening of the data, its descriptive statistical results were shown in Table 1.

Table 1. Descriptive statistic results of the variables.

\begin{tabular}{cccccc}
\hline Variables & Unit & Max & Min & Mean & Standard Deviation \\
\hline$C$ & ten thousand tons & $61,360.5100$ & 1257.0579 & $17,153.4307$ & $11,620.5029$ \\
$E$ & ten thousand tce & $27,650.3057$ & 618.6491 & 7503.2948 & 5020.2217 \\
$G(G D P)$ & hundred million RMB & $44,217.1630$ & 390.2000 & 8827.2409 & 7853.7926 \\
$R C$ & hundred million RMB & $14,386.5689$ & 161.7782 & 2572.7959 & 2111.0474 \\
$p_{u}$ & $\%$ & 89.3000 & 21.0472 & 48.4049 & 14.7594 \\
$p_{r}$ & $\%$ & 78.9528 & 10.7000 & 51.5951 & 14.7594 \\
$s_{u}^{b}$ & $\%$ & 72.3332 & 35.2805 & 54.9927 & 6.8414 \\
$s_{u}^{i b}$ & $\%$ & 28.0889 & 9.8375 & 16.9141 & 3.3583 \\
$s_{r}^{b}$ & $\%$ & 43.3378 & 4.0469 & 22.8320 & 7.9634 \\
$s_{r}^{i b}$ & $\%$ & 9.9767 & 0.8790 & 5.2612 & 1.7912 \\
$P($ population $)$ & ten thousand persons & $10,594.0000$ & 534.0000 & 4363.0800 & 2631.6981 \\
children & $\%$ & 44.6500 & 9.6400 & 24.6453 & 7.3184 \\
elderly & $\%$ & 21.8800 & 7.4400 & 12.2259 & 2.3825 \\
sex & Male/Female & 115.2300 & 94.9200 & 103.9320 & 3.4372 \\
senior & $\%$ & 29.0483 & 4.8842 & 14.3981 & 4.0935 \\
college & $\%$ & 37.3503 & 1.8284 & 8.4561 & 5.5171 \\
occupation & $\%$ & 62.9000 & 11.5000 & 36.1880 & 11.6511 \\
urban & $\%$ & 89.3000 & 21.0472 & 48.4049 & 14.7594 \\
\hline
\end{tabular}

Data sources: the author sorted and obtained data through collecting initial data from the China Statistical Yearbook [1] in 2004-2013, China Energy Statistical Yearbook [45] in 2004-2013, and the China Labour Statistical Yearbook [3] in 2004-2013. Data of regional GDP and regional total residents' consumption was adjusted by taking 2003 as the base period.

\section{Decomposed Results and Discussion}

According to the above statistical results, these were combined with the decomposed method and Equations (9)-(16) to calculate change of carbon emission in China from 2003 to 2012. The calculated results were shown in Figure 2. 
According to Figure 2, it was found that total carbon emission (tce) in China increased by 4.2117 billion tons from 2003 to 2012. Consumption inhibitory factor effect, urbanization effect, residents' consumption effect, and population scale effect, which related factors of population and residents' consumption, promoted the increasing of carbon emission in China. The influence of residents' consumption effect ( $r c e$ ) is the largest among them, followed by consumption inhibitory factor effect (cife). These led carbon emissions to rise by 3.7222 and 1.1595 billion tons during the sample period, respectively. Urbanization effect $(u e)$ and population scale effect ( $p c e)$ drove carbon emission increases of 0.5842 and 0.2985 billion tons, respectively. However, the impact of carbon emission factor effect and energy intensity effect on carbon emission was negative in 2003-2012. The influence of energy intensity effect (eie) was more obvious, and it caused carbon emission reduction of 1.4161 billion tons from 2003 to 2012, while the contribution value of the carbon emission factor effect (cefe) was only -0.1366 billion tons. Wang [4] believed that the carbon emission factor and energy intensity embodied a technical level of energy utilization to some degree. Therefore, the above result showed that energy utilization technology was improved during the sample period in China, and reached the effect of "emission reduction by technology". However, overall carbon emission in China was increasing due to the influence of a series of external variables as total consumption of residents, population scale and urbanization, and so on.

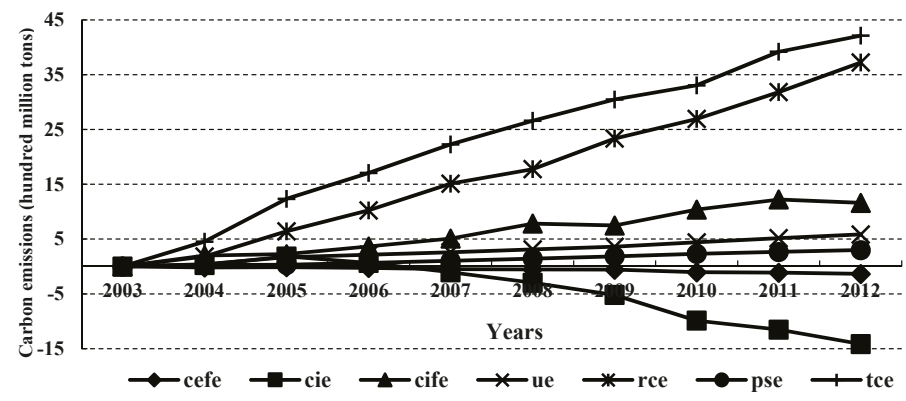

Figure 2. Decomposed results of total carbon emission in China from 2003 to 2012.

Figure 3 showed the mean contribution ratio of each decomposed effect of carbon emission. During 2003 to 2012, the contribution ratio of residents' consumption effect was $74.96 \%$ and it was the largest factor, followed by consumption inhibitory factor effect and energy intensity effect-their contribution ratios were $27.44 \%$ and $-18.46 \%$, respectively-and the contribution ratios of the urbanization effect, population scale effect, and carbon emission factor effect were $12.70 \%, 5.90 \%$, and $-2.54 \%$. Residents' consumption effect and consumption inhibitory factor effect were the largest affected factors which affect the change of regional carbon emission at the regional level. However, there was a significant difference between carbon emission factor effect, energy intensity effect, and population size effect in three regions. The contribution ratio of the energy intensity effect in the eastern region was significantly smaller than in central and western regions, but its contribution ratio of population scale effect was significantly larger than the other two regions. The carbon emission factor effect of the central region was significantly larger than that of the eastern and western regions, and its population scale effect was almost 0 . We would analyze in-depth the decomposed results of carbon emission from three aspects as technology, residents' consumption, and population factors due to the above characteristics of decomposed effects in the three regions. 


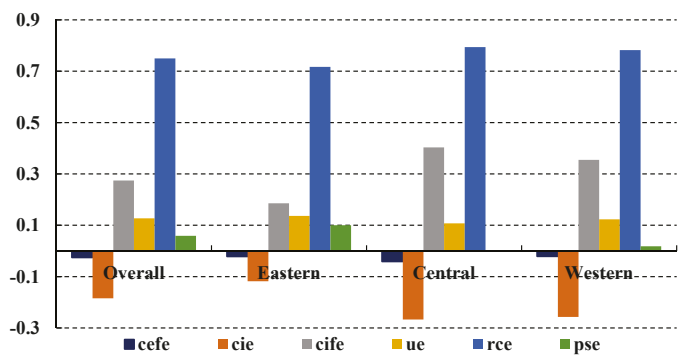

Figure 3. Contribution ratios of six decomposed effects on the increasing of regional carbon emission.

Firstly, the technical factors include two effects of carbon emission factor effect and energy intensity effect, their change tendency is shown in Figure 4. The influence of carbon emission factor and energy intensity on change of the regional carbon emission was negative overall during the sample period. Where, in 2003-2006, the contribution value in the three regions was around 0 , they showed an obvious downward tendency in 2007-2012. It indicated that the effect of "technical emission reduction" in the three regions was gradually emerging and strengthening since 2007. The possible explanation is that after the implementation of the Kyoto Protocol, which was drawn up at the global climate conference of Montreal in 2005, the Chinese government positively implemented a low carbon economy policy on the two levels of technology and policy, and obtained the initial effect in 2007. In addition, carbon emission factor effect and energy intensity effect of the central region was always lower than in the eastern and western regions from 2006 to 2012. Namely, contribution of carbon emission factor effect and energy intensity effect on reduction of carbon emission in the central region was the largest. It showed that technological progress of carbon emission in the central region was higher than in the eastern and western regions. The possible reason was that the foundation of energy utilization technology in the east was better, and led to technological progress becoming more difficult. While the foundation of the economy in the western region was poor, it caused a lack of conditions conducive to technological progress.

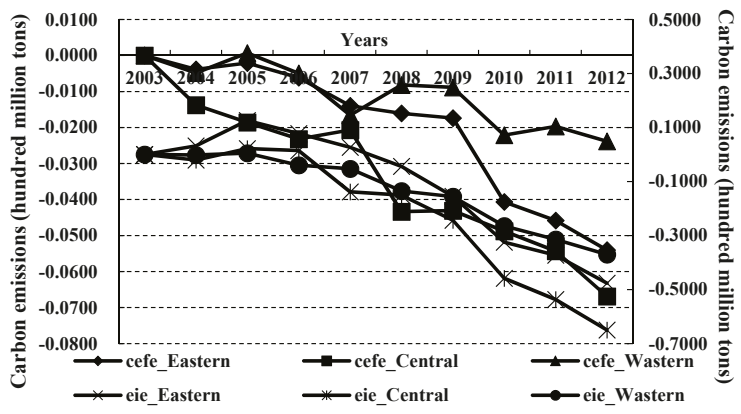

Figure 4. Change tendencies of energy intensity effect and carbon emission factor effect in three areas in 2003-2012.

Carbon emission factor effect was much lower than energy intensity effect; the main reason was that carbon emission coefficients of different types of energy were constant in this paper, and change of carbon emission factor was from the adjustment of energy structure, while we could find that the energy consumption in China was still mainly coal and petroleum during the sample period, according to statistical data from the China Statistical Yearbook [1] in 2004-2013. The proportion of consumption of coal and petroleum in Chinese total energy consumption decreased $2.5 \%$ and $2.2 \%$, respectively, 
in 2012 compared to 2003, while the proportion of clean energy (non-fossil energy) rose only 1.2\%, indicating that adjustment of energy structure was minimal. At the provincial level, the proportion of coal consumption declined $14.29 \%$ in Shanxi province, which was far higher than the national average. This led its carbon emission factor effect to become larger than other provinces, and this result was also in accordance with the above conclusion. On the other hand, the regional energy intensity continued to decline significantly in recent years due to the strict implementation of "energy saving and emission reducing" policy. It led to the effective reduction of regional carbon emission; the energy intensity effect was much higher than carbon emission factor effect.

Residents' consumption factors include consumption inhibitory factor effect and residents' consumption effect. Figure 5 presented the change tendency of the above two effects from 2003-2012. Influence of consumption inhibitory factor effect on the change of carbon emission in three regions exhibited an upward trend during the sample period, and did not show its inhibitory effect because its impact was positive. According to the expenditure approach definition of GDP, regional GDP was equal to the sum of residents' consumption, government consumption, fixed-asset investment, and net export, so the change direction of the consumption inhibitory factor was the same as summing government consumption, fixed-asset investment, and net export of domestic demand in Chinese economic development, and caused the reverse change relation between regions. Calculation results of consumption inhibitory factor effect show that the carbon emission intensity of the industry dimension of residents' consumer goods may be lower than the other three economic dimensions. Namely, the reduction of the consumption ratio would cause the rise of government consumption, fixed-asset investment, and net export when the economic output was fixed, and then promote the increase of total carbon emissions. However, according to the China Statistical Yearbook [1], although the total residents' consumption and per capita consumption increased, respectively, 6.8084 trillion and 4.8810 thousand RMB from 2003 to 2012, the residents' consumption ratio dropped from $34.25 \%$ to $27.29 \%$, which indicated that it was a lack residents' consumption ratio and carbon emission. Therefore, the residents' consumption ratio dropped to $3.15 \%$ in the central region, which was much higher than the eastern and western areas. Its consumption inhibitory factor effect was also significantly higher than that of the eastern and western areas during this period.

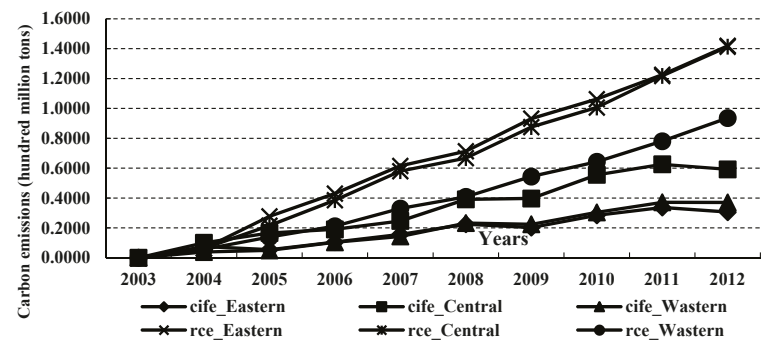

Figure 5. Change tendencies of consumption inhibitory factor effect and residents' consumption effect in three areas in 2003-2012.

The contribution value of residents' consumption on change of regional carbon emission was the maximum in absolute terms, and it was the most important influencing factor. Figure 5 showed that residents' consumption effect in three regions were $0.1419,0.1413$, and 0.0936 billion tons in 2012, and they clearly rose during the sample period; namely, the rising of per capita consumption caused carbon emission to increase $0.1419,0.1413$, and 0.0936 billion tons, respectively, in the eastern, central, and western areas. Residents' consumption effect in the western region was always much lower than that of the eastern and central areas in 2003-2012. The possible explanation could be that the economic development level and its growth rate in the western area was much lower than the other two regions, which caused its growth rate of per capita consumption to be much less than the eastern and central areas. 
Equation (13) in this paper divided residents' consumption effect into two parts as residents' basic living and non-basic living consumption effect (brce, nbrce). Residents' basic living consumption effect represents the effects of five kinds of basic living consumption (food, clothing, housing, household appliances and services, transportation, and communication) on changes in carbon emission, while residents' non-basic living consumption effect represents the effects of other kinds of consumption on change in regional carbon emission. The results are shown in Figure 6.

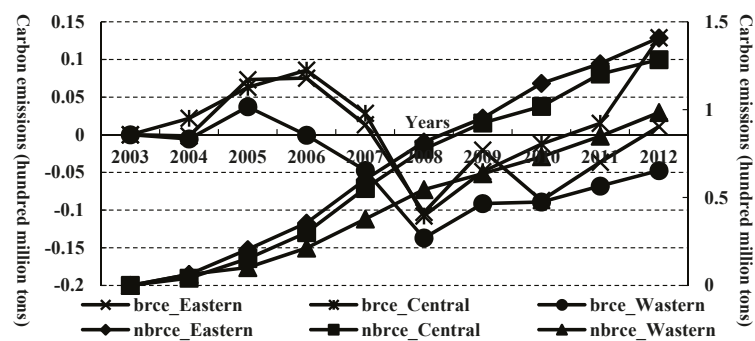

Figure 6. Change tendency of consumption structure in three areas from 2003 to 2012.

Figure 6 showed that there was a significant difference between impacts of residents' basic living consumption and residents' non-basic living consumption on change in regional carbon emission. The change tendency of residents' basic living consumption effect was similar to residents' consumption effect. Contribution values of residents' basic living consumption on change of regional carbon emission in eastern, central, and western areas were $0.1409,0.1284$, and 0.0983 billion tons by 2012. While residents' non-basic living consumption effect in three areas changed as graphic " $\mathrm{N}$ " around 0; it exhibited a fluctuating upward trend in 2003-2005 and in 2009-2012, and appeared to fluctuate down in 2006-2008. Influence of residents' non-basic living consumption effect on regional carbon emission presented as a weak negative effect, so the main source of residents' consumption effect was the residents' basic living consumption effect. There may be two reasons for this phenomenon. First, the proportion of residents' non-basic living consumption in residents' living consumption was very small. According to the statistical data, it was less than $20 \%$ in many provinces, and still kept decreasing. Second, residents' non-basic living consumption corresponded with education, entertainment and other service industries. Zhang [46] found that energy efficiency of education, entertainment and other service industries was high; namely, unit consumption of these industries consumed less energy, and then carried less carbon emission. Therefore, impact of change of residents' non-basic living consumption on change of carbon emission was relatively weak.

Figure 7 offered impact of population factors on change of carbon emission in three regions, mainly including two aspects: urbanization effect and population scale effect. According to Figure 7, the contribution of urbanization on carbon emission in the eastern, central, and western areas in China was $0.0236,0.0199$, and 0.0143 billion tons, respectively, from 2003 to 2012. Contribution of change of population size on carbon emission was $0.0196,0.0030$, and 0.0024 billion tons, respectively. Obviously, the urbanization effect was much larger than population scale effect in all the three regions, and demographic urbanization had become the main population factor which affects the change of carbon emission during the sample period. In addition, although the population scale effect was positive in central and western regions overall, its contribution was always close to 0 , which was significantly lower than the population scale effect in the eastern area, and it manifested as a negative effect in the central area from 2005 to 2008. According to the conclusion of Cai [47], there was always an obvious population "Eastern aggregation" phenomenon in China since 1990s, especially the central region which was close to the eastern region, and the phenomenon of population flow to the eastern area was more obvious. It may be the main reason for the above characteristics in regional population scale effect. 


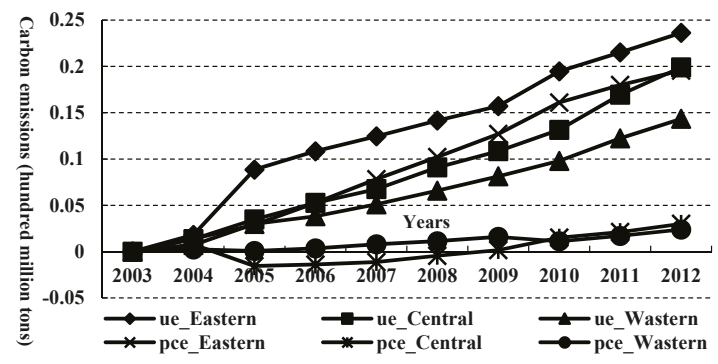

Figure 7. Change tendencies of urbanization effect and population scale effect in three areas from 2003 to 2012 .

\section{Empirical Results and Discussion}

According to the previous study, population structure change has a great impact on the change of carbon emission. In this paper, we took seven indicators to represent population structure. Firstly, we selected the children dependency ratio (children) and the elderly people dependency ratio (elderly) to refer to the regional population age structure. The existing studies showed that, due to higher income level and the strong consumption demand of the middle-aged population, their per capita carbon emission was obviously higher than that of children and the elderly $[5,28,29]$. Therefore, we expected that the regression coefficients of these two indicators were negative. Secondly, we used the sex ratio of the total population (sex) to refer to the regional population sex structure. Due to the different consumption preferences between men and women, population sex structure also affected regional carbon emission. Thirdly, we used proportion of the population of senior high school (senior) and the proportion of the population of college and above (college) to refer to the regional population education structure. Generally, income of residents was increased with the increasing of a high-degree education population, thus causing the growth of residents' consumption ability and carbon emissions. However, high-degree education would also improve residents' environmental protection consciousness. Therefore, we believed that the effect of population education structure on carbon emission was uncertain. The data for the above five indicators are from the China Statistical Yearbook [1]. Fourthly, we used the proportion of employees in state-owned units in total Chinese urban employment (occupation) to refer to the regional population occupation structure. Compared with other employees, employees in state-owned units have more stable income and old-age security. It leads to the different consumption attitude between them and other employees, which affected regional carbon emission. Its data is from the China Labour Statistical Yearbook [3]. Finally, we used the proportion of urban population (urban) to refer to the population structure of urban and rural areas. Obviously, the income level and consumption capacity of rural residents were far behind the urban residents. This suggests that per capita carbon emission of rural residents was significantly less than urban residents, so the population structure of urban and rural areas was also an important factor which affected regional carbon emission [33-35]. This data is also from the China Statistical Yearbook [1].

In order to validate the relationship between change in population structure and carbon emission, we needed to conduct regression analysis. We used the total effect of change of regional carbon emission $(\Delta C)$ as the dependent variable, and took the seven indicators (children, elderly, sex, senior, college, occupation, urban) which referred to change of regional population structure in China as the independent variables. We then used regional GDP (GDP) and regional population scale (population) as controlled variables, conducted regression analysis of the effect of population structure change on the change in carbon emission. The regression model was as Equation (17):

$$
\begin{aligned}
\Delta C= & \alpha+\beta_{1} \text { children }+\beta_{2} \text { elderly }+\beta_{3} \text { sex }+\beta_{4} \text { senior }+\beta_{5} \text { college }+ \\
& \beta_{6} \text { occupation }+\beta_{7} \text { urban }+\beta_{8} G D P+\beta_{9} \text { population }+\varepsilon
\end{aligned}
$$


where: $\alpha$ was a constant, $\beta_{i}(i=1, \ldots, 9)$ and represented the regression coefficient of the variable, and $\varepsilon$ represented random error.

Table 2 shows the correlation matrix of the variables. We find that the dependent variable is strongly correlated with each independent variable, and the correlation coefficients between independent variables are relatively weak.

Table 2. Correlation matrix of variables.

\begin{tabular}{ccccccccccc}
\hline Variables & $\Delta \boldsymbol{C}$ & Children & Elderly & Sex & Senior & College & Occupation & Urban & GDP & Population \\
\hline$\Delta C$ & 1.000 & & & & & & & & & \\
children & -0.832 & 1.000 & & & & & & & & \\
elderly & -0.327 & -0.140 & 1.000 & & & & & & & \\
sex & -0.117 & -0.154 & 0.159 & 1.000 & & & & & & \\
senior & -0.452 & 0.182 & -0.212 & -0.236 & 1.000 & & & & \\
college & -0.367 & 0.169 & -0.176 & -0.233 & -0.041 & 1.000 & & & \\
occupation & -0.463 & 0.220 & -0.118 & -0.263 & 0.160 & 0.157 & 1.000 & & \\
urban & 0.480 & -0.245 & 0.245 & -0.064 & -0.171 & -0.116 & -0.291 & 1.000 & & \\
GDP & 0.555 & 0.286 & -0.300 & 0.006 & 0.185 & 0.251 & 0.305 & -0.356 & 1.000 & \\
population & 0.568 & 0.342 & -0.294 & -0.113 & 0.305 & 0.174 & 0.218 & -0.163 & 0.317 & 1.000 \\
\hline
\end{tabular}

In order to avoid spurious regression, this paper used Levin, Lin, and Chut, Fisher-ADF and Im, Pesaran, and Shin methods to complete the unit root test. Its results are shown in Table 3. Results show that the total effect of change of carbon emission $(\Delta C)$ was 0 -stage integration, lower than the integrated stage of all the other variables. Thus, the sample was suitable for regression analysis.

Table 3. Unit root test of variables.

\begin{tabular}{|c|c|c|c|c|c|c|c|}
\hline & & \multicolumn{3}{|c|}{ Level } & \multicolumn{3}{|c|}{ 1st Difference } \\
\hline \multicolumn{2}{|c|}{ Test } & \multicolumn{6}{|c|}{$(c, t)$} \\
\hline Variables & Parameters & LLC & Fisher-ADF & IPS & LLC & Fisher-ADF & IPS \\
\hline$\Delta C$ & \multirow{13}{*}{$\begin{array}{l}\text { Statistics } \\
\text { (Pro.) }\end{array}$} & $\begin{array}{c}-16.0600 * * * \\
(0.0000)\end{array}$ & $\begin{array}{c}108.6670 * * * \\
(0.0000)\end{array}$ & $\begin{array}{c}-1.5614^{*} \\
(0.0592)\end{array}$ & $\begin{array}{c}-14.4271 * * * \\
(0.0000)\end{array}$ & $\begin{array}{c}97.6317^{* * *} \\
(0.0015)\end{array}$ & $\begin{array}{c}-1.5265 * \\
(0.0613)\end{array}$ \\
\hline children & & $\begin{array}{c}-9.2836^{* * *} \\
(0.0000)\end{array}$ & $\begin{array}{c}106.7150 \text { *** } \\
(0.0002)\end{array}$ & $\begin{array}{l}-0.7277 \\
(0.2334)\end{array}$ & $\begin{array}{c}-32.4082 * * * \\
(0.0000)\end{array}$ & $\begin{array}{c}216.4500 * * * \\
(0.0000)\end{array}$ & $\begin{array}{c}-5.8521^{* * * *} \\
(0.0000)\end{array}$ \\
\hline elderly & & $\begin{array}{c}-11.0706 \text { *** } \\
(0.0000)\end{array}$ & $\begin{array}{c}80.8367 * * \\
(0.0378)\end{array}$ & $\begin{array}{l}-0.7182 \\
(0.2363)\end{array}$ & $\begin{array}{c}-9.3649 * * * \\
(0.0000)\end{array}$ & $\begin{array}{c}80.6729 * * \\
(0.0388)\end{array}$ & $\begin{array}{c}-1.4363 * \\
(0.0713)\end{array}$ \\
\hline $\operatorname{sex}$ & & $\begin{array}{c}-12.2982 * * * \\
(0.0000)\end{array}$ & $\begin{array}{c}114.0410 * * * \\
(0.0000)\end{array}$ & $\begin{array}{c}-1.7438 \text { ** } \\
(0.0406)\end{array}$ & $\begin{array}{c}-21.3471 * * * \\
(0.0000)\end{array}$ & $\begin{array}{c}109.3150 * * * \\
(0.0001)\end{array}$ & $\begin{array}{c}-2.2791 \text { ** } \\
(0.0113)\end{array}$ \\
\hline senior & & $\begin{array}{c}-10.8482 \text { *** } \\
(0.0000)\end{array}$ & $\begin{array}{c}88.6095 * * * \\
(0.0096)\end{array}$ & $\begin{array}{l}-0.6717 \\
(0.2509)\end{array}$ & $\begin{array}{c}-8.6645^{* * *} \\
(0.0000)\end{array}$ & $\begin{array}{c}99.7102 * * * \\
(0.0010)\end{array}$ & $\begin{array}{c}-1.4869 * \\
(0.0643)\end{array}$ \\
\hline college & & $\begin{array}{c}-9.6667 * * * \\
(0.0000)\end{array}$ & $\begin{array}{c}79.6100 * * \\
(0.0460)\end{array}$ & $\begin{array}{l}-0.3295 \\
(0.3709)\end{array}$ & $\begin{array}{c}-14.6147^{* * *} \\
(0.0000)\end{array}$ & $\begin{array}{c}125.5700 * * * \\
(0.0000)\end{array}$ & $\begin{array}{c}-2.0845^{* *} \\
(0.0186)\end{array}$ \\
\hline occupation & & $\begin{array}{c}-10.1579 \text { *** } \\
(0.0000)\end{array}$ & $\begin{array}{c}85.4663 \text { ** } \\
(0.0171)\end{array}$ & $\begin{array}{l}-0.8982 \\
(0.1845)\end{array}$ & $\begin{array}{c}-12.8208 * * * \\
(0.0000)\end{array}$ & $\begin{array}{c}105.0820 \text { *** } \\
(0.0003)\end{array}$ & $\begin{array}{c}-1.3890 * \\
(0.0824)\end{array}$ \\
\hline urban & & $\begin{array}{c}-17.9312 * * * \\
(0.0000)\end{array}$ & $\begin{array}{c}112.8150 * * * \\
(0.0000)\end{array}$ & $\begin{array}{c}-3.0377^{* * *} \\
(0.0012)\end{array}$ & $\begin{array}{c}-26.5032 \text { *** } \\
(0.0000)\end{array}$ & $\begin{array}{c}194.4340 * * * \\
(0.0000)\end{array}$ & $\begin{array}{c}-6.1255^{* * * *} \\
(0.0000)\end{array}$ \\
\hline$G D P$ & & $\begin{array}{c}-4.5980 * * * \\
(0.0000)\end{array}$ & $\begin{array}{l}24.6834 \\
(1.0000)\end{array}$ & $\begin{array}{c}2.2162 \\
(0.9867)\end{array}$ & $\begin{array}{c}-48.9063^{* * *} \\
(0.0000)\end{array}$ & $\begin{array}{c}112.7480 \text { *** } \\
(0.0000)\end{array}$ & $\begin{array}{c}-3.1260 \text { *** } \\
(0.0009)\end{array}$ \\
\hline population & & $\begin{array}{c}-7.3813^{* * *} \\
(0.0000)\end{array}$ & $\begin{array}{l}67.1597 \\
(0.2452)\end{array}$ & $\begin{array}{c}0.4411 \\
(0.6704)\end{array}$ & $\begin{array}{c}-3.5134 * * * \\
(0.0002)\end{array}$ & $\begin{array}{c}88.2176^{* *} \\
(0.0103)\end{array}$ & $\begin{array}{c}-2.0025^{* *} \\
(0.0224)\end{array}$ \\
\hline$\Delta C_{e i}$ & & $\begin{array}{c}-26.8766 * * * \\
(0.0000)\end{array}$ & $\begin{array}{c}139.5560 * * * \\
(0.0000)\end{array}$ & $\begin{array}{c}-3.7129 * * * \\
(0.0001)\end{array}$ & $\begin{array}{c}-48.5369 * * * \\
(0.0000)\end{array}$ & $\begin{array}{c}177.8920 \text { *** } \\
(0.0000)\end{array}$ & $\begin{array}{c}-7.6320^{* * * *} \\
(0.0000)\end{array}$ \\
\hline$\Delta C_{b-i b}$ & & $\begin{array}{c}-3.3387^{* * *} \\
(0.0004)\end{array}$ & $\begin{array}{c}152.1686^{* * *} \\
(0.0000)\end{array}$ & $\begin{array}{c}-1.4127 * \\
(0.0734)\end{array}$ & $\begin{array}{c}-14.4752 * * * \\
(0.0000)\end{array}$ & $\begin{array}{c}109.1800 * * * \\
(0.0001)\end{array}$ & $\begin{array}{c}-1.6076 * \\
(0.0540)\end{array}$ \\
\hline$\Delta C_{c i f}$ & & $\begin{array}{c}-11.5972 * * * \\
(0.0000)\end{array}$ & $\begin{array}{c}92.0104^{* *} \\
(0.0049)\end{array}$ & $\begin{array}{c}-1.5105^{*} \\
(0.0625)\end{array}$ & $\begin{array}{c}-16.5986 * * * \\
(0.0000)\end{array}$ & $\begin{array}{c}117.8310 \text { *** } \\
(0.0000)\end{array}$ & $\begin{array}{c}-2.0217^{* *} \\
(0.0216)\end{array}$ \\
\hline
\end{tabular}

$*, * *, * *$, respectively represented $1 \%, 5 \%, 10 \%$ of significance (same in below), $(\mathrm{c}, \mathrm{t})$ represented the test included intercept and trend.

The regression results were shown in Table 4. 


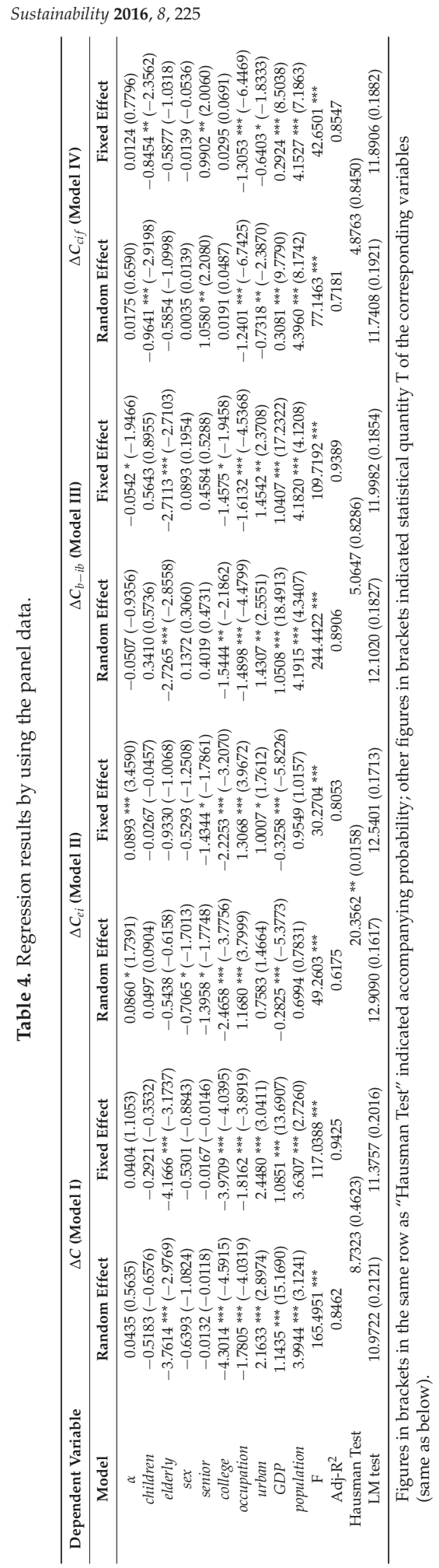


Table 4 showed that the Hausman test statistic of model I was 8.7323 , and its probability was 0.4623 . So the random effect model was more suitable to the sample. Results of the LM test illustrated that the regression residuals are stable, and the regression result is effective. Firstly, the regression coefficient of the regional elderly dependency ratio (elderly) was negative, and it had $1 \%$ significance, indicating that the ageing population would reduce carbon emission from energy consumption. Studies of Liddle et al. [28] and Okada [6] also obtained a similar conclusion. The possible explanation was that income of the elderly population gradually reduces with the growth of age, so their consumption scale and consumption levels were much lower than middle-aged or youth population, and then caused the decreasing of carbon emission. Secondly, the regression coefficient of the regional proportion of the population of college and above (college) was negative, and it had $1 \%$ significance, indicated that rising of population quality was helpful to decrease regional carbon emission, in contrast with the conclusion of Katircioğlu [10]. There may be two reasons to explain this result: the first, that the proportion of the highly educated population not only reflected the level of human capital, but also was the source of regional technology innovation. Thus, an increase in education was helpful to renew the energy utilization technology. The second, that this population could effectively fulfill the development concept of "energy-saving and emission-reducing", especially in the economic department of consumption, the highly educated population preferred to choose the environmentally friendly products. This was helpful to reduce carbon emission. Thirdly, the regression coefficient of the proportion of employees in state-owned units in total Chinese urban employment (occupation) was negative, and it had 1\% significance, indicating that reducing the proportion of employees in state-owned units promoted the increasing of carbon emission, which was in contrast with the expectation of this paper. The proportion of employees in state-owned units reflected the proportion of the state-owned economy to some extent. Due to the inefficiency of state-owned economic departments, the rapid development of market economics caused the increasing of energy consumption, and then caused a rise in carbon emission. This explains why the regression coefficient of occupation was negative. Finally, the regression coefficients of regional population urban and rural structure (urban), regional total GDP (GDP) and regional total population (Population) were positive, and were all of $1 \%$ significance. This met our expectation completely, indicating that the development of urbanization, economic growth, and expansion of the regional population scale would promote the increasing of carbon emission from energy consumption.

In addition, the carbon emission factor effect $\left(\Delta C_{c i}\right)$ was decided by the energy emission coefficient and energy structure; the effect of population structure on it was small. Urbanization effect $\left(\Delta C_{u-r}\right)$ expressed the impact of change of urban and rural population on carbon emission. It was only related to the change of urban and rural population structure (urban), and population scale effect $\left(\Delta C_{P}\right)$ only expressed the impact of change of population scale on carbon emission. Obviously, the above three decomposed effects were hardly affected by the seven indices of population structure change. Therefore, energy intensity effect $\left(\Delta C_{e i}\right)$, residents' consumption effect $\left(\Delta C_{b-i b}\right)$ and consumption inhibitory factor effect $\left(\Delta C_{c i f}\right)$ may be the main path which conducted the effect of change of population structure on change in carbon emission. Then we would take three decomposed effects $\left(\Delta C_{e i}, \Delta C_{b-i b}, \Delta C_{c i f}\right)$ as dependent variables respectively to analyze the path which conducted the effect of change of population structure on change of carbon emission in the content of this paper below. The regression model was as Equation (18):

$$
\begin{array}{r}
\Delta C_{e i}=\begin{array}{c}
\alpha_{1}+\beta_{1} \text { children }+\beta_{2} \text { elderly }+\beta_{3} \text { sex }+\beta_{4} \text { senior }+\beta_{5} \text { college }+ \\
\beta_{6} \text { occupation }+\beta_{7} \text { urban }+\beta_{8} G D P+\beta_{9} \text { population }+\varepsilon_{1}
\end{array} \\
\Delta C_{b-i b}=\begin{array}{c}
\alpha_{2}+\beta_{1} \text { children }+\beta_{2} \text { elderly }+\beta_{3} \text { sex }+\beta_{4} \text { senior }+\beta_{5} \text { college }+ \\
\beta_{6} \text { occupation }+\beta_{7} \text { urban }+\beta_{8} G D P+\beta_{9} \text { population }+\varepsilon_{2}
\end{array} \\
\Delta C_{\text {cif }}=\begin{array}{c}
\alpha_{3}+\beta_{1} \text { children }+\beta_{2} \text { elderly }+\beta_{3} \text { sex }+\beta_{4} \text { senior }+\beta_{5} \text { college }+ \\
\beta_{6} \text { occupation }+\beta_{7} \text { urban }+\beta_{8} G D P+\beta_{9} \text { population }+\varepsilon_{3}
\end{array}
\end{array}
$$


where $\alpha_{i}(i=1,2,3)$ was a constant, $\beta_{i}(i=1, \ldots, 9)$ which represented the regression coefficient of the variable, and $\varepsilon_{i}(i=1,2,3)$ represented random error. The regression results are shown in Table 3. The results showed that the Hausman test statistical quantity in model II was 20.3562, and it was of $5 \%$ significance. Thus, the fixed effect model was more suitable to model II, while we should select a random effect model in model III and model IV.

Firstly, in model II, regression coefficients of the regional proportion of the population of senior high school (senior) and the proportion of the population of college and above (college) indices were negative, and they were of $10 \%$ and $1 \%$ significance, respectively, indicating that improvement of the population quality was helpful to reduce the regional energy intensity effect $\left(\Delta C_{e i}\right)$. Energy intensity reflected the development of technology of energy utilization. The regression coefficient of the regional proportion of employees in state-owned units in the total Chinese urban employment (occupation) was positive, and it showed $1 \%$ significance, which indicated that the proportion of employees in state-owned enterprises hindered the advance of energy utilized technology. This result corresponded to the inefficiency of state-owned economic components. Regression coefficients of regional population urban and rural structure (urban) and total GDP (GDP) indices were of $10 \%$ and 1\% significance, respectively, and the regression coefficient of regional total GDP (GDP) was negative, which indicated that improvement of the economy in China was helpful to promote the progress of energy utilized technology during the sample period.

Secondly, identical to model I, when $\Delta C_{b-i b}$ is taken as the dependent variable, the effect of the regional elderly people dependency ratio (elderly), proportion of the population of college and above (college), proportion of employees in state-owned units in total China urban employment (occupation), population urban and rural structure (urban), total GDP (GDP) and total population (population) indices were significant, and the sign of their regression coefficients were the same as in model I. This indicated that the population education structure, population occupation structure, and population urban and rural structure could further affect regional carbon emission from energy consumption through affecting residents' consumption scale and consumption levels.

Thirdly, in model IV, the regression coefficient of children dependency ratio (children) index was negative, and it showed 1\% significance. Due to the low consumption capacity of the juvenile population, the increasing of the children dependency ratio (children) would inevitably cause the residents' consumption ratio to decrease, thereby reducing carbon emission from energy consumption. Contrary to the former three models, the regression coefficient of regional population urban and rural structure (urban) was negative, and it showed 10\% significance, indicated that development of urbanization would reduce the consumption inhibitory factor effect $\left(\Delta C_{c i f}\right)$. Although the development of urbanization has promoted the rising of the urban population, and increased the amount of residents' consumption, the residents' consumption ratio in provinces of China decreased continuously during the sample period according to the data of the China Statistical Yearbook [43]. Therefore, the contribution of urbanization development on the overall economy was stronger than on residents' consumption. This may explain why the regression coefficient of regional population urban and rural structure (urban) was negative. In addition, identical to model I and model III, the regression coefficients of occupation, GDP, and population all showed $1 \%$ significance.

Finally, through comparing the results of the above models, we found that population structure change affected change of regional carbon emission from energy consumption mainly through affecting residents' consumption ratio and consumption level. Population education structure affected change of regional carbon emission mainly by two paths as progress of energy utilized technology and change of residents' consumptive conception. Paths of impact of population occupation structure and population urban and rural structure all included progress of energy utilized technology, scale, and level of residents' consumption, residents' consumption ratio. Although the effect of population sex structure (sex ratio) index on regional carbon emission was always not significant, the sex ratio at birth in China was always higher than 115 during the sample period; this may cause serious gender imbalance in the future. It should catch our attention whether this phenomenon would have significant impact on carbon emission from energy consumption in China in the future. 
Due to the large gap of change of carbon emission and its decomposed effects between three regions, this paper analyzed effect of population structure change on carbon emission and its decomposed effects in different regions by introducing dummy variables into Equation (17) and Equation (18). Dummy variables were set up as follows:

$$
\text { Eastern }=\left\{\begin{array}{rr}
1 & (\text { Eastern }) \\
0 & \text { (Other areas) }
\end{array} \quad \text { Central }=\left\{\begin{array}{rr}
1 & \text { (Central) } \\
0 & \text { (Other areas })
\end{array}\right.\right.
$$

$\Delta C, \Delta C_{e i}, \Delta C_{b-i b}, \Delta C_{i f}$ were taken as dependent variables, respectively, introduced dummy variables into the regression model, and obtained the results as shown in Table 5.

Table 5. Regression results by using the panel data (including dummy variables).

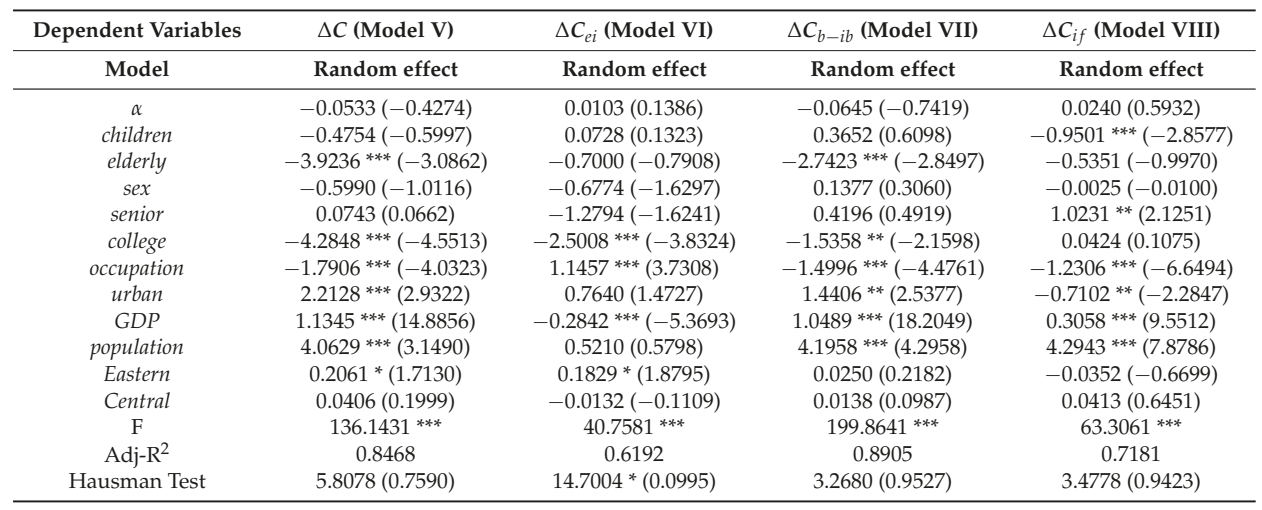

According to the results of the Hausman test, the random effect model was more suitable to this study. Due to space limitations, we only provide the regression results of the random effect model in this paper; the author could provide regression results of the fixed effect model if necessary.

Table 5 showed that the regression coefficient of Eastern in model V was 0.2061, and it was significant. This indicated that change of carbon emission from energy consumption in the eastern region was significantly higher than that in the central and western regions. The regression coefficient of Eastern in model VI was 0.1829 , and it was also significant, while the effect of dummy variables was not significant in the other models. This result further showed that the foundation of energy utilization technology in the east was better, and met the above conclusion.

\section{Conclusions}

On the basis of Kaya identity, this paper expanded the LMDI model through introducing population urbanization, residents' consumption and other factors, and decomposed the change of carbon emission in China into six effects: carbon emission factor effect, energy intensity effect, consumption inhibitory factor effect, urbanization effect, residents' consumption effect, and population scale effect. It then explored contribution ratios and action mechanism of the above six effects on change of carbon emission. Then, we analyzed the effect of population structure change on carbon emission by taking 2003-2012 as a sample period, and combined this with the panel data of 30 provinces in China. The main conclusions of this paper are as follows:

(1) In 2003-2012, total carbon emission in China increased by 4.2117 billion tons. Consumption inhibitory factor effect, urbanization effect, residents' consumption effect, and population scale effect could promote the increasing of carbon emission, while the influence of carbon emission factor effect and energy intensity effect on carbon emission were negative, indicating that Chinese energy technology utilized during the samples was improved and reached the effect of "technical carbon emission reduction" to some extent. Specifically, the contribution ratio of residents' 
consumption effect affected change of carbon emission was greatest, which reached $74.96 \%$, followed by the consumption inhibitory effect and energy intensity effect. Their contribution ratios were $27.44 \%$ and $-18.46 \%$, respectively. The contribution ratio of impact of urbanization effect, population scale effect and carbon emission factor effect on carbon emission was $12.700 \%$, $5.90 \%$, and $-2.54 \%$ respectively.

(2) Firstly, there was a significant difference between the carbon emission factor effect, energy intensity effect, and population scale effect in the three areas. Contribution ratio of energy intensity effect in the eastern region was significantly smaller than the central and western areas, while contribution ratio of its population scale effect was larger than the other two regions. Carbon emission factor effect of the central area was significantly higher than that in the eastern and western regions, and its population scale effect was close to 0 . Secondly, the influences of carbon emission factor and energy intensity on the changing of regional carbon emission were all negative. The carbon emission factor effect and energy intensity effect in the three regions were around 0 from 2003 to 2006, while in 2007-2012 they all showed obvious decline. Thirdly, influences of the consumption inhibitory factor effect on changing of regional carbon emission in three areas showed a fluctuating upward trend, their effect were positive and did not show their inhibition. The residents' consumption effect in the three regions showed a clear upward trend, and the residents' consumption effect in the eastern, central, and western regions were $0.1419,0.1413$, and 0.0936 billion tons in 2012, respectively. The residents' consumption effect became the most important influencing factor which affected change of carbon emission and its contribution ratio was the greatest. The main source of the residents' consumption effect in the three regions was the residents' basic living consumption effect, while residents' non-basic living consumption effect in the three areas changed as a graphic " $\mathrm{N}$ " around 0 ; it showed a fluctuating upward trend in 2003-2005 and in 2009-2012, and appeared to fluctuate downwards in 2006-2008. Finally, the "eastern aggregation" phenomenon of population caused the population scale effect of the eastern area to be obviously larger than the central and western areas. The urbanization effect in all three regions were obviously larger than the population scale effect, which indicated that demographic urbanization has become the main population factor which affected the change of carbon emission.

(3) Secondly, the impact of regional people dependency ratio on regional carbon emission was negative and significant, as was the proportion of the population of college and above, and the proportion of employees in state-owned units in total Chinese urban employment, while the effect of regional population urban and rural structure, total GDP and total population were positive and significant. Based on the analysis of the decomposition effects, we found that population structure change affected change in regional carbon emission from energy consumption mainly through affecting residents' consumption ratio and consumption levels. Population education structure affected change of regional carbon emission mainly by two paths, as progress of energy utilized technology and change of residents' consumptive conception. While the path of the impact of population occupation structure and population urban and rural structure all included progress of energy utilized technology, scale, and the level of residents' consumption and residents' consumption ratio, the effect of population sex structure (sex ratio) index on regional carbon emission was always non-significant. Finally, we found that the change of carbon emission in the eastern region was significantly higher than that in the central and western regions when dummy variables were introduced into the regression model. The foundation of energy utilized technology in the eastern region was also significantly better than in the other two regions.

Acknowledgments: This work was financially supported by Funding of Jiangsu Social Sciences (No. 12EYA001), Funding of Jiangsu University Philosophy and Social Science (No. 11ZDIXM051), Funding of Anhui Humanities and Social Sciences (No. SK2014A099), Funding of Jiangsu Innovation Program for Graduate Education (No. KYZZ_0107 \& No. CXLX12_0178), China Scholarship Council: “Graduate Programs of National Construction High Level University in 2014".

Author Contributions: Wen Guo and Tao Sun wrote the paper, Wen Guo and Hongjun Dai analyzed the data. 
Conflicts of Interest: The authors declare no conflict of interest.

\section{References}

1. National Bureau of Statistics of China. China Statistical Yearbook; China Statistics Press: Beijing, China, 2001-2014.

2. Zhuang, Y.E.; Zhang, L.P. China Commonly Used Population Data Set Since 1990; China Population Press: Beijing, China, 2003.

3. National Bureau of Statistics of China. China Labour Statistical Yearbook; China Statistics Press: Beijing, China, 2001-2014.

4. Wang, Q. Effects of urbanization on energy consumption in China. Energy Policy 2014, 65, 332-339. [CrossRef]

5. Liddle, B. Consumption-driven environmental impact and age structure change in OECD countries: A cointegration-STIRPAT analysis. Demogr. Res. 2011, 30, 749-770. [CrossRef]

6. Okada, A. Is an increased elderly population related to decreased $\mathrm{CO}_{2}$ emissions from road transportation? Energy Policy 2012, 45, 286-292. [CrossRef]

7. Menz, T.; Welsch, H. Population aging and carbon emissions in OECD countries: Accounting for life-cycle and cohort effects. Energy Econ. 2012, 34, 842-849. [CrossRef]

8. Zhu, H.M.; You, W.H.; Zeng, Z. Urbanization and $\mathrm{CO}_{2}$ emissions: A semi-parametric panel data analysis. Econ. Lett. 2012, 3, 848-850. [CrossRef]

9. Knight, K.W.; Rosa, E.A.; Schor, J.B. Could working less reduce pressures on the environment? A cross-national panel analysis of OECD countries, 1970-2007. Glob. Environ. Chang. 2013, 23, 691-700. [CrossRef]

10. Katircioğlu, S.T. Estimating higher education induced energy consumption: The case of Northern Cyprus. Energy 2014, 66, 831-838. [CrossRef]

11. Cellura, M.; Longo, S.; Mistretta, M. Application of the structural decomposition analysis to assess the indirect energy consumption and air emission changes related to Italian households consumption. Renew. Sustain. Energy Rev. 2012, 16, 1135-1145. [CrossRef]

12. Zhao, X.; Li, N.; Ma, C. Residential energy consumption in urban China: A decomposition analysis. Energy Policy 2012, 41, 644-653. [CrossRef]

13. Hoekstra, R.; Bergh, J.C.J.M. Comparing Structural and Index Decomposition Analysis. Energy Econ. 2003, 25, 39-64. [CrossRef]

14. Ang, B.W. Decomposition Analysis for Policymaking in Energy: Which is the Preferred Method. Energy Policy 2004, 32, 1131-1139. [CrossRef]

15. Ang, B.W.; Zhang, F.Q. A Survey of Index Decomposition Analysis in Energy and Environmental Studies. Energy 2009, 25, 1149-1176. [CrossRef]

16. Ang, B.W.; Huang, H.C.; Mu, A.R. Properties and linkages of some index decomposition analysis methods. Energy Policy 2009, 11, 4624-4632. [CrossRef]

17. Choi, Y.; Zhang, N.; Zhou, P. Efficiency and abatement costs of energy-related $\mathrm{CO}_{2}$ emissions in China: A slacks-based efficiency measure. Appl. Energy 2012, 98, 198-208. [CrossRef]

18. Zhang, N.; Choi, Y. Total-factor carbon emission performance of fossil fuel power plants in China: A metafrontier non-radial Malmquist index analysis. Energy Econ. 2013, 40, 549-559. [CrossRef]

19. Su, B.; Ang, B.W. Structural decomposition analysis applied to energy and emissions: Some methodological developments. Energy Econ. 2012, 34, 177-188. [CrossRef]

20. Zhang, N.; Zhou, P.; Choi, Y. Energy efficiency, $\mathrm{CO}_{2}$ emission performance and technology gaps in fossil fuel electricity generation in Korea: A meta-frontier non-radial directional distance function analysis. Energy Policy 2013, 56, 653-662. [CrossRef]

21. Rosa, E.A.; York, R.; Dietz, T. Tracking the anthropogenic drivers of ecological impacts. AMBIO A J. Hum. Environ. 2004, 8, 509-512. [CrossRef]

22. O'Neill, B.C.; Liddle, B.; Jiang, L.; Smith, K.R.; Pachauri, S.; Dalton, M.; Fuchs, L. Demographic change and carbon dioxide emissions. Lancet 2012, 380, 157-164. [CrossRef]

23. Wang, P.; Wu, W.; Zhu, B.; Wei, Y. Examining the impact factors of energy-related $\mathrm{CO}_{2}$ emissions using the STIRPAT model in Guangdong Province, China. Appl. Energy 2013, 106, 65-71.

24. Satterthwaite, D. The Implications of Population Growth and Urbanization for Climate Change. Environ. Urban. 2009, 2, 545-567. [CrossRef] 
25. Yao, C.; Chen, C.; Li, M. Analysis of rural residential energy consumption and corresponding carbon emissions in China. Energy Policy 2012, 41, 445-450. [CrossRef]

26. Wang, L.; Chen, Z.; Ma, D.; Zhao, P. Measuring carbon emissions performance in 123 countries: Application of minimum distance to the strong efficiency frontier analysis. Sustainability 2013, 5, 5319-5332. [CrossRef]

27. York, R. Demographic trends and energy consumption in European Union Nations, 1960-2025. Soc. Sci. Res. 2007, 3, 855-872. [CrossRef]

28. Liddle, B.; Lung, S. Age-structure, urbanization, and climate change in developed countries: Revisiting STIRPAT for disaggregated population and consumption-related environmental impacts. Popul. Environ. 2010, 5, 317-343. [CrossRef]

29. Lugauer, S.; Jensen, R.; Sadler, C. An estimate of the age distribution's effect on carbon dioxide emissions. Econ. Inq. 2014, 2, 914-929. [CrossRef]

30. Zagheni, E. The leverage of demographic dynamics on carbon dioxide emissions: Does age structure matter? Demography 2011, 1, 371-399. [CrossRef] [PubMed]

31. Laureti, T.; Montero, J.M.; Fernández-Avilés, G. A local scale analysis on influencing factors of NOx emissions: Evidence from the Community of Madrid, Spain. Energy Policy 2014, 74, 557-568. [CrossRef]

32. Jorgenson, A.K. Does foreign investment harm the air we breathe and the water we drink? A cross-national study of carbon dioxide emissions and organic water pollution in less-developed countries, 1975 to 2000. Organ. Environ. 2007, 2, 137-156. [CrossRef]

33. Jorgenson, A.K. The sociology of ecologically unequal exchange and carbon dioxide emissions, 1960-2005. Soc. Sci. Res. 2012, 2, 242-252. [CrossRef] [PubMed]

34. Jorgenson, A.K.; Clark, B. Assessing the temporal stability of the population/environment relationship in comparative perspective: A cross-national panel study of carbon dioxide emissions, 1960-2005. Popul. Environ. 2010, 1, 27-41. [CrossRef]

35. Jorgenson, A.K.; Clark, B. Are the Economy and the Environment Decoupling? A Comparative International Study, 1960-2005. Am. J. Soc. 2012, 1, 1-44. [CrossRef]

36. Poumanyvong, P.; Kaneko, S. Does urbanization lead to less energy use and lower $\mathrm{CO}_{2}$ emissions? A cross-country analysis. Ecol. Econ. 2010, 2, 434-444. [CrossRef]

37. Martinez-Zarzoso, I.; Maruotti, A. The impact of urbanization on $\mathrm{CO}_{2}$ emissions: Evidence from developing countries. Ecol. Econ. 2011, 70, 1344-1353. [CrossRef]

38. Poumanyvong, P.; Kaneko, S.; Dhakal, S. Impacts of urbanization on national transport and road energy use: Evidence from low, middle and high income countries. Energy Policy 2012, 46, 268-277. [CrossRef]

39. Fang, W.; Miller, S.; Yeh, C.C. The effect of ESCOs on energy use. Energy Policy 2012, 51, 558-568. [CrossRef]

40. Mishra, V.; Smyth, R.; Sharma, S. The energy-GDP nexus: Evidence from a panel of Pacific Island countries. Resour. Energy Econ. 2009, 3, 210-220. [CrossRef]

41. Hossain, $\mathrm{S}$. Panel estimation for $\mathrm{CO}_{2}$ emissions, energy consumption, economic growth, trade openness and urbanization of newly industrialized countries. Energy Policy 2011, 11, 6991-6999. [CrossRef]

42. Al-mulali, U.; Fereidouni, H.G.; Lee, J.Y.M.; Sab, C.N.B.C. Exploring the relationship between urbanization, energy consumption, and $\mathrm{CO}_{2}$ emission in MENA countries. Renew. Sustain. Energy Rev. 2013, 23, 107-112. [CrossRef]

43. Liddle, B. Impact of population, age structure, and urbanization on carbon emissions/energy consumption: evidence from macro-level, cross-country analyses. Popul. Environ. 2014, 3, 286-304. [CrossRef]

44. Song, M.L.; Zhou, Y.X. Analysis of Carbon Emissions and Their Influence Factors Based on Data from Anhui of China. Comput. Econ. 2014, 1, 1-16. [CrossRef]

45. National Bureau of Statistics of China. China Energy Statistical Yearbook; China Statistics Press: Beijing, China, 2004-2013.

46. Zhang, J.F.; Deng, W. Industrial structure change and its eco-environmental influence since the establishment of municipality in Chongqing, China. Procedia Environ. Sci. 2010, 2, 517-526. [CrossRef]

47. Cai, F.; Lu, Y. Population change and resulting slowdown in potential GDP growth in China. China World Econ. 2013, 2, 1-14. [CrossRef]

(C) 2016 by the authors. Licensee MDPI, Basel, Switzerland. This article is an open access article distributed under the terms and conditions of the Creative Commons Attribution (CC BY) license (http:/ / creativecommons.org/licenses/by/4.0/). 


\title{
A Study on Estimation of Land Value Using Spatial Statistics: Focusing on Real Transaction Land Prices in Korea
}

\author{
Bongjoon Kim ${ }^{1}$ and Taeyoung Kim ${ }^{2, *}$ \\ 1 Department of Research and Development, Research Institute of Korea Appraisal Board, 291, Innovalley-ro, \\ Dong-gu, Daegu Metropolitan City 701-870, Korea; k04422@kab.co.kr \\ 2 Department of Public Administration, Kyung Hee University, Seoul 02447, Korea \\ * Correspondence: tykim@khu.ac.kr; Tel.: +82-2961-0493; Fax: +82-10-3664-3856
}

Academic Editors: Yongrok Choi, Malin Song and Seunghwan Myeong Received: 30 November 2015; Accepted: 19 February 2016; Published: 25 February 2016

\begin{abstract}
The aim of this research is to compare OLS (Ordinary Least Squares) and spatial regression models which are methods of calculating the traditional value of land-using data on the practical transaction price of land—and to enhance the applicability of estimation of official land assessment prices set by the Korean government while deducing policy implications for effective implementation. That is, as a way to overcome the limitations of the traditional regression model, we compare various Generalized Regression Models such as SLM (Spatial Lag Model), SEM (Spatial Error Model) with OLS. Consequently, an in-depth diagnosis is conducted to generate a proper estimation model for land pricing, and, also, the analysis focuses on vertical and horizontal equity using COD (Coefficient of Dispersion), COV (Coefficient of Variation) and PRD (Price-Related Differential). The results indicate that SEM is more appropriate than AIC (Akaike info criterion) and SC (Schwarz criterion) in terms of measuring log-likelihood, demonstrating that the spatial autocorrelation model is superior to the traditional regression model. It shows that the SEM is also the best among the tested models with regard to measuring horizontal equity. The spatial econometric model, therefore, is strongly recommended for estimating the prices of land and houses.
\end{abstract}

Keywords: ordinary least squares; spatial autocorrelation; spatial econometric model; real transaction land prices; assessment uniformity

\section{Introduction}

In general, real estate prices are determined by various factors such as diverse environmental conditions, features of neighboring lots and the attributes of surrounding areas due to their fixedness and locality. The hedonic model of estimating the prices of real estate has been regarded as the best among various approaches for its accuracy [1]. The research of Rosen (1974) using the hedonic model has had much impact on approaches to measuring the value of land, apartments, and offices [2-4].

The hedonic model, however, has limits in estimating parameters with OLS, generating autocorrelation errors [5]. Specifically, estimating real estate prices without considering the spatial effect of spatial data causes spatial autocorrelation errors, thereby increasing the standard error of estimated parameters [6-8]. Furthermore, it may also lead to a biased result in the statistical verification [9]. Hereupon, Dubin $(1988,1992)$, assuming that spatial autocorrelation was caused by various characteristics including the accessibility of neighboring areas, argued that estimating real estate price without considering the location related properties, which were important in the hedonic price model, would cause the residuals to be spatially auto-correlated [10,11]. 
That is, the estimate of a parameter and the estimate of standard error are biased. This will affect statistical deduction, thereby causing a distortion in estimated prices [12,13]. In particular, the aforementioned problem may lead to a more critical problem such as inequity of taxation and distrust of government administration when estimating public land value which is the reference value for taxation and a range of public information [14]. For example, in 1989, the Korean government introduced the publically announced land price system to provide land information to real estate market participants and to establish the criteria for various taxations and charges [15], and it has announced the prices every year. The model, however, has relied on a land price comparison table, which is based on the hedonic price model, to calculate publically announced land prices [16]. The model could not adjust to spatial autocorrelations consequently.

Recently, in Korea, the spatial econometric model, which can reduce spatial autocorrelation problems, has started to gain attention. Particularly, the Korean government has been searching for a method to calculate publically announced prices similar to market prices of real estate with which sellers and buyers trade land (hereafter this will be called real transaction prices). As a specific method of estimating land prices, various researches have turned to the spatial econometric model. However, most of the previous research has focused on publically announced house prices, and there have been rare studies on spatial statistical models to estimate publically announced land prices using real transaction prices [17-23].

Accordingly, this study employs a spatial statistical model to estimate land prices using real transaction prices. It compares the traditional land value calculation model and OLS comparative method to determine applicability and improve the publically announced land price estimation model. To achieve the research aim, it uses the Spatial Error Model (SEM) and Spatial Lag Model (SLM) to more effectively grasp spatial dependence represented by spatial autocorrelation. The spatial area of this study is the city of Seoul, the capital of the Republic of Korea.

\section{Materials and Methods}

\subsection{Study Area and Data}

The study area is Seoul shown in Figure 1, the capital city of the Republic of Korea in Northeast Asia. Seoul is a cosmopolitan city and also a hub for politics, economy and culture. Therefore, it is the most frequently used region when it comes to doing research on the policies and systems of the Korean government. The administrative district of Seoul consists of the 25 boroughs and 467 administrative towns. It has a population of about 10,369,000 [24].

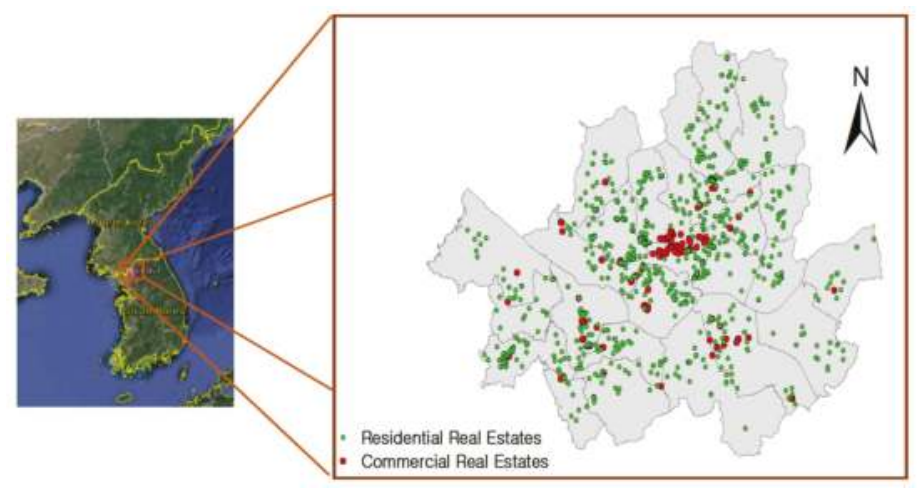

Figure 1. Study area (Seoul Metropolitan City in the Republic of Korea). 
Currently, the zoning of Seoul is classified according to residential areas, commercial areas, industrial areas, green zones and the green belt area. For effective research, this study focuses on residential and commercial areas as its subject of analysis. Though this area is comparatively small- $605.21 \mathrm{~km}^{2}$, equivalent to $0.6 \%$ of the whole area of ROK (South Korea)—it has the population of about 10.4 million, amounting to $1 / 5$ of the total population [16]. Thus, the population density of the city is very high. As shown in Table 1, most areas are residential or commercial areas. It implies that land use plans of the Seoul city government are performed centering on those two types of areas. Also, it is very likely that most land transactions are made in those two areas. In this regard, this study deals only with residential and commercial areas as its subject of analysis.

Table 1. Status of use districts and their comparative areas in Seoul.

\begin{tabular}{ccccccc}
\hline Classification & $\begin{array}{c}\text { Total Number } \\
\text { of Parcel }\end{array}$ & $\begin{array}{c}\text { Residential } \\
\text { Area }\end{array}$ & $\begin{array}{c}\text { Commercial } \\
\text { Area }\end{array}$ & $\begin{array}{c}\text { Industrial } \\
\text { Area }\end{array}$ & $\begin{array}{c}\text { Green } \\
\text { Zone }\end{array}$ & $\begin{array}{c}\text { Green Belt } \\
\text { Area }\end{array}$ \\
\hline Number of & 937,355 & 796,281 & 62,733 & 25,808 & 18,938 & 33,595 \\
Parcel $(\%)$ & $(100.00 \%)$ & $(84.95 \%)$ & $(6.69 \%)$ & $(2.75 \%)$ & $(2.02 \%)$ & $(3.58 \%)$ \\
\hline
\end{tabular}

Source: Portal Urban Planning of Seoul Metropolitan Government. Urban.seoul.go.kr. Available online: http://stat.seoul.go.kr/jsp3/index.jsp [24].

With regard to location data, this study utilized the continuous land registration map found in the Korea Land Information System (KLIS) of the Ministry of Land, Infrastructure and Transportation. As for the major variables of the analysis, we selected 18 land attribute factors that were utilized as the feature factors in the current version of the officially assessed land price calculation model [16]. However, including all variables as independent variables in the model would create the problem of multicollinearity, thereby making it difficult to establish a regression model. In addition, it would also increase dispersion even though it might minimize the degree of bias. As a result, it would be difficult to make an accurate estimation because it could not be guaranteed that mean square error is minimized [16].

Statistical methods to deal with these problems consist of variable selection methods such as the forward selection method, backward elimination method, and stepwise selection method [25].

Among these three methods, the forward selection method has a limit in which, even if a previously selected explanatory variable is deemed unimportant by an explanatory variable selected later, the variable cannot be eradicated. The backward elimination method has its own limitation in which the explanatory variable eradicated previously cannot be considered again in the estimation model. To compensate for the defects of these two methods, the stepwise selection method was suggested and has been widely used. The method allows us to examine variables to add or eradicate in each step. Accordingly, this study also used the stepwise selection method to select variables used in the spatial statistical model in estimating real transaction prices. As a result, this study selected seven important variables for residential areas, and six ones for commercial areas as shown in Table 2.

Table 2. Variables applied in the model and basic statistics (Unit: million won).

\begin{tabular}{|c|c|c|c|c|c|c|c|c|c|c|c|}
\hline \multirow{2}{*}{\multicolumn{2}{|c|}{ Classification }} & \multicolumn{5}{|c|}{ Residential } & \multicolumn{5}{|c|}{ Commercial } \\
\hline & & Mean & Sd & Min & $\operatorname{Max}$ & Median & Mean & Sd & Min & Max & Median \\
\hline \multicolumn{2}{|c|}{ Real transaction price } & 4.1 & 2.1 & 0.1 & 10.3 & 3.7 & 13.3 & 7.7 & 1.8 & 35.3 & 12.0 \\
\hline \multirow{5}{*}{ Land use } & Residential & 3.5 & 1.7 & 0.3 & 10.0 & 3.2 & 5.8 & 2.5 & 2.1 & 10.8 & 5.5 \\
\hline & commercial & 6.3 & 2.0 & 0.1 & 10.3 & 6.4 & 14.4 & 7.8 & 1.8 & 35.3 & 14.6 \\
\hline & $\begin{array}{l}\text { residential and } \\
\text { commercial }\end{array}$ & 5.3 & 2.1 & 1.1 & 10.1 & 5.0 & 11.0 & 5.3 & 4.9 & 21.9 & 8.5 \\
\hline & Industrial & 3.4 & 1.3 & 1.0 & 5.4 & 3.2 & - & - & - & - & - \\
\hline & Farmland & 1.1 & 0.8 & 0.3 & 2.2 & 0.5 & - & - & - & - & - \\
\hline \multirow{2}{*}{$\begin{array}{l}\text { Designated use } \\
\text { district }\end{array}$} & not designated & 4.0 & 2.0 & 0.1 & 10.1 & 3.5 & 11.3 & 6.4 & 1.8 & 35.3 & 9.1 \\
\hline & Designated & 4.5 & 2.3 & 0.3 & 10.3 & 4.2 & 15.9 & 8.5 & 2.1 & 35.0 & 15.0 \\
\hline
\end{tabular}


Table 2. Cont.

\begin{tabular}{|c|c|c|c|c|c|c|c|c|c|c|c|}
\hline & \multirow{2}{*}{ Classification } & \multicolumn{5}{|c|}{ Residential } & \multicolumn{5}{|c|}{ Commercial } \\
\hline & & Mean & $\mathrm{Sd}$ & Min & Max & Median & Mean & Sd & Min & Max & Median \\
\hline \multirow{5}{*}{ Altitude } & Lowland & 3.6 & - & 3.6 & 3.6 & 3.6 & - & - & - & - & - \\
\hline & Flatland & 4.3 & 2.2 & 0.1 & 10.3 & 3.9 & 13.4 & 7.7 & 1.8 & 35.3 & 12.2 \\
\hline & mild slope & 4.0 & 1.9 & 0.5 & 9.1 & 3.5 & 3.7 & 1.7 & 2.5 & 4.9 & 3.7 \\
\hline & steep slope & 2.2 & 1.1 & 0.3 & 5.1 & 2.1 & - & - & - & - & - \\
\hline & high land & 1.1 & 0.6 & 0.3 & 2.2 & 0.9 & - & - & - & - & - \\
\hline \multirow{8}{*}{ Land form } & square type & 4.1 & 1.6 & 1.3 & 8.7 & 3.9 & 19.1 & 10.9 & 5.6 & 35.0 & 19.0 \\
\hline & horizontally rectangle & 4.6 & 2.0 & 0.1 & 10.1 & 4.2 & 13.8 & 7.4 & 1.8 & 31.5 & 12.3 \\
\hline & vertically rectangle & 4.7 & 2.4 & 0.5 & 10.0 & 4.5 & 12.5 & 7.4 & 3.5 & 28.3 & 9.3 \\
\hline & Ladder & 4.1 & 2.1 & 0.3 & 10.3 & 3.6 & 13.8 & 7.9 & 1.9 & 32.9 & 14.0 \\
\hline & Triangle & 3.2 & 2.1 & 0.4 & 8.6 & 2.6 & 14.9 & 3.8 & 8.9 & 20.4 & 15.9 \\
\hline & inverse triangle & 1.1 & - & 1.1 & 1.1 & 1.1 & 5.8 & - & 5.8 & 5.8 & 5.8 \\
\hline & un-formed & 3.7 & 1.9 & 0.3 & 10.0 & 3.4 & 10.6 & 7.2 & 1.9 & 35.3 & 7.6 \\
\hline & bag-typed & 3.5 & 1.5 & 0.6 & 8.2 & 3.4 & 8.2 & 8.9 & 2.1 & 18.4 & 4.0 \\
\hline \multirow{13}{*}{$\begin{array}{l}\text { Contact with } \\
\text { road }\end{array}$} & More than $25 \mathrm{~m}$ wide road & 4.7 & 2.0 & 1.0 & 10.0 & 4.2 & 11.9 & 6.5 & 4.0 & 28.3 & 9.2 \\
\hline & $\begin{array}{c}\text { More than } 25 \mathrm{~m} \text { wide road } \\
\text { (corner lot) }\end{array}$ & 5.0 & 1.8 & 1.1 & 10.3 & 4.6 & 15.6 & 7.9 & 6.8 & 35.0 & 16.2 \\
\hline & $12-25 \mathrm{~m}$ wide road & 4.8 & 1.6 & 2.5 & 8.3 & 4.3 & 13.6 & 10.7 & 7.5 & 34.7 & 8.6 \\
\hline & $\begin{array}{l}\text { 12-25 m wide road } \\
\text { (corner lot) }\end{array}$ & 5.8 & 1.9 & 1.9 & 9.2 & 5.5 & 19.1 & 9.1 & 5.7 & 32.9 & 19.7 \\
\hline & $\begin{array}{l}\text { 12-25 m wide road } \\
\text { (corner lot) }\end{array}$ & 5.7 & 2.1 & 1.8 & 10.0 & 5.1 & 16.4 & 7.6 & 6.5 & 30.7 & 16.8 \\
\hline & $8-12 \mathrm{~m}$ wide road & 4.6 & 2.3 & 0.6 & 10.1 & 4.1 & 14.1 & 5.3 & 1.9 & 21.3 & 15.2 \\
\hline & $\begin{array}{l}\text { 8-12 m wide road (corner } \\
\text { lot) }\end{array}$ & 4.4 & 2.3 & 0.1 & 9.2 & 3.8 & 12.2 & 8.2 & 6.6 & 31.5 & 8.7 \\
\hline & Less than $8 \mathrm{~m}$ wide road & 3.6 & 1.8 & 0.3 & 10.0 & 3.2 & 12.1 & 7.2 & 2.1 & 35.3 & 9.9 \\
\hline & $\begin{array}{l}\text { Less than } 8 \mathrm{~m} \text { wide road } \\
\text { (corner lot) }\end{array}$ & 4.2 & 2.1 & 0.5 & 9.8 & 3.7 & 10.1 & 3.3 & 5.8 & 16.8 & 9.5 \\
\hline & $\begin{array}{l}\text { Less than } 8 \mathrm{~m} \text { wide } \\
\text { road (vehicle inaccessible) }\end{array}$ & 3.4 & 1.7 & 0.4 & 8.7 & 3.0 & 11.4 & 7.5 & 1.8 & 29.3 & 9.1 \\
\hline & $\begin{array}{l}\text { Less than } 8 \mathrm{~m} \text { wide } \\
\text { road (vehicle inaccessible }\end{array}$ & 4.0 & 2.2 & 1.0 & 8.2 & 4.0 & 4.0 & 1.6 & 2.5 & 5.6 & 3.7 \\
\hline & \& corner lot) & 4.0 & 2.2 & 1.0 & 0.2 & 4.0 & 4.0 & 1.0 & 2.0 & 3.0 & 0.7 \\
\hline & Landlocked lot & 2.0 & 1.3 & 0.3 & 5.8 & 1.8 & 21.4 & 8.6 & 11.6 & 32.9 & 17.7 \\
\hline \multirow{5}{*}{$\begin{array}{l}\text { Distance from } \\
\text { railroad }\end{array}$} & related area & 2.8 & - & 2.8 & 2.8 & 2.8 & 5.7 & & 5.7 & 5.7 & 5.7 \\
\hline & within $50 \mathrm{~m}$ & 4.6 & 1.8 & 1.9 & 9.0 & 4.2 & 7.1 & 1.5 & 4.0 & 9.8 & 7.1 \\
\hline & within $100 \mathrm{~m}$ & 4.7 & 2.1 & 0.9 & 10.0 & 4.6 & 9.6 & 1.3 & 8.5 & 11.0 & 9.3 \\
\hline & within $500 \mathrm{~m}$ & 3.8 & 1.9 & 0.5 & 10.0 & 3.3 & 11.5 & 6.2 & 4.4 & 25.0 & 9.5 \\
\hline & farther than $500 \mathrm{~m}$ & 4.2 & 2.1 & 0.1 & 10.3 & 3.9 & 14.5 & 8.1 & 1.8 & 35.3 & 14.8 \\
\hline \multirow{5}{*}{$\begin{array}{l}\text { Distance from } \\
\text { waste } \\
\text { treatment } \\
\text { facilities }\end{array}$} & within $50 \mathrm{~m}$ & 4.1 & 0.1 & 4.0 & 4.3 & 4.0 & - & - & - & - & - \\
\hline & within $100 \mathrm{~m}$ & 5.4 & - & 5.4 & 5.4 & 5.4 & - & - & - & - & - \\
\hline & within $500 \mathrm{~m}$ & 3.2 & 1.6 & 0.5 & 5.2 & 3.4 & - & - & - & - & - \\
\hline & within $1 \mathrm{~km}$ & 2.9 & 1.2 & 0.7 & 4.1 & 3.4 & 7.6 & 2.8 & 5.8 & 10.8 & 6.2 \\
\hline & farther than $1 \mathrm{~km}$ & 4.1 & 2.1 & 0.1 & 10.3 & 3.7 & 13.6 & 7.8 & 1.8 & 35.3 & 12.5 \\
\hline \multirow{2}{*}{ Big projects } & not designated & 3.9 & 2.1 & 0.1 & 10.1 & 3.6 & 12.2 & 7.3 & 1.9 & 35.0 & 9.6 \\
\hline & designated & 4.4 & 2.0 & 0.3 & 10.3 & 4.0 & 14.9 & 8.0 & 1.8 & 35.3 & 15.3 \\
\hline
\end{tabular}

Note: One million Korean won is about 837 USD (as of 25 January 2016); for a more detailed description on contact with roads, please refer to appendix.

\subsection{Method}

\subsubsection{Spatial Autocorrelation}

According to the first law of geography of Tobler (1970), "everything is related everything else, but near things are more related than distant things" [26]. That is to say, those things within a space are not randomly distributed within that space. Rather, they are influencing each other. Moreover, the closer they are geographically, the more similar values they may have (regardless of whether they have a positive spatial autocorrelation or a negative spatial autocorrelation).

The methods to measure spatial association consist of two kinds: global statistics and local statistics. The former is an indicator showing general tendencies of similar values, and the latter provides detailed statistics indicating spatial group patterns of similar values focusing on a specific area. This study tests the statistics using Moran's I statistics invented by Moran (1950) as global measurement [27] and LISA (Locally Indicator of Spatial Association) developed by Anselin (1988) 
to measure spatial association within a local dimension [28]. Moran's I is calculated as shown in Formula (1). For instance, it can be defined as the correlation coefficient between variance $W_{i j}$ of ith raw and $\mathrm{jth}$ column in $\mathrm{m} \times \mathrm{n}$ matrix and variance adjacent to the surrounding area of a corresponding site.

$$
I=\frac{n \sum \sum W_{i j}\left(X_{i}-\bar{X}\right)\left(X_{j}-\bar{X}\right)}{W \sum\left(X_{i}-\bar{X}\right)^{2}}
$$

Local Moran's I method is shown in Formula (2). Here, the formula means the attribute of X, and $\bar{X}$ means average of $X$, and means spatial weight of and $X$.

$$
\begin{gathered}
I_{i}=\frac{X_{i}-\bar{X}}{S_{i}{ }^{2}} \sum_{j=1, j \neq 1}^{n} W_{i, j}\left(X_{i}-\bar{X}\right) \\
S_{i}{ }^{2}=\frac{\sum_{j=1, j \neq 1}^{n} W_{i, j}}{n-1}-\bar{X}^{2}
\end{gathered}
$$

\subsubsection{Spatial Regression Model}

The spatial regression analysis model adds a spatial weighting matrix to a general linear model. The weighting matrix is included as an explanatory variable. Thus, it can be regarded as a form of Formula (3), which is expanded from the general linear regression model. Such a spatial regression model can be classified according to the spatial lag model and spatial error model [29].

The spatial lag model takes the form of Formula (4) as a semi-form because it adds an explanatory variable matrix to the basic hedonic price function. That is to say, it actively captures and interprets autocorrelation based on the concept of leveraging spatial autocorrelation as another explanatory variable [30].

$(1-p W)^{-1}$ of Formula (5) refers to spatial multiplier. This spatial multiplier refers to an indirect effect or an overall external effect as to a spatial interaction. Also, it means that all points are related to each other in a single system [31]. Thus, the regression coefficient in a spatial lag model is $\beta \times(1-p W)^{-1}$ rather than $\beta$. The Parcel of corresponding area is affected by not only its regional attributes but also the attributes of other regions through the spatial weighting matrix

$$
\begin{gathered}
Y=p W_{1} Y+X \beta+\mu \\
\mu=\lambda W_{2 \mu+\mu \varepsilon} \varepsilon \sim \operatorname{MNV}\left(0, \sigma^{2} I_{n}\right) \\
Y=(I-p W)^{-1} X \beta+(I-p W)^{-1} \varepsilon \\
(I-p W)^{-1}=I+p W+P^{2} W^{2}+\cdots \approx \frac{1}{1-p} \\
(I-p W)^{-1}: \text { spatial multiplier }
\end{gathered}
$$

The spatial error model should be used when spatial dependence is found in error terms. If heterogeneity cannot be removed because the covariance of prediction errors is not independent, estimation results of the regression model may cause a convenience related problem. Thus, a covariance structure of errors must be created in order to resolve such problems. That is to say, the degree of spatial interactions should be reflected in the model. In the same context, the spatial weighting matrix is added to error terms in order to remove spatial dependence which is largely affected by the independent variables of surrounding areas in the spatial error model [32].

\section{Analysis}

\subsection{Analysis of Spatial Autocorrelation and Heteroscedasticity, Non-Normality}

In general, the tools to measure spatial autocorrelation in land and house prices are Geary C (Geary's Coefficient), G statistical values, and LISA, etc. [31,33], in addition to Moran's I. Among them, 
in general, Moran's I is frequently used as the tool to measure spatial autocorrelation in land and house prices [34]. If observation values are similar, Moran's I value becomes positive (+), and, if they are not similar, the value becomes negative $(-)$. Moran's I in residential and commercial areas are 0.377779 and 0.384244 , respectively, both of which are significant at the $1 \%$ significance level in standard normal distribution and statistically accepting the existence of spatial dependency (see Figure 2). To identify geographic locations where spatial autocorrelation occurs, this study performed an analysis of LISA (Local Indicator of Spatial Association) as a spatial autocorrelation analysis. Through the LISA analysis, it was possible to create a cluster map showing local cases (administrative dongs) where spatial autocorrelation exists, as well as hot spot areas and cold spot areas. Here, hot spot (High-High) areas are the areas where land prices are high and it is similar to those of neighboring areas, and cold spot (Low-Low) areas are the areas where land prices are low, similar to those of neighboring areas. These are mapped in Figure 3 below.

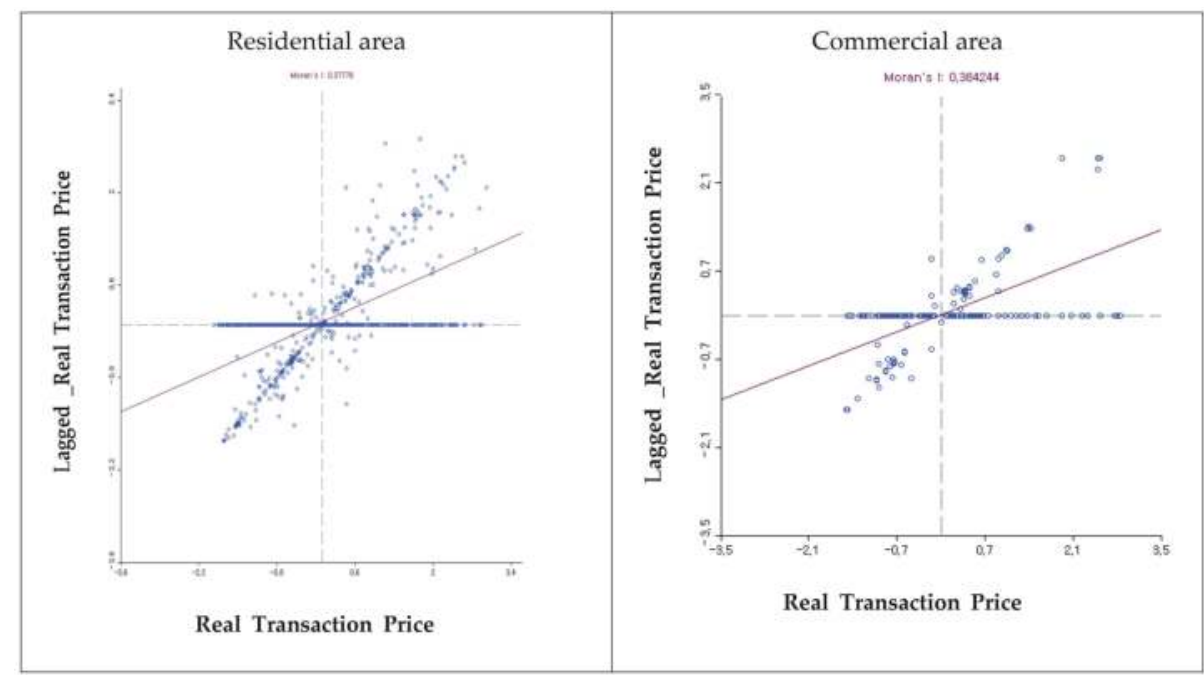

Figure 2. Moran's I values and scatter plots.

Next, for the OLS model, heteroscedasticity and non-normality of error terms are tested. Breusch-Pagan tests heteroscedasticity, and Jarque-Bera reveals non-normality of error terms. As shown in Table 3, in the heteroscedasticity test, Breusch-Pagan values were $124.891(p=0.000)$ for residential areas, and $72.0873(p=0.000)$ for commercial areas; Jarque-Bera values were 68.5969 $(p=0.000)$ for residential areas, and $34.2445(p=0.000)$ for commercial areas.

Consequently, the null hypothesis in the OLS model that there is no non-normality and heteroscedasticity is rejected for both residential areas and commercial areas. Thus, it seems more suitable to apply a spatial regression model to estimate and calculate real transaction land prices. 


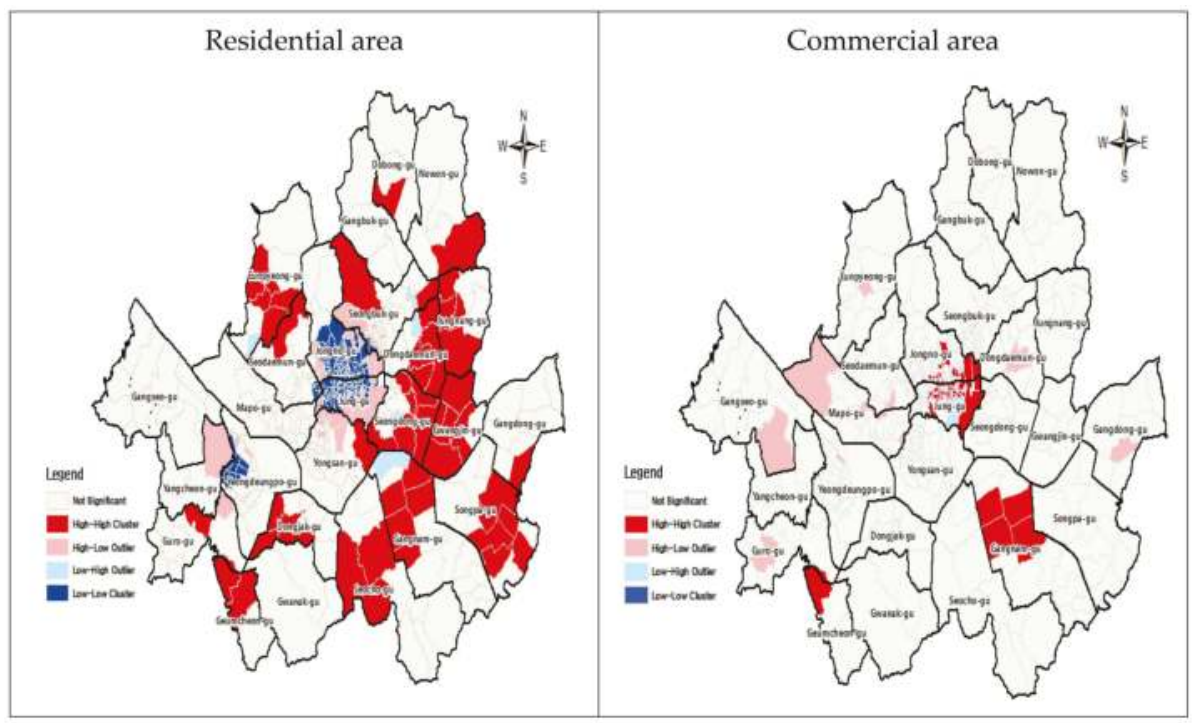

Figure 3. Local Moran's I-based hot spots and cold spots.

Table 3. Test of heteroscedasticity and non-normality in residential areas and commercial areas.

\begin{tabular}{ccccc}
\hline \multicolumn{2}{c}{ Classification } & DF & Value & Prob \\
\hline \multirow{2}{*}{ Breusch-Pagan } & Residential & 64 & 124.891 & 0.0000 \\
& Commercial & 28 & 72.0873 & 0.0000 \\
\multirow{2}{*}{ Jarque-Bera } & Residential & 2 & 68.5969 & 0.0000 \\
& Commercial & 2 & 34.2445 & 0.0000 \\
\hline
\end{tabular}

\subsection{Result of Spatial Regression Analysis}

Since the spatial econometrics model considering spatial autocorrelation and spatial error effects is estimated using the MLE (Maximum Likelihood Estimation) method, strictly saying, there is no statistical standards comparable to the OLS estimation model. In spatial econometrics model, model aptness is not tested with $\mathrm{R}^{2}$, but with Log-likelihood, AIC (Akaike Information Criterion), and SC (Schwarz Criterion). In general, if Log-likelihood increases, and AIC and SC decrease, it is considered that the model aptness is improved. Comparison of models showed that the SEM model had the highest $\mathrm{R}^{2}$ and log-likelihood, and the lowest AIC and SC, demonstrating that SEM is more suitable than SLM, not to mention the OLS. In general, spatial econometrics was shown to be higher in $\mathrm{R}^{2}$ and Log-likelihood, and lower in AIC, SC, and RMSE than OLS. In estimated regression coefficients, it showed lower coefficient values for most variables than the OLS model did, because spatial effects were separated. Considering land use, among attribute variables, we could find that, compared with land for residential use, the value of land for commercial business has increased by about $50 \%$, and the value of land for residential and commercial use by about $32 \%$. On the other hand, the value of farmland has been reduced by $120 \%$. Furthermore, in most development project districts, land prices are determined to be about $16 \%$ higher than those in other districts. Land prices within $500 \mathrm{~m}$ from a railroad were $16 \%$ lower than those of other areas. Meanwhile, there were differences in land prices depending on the altitude of land as shown in Table 4. 
Table 4. Estimated results of OLS and spatial econometric model (residential area).

\begin{tabular}{|c|c|c|c|c|}
\hline & \multirow[t]{2}{*}{ Classification } & OLS (Semi-log) & $\begin{array}{l}\text { Spatial Lag Model } \\
\text { (SLM) }\end{array}$ & $\begin{array}{l}\text { Spatial Error Model } \\
\text { (SEM) }\end{array}$ \\
\hline & & Coefficient & Coefficient & Coefficient \\
\hline \multicolumn{2}{|r|}{ CONSTANT } & 14.83472 & 14.82524 & 14.85509 \\
\hline Land use & $\begin{array}{c}\text { residential@ } \\
\text { commercial } \\
\text { residential and commercial } \\
\text { industrial } \\
\text { farmland }\end{array}$ & $\begin{array}{c}0.5469259^{* * *} \\
0.3771436^{* * *} \\
0.1832284 \\
-1.196621^{* * *}\end{array}$ & $\begin{array}{c}0.5416114 \text { *** } \\
0.3748667 * * * \\
0.1722477 \\
-1.20475^{* * *}\end{array}$ & $\begin{array}{c}0.5093336^{* * * *} \\
0.3227859^{* * *} \\
0.03741222 \\
-1.214586^{* * *}\end{array}$ \\
\hline Designated use district & $\begin{array}{c}\text { not designated@ } \\
\text { designated }\end{array}$ & -0.0120364 & -0.01184117 & -0.01881827 \\
\hline Altitude & $\begin{array}{l}\text { lowland } \\
\text { flatland@ } \\
\text { mild slope } \\
\text { steep slope } \\
\text { high land }\end{array}$ & $\begin{array}{c}0.2841206 \\
0.04743765 \\
-0.3338102^{* * *} \\
-1.044598^{* * *} \\
\end{array}$ & $\begin{array}{c}0.2896764 \\
\\
0.0447668 \\
-0.3374818^{* * *} \\
-1.043713^{* * *} \\
\end{array}$ & $\begin{array}{c}0.258335 \\
0.04567435 \\
-0.3875679 \text { *** } \\
-0.986019^{* * *} \\
\end{array}$ \\
\hline Land form & $\begin{array}{c}\text { Square type } \\
\text { horizontally rectangle } \\
\text { vertically rectangle } \\
\text { ladder@ } \\
\text { triangle } \\
\text { inverse triangle } \\
\text { un-formed } \\
\text { bag-typed } \\
\end{array}$ & $\begin{array}{c}0.1110292^{*} \\
0.06804747 \\
0.07785566 * \\
\\
-0.2830486^{* * *} \\
-0.8766148^{*} \\
-0.07472117^{*} \\
0.08350172\end{array}$ & $\begin{array}{c}0.1145919^{*} \\
0.06577143 \\
0.07764363 * \\
\\
-0.2826095 * * \\
-0.8711198^{*} \\
-0.07319313 * \\
0.08218725 \\
\end{array}$ & $\begin{array}{c}0.1094205^{*} \\
0.07135691 \\
0.09032908^{* *} \\
\\
-0.2563851^{* * *} \\
-0.9126258^{* *} \\
-0.06475986^{*} \\
0.03499114 \\
\end{array}$ \\
\hline \multirow[t]{5}{*}{ Contact with road } & $\begin{array}{c}\text { More than } 25 \mathrm{~m} \text { wide road } \\
\text { More than } 25 \mathrm{~m} \text { wide road (corner lot) } \\
\text { More than } 25 \mathrm{~m} \text { wide road (corner lot) } \\
12 \sim 25 \mathrm{~m} \text { wide road } \\
12 \sim 25 \mathrm{~m} \text { wide road (corner lot) } \\
8 \sim 12 \mathrm{~m} \text { wide road } \\
8 \sim 12 \mathrm{~m} \text { wide road (corner lot) } \\
\text { Less than } 8 \mathrm{~m} \text { wide road@ }\end{array}$ & $\begin{array}{c}0.1753543^{* *} \\
0.2648574^{* * * *} \\
0.04102786 \\
0.2121089^{* * * *} \\
0.2035506^{* * *} \\
0.1143958^{*} \\
-0.05901025\end{array}$ & $\begin{array}{c}0.173421^{* *} \\
0.2695362 * * * \\
0.0453212 \\
0.2099386^{* * *} \\
0.2020034^{* * *} \\
0.1180087^{*} \\
-0.05664801\end{array}$ & $\begin{array}{c}0.1407968 \\
0.2834018^{* * * *} \\
0.08430525 \\
0.1959752^{* * *} \\
0.2030704^{* * *} \\
0.1441317^{* *} \\
-0.05843944\end{array}$ \\
\hline & Less than $8 \mathrm{~m}$ wide road (corner lot) & 0.07113948 & 0.07390742 & 0.04711873 \\
\hline & $\begin{array}{c}\text { Less than } 8 \mathrm{~m} \text { wide road (vehicle } \\
\text { inaccessible) }\end{array}$ & -0.02160676 & -0.01787072 & -0.00940768 \\
\hline & $\begin{array}{l}\text { Less than } 8 \mathrm{~m} \text { wide road (vehicle } \\
\text { inaccessible \& corner lot) }\end{array}$ & 0.04261649 & 0.04581873 & 0.09876319 \\
\hline & Landlocked lot & -0.2218566 ** & -0.2260322 ** & $-0.1948716^{*}$ \\
\hline Distance from railroad & $\begin{array}{c}\text { related area } \\
\text { within } 50 \mathrm{~m} \\
\text { within } 100 \mathrm{~m} \\
\text { within } 500 \mathrm{~m} \\
\text { farther than } 500 \mathrm{~m} @\end{array}$ & $\begin{array}{c}-0.3568872 \\
0.1215657 \\
0.2486583^{* * *} \\
-0.04780102\end{array}$ & $\begin{array}{c}-0.3745543 \\
0.1115059 \\
0.2464752 \text { *** } \\
-0.04754497\end{array}$ & $\begin{array}{c}-0.2599451 \\
0.05919571 \\
0.1716129^{* *} \\
-0.04435743\end{array}$ \\
\hline $\begin{array}{l}\text { Distance from waste } \\
\text { treatment facilities }\end{array}$ & $\begin{array}{c}\text { within } 50 \mathrm{~m} \\
\text { within } 100 \mathrm{~m} \\
\text { within } 500 \mathrm{~m} \\
\text { within } 1 \mathrm{~km} \\
\text { farther than } 1 \mathrm{~km} @\end{array}$ & $\begin{array}{c}-0.06168175 \\
0.03166474 \\
-0.1276944 \\
-0.3795877^{* * *}\end{array}$ & $\begin{array}{c}-0.07671985 \\
0.04685257 \\
-0.1279039 \\
-0.3707301 \text { ** }\end{array}$ & $\begin{array}{c}-0.05218356 \\
0.05161758 \\
-0.07557862 \\
-0.3885153^{\text {**** }}\end{array}$ \\
\hline Big projects & $\begin{array}{c}\text { not designated@ } \\
\text { designated }\end{array}$ & $0.19963^{* * *}$ & $0.19671^{* * *}$ & $0.16678^{* * *}$ \\
\hline \multirow{6}{*}{ Model Summary } & $\rho$ & & 0.00214987 & \\
\hline & $\begin{array}{c}\lambda \\
\mathrm{R} 2\end{array}$ & & & $\begin{array}{l}0.45051 \\
0.49083\end{array}$ \\
\hline & $\mathrm{F}$ & 19.60830 & 0.30037 & \\
\hline & log likelihood & -790.14000 & -789.53400 & -712.32676 \\
\hline & AIC & 1654.28000 & 1655.07000 & 1498.65000 \\
\hline & $\mathrm{SC}$ & 1842.30000 & 1848.17000 & 1686.68000 \\
\hline
\end{tabular}

Note: @ is standard variable; ${ }^{* *}$ : within statistical significance level $1 \%,{ }^{* *}$ : within statistical significance level

$5 \%, *$ : within statistical significance level $10 \%$.

Spatial effects were found in commercial areas with the same standard applied to residential areas. The analysis showed that the SEM model had the highest $\mathrm{R}^{2}$ and log-likelihood, and the lowest AIC and SC. Accordingly, it was considered to be the most suitable model in estimating land prices in commercial areas. The results show as shown in Table 5 that in commercial areas, like in residential areas, the SEM model had lower values for most variables than in the case of the OLS model, because spatial effects were separated. In terms of land use, among attribute variables, land for residential use has decreased by about $34 \%$ compared with land for commercial business use. In the case of land forms, the rectangular form has increased by $40 \%$ compared with ladder form. Also, in terms of road proximity, land with less than $8 \mathrm{~m}$ wide roads (vehicle inaccessible \& corner lots) has increased by $79 \%$, compared with land with less than $8 \mathrm{~m}$ wide roads. On the other hand, in terms of designation 
of use, OLS and SLM were significant at the 5\% level, but SEM was not statistically significant when non-designation is standard.

Table 5. Estimated results of OLS and spatial econometric model (commercial area).

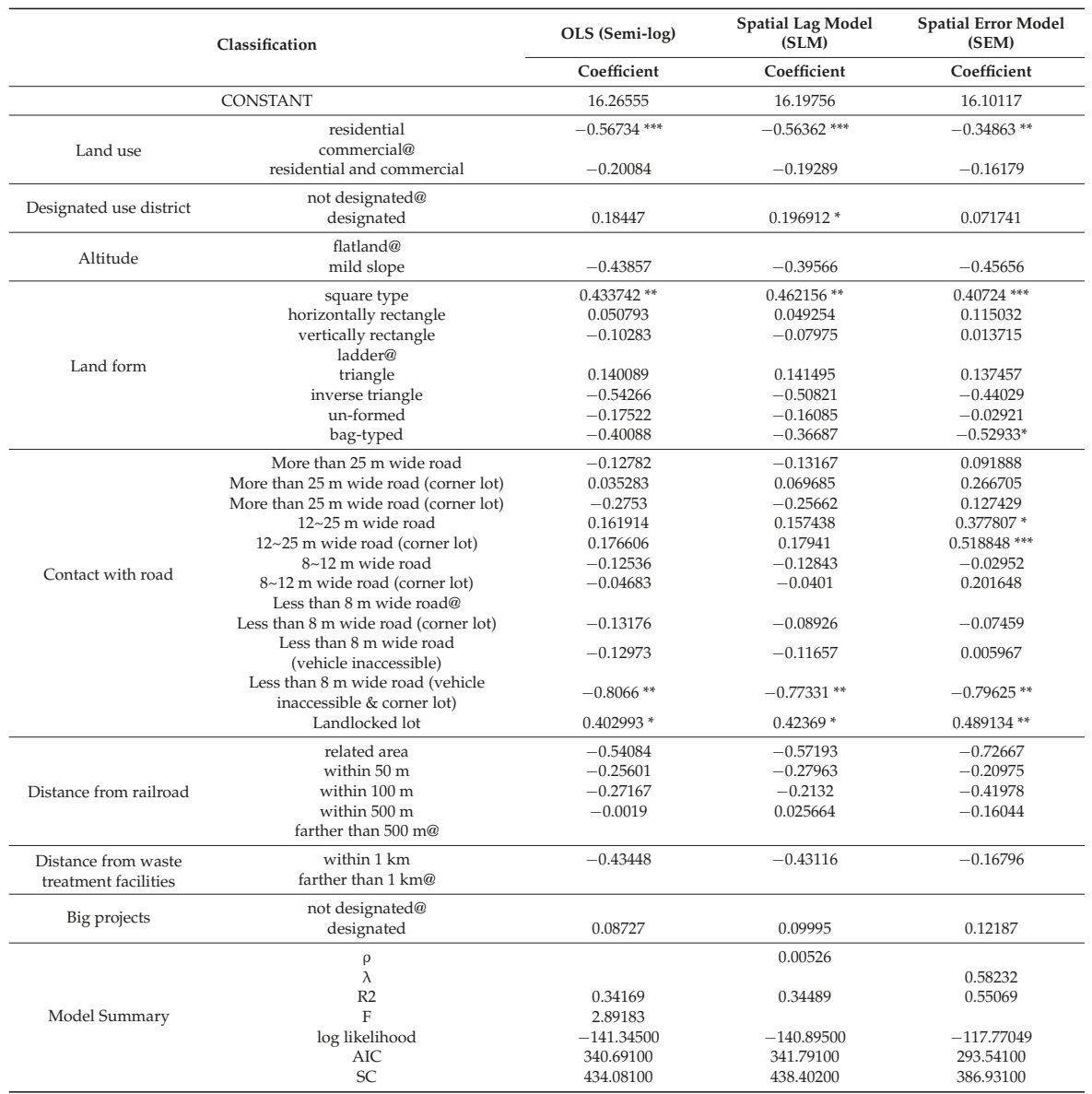

Note: @ is standard variable; ${ }^{* *}$ : within statistical significance level $1 \%,{ }^{* *}$ : within statistical significance level $5 \%$, *: within statistical significance level $10 \%$.

\section{Performance Verification of Model}

So far, comparison and analysis have been conducted on the autocorrelation and spatial effects of practical transaction prices adopting the OLS model and spatial auto-regressive model (spatial lag, spatial error model) focusing on residential areas and commercial areas of Seoul City. Verification of model performance is conducted adopting the ratio (Assessment Price/Sale Price: AP/SP) between the land assessment price estimated by way of such analysis and the sale price on the real estate market. The verification will involve analyzing vertical/horizontal equity of taxation assessment suggested by the International Association of Assessing Officers [35]. Prior to carrying out this process, IAAO indicates that is important to consider that, in general, the observed value of IQR deviates by 1.5 times from the outlier. Thus, in this study, an analysis of box plot was conducted applying the method suggested by IAAO. 


\subsection{Horizontal Equity}

Horizontal equity for taxation of real estate means that real estate having equivalent market value should be equally treated and should be assessed at the same rate as market value [36]. In general, the estimated price of real estate by the mass assessment model can determine the level of equity through analysis of Coefficient of Dispersion or Coefficient of Variation (Refer Table 6).

Table 6. Test criteria of Vertical Horizontal Equity.

\begin{tabular}{|c|c|c|c|c|}
\hline \multirow{3}{*}{$\begin{array}{l}\text { Verification of } \\
\text { horizontal } \\
\text { equity }\end{array}$} & \multirow{3}{*}{ COD } & \multirow{2}{*}{$\begin{array}{c}\text { Formula } \\
\\
\left.i o_{i}-m\right)^{2} /(n-1) \\
\end{array}$} & \multicolumn{2}{|c|}{ Interpretation } \\
\hline & & & $\begin{array}{l}\text { Independent house } \\
\text { and apartment house }\end{array}$ & $\begin{array}{l}5.0-15.0 \\
\text { (5.0-20.0 only in case of } \\
\text { many new house and } \\
\text { residential area of } \\
\text { same quality) }\end{array}$ \\
\hline & & $m$ & $\begin{array}{l}\text { Other real estate for } \\
\text { resident }\end{array}$ & $5.0-20.0$ \\
\hline & & & $\begin{array}{l}\text { Real estate for } \\
\text { commercial use }\end{array}$ & $\begin{array}{c}5.0-20.0 \\
\text { (but } 5.0-15.0 \text { only for } \\
\text { areas of big cities) }\end{array}$ \\
\hline & & & Vacant land & $5.0-20.0$ \\
\hline & & & Other real estate & $\begin{array}{l}\text { Different depending on } \\
\text { local condition }\end{array}$ \\
\hline & $\mathrm{COV}$ & $\frac{\sum_{i=1}^{n}\left(\text { Ratio }_{i}-M\right) / n}{M}$ & $\begin{array}{l}\text { Assessing the better } \\
\text { the lower the value }\end{array}$ & \\
\hline \multirow[t]{2}{*}{$\begin{array}{l}\text { Verification of } \\
\text { vertical PRD }\end{array}$} & \multirow[t]{2}{*}{ PRD } & \multirow{2}{*}{$\begin{array}{l}\text { arithmetic mean of actualization } \\
\text { ratio of taxation } \\
\text { weighted mean of actualization } \\
\text { ratio of taxation }\end{array}$} & $\begin{array}{c}\text { Formation of } \\
\text { regressive inequity }\end{array}$ & $\operatorname{Prd}>1.03$ \\
\hline & & & $\begin{array}{c}\text { Formation of } \\
\text { progressive inequity }\end{array}$ & $\mathrm{PRD}<0.98$ \\
\hline
\end{tabular}

Ratio: Individual taxation value/individual market value; M: median of ratio; m: Mean of ratio; n: number of sample; Source: International Association of Assessing Officers. 2013. Standard on Ratio Studies; Noh. M.j; Yoo. S.J. A Study on Horizontal and Vertical Equity of Tax Assessment in Land. Korea Spat. Plan. Rev. 2014, 81, 21-33.

Checking the degree of horizontal equity of the three models (OLS, SEM, SLM) compared in the study, SEM appeared to have the smallest value of COD and COV. The value of COD and COV could be interpreted as being excellent in terms of its horizontal equity as it becomes smaller, and IAAO recommends that the value of COD below 20.0 be acceptable for estimating assessment standards.

Though OLS, SLM and SEM conform with the recommendations given by IAAO. However, comparing the relative horizontal equity among these three models, SEM is judged to be most suitable for the estimation model for practical transaction prices of land as shown in Table 7.

Table 7. Horizontal Comparison among OLS, SLEM, SEM.

\begin{tabular}{ccccccc}
\hline \multirow{2}{*}{ Division } & \multicolumn{2}{c}{ OLS } & \multicolumn{2}{c}{ SLM } & \multicolumn{2}{c}{ SEM } \\
\cline { 2 - 7 } & COD & COV & COD & COV & COD & COV \\
\hline residential area & 19.1762 & 35.02 & 19.68803 & 35.11 & 18.96052 & 32.65 \\
\hline commercial area & 15.0438 & 35.12 & 15.66974 & 35.44 & 14.8889 & 33.00 \\
\hline
\end{tabular}

\subsection{Vertical Equity}

COD and COV treat horizontal dispersion (or random dispersion) in specific blocks that have no relation to the price level of the individual lots. Furthermore, other forms of inequity include vertical inequity arising in the assessment of low and high assets. Vertical equity in mass assessment models of real estate means setting equivalent standards of assessment of real estate even in different price blocks by performing equiproportional assessments instead of using market sale prices. This time, when 
taxation value reduces as market value rises, it is said to carry regressive and vertical inequity, while when taxation value rises as market value is raised higher, it is said to carry progressive and vertical inequity [37]. The most basic method of measuring such vertical equity is comparing the taxation assessment rate of land, which is the ratio between taxation assessment price of land and market sale price ratio of land [38].

Vertical equity through analysis of such ratio can be measured through Price-Related Differential. When value of PRD is bigger than 1.0, existence of regression of taxation assessment is seen, while when adversely it is smaller than 1.0, existence of progression of taxation assessment is seen, and vertical equity is recognized when it is within the scope of $0.98 \leqslant \mathrm{PRD}<1.03$ having a more or less margin between the top and bottom of 1.0 at the working level [37].

Based on recommendations by IAAO, the results of analysis on vertical equity of estimate pricea for each model are shown in Table 6. SEM in residential areas and OLS in commercial areas appeared to be the best in terms of vertical equity among OLS, SLM and SEM.

\section{Conclusions and Future Research}

Land price is an indicator representing the dynamic changes of a city across real estate value rises and declines, and summarily expresses the social and economic characteristics of a country. Land prices have been typically estimated with a traditional regression model. However, this model has some limitations in the sense that it fails to consider the spatial effects which occur in each region. To overcome the limitations of the traditional regression model, this research compared SLM, SEM and OLS, models of spatial econometrics, and developed instead a proper estimation model. The analysis showed the log-likelihood, AIC, and SC of the SEM model better considers spatial dependency and heterogeneity than the traditional regression model. In order to evaluate the estimation model, vertical equity and horizontal equity were analyzed for estimated prices. According to IAAO regulations, the estimated prices given by SEM for both residential and commercial areas offered an acceptable level of accuracy.

Accordingly, if we search for and eradicate the causes of spatial autocorrelation of a relevant area when we estimate land and house prices, we could improve the accuracy of the SEM model. In particular, given that, in Korea, official land prices serve as a standard to impose taxes, as well as a basis for establishing and executing various government policies such as welfare endowments and various fees, it seems necessary to conduct further research in this area and base policies on the application of spatial statistical models to estimate official land prices.

The authors recognize that not only the GWR model, which is able to evaluate spatial heterogeneity, but also the spatio-temporal and Bayesian spatial statistical methods should be incorporated in future research. The applied IAAO's measurement standard of vertical and horizontal equity possesses some limitations when being applied directly to Korean tax valuations. Thus, new Korean standards of tax valuation should be proposed. Based on our evaluation of its institutional application, the assessment system for land value appraisals should be further developed.

Author Contributions: All authors contributed equally to this work for drafting the paper, reviewing relevant studies, compiling and analyzing the data. All authors wrote, reviewed and commented on the manuscript. All authors have read and approved the final manuscript.

Conflicts of Interest: The authors declare no conflict of interest. 


\section{Appendix}

Table A1. Classification of road-adjacent land.

\begin{tabular}{|c|c|}
\hline Classification & Description \\
\hline More than $25 \mathrm{~m}$ wide road & $\begin{array}{l}\text { Land one side of which is adjacent to a street of } 25 \mathrm{~m} \text { wide } \\
\text { or over }\end{array}$ \\
\hline More than $25 \mathrm{~m}$ wide road (corner lot) & $\begin{array}{l}\text { Land one side of which is adjacent to a wide street, and one or } \\
\text { more sides of which are adjacent to a small-sized street (8-12 m } \\
\text { wide) or a bigger one }\end{array}$ \\
\hline More than $25 \mathrm{~m}$ wide road (corner lot) & $\begin{array}{l}\text { Land one side of which is adjacent to a wide street, and one or } \\
\text { more sides of which are adjacent to a narrow street (ga) where } \\
\text { car can pass }\end{array}$ \\
\hline 12 $25 \mathrm{~m}$ wide road & Land one side of which is adjacent to a street of $12-25 \mathrm{~m}$ wide \\
\hline 12 25 m wide road (corner lot) & $\begin{array}{l}\text { Land one side of which is adjacent to a mid-sized street, and one } \\
\text { or more sides of which are adjacent to mid-sized, small-sized, or } \\
\text { narrow street (ga) where car can pass }\end{array}$ \\
\hline $8 \sim 12 \mathrm{~m}$ wide road & Land one side of which is adjacent to a street of $8-12 \mathrm{~m}$ wide \\
\hline $8 \sim 12 \mathrm{~m}$ wide road (corner lot) & $\begin{array}{l}\text { Land one side of which is adjacent to a small-sized street, and } \\
\text { one or more sides of which are adjacent to small-sized, or narrow } \\
\text { street (ga) where car can pass }\end{array}$ \\
\hline Less than $8 \mathrm{~m}$ wide road & $\begin{array}{l}\text { Land one side of which is adjacent to a street whose width is } \\
\text { narrower than } 8 \mathrm{~m} \text {, but where car can pass }\end{array}$ \\
\hline Less than $8 \mathrm{~m}$ wide road (corner lot) & $\begin{array}{l}\text { Land more than two sides of which are adjacent to a narrow } \\
\text { street where car can pass }\end{array}$ \\
\hline $\begin{array}{l}\text { Less than } 8 \mathrm{~m} \text { wide road (vehicle } \\
\text { inaccessible) }\end{array}$ & $\begin{array}{l}\text { Land one side of which is adjacent to a narrow road where can } \\
\text { cannot pass, but two-wheeled vehicle can pass }\end{array}$ \\
\hline $\begin{array}{l}\text { Less than } 8 \mathrm{~m} \text { wide road (vehicle } \\
\text { inaccessible \& corner lot) }\end{array}$ & $\begin{array}{l}\text { Land two or more sides of which are adjacent to a narrow road } \\
\text { where can cannot pass, but two-wheeled vehicle can pass }\end{array}$ \\
\hline Landlocked lot & $\begin{array}{l}\text { Land adjacent to a narrow road where two-wheeled vehicle } \\
\text { cannot pass, or land which is not adjacent to road }\end{array}$ \\
\hline
\end{tabular}

\section{References}

1. Malpezzi, S. Hedonic Pricing Models: A Selective and Applied Review. In Housing Economics: Essays in Honor of Duncan Maclennan; O'Sullivan, A., Gibb, K., Eds.; Blackwell: Oxford, UK, 2003; pp. 67-89.

2. Rosen, S. Hedonic Prices and Implicit Market: Product Differentiation in Pure Competition. J. Political Econ. 1974, 82, 34-55. [CrossRef]

3. Kumar, P.; Pardhan, B.K.; Subramanian, A. Farmland Prices in a Developing Economy: Some Stylised Facts and Determinants. J. Int. Area Stud. 2005, 12, 93-113.

4. Plantinga, A.J.; Lubowski, R.N.; Stavins, R.N. The Effects of Potential Land Development on Agricultural Land Prices. J. Urban Econo. 2002, 52, 561-581. [CrossRef]

5. Basu, S.; Thibodeau, T. Analysis of Spatial Autocorrelation in House Prices. J. Real Estate Financ. Econ. 1998, 17, 61-85. [CrossRef]

6. Patton, M.; McErlean, S. Spatial Effects within the Agricultural Land Market in Northern Ireland. J. Agric. Econ. 2003, 1, 35-54. [CrossRef]

7. Pace, R.; Barry, J.; Rodriques, M. Spatiotemporal Autoregressive Models of Neighborhood Effects. J. Real Estate Financ. Econ. 1998, 17, 15-33. [CrossRef]

8. Can, A. Specification and Estimation of Hedonic Price Model. Reg. Sci. Urban Econo. 1992, 22, $453-473$. [CrossRef] 
9. Gillen, K.; Thibodeau, T.; Wachter, S. Anisotropic Autocorrelation in Housing Prices. J. Real Estate Financ. Econ. 2001, 23, 5-30. [CrossRef]

10. Dubin, R. Estimation of Regression Coefficients in the Presence of Spatially Autocorrelated Error Terms. Rev. Econ. Stat. 1988, 70, 466-474. [CrossRef]

11. Dubin, R. Spatial Autocorrelation and Neighborhood Quality. Reg. Sci. Urban Econ. 1992, 22, 433-452. [CrossRef]

12. Olmo, J.C. Spatial Estimation of Housing Price and Locational Rents. Urban Stud. 1995, 32, 1331-1344. [CrossRef]

13. Pace, R.K.; Barry, R.; Sirmans, C.F. Spatial Statistics and Real Estates. J. Real Estate Financ. Econ. 1999, 17, 5-13. [CrossRef]

14. Park, H.S. A Study on Estimation of Farmland Price Using Spatial Econometrics Approach: Focus on Urban Fringe in Seoul Metropolitan Area. Korea Spat. Plan. Rev. 2012, 72, 121-140.

15. Ministry of Land, Infrastructure and Transport (MOLIT). Annual Report on Real-Estate Price System in 2015; Korea Government: Sejong, Korea, 2011. (in Korea).

16. Ministry of Land Infrastructure and Transport (MOLIT). A Study on Land Price Comparison Table for 2015; Korea Government: Sejong, Korea, 2014. (in Korea).

17. Hur, Y.K. A Study on the Estimation of House Price in Regard of Spatial Effects. Hous. Stud. Rev. 2007, 15, 5-23.

18. Choi, Y.; Lee, B.H. A Study on the Estimation of Land Price Considering Characteristic of the Adjacent Land Use and Spatial Autocorrelation in residential Zone. J. Korea Plan. Assoc. 2006, 41, 45-60.

19. Park, H.S. The Estimation of Seoul Apartment Prices Using Spatiotemporal Autoregressive Models. Korea Spat. Plan. Rev. 2003, 38, 95-106.

20. Kim, S.W.; Chung, K.S. The Robust Estimation with Spatial Econometrics Models using 3-Dimension Weight Matrix considering the Height of the House. Hous. Stud. Rev. 2010, 18, 73-92.

21. Park, H.M. An Analysis of the Factors Affecting on the Prices of the Urban-life Housing Type of the Structure of the Urban Spaces in Seoul: Focused on the System of Structured Spaces in the basic city planning of Seoul 2030. J. Korea Plan. Assoc. 2013, 48, 419-435.

22. Lee, C.R.; Park, K.H. The Effects of Neighborhood Segmentation on the Adequacy of a Spatial Regression Model. J. Korean Geogr. Soc. 2013, 48, 978-993.

23. Cho, M.J.; Lee, M.H. Effects of regional and neighborhood living environment to the prices of aged apartments. J. Korea Plan. Assoc. 2015, 50, 23-47. [CrossRef]

24. Seoul Statistics of Seoul Metropolitan Government. Available online: http://stat.seoul.go.kr/jsp3/index.jsp (accessed on 18 February 2016).

25. Rawlings, J.O.; Pantul, S.G.; Dickey, D.A. Applied Regression Analysis: A Research Tool, 2nd ed.; Springer: Berlin, Germany, 2001; pp. 213-214.

26. Tobler, W.R. A Computer Movie Simulating Urban Growth in the Detroit Region. Econ. Geogr. 1970, 46, 234-240. [CrossRef]

27. Moran, P. Notes on Continuous Stochastic Phenomena. Biometrika 1950, 37, 17-23. [CrossRef] [PubMed]

28. Anselin, L. Spatial Econometrics: Methods and Models; Kluwer Academic Publisher: Dordrecht, The Netherlands, 1988.

29. Kissling, W.D.; Carl, G. Spatial Autocorrelation and the Selection of Simultaneous Autoregressive Models. Glob. Ecol. Biogeogr. 2008, 17, 59-71. [CrossRef]

30. Stakhoych, S.; Bijmolt, T. Specification of Spatial Models: A Simulation Study on Weights Matrices. Pap. Reg. Sci. 2008, 88, 389-408. [CrossRef]

31. Anselin, L. Local Indicators of Spatial Association-LISA. Geogr. Anal. 1995, 27, 93-115. [CrossRef]

32. Aselin, L. Exploring Spatial Data with GeoDa ${ }^{T M}$ : A Workbook; Center for Spatially Integrated Social Science: Santa Barbara, CA, USA, 2005.

33. Getis, A.; Ord, J.K. The Analysis of Spatial Association by Use of Distance Statistics. Geogr. Anal. 1992, 24, 189-207. [CrossRef]

34. European Central Bank. Spatial Dependence in Commercial Property prices Micro Evidence from the Netherlands. Work. Pap. Ser. 2014, 1627, 1-32.

35. International Association of Assessing Officers (IAAO). Standard on Ratio Study; IAAO: Kansas City, MO, USA, 2010. 
36. International Association of Assessing Officers (IAAO). Improving Real Property Assessment: A Reference Manual; IAAO: Chicago, IL, USA, 1978.

37. Sirmans, S.G.; Diskin, B.S.; Friday, S.H. Vertical Inequity in the Taxation of Real Property. Natl. Tax J. 1995, 48, 71-84.

38. Oldman, O.; Aaron, H. Assessment-Sale Ratios under the Boston Property Tax. Natl. Tax J. 1965, 18, 36-49.

(C) 2016 by the authors. Licensee MDPI, Basel, Switzerland. This article is an open access article distributed under the terms and conditions of the Creative Commons Attribution (CC BY) license (http:/ / creativecommons.org/licenses/by/4.0/). 
Article

\title{
Sustaining Competitiveness: Moving Towards Upstream Manufacturing in Specialized-Market-Based Clusters in the Chinese Toy Industry
}

\author{
Huasheng Zhu *, Xue Huang, Qingcan He, Jie Li and Lingzhi Ren \\ School of Geography, Beijing Normal University, Beijing 100875, China; huangxue@mail.bnu.edu.cn (X.H.); \\ heqingcan@163.com (Q.H.); 201321170103@mail.bnu.edu.cn (J.L.); renlingzhi1015@126.com (L.R.) \\ * Correspondence: zhuhs@bnu.edu.cn; Tel.: +86-10-5880-7455 (ext. 1466)
}

Academic Editor: Yongrok Choi

Received: 31 October 2015; Accepted: 30 January 2016; Published: 18 February 2016

\begin{abstract}
Western industrial cluster literature pays little attention to specialized markets (SMs) and the geographical agglomeration of distributors or sale agencies (SAs). This paper takes Linyin, Shandong, a famous commodity city in Northeastern China, as an example, to discuss the determinants that make SAs in SMs of the toy industry move towards upstream manufacturing. A structured questionnaire survey and subsequent interviews were carried out during 2011 and 2012 to collect data, and a Binary Logistic Regression Model was used to process the data. This paper looks from the perspective of global production networks theory, establishes an analytical framework that combines individual motivations of intra-firm coordination, local inter-firm relationships and dynamic cross-regional level relationships. The findings indicate that the expansion of SAs towards manufacturing allows them to sustain competitiveness under changing circumstances. The local inter-firm relationships within SM-based clusters not only makes it easy to obtain material and human resources with lower manufacturing costs, but also facilitates the access to production knowledge and technologies for an expansion of production scale. Cross-regional relationships with suppliers provide an informal channel for SAs to obtain skills, which is fundamental for an expansion into manufacturing. In addition, it is a preference for strengthening competitiveness rather than the simple pursuit of economic profit that encourages SAs to invest in manufacturing.
\end{abstract}

Keywords: specialized markets; industrial clusters; global production networks (GPN); sustainable competitiveness; value chains

\section{Introduction}

Sales or marketing activities have been addressed in the literature as an indispensable component of value chains in industrial clusters. Intermediary businesses connecting local manufacturers and the international market are considered to be an important factor in the development of clusters [1]. At present, multinational companies have tended to incorporate industrial clusters in developing countries into their global value chains through outsourcing production or contract manufacturing [2,3], which provides a boost to the commercialization of industrial clusters [4] and to the regeneration $[5,6]$ or upgrading $[7,8]$ of these clusters. However, in the literature regarding industrial clusters in Western countries, little consideration has been paid towards the geographical distribution and location of small and medium sales agencies (SAs) that connect manufacturers to customers, and less is mentioned about specialized markets (SMs) as physical exchange platforms or spaces for SAs and their clients. In fact, studies on industrial clusters in developing countries, such as China, have pointed out that SMs 
and manufacturing clusters have been important driving forces in rural industrialization since the late 1970s [9]. In fact, SMs have triggered the development of local manufacturing clusters or, conversely, local manufacturing clusters have brought about the prosperity in SMs, which also reveals that SAs in SMs have a close relationship with local manufacturing firms [10].

SMs differ from the traditional business model in that they are a two-sided platform model in the small- and medium-sized-enterprise cluster, which provide services for both buyers and sellers and address procurement, price-setting and distribution [11]. SMs are places for trading where a specific kind of utility commodity (in some cases mixed with a small amount of other kinds of commodities) are sold in bulk for both vast domestic and global markets [11]. Those commodities are either made in neighboring areas or further away. According to the statistics from 2013, the average number of SAs (booths) in a SM in China is 612, while some may contain thousands [12]. SAs are generally local independent merchants or sales departments attached to local manufacturers or even external producers in other places. They connect the local manufacturing with external clients and even foreign markets, and act as an important channel of products and information. The first generation of SMs in China formed spontaneously in the early 1980s at local (temporary) fairs. At that time, China implemented a unified distribution system of commodity circulation and prohibited the development of private-owned sectors. Therefore, those SMs were considered as a kind of institutional innovation [13-15], and provided an important kind of sale channel for local family-owned factories. SAs in the SMs have their own factories or local suppliers, connect local production networks with customers outside the clusters [11,16], and consequently enhance the prosperity of local economies [17]. As a result of those initial successful experiences, it became popular to construct various types of SMs to trigger local development, especially in regions with weak industrial base. Yiwu city in Zhejiang province and Linyi city in Shandong Province are two typical examples, well known as "commodity market", situated in the north and south of China, respectively. Even recently, some cities in Mainland China, such as Shenyang in Liaoning Province, Changsha in Hunan Province, Changzhou in Guangdong Province, and Langfang in Hebei Province, have drawn up blueprints to construct or regenerate agglomerations of SMs in their urban planning [18].

In fact, manufacturing companies have become less dependent on local SMs as a result of the diversification of sales channels since the late 1990s, which has caused the degeneration or even demise of SMs as transaction platforms in the coastal areas of China [17]. For a group of dominant SAs, constructing SMs in other regions at home or abroad was an alternative to the serious challenges being faced and was also a positive response to changing circumstances [19]. SMs have encountered another round of crises recently due to the rising popularity of e-commerce. The transmission efficiency of business information has been improved greatly, and transaction costs of product exchanges have decreased. Therefore, the traditional advantages of physical SMs have been further weakened [20]. In line with the fact that sales in commodity markets have decreased or even been forced to close, numerous "Taobao villages" (Taobao is the name of a most popular B2C e-commerce platform in China; a Taobao village is a village where the number of physical shops reaches more than $10 \%$ of the local households, and the transactions of electronic commerce amounts to more than 10 million yuan per year), which are more dependent on e-commerce than physical SMs have emerged throughout China. It is therefore urgent for both SMs and SAs to make a prompt transition. Some SMs have turned to focus on the development of information economy [11], intensifying connections with foreign markets as a bridge between China and overseas in fragmented production [16]. It has become the norm for a group of SAs to make expansions into e-commerce services [20].

However, two important points have been neglected in the literature. The first concerns the function of SMs as a bridge between local manufacturers and external customers, and the interactions between SMs and their neighboring manufacturing clusters; while focusing little interest on those SMs which connect remote small- and medium-sized manufacturers with remote clients besides local clients. In fact, in under-developed areas in particular, local SMs were supposed to undertake the crucial role of being a trigger to local industrialization [21]. Second, the literature discusses SMs as a 
whole and concerns itself little with the various kinds of actors in the SMs, such as SAs. SMs actually appear like "black boxes". Especially under changing circumstances, it is not clear how those actors respond and what their effects on local economic development are as a consequence.

This paper focus on the response of traditional SMs to the changing circumstances in less industrialized areas, where SMs originally relied on far-way areas instead of local industrial clusters and SAs have been facing diluted profits from traditional manufacturing [22]. According to the field survey, local SAs have been turning to the relevant product manufacturing, which has been paid little attention to in recent literature. The authors have concerned themselves with which factors drive SAs on SM-based clusters to incorporate manufacturing into their intra-firm value chains. Furthermore, which factors cause SAs to expand manufacturing scale and bring about the burgeoning of local manufacturing is also investigated.

Section 2 conducts a review of the literature and forms some hypotheses. Section 3 covers the research area, methodology, and data collection. Section 4 presents the data, analyses and results. The final section then draws conclusions and provides some discussions.

\section{Literature Review and Main Hypotheses}

The extension of value chains in SM-based clusters (SMBCs) to manufacturing can be understood as an upgrading of regional industries. Literature on industrial clusters discusses some innovation-related topics such as knowledge transfer and learning [23]. Industrial upgrading has also been much debated in strands of literature on global production networks [24,25] (GPNs) or global value chains (GVCs) [26]. From the perspective of GPN theory, chains and networks are merely organizational devices providing opportunities for actor-specific learning, practice, and upgrading [27]. GPN-GVC studies focus on the strategic coupling of clusters and regions within global production systems [28,29], and demonstrate four categories of industrial upgrading [26].

Much of the existing debates on GPNs and GVCs centers around the governance structures of three typical chains, modular, relational, and captive chains [30], and relational network configurations [31]. An updated GPN theory, called "GPN 2.0" by Yeung and Coe, takes an actor-centered focus, highlights the competitive dynamics (optimizing cost-capability ratios, market imperatives and financial discipline) and risk environments, and states their effects on shaping the actors' organizational relationships within global production networks in different industries. Compared with previous GPN studies, GPN 2.0 states two relationships, intra-firm coordination and extra-firm bargaining, beyond inter-firm control and inter-firm partners. The latter two inter-firm relationships originate from the three types of chains as mentioned above.

Although global production networks are considered as cross-border organizational platforms, GPN theory also attempts to analyze regional development between and within countries in global production systems. Moreover, the updated GPN theory focuses much more on the actors and their organizational relationships shaped by "capitalist dynamics", and intends to explore their ultimate effects on the developmental outcomes in different regions and countries. In fact, it provides an actor-relationship approach in analyzing cluster upgrading within cross-regional production networks (CRPNs) in a country like China, where there are economic, cultural, and institutional differences between different regions [27,32]. GPN 2.0 not only identifies diverse firm actors, ranging from lead firms, strategic partners, specialized suppliers and generic suppliers to customers, but also introduces non-firm actors, such as the state, international organizations, labor groups, and civil society organizations. However, it pays little attention to such firm or non-firm actors as the gatekeepers or intermediate agents who connect local clusters worldwide and whose importance is highlighted, especially in the learning dynamics of industrial clusters [33].

The authors have selected SAs, local merchants with intensive relationships with the outside, as a targeted firm actor, in order to explore the upgrading of SM-based clusters within CRPNs. It is believed that SAs with a certain amount of capital and technical ability move into manufacturing out of economic interests or o avoid the large pressures from market competition [34]. The pursuit of economic profit 
is related to the intra-firm factors, and the pressure from competition is most probably caused by a large number of local and external counterparts, and even from abroad (such as international buyers), and the emergence of e-commerce vendors. The increasing competition between local SAs and their counterparts leads to a change in their bargaining power with suppliers [35]. In addition, although SAs can accumulate technical skills through self-learning or their own innovation, it is common practice for them to learn from their peers and longstanding partners. As a consequence, the authors of GPN 2.0 pay special attention to intra-firm coordination, local inter-firm relationships, and cross-regional inter-firm bargaining and partnerships.

\subsection{SAs' Motivations for Setting Foot in Manufacturing as Intra-firm Coordination}

"Intra-firm coordination" refers to the internalization and consolidation of value activities, including management and logistics of production, design, research and development (R\&D), and monitoring of quality standards and production outcomes within various actors [27]. Through intra-firm coordination, various actors within GPNs can improve firm-specific efficiencies such as cost control, market responsiveness, and higher-quality products or services. Setting foot in manufacturing can be viewed as intra-firm coordination within SAs in the SMs, and it is reasonable to consider that benefits concerning firm-specific efficiencies or competitiveness, in turn become intra-firm motivations for SAs to take on such coordinated strategies.

As previously mentioned, a body of literature believes that that SAs move into manufacturing out of economic interests. It was common for SAs to move into production in the 1980s and 1990s in China when the country had a smaller economy and manufacturing yielded higher profits than ever. However, the situation has dramatically changed recently. As production costs have increased, the profits from traditional product manufacturing have declined. Some manufacturing companies have struggled to make changes, and others have even moved to neighboring countries to take advantage of lower production costs [36]. Under such circumstance, it is in doubt as to whether or not the purpose of improving profits is strong enough for SAs to enter into the traditional manufacturing sector. From the perspective of transaction costs, it would be rational for SAs to move into manufacturing instead of completely relying on external suppliers when the administrative costs of internal production is less than the transaction costs of external purchasing [37]. As a result, setting foot in manufacturing can be considered as SAs' response in decreasing costs and strengthening their competitiveness (the so-called "cost-capability ratio" as stated by Yeung and Coe) even when there is little profit to be made from the traditional manufacturing.

Meanwhile, with the rapid development of e-commerce services and increasing diversity of demand, more and more small- and medium-sized manufacturers have turned to focus on small batch, customized, and timely production, and have paid more attention to new product development and innovation to obtain and sustain competitiveness [38]. Accordingly, SAs setting foot in manufacturing could hardly survive the increasingly serious competition in manufacturing sectors without the capability of product innovation. From the viewpoint of transaction costs, innovative products are usually those with high asset specificity, and their transaction cost is higher than that of ordinary products [37]. In this case, it is reasonable for SAs to choose self-production rather than outsourcing production for the sake of innovation protection and quality control of new products. The more non-standardized and innovative the products are and the more rapid the change of customers' tastes, the more likely SAs will turn to depend on internal production.

Therefore, the authors put forward the following hypothesis.

H1: SAs setting foot in manufacturing is positively affected by their motivation for increasing firm-specific efficiency (e.g. cost control, market responsiveness, and higher-quality products or services) rather than that for obtaining greater economic profit in manufacturing.

SAs' setting foot in manufacturing can lead to the emergence of manufacturing activity in SMBCs. The burgeoning of manufacturing and subsequent SMBC upgrading depends on the SAs' manufacturing scale, which is also viewed as a continuous intra-firm coordination. Therefore, the 
authors believe that SAs' manufacturing scale should be also taken into consideration. Internalization of manufacturing is one kind of firm growth or expansion, and so the intra-firm determinants sustained by SAs' setting foot into manufacturing could also be attributed to SAs' manufacturing scale. From the perspective of economic profits, it is reasonable to think the enlargement of production scale is down to chasing scale economies. However, under such circumstances as mentioned before, it is doubtful that SAs have significant enough motivations to expand manufacturing for scale economies. Moreover, according to Penrose's view of firm growth [39], unused resources within the firm originate sales, managerial, research or productive excess capacity. It is supposed that the motivations to use those unused resources to strengthen firms' competitiveness lead to diversification or expansion of the firm.

Therefore, the authors put forward the following hypothesis.

H2: SAs' manufacturing scale is positively affected by their motivations to increase their firm-efficiency by using competitiveness-related resources rather than that for obtaining scale economies.

\subsection{Local Inter-Firm Relationships and Accessibility to SMBC-Specific Benefits}

It is generally believed that external economies of scope are an excellent advantage of the agglomeration of various SMs in an area where there are intensive formal and informal intensive relationships. Customers can conveniently shop for a variety of commodities in the same place, which decreases the time and financial costs [40,41]. However, it is unclear whether or not external economies of scope have an important impact on expansion of SAs to related manufacturing. In terms of input-and-output linkage between different products in different local SMs, SAs in a specific SM are supposed to get products as raw materials or components from other SMs nearby, which makes SAs competitive when setting foot in manufacturing by reducing transportation and transaction costs as mentioned in literature on industrial clusters [42].

The agglomeration of SAs in SMs can lead to fierce the competition between local SAs, forcing them to improve their innovation capability, which is common in manufacturing clusters [42]. Meanwhile, SMs are a typical kind of information economy, which also bring about external economies of scale. Generally speaking, the agglomeration of SAs makes it more convenient for customers to get access to transparent information about homogeneous commodities for a low transaction cost [43]. Moreover, local firms in the same location share value and cultural traditions in common, which is helpful in building up formal and informal trust-based relationships [44]. The importance of these close and intensive relationships between local firms is highlighted in the decrease of transaction costs and transmission of knowledge and information in particular [45,46]. Once a SA takes the initiative to invest in related manufacturing and achieves great success in business, other SAs in the same SMs and even other SMs of different commodities in the locality would follow up its experience.

With an increasing number of SAs setting foot in manufacturing, local related manufacturing clusters are burgeoning, with external economies of scale being increasingly enhanced [47]. It is easy for SAs and new entrants to get access to a skilled local labor pool, improve the production efficiency, and promote the growth of firms by virtue of local production networks [48]. In addition, intensive local relationships between different organizations provide channels for the transmission of crucial knowledge and skills concerning related production for local manufacturers and SAs after setting foot in manufacturing. The dynamics of local learning are able to sustain a local competitive advantage [49]. Based on the above theoretical analysis, the authors put forward the following hypothesis.

H3: SAs' setting foot in manufacturing is positively affected by accessibility to SMBC-specific benefits from local inter-firm relationships.

For similar reasons concerning the context of raising $\mathrm{H} 2$, the accessibility to local resources or benefits probably has a positive effect on SAs' manufacturing scale. Moreover, although Penrose highlights the importance of firm's endogenous growth, she further states that the growth of firms may be consistent with the most efficient use of a society's resources, and acknowledges the interaction between internal and external factors. Therefore, the authors put forward the following hypothesis. 
H4: SAs' manufacturing scale is positively affected by the accessibility to SMBC-specific benefits from local inter-firm relationships.

\subsection{Dynamic Cross-Regional Inter-Firm Relationships and Accessibility to External Knowledge/Technology}

The importance of innovation in regional development is highlighted in some strands of literature regarding industrial clusters, learning regions, and regional innovation systems. The inter-organizational networks are believed to underpin the flow of knowledge within and across regions [50], and the dynamic relationships between economic globalization and regional development is one area in particular in which much attention has been paid [28]. Cross-border linkages [51], such as global pipelines [23], and GPNs and GVCs [52], discussed in the beginning of this section, are important channels for local firms in obtaining heterogeneous knowledge and information, and furthermore promote cluster upgrading $[53,54]$. In addition, competition between same-level suppliers and the high-level requirements for quality, force firms in the GVCs or GPNs to focus on innovation $[52,53]$.

In fact, upgrading is a complicated process. Global technology forerunners tend to delimitate against the chances of being caught up by their suppliers in developing countries [26]. Therefore, it is much easier for the latter to make process and upgrade their products than to carry out functional and chain upgrades [26]. Another line of literature demonstrates that cross-regional production networks (CRPNs) within a nation provide more possibilities for firms in less developed countries to move up to higher value-added activities by embedding into national or regional value chains than into a GVC or GPN [55]. The reason for this is because tacit knowledge is often embedded in the relationships between related firms with a common cultural background and is transmitted easily between firms in value chains within a country or region [55]. However, later studies do not deny the feasibility of using the analytical framework of GPN theory to explore industrial upgrading and regional development.

It supposes that CRPNs make it possible for SAs to gain knowledge and skills for production from their suppliers. Moreover, the dynamics of inter-relationships between SAs and their suppliers across the region may have an impact on the extension of value chain to manufacturing. On the one hand, as more and more suppliers incorporate into the GPNs of global companies, or depend more on e-commerce services, their connections with SAs loosen; on the other hand, as SAs enter into manufacturing, in their suppliers' eyes, the competition between them outweighs the benefits of cooperation. That means SAs would further expand the production scale to depend more on internal manufacturing, given their bargaining power and learning opportunities from their upstream suppliers decrease. Therefore, the authors put forward the following hypotheses.

H5: SAs' setting foot in manufacturing is positively affected by the accessibility to knowledge/technology based on dynamic relationships with cross-regional suppliers.

H6: SAs' manufacturing scale is negatively affected by the accessibility to knowledge/technology based on dynamic relationships with cross-regional suppliers.

\section{Research Area and Data Source}

\subsection{Case Selection and Overview}

Linyi, a city located in Shandong Province, China (Figure 1), was once an isolated area with underdeveloped manufacturing and business services. However, since the establishment of the Linyi Western Suburbs Wholesale Market in the mid-1980s, the city has become a large distribution hub for the area north of the Yangtze River, and well-known for trade and logistics throughout China. This paper selects Linyi, the city on the border of Shandong Province and Jiangsu Province, as the study area for the following reasons. First, there are 101 SMs in the downtown of Linyi, including 57,000 shops and stalls, employing 233,000 staff and catering to 300,000 customers per day [56]. The products in Linyi cover the major categories of daily consumer goods, so we have chosen the so-called "The Northern China Yiwu" (Yiwu is a county-level city in Zhejiang Province known as "China's Commodity City"). Second, there is much literature based on the experiences of 
Zhejiang Province in China that emphasizes the co-evolution between SMs and their neighboring manufacturing clusters, while little is concerned about regions such as Linyi where local economies rely on SMs but have no related manufacturing sectors nearby. Third, recent evidence shows that local SAs no longer focus on sales, but have begun to invest in related product manufacturing, resulting in the development of local manufacturing clusters. This change means that the development of SMs is not only accelerating the urbanization, but also contributing to the development of local manufacturing. Therefore, a case study of Linyi has general meaning and reference value.

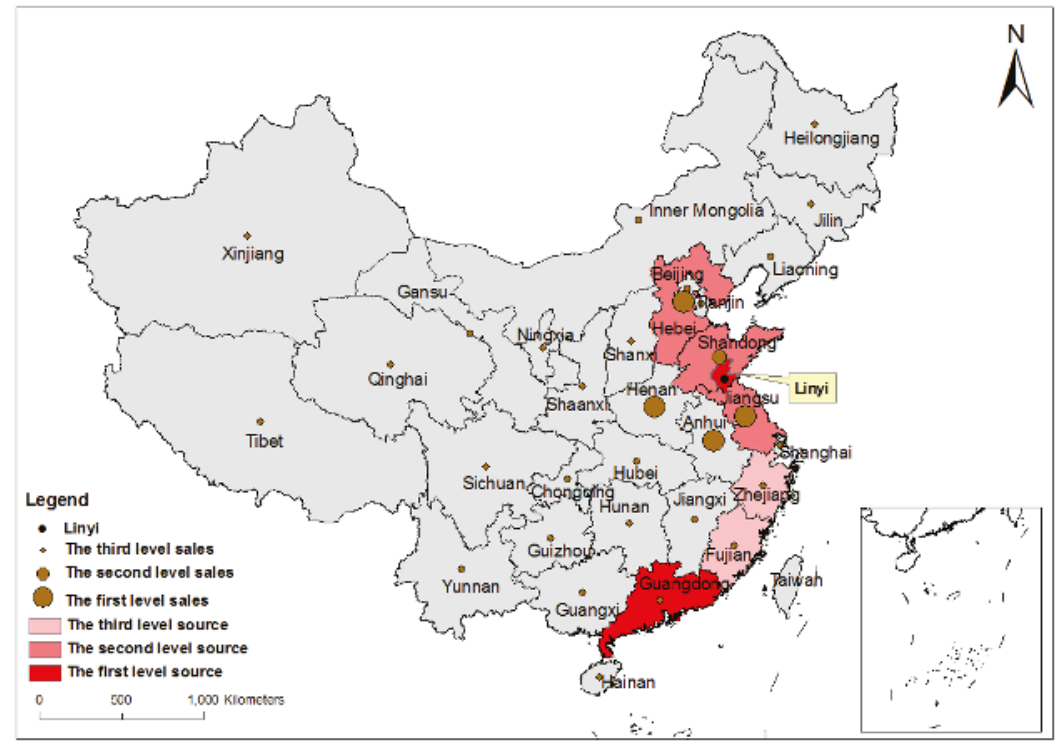

Figure 1. Primary source locations and distribution destinations of toys in Yongxing Market.

Linyi is the largest toy SM in Shandong Province and the second major location for warehouses for toy manufacturers in China (Chinese toy industry markets are characterized as export-oriented, and mainly depend on original equipment manufacturers, with few self-owned brands. In 2013, about 70\% of the world's toys were made in China [57]. External demand contraction and reduced export orders caused by the economic crisis, Chinese toy exporters suffered terribly and had to turn to domestic markets or create its own brand. In 2007, the number of Chinese toy exporters was 8610 , but by 2008, the number had plummeted to 4388 [58].). Besides this, Linyi has been listed as one of the top ten distribution centers of toys in China since 2011 [59]. The first group of toy SAs set up shop in the 1990s in the wholesale market of Linyi downtown, which was known as the "Mainland Business Village". As the sale of toys and the number of toy SAs rapidly increased, Linyi Yongxing International Toy Wholesale Market ("Yongxing Market" for short), a unique SM for toys in Shandong Province, was established in 2007 to improve the business environment for toy SAs. Since Yongxing Market's establishment, many SAs for toys have gradually moved in, and the sales of toys have risen rapidly. In 2014, the market was home to more than 600 SAs and 1,200 operating booths. The success of Yongxing Market can be attributed to its geographical proximity to the inter-city bus station of Linyi and the entrance to the Beijing-Shanghai Highway. Moreover, many other SMs and logistics distribution centers are located around the market (Figure 2). Today, only a small percentage of toy SAs are still located in the toy retail market in Linyi's People's Square and Linyi Small Commodities Market, with the majority of these conglomerates belong in Yongxing Market. Toys in Yongxing Market 
are sold throughout the country, but mainly to the neighboring provinces of Shandong, such as Henan, Anhui, Hebei and Jiangsu (Figure 1).

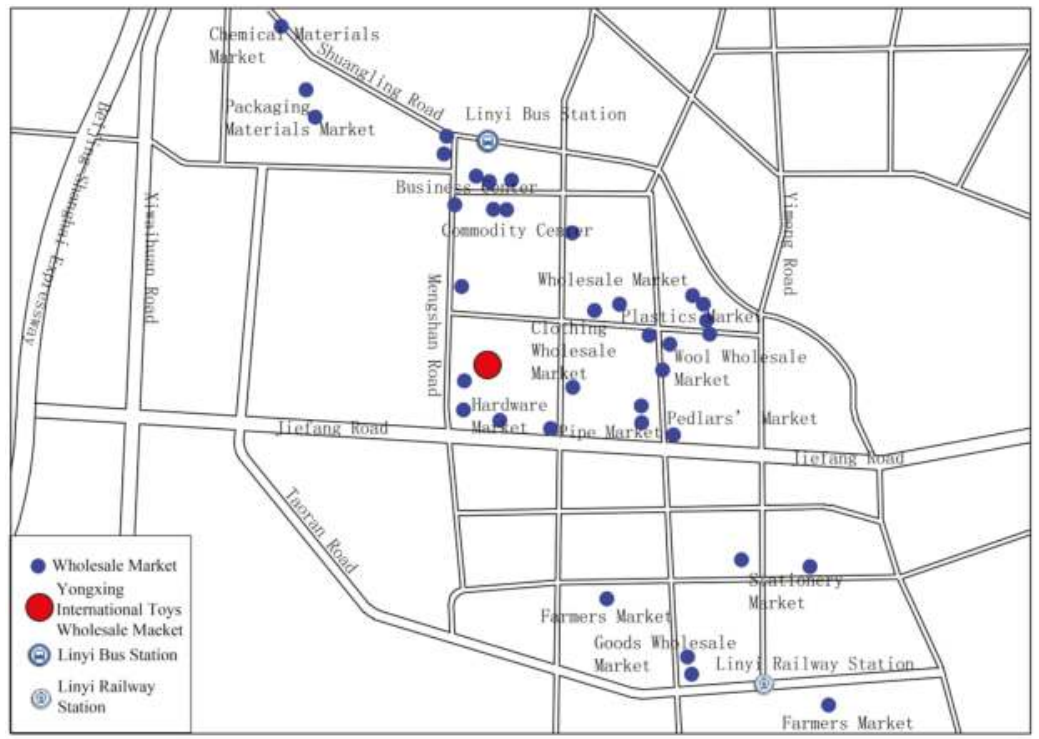

Figure 2. Sketch Location Map of Yongxing Market in Linyi, Shandong.

Initially, the toys in Linyi were mainly manufactured in Guangdong, Jiangsu and a couple of other cities of Shandong. Recently, the market share of toys made in Linyi has risen. According to this survey on local toy SAs, local products account for $40 \%$ of all sales in Yongxing Market. Linyi is the second largest source of toys, after Guangdong Province. More than half of toy SAs in the market have already invested in manufacturing, and especially in plush-toy manufacturing, whereby $80 \%$ of the SAs manufacture products of their own. Following those SAs' lead, new entrants emerged, and manufacturing villages in the surrounding suburban areas of Linyi burgeoned. Most of these factories are family-owned and small in size.

\subsection{Data Collection}

Based on interviews with members of staff and SAs in Yongxing Market carried out in August 2011, the authors learned about the history, competition and transition to manufacturing of the market, and also confirmed toy SMs as the object of study. Subsequently, the authors created a structured questionnaire to collect relevant data.

The second on-site questionnaire survey was conducted between December 2011 and January 2012. A total of 486 questionnaires were distributed, accounting for approximately $80 \%$ of the total number of existing SAs in the market; 126 questionnaires were returned (the return rate was $25.9 \%$ ), and 117 questionnaires were valid (the validity rate was 92.9\%). Among the 117 valid questionnaires, 54 SAs have invested in manufacturing activities, which is roughly the same as the proportion of the whole market. The basic information for the 117 sample SAs is illustrated in Table 1. Some of the SAs took part in semi-structural interviews during the second survey. In June 2012 and July 2015, the authors re-interviewed several SAs online. 
Table 1. Basic information from 117 valid questionnaires on Yongxing Market in Linyi China.

\begin{tabular}{|c|c|c|c|}
\hline Attributes & Number of Samples & Attributes & Number of Samples \\
\hline Toy category & & The number of sales people & \\
\hline Plush toy & $\begin{array}{l}37 \text { (Accounting for } 31.6 \% \text {; } \\
31 \text { are involved in the } \\
\text { manufacturing sector) }\end{array}$ & $<3$ persons & $33(28.2 \%)$ \\
\hline $\begin{array}{l}\text { Plastic and electronic } \\
\text { toys }\end{array}$ & $\begin{array}{l}80 \text { (Accounting for } 68.4 \% \text {; } \\
23 \text { are involved in the } \\
\text { manufacturing sector) }\end{array}$ & 3-6 persons & $81(69.2 \%)$ \\
\hline $\begin{array}{l}\text { Total } \\
\text { Business scope of SAs }\end{array}$ & 117 & $\begin{array}{l}>6 \text { persons } \\
\text { Top three sources of toys }\end{array}$ & $3(2.6 \%)$ \\
\hline Sales & $63(53.8 \%)$ & Guangdong & $66(56.4 \%)$ \\
\hline Sales + Manufacturing & $54(46.2 \%)$ & $\begin{array}{l}\text { Linyi } \\
\text { Hebei }\end{array}$ & $\begin{array}{l}49(41.9 \%) \\
9(7.7 \%)\end{array}$ \\
\hline $\begin{array}{l}\text { Sales duration } \\
<5 \text { years }\end{array}$ & $64(54.7 \%)$ & Manufacturing duration & \\
\hline $\begin{array}{l}5-10 \text { years } \\
>10 \text { years }\end{array}$ & $\begin{array}{l}46(39.3 \%) \\
7(6.0 \%)\end{array}$ & $\begin{array}{l}<3 \text { years } \\
3-6 \text { years }\end{array}$ & $\begin{array}{l}29(53.7 \%) \\
22(40.7 \%)\end{array}$ \\
\hline Area of shops & & $\begin{array}{l}>6 \text { years } \\
\text { The number of production }\end{array}$ & $3(5.6 \%)$ \\
\hline $\begin{array}{l}<75 \mathrm{~m}^{2} \\
75-150 \mathrm{~m}^{2} \\
>150 \mathrm{~m}^{2}\end{array}$ & $\begin{array}{l}62(53.0 \%) \\
49(41.9 \%) \\
6(5.1 \%)\end{array}$ & $\begin{array}{l}\text { workers } \\
<20 \text { persons } \\
20-50 \text { persons } \\
>50 \text { persons }\end{array}$ & $\begin{array}{l}40(74.1 \%) \\
14(25.9 \%) \\
0(0.0 \%)\end{array}$ \\
\hline
\end{tabular}

Note: the number of valid questionnaires related to "Manufacturing duration" and "The number of production workers" is 54 from a total of 117 , and the remainder is 117 .

According to the questionnaire, the surviving SAs under the influence of commerce modality changes in China's wholesale market have three directions of business transition: (1) establishing SMs in other cities (not very popular in Linyi); (2) making extension to e-commerce services by establishing an e-commerce platform or co-operating with internet service companies (33.3\% of all the samples provide e-commerce services); and (3) moving into toy manufacture ( $46.2 \%$ of all the samples).

\section{Data Analysis and Results}

This paper discusses the factors that exert influence on the expansion of SAs from wholesale to manufacturing and on the scale of internal production. Based on the literature reviewed in Section 2, the authors selected three kinds of determinants, namely, individual motivations of entrepreneurial innovation, local agglomeration effects of SMs, and dynamic relationships within CRVCs, as independent variables, and defined "whether or not SAs set foot in related product manufacturing" and "the production scale of SAs" as the dependent variables, respectively.

\subsection{Factors Affecting SAs to Investing in Manufacturing}

According to the literature analysis in the second section, eight variables were selected as independent variables presenting individual motivations of intra-firm coordination, local inter-firm relationships for facilitation to get SMBC-specific benefits, and dynamic cross-regional inter-firm relationships for accessibility to crucial resources. "Sales duration", "Size of SAs" and "Industry specialization" were the control variables, and "whether or not SAs set foot in related product manufacturing" as the dependent variable. All variables and their meanings, and their scores quantitative criteria are shown in Table 2.

Based on the related data of 117 valid samples, the authors used the "Backward: LR" method of Binary Logistic Regression, which first starts with all variables in the regression equation, and then removes the independent variables that have no significant effect on the dependent variable according to the probability value of statistic derived from the Maximum Likelihood Estimation. The judgment probability is set as 0.05 , so that the performance of the model is more optimized. The logistic regression model estimation results are shown in Tables 3 and 4. 


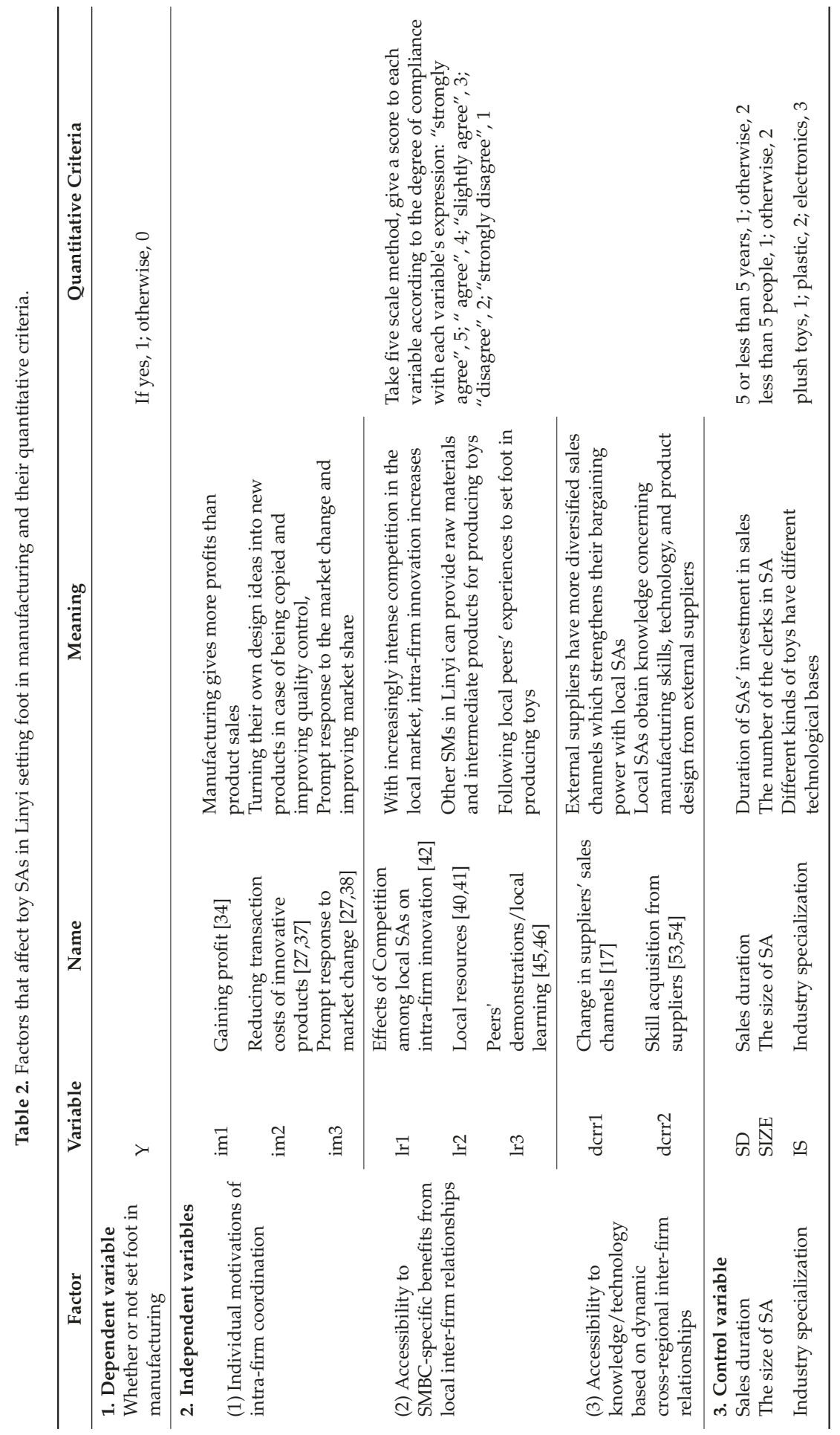




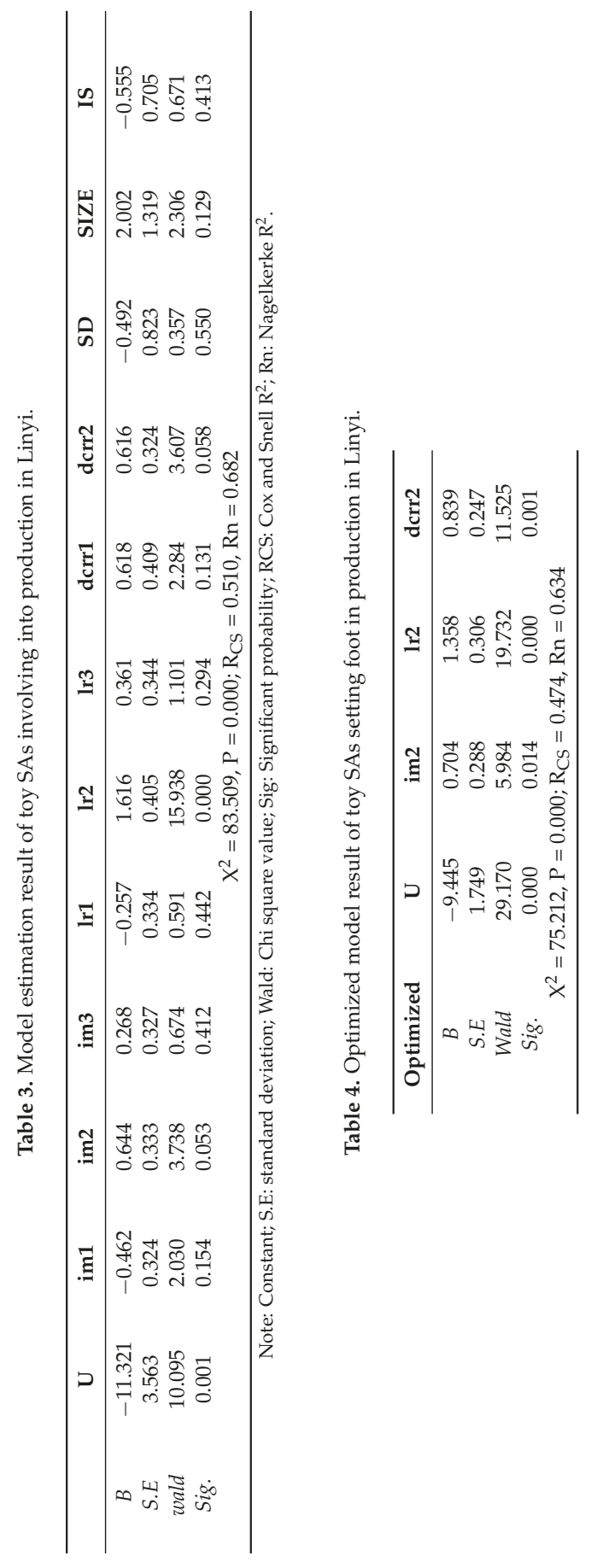


According to Table 4 , the overall fitting degree is good $\left(X^{2}=83.509, P=0.000\right)$, which shows that the independent variables on the whole have a significant effect on the dependent variable $(\mathrm{P}<0.05)$. Only one independent variable, namely $\mathrm{lr} 2$, had a significant effect on the dependent variables $(P<0.05)$, while the other independent variables did not have significant effect. According to the probability value of statistics derived from the Maximum Likelihood Estimation, the irrelevant independent variables were removed and the optimized results are shown in Table 4.

The optimized model result shows that the effect of im2, lr2, and dcrr2 on the dependent variable is clear, and the corresponding regression coefficients are $0.704,1.358$, and 0.839 respectively. It indicates that the three factors, "reducing transaction costs of innovative products", accessibility to "local resources", and "skill acquisition from suppliers" drive SAs to invest in related manufacturing. They, respectively, represent "individual motivations of intra-firm coordination" (related to the firm-specific efficiency), "accessibility to SMBC-specific benefits from local inter-firm relationships" and "accessibility to knowledge/technology based on dynamic cross-regional inter-firm relationships", which verify hypotheses 1,3 and 5 . The coefficient of $\operatorname{lr} 2$ is higher than dcrr 2 and im 2 , which means that accessibility to "local resources" is the most significant, and "accessibility to SMBC-specific benefits from local inter-firm relationships" play a much more important role than "accessibility to knowledge/technology based on dynamic cross-regional inter-firm relationships" and "individual motivations of intra-firm coordination" in driving SAs to invest in the manufacturing sector. In fact, due to a variety of different SMs nearby, toy SAs can easily get access to raw materials at a low cost of transportation and transaction. The external economies of scope in the agglomeration of SMs provide an important precondition or advantage for SAs in making an expansion into manufacturing.

Long-term business collaborations with trans-local toys manufacturers are an important learning channel for SAs to acquire indispensable technical support in the initial stages of entering into manufacturing. Despite the fact that more than half have their own ideas of product design in general as mentioned below, 23 SAs setting foot in manufacturing (making up $42.6 \%$ of the similar SAs) claimed in the questionnaire survey that they remained the business cooperation with their previous trans-local suppliers for access to new information about product development and design The subsequent interviews further indicated that local toy SAs were not bold when making investment in manufacturing without acquiring knowledge about it first. There is little evidence to indicate that those suppliers have turned to depend more on other sales channels than traditional SMs.

No matter whether they invested in manufacturing or not, almost all the SAs surveyed claimed that there is very little profit in toy manufacturing. This is the reason why the variable, "gaining profit", is not significant to the dependent variable, and it can also explain the reason why the dependent variable "peer's demonstration" has no significant relationship with the business expansion of SAs. Meanwhile, due to intensive contact sub-level distributors all over the country, some toy SAs are sensitive to the market changes and often figure out innovative ideas about the new product development. 35 SAs setting foot in manufacturing (making up $64.8 \%$ of the similar SAs) claimed in the questionnaire survey that they often created some good ideas of product design by virtue of their marketing experiences for years. Those SAs prefer to adopt internal production rather than outsource production in case their innovations are leaked out.

Interestingly, although the two variables concerning individual motivations, "prompt response to the market change" and "gaining profit", have no significance on SAs setting foot in manufacturing in the model, the questionnaire result indicates that internal production does improve the competitiveness and the profit levels for SAs. Table 5 shows that the majority of SAs in the questionnaire survey claimed that their competitiveness had improved to some extent after moving to internal production, sales and profits had increased, and accordingly external purchase of toys had decreased. Furthermore, during the subsequent interview, a couple of SAs mentioned that increasing uncertainty in the toy market requires a prompt response from SAs to the rapid changes in demands. As a consequence, SAs adopt low-volume production for the initial stage of launching new products and then promptly move to organize mass production once those new products are successful. Otherwise, SAs would 
not be able get much economic return as their creative ideas would be widely copied in a short time. That situation requires geographical proximity of sales to toy production, which helps improve their competitiveness.

Table 5. The effects of setting foot in manufacturing on the business operation of SAs.

\begin{tabular}{lcccc}
\hline $\begin{array}{c}\text { Extent of Agree or } \\
\text { Disagree }\end{array}$ & $\begin{array}{c}\text { Increase in } \\
\text { Sales }\end{array}$ & $\begin{array}{c}\text { Competitiveness } \\
\text { Improvement }\end{array}$ & $\begin{array}{c}\text { Increase in } \\
\text { Profit }\end{array}$ & $\begin{array}{c}\text { Decrease in External } \\
\text { Purchasing }\end{array}$ \\
\hline Strongly agree & 20 & 16 & 8 & 11 \\
agree & 14 & 10 & 28 & 9 \\
Slightly agree & 18 & 27 & 8 & 30 \\
disagree & 0 & 0 & 5 & 2 \\
Strongly disagree & 2 & 1 & 5 & 2 \\
\hline
\end{tabular}

\subsection{Factors Affecting the Production Scale of SAs}

The 54 SAs setting foot in manufacturing showed a big difference in production scales. In terms of the percentage of internal production to the total sales volume, nearly half of these SAs (25) reached more than $30 \%$, and a couple of SAs even amounted to more than $90 \%$, while some SAs account for less than $10 \%$. In this section, the authors explore which factors affect the production scale of SAs after moving into manufacturing. Nine variables have been selected as independent variables, which respectively present individual motivations, local agglomerations and dynamic trans-local relationships as mentioned before, with "technical change" and "financial capital" added as two control variables; "the scale of internal production" is the dependent variable. All variables and their meanings are explained in Table 6.

The estimated results of the logistic regression model are shown in Tables 7 and 8 . Table 7 shows that the overall fitting degree is not good $\left(\mathrm{X}^{2}=17.499, \mathrm{P}=0.095\right)$, which indicates that the whole independent variables do not have a significant effect on the dependent variable $(\mathrm{P}>0.05)$. Independent variables LR1and LR4 have a significant effect on the dependent variables $(\mathrm{P}<0.05)$. According to the probability value of statistics derived from the Maximum Likelihood Estimation, the irrelevant independent variables are removed and the optimized results are shown in Table 8.

Table 8 shows as a whole, the independent variables have a significant effect on the dependent variable $(\mathrm{P}<0.05)$. The optimized model result shows that only LR1, LR3 and LR4 are significant at the $5 \%$ level, and their corresponding regression coefficients are 1.416, 0.878 and 1.115, respectively. That is to say, accessibility to "local resources", "local learning", and "local labor resources" encourage SAs to expand the scale of manufacturing. These three factors are part of the local cluster effects, which verifies hypothesis 4 that accessibility to SMBC-specific benefits from local inter-firm relationships positively impacts on the scale of SAs' internal production. The authors made a further comparison between the two groups of samples. The results show that for SAs whose production percentage is more than 30\%, the means of LR1, LR3 and LR4 are, respectively, 4.7, 3.8, and 3.4, which is much higher than those of SAs with less than $30 \%$ (the means of the three variables are 4.1,3.3, and 2.6, respectively). 


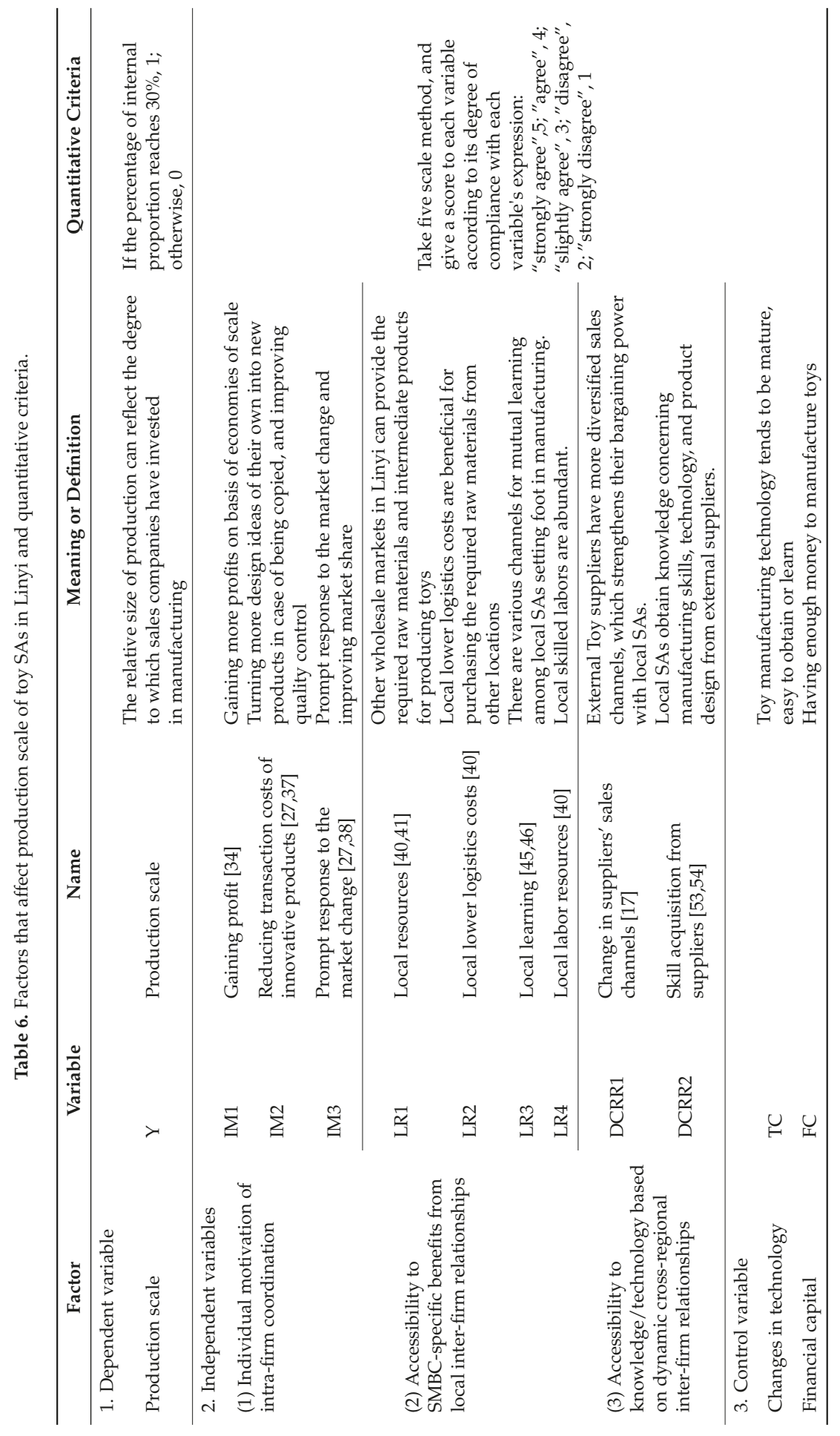


Table 7. Model estimation result of production scale of toy SAs in Linyi.

\begin{tabular}{|c|c|c|c|c|c|c|c|c|c|c|c|c|}
\hline & $\mathbf{U}$ & IM1 & IM2 & IM3 & LR1 & LR2 & LR3 & LR4 & DCRR1 & DCRR2 & TC & FC \\
\hline$B$ & -0.354 & -0.767 & -0.074 & -0.553 & 1.290 & 0.339 & 0.777 & 0.967 & 0.085 & -1.009 & -1.029 & 0.135 \\
\hline S.E & 4.241 & 0.448 & 0.430 & 0.559 & 0.574 & 0.460 & 0.420 & 0.469 & 0.521 & 0.535 & 0.626 & 0.384 \\
\hline wald & 0.007 & 2.924 & 0.030 & 0.979 & 5.052 & 0.543 & 3.413 & 4.258 & 0.027 & 3.556 & 2.703 & 0.123 \\
\hline Sig. & 0.933 & 0.087 & 0.863 & 0.322 & 0.025 & 0.461 & 0.065 & 0.039 & 0.870 & 0.059 & 0.100 & 0.726 \\
\hline \multicolumn{13}{|c|}{$\mathrm{X}^{2}=17.499, \mathrm{P}=0.094 ; \mathrm{R}_{\mathrm{CS}}=0.277, \mathrm{Rn}=0.370$} \\
\hline
\end{tabular}

Note: Constant; S.E: standard deviation; Wald: Chi square value; Sig: Significant probability; RCS: Cox and Snell $R^{2}$; Rn: Nagelkerke $R^{2}$.

Table 8. Optimized model result of production scale of toy SAs in Linyi.

\begin{tabular}{cccccccc}
\hline & U & IM1 & LR1 & LR3 & LR4 & DCRR2 & TC \\
\hline B & -3.496 & -0.635 & 1.416 & 0.878 & 1.115 & -0.753 & -0.916 \\
S.E & 1.992 & 0.385 & 0.562 & 0.414 & 0.432 & 0.415 & 0.559 \\
wald & 3.080 & 2.720 & 6.352 & 4.511 & 6.671 & 3.297 & 2.691 \\
Sig. & 0.079 & 0.099 & 0.012 & 0.034 & 0.010 & 0.069 & 0.101 \\
\multicolumn{7}{c}{$X^{2}=16.034, \mathrm{P}=0.014 ;$} & $\mathrm{R}_{\mathrm{CS}}=0.257, \mathrm{Rn}=0.343$ \\
\hline
\end{tabular}

The variable "(accessibility to) local resources" is closely related to the external economies of scope in agglomeration of SMs. Local related SMs not only provide raw materials and components for SAs to set foot in toy manufacturing, but also have a positive effect on the expansion of the production scale. Local learning between SAs does not have a significant bearing on the decision about whether or not SAs set foot in manufacturing, but local mutual learning between SAs setting foot in manufacturing can promote the expansion of the production scale. Although the variable "local lower logistics costs" is not significant in the model, subsequent interviews show that fast local logistics services and its lower costs make it convenient for SAs to purchase some raw materials and toys from outside.

Individual motivations of intra-firm coordination can inspire SAs to set foot into related manufacturing; however, their subsequent impact on the expansion of production scale is not significant. That probably implies that SAs' administration capabilities are more important than their motivations in realizing an expansion of production. Despite the fact that accessibility to knowledge/technology based on dynamic inter-firm relationships across regions have no significance on the production scale, a couple of the SAs interviewed responded by saying that they still paid attention to business cooperation with trans-local suppliers as it helps them get access to the updated information about new products. SAs often purchase toys in small quantities and promptly organize internal production once those products are welcomed in the market. In fact, local manufacturers often encounter problems concerning complicated skills, product design, and crucial technologies, and have difficulties in learning those from their suppliers across regions. This is particularly true in the manufacturing of electronic toys.

\section{Conclusions and Discussion}

Western cluster literature mentions little about SMs and the geographical location of SAs. Chinese scholars have noted the role of SMs in the burgeoning of industrial clusters and have placed an emphasis on the interdependent and co-evolutionary relationships between prosperous SMs and mature industrial clusters nearby, but ignored the response of SAs in the SMs to the changing circumstances and their importance in regional development. One contribution of this paper is to fill in the gap between the existing research on cluster upgrading and Chinese practice through providing the case of Linyi where SMBCs incorporate manufacturing into local value chains. Another contribution is to use the updated GPN theory to set up the analytical framework, and to explain how competitive dynamics and risk management shape the four types of relationship, and then have an effect on local development. The empirical results show that individual motivations of 
intra-firm coordination, regional inter-firm relationships and cross-regional inter-firm relationships have a significant and positive impact on the upgrading of local industrial clusters so as to sustain local competitiveness. Moreover, it also demonstrates that SAs could trigger the burgeoning of industrial clusters and speed up the process of industrialization through their investments in manufacturing in less-developed industrialized areas. The SAs in SMs actually act as the intermediate agents or the gatekeepers between local production networks and global flows in the cluster learning literature, whose role is neglected in GPN 2.0 theory. In addition, there is a group of small- and medium-sized business trade cities in China, especially for those newly burgeoning e-commercial towns without strong economies and those with emerging economies. The case of Linyi provides experiences for those places to reshape regional competitiveness on the basis of adding advantages through trade.

In the case of Linyi, three important points are worth being highlighted. First, in terms of such kind of traditional products as toys, due to shrinking profit margins, intensifying competition and rapid changes in consumer tastes, it is preferable for the increase in efficiencies or firm competitiveness rather than simple pursuit of economic profit that encourages SAs to move into manufacturing. Therefore, innovation-based internal production could sustain SAs' competitiveness through the improvement of product quality and instantly responding to changing situations. Second, agglomeration of various kinds of SMs in the same place and the local inter-firm relationships within SM-based clusters facilitate access to material and human resources with lower manufacturing costs, and production knowledge and technologies for an expansion of manufacturing scale, which is beneficial to reshaping local competitiveness, whereas an isolated SM cannot easily benefit from these advantages. Mutual learning between toy SAs setting foot in manufacturing and new entrants as manufacturers are an important channel for the sharing of knowledge, and so it is helpful for SAs to make expansions in terms of production scales. That implies it is necessary to improve local innovation networks. Third, a dynamic relationship with cross-regional suppliers is an important channel of knowledge transmission; however, it cannot guarantee efficient access to core technologies and crucial knowledge for SAs without knowledge-oriented cooperation. That probably means it is indispensible to establish cross-regional learning channels to further strengthen the competitiveness of SAs and SMBCs.

Some issues worthy of further discussion remain. First, although this paper uses an analytical framework on the basis of GPN 2.0 theory, there is no direct linkage between local SAs in Linyi and foreign multinational companies. The result is probably different if such international linkages exist. Second, extra-firm partners mentioned in GPN2.0 theory are not taken into consideration in this paper. The authors focused on the CRCV but have not covered external learning channels with knowledge institutions as the preliminary survey evidence, which showed that local SAs have little interest in establishing external technology-based cooperation. The emergence and dynamics of such relationships for access to external knowledge deserves concern. Additionally, local authorities and other institutions are not integrated into the analytical framework. Although almost all SAs in the survey claimed that local governments made little effort in promoting the development of toy manufacturing, it has been reported that the Linyi municipal government has proposed industrial policies and established industrial parks to "stimulate prosperity in manufacturing sectors by taking advantage of local SMs strategy". Finally, the relationships between SAs and local toy factories in the suburban areas are worth investigation in order to gain a better understanding of the role of SAs in local development.

Acknowledgments: Acknowledgments: This research is supported by the National Natural Science Foundation of China (projectcode: 41171098). The authors would also wish to extend their thanks to two anonymous referees, and Wang Maojun at Capital Normal University, and Wang He at Hong Kong City University, and Pan Fenghua at Beijing Normal University for their valuable comments.

Author Contributions: Author Contributions: Huasheng Zhu contributed to the analytical framework and the methodology design and wrote the article. Xue Huang and Qingcan He contributed to the data analysis. Jie Li and Lingzhi Ren sent out questionnaires and collected data.

Conflicts of Interest: Conflicts of Interest: The authors declare no conflict of interest. 


\section{References}

1. Rabellotti, R. External Economies and Cooperation in Industrial Districts: A Comparison of Italy and Mexico; Macmillan Press Ltd.: London, UK, 1997.

2. Plambeck, E.L.; Taylor, T.A. Sell the plant? The impact of contract manufacturing on innovation, capacity, and profitability. Manag. Sci. 2005, 51, 133-150.

3. Scott, A.J. The changing global geography of low-technology, labor-intensive industry: Clothing, footwear, and furniture. World Dev. 2006, 34, 1517-1536. [CrossRef]

4. Kaplinsky, R.; Morris, M.; Readman, J. The globalization of product markets and immiserizing growth: Lessons from the South African furniture industry. World Dev. 2002, 30, 1159-1177. [CrossRef]

5. Nassimbeni, G.; Sartor, M. The internationalization of local manufacturing systems: Evidence from the Italian chair district. Prod. Plan. Control 2005, 16, 470-478. [CrossRef]

6. Grandinetti, R.; Nassimbeni, G.; Sartor, M. Foreign direct investments in manufacturing by district firms: Evidence from the Italian chair district. Prod. Plan. Control 2009, 20, 403-419. [CrossRef]

7. Pietrobelli, C.; Rabellotti, R. Global value chains meet innovation systems: Are there learning opportunities for developing countries? World Dev. 2011, 39, 1261-1269. [CrossRef]

8. Pipkin, S. Local means in value chain ends: Dynamics of product and social upgrading in apparel manufacturing in Guatemala and Colombia. World Dev. 2011, 39, 2119-2131. [CrossRef]

9. Lu, L.J. Yiwu mode of China commodity city and rural economic development. Bus. Econ. Manag. 1997, 6, 4-9. (In Chinese)

10. Lu, L.J.; Yu, H.D.; Lu, Y. Specialized Market and Industrial Cluster: Linkage and Influential Factors. China Ind. Econ. 2011, 1, 151-160. (In Chinese)

11. Ding, K. Market Platforms, Industrial Clusters and Small Business Dynamics: Specialized Markets in China; Edward Elgar Publishing: Cheltenham, UK, 2012.

12. Statistical Yearbook of China Commodity Exchange Market in 2014. Available online: http://tongji.cnki.net/ kns55/Navi/YearBook.aspx?id=N2014110013\&floor=1 (accessed on 25 December 2015).

13. Cai, J.J.; Wang, S.H. Analysis of the development of the specialized market based on industry cluster-A case study of Taizhou, Zhejiang. Contemp. Financ. Econ. 2005, 8, 88-91+96. (In Chinese)

14. Xie, S.H.; Zhou, J.Y. The temporal and spatial dynamics patterns and its causes of specialized markets development in China. Econ. Geogr. 2013, 11, 77-83. (In Chinese)

15. Yang, Y.; Qu, H.J.; Xu, Z.B. Effect of textile \& garment specialized market on regional industrial clusters. Shanghai Text. Sci. Technol. 2013, 10, 53-57. (In Chinese)

16. Bellandia, M.; Lombardib, S. Specialized markets and Chinese industrial clusters: The experience of Zhejiang Province. China Econ. Rev. 2012, 23, 626-638. [CrossRef]

17. Zhu, H.S. The Industrial Clusters of Zhejiang: Industrial Network, Growth Trajectory and Development Momentum; Zhejiang University Press: Hangzhou, China, 2003. (In Chinese)

18. Fang, X.S.; Xiao, D.W. Research of specialized markets development and planning. City Plan. Rev. 2002, 10, 61-63. (In Chinese)

19. Liu, S.A. The development and evolution of Zhejiang specialized market in e-commerce era of. Commer. Res. 2006, 03, 187-189. (In Chinese)

20. Du, L.L. The opportunity and challenge of the traditional specialized market in the era of e-commerce. China Logist. Purch. 2014, 12, 68-69. (In Chinese)

21. Lu, L.J.; Yu, H.D. On the professional market, driven by industrial cluster and upgrade-Yiwu City, Zhejiang Province-based survey and analysis. East China Econ. Manag. 2009, 23, 50-54. (In Chinese)

22. Zhou, C.S.; Li, Y.F.; Zhang, G.J. Research on Upgrading of the Traditional Manufacturing Industry Based on Global Value Chains: A Case of Shantou. Areal Res. Dev. 2014, 01, 28-33. (In Chinese)

23. Bathelt, H.; Malmberg, A.; Maskell, P. Clusters and knowledge: Local buzz, global pipelines and the process of knowledge creation. Prog. Hum. Geogr. 2004, 28, 31-56. [CrossRef]

24. Henderson, J.; Dicken, P.; Hess, M.; Coe, N.M.; Yeung, H.W.C. Global production networks and the analysis of economic development. Rev. Int. Polit. Econ. 2002, 9, 436-464. [CrossRef]

25. Coe, N.M.; Hess, M.; Yeung, H.W.C.; Dicken, P.; Henderson, J. “Globalizing” regional development: A global production networks perspective. Trans. Inst. Br. Geogr. 2004, 29, 468-484. [CrossRef] 
26. Humphrey, J.; Schmitz, H. How does insertion in global value chains affect upgrading in industrial clusters? Reg. Stud. 2002, 36, 1017-1027. [CrossRef]

27. Yeung, H.W.C.; Coe, M.N. Toward a dynamic theory of global production networks. Econ. Geogr. 2015, 91, 29-58. [CrossRef]

28. Yeung, H.W.C. Regional development and the competitive dynamics of global production networks: An East Asian perspective. Reg. Stud. 2009, 43, 325-351. [CrossRef]

29. MacKinnon, D. Beyond strategic coupling: Reassessing the firm-region nexus in global production networks. J. Econ. Geogr. 2012, 12, 227-245. [CrossRef]

30. Gereffi, G.; Humphrey, J.; Sturgeon, T. The governance of global value chains. Rev. Int. Polit. Econ. 2005, 12, 78-104. [CrossRef]

31. Dicken, P.; Kelly, P.; Olds, K.; Yeung, H.W.C. Chains and networks, territories and scales: Towards an analytical framework for the global economy. Glob. Netw. 2001, 1, 89-112. [CrossRef]

32. Parrilli, M.D.; Nadvi, K.; Yeung, H.W.C. Local and regional development in global value chains, production networks and innovation networks: A comparative review and the challenges for future research. Eur. Plan. Stud. 2013, 21, 967-988. [CrossRef]

33. Guiliani, E. Role of technological gatekeepers in the growth of industrial clusters: Evidence from Chile. Reg. Stud. 2011, 45, 1329-1348. [CrossRef]

34. Wang, J. Derived cluster: The formation mechanism of industrial cluster in the west bank of Pearl River Delta. Manag. World 2005, 8, 80-86. (In Chinese)

35. Chang, P.Y. Optimizing Supply Chain Collaboration Based on Negotiation and Bargain Power for Single Retailer And Single Supplier. Lect. Notes Eng. Comput. Sci. 2013, 2, 1.

36. Wise, R.; Baumgartner, P. Go Downstream: The New Profit Imperative in Manufacturing. Harv. Bus. Rev. 1999, 77, 133-141.

37. Gooroochurn, N.; Hanley, A. A tale of two literatures: Transaction costs and property rights in innovation outsourcing. Res. Policy 2007, 36, 1483-1495. [CrossRef]

38. Danneels, E. The dynamics of product innovation and firm competences. Strateg. Manag. J. 2002, 12, 1095-1121. [CrossRef]

39. Volpe, L.; Biferali, D. Edith Tilton Penrose, the Theory of the Growth of the Firm. J. Manag. Gov. 2008, 12, 119-125. [CrossRef]

40. Bai, X.H. Economies of scope and economies of scale of specialized wholesale market: An empirical analysis of Yiwu. Financ. Trade Econ. 2004, 2, 55-59. (In Chinese)

41. Sheng, K.R.; Fan, J. Economies of scope and concentration of differentiated stores. Econ. Geogr. 2010, 30, 531-536.

42. Porter, M.E. Clusters and the new economics of competition. Harv. Bus. Rev. 1998, 76, 77-90. [PubMed]

43. Wei, J.F. Toward the effect of commerce clusters-Analysis based on informatics. Modern Econ. Sci. 2006, 28, 93-96. (In Chinese)

44. Rocha, H.O.; Sternberg, R. Entrepreneurship: The Role of Clusters Theoretical Perspectives and Empirical Evidence from Germany. Small Bus. Econ. 2005, 24, 267-292. [CrossRef]

45. Keeble, D.; Wilkinson, F. Collective Learning and Knowledge Development in the Evolution of Regional Clusters of High Technology Smes in Europe. Reg. Stud. 1999, 33, 295-303. [CrossRef]

46. Scott, A.J. Entrepreneurship, innovation and industrial development: Geography and the creative field revisited. Small Bus. Econ. 2006, 26, 1-24. [CrossRef]

47. Riordan, M.H.; Williamson, O.E. Asset Specificity and Economic Organization. Int. J. Ind. Organ. 1985, 3, 365-378. [CrossRef]

48. Delgado, M.; Porter, M.E.; Stern, S. Clusters and Entrepreneurship. J. Econ. Geogr. 2010, 10, 495-518. [CrossRef]

49. Farsani, J.J.; Bidmeshgipour, M.; Habibi, M.; Rashidi, M.M. Intellectual Capital and Organizational Learning Capability in Iranian Active Companies of Petrochemical Industry. Procedia Soc. Behav. Sci. 2012, 62, 1297-1302. [CrossRef]

50. Huggins, R.; Thompson, P. A Network-based view of regional growth. J. Econ. Geogr. 2014, 14, 511-545. [CrossRef]

51. Hansen, M.W.; Kuada, J. Transnational Corporations and Local Firms in Developing Countries: Linkages and Upgrading; Copenhagen Business School Press: Copenhagen, Danmark, 2006; p. 29. 
52. Humphrey, J.; Schmitz, H. Governance and Upgrading: Linking Industrial Cluster and Global Value Chain Research; IDS Working Paper 120; IDS: Brighton, UK, 2000.

53. Ernst, D. Global production networks, knowledge diffusion, and local capability formation. Res. Policy 2002, 31, 1417-1429. [CrossRef]

54. Singh, J. Distributed R \& D, Cross-Regional Knowledge Integration and Quality of Innovative Output. Res. Policy 2008, 37, 77-96.

55. Navas-Alemán, L. The impact of operating in multiple value chains for upgrading: The case of the Brazilian furniture and footwear industries. World Dev. 2011, 39, 1386-1397. [CrossRef]

56. Introduction to the Market. Available online: http://www.linyi.gov.cn/lysc/scjj.htm (accessed on 20 July 2014).

57. Chinese Toy Industry, from "Manufacturing" to "Create". Available online: http://news.xinhuanet.com/ world/2015-02/03/c_127450678.htm (accessed on 20 December 2015).

58. Toy Industry Need to Speed up Product Innovation. Available online: http://lib.cet.com.cn/paper/ szb_con/36957.html (accessed on 20 December 2015).

59. ChinaToyTrade.com Picked Out the Top Ten Toy Distribution Centers in China. Available online: http:/ /news.ctoy.com.cn/show-11697.html (accessed on 15 March 2015).

(C) 2016 by the authors. Licensee MDPI, Basel, Switzerland. This article is an open access article distributed under the terms and conditions of the Creative Commons Attribution (CC BY) license (http://creativecommons.org/licenses/by/4.0/). 
Article

\title{
Brownfield Redevelopment Evaluation Based on Fuzzy Real Options
}

\author{
Hongjun Dai ${ }^{1,2, *}$, Tao Sun ${ }^{1}$ and Wen Guo ${ }^{1}$ \\ 1 College of Economic and Management, Nanjing University of Aeronautics and Astronautics, \\ Nanjing 211106, China; suntao@nuaa.edu.cn (T.S.); xsyjgw@nuaa.edu.cn (W.G.) \\ 2 College of Economic and Management, Huainan Normal University, Huainan 232000, China \\ * Correspondence: dhj@hnnu.edu.cn; Tel./Fax: +86-554-686-2873 \\ Academic Editors: Seunghwan Myeong and Malin Song \\ Received: 31 October 2015; Accepted: 2 February 2016; Published: 16 February 2016
}

\begin{abstract}
There are a great amount of brownfield in Chinese mining cities. In order to promote mining cities sustainable development, it is necessary to redevelop brownfield. There is a great deal of uncertainty in the process of brownfield redevelopment owing to the influences of pollution. Normal fuzzy numbers were used to describe the fuzziness of the expected DCF (discounted cash flow) value of brownfield redevelopment projects. In view of experts' preferences, the weight of fuzzed estimation intervals of the expected DCF value was determined by means of the lattice closeness degree to find the volatility of the expected DCF value. Combining the results with the B-S (Black-Scholes) real option model, we built a fuzzy real option model which could be applied to the brownfield redevelopment projects. The empirical results showed that the valuation results of the fuzzy real option model, considering the experts' risk preferences, were relatively objective and accurate.
\end{abstract}

Keywords: mining city; sustainable development; brownfield redevelopment; fuzzy real option; normal fuzzy number

\section{Introduction}

In the last thirty years, China has achieved rapid economic growth. China's high-speed economic growth is largely dependent on massive energy consumption [1]. Excessive energy consumption causes serious environmental pollution in China. Environmental control has become a priority of government work. Some scholars have begun to study China's pollution problems from different angles, such as environmental performance evaluation and environmental policy [2,3]. This paper tries to study this from the angle of environmental project assessment.

Brownfield, the opposite word of "greenfield", generally refers to contaminated lands. Those wastelands not only occupy precious land resources, but also ruin the surrounding environment. Therefore, wasteland redevelopment can ease the land shortage crisis, create conditions for city transformation, and can also improve the ecological environment, ensuring inhabitants' physical and psychological health, and improve the quality of the city, which ensures the successful implementation of a sustainable development strategy, as well.

The concept of "brownfield" was coined in Western developed countries. Kivel (1993) [4], Niall (2001) [5], and Rosalind (2004) [6] give multiple definitions from different perspectives. Comprehensive Environmental Response, Compensation, and Liability Act, (also called CERCLA) defines "brownfield" as lands which are previously used for industrial purposes or some commercial uses and may be contaminated by low concentrations of hazardous waste or pollution [7]. Those contaminated lands, after remediation, still have considerable development value $[8,9]$. Therefore, Western developed countries attach great importance to the redevelopment of brownfield. The redevelopment of 
brownfield was mainly affected by two factors, namely, property rights and finance disputes related to the brownfield, and pollution treatment [10]. In addition, it is also affected by other factors, such as policies and funding [11,12]. There are a lot of achievements regarding value evaluation on brownfield redevelopment in Western countries. Among the commonly-used valuation methods are the market comparison method, the income capitalization approach, the cost approach method, and the hedonic pricing method. In 1967, Ridker and his coworkers, using the hedonic pricing method, conducted a quantitative analysis on influences of environment quality on the value of the real estate [13]. Rosen (1974) put forward a general method framework for the quantitative analysis [14]. Anish adopted a method combining the hedonic pricing method with GIS when evaluating the value of contaminated real estate in 2007 [15]. The market comparison approach was first applied to evaluate the contaminated land by Campanella in 1984 [16]. Based on land transaction data in southern California, Jackson made a contrastive analysis on brownfields and uncontaminated lands to get the value loss of pollution in 2001 [17]. Wilson studied the cost of brownfield pollution clean-up by means of the probability theory method in 1999 [18]. Mundy drew the conclusion that value loss of land pollution were more than the pollution clean-up cost [19]. Patchin did similar research in 1996 [20]. Bell held the idea that the cost of brownfield pollution clean-up was usually more than what was expected [21]. Richards believed that the influences of pollution on the value of brownfield should also include potential cost of the brownfield which would affect the cash flow in the future, and the negative influences of the stigma effect [22]. Syms came up with a valuation method applicable to the remediation and redevelopment of industrial estate [23]. In further studies, some foreign scholars evaluated the value of brownfield redevelopment using real option approach. Qian Wang and Keith W. Hipel thought there was a great deal of uncertainty and risk for the redevelopment of brownfield [24]. The real option method took the flexibility of the project into account, so it was much better than such traditional methods as the DCF (discounted cash flow) method, and can evaluate the value of brownfield redevelopment projects more accurately. Moreover, combining fuzzy mathematics with real option models, we set up a fuzzy real optional model for evaluating the brownfield redevelopment project. Qian Wang, Hipel [25], Qian Wang, and D. Marc Kilgour improved fuzzy real optional models from different perspectives [26].

In China, the public have not recognized the seriousness of the brownfield problem, and there are few practical and academic research results on brownfield redevelopment. At present, published literature about the valuation of brownfield redevelopment are as follows. Yi Dong et al. summarized the previous research results, discussed and defined key concepts, and emphatically investigated amendments for the traditional valuation methods [27]. Zhang Lin made a contrastive analysis on four popular valuation methods abroad, discussed some representative brownfield redevelopment cases, and then put forward a list of inspiration points for Chinese brownfield redevelopment from four aspects [28]. Yao Shangli described the expected DCF value of the real option model by means of triangular fuzzy numbers, conducted empirical research on a brownfield redevelopment case, and contrasted results with those gotten from the traditional DCF method. The empirical results show that the fuzzy real option method has superiority over other methods for those uncertain investment projects like brownfield redevelopment [29].

To sum up, the brownfield redevelopment project, influenced by pollution factors, is more complicated than general land consolidation projects. At present, the public pay much attention to environmental factors, resulting in high risk and uncertainty for brownfield redevelopment. The brownfield redevelopment can improve the ecological environment and ensure inhabitants' physical and psychological health. There are not only economic benefits, but also social benefits in brownfield redevelopment. This article mainly improves the evaluation methods of economic benefits. Thus, we do not take into account the social benefits of the brownfield redevelopment project in this paper.

The traditional DCF method can generally reflect the static value of the project investment, but cannot reflect the growth opportunity of enterprise investment. Thus, it is likely to lead to underestimate the value of brownfield redevelopment project. There is a two-dimensional (immediately investment and give up the investment) choice in the DCF method. The real option approach considers 
the impact of investment uncertainty. Thus, it is three-dimensional (immediately investment, postpone investment and give up the investment), and it considers the impact of managerial flexibility on project value. Fuzzy decision theory is not based on data (information), but in a data (information) range. Thus, we apply a fuzzy real option model on redevelopment projects.

\section{Application Analysis of Fuzzy Real Option on Redevelopment Projects}

\subsection{Real Option}

The real option theory derives from financial option theories. Option refers to a right of choice, which means the person holding the option can, but is not obliged to, buy assets from the seller according to the predetermined price and amount. Of course, this kind of right comes with a price. As early as 1973, American scholars Black and Scholes set up an option pricing model called Black-Scholes (B-S option model for abbreviation), which was suitable for the call option without dividend-paying stocks. The B-S option model has been honored as the cornerstone of modern finance option pricing theories [30]. It can be read from the B-S option model that prices of underlying stocks, exercise prices, expiration date, return rate and volatility of the underlying stocks, and risk-free interest are the main factors influencing the option price. In 1977, American scholar Stewart Myers [31] proposed a real option theory, in which a project investment opportunity was taken as another kind of option and included in the total value of the project; this kind of option was evaluated in accordance with pricing methods for financial options. Generally speaking, according to specific situations of each investment project, real options can be divided into many groups, such as an option to defer, option to contract, option to expand, option to growth, option to switch, and option to abandon.

\subsection{Fuzzy Real Option}

Although the real option approach takes into account the value of investment opportunities, it also has a disadvantage. The parameters in the model, such as the present value of future cash flows, are assumed to be a fixed value. In fact, it is difficult to make accurate estimates of these parameters. We can only estimate a range of these parameters. Fuzzy numbers can be expressed in a range. The emergence of the fuzzy theory provides a new train of thought for solving real option pricing problems. Therefore, some scholars apply fuzzy mathematics theories to the process of real option pricing. Carlsson and Fuller are forerunners who improved the B-S pricing model by means of fuzzy mathematics theory [32]. In 2003, Carlsson and Fuller set up a real option pricing model for the fuzzy environment. Most of later scholars, along this way of thinking, improved fuzzy real option pricing models and their applications [33-35].

\subsection{Real Option Characteristics of Brownfield Redevelopment Projects}

\subsubsection{Uncertainty}

Brownfield redevelopment is, typically, complex system engineering. It involves environmental systems, social systems, and their subsystems. There is a nonlinear relationship between them. Thus, there are many problems in it, such as uncertainty of development costs, limitations of knowledge and technology, as well as potentially high debt.

\subsubsection{Irreversibility}

Brownfield redevelopment are capital-intensive projects. According to international experience, large sums of money need to be invested in it. At least some of the money is not reversible. This part of the investment are called sunk costs. Land leasing and soil remediation costs are not reversible when the investor wants to change the development strategy. 


\subsubsection{Flexibility}

The flexibility mainly refers to the flexibility of management. The manager can adjust the investment plan of the project according to the investment environment. For example, the manager can delay, reduce, or even abandon the project, to reduce the loss when the external environment is not conducive to investors.

The real option method is more suitable for the evaluation of the brownfield redevelopment project compared with the traditional DCF method. To sum up, the real option in this brownfield redevelopment project involves the option to wait, option to abandon, option to switch, and so on.

\subsection{Applicability of Fuzzy Real Option in Brownfield Redevelopment Projects}

The parameters in the real option pricing model are fixed values, such as the present value of future cash flows and investment costs. However, the present value of future cash flows and investment costs in the brownfield redevelopment project can only estimate the general scope because of pollution factors. In view of this situation, these parameters are represented by fuzzy numbers. Thus, the fuzzy real option is a model which is very appropriate for the evaluation of brownfield redevelopment projects.

This paper describes the expected DCF value in a real option model by means of the normal fuzzy numbers, gets the volatility of the DCF value, combines with the B-S real option model, develops a fuzzy real option model, and finally applies the model to an industrial wasteland redevelopment project in Huainan City, China. There are two reasons for the usage of normal fuzzy numbers: one is that normal fuzzy numbers can reflect the fuzziness of the expected DCF value in brownfield redevelopment projects, and its cut-sets embody experts' risk preferences; the other one is that it is more suitable for assumed conditions of the Black-Scholes option [29].

\section{A Fuzzy Real Option Model}

\subsection{Basic Real Option Model}

Pricing methods for a real option is patterned after methods for the financial option. Making comparisons of parameters of real options and financial options can get a real option pricing model. The B-S option model is the most commonly used pricing model currently:

$$
C=V N\left(d_{1}\right)-X e^{-r T} N\left(d_{2}\right) .
$$

where, $d_{1}=\frac{\ln (V / X)+\left(r+\frac{\sigma^{2}}{2}\right)}{\sigma \sqrt{T}}, d_{2}=d_{1}-\sigma \sqrt{T}, C$ represent the values of project choice ROV (Real Options Value) $V$ represents the expected DCF value, $X$ represents expected investments or the cost of the project, $T$ represents the maximum deferred time, $r$ represents the risk-free interest, $\sigma$ represents the volatility of the expected DCF value, and $N(*)$ is a probability distribution function with standard normal distribution.

When applying B-S real option pricing models to mining brownfield redevelopment projects, we often find that it is difficult to evaluate the expected DCF value $V$ and its volatility $\sigma$. This paper describes the expected DCF value $V$ by means of normal fuzzy numbers and evaluates its volatility $\sigma$.

\subsection{Valuation of the Expected DCF Value}

\subsubsection{Fuzzy Process of Experts' Opinions}

First of all, an expert panel provides analysis on a project and each expert gives an estimation interval for the expected value of DCF independently: 


$$
V^{K}=\left[V^{K_{1}}, V^{K_{2}}\right], k=1,2, \ldots, n,
$$

where $V^{K}$ is regarded as a $\alpha$ level set of a certain normal fuzzy number. Herein, the value range of $\alpha$ is $(0,1]$. If conservative experts are more prudent about the valuation, then the value of $\alpha$ will be relatively large, and generally larger than 0.5 . On the contrary, aggressive experts are more optimistic about the expected value, so the value of $\alpha$ will be relatively small, and generally smaller than 0.5 . In this way, the value of $\alpha$ can reflects the experts' risk preferences.

Next, subordinating degree functions within each expert's valuation intervals are found according to the $\alpha$ level cut-set formula for normal fuzzy numbers:

$$
\mu_{V^{k}}=e^{-\left|\frac{x-\alpha_{k}}{\sigma_{k}}\right|}, k=1,2, \ldots, n
$$

Hence, normal fuzzy numbers can be gotten after fuzzification of each expert's valuation intervals.

$$
\begin{gathered}
V^{k}=\left[V^{k_{1}}, V^{k_{2}}\right]=\left[a_{k}-\sigma_{k} \sqrt{-\ln \alpha}, \mathrm{a}_{k}+\sigma_{k} \sqrt{-\ln \alpha}\right], \\
a_{k}=\frac{V_{1}^{k_{1}}+V_{2}^{k_{2}}}{2}, \sigma_{k}=\frac{V_{2}^{k_{2}}-V_{1}^{k_{1}}}{2 \sqrt{\ln \alpha}}, k=1,2, \ldots, n .
\end{gathered}
$$

\subsubsection{Weight Determination for Experts' Opinions}

In order to minimize the negative influences from individuality deviation of experts, each expert's opinion should be weighted appropriately in the first place. The basic principle is that estimation intervals recognized by most experts are given higher weight. Firstly, the closeness degree of normal fuzzy sets given by two experts is figured out in accordance with the closeness degree formula for fuzzy numbers. If estimation intervals given by the expert $i$ and the expert $j$ are converted to two normal fuzzy numbers $\bar{V}^{i}$ and $\bar{V}^{j}$, then their subordinating degree is $\mu_{V^{i}}=e^{-\left|\frac{x-a_{i}}{\sigma_{i}}\right|}$ and $\mu_{V^{j}}=e^{-\left|\frac{x-a_{j}}{\sigma_{j}}\right|}$ respectively, and the closeness of their fuzzy sets can be shown in Figure 1.

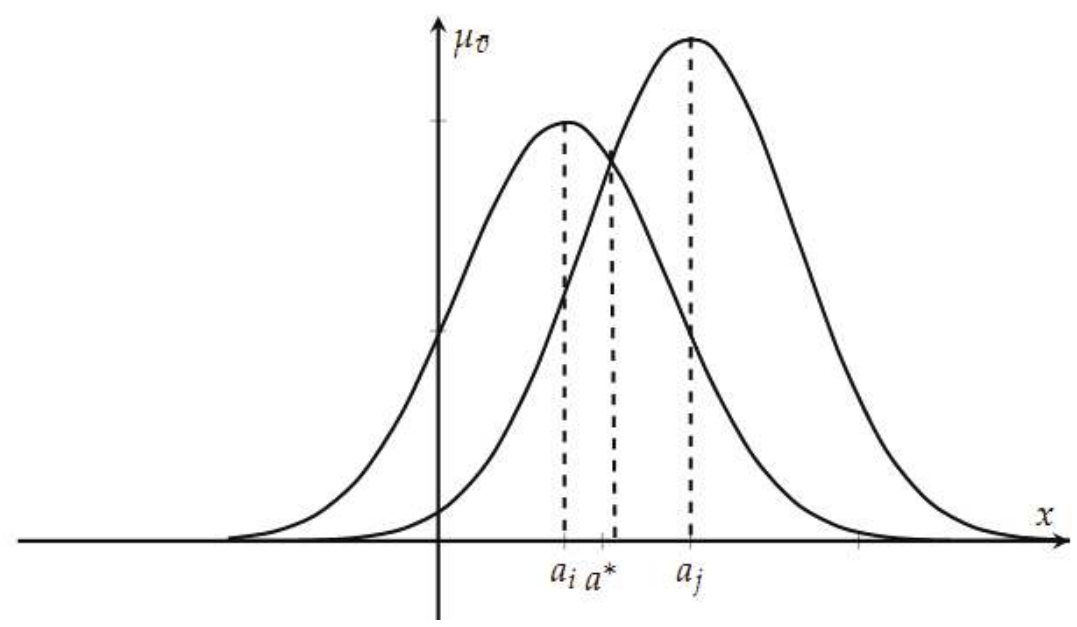

Figure 1. Schematic of the fuzzy closeness degree. 
Its corresponding computational formula is as follows:

$$
N_{L}\left(\bar{V}^{i}, \bar{V}^{j}\right)=\left(\bar{V}^{i} \oplus \bar{V}^{j}\right) \wedge\left(1-\bar{V}^{i} \oplus \bar{V}^{j}\right)=\bar{V}^{i} \oplus \bar{V}^{j}=e^{-\left|\frac{a_{j}-a_{i}{ }^{2}}{\sigma_{i}+\sigma_{j}}\right|^{2}}
$$

Then, a decision relation matrix is formulated on the basis of the results from pairwise comparisons of the closeness degree:

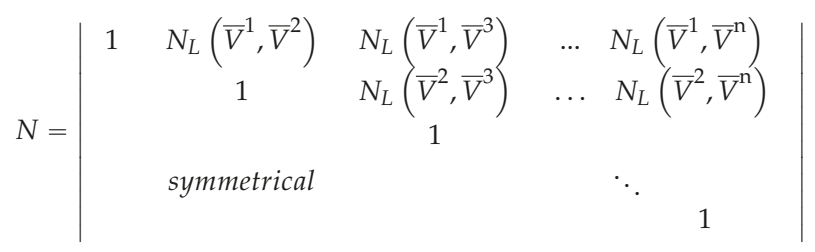

Given $N_{L}^{i}$ expresses the closeness degree of expert $i$ and other experts:

$$
N_{L}^{i}=\sum_{j=1, j \neq i}^{n} N_{L}\left(\bar{V}^{i}, \bar{V}^{j}\right), i=1,2, \ldots, \mathrm{K}
$$

The smaller the value of $N_{L^{\prime}}^{i}$, the fewer differences between the expert $i$ and other experts are. Thus, experts' weights can be gotten from the following formula:

$$
W_{i}=\frac{N_{L}^{i}}{\sum_{j=1}^{n} N_{L}^{j}}, i=1,2, \ldots, \mathrm{K}
$$

\subsubsection{Determination of the Expected Value of DCF}

In the previous parts, it is known how the estimation intervals given by experts have been fuzzed, and the results can be regarded as different $\alpha$ level cut-sets of normal fuzzy numbers.

$$
\bar{V}_{\alpha}^{k}=\left[\bar{V}_{1}^{k}, \bar{V}_{2}^{k}\right], k=1,2, \ldots, n .
$$

According to the weight of experts' opinions discussed in previous parts of this paper, multiple experts' opinions can be divided into different sets with various confidence coefficients $\alpha$, and the estimation interval of expected value of DCF $S$ will be obtained. In line with the extension principle of fuzzy sets, it can be found that $\bar{V}_{\alpha}$ is still an $\alpha$ level cut-set of fuzzy numbers.

$$
\begin{gathered}
\bar{V}_{\alpha}=\sum_{i=1}^{n} W_{k} \times \bar{V}_{\alpha}^{k} \\
\bar{V}_{\alpha}=\left[\sum_{k=1}^{n} W_{i} \times \bar{V}_{1}^{i}, \sum_{i=1}^{n} W_{i} \times \bar{V}_{2}^{i}\right]=\left[\bar{V}_{1}, \bar{V}_{2}\right]
\end{gathered}
$$

\subsection{Estimation of Volatility $\sigma$ of the Expected DCF Value}

Generally speaking, valuation for parameters volatility $\sigma$ in real option models are mainly rely on logarithmic income method, assets price fluctuation method, GARCH method, decision-making level approximation method, and so on. This paper adopts the assets price fluctuation method. It can be 
known from the previous parts that the expected DCF value is still a normal fuzzy number, and the corresponding subordinating function of its $\alpha$ level cut set $\bar{V}_{\alpha}$ is as follows:

$$
\mu_{\bar{V}_{\alpha}}=e^{-\left|\frac{x-a}{\sigma /}\right| 2}, \text { where } a=\frac{\bar{V}_{1}+\bar{V}_{2}}{2}, \sigma^{\prime}=\frac{\bar{V}_{2}-\bar{V}_{1}}{2 \sqrt{-\ln \alpha}} .
$$

The volatility is obtained:

$$
\sigma=\frac{\sigma^{\prime}}{a}=\frac{\bar{V}_{2}-\bar{V}_{1}}{\left(\bar{V}_{1}+\bar{V}_{2}\right) \sqrt{-\ln \alpha}} .
$$

\subsection{A Fuzzy Real Option Model in Consideration of Experts' Preferences}

Combing with the expected DCF value $V$, its volatility $\sigma$, and the previously mentioned real option pricing model from Equation (1), we can get a fuzzy real option model based on normal fuzzy numbers as follows:

$$
\begin{aligned}
& \qquad \tilde{C}=\bar{V} N\left(d_{1}\right)-X e^{-r T} N\left(d_{2}\right) . \\
& \text { Wherein, } d_{1}=\frac{\ln (a / X)+\left(r+\frac{\sigma^{2}}{2}\right) T}{\sigma \sqrt{T}} ; d_{2}=d_{1}-\sigma \sqrt{T} .
\end{aligned}
$$

The real option value gotten is still an $\alpha$ level cut-set of normal fuzzy numbers. In accordance with Equation (12), its expected value can be obtained as follows:

$$
E(\widetilde{C})=\frac{\widetilde{C}_{1}+\widetilde{C}_{2}}{2}
$$

\section{Case Study Results and Analysis}

\subsection{Case Introduction}

The case is a subproject of a redevelopment project for a mining subsidence area in a mining industrial city. The area, covering an area of 40 square hectometers, was an abandoned land of a small-scale coal mine. This moderately-polluted area is five kilometers away from downtown, and has few geographic advantages. The risk-free interest $r$ is designated as 5\%. After argumentation of the expert panel, the initial investment of this project is expected as 432,000 Yuan (RMB). The expected DCF value was given by five members of the expert panel, and their estimation intervals are as follows (Table 1):

Table 1. Estimation intervals of expected DCF value by five experts.

\begin{tabular}{cccccc}
\hline $\boldsymbol{V}$ & Exert 1 & Expert 2 & Expert 3 & Expert 4 & Expert 5 \\
\hline$V_{1}^{k}$ & 376,000 & 355,000 & 400,000 & 368,000 & 400,000 \\
$V_{2}^{k}$ & 398,332 & 445,000 & 440,000 & 456,000 & 500,000 \\
\hline
\end{tabular}

\subsection{Identification of the Real Option in the Case}

Mining wasteland redevelopment projects differ from common land development projects owing to the fact that the mining wasteland redevelopment projects could be deferred, abandoned, changed before their pollution factors are eliminated completely, or the redevelopment has not met the national development criteria. Moreover, according to Decree No. 20 issued by Ministry of Land and Resources in June, 2012, the maximum term for land development is two years, which means the mining wasteland redevelopment projects have a two-year elimination period or waiting period. To sum up, the real option in this project involves an option to wait, option to abandon, option to switch, and so on. This paper only discusses an option to wait or waiting option for simplification. 


\subsection{Empirical Results}

First of all, estimation intervals given by the expert panel were regarded as an $\alpha$ level cut-set of a normal fuzzy number. For the sake of simple calculation, given that each expert's risk preference is neutral and $\alpha$ is $0.5, a_{k}$ and $\sigma_{k}$ of the subordinating function can be found by means of Equation (5) as follows (Table 2):

Table 2. Parameter values.

\begin{tabular}{cccccc}
\hline Parameter & Expert 1 & Expert 2 & Expert 3 & Expert 4 & Expert 5 \\
\hline$a_{k}$ & 387,166 & 400,000 & 420,000 & 412,000 & 450,000 \\
$\sigma_{k}$ & 13,412 & 54,051 & 24,022 & 52,849 & 60,056 \\
\hline
\end{tabular}

The closeness degree of fuzzy sets was found by means of Equation (6), in accordance with parameters $a_{k}$ and $\sigma_{k}(k=1,2, \ldots, \mathrm{n})$. For instance, $N_{L}\left(\bar{V}^{1}, \bar{V}^{2}\right)=N_{L}\left(\bar{V}^{2}, \bar{V}^{1}\right)=e^{-\left|\frac{a_{2}-a_{1}}{\sigma_{1}+\sigma_{2}}\right|^{2}}=$ 0.964457. On this basis, a strategy correlation matrix was constructed and the weight of experts' estimated information was determined in line with Equations (8) and (9).

$$
W_{1}=0.167551, W_{2}=0.223994, W_{3}=0.197200, W_{4}=0.225492, W_{5}=0.185763
$$

Given the confidence level $\alpha$ is 0.5 , through Equations (11) and (12), the fuzzy estimation intervals of the expected DCF value were found as follows:

$$
\bar{V}_{0.5}=\left[\sum_{k=1}^{5} W_{i} \times \bar{V}_{1}^{i}, \sum_{i=1}^{5} W_{i} \times \bar{V}_{2}^{i}\right]=\left[\bar{V}_{1}, \bar{V}_{2}\right]=[378683,448892]
$$

Two parameters of the subordinate function are $a=\frac{\bar{V}_{1}+\bar{V}_{2}}{2}=413788, \sigma^{\prime}=\frac{\bar{V}_{2}-\bar{V}_{1}}{2 \sqrt{-\ln \alpha}}=42165$ respectively. The volatility of the expected DCF value is obtained by Equation (14), $\sigma=\frac{\sigma^{\prime}}{a}=\frac{42165}{413788} \approx$ 0.1019 .

Given the risk-free interest $r$ is $5 \%$, maximum tardiness $T$ is two years, the estimation intervals of the waiting option are $\widetilde{C}=[10616,49549]$, and its expected value is $E(\widetilde{C})=30078$.

\subsection{Results Analysis}

As the expected investment is 432,000 Yuan, and the expected DCF value is 413,788 Yuan, the net present value is $E(N P V)=-182120$, which means this project is infeasible and should be given up.

If the waiting option is considered, the investment value of this project is $V=E(N P V)+$ $E(\tilde{C})=11866$, which is far greater than 0 , then this project is feasible and should not be given up. Rather than implement the project immediately, it is better to execute its waiting option two years later. It can be read from the empirical results that the fuzzy real option method takes project management flexibility and uncertainty into consideration, which is helpful to accurately evaluate the investment value.

\section{Conclusions and Prospects}

Pollution factors make mining brownfield redevelopment projects full of risks and uncertainty. Such traditional value evaluation methods as the net present value method do not consider the project flexibility and uncertainty for mining brownfield redevelopment, which will underestimate the projects' investment value. This paper built a real option model based on normal fuzzy numbers. The empirical results show that the application of normal fuzzy numbers not only reflects fuzziness 
of the expected DCF value of mining brownfield redevelopment projects, but also considers experts' risk preferences, which makes valuation results more objective and accurate. An objective weighting approach based on the lattice closeness degree minimizes deviation of experts' individuality. The application of real options takes account of investment project's flexibility, which making the valuation results more accurate.

This paper only discusses the waiting option implying in mining brownfield redevelopment projects, filtering other options, such as option to contract or option to switch. Therefore, defining those options, their correlation, and their influences on mining brownfield redevelopment projects are subject to the further study.

Acknowledgments: Acknowledgments: This study was supported in part by: the Ministry of Education Foundation for Humanities and Social Science (No. 11YJA790133), the Jiangsu Province Foundation for Philosophy and Social Sciences (No. 12EYA001), the Bidding Project of the Research Center for Resource-based Cities' Development of Huainan Normal University (No. SK2014A099), the Program for Innovative Research Team in Huainan Normal University, the CNAC Foundation for Generalized Virtual Economics (No. GX2012-1023(Y)), Jiangsu Province Foundation for the Innovation Cultivation of graduate students (CXLX12_0178)

Author Contributions: Author Contributions: All of the authors made contributions to the work in this paper Tao Sun and Hongjun Dai designed the research. Hongjun Dai contributed to model development, data collection. Wen Guo analyzed the data. Tao Sun provided guidance for writing this paper. Hongjun Dai wrote the paper. All authors have read and approved the final manuscript. We would like to acknowledge the reviewers for the comments that enhanced the quality of the manuscript.

Conflicts of Interest: Conflicts of Interest: The authors declare no conflict of interest.

\section{References}

1. Song, M.; Wang, S.; Yu, H.; Yang, L.; Wu, J. To reduce energy consumption and to maintain rapid economic growth: Analysis of the condition in China based on expended IPAT model. Renew. Sustain. Energy Rev. 2011, 15, 5129-5134. [CrossRef]

2. Zhang, N.; Kong, F.; Choi, Y.; Zhou, P. The effect of size-control policy on unified energy and carbon efficiency for Chinese fossil fuel power plants. Energy Policy 2014, 70, 193-200. [CrossRef]

3. Choi, Y.; Zhang, N.; Zhou, P. Efficiency and abatement costs of energy-related $\mathrm{CO}_{2}$ emissions in China: A slacks-based efficiency measure. Appl. Energy 2012, 98, 198-208. [CrossRef]

4. Kivel, P. Land and the City: Patterns and Processes of Urban Change; Routledge: London, UK, 1993.

5. Niall, G.K. Production Site: The Thinking of Post-Industrial Landscape; E\&F SPonp Press: London, UK, 2001.

6. Rosalind, G.; Yesim, S.E. Recycling the City-The Use and Reuse of Urban and the Land; Lincoln Institute of Land Policy: Cambridge, MA, USA, 2004.

7. David, B.F. Brownfield Redevelopment Initiatives: Federal and Selected State Programs. Aliaba Course Study 2007, 10, 18-19.

8. Hugehes, A.; Mark, A. Dirt into Dollars: Converting Vacant Land Into Valuable Development. Available online: http://www.brookings.edu/research/articles/2000/06/summer-metropolitanpolicy-hughes (accessed on 3 February 2016).

9. Rutherford, H.P; Rowan, R. The Metropolitan Portland Urban Natural Resource Program in the Ecological City; University of Massachusetts Press: Amherst, MA, USA, 1994; pp. 251-267.

10. Cao, K.; Jin, T. A Discussion on Brownfield Redevelopment Strategies in Western Countries and Its Inspiration to China. China Popul. Resour. Environ. 2007, 17, 124-129.

11. Tang, Y.-T.; Nathanail, C.P. Sticks and Stones: The Impact of the Definitions of Brownfield in Policies on Socio-Economic Sustainability. Sustainability 2012, 4, 840-862. [CrossRef]

12. BenDor, T.K.; Metcalf, S.S.; Paich, M. The Dynamics of Brownfield Redevelopment. Sustainability 2011, 3, 914-936. [CrossRef]

13. Ridker, G.R.; Henning, J.A. The determinants of residential property values with special reference to air pollution. Rev. Econ. Stat. 1967, 49, 246-257. [CrossRef]

14. Rosen, S. Hedonic prices and implicit markets: Product differentiation in pure competition. J. Polit. Econ. 1974, 82, 34-55. [CrossRef] 
15. Anish, N.; Kent, G. Urban Property Values and Contaminated Sites: A Hedonic Analysis of Scdney, Nova Scotia. J. Environ. Manag. 2008, 88, 1212-1220.

16. Campanella, J. Valuing partial losses in contamination cases. Apprais. J. 1984, 52, 301-304.

17. Jackson, T.O. The Effects of Previous Environmental Contamination on Industrial Real Estate Prices. Apprais. J. 2001, 69, 200-210.

18. Kinnard, W.N.; Worzala, E.M. How North American appraisers value contaminated property and associated stigma. Apprais. J. 1999, 67, 269-279.

19. Mundy, B. The Impact of Hazardous Materials on Property Value. Available online: http:/ / onlineed.appraisalinstitute.org/ai/OnlineEd/Resources/ol667/bibliography/w18_ hazardousmaterials.pdf (accessed on 3 February 2016).

20. Patchin, P.J. Contaminated properties and the sales comparison approach. Apprais. J. 1994, 62, 402-409.

21. Jacilson, T.O. The effects of environmental contamination on real estate: A literature review. J. Real Estate Lit. 2001, 9, 93-116.

22. Richards, T. Valuing contaminated land and property: Theory and practice. J. Propert. Valuat. Invest. 1996, 14, 6-17. [CrossRef]

23. Syms, P.M. Contaminated Land: The Practice and Economics of Redevelopment; Blackwell Scince: London, UK, 1997; pp. 30-31.

24. Wang, Q.; Keith, W.H. Fuzzy real options in brownfield redevelopment evaluation. J. Appl. Math. Decis. Sci. 2009, 2009, 1-16. [CrossRef]

25. Wang, Q.; Keith, W.H. A numerical method of evaluation brownfields using fuzzy boundaries and fuzzy real options. Syst. Man Cybern. 2010. [CrossRef]

26. Wang, Q.; Kilgour, D.M. Fuzzy real options for risky project evaluation using least squares Monte-Carlo simulation. IEEE Syst. J. 2011, 5, 385-395. [CrossRef]

27. Ai, D.; Zhu, T.; Yue, X. Discussion on Valuing Contaminated Land. Ecol. Environ. Sci. 2010, 5, $1253-1260$.

28. Zhang, L.; Li, Y.; Li, J. Summary and Review of Foreign Methods and Practice for Brownfield Valuation. China Popul. Res. Environ. 2012, 4, 131-136.

29. Yao, S. Fuzzy Real Option Valuation in a Brownfield Redevelopment Project. Master's Thesis, Hefei University of Technology, Hefei, China, 2013.

30. Fischer, B.; Myron, S. Scholes, The pricing of options and corporate liabilities. J. Polit. Econ. 1973, 81, 635-654.

31. Myers, S.C. Determinants of corporate borrowing. J. Financ. Econ. 1977, 5, 147-175. [CrossRef]

32. Carlssona, C.; Fullera, R. On Fuzzy Real Option Valuation. Available online: http://uni-obuda.hu/users/ fuller.robert/TR367.pdf (accessed on 3 Ferurary 2016).

33. Carlssona, C.; Fullera, R. A fuzzy approach to real option valuation. Fuzzy Set. Syst. 2003, 139, $297-312$. [CrossRef]

34. Wang, J.; Hwang, W.L. A fuzzy set approach for R\&D portfolio selection using a real options valuation model. Omega 2007, 35, 247-257.

35. Lee, C.; Tzeng, G.; Wang, S. A fuzzy set approach for generalized crr model: An empirical analysis of S\&P 500 index options. Rev. Quant. Financ. Account. 2005, 25, 255-275.

(C) 2016 by the authors. Licensee MDPI, Basel, Switzerland. This article is an open access article distributed under the terms and conditions of the Creative Commons Attribution (CC BY) license (http:/ / creativecommons.org/licenses/by/4.0/). 
Article

\title{
Does Foreign Direct Investment Affect Green Growth? Evidence from China's Experience
}

\author{
Shujing Yue *, Yang Yang and Yaoyu Hu \\ School of Economics \& Management, Southeast University, 2 Si Pai Lou, Nanjing 210000, China; \\ 220151825@seu.edu.cn (Y.Y.); 220131729@seu.edu.cn (Y.H.) \\ * Correspondence: yueshujing@seu.edu.cn or yue_shujing@126.com; Tel.: +86-25-5209-0700; \\ Fax: +86-25-5209-0702
}

Academic Editors: Yongrok Choi, Malin Song and Seunghwan Myeong Received: 29 October 2015; Accepted: 2 February 2016; Published: 16 February 2016

\begin{abstract}
Foreign Direct Investment (FDI) not only affects the economic growth but also affects the environmental protection of the host country. With China's background of pursuing green growth, we need to consider the performance of FDI from the economic and environmental benefit aspects. On this basis, using slacks-based measure directional distance function (SBMDDF) to build up green growth efficiency, economic efficiency and environmental efficiency indexes, empirical research on FDI in 104 Chinese cities from 2004 to 2011 has shown that: (1) Different cities have differences in their green growth efficiency. Shenzhen city is always efficient in green economic growth. (2) Overall, FDI is positive on Chinese cities' green growth. (3) When the green growth efficiency is broken down into economic efficiency and environmental efficiency, FDI promotes China's economic green growth through both environmental benefits and economic benefits. (4) The effect of FDI differs in different sectors. FDI in the emission-intensive sector promotes green efficiency mainly through the improvement of economic efficiency. FDI in the non-emission-intensive sector promotes economic efficiency, environmental efficiency and green efficiency.
\end{abstract}

Keywords: green efficiency; FDI; economic growth; environmental pollution; China

\section{Introduction}

In the past 30 years, China has maintained a sustained and stable economic growth. The rapid growth of China's economy has benefitted from the promotion of many factors, and Foreign Direct Investment (FDI) is one of them. Since the early 1990s China has seen large inflows of FDI and has become one of the biggest recipients of FDI among the developing countries. According to the China City Statistical Yearbook, in 2014, the amount of FDI that China introduced has reached 11.9562 trillion dollars, which is 34 times that of the amount 1990.

With rapid economic growth, the inefficient use of resources, increasing environmental pollution, as well as the large range and frequent appearance of smog and thick haze in recent years have prompted the Chinese government to transfer from the original model of economic growth, which involves high pollution, high energy consumption and high emissions, to a low pollution, low energy consumption and low emissions economic growth model. These requirements may have negative impacts on the current economic growth. Therefore, China's economy is facing the following question: "Economic growth first, or environmental protection first?"

Considering that China is in the developing stage, on the one hand, it needs continued economic growth because most of the problems which are currently faced by China rely on economic growth to be solved. On the other hand, China also needs a suitable and sustainable ecological environment because large forests, clear streams, and clean air are not only ecological barriers of economic growth, but also the basis of China's sustainable economic development. Therefore, taking into account both 
economic growth and environmental protection, which is also called "green growth", it has become China's actual choice.

FDI can not only have an impact on the economic growth of the host country, but can also exert an influence on the environment of the host country. Thus, FDI would have an impact on green growth concerning both economic growth and environmental pollution. From the background of green growth, when evaluating the impact of FDI on China's economy, we should not just evaluate the impact of FDI on traditional economic growth, but also consider the impact of FDI on energy consumption and environmental pollution.

The impact of FDI on China's green growth will directly influence the adjustment of China's FDI policy. If FDI is negative for China's green growth, the Chinese government should not continue to give more incentives and preferential policies to foreign investment, but should focus on improving the efficiency of domestic capital use. If FDI is positive for China's green growth, the Chinese government should continue to introduce and attract foreign investments through fiscal and financial instruments. Furthermore, behind the influence of FDI on China's green growth, if we can judge the main effects of FDI, whether on economic growth or on environmental pollution, and we can implement targeted policies, making best use of the advantages and bypassing the disadvantages, absorbing the positive spillover effects of FDI and reducing its negative effects.

Most literature explores the economic impacts of FDI and the environmental impacts of FDI on the host country, respectively. However, literature research on the impact of FDI on the host country's economy and environment in comprehensive ways is scarce. This paper takes 104 cities in China as research objectives, builds a comprehensive index reflecting the economic and environmental effects of FDI, and explores the economic effects and environmental effects of FDI on the host country, respectively. This paper will make three main contributions to the studies on China's green growth. First, this paper analyzes the green growth of China at the city level by using an SBM-DDF (slacks-based measure directional distance function) model. Second, through breaking down the green growth efficiency into economic efficiency and environmental efficiency, this paper explores the effects of FDI on green growth, economic growth and environmental pollution, respectively. Third, this paper proposes effective countermeasures to improve the effect of FDI on China's green economic growth.

The remainder of this paper is organized as follows: Section 2 briefly reviews the previous studies. Section 3 calculates the green efficiency of Chinese cities. Section 4 establishes the econometric model and presents the empirical findings. Section 5 concludes with some policy suggestions.

\section{Literature Overview}

Different from the present research which studies the impact of FDI on the host country's economy and environment separately, our paper focuses on the comprehensive impact of FDI to the host country's economic growth and environmental protection under a unified framework. Our paper is particularly related to two strands of literature.

The first strand focuses on the relationship between FDI and economic growth. As for FDI and economic growth, empirical studies provide a blurred picture of this relationship with some studies reporting positive effects and others reporting negative effects of FDI on economic growth. On the one hand, FDI has the following three important effects on the growth of the host country: providing a source of external capital, creating new job opportunities, and easing the transfer of technology and managerial skills [1,2]. Performing both cross-section and panel data analysis on a dataset covering 90 countries, Johnson [3] finds indications that FDI enhances economic growth in developing economies but not in developed economics. As for China, Cheung and Lin [4] found positive effects of FDI on the number of domestic patent applications in China, using provincial data from 1995 to 2000. Yao [5] focused on the effect of FDI on economic performance, using a panel data set encompassing 28 Chinese provinces over the period 1978-2000. The results of this study showed that FDI had a strong and positive effect on economic growth. Tang et al. [6] investigated the causal link between FDI and economic growth in China for the period of 1988-2003 using a multivariate 
Vector Auto-regression (VAR) system, and found single-directional causality from FDI to GDP in China. Hong [7] employed Generalized Method of Moments (GMM) to evaluate the effect of FDI on economic growth in China, and found that FDI exerted a positive impact on the economic growth during the period of 1994-2010.

On the other hand, FDI may have negative effects on economic growth by crowding out domestic investment, increasing external vulnerability, and causing dependence [8,9]. Carkovic and Levine [10] used a panel dataset covering 72 developed and developing countries and concluded that there is no robust link running from inward FDI to the host country's economic growth. Herzer et al. [11] challenged the belief that FDI has a positive impact on economic growth in developing countries. This paper used co-integration techniques for 28 countries and suggested that there is no causal relation between the FDI and GDP growth rate. Yalta [12] investigated the causal relationship between foreign direct investment and gross domestic product in China for the 1982-2008 period, and showed that a statistically significant relationship between FDI and GDP growth did not exist. Lian and Ma [13] also found that FDI did not lead to economic growth in the western region of China using time-series data from 1986 to 2010.

The second strand of research is concerned with the nexus between environmental degradation and FDI inflows. This issue has received much less attention from academic researchers compared with the extensive literature investigating the relationship between economic growth and FDI inflows. Economic theory is ambiguous concerning whether FDI is positive or negative to environmental pollution, because there are two different possible outcomes associated with FDI inflows.

One possibility is that countries experiencing increased FDI inflows obtain low environmental efficiency as the foreign investors choose the low-regulation countries and the scale of heavy industrial production increases. This is a pollution haven effect [14]. Xing and Kolstad [15] explore how the laxity of environmental regulations in a host country attracts FDIs and influences the location of heavily polluting industries, and find that lax environmental regulation in a host country is a significant determinant of FDI from the US. He [16] constructs a simultaneous model using a panel of data from China's 29 provinces to study the FDI-emission nexus in China, and the results show that with a $1 \%$ increase in FDI, industrial emissions will increase by $0.099 \%$. Baek and Koo [17] apply integration analysis and a vector error-correction model to explore the short-run and long-run relationship between FDI and the environment in China and India, and the estimates are also consistent with the pollution haven effect.

Conversely, it is possible that FDI improves environmental efficiency in host countries because such new capital helps to modernize the capital stock [18]. Foreign companies employ better management practices and up-to-date technologies that result in a relatively clean environment in the host countries [19]. List and Co [20] suggest that FDI helps promote the energy efficiency of the host countries and decrease pollution emissions. Tamazian et al. [21] find that the increase in FDI inflows is associated with lower levels of $\mathrm{CO}_{2}$ emissions, because FDI inflows encourage Research \& Development (R\&D) investments, possibly leading to higher technological energy-related efficiency, and therefore lower emissions. Wang and Yanhong [22] find foreign firms are significantly more energy efficient and use cleaner types of energy than the domestic-owned firms in a study examining firm level pollution discharge in more than 1000 firms in China. Zheng et al. [23] test the hypothesis concerning the relationship between FDI and ambient air pollution across major Chinese cities, and find cities featuring higher per-capita FDI flows have lower pollution levels. By using panel data on manufacturing FDI from a large sample of highly heterogeneous countries between 1995 and 2008, Natalia [24] investigates the existence and the conditionality of the controversial FDI-induced effects on industrial emissions, and the paper finds that FDI is associated with pollution reduction in countries with a low to average capital-to-labor ratio but not too-lax environmental regulations.

In summary, the existing literature has intensively studied the effects of FDI on a country's economic development and environmental pollution respectively, but comprehensive measurements of the effects of FDI on both economic growth and environmental pollution in the literature are lacking. 
Therefore, this paper attempts to measure the comprehensive effects (including both economic effects and environmental effects) of FDI on host countries and make an empirical study on these effects of FDI on China's 104 cities.

\section{Measurements of the Green Efficiency of Urban Growth}

\subsection{Comprehensive Measurements of FDI Externalities: Green Growth Efficiency}

Green growth efficiency is an index reflecting FDI's comprehensive externalities. Considering energy consumption and environmental pollution, the essence of green growth efficiency is "green + growth". No matter the strengthening of green degree, or the strengthening of growth ability, they will reflect on the increase of green growth efficiency. Therefore, the green growth efficiency is an appropriate indicator to analyze dilemmas faced by China in economic growth and environmental protection. We will make green growth efficiency the comprehensive measure of FDI economic and environmental effects: On the premise of other conditions unchanged, the value of FDI inflows is given such that if FDI helps gain more (or less) GDP and less environmental pollution (or higher), then the green growth efficiency will be improved higher (or lower). Additionally, the greater (or lesser) GDP reflects the positive (or negative) effects of FDI on economic growth. The lesser (or greater) pollution of the environment reflects the positive (or negative) effects of FDI on the environment. The green growth efficiency embodies the comprehensive measurements of FDI's effects on the economy and the environment.

Data Envelopment Analysis (DEA), using a non-parametric linear programming method for estimating a production frontier with multiple inputs and outputs, is the main way to evaluate and analyze the efficiency. Since Charnes, Cooper and Rhodes [25] first invented DEA, this method has been widely used because there is no need to set any prior functions or parameter weights. With the worsening of environmental pollution, undesirable outputs such as pollution emissions should be considered in the DEA. Traditional DEA usually assumes that producing more output relative to less input resources is a criterion of efficiency. In the presence of undesirable output, however, technologies with more desirable output and less undesirable output relative to less input resources should be recognized as efficient. For this purpose Hailu and Veeman [26] used undesirable outputs as input factors to calculate environmental efficiency. Scheel [27] even used the reciprocal transformation method in calculation. However, these methods are not consistent with the actual production process, and a deviation exists. Seiford and Zhu [28] transformed undesirable outputs into positive inputs through vector transformation. Fare et al. [29] established an output-oriented distance function to evaluate the environmental efficiency.

However, many studies have adopted radial and oriented DEA for analysis. When the slack variables exist, radical DEA will lead to biased results. Oriented DEA ignores aspects of inputs or outputs and also leads to inaccurate results. To overcome these problems, Fare et al. [29] and Fukuyama and Weber [30] developed the slacks-based measure directional distance function (SBMDDF) which is based on the SBM model dealing with the undesirable outputs of Tone [31].

We use SBMDDF to evaluate green growth efficiency. We assume each city is a decision-making unit to construct a green production frontier. Suppose that each city has three factors: inputs, good (desirable) outputs and bad (undesirable) outputs, as represented by three vectors of $x=$ $\left(x_{1}, x_{2} x_{3} \ldots x_{N}\right) \in R_{N^{\prime}}^{+} y=\left(y_{1}, y_{2} y_{3} \ldots y_{M}\right) \in R_{M^{\prime}}^{+}\left(b=\left(b_{1}, b_{2}, b_{3} \ldots b_{I}\right) \in R_{I}^{+}\right.$. In different times ( $\mathrm{t}$ is equal to $1, \ldots, \mathrm{T})$, the input and output of $\mathrm{K}$ city is $\left(x^{k . t}, y^{k . t}, b^{k . t}\right)$. By imposing the assumption that desirable output and undesirable output are together weakly disposable, the production possibility set $(\mathrm{P})$ is defined by:

$$
P^{t}\left(x^{t}\right)=\left\{\left(y^{t}, b^{t}\right): \sum_{k=1}^{K} z_{k}^{t} y_{k m}^{t} \geqslant y_{k m}^{t}, \forall m ; \sum_{k=1}^{K} z_{k}^{t} b_{k i}^{t} \leqslant b_{k i}^{t}, \forall i ; \sum_{k=1}^{K} z_{k}^{t} x_{k n}^{t} \leqslant x_{k n}^{t}, \forall n ; z_{k}^{t} \geqslant 0, \forall k\right\}
$$


where $z$ is the intensity vector, and the three inequalities in the P function stand for when, respectively, the actual desirable output levels are below the frontier desirable output level, the actual undesirable output is greater than the frontier undesirable output level, and the actual input level is greater than the frontier input level.

According to Fukuyama and Weber [30] and Tone et al. [31], the SBMDDF under the consideration of energy and environment can be expressed as:

$$
\begin{gathered}
S_{v}^{t}\left(x^{t, k^{\prime}}, y^{t, k^{\prime}}, b^{t, k^{\prime}}, g^{x}, g^{y}, g^{b}\right)=\max _{s^{x}, s^{y}, s^{b}} \frac{\frac{1}{N} \sum_{n=1}^{N} \frac{s_{n}^{x}}{g_{n}^{x}}+\frac{1}{M+I}\left(\sum_{m=1}^{M} \frac{s_{m}^{y}}{g_{m}^{y}}+\sum_{i=1}^{I} \frac{s_{i}^{b}}{g_{i}^{b}}\right)}{2} \\
\text { s.t. } \sum_{k=1}^{K} z_{k}^{t} x_{k n}^{t}+s_{n}^{x}=x_{k^{\prime} n^{\prime}}^{t}, \forall \mathrm{n} ; \sum_{k=1}^{K} z_{k}^{t} y_{k m}^{t}-s_{m}^{y}=y_{k^{\prime} m^{\prime}}^{t}, \forall m ; \sum_{k=1}^{K} z_{k}^{t} b_{k i}^{t}+s_{i}^{b}=b_{k^{\prime}{ }^{\prime}}^{t}, \forall i ; \\
z_{k}^{t} \geqslant 0, \forall k ; s_{n}^{x} \geqslant 0, \forall n ; s_{m}^{y} \geqslant 0, \forall m ; s_{i}^{b} \geqslant 0, \forall i
\end{gathered}
$$

The vector $\left(x^{t, k^{\prime}}, y^{t, k^{\prime}}, b^{t, k^{\prime}}\right)$ indicates the $k$ th Decision Making Unit's input, good output and bad output vector. Vector $\left(s_{n}^{x}, s_{m}^{y}, s_{i}^{b}\right)$ is the positive directional vector that contracts inputs, contracts bad outputs and expands good outputs, and $\left(g^{x}, g^{y}, g^{b}\right)$ is the direction vector. The objective is to maximize the sum of the average input inefficiency, average good output inefficiency, and average bad output inefficiency. This model gives the results of inefficiency for green growth. A smaller value shows that the efficiency of green growth is higher, while a greater value shows that the efficiency of green growth is lower. In the following analysis, we will adopt green growth inefficiency.

Based on 104 cities in China, we calculate the green growth inefficiency for each city from 2004 to 2011. The choice of China's civic level data during 2004-2011 to carry out our analysis is due to the following considerations. Firstly, China's nation-wide unified statistical system assures our comparable empirical study, and avoids the generally encountered critiques as data-incoherent problems by those international experience studies. Secondly, the China City Statistical Yearbook did not give urban energy consumption data before 2004, and the updated official data has not been released. Thirdly, given the increase in the FDI flow to China and the escalation of environmental degradation, focusing our analysis in the period will allow us to study the principal influence of FDI on both China's economic and environmental situation.

Green inefficiency is affected by economic and environmental factors, so we should consider environmental input-output as well as economic input-output. This study constructed an indicator system for green growth inefficiency evaluation (see Table 1) using the following input and output indicators. The input factors mainly include capital, labor and energy. We chose the total investment in fixed assets as the capital input. The number of persons employed in various units at year-end was selected as the labor input. We chose the industrial coal consumption as the energy input. We chose the gross regional product as the desirable output, and industrial sulfur dioxide emissions as undesirable output (among the available statistic data describing China's environmental situation, sulfur dioxide emission is the environmental index having the longest time dimension without interruptions). Data used in this paper is from the official statistical yearbooks.

Table 1. Input and output indicators.

\begin{tabular}{lclc}
\hline Variable Category & Variable Name & \multicolumn{1}{c}{ Description } & Units \\
\hline \multirow{2}{*}{ Inputs } & Capital & total investment in fixed assets & 10,000 yuan \\
\cline { 2 - 4 } & Labor & $\begin{array}{l}\text { persons employed in various } \\
\text { units at year-end }\end{array}$ & 10,000 persons \\
\cline { 2 - 4 } & Energy & industrial coal consumption & $10,000 \mathrm{t}$ \\
\hline Desirable outputs & $\mathrm{GDP}$ & gross regional product & 100 million yuan \\
\hline Undesirable outputs & $\mathrm{SO}_{2}$ & Industrial sulfur dioxide & $10^{8} \mathrm{~m}^{3}$ \\
\hline
\end{tabular}


According to Equation (1), we can break the green growth inefficiency into input (capital, labor, energy) inefficiency, desirable output (GDP) inefficiency, and undesirable output (sulfur dioxide) inefficiency. To conveniently analyze the different effects of FDI on green economic growth, we call the sum of capital, labor and GDP inefficiencies economic inefficiencies (traditional growth inefficiencies), and the sum of energy and sulfur dioxide inefficiencies as environmental inefficiencies. These two inefficiencies are added together to make up green growth inefficiencies.

Economic inefficiency is made up of capital, labor and GDP inefficiencies.

$$
\text { ECOINEF }=\frac{1}{2 \times 3}\left(\frac{s_{n}^{l}}{g_{n}^{l}}+\frac{s_{n}^{k}}{g_{n}^{k}}\right)+\frac{1}{2 \times(1+1)} \frac{s_{m}^{g d p}}{g_{m}^{g d p}}
$$

Environmental inefficiency is the total inefficiency of energy and sulfur dioxide inefficiencies

$$
\text { ENVIRINEF }=\frac{1}{2 \times 3}\left(\frac{s_{n}^{e}}{g_{n}^{e}}\right)+\frac{1}{2 \times(1+1)} \frac{s_{i}^{s 02}}{g_{i}^{s 02}}
$$

Green inefficiency is equal to the sum of economic inefficiency and environmental inefficiency.

$$
\text { GREENINEFF }=\text { ECOINEF }+ \text { ENVIRINEF }
$$

In the following analysis, we respectively make green growth inefficiency, economic inefficiency and environmental inefficiency dependent variables, and analyze the effects of FDI on China's green economic growth, traditional economic growth and environmental pollution.

\subsection{Calculation Results and Analysis}

According to the selection of the index variables and the measure of the model described above, the green growth inefficiencies of different cities in different years are shown in Table 2.

Due to space limitation, we chose the capital city of each province as samples, and analyzed the green growth efficiency from the economic and environmental comprehensive aspects. We divided the cities into three regions (eastern, middle and western) according to geographical locations. As we can see from Table 2, the average value of China's green inefficiency is 0.49 from 2004 to 2011; economic inefficiency and environmental inefficiency are respectively separated as 0.16 and 0.33 . This indicates that the main cause of green growth inefficiency is from the inefficiency of the environment. In the process of China's rapid economic growth, there are many phenomena of irrational uses of resources and energy, as well as the destruction and deterioration of the natural environment, which results in low efficiency of the environment.

From the perspective of different regions, the average value of the eastern, middle and western regions' green growth inefficiencies from 2004 to 2011 are $0.37,0.46$ and 0.61 , respectively. The average values of economic inefficiencies are $0.17,0.11$ and 0.28 , and the average values of the environment inefficiencies are as high as $0.26,0.29$ and 0.33 . On the one hand, it shows that there is a gap between the green growth of the eastern, middle and western regions. On the other hand, the eastern, middle and western regions' green growth shows the same situation, and it is obvious that the environmental inefficiency is always higher than economic inefficiency in the eastern, middle and western regions.

There are significant differences in the inefficiency of green growth between different cities even in the same region. In the eastern region, the green growth inefficiency values of Shenzhen, Guangzhou, Shanghai, Hangzhou and other cities are relatively lower than the average value. Among them, the green growth inefficiency value of Shenzhen is zero, and the economic inefficiency value and environmental inefficiency values are also zero. This shows that Shenzhen is one of China's best green growth cities. Tianjin, Fuzhou and Nanjing are also in the eastern region, but their green inefficiency values are relative high. The green growth inefficiency average value of Tianjin and Fuzhou is 0.50, Nanjing's green growth inefficiency average value is as high as 0.47 . These cities' high inefficiency is 
mainly due to the low efficiency of the environment (see Table 2). In the middle region, the average value of green growth inefficiency is as high as 0.65 , which is higher than the eastern region. Taiyuan, as a typical resourceful city in the middle region has higher green growth inefficiency than other cities in the same region. Taiyuan's leading industry is coal mining which inevitably destroys the local environment, resulting in high environmental inefficiency and poor green growth efficiency. In the western region, most cities' green growth inefficiencies are generally high, and about $80 \%$ of the cities' green development inefficiency values were higher than $0.5 \mathrm{in} 2011$. This indicates that under the economic and environmental double-win assessment criteria, there is a large gap between western cities, eastern cities and middle cities.

Table 2. Green growth inefficiency of typical cities from 2004 to 2011.

\begin{tabular}{|c|c|c|c|c|c|c|c|c|c|c|}
\hline \multirow[b]{2}{*}{ Category } & \multirow[b]{2}{*}{ City } & \multicolumn{3}{|c|}{2004} & \multicolumn{3}{|c|}{2011} & \multicolumn{3}{|c|}{ Average Value } \\
\hline & & $\begin{array}{l}\text { ECO } \\
\text { INEF }\end{array}$ & $\begin{array}{c}\text { ENVIR } \\
\text { INEF }\end{array}$ & $\begin{array}{l}\text { GREEN } \\
\text { INEFF }\end{array}$ & $\begin{array}{l}\text { ECO } \\
\text { INEF }\end{array}$ & $\begin{array}{c}\text { ENVIR } \\
\text { INEF }\end{array}$ & $\begin{array}{l}\text { GREEN } \\
\text { INEFF }\end{array}$ & $\begin{array}{l}\text { ECO } \\
\text { INEF }\end{array}$ & $\begin{array}{c}\text { ENVIR } \\
\text { INEF }\end{array}$ & $\begin{array}{l}\text { GREEN } \\
\text { INEFF }\end{array}$ \\
\hline \multirow{10}{*}{$\begin{array}{l}\text { Eastern } \\
\text { Region }\end{array}$} & Beijing & 0.21 & 0.23 & 0.44 & 0.16 & 0.28 & 0.44 & 0.17 & 0.19 & 0.36 \\
\hline & Tianjin & 0.11 & 0.34 & 0.45 & 0.35 & 0.35 & 0.70 & 0.15 & 0.35 & 0.50 \\
\hline & Shenyang & 0.10 & 0.13 & 0.23 & 0.10 & 0.30 & 0.40 & 0.12 & 0.27 & 0.39 \\
\hline & Shanghai & 0.05 & 0.29 & 0.35 & 0.07 & 0.37 & 0.43 & 0.07 & 0.30 & 0.37 \\
\hline & Nanjing & 0.11 & 0.34 & 0.44 & 0.11 & 0.39 & 0.50 & 0.11 & 0.35 & 0.47 \\
\hline & Hangzhou & 0.03 & 0.10 & 0.14 & 0.21 & 0.33 & 0.54 & 0.12 & 0.29 & 0.42 \\
\hline & Fuzhou & 0.05 & 0.23 & 0.28 & 0.23 & 0.39 & 0.61 & 0.17 & 0.33 & 0.50 \\
\hline & Guangzhou & 0.03 & 0.28 & 0.31 & 0.07 & 0.33 & 0.40 & 0.04 & 0.25 & 0.29 \\
\hline & Shenzhen & 0.00 & 0.00 & 0.00 & 0.00 & 0.00 & 0.00 & 0.00 & 0.00 & 0.00 \\
\hline & Average & 0.08 & 0.22 & 0.29 & 0.14 & 0.30 & 0.45 & 0.11 & 0.26 & 0.37 \\
\hline \multirow{10}{*}{$\begin{array}{l}\text { Middle } \\
\text { Region }\end{array}$} & Taiyuan & 0.30 & 0.34 & 0.64 & 0.25 & 0.40 & 0.64 & 0.29 & 0.36 & 0.65 \\
\hline & Changchun & 0.04 & 0.16 & 0.21 & 0.12 & 0.39 & 0.51 & 0.14 & 0.32 & 0.46 \\
\hline & Harbin & 0.11 & 0.25 & 0.36 & 0.20 & 0.38 & 0.58 & 0.20 & 0.29 & 0.49 \\
\hline & Hefei & 0.14 & 0.30 & 0.45 & 0.17 & 0.37 & 0.54 & 0.15 & 0.31 & 0.47 \\
\hline & Nanchang & 0.12 & 0.25 & 0.37 & 0.23 & 0.33 & 0.56 & 0.17 & 0.26 & 0.43 \\
\hline & Zhengzhou & 0.11 & 0.35 & 0.46 & 0.15 & 0.39 & 0.54 & 0.16 & 0.36 & 0.52 \\
\hline & Wuhan & 0.11 & 0.32 & 0.44 & 0.16 & 0.35 & 0.51 & 0.20 & 0.30 & 0.50 \\
\hline & Changsha & 0.00 & 0.00 & 0.00 & 0.10 & 0.16 & 0.26 & 0.04 & 0.08 & 0.12 \\
\hline & Shijiazhuang & 0.09 & 0.37 & 0.45 & 0.11 & 0.38 & 0.49 & 0.14 & 0.37 & 0.51 \\
\hline & Average & 0.11 & 0.26 & 0.38 & 0.17 & 0.35 & 0.51 & 0.17 & 0.29 & 0.46 \\
\hline \multirow{12}{*}{$\begin{array}{l}\text { Western } \\
\text { Region }\end{array}$} & huhehot & 0.17 & 0.36 & 0.53 & 0.03 & 0.31 & 0.34 & 0.10 & 0.35 & 0.44 \\
\hline & Nanning & 0.14 & 0.33 & 0.47 & 0.25 & 0.33 & 0.57 & 0.26 & 0.28 & 0.54 \\
\hline & Chengdu & 0.11 & 0.26 & 0.37 & 0.16 & 0.33 & 0.49 & 0.17 & 0.29 & 0.46 \\
\hline & Chongqing & 0.23 & 0.32 & 0.55 & 0.18 & 0.39 & 0.57 & 0.25 & 0.36 & 0.61 \\
\hline & Guiyang & 0.40 & 0.33 & 0.73 & 0.46 & 0.36 & 0.81 & 0.49 & 0.34 & 0.83 \\
\hline & Kunming & 0.13 & 0.34 & 0.47 & 0.33 & 0.38 & 0.71 & 0.30 & 0.34 & 0.63 \\
\hline & Xi'an & 0.18 & 0.31 & 0.49 & 0.29 & 0.34 & 0.63 & 0.35 & 0.28 & 0.63 \\
\hline & Lanzhou & 0.19 & 0.34 & 0.54 & 0.26 & 0.40 & 0.66 & 0.29 & 0.36 & 0.66 \\
\hline & Xining & 0.32 & 0.34 & 0.66 & 0.31 & 0.39 & 0.70 & 0.32 & 0.38 & 0.70 \\
\hline & Yinchuan & 0.50 & 0.22 & 0.73 & 0.20 & 0.41 & 0.61 & 0.37 & 0.30 & 0.67 \\
\hline & Urumqi & 0.12 & 0.38 & 0.50 & 0.11 & 0.40 & 0.52 & 0.16 & 0.39 & 0.55 \\
\hline & Average & 0.23 & 0.32 & 0.55 & 0.23 & 0.37 & 0.60 & 0.28 & 0.33 & 0.61 \\
\hline
\end{tabular}

Note: The value in the table is green growth inefficiency. The larger the value is, the lower the efficiency of green growth; the smaller the value is, the higher the efficiency of green growth.

\section{An Empirical Analysis of FDI Impact on Green Growth Inefficiency}

\subsection{The Influence of FDI on the Green Growth Inefficiency}

FDI not only has an impact on the economic benefits of urban growth, but also exerts environmental impacts on urban growth. FDI's positive (or negative) economic effect and environmental effect on cities' growth may induce higher (or lower) green growth efficiency. Therefore, green growth efficiency can be used as a comprehensive measure of FDI's performance. So we take Green Growth Inefficiency (GREENINEFF) as the dependent variable; Foreign Direct Investment (FDI) as the key independent variable; Environmental Regulation (ER), Per Capita Gross Domestic Product 
(PCGDP), Industrial Structure (IS), Per Capita Scientific and Technology Investment (PCSTI) as the control variables, and established Equation (5):

$$
\text { GREENINEFF }_{\mathrm{t}}=\mathrm{C}_{1}+\mathrm{a}_{1} \text { FDI }_{\mathrm{t}}+\mathrm{a}_{2} \text { ER }_{\mathrm{t}}+\mathrm{a}_{3} \text { PCGDP }_{\mathrm{t}}+\mathrm{a}_{4} \mathrm{IS}_{\mathrm{t}}+\mathrm{a}_{5} \text { PCSTI }_{\mathrm{t}}+\mu_{\mathrm{t} 1}
$$

where subscripts $i$ and $t$ denote city and time period, respectively. The coefficient $\mathrm{a}_{1}$ measures the magnitude of the comprehensive effects of FDI.

Among them, the selection of the variables and the data is as follows:

Dependent variable - Green Growth Inefficiency (GREENINEFF). The inefficiency of urban green growth is calculated as mentioned before. It should be noted that in the results of the regression model, the larger the dependent variable the lower the green growth efficiency.

Independent variable-Foreign Direct Investment (FDI). Foreign direct investment is an important form of foreign technology and knowledge inflow. It may bring technology spillover and knowledge expansion, which has a possible positive effect on the promotion of green efficiency. However, FDI can also bring resource-dependence and environmental damage and may play a negative role on the promotion of green efficiency.

In this section, FDI equals gross FDI inflows as a share of GDP (the FDI/GDP ratio) [3,10,32]. We also try to use different FDI indicators. We have looked at indicators for FDI such as the ratio of FDI in gross capital formation, the ratio of foreign firm employees in the total employees, the FDI inflows per capita, etc. However, the correlation coefficients of different FDI indicators are significantly higher, and none of the indicators are significantly different with the estimated results in Table 3.

Control variable-Environmental Regulation (ER). We use the sulfur dioxide $\left(\mathrm{SO}_{2}\right)$ removal rate to measure Environmental Regulation. Generally speaking, the higher the removal rate of $\mathrm{SO}_{2}$, the stricter the city environmental regulation, and strict environmental regulations can guide enterprises to pay more attention to clean production technology, resulting in the reduction of environmental pollution, which promotes green growth efficiency.

Control variable-Per Capita GDP (PCGDP). The higher the GDP per capita, the better the city's economic development condition. The awareness of environmental protection of the local government and the public is relatively high in cities with high GDP per capita; meanwhile, these cities will also pay more attention to the protection of the environment, which can play a positive role in the green development efficiency.

Control variable-Industrial Structure (IS). We use the proportional measurement of value added as secondary to the GDP. The secondary industry is the main industry where FDI inflows, which is also the important source to promote the development of the urban economy, but also an important source of urban environment pollution.

Control variable-Per Capita Science and Technology Investment (PCSTI). Investment in science and technology is an important force of promoting the transformation of the green economy. Increasing investment in science and technology not only improves the production efficiency of economic activities, but also can increase the promotion and popularization of green technologies.

When examining the FDI's comprehensive effect on green growth, we recognize that there is a valid concern about possible reverse causality. The quality of green growth, whether it is low or high, may influence FDI flows. Therefore, we take on two methods to attenuate the problem of endogeneity. One is considering a model with one lag of all the explanatory variables, including FDI, for regression analysis. The other is a model where we use one lag of FDI as the Instrumental Variable (IV), and our justification for this strategy is that this measure is correlated with FDI flows and the quality of green growth is unlikely to have an effect on one-period lagged FDI flows. Table 3 columns (1), (2) and (3) report the OLS (Ordinary Least Squares), one lag of explanatory variables and IV results based on Equation (5) respectively. Column (1), column (2) and column (3) give consistent basic conclusions. The estimated results show that FDI has a negative effect on the dependent variable, which means the increase of FDI will cause a reduction in the dependent variable, which means that FDI is positive in improving the efficiency of green growth. 


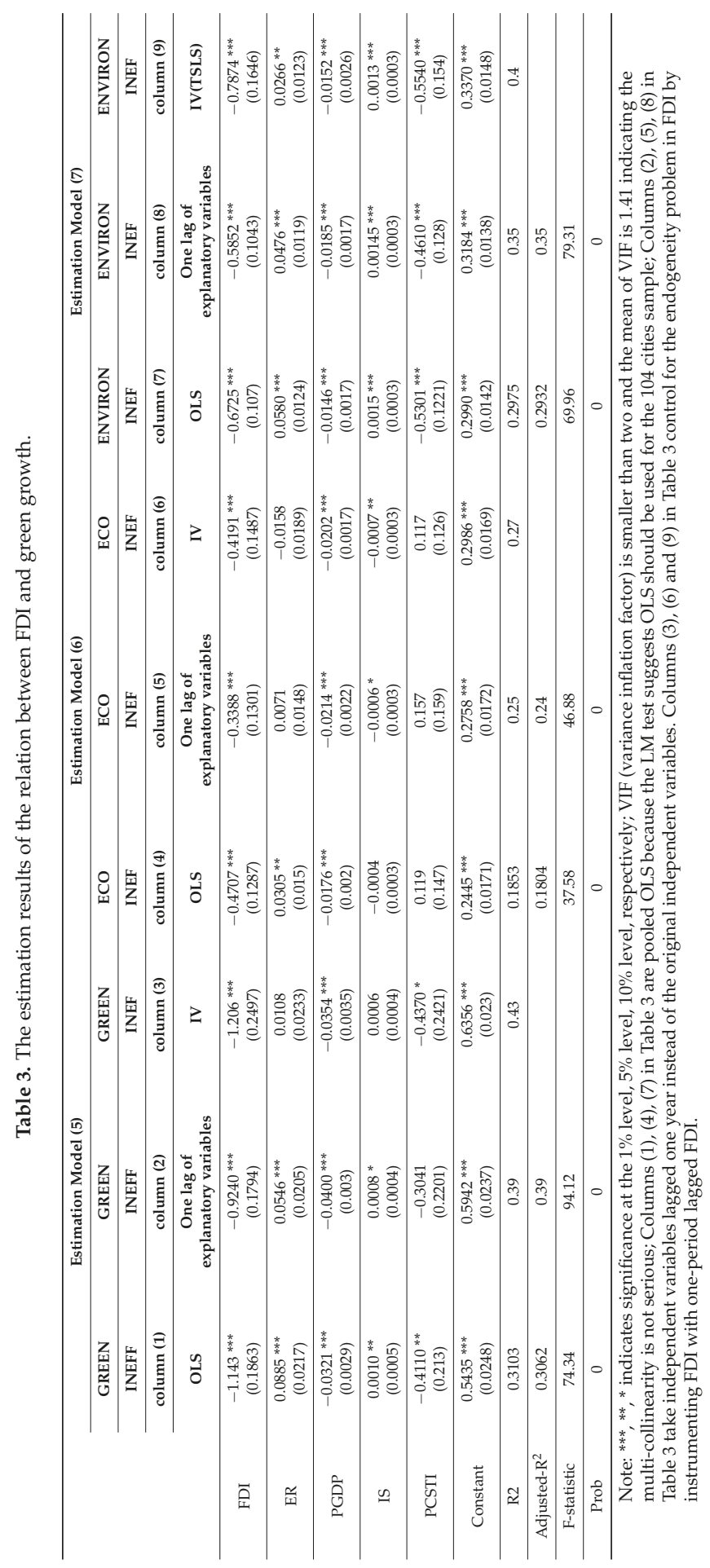


As to the control variables, the environmental regulation (ER) has a positive effect on the dependent variable, which means that the enhancement of the environmental regulation is not effective in promoting the green growth efficiency. This result may be due to the administrative management's main role in the current environmental regulations in China, and therefore it may not have brought about the desired results. Per capita GDP (PCGDP) that passes the $1 \%$ significance test has a negative coefficient. This means that the economic development level has a positive effect on urban green growth efficiency. It seems that people's environmental awareness is stronger in cities with higher per capita GDP, and these cities' environmental protection is more general than that of other cities. Industrial structure (IS) that passes the $10 \%$ significance test has a positive coefficient. This means that the secondary industry has a negative effect on the urban green growth efficiency, and the main reason is that the secondary industry growth brings many energy consumption and pollutant emissions. Per capita scientific and technological investment (PCSTI) has a negative coefficient. This means that the growth of scientific and technological investment has a positive effect on the urban green growth efficiency.

\subsection{The Impact of FDI on Urban Economic Growth}

Since green growth efficiency is the comprehensive measurement of the economic and environmental benefits of FDI, we use the economic inefficiency (ECOINEF) as a dependent variable to discuss the impact of FDI on China's cities from the perspective of economic efficiency. We established the following regression in Equation (6):

$$
\mathrm{ECOINEF}_{\mathrm{t}}=\mathrm{C}_{1}+\mathrm{a}_{1} \mathrm{FDI}_{\mathrm{t}}+\mathrm{a}_{2} \mathrm{ER}_{\mathrm{t}}+\mathrm{a}_{3} \mathrm{PCGDP}_{\mathrm{t}}+\mathrm{a}_{4} \mathrm{IS}_{\mathrm{t}}+\mathrm{a}_{5} \mathrm{PCSTI}_{\mathrm{t}}+\mu_{\mathrm{t} 2}
$$

When examining the FDI's economic effect on green growth, we also deal with the potential problem of the FDI increasing endogenously with higher economic efficiency. Therefore, we take on two methods to attenuate the problem of endogeneity. One is considering a model with one lag of all the explanatory variables, including FDI, for regression analysis. The other is that we use one lag of FDI as the instrumental variable (IV). Table 3 columns (4), (5) and (6) report the OLS, one lag of explanatory variables and IV results based on Equation (6), respectively. Column (4), column (5) and column (6) give consistent basic conclusions. The results show that FDI which passes the $1 \%$ significance test has a negative coefficient. This means that the introduction of FDI in China's economic growth has a positive effect.

\subsection{The Impact of FDI on Urban Environmental Pollution}

Since green growth efficiency is the comprehensive measurement of the economic effects and environmental effects of FDI, we use environmental inefficiency (ENVIRINEF) as a dependent variable to discuss the impact of FDI on China's cities from the perspective of environmental efficiency. We established the following regression in Equation (7)

$$
\text { ENVIRINEF }_{\mathrm{t}}=\mathrm{C}_{1}+\mathrm{a}_{1} \mathrm{FDI}_{\mathrm{t}}+\mathrm{a}_{2} \mathrm{ER}_{\mathrm{t}}+\mathrm{a}_{3} \text { PCGDP }_{\mathrm{t}}+\mathrm{a}_{4} \mathrm{IS}_{\mathrm{t}}+\mathrm{a}_{5} \text { PCSTI }_{\mathrm{t}}+\mu_{\mathrm{t} 3}
$$

Concerned that FDI may be an endogenous variable, we contrast the OLS, one lag of explanatory variables and IV results in columns 7-9 of Table 3. We see clear evidence that these estimates are mainly the same, negative and statistically significant. Using an OLS and IV strategy, we find that FDI is associated with high environmental efficiency, which means FDI does not appear to facilitate the growth of "pollution havens" in China. From the perspective of different sectors, FDI's promotion of environmental efficiency may be due to the FDI largely flowing into low-polluting sectors. The FDI's promotion of environmental efficiency can also be caused by clean technology transfer and environmental technology spillover to high-polluting sectors. We will present further study in Section 4.4. 
In the controlled variable, ER has a positive effect on ECOINEF. ER is also a positive and significant factor for environment inefficiency mainly because most of the regulations are administrative regulations, not market-oriented regulations. The coefficient of IS to ECOINEF is negative and significant. The coefficient of IS to ENVIRINEF is positive and significant. It indicates that, though promoting the improvement of economic efficiency, the secondary industry is also the particular industry that causes China's environmental problems. The coefficients of PCGDP to ECOINEFF and ENVIRINEF are all significantly negative, meaning that per capita GDP contributes to the decrease of economic inefficiency and environmental inefficiency. Therefore, the increase of PCGDP is positive for China's economic green growth. The coefficient of PCSTI to ECOINEFF is positive but insignificant, and the coefficient of PCSTI to ENVIRINEF is significantly negative.

\subsection{FDI's Effect on Different Industries}

The above analysis viewed FDI as an integral index and analyzed the impact of FDI on green growth, economic growth and environmental protection, respectively. However, the effect of FDI may differ in different sectors. For instance, the effect of FDI on emission-intensive sectors may be different from that of non-emission-intensive sectors. We will analyze the comprehensive effect of FDI on the host country (China) from different sectors in the following.

We could not find official data about FDI in different sectors in most of the cities. We searched the statistical data for each of the 104 cities year by year, and only got qualified statistical data from seven cities (Shijiazhaung, Tangshan, Handan, Dalian, Changzhou, Nantong and Ningbo). The limitation of statistical data causes us to narrow down the samples. We analyzed the Manufacturing of Raw Chemical Materials and Chemical Products, Manufacturing of Communication Equipment and Computers of seven cities, respectively. The reasons for choosing these two sectors are as follows: Firstly, FDI in some industries among these seven cities is quite small, such as the Primary Industry. Very few of the cities reported the statistical data of FDI in some sectors such as the Manufacturing of Foods, Manufacturing of Textile, etc. The statistical data of these two sectors are relatively integral. Secondly, the Manufacturing of Raw Chemical Materials and Chemical Products, Manufacturing of Communication Equipment and Computers are the main sectors for FDI to flow into China. Taking the year of 2011 as an example, the FDI of the two sectors mentioned above is ranked third and first, respectively, among 36 industries. Thirdly, the Manufacturing of Raw Chemical Materials and Chemical Products is the typical emission-intensive sector, whereas the Manufacturing of Communication Equipment and Computers is the typical non-emission-intensive sector. Taking the year of 2011 as an example, the volume of sulphur dioxide emissions in the two sectors mentioned above is ranked third and 30th, respectively, among 36 industries.

In Section 3.1, this paper uses industrial coal consumption as the energy input and industrial sulfur dioxide emissions as the undesirable output. So we do not choose sectors such as software and real estate, because these sectors belong to the Tertiary Industry, whose coal consumption and sulfur dioxide emissions are quite low.

We replace the gross FDI with sectoral FDI which equals sectoral FDI inflows as a share of GDP, and estimate the regression in Equations (5), (6) and (7). Table 4 shows the analysis consequence of the seven cities. We can see that the effect of FDI in the Manufacturing of Raw Chemical Materials and Chemical Products (FDI1) on green efficiency, economic efficiency and environmental efficiency is quite different from that of FDI in the Manufacturing of Communication Equipment and Computers (FDI2). FDI1 promotes green efficiency mainly through the improvement of the economic efficiency. FDI1 does not significantly promote environmental efficiency. However, FDI2 promotes economic efficiency, environmental efficiency and green efficiency. 
Table 4. The effect of FDI in different industries on cities' green growth.

\begin{tabular}{|c|c|c|c|c|c|c|}
\hline & \multicolumn{3}{|c|}{$\begin{array}{l}\text { FDI in Manufacturing of Raw Chemical } \\
\text { Materials and Chemical Products }\end{array}$} & \multicolumn{3}{|c|}{$\begin{array}{c}\text { FDI in Manufacturing of Communication } \\
\text { Equipment and Computers }\end{array}$} \\
\hline & GREEN & ECO & ENVIR & GREEN & ECO & ENVIR \\
\hline & INEFF & INEF & INEF & INEF & INEF & INEF \\
\hline & Model (5) & Model (6) & Model(7) & Model (5) & Model (6) & Model (7) \\
\hline FDI1 & $\begin{array}{l}-0.1017^{* *} \\
(0.0665)\end{array}$ & $\begin{array}{l}-0.0340^{* *} \\
(0.0160)\end{array}$ & $\begin{array}{l}-0.0676 \\
(0.0542)\end{array}$ & & & \\
\hline FDI2 & & & & $\begin{array}{c}-0.1189 * * * \\
(0.0429)\end{array}$ & $\begin{array}{l}-0.0300 * * \\
(0.0105)\end{array}$ & $\begin{array}{l}-0.0889 * * \\
(0.0351)\end{array}$ \\
\hline ER & $\begin{array}{c}0.1393 \\
(0.1101)\end{array}$ & $\begin{array}{c}0.0391 \\
(0.0264)\end{array}$ & $\begin{array}{c}0.1003 \\
(0.0897)\end{array}$ & $\begin{array}{c}0.0777 \\
(0.1069)\end{array}$ & $\begin{array}{c}0.0232 \\
(0.0261)\end{array}$ & $\begin{array}{l}0.0546 \\
(0.0875)\end{array}$ \\
\hline PGDP & $\begin{array}{l}-0.0455^{* * *} \\
(0.0157)\end{array}$ & $\begin{array}{l}-0.0081 \text { ** } \\
(0.0038)\end{array}$ & $\begin{array}{l}-0.0375^{* * *} \\
(0.0013)\end{array}$ & $\begin{array}{l}-0.0362 * * \\
(0.0154)\end{array}$ & $\begin{array}{l}-0.0058 \\
(0.0038)\end{array}$ & $\begin{array}{l}-0.0304^{* *} \\
(0.0126)\end{array}$ \\
\hline IS & $\begin{array}{l}0.00774 \\
(0.0051)\end{array}$ & $\begin{array}{l}-0.0013 \\
(0.0012)\end{array}$ & $\begin{array}{l}0.0071^{*} \\
(0.0040)\end{array}$ & $\begin{array}{l}0.0068^{*} \\
(0.0038)\end{array}$ & $\begin{array}{c}-0.0026^{* *} \\
(0.0012)\end{array}$ & $\begin{array}{l}0.0093^{* *} \\
(0.0039)\end{array}$ \\
\hline PCSTI & $\begin{array}{c}1.7591 \\
(2.0881)\end{array}$ & $\begin{array}{c}0.4320 \\
(0.5020)\end{array}$ & $\begin{array}{c}1.3270 \\
(1.7021)\end{array}$ & $\begin{array}{c}1.8231 \\
(1.9880)\end{array}$ & $\begin{array}{c}0.4412 \\
(0.4862)\end{array}$ & $\begin{array}{c}1.3822 \\
(1.6273)\end{array}$ \\
\hline Constant & $\begin{array}{c}0.6253^{* * *} \\
(0.2842)\end{array}$ & $\begin{array}{l}0.1019^{*} \\
(0.0683)\end{array}$ & $\begin{array}{c}0.5232^{* *} \\
(0.2317)\end{array}$ & $\begin{array}{c}0.8689 * * * \\
(0.2675)\end{array}$ & $\begin{array}{c}0.1720^{* *} \\
(0.0654)\end{array}$ & $\begin{array}{c}0.6968^{* * *} \\
(0.2189)\end{array}$ \\
\hline$R^{2}$ & 0.45 & 0.36 & 0.45 & 0.50 & 0.40 & 0.50 \\
\hline Adjusted- $R^{2}$ & 0.40 & 0.30 & 0.40 & 0.46 & 0.34 & 0.45 \\
\hline
\end{tabular}

From the perspective of economic efficiency, FDI1 and FDI2 both promote economic efficiency, which is the same as the conclusion in Section 4.2. Concerning the environmental efficiency, the conclusion is that FDI promotes environmental efficiency inconsistently in different sectors. The Manufacturing of Communication Equipment and Computers is the biggest sector for FDI inflow and it is a typical low-emission industry. FDI in the Manufacturing of Communication Equipment and Computers largely accounts for the promotion of environmental efficiency in the above Section 4.3 when we lump FDI into one whole measure. However, FDI's promotion in environmental efficiency through clean technology transfer and environmental technology spillover may be not obvious, as can be seen from the fact that FDI in the Manufacturing of Raw Chemical Materials and Chemical Products did not promote the environmental efficiency significantly. As the research sample is limited, further study based on more cities needs to be carried out to support that point in the future.

\section{Conclusions and Recommendations}

Taking 104 cities in China as the research objectives, based on the SBMDDF model, this paper makes the green growth efficiency the comprehensive index of China's green growth. After dividing the green growth efficiency into economic efficiency and environmental efficiency, this paper discusses the effects of FDI on the green growth efficiency, economic efficiency and environmental efficiency of China's urban green growth, respectively. The main conclusions are as follows.

FDI has a positive correlation with the urban green growth efficiency. FDI is helpful for China's green economic growth, and plays an active role in China's green economic growth. When the green growth efficiency is broken into economic efficiency and environmental efficiency, we can see that FDI promotes China's green economic growth through the promotion of environmental effects and economic effects. The analysis of FDI in different sectors shows that FDI's promotion of environmental efficiency in China is largely due to FDI flowing into low-polluting and low-emission 
sectors. However, FDI's promotion of environmental efficiency by clean technology transfer and environmental technology spillover may be not obvious.

Finally, we give some suggestions for improving China's future green growth from the FDI impact perspective. When introducing foreign direct investment capital, the government should first consider the "quality" of FDI. It must not only be concerned about the "quality" of the economic effects, but must also pay attention to the "quality" of the environmental effects. In addition, the approval process for the resource pollution type of foreign projects should be more strictly regulated, and a higher quality FDI which is good for the economy and environmental benefits should be actively encouraged. All the above is to improve the quality of foreign investment and to promote China's green growth from the levels of economic efficiency and environmental efficiency.

This paper still has some limitations. With more available statistical data from other sectors, the effect of FDI on economic growth and environmental pollution can be considered more rigorously. The upstream and downstream effects of FDI can be estimated with the new city-level Input-Output Table released by the National Bureau of Statistics of China in the future.

Acknowledgments: This work is supported by the National Natural Science Foundation of China (71303042), National Social Science Foundation of China (12\&ZD207), and the Key Project of Philosophy and Social Science Research in Colleges and Universities of Jiangsu Province (2015ZDIXM004).

Author Contributions: Shujing Yue and Yang Yang had the original idea for the study. Yaoyu Hu was responsible for data collecting. Shujing Yue and Yang Yang carried out the analyses.

Conflicts of Interest: The authors declare no conflict of interest.

\section{References}

1. Hu, A.; Jefferson, G. FDI, Technological Innovation, and Spillover: Evidence from Large and Medium Size Chinese Enterprises; Brandeis University: Waltham, MA, USA, 2001.

2. De Gregorio, J. The Role of Foreign Direct Investment and Natural Resources in Economic Development. In Multinationals and Foreign Investment in Economic Development; Palgrave Macmillan: London, UK, 2003.

3. Johnson, A. The Effects of FDI Inflows on Host Country Economic Growth. 2006. Available online: https://static.sys.kth.se/itm/wp/cesis/cesiswp58.pdf (accessed on 3 February 2016).

4. Cheung, K.Y.; Lin, P. Spillover effects of FDI on Innovation in China: Evidence from the Provincial data. China Econ. Rev. 2004, 15, 25-44. [CrossRef]

5. Yao, S. On economic growth, FDI and exports in China. Appl. Econ. 2006, 38, 339-351. [CrossRef]

6. Tang, S.; Selvanathan, E.A.; Selvanathan, S. Foreign direct investment, domestic investment and economic growth in China: A time series analysis. World Econ. 2008, 31, 1292-1309. [CrossRef]

7. Hong, L.M. Does and How does FDI Promote the Economic Growth? Evidence from Dynamic Panel Data of Prefecture City in China. IERI Procedia 2014, 6, 57-62. [CrossRef]

8. Aitken, B.; Harrison, A. Do domestic firms benefit from direct foreign investment? Evidence from Venezuela. Am. Econ. Rev. 1999, 89, 605-618. [CrossRef]

9. Lipsey, R.E. Home and Host Country Effects of FDI. 2002. Available online: http://www.nber.org/ papers/w9293.pdf (accessed on 3 February 2016).

10. Carkovic, M.; Levine, R. Does Foreign Direct Investment Accelerate Economic Growth? 2002. Available online: http://dx.doi.org/10.2139/ssrn.314924 (accessed on 3 February 2016).

11. Herzer, D.; Klasen, S.; Nowak-Lehmann, F. In search of FDI-led growth in developing countries: The way forward. Econ. Model. 2008, 25, 793-810. [CrossRef]

12. Yalta, A.Y. Revisiting the FDI-led growth Hypothesis: The case of China. Econ. Model. 2013, 31, 335-343. [CrossRef]

13. Lian, L.; Ma, H.Y. FDI and Economic Growth in Western Region of China and Dynamic Mechanism: Based on Time-Series Data from 1986 to 2010. Int. Bus. Res. 2013, 6, 180-186. [CrossRef]

14. Copeland, B.R.; Taylor, M.S. Trade, growth, and the environment. J. Econ. Liter. 2004, 42, 7-71. [CrossRef]

15. Xing, Y.; Kolstad, C.D. Do lax environmental regulations attract foreign investment? Environ. Resour. Econ. 2002, 21, 1-22. [CrossRef] 
16. He, J. Pollution haven hypothesis and environmental impacts of foreign direct investment: The case of industrial emission of sulfur dioxide $\left(\mathrm{SO}_{2}\right)$ in Chinese province. Ecol. Econ. 2006, 60, 228-245. [CrossRef]

17. Baek, J.; Koo, W.W. A dynamic approach to the FDI-environment nexus: The case of China and India. J. Int. Econ. Stud. 2009, 13, 87-108. [CrossRef]

18. Dasgupta, S.; Laplante, B.; Wang, H.; Wheeler, D. Confronting the environmental Kuznets curve. J. Econ. Perspect. 2002, 16, 147-168. [CrossRef]

19. Zarsky, L. Foreign Direct Investment and the Environment. 1999. Available online: http://www.oecd.org/ investment/mne/2089912.pdf (accessed on 3 February 2016).

20. List, J.A.; Co, C.Y. The effect of environmental regulation on foreign direct investment. J. Environ. Econ. Manag. 2000, 40, 1-20. [CrossRef]

21. Tamazian, A.; Chousa, J.P.; Vadlamannati, C. Does higher economic and financial growth lead to environmental degradation: Evidence from the BRIC countries. Energy Policy 2009, 37, 246-253. [CrossRef]

22. Wang, H.; Yanhong, J. Industrial ownership and environmental performance: Evidence from China. Environ. Resour. Econ. 2007, 36, 255-273. [CrossRef]

23. Zheng, S.Q.; Matthew, E.K.; Liu, H.Y. Towards a system of open cities in China: Home prices, FDI flows and air quality in 35 major cities. Reg. Sci. Urban Econ. 2010, 40, 1-10. [CrossRef]

24. Natalia, Z.S. How does Foreign Direct Investment Affect Pollution? Toward a Better Understanding of the Direct and Conditional Effects. Environ. Resour. Econ. 2015. [CrossRef]

25. Charnes, A.; Cooper, W.W.; Rhodes, E. Measuring the Efficiency of Decision Making Units. Eur. J. Oper. Res. 1978, 2, 429-444. [CrossRef]

26. Hailu, A.V.; Veeman, T.S. Non-parametric productivity analysis with undesirable outputs: An application to the Canadian pulp and paper industry. Am. J. Agric. Econ. 2001, 83, 605-616. [CrossRef]

27. Scheel, H. Undesirable outputs in efficiency evaluation. Eur. J. Oper. Res. 2001, 132, 400-410. [CrossRef]

28. Seiford, L.M.; Zhu, J. Modeling undesirable factors in efficiency evaluation. Eur. J. Oper. Res. 2002, 142, 16-20. [CrossRef]

29. Fare, R.; Grosskopf, S.; Lovell, C.A.K. Multilateral productivity comparisons when some outputs are undesirable: A nonparametric approach. Rev. Econ. Stat. 1989, 71, 90-98. [CrossRef]

30. Fukuyama, H.; Weber, W.L. A Directional Slacks-based Measure of Technical Inefficiency. Socio-Econ. Plan. Sci. 2009, 4, 274-287. [CrossRef]

31. Tone, K.R. Dealing with Undesirable Outputs in DEA: A Slacks-based Measure (SBM) Approach. Oper. Res. Soc. Jpn. 2003, 5, 44-45.

32. Zhang, Y.J. The impact of financial development on carbon emissions: An empirical analysis in China. Energy Policy 2011, 39, 2197-2203. [CrossRef]

(C) 2016 by the authors. Licensee MDPI, Basel, Switzerland. This article is an open access article distributed under the terms and conditions of the Creative Commons Attribution (CC BY) license (http:/ / creativecommons.org/licenses/by/4.0/). 


\title{
Article
}

\section{Regional Convergence and Sustainable Development in China}

\author{
Fang Yang ${ }^{1,2}$, Shiying Pan ${ }^{3}$ and Xin Yao ${ }^{3,4, *}$ \\ 1 Collaborative Innovation Center for Peaceful Development of Cross-Strait Relations, Xiamen University, \\ Xiamen 361005, China; yangfang@xmu.edu.cn \\ 2 School of Economics, Xiamen University, Xiamen 361005, China \\ 3 China Center for Energy Economics Research, School of Economics, Xiamen University, \\ Xiamen 361005, China; 31320131152237@stu.xmu.edu.cn \\ 4 Collaborative Innovation Center for Energy Economics and Energy Policy, Xiamen University, \\ Xiamen 361005, China \\ * Correspondence: yaoxin@xmu.edu.cn or lyhneyao@hotmail.com; Tel.: +86-592-218-6076; \\ Fax: +86-592-218-6075
}

Academic Editors: Yongrok Choi, Malin Song and Seunghwan Myeong Received: 30 November 2015; Accepted: 21 January 2016; Published: 28 January 2016

\begin{abstract}
Based on the convergence theory of economic growth, this paper extends this concept to the human development index and carries out an empirical analysis of regional development in China between 1997 and 2006. Our research shows that the conditional convergence has been identified. Investment in fixed assets, government expenditure on education, health and infrastructure construction have positive effects on regional convergence of social development. Population weighted analysis of human development index provides support for weak convergence amongst provinces. Analysis of dynamics of regional distribution reveals the club convergence, which indicate two different convergence states. Central China is in the shade and lags behind, giving rise to the so-called "central downfall". To solve this problem, the "Rise of Central China" Plan is necessary to promote the connection between coastal and inland regions of China and reduce the regional development gap.
\end{abstract}

Keywords: social development; human development index; convergence; inequality

\section{Introduction}

In recent years, with China's rapid economic growth, issues of regional disparity in China have attracted the attention of scholars at home and abroad and been discussed in detail. However, previous research mainly focused on economic growth, and the indicator commonly used was income level, which is a great limitation for measuring levels of development of different regions. For a country or region, the ultimate goal of social development is common development of all members and enhancement of human capacity. This "capacity" includes: capacity to live a healthy and long life; capacity to have access to culture and technology and share the fruits of social civilization, and capacity to lift themselves out of poverty and improve the standard of living (UNDP, 2005) [1]. Economic development is the foundation of social development. A country can maintain rapid economic growth in the short term, but it does not mean that the social development indicators also improve. In the long run, economic growth at the cost of ignoring social development is unsustainable. As a more environmentally-friendly way to enhance human well-being. Mikkelson [2] tested the merits of equality through analysis of a few key national economic and ecological variables across time and space. In addition, the results confirmed the hypothesis that equality did far less harm to the ecosystem than growth did. 
The human development index (HDI), introduced by the United Nations Development Program (UNDP) in 1990, is a comprehensive indicator for measuring social development of different countries or regions, reflecting three major dimensions of human development: income, health and education. Since reform and opening up, China has made significant progress in economy, education and health, but the fact of regional disparity should not be ignored. Regional differences in human development limit the potential for sustainable development in China. China is in urgent need to cope with the challenge of social justice, that is, how to achieve equal opportunities and capabilities for its huge population. This not only coincides with the current goal of "building a harmonious society", but also becomes an important part of the Millennium Development Goals (MDGs).

Since the middle of the 1990s, many domestic scholars have used the human development index (HDI) to undertake a study on differences in social development of different regions in China, and found the regional imbalance of social development. That is, the Eastern China develops much better than the Western and Central China. Li, et al. [3] analyzed the human development index of China's provinces in 1999, and found that the differences between various provinces was narrowing. Tan and Luo [4] thought, in spite of the shrinking gap between provinces, at the same time, there has been a polarization. That is, the pattern of high east and low west is strengthening. Song [5] estimated the HDI gap between the urban and rural areas. Results showed that the urban-rural income gap was the highest. Inequality among countries was not taken into consideration in most studies on HDI. Grimm [6] proposed a methodology where HDI could be computed for quintiles of the income distribution. By this method, human development levels of poor and rich countries could be compared. Harttgen and Klasen [7] provided a method for estimating HDI at the household level with data of 15 developing countries. This method could be used to analyze human development and inequality across population subgroups. Eric [8] analyzed 155 countries and concluded that 42 countries could not achieve unsustainable development because of low HDI.

Since the concept was put forward, the index was extended and developed constantly. The United Nations introduced the new HDI in 2010. Felice and Vasta [9] discussed and presents estimate of the new HDI to analyze the convergence in Italy from 1871-2007. They found different parts of Italy began to convergence from the late nineteenth century to 1970, but stopped in the last decades of the twentieth century. The Human Sustainable Development Index (HSDI) which adds the environmental dimension is a way to amend the traditional HDI. It was found by Bravo [10]. Although the HSDI was a step ahead compared to HDI, it was still insufficient when representing the environmental sustainability. Hou et al. [11] put forward a different way to construct HDI in terms of capturing the pure flow of human development in the areas of material well-being, education and health. Ravallion [12] put forward an alternative index which had less troubling tradeoffs while imperfect substitution was still allowed.

Scholars are also interested in the relationship between HDI and other variables. Samuel [13] analyzed the association between worldwide prevalence of physical inactivity with development level of each country. They found that HDI was positively correlated with prevalence of physical inactivity. Li et al. [14] studies HDI of 141 countries and found it was inversely correlated with HIV/AIDS mortality, prevalence, and incidence rates. Yekeen [15] used HDI to measure deprivations among urban households in Minna, Nigeria. Freddie [16] divided HDI into four levels (low, medium, high, and very high) to investigate global cancer transitions. Nadia [17] used a panel cointegration and error correction model to analyze the causality relationship between energy consumption as well as electricity consumption and HDI. They found little relationship between in the short term, but a negative cointegration relationship between energy consumption and the HDI, as well as a positive cointegration relationship between electricity consumption and HDI.

Yang et al. [18,19] used the method of principal component analysis based on the covariance matrix to analyze human development in all regions in China since 1990, and results showed that regional disparities in economy, education, health and other aspects were obvious. The income and wage inequality are the focus of most scholars, such as $\mathrm{Hu}$ [20], Qin et al. [21], Gustafsson [22], 
Appleton et al. [23]. Many researchers also pay attention to regional disparity and its influencing factors. Naranpanawa [24] found that the rich and fast-growing middle-income states would benefit from trade liberalization, while it had a marginal or negative influence on the poor states in the short run, by using a multiregional Computable General Equilibrium (CGE) model of Indian. Duan [25] found that population mobility of China also had a significant impact on the tendency and structure of regional disparity, and the regional disparity was enlarged by the population mobility since 1978 . Chirila [26] investigated how the regional disparities were influenced by economic and financial crisis in Romania and European Union. Song [27] analyzed intercity regional disparity in China and presented evidence on the evolution and magnitude of regional disparities. He also estimated how regional per capita income (PCI) and per capita gross domestic product (PCGDP) responded to specific regional and national policies. By conducting counterfactual experiments, Liu [28] assessed the influences of technological changes on China's regional disparities. The results generally suggested that China's regional disparities were enlarged by overall technological change between 1987 and 2000. Literatures both at home and abroad on regional disparities from an empirical perspective adopted two ways: one was to validate the convergence hypothesis (Barro [29], Mankiw [30].); the other was to measure the inequality and analyze its dynamic changes (Quah [31], Sala-i-Martin [32]). Goals of those two methods were consistent, which were to test whether the income distribution of developed and underdeveloped regions was equal or polarized. Most of those studies concentrated on the indicator of income, but few scholars used other welfare indicators to analyze the social development in China. With the improvement of technology and communication, compared with researches on income gap, analysis of disparities in education, health care and others is also of practical significance. Therefore, based on the convergence theory, we use abovementioned methods to analyze regional disparities in social development and compensate the shortage of existing literature.

Almost every country takes sustainable development as its ultimate goal of development. The existing literatures usually focus more on how to achieve sustainable development. Cristina [33] analyzed the steps needed to progress towards a valid sustainable development. Cornescu [34] selected the indicators of sustainable development according to the characteristic of each country to extend the sustainability assessment framework. Nuzir [35] studied the role of education facility in sustainable urban development by estimating its influence on the development of economy, society and environment. Radjiyev et al. [36] found the ergonomics could have an impact on sustainable development. Based on the PCA, Bolcárová [37] aimed to create an aggregated index of sustainable development from SDIs for $27 \mathrm{EU}$ countries. This new aggregated index was related with economic growth and they found that the correlation between the economic growth and aggregated SD index was negative in most of the $27 \mathrm{EU}$ countries. Can every country achieve it? Chansarn [38] used the Data Envelopment Analysis (DEA) to study the sustainable human development of 115 high and middle income countries which were divided into three groups according to their income levels. The findings revealed that certain countries could realize the sustainable human development while other countries could not. Elizabeth A. Stanton [39] explored the dimensions of equity/sustainability linkage from the perspective of public goods analysis. Qin [40] pointed out that in the process of social transformation, sustainable development in China faced new challenges and advised several aspects including environmental law, principle of prevention, environmental impact and risk assessment system and green tax system to better respond to these challenges. Corina Rădulescu et al. [41] proposed a conceptual integrated model which promoted a balance of interaction between systems-economy, human, environment and technology-in a dynamic, flexible and functional process, in order to promote the sustainable development in Maramures County.

The main structure of this paper is as follows: in Section 2, we use the convergence theory to analyze differences in the human development index after a brief review of literature; Section 3 makes an empirical study of convergence of social development of China's 31 provinces and analysis of influencing factors of social development through the method of $\beta$ and $\sigma$ convergence; in Section 4, 
regional inequality in social development of China is measured, and its dynamic changes are further discussed and explored; Section 5 presents corresponding conclusions and policy recommendations.

\section{Convergence of the Human Development Index (HDI)}

\subsection{Theories and Methods of Convergence}

The convergence hypothesis is derived from the neo-classical growth theory which emphasizes the effect of capital investment on economic growth. A production function with constant returns to scale and the diminishing returns of capital is assumed. That is, the economy with lower level of initial productivity enjoys a higher rate of growth in productivity and as such will catch up with the more developed economies. Validation of the convergence hypothesis is of great theoretical and practical significance. It can not only test neo-classical growth theory in some areas, but also analyze its influencing factors and internal development mechanism.

To explain the process of catching up among countries or regions, Barro [42], Barro and Sala-I-Martin [43] proposed two methods to validate the convergence hypothesis, namely the $\beta$-convergence method and $\sigma$-convergence method. The former one mainly concentrates on the difference in growth rate among countries or regions while the latter one focuses on distribution difference in growth rate. In addition, the $\beta$-convergence method can be classified into the absolute convergence and conditional convergence method. The absolute convergence method assumes that conditions in all regions are the same except the initial capital. That is to say, not only all regions can reach the steady state, with similar technological advances and policies, but also the long-term equilibrium levels of different regions are the same. The conditional convergence assumes different speeds of technological progress or different levels of output per capita in different regions. Economic growth depends on the initial level of income, but is restricted by other factors, such as savings, population growth rate and environmental policies. When it comes to the conditional convergence, the convergence path may be different in different countries or regions, but after introducing some key control variables, all countries eventually converge to the same steady-state.

In addition, some scholars further extended the concept of convergence and proposed the "convergence clubs". The "convergence clubs" emphasizes that due to differences in initial state, different economies can lead to different kinds of equilibrium, which is different from the concept of conditional convergence. Hence, underdeveloped countries (or regions) and developed countries (or regions) have their own conditional convergences, but the differences between the two groups present no sign of narrowing. Galor [44] argued that this phenomenon was caused by differences in labor endowment.

In recent years, a great deal of empirical analysis has been made of the convergence of regional economic growth in China (Lin and Liu, [45]). Many scholars also applied the convergence method in other fields for empirical test. Zhang and Liu [46] studied the convergence of fiscal policies of 29 provinces in China during 1994-2005, arguing that tax revenue per capita, individual income tax per capita and other variables at provincial level in China converged. Those studies not only enriches the content of convergence, provides new analysis perspectives, but also gives insight into analysis of regional differences in social development in China.

Analysis of the convergence of the human development index has also attracted attention of foreign scholars. Noorbakhsh [47] studied differences in social development of developed and developing countries with data of 93 countries during 1975-2001, and analyzed the inequalities in social development among different countries and their dynamic changes. After making appropriate improvements, on the basis of studies of Noorbakhsh [47], we analyze the issue with panel data of 31 provinces in China during 1997-2006. 


\subsection{Convergence of the Human Development Index (HDI)}

As a comprehensive indicator of social development, the human development index, proposed by the United Nations in 1990, is a composite index of four indicators. Its components are to reflect three major dimensions of development: (1) longevity, represented by life expectancy at birth; (2) acquisition of knowledge, represented by a measure of educational achievement based on a weighted sum of adult literacy rate and gross enrolment ratio in primary school, middle school and university; (3) a decent standard of living, represented by the logarithm of real income per capita (purchasing power parity) Therefore, the HDI includes two non-income indices: the education index and life expectancy index. Whether the convergence hypothesis can be applied to those two indices?

Based on the assumptions of neo-classical growth model, convergence of economic growth lies in diminishing marginal returns on capital. Firstly, the assumption of diminishing marginal returns on capital can not only be applied to the income component of HDI (real income per capita), but also can be used to two other non-income components of HDI-education and life expectancy index. As two regions with different initial levels of development, an equal amount of investment in education and health will bring in different returns. The rates of return of investment in education and health decline with the increase of investment, so the region with low initial level of investment achieves a higher growth rate, and ultimately converges. Secondly, the concept of steady-state growth rate can also be applied to education and life expectancy. Compared with output and income in the neo-classical growth model, indicators of adult literacy rate, life expectancy and gross enrolment ratio are obtained at national (or provincial) level and corresponding upper bounds are defined. Therefore, the steady-state growth rates of these indicators are more homogeneous. What is more important is that for countries (regions) with low quality of life, it is more meaningful to have access to technologies related to education and health to improve the literacy rate, life expectancy and gross enrolment ratio and achieve their basic standard of living, rather than to obtain technologies to raise their productivity levels.

Based on the analysis above, we think that in the long run, underdeveloped regions with initially low levels of social development will have higher growth rates than those developed regions and eventually reach the steady state. In the next section, we will use panel data of 31 provinces in China from 1997 to 2006 to verify the convergence of HDI empirically. Compared with the cross-country study of Noorbakhsh [47], the use of data of different regions in one country can effectively avoid explanation for plenty of non-economic factors, which can be represented by dummy variables. For different provinces, there is no difference in these non-economic factors at the same time.

\section{Empirical Analysis of Regional Convergence of Social Development in China}

\subsection{Empirical Analysis of $\beta$ Convergence of HDI in China}

The $\beta$ convergence method is derived from the neo-classical growth model, that is, to examine the convergence of regional economic growth by measuring the $\beta$ convergence coefficient. Its economic implication is: if the economic growth rate of underdeveloped region is higher than that of the developed region, then per capita income (output) of underdeveloped region will eventually catch up with that of the developed region. The $\beta$ convergence coefficient refers to the speed of certain economic indicator of undeveloped region to catch up with that of the developed region. The $\beta$ convergence model of HDI proposed by Noorbakhsh [47] is as follows:

$$
\frac{1}{T} \log \left(\frac{h d i_{i t+T}}{h d i_{i t}}\right)=\alpha+\beta \log \left(h d i_{i t}\right)+\sum_{j=1}^{j k} \lambda_{i j} S_{i j}+\mu_{i t}, \text { for } k=0,1,2, \ldots, k
$$

where, $h d i_{i t}=\frac{H D I_{i t}}{H D I_{t}}$ is the proportion of HDI of region $i$ in the average of HDI of all regions. This standardized human development index can reflect changes in the relative positions of different provinces, thus to indicate true level of development $\left(h d i_{i, t}>1\right.$ means the development level of province 
$i$ in year $t$ exceeds the national average, and $h d i_{i, t}<1$ means the development level of province $i$ in year $t$ is lower than the national average). $\frac{1}{T} \log \left(\frac{h d i_{i t+T}}{h d i_{i t}}\right)$ represents the average annual growth rate of HDI of region $i$ from period t to T. If $-1<\beta<0$, it means there exists $\beta$ convergence. It is equivalent to say that the growth rate of HDI is negatively related to the initial HDI level, and underdeveloped regions develop faster than developed regions. The closer $\beta$ approaches -1 , the faster the convergence speed is. The closer $\beta$ approaches 0 , the slower the converge speed is ( $\beta=0$ indicates no convergence; m means divergence). $S_{i j}$ indicates the $\mathrm{j}$-th structural condition variable, and $\lambda_{i j}$ is the corresponding coefficient. When the structural condition variable changes, there are $\mathrm{k}$ different models. When $k=0$, there is no structural condition variable, and Equation (1) is the absolute $\beta$ convergence model.

According to the modeling framework of Noorbakhsh [47], we set $\mathrm{T}=2$ to examine the average annual growth rate of HDI every three years during 1997-2006 and eliminate the effects of short-term fluctuations during the economic cycle. We adopt the fixed effects model to estimate the convergence Equation (1). First of all, based on the economic theories embodied in the regression equation, there is a correlation between the individual effects of the regression equation and other explanatory variables. To set the individual effects fixed can be theoretically supported. Instead, the random effects assume that unobservable individual effects have no correlation with the explanatory variables in the regression equation, which is considered to be inappropriate in this model. In addition, from the perspective of econometrics, we also use the fixed effects and random effects to estimate the individual effects, and all Hausman test results are highly significant. That is, the fixed effects method is better than the random effects approach. Thus, only estimation results of fixed effects method are presented.

In the choice of main variables of the model, we choose control variables reflecting conditional convergence based on contribution of components of the human development index. The proportion of fixed asset investment in GDP (tzl) of certain province reflects the impacts on income index of HDI. The share of public expenditure on health and education in total GDP of one province (JW) represents the contribution to life expectancy index and education index, respectively. The proportion of investment in electric power infrastructure in fixed asset investment indicates the level of infrastructure (Data of HDI comes from Tian et al. (2008) [48]; data of fixed asset investment and expenditure on science, education, culture and hygiene is from "China Statistical Yearbook" during 1998-2007 [49]; data of investment in electric power infrastructure is derived from "China Electric Power Yearbook") [49]. We verify the $\beta$ convergence hypothesis of HDI through a series of models, including conditional and absolute convergence. Empirical results are shown in Table 1.

Table 1. $\beta$ convergence model of HDI.

\begin{tabular}{|c|c|c|c|c|}
\hline model/variable & 1 & 2 & 3 & 4 \\
\hline Constant & $-0.0001(0.0002)$ & $0.0042(0.0012) * * *$ & $0.0149(0.0045) * * *$ & $0.0186(0.0046) * *$ \\
\hline Ln(hdi) & $-0.1081(0.0198) * * *$ & $-0.1213(0.0203) * * *$ & $-0.1175(0.0198) * * *$ & $-0.1344(0.0191)^{* * *}$ \\
\hline $\operatorname{Ln}(\mathrm{tzl})$ & & $0.0043(0.0012) * * *$ & $0.0061(0.0014) * * *$ & $0.0054(0.0014) * * *$ \\
\hline $\operatorname{Ln}(j w)$ & & & $0.0061(0.0025) * *$ & $0.0039(0.0027)$ * \\
\hline $\operatorname{Ln}(\mathrm{dltz})$ & & & & $0.0032(0.0006)^{* * *}$ \\
\hline Adjusted $\mathrm{R}^{2}$ & 0.5927 & 0.6813 & 0.6954 & 0.6990 \\
\hline F statistic & $12.5956 * * *$ & $17.4978 * * *$ & $18.0853 * * *$ & $17.8671 * * *$ \\
\hline
\end{tabular}

As is shown in Table 1, Model 1 reflects the absolute $\beta$ convergence. The coefficient of the variable $\ln \left(h d i_{i t}\right)$ is negative and significant at the $1 \%$ level, indicating clear tendency to convergence amongst provinces in the samples. However, the magnitude of the coefficient indicates very slow speed of convergence over the period. 
Model 2-4 introduces various control variables to reflect the conditional convergence hypothesis gradually. The neo-classical growth model emphasizes the role of capital investment in economic growth. When other variables are equal, in the long run, the higher the proportion of capital investment in GDP is, the more productive the effective labor is. Therefore, we introduce a variable into Model 2-proportion of capital investment in GDP (tzl) to reflect the effects on income component of HDI (real income per capita). As can be seen from Table 1, the coefficient of proportion of fixed assets investment is positive and significant at the $1 \%$ level, which is in accordance with the expectation of neo-classical growth theory. The coefficient of $\ln \left(h d i_{i t}\right)$ is negative and significant at the level of $1 \%$, and the absolute value of the coefficient in Model 2 is larger than that in Model 1, indicating that capital investment increases the speed of convergence from underdeveloped regions to developed regions. The new variable-proportion of public expenditure on education and health in GDP (JW) introduced into Model 3 on the basis of Model 2 reflects the effects on non-income components of HDI (education index and life expectancy index). The coefficient of this variable is positive and significant at the level of $5 \%$. However, the coefficient of $\ln \left(h d i_{i t}\right)$ is significantly negative, indicating the existence of conditional convergence.

Finally, we introduce the variable-share of electric power investment in fixed assets investment (dltz) into Model 4 to reflect the control variable of infrastructure. Energy is a prerequisite for meeting basic human needs. Suarez [50] believed that, in the initial stage, energy inputs play a significant role in promoting the increase of the human development index (HDI). Electricity power, an important secondary energy, is an important symbol of modern civilization. The supply and configuration of electric power infrastructure is a reflection of economic and social development. Therefore, on the basis of Model 3, the share of electricity power investment in fixed-asset investment (dltz) is introduced into Model 4. Results show that the coefficient of the variable is significantly positive at the $1 \%$ level. Meanwhile, $\overline{R^{2}}$ of the equation becomes larger, which means the electric power investment has a positive effect on social development. The coefficient of $\ln \left(h d i_{i t}\right)$ remains significantly negative and its absolute value is maximum in Model 4, indicating the fastest convergence speed.

Empirical analysis above provides support for the proposition of conditional $\beta$ convergence and weak absolute convergence of social development in China. In the models above, coefficients of $\ln \left(h d i_{i t}\right)$ are significantly negative, indicating that the results are robust. After control variables are introduced, the convergence speed becomes faster. As can be seen from the influencing factors of conditional convergence, the speed of regional convergence of social development is related with fixed assets investment, public expenditure on health and education as well as infrastructure investment. From the perspective of economic theories, due to diminishing marginal returns on capital, underdeveloped areas with less capital have larger margins of capital and higher rates of capital accumulation, thus to attract capital inflows. Increasing health and education investments in underdeveloped regions contributes to high-quality and healthy human capital for regional economic and social development. In addition, infrastructure is a prerequisite for economic growth and social development. Effective investment in electric power infrastructure is beneficial to transforming resource superiority of underdeveloped regions into economic growth, increasing tax revenues, improving employment and promoting the social development convergence.

\subsection{Empirical Analysis of $\sigma$ Convergence of Regional Human Development Index in China}

The so-called $\sigma$ convergence refers to: in the long run, countries or regions that deviate from the mean would converge to the steady state. The $\sigma$ convergence is a necessary but not sufficient condition for $\beta$ convergence. In the existing literature, empirical researches on $\sigma$ convergence generally focus on the standard deviation of a log transformed variable, whose implicit assumption is that for all countries (or regions), the steady-state levels and time trends of the examined variables are the same. Therefore, the $\sigma$ convergence of HDI indicates that as time goes by, the standard deviation of HDI 
of different countries (or regions) is decreasing, and that social development level shows a trend of convergence. Set $\sigma_{t}$ as standard deviation of $\log$ (hdi) in time $t$, namely:

$$
\sigma_{t}=\sqrt{\frac{\sum_{p=1}^{n}\left[\log \left(\mathrm{hdi}_{i t}\right)-\overline{\log \left(\mathrm{hdi}_{i t}\right)}\right]^{2}}{n-1}}
$$

where, $\mathrm{n}$ is the number of the provinces. In addition, Liu and Zhang [51] estimated the $\sigma$ convergence by calculating the coefficient of variation and Gini coefficient as a complement to the standard deviation method. Therefore, we use the abovementioned method to measure the $\sigma$ convergence of regional distribution of HDI in China during 1997-2006, as is shown in Table 2. The SD in Table 2 is the standard deviation of $\log (\mathrm{hdi})$. CV represents the coefficient of variation, which is the ratio of standard deviation to the mean of distribution, while the Gini coefficient (Gini) is a measure of dispersion amongst provinces (Here, calculation of the Gin coefficient does not take population into account. The simplified formula is: Gini $=\frac{1}{2 n^{2} \mu} \sum_{i=1}^{N} \sum_{j=1}^{N}\left|y_{i}-y_{j}\right|$, where, $n$ is the number of regions and $y_{i}$ is the HDI of region $i)$.

Table 2. Estimate of $\sigma$ convergence of HDI.

\begin{tabular}{cccccccc}
\hline Year & SD Log(hdi) & CV & Gini & Year & SD Log(hdi) & CV & Gini \\
\hline 1997 & 0.0941 & 0.0910 & 0.0488 & 2002 & 0.0751 & 0.0740 & 0.0407 \\
1998 & 0.0951 & 0.0915 & 0.0488 & 2003 & 0.0783 & 0.0760 & 0.0405 \\
1999 & 0.0918 & 0.0881 & 0.0468 & 2004 & 0.0682 & 0.0671 & 0.0364 \\
2000 & 0.0856 & 0.0829 & 0.0446 & 2005 & 0.0656 & 0.0644 & 0.0352 \\
2001 & 0.0813 & 0.0792 & 0.0427 & 2006 & 0.0649 & 0.0635 & 0.0344 \\
\hline
\end{tabular}

Obviously, as time goes on, the standard deviation (SD), coefficient of variation (CV) and Gini coefficient (Gini) become smaller. All measures show that social development of different regions in China converge at a certain speed. However, the pace of convergence seems to be a little slow, which is consistent with our previous results of $\beta$-convergence.

\section{Measurement of Population-Weighted Regional Inequality and Its Dynamic Changes}

The previous section focuses on validation for the convergence of social development in China. However, the abovementioned method of assessing the degree of convergence among different regions does not take into account the population of the provinces concerned. In addition, as convergence is basically about poor countries catching up with rich countries, Quah [31] believed that it is better to analyze the dynamic distribution of cross-regional economic development but not the convergence of individual economy to their own steady state. As can be seen from the literature on economic growth in recent years, this method has become one of the hot issues for scholars (Quah [31]; Morrisson [52]). Therefore, in this section, from the viewpoint of economic growth distribution, we investigate regional inequality of social development and its dynamic changes in China.

First of all, we use two methods to measure inequality - the Gini coefficient and Theil index, and take into account the population share of provinces. The Gini coefficient is a statistical indicator measuring the inequality of income in a country or region, whose range is [0,1]. Currently, there exist many formulas and algorithms for calculation and decomposition of Gini coefficient. Here we adopt the population-weighted Gini coefficient, which is calculated as follows:

$$
\text { Ginip }=\frac{1}{\mu} \sum_{i=1}^{N} \sum_{j=1}^{N} f\left(y_{i}\right) \mathrm{f}\left(\mathrm{y}_{j}\right)\left|y_{i}-y_{j}\right|
$$


where, $n$ is the number of regions; $y_{i}$ and is HDI of region $i ; f\left(y_{i}\right)$ represents the proportion of population of region $i$ in the total population; $\mu$ indicates the average of HDI of all regions. While the formula of Theil index is as follows:

$$
T=\sum_{i=1}^{N} Y_{i} \log \frac{Y_{i}}{X_{i}}
$$

where, $n$ is the number of regions, $Y_{i}$ and $X_{i}$ is HDI and the proportion of population of region $i$ in the total population, respectively. The Larger the Theil index is, the higher the regional inequality is; conversely, the smaller the Theil index is, the lower the inequality in social development is.

Most of the literature on decomposition results of Gini coefficient and Theil coefficient show that regional inequality in China is mainly from provincial inequality, and provincial inequality accounts for a small share (Yao and Zhang, [53]). Therefore, we mainly use these two methods to calculate the Gini coefficient and Theil index of provincial social development level in China. Results are shown in Table 3.

Table 3. Measurement of population-weighted inequality.

\begin{tabular}{ccc}
\hline Year & Gini coefficient P (country) & Theil index (country) \\
\hline 1998 & 0.0686 & 0.2841 \\
2000 & 0.0614 & 0.2813 \\
2002 & 0.0528 & 0.2844 \\
2004 & 0.0570 & 0.2816 \\
2006 & 0.0562 & 0.2746 \\
\hline
\end{tabular}

As can be seen from the results in Table 3, The Gini coefficients of HDI of different provinces of China show a trend of slight decline and weak convergence. The Theil index changes little. It rises slightly only in 2002, and declines little throughout the period, of which the overall trend is in line with the conclusion of weak convergence in the previous section.

Another way to analyze regional distribution of HDI is to study the degree of changes in distribution of different regions throughout the country over time. In most domestic studies, China is divided into Eastern, Central and Western regions. Regional economic policies are conducted according to the pattern of the three regions, which occupies an important position in China's classification system of economic zone. Therefore, this paper still adopts the abovementioned classification of the three regions (In this article, the Eastern China includes Beijing, Tianjin, Shanghai, Liaoning, Shandong, Jiangsu, Zhejiang, Fujian, Guangdong, Hainan, and Hebei; the Central China includes Anhui, Henan, Hubei, Hunan, Heilongjiang, Jilin, Shanxi and Jiangxi; the Western China includes Gansu, Tibet, Qinghai, Ningxia, Sichuan, Shanxi, Inner Mongolia, Xinjiang, Guangxi, Guizhou and Chongqing). Table 4 shows the regional composition of various quintiles of the distribution of HDI for all provinces during the sample period.

It shows that there is disparity of social development in the distribution of provinces in China. First, the second row of the table shows the distribution of provinces in various regions of China. The share of the number of provinces in Eastern, Central and Western China in the total country is $35.5 \%, 25.8 \%$ and $38.7 \%$, respectively. However, we find that, those provinces at the upper one-third percentile are dominated by the Eastern China, while provinces at the lower one-third percentile are dominated by the Western China. The overall picture for the dynamics of human development during the entire period (1997-2006) reveals little change for the most developed region (Eastern China), while the changes in the distribution between Central and Western China are more notable. 
Table 4. Changes in regional HDI distribution at different percentile levels (\%).

\begin{tabular}{cccccc}
\hline \multirow{2}{*}{1} & Eastern China & Central China & Western China & Total \\
\cline { 2 - 6 } \multirow{3}{*}{1997} & distribution & $\mathbf{3 5 . 5}$ & $\mathbf{2 5 . 8}$ & $\mathbf{3 8 . 7}$ & $\mathbf{1 0 0 . 0}$ \\
\hline \multirow{3}{*}{2001} & lower 1/3 & 0.0 & 10.0 & 90.0 & 100.0 \\
& Middle 1/3 & 18.2 & 54.5 & 27.3 & 100.0 \\
& Upper 1/3 & 90.0 & 10.0 & 0.0 & 100.0 \\
\hline \multirow{3}{*}{2006} & Lower 1/3 & 0.0 & 20.0 & 80.0 & 100.0 \\
& Middle 1/3 & 18.2 & 45.4 & 36.4 & 100.0 \\
& Upper 1/3 & 100.0 & 0.0 & 0.0 & 100.0 \\
& Lower 1/3 & 0.0 & 30.0 & 70.0 & 100.0 \\
& Middle 1/3 & 18.2 & 36.4 & 45.4 & 100.0 \\
& Upper 1/3 & 90.0 & 10.0 & 0.0 & 100.0 \\
\hline
\end{tabular}

In 1997, the vast majority of provinces at the upper one-third percentile of HDI are in Eastern China (Eastern China, 90\%; Central China, 10\%, respectively), whereas the number of provinces in Western and Eastern China accounts for $90 \%$ and $10 \%$ of total provinces at the lower one-third percentile, respectively. The HDI distribution changed in 2001, as opposed to 1997. The number of provinces in the Western and Eastern China accounts for $80 \%$ and $20 \%$ of total provinces at the lower one-third percentile, respectively. This is because after 1997, with the establishment of Chongqing municipality, location advantage of Chongqing played an important role, and its economic and social indicators improved substantially, leading the HDI of Chongqing Province to rise to the upper one-third percentile. While during this period, the ranking of HDI of Anhui Province in the whole country declined. For provinces at the upper one-third percentile, as the HDI of Heilongjiang province decreased, while the HDI of Hainan Province increased, provinces at the upper one-third percentile are all in Eastern China. Since 2006, the number of provinces in Western and Eastern China have even accounted for $70 \%$ and $30 \%$ of total provinces at the lower one-third percentile of HDI, respectively. The reason is that Inner Mongolia in Western China has developed rapidly in recent years, while Hunan and other provinces in Central China have declined. The share of provinces in Central China provinces in total provinces at the middle one-third percentile decreased from $54.5 \%$ in 1997 to $36.4 \%$ in 2006 , while the share of provinces in the western part increased from $27.3 \%$ to $45.4 \%$. In terms of changes in social development in China, during 1997-2006, with the implementation of the Western Development Strategy, compared to provinces in Central China, provinces in Western China developed fast, and the gap between Central and Western China was narrowed. There is a trend of "convergence club" in Central and Western China. It seems that original poor regions (Western China) have remain stable while provinces in Central China which are relatively developed regions have declined.

In order to further study dynamic changes in regional inequality, we need to find out how countries change position over time at different intervals (taking population into account). This method has been often used in researches on changes in income distribution among different countries in recent years. Therefore, we use it to divide the HDI in each sub-period into four intervals according to the degree of deviation from the sample mean, and calculate corresponding dynamic changes of all sample points at different intervals. Table 5 shows that during each sub-period, the population share changes at different HDI intervals. The "population share" in the rows and columns of the table represents the population share at the beginning and the end of sample period. Comparing rows with columns in the matrix, we can analyze changes in regional inequality during each sample period. The retention rate represents the population share that does not change during the examined sample period while the upward rate and downward rate is the population share that moves to regions with higher and lower HDI, respectively.

As is shown in Table 5, during 1997-2001, regional distribution of HDI did not change obviously. $86.4 \%$ of population still stayed in the original interval, and the upward rate and downward rate was only 3.3\%, 10.3\%, respectively, which was the result of rise of position of Qinghai and Shanxi province 
(moving from the interval less than $5 / 6$ to the interval $(5 / 6,1)$ and decrease of position of Guangxi and Hunan (moving from the interval $(1,7 / 6)$ to the interval $(5 / 6,1)$. In addition, developed provinces in Eastern China converged to the interval $(1,7 / 6)$. As a result, the population share in the interval more than $7 / 6$ decreased from $1.2 \%$ in 1997 to $0 \%$ in 2001. During 2001-2006, the retention rate still kept high $(82.1 \%)$, while both the upward rate and upward rate increased to $10.3 \%$ and $7.6 \%$, respectively. During this period, due to accelerated development of Inner Mongolia and Chongqing, their HDI rose from the interval $(5 / 6,1)$ to the interval $(1,7 / 6)$. In addition, development of Tibet province made the population share in the interval less than $5 / 6$ declined to 0 . Those declined provinces are Hubei and Shanxi.

Table 5. Transfer matrix of HDI based on the population share and corresponding rates of change.

\begin{tabular}{|c|c|c|c|c|c|c|}
\hline \multirow{2}{*}{$\begin{array}{l}\text { Intervals with HDI } \\
\text { deviating from mean at } \\
\text { the end of sample period }\end{array}$} & \multicolumn{4}{|c|}{$\begin{array}{l}\text { Intervals with HDI deviating from mean } \\
\text { at the beginning of sample period }\end{array}$} & \multirow{2}{*}{$\begin{array}{l}\text { Population } \\
\text { share }\end{array}$} & \multirow{2}{*}{$\begin{array}{l}\text { Rate of } \\
\text { change }\end{array}$} \\
\hline & more than $7 / 6$ & $(1,7 / 6)$ & $(5 / 6,1)$ & Less than $5 / 6$ & & \\
\hline \multicolumn{7}{|c|}{ 1997-2001 } \\
\hline more than $7 / 6$ & 0.0 & 0.0 & 0.0 & 0.0 & 0.0 & \\
\hline$(1,7 / 6)$ & 100.0 & 85.1 & 7.8 & 0.0 & 56.3 & \\
\hline$(5 / 6,1)$ & 0.0 & 14.9 & 92.2 & 33.3 & 43.5 & \\
\hline Less than $5 / 6$ & 0.0 & 0.0 & 0.0 & 66.7 & 0.2 & \\
\hline Population share & 1.2 & 61 & 37.2 & 0.6 & 100.0 & \\
\hline Retention rate & & & & & & 86.4 \\
\hline Upward rate & & & & & & 3.3 \\
\hline Downward rate & & & & & & 10.3 \\
\hline \multicolumn{7}{|c|}{ 2001-2006 } \\
\hline more than $7 / 6$ & 0.0 & 0.0 & 0.0 & 0.0 & 0.0 & \\
\hline$(1,7 / 6)$ & 0.0 & 86.5 & 23.3 & 0.0 & 60.2 & \\
\hline$(5 / 6,1)$ & 0.0 & 13.5 & 76.7 & 100.0 & 39.8 & \\
\hline Less than $5 / 6$ & 0.0 & 0.0 & 0.0 & 0.0 & 0.0 & \\
\hline Population share & 0.0 & 56.3 & 43.5 & 0.2 & 100.0 & \\
\hline Retention rate & & & & & & 82.1 \\
\hline Upward rate & & & & & & 10.3 \\
\hline Downward rate & & & & & & 7.6 \\
\hline \multicolumn{7}{|c|}{ 1997-2006 } \\
\hline more than $7 / 6$ & 0.0 & 0.0 & 0.0 & 0.0 & 0.0 & \\
\hline$(1,7 / 6)$ & 100.0 & 77.3 & 57.5 & 0.0 & 60.2 & \\
\hline$(5 / 6,1)$ & 0.0 & 22.7 & 42.5 & 100.0 & 39.8 & \\
\hline Less than $5 / 6$ & 0.0 & 0.0 & 0.0 & 0.0 & 0.0 & \\
\hline Population share & 1.2 & 61 & 37.2 & 0.6 & 100.0 & \\
\hline Retention rate & & & & & & 74.1 \\
\hline Upward rate & & & & & & 10.8 \\
\hline Downward rate & & & & & & 15.1 \\
\hline
\end{tabular}

The last part of Table 5 shows dynamic changes in distribution of HDI during the examined sample period (1997-2006). Although the retention rate was high (74.1\%), but the upward or downward trend was obvious. The upward and downward rate was $10.8 \%$ and $15.1 \%$, respectively. We find that developed provinces which originally concentrated in the interval more than $7 / 6$ moved to the interval $(1,7 / 6)$, while underdeveloped provinces moved from the interval less than $5 / 6$ to the interval $(5 / 6,1)$. What is more important is that during this period, rapid development of some provinces in Western China contributed to rise of their positions, while provinces in Central China developed slowly, leading to the gap between provinces in central and western narrowed. Therefore, in the long run, regional distribution of social development in China evolves from the "solo peak" to "twin peaks", and shows a trend of "twin-peak convergence". That is, coastal provinces, which are in Eastern China, converge to the rich ones, while inland provinces which are in Western and Central China converge to the poor ones.

The main reasons for this phenomenon are: from the reform and opening up to the early 1990s, China gave priority to development of coastal regions, which are in Eastern China. Introduction of capital and talents, as well as the geographical advantage of coastal regions exacerbated the gap 
between coastal and inland regions. After 2000, the central government implemented the Western Development Strategy, and significantly increased investment in the construction of Western China. Provinces in Western China such as Chongqing and Inner Mongolia developed much. Therefore, as the Eastern China rapidly developed and Western China experienced considerable progress, the Central China was in the shade and lagged behind, giving rise to the so-called "central downfall".

\section{Conclusions and Policy Implications}

By applying the theory of convergence and concept of inequality to study the evolution of social development, we analyze regional inequality in social development in China both theoretically and empirically .First of all, empirical results of methods of $\beta$ and $\sigma$ convergence show evidence of weak absolute convergence and conditional convergence of provincial human development. Results of various models are robust and remain the same. Test results of $\sigma$ convergence are in line with those for $\beta$-convergence. Meanwhile, we find fixed-asset investment, public expenditure on education and health and infrastructure construction have positive effects on social development.

When the population of provinces are taken into account, the results show that the change of Gini coefficient and Theil index is small in spite of the downward trend. Furthermore, using the method of distribution dynamics to analyze dynamic changes and the degree of changes in social development in different provinces, we find that the distribution of provincial social development in China has a tendency to converge as "twin peaks". That is, provinces of Eastern China converge to the rich ones, while the West and Central China converge to the poor ones, and the Central China was in the shade and lagged behind. Therefore, the "rise of Central China" plan is necessary because it can play an important role in promoting effective link between developed Eastern China and underdeveloped Western China, which is of great significance in promoting balanced development among regions and sustainable development of macro economy.

To promote the "rise of central China", the existing "three bases, one hub" should be strongly highlighted and developed. It enhances industrial level, promotes the industrialization and urbanization and plays an active role in connecting the Eastern and Western China. First of all, the central China is rich in fertile land resources. As one of China's main grain produce areas, it should focus on food production, agricultural structure adjustment and agriculture industrialization. Secondly, in terms of energy and raw materials, Shanxi, Henan, Hubei, Anhui and other places have abundant coal resources. In accordance with the principles of optimized layout, efficient utilization, safety and environmental protection, it is necessary to consolidate and enhance the role of Central China as an energy and raw material base, accelerate power grid construction, and vigorously develop the deep processing of raw materials. Thirdly, with regards to equipment manufacturing, Wuhan, Changsha, Zhuzhou, Zhengzhou and other old industrial bases should be brought into full play, to promote independent innovation, accelerate the development of high-tech industries, and enhance the overall strength of equipment manufacturing industry. Finally, advantages of transport hubs in the Central China should be made full use, in order to optimize the allocation of transport resources, accelerate the construction of railway networks and power grids, perfect the road network, and improve the capacity of water and pipeline transport. Implementing the "Rise of Central China" strategy and promote economic and social development in Central China is of great significance to promote the balanced development between regions.

Acknowledgments: Acknowledgments: This paper is supported by the Fundamental Research Funds for the Central Universities (No. 20720151039) and the National Natural Science Foundation of China (No.71203186).

Author Contributions: Author Contributions: Yang, F. constructed econometric models, performed all calculations and wrote most of the paper. Pan, S.Y. collected data on HDI and wrote the literature review. Yao, X. proposed research ideas, analyzed research results and offered policy suggestions.

Conflicts of Interest: Conflicts of Interest: The authors declare no conflict of interest. 


\section{References}

1. United Nations Development Programme. Human Development Report; Hoechstetter Printing: Pittsburgh, PA, USA, 2005.

2. Mikkelson, G.M. Growth Is the Problem; Equality Is the Solution. Sustainability 2013, 5, 432-439. [CrossRef]

3. Li, S.T.; Hou, Y.Z.; Feng, J.; He, J.W.; Xuan, X.W. The Past, the Present and the Future of the Regional Disparity in China. J. Reform 2004, 5, 6-18. (In Chinese).

4. Qin, C.L.; Luo, Q. A Study on the Regional Disparities of Human Development in China. J. Econ. Surv. 2004, 6, 49-51. (In Chinese)

5. Song, H.Y.; Ma, Y.L. Measuring Rural-Urban Disparity in China by Human Development Index Method. Econ. Res. J. 2004, 11, 4-15. (In Chinese)

6. Grimm, M.A. Human Development Index by Income Groups. World Dev. 2008, 36, 2527-2546. [CrossRef]

7. Harttgen, K.; Klasen, S. A Household-Based Human Development Index. World Dev. 2012, 40, 878-899.

8. Eric, N. The Human Development Index and Sustainability-A Constructive Proposal. Ecol. Econ. 2001, 39, 101-114.

9. Felice, E.; Vasta, M. Passive Modernization? Social Indicators and Human Development in Italy's Regions (1871-2009). Eur. Rev. Econ. Hist. 2015, 19, 44-66. [CrossRef]

10. Bravo, G. The Human Sustainable Development Index: New calculations and a first critical analysis. Ecol. Indic. 2014, 37, 145-150. [CrossRef]

11. Hou, J.; Walsh, P.P.; Zhang, J. The dynamics of Human Development Index. Soc. Sci. J. 2014. [CrossRef]

12. Ravallion, M. Troubling tradeoffs in the Human Development Index. J. Dev. Econ. 2012, 99, 201-209. [CrossRef]

13. Samuel, C.D.; Pedro, C.H.; Rodrigo, S.R.; Harold, W.K. Worldwide prevalence of physical inactivity and its association with human development index in 76 countries. Prev. Med. 2011, 53, 24-28.

14. Li, X.L.; Yi, C.; Chao, H.Y.; You, M.L.; Juan, Y. National HIV/AIDS mortality, prevalence, and incidence rates are associated with the Human Development Index. Am. J. Infect. Control 2014, 42, 1044-1048.

15. Yekeen, A.S. Application of human development index to measurement of deprivations among urban households in Minna, Nigeria. Habitat Int. 2008, 32, 384-398.

16. Freddie, B.; Ahmedin, J.; Nathan, G.; Jacques, F.; David, F. Global cancer transitions according to the Human Development Index (2008-2030): A population-based study. Lancet Oncol. 2012, 13, 790-801.

17. Nadia, S.O. Energy consumption and human development: Evidence from a panel cointegration and error correction model. Energy 2013, 63, 28-41.

18. Yang, Y.H.; Hu, A.G.; Zhang, N. An Alternative to Human Development Index with Principal Component Analysis. Econ. Res. J. 2005, 7, 4-17. (In Chinese)

19. Yang, Y.H.; Hu, A.G.; Zhang, N. The Regional Disparities and Imbalance of China's Human Development: A Historical Perspective of "One China, Four worlds". China Econ. Q. 2006, 5, 803-816. (In Chinese)

20. Hu, D.P. Trade, rural-urban migration, and regional income disparity in developing countries: A spatial general equilibrium model inspired by the case of China. Reg. Sci. Urban Econ. 2002, 32, 311-338. [CrossRef]

21. Qin, D.; Cagas, M.A.; Ducanes, G.; He, X.H.; Liu, R.; Liu, S.G. Effects of income inequality on China's economic growth. J. Policy Model. 2009, 31, 69-86. [CrossRef]

22. Gustafsson, B.; Sai, D. Rank, income and income inequality in urban China. China Econ. Rev. 2009, 20, 497-507. [CrossRef]

23. Appleton, S.; Song, L.; Xia, Q.J. Understanding Urban Wage Inequality in China 1988-2008: Evidence from Quantile Analysis. World Dev. 2014, 62, 1-13. [CrossRef]

24. Naranpanawa, A.; Arora, R. Does Trade Liberalization Promote Regional Disparities? Evidence from a Multiregional CGE Model of India. World Dev. 2014, 64, 339-349. [CrossRef]

25. Duan, P.Z. Influence of China's Population Mobility on the Change of Regional Disparity since 1978. China Popul. Resour. Environ. 2008, 18, 27-33.

26. Chirila, V.; Chirila, C. The impact of economic and financial crisis on the regional disparities in Romania and European Union. Proced. Soc. Behav. Sci. 2014, 109, 502-506. [CrossRef]

27. Song, S.F.; Chu, G.S.F.; Chao, R.Q. Intercity regional disparity in China. China Econ. Rev. 2000, 11, $246-261$. [CrossRef] 
28. Liu, X.Y.; Wang, X.Q.; Whalley, J.; Xin, X. Technological change and China's regional disparities-A calibrated equilibrium analysis. Econ. Model. 2011, 28, 582-588. [CrossRef]

29. Barro, R.J.; Sala-i-Martin, X. Convergence. J. Polit. Econ. 1992, 100, 223-251. [CrossRef]

30. Mankiw, N.G.; Romer, D.; Weil, D.N. A Contribution to the Empirics of Economic Growth. Q. J. Econ. 1992, 107, 407-437. [CrossRef]

31. Quah, D.T. Twin Peaks: Growth and Convergence in Models of Distribution Dynamics. Econ. J. 1996, 106, 1045-1055. [CrossRef]

32. Sala-i-Martin, X. The Disturbing "Rise" of Global Income Inequality. Natl. Bur. Econ. Res. 2002. Available online: http:/ / www.nber.org/papers/w8904.pdf (accessed on 25 January 2016).

33. Cristina, M.D. Saferational approach to a valid sustainable development. Proced. Econ. Financ. 2014, 8, 497-504. [CrossRef]

34. Cornescu, V.; Adam, R. Considerations regarding the role of indicators used in the analysis and assessment of sustainable development in the EU. Proced. Econ. Financ. 2014, 8, 10-16. [CrossRef]

35. Nuzir, F.A.; Dewancker, B.J. Understanding the role of education facilities in sustainable urban development: A case study of KSRP, Kitakyushu, Japan. Proced. Environ. Sci. 2014, 20, 632-641. [CrossRef]

36. Radjiyev, A.; Qiu, H.; Xiong, D.P.; Nam, K. Ergonomics and sustainable development in the past two decades (1992e2011): Research trends and how ergonomics can contribute to sustainable development. Appl. Ergon. 2015, 46, 67-75. [CrossRef] [PubMed]

37. Bolcárová, P.; Kološta, S. Assessment of sustainable development in the EU 27 using aggregated SD index. Ecol. Indic. 2014, 48, 699-705. [CrossRef]

38. Chansarn, S. The Evaluation of the Sustainable Human Development: A Cross-Country Analysis Employing Slack-Based DEA. Proced. Environ. Sci. 2014, 20, 3-11. [CrossRef]

39. Elizabeth, A.S. The Tragedy of Maldistribution: Climate, Sustainability, and Equity. Sustainability 2012, 4, 394-411.

40. Qin, T.B. Challenges for Sustainable Development and Its Legal Response in China: A Perspective for Social Transformation. Sustainability 2014, 6, 5075-5106. [CrossRef]

41. Corina, R.; Rita, T.; Gratiela, B.; Madela, A.; Cristian, A.; Diana, C.T. Sustainable Development in Maramures County. Sustainability 2015, 7, 7622-7643.

42. Barro, R.J. Economic Growth in a cross section of countries. Q. J. Econ. 1991, 106, 407-443. [CrossRef]

43. Barro, R.J.; Sala-i-Martin, X. Economic Growth; McGraw Hill: New York, NY, USA, 1995.

44. Galor, O. Convergence? Inferences from Theoretical Models. Econ. J. 1996, 106, 1056-1069. [CrossRef]

45. Lin, Y.F.; Liu, M.X. Growth Convergence and Income Distribution in China. J. World Econ. 2003, 8, 3-14. (In Chinese)

46. Zhang, Y.L.; Liu, R. Analysis of China's Provincial Fiscal Policy Convergence: A Demonstration on Spatial Econometric Model. J. Cent. Univ. Financ. Econ. 2008, 4, 19-23. (In Chinese)

47. Noorbakhsh, F. International Convergence or Higher Inequality in Human Development? Evidence for 1975 to 2002. Available online: https:/ / www.econstor.eu/dspace/bitstream/10419/63439/1/510833616.pdf (accessed on 25 January 2016).

48. Tian, H.; Sun, J.P.; Zhu, Y.M. Comprehensive Measurement and Analysis for local Economic and Social Development-A Research Based on HDI. Econ. Manag. 2008, 2, 69-76. (In Chinese).

49. National Bureau of Statistics of the People's Republic of China. China Statistical Yearbook; China Statistical Publishing House: Beijing, China, 1998-2014. (In Chinese)

50. Suarez, C.E. Human Development and Energy: A View from the Developing Countries. In Energy for Survival and Development; Chagas, C., Colombo, U., Eds.; Ex Aedibvs Academicis in Civitate Vaticana: Vaticana City, Vaticana, 1996; pp. 93-116. Available online: http://www.casinapioiv.va/content/dam/ accademia/pdf/sv57pas.pdf (accessed on 25 January 2016).

51. Liu, S.C.; Zhang, X.J. The Features of China's Sustained High Growth and the Decline of Regional Economic Disparity. Econ. Res. J. 2007, 10, 17-31. (In Chinese) 
52. Bourguignon, F.; Morrisson, C. Inequality among World Citizens: 1820-1992. Am. Econ. Rev. 2002, 92, 727-744. [CrossRef]

53. Yao, S.J.; Zhang, Z.Y. On regional inequality and diverging clubs: A case study of contemporary China. J. Comp. Econ. 2001, 29, 466-484. [CrossRef]

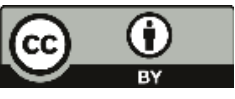

(C) 2016 by the authors. Licensee MDPI, Basel, Switzerland. This article is an open access article distributed under the terms and conditions of the Creative Commons Attribution (CC BY) license (http:/ / creativecommons.org/licenses/by/4.0/). 
Article

\title{
Does the Sustainable PPI Investments Promote Financial Market's Sustainable Development?
}

\author{
Tong Fu ${ }^{1, *}$, Hongzhang Chen ${ }^{2}$ and Yongrok Choi ${ }^{3, *}$ \\ 1 Institute of Industrial Economics, Jiangxi University of Finance and Economics, Nanchang 330013, China \\ 2 The Collaborative Innovation Center, Jiangxi University of Finance and Economics, Nanchang 330022, \\ China; chenhongz@jxufe.edu.cn \\ 3 Department of International Trade, Inha University, Inha-ro 100, Nam-gu, Incheon 402-751, Korea \\ * Correspondence: canjianft@hotmail.com or tfu@jxufe.edu.cn (T.F.); yrchoi@inha.ac.kr (Y.C.); \\ Tel.: +82-10-3281-8790 (Y.C.); Fax: +82-32-876-9328 (Y.C.)
}

Academic Editor: Malin Song

Received: 4 December 2015; Accepted: 20 January 2016; Published: 28 January 2016

\begin{abstract}
Since the late 1980s, most developing countries adopt a policy of attracting investments for Private Participation in Infrastructure (PPI) projects. With a perspective of sustainability, this paper offers a first attempt to examine whether the sustainable PPI investments promote financial market development. First, we demonstrate how the PPI policy enlargers the size of financial markets and then fosters the liquidity of financial markets in the static and dynamic conditions. Using the data from 33 developing countries during 1997-2012, we discover the significant promotion effect of PPI investments on the development of financial markets in the dimensions of size and liquidity. Additionally, we confirm the significant mediator effect of financial market size for the positive relationship between PPI investments and financial market liquidity. Both the promotion effect and mediation effect are robust to different control variables and estimation techniques used.
\end{abstract}

Keywords: sustainable investments; private participation in infrastructure; sustainable financial market development

\section{Introduction}

Since the late 1980s, most developing countries adopt a variety of Private Participation in Infrastructure (PPI) programs. Referring to Environmental, Social and Governance (ESG) criteria suggested by recent sustainability literature [1-5], both PPI investments and financial markets development (hereafter FMD) are sustainable (discussed in the second section). With a sustainability perspective, this paper studies whether the PPI investments promote FMD. However, some evidence suggests that governmental policies are unsustainable [6-8] and that sustainable investments do not spur sustainable development [9]. To examine the promotion effect, this paper first demonstrates the theoretical effect of the PPI policy on financial markets in the static and dynamic conditions. With historical data, we then provide objective evidence of the positive relationship between PPI investments and FMD. To the best of our knowledge, we offer a first attempt to examine the promotion effect of the sustainable PPI investments on the sustainable development of financial markets. Given that PPI investments and financial market development are sustainable, we omit the term of sustainability (or sustainable) hereafter unless otherwise especially emphasized.

This paper is motivated by the fact that the PPI policy attracts a large amount of investment capital into financial markets of developing countries. As discovered by Fu [10], 24.457\% (13.078\%) of PPI investments are larger than foreign direct investment (FDI) in 109 developing countries during 1984-2007. Namely, PPI investments can be significant for financial markets as FDI (for economic growths) are concerned (FDI [11] and inflation [12] are regarded as independent variables 
for FMD).This paper is also motivated by the poor explanation of economic theories for PPI programs. The existing industrial economics cannot explain the surge of PPI investments in developing countries. Many industrial economists have been "flirting with the idea of PPI and often owed to it" [13], but the efficiency gains of the PPI policy are "neither systematic nor guaranteed" in reality [14]. Most relevant works explicitly or implicitly assume that the privatization policy improves industrial efficiency [15-20]. Therefore, the existing literature cannot explain why the PPI policy is prevalent though its efficiency is controversial.

In contrast with the traditional government procurement, a PPI policy attracts investment capitals into the financial market. In a static condition, PPI investments necessarily enlarge the size of financial markets and improve the liquidity of financial markets. To describe the promotion effect of PPI policy in a dynamic condition, we follow the framework of Perotti and Laeven [21] to explain how the PPI policy establishes the government credibility and then builds the confidence of shareholders.

We use three empirical approaches to deal with the above mentioned concerns. First, we include the fixed effects of country and time in estimation to account for un-measurable country characteristics and common shocks across countries, respectively. Second, to address the potential heteroskedasticity and auto-correlation issue, we estimate the same equations with robust standard errors. Third, we conduct instrumental variable (hereafter, IV) estimations to address the endogeneity issues. We net out the country-specific component to yield a measure of PPI investments that only depends on the underlying characteristics inherent to the particular year and legal origin. Precisely, our instrument variable is the average of PPI investments within other countries at the same year and with the same legal origin. To lessen the concern of reverse causality, we lag all independent variables one period in IV estimations. We provide evidence of the significant promotion effect and mediation effect, irrespective of different control variables and estimation techniques used.

The paper is structured in six sections. Section 2 reviews the existing literature and illustrates our contributions. Section 3 demonstrates the promotion effect and mediation effect. Section 4 introduces our data and empirical methodology. Section 5 reports the estimation results and Section 6 presents the conclusions.

\section{PPI in Developing Countries}

Scholars expect an investment increase due to PPI policy, but overlook the promotion effect of sustainable PPI investments on FMD. The following explains the overlook, then introduces the sustainability perspective for PPI investments and FMD and finally illustrates our contributions.

\subsection{The Gap in the Existing Literature}

First, most sustainability scholars focus on social behavior or policies that directly impact ecological systems, e.g., the issue concerning resource consumption, carbon dioxide emissions [22,23] or waste recycling [24,25]. However, not only sustainable investments [26-28] but also the market share of sustainable investments [29] has been increasing at a fast pace in recent years. Some investors realize the relevance of sustainability for capital markets [30], but no academic works study the effect of sustainable investments on financial markets.

Second, a number of industrial economists analyze how the industrial behavior is affected by the particular types of private participation, including the privatization issue, Public Private Partnerships issue and concession issue (According to PPIAF [31], there is a fourth type of private participation, management \& lease contract. However, the management \& lease contract is equal to concession contract when it does not involve the construction of projects; otherwise, it equals actually Public Private Partnerships). However, the private participation literature ignores the effect of PPI on financial markets. Estache [13] explains the history of PPI, whereas Estache and Philippe [14] summarize the lessons of PPI in developing countries. The performance of PPI programsis qualitatively studied [32-34] or quantitatively assessed [35], but the corresponding findings are limited in the particular infrastructure sectors such as electricity. 
Third, financial or development economists uncover the sources of FMD, but overlook PPI investments. Financial economists have studied the link between FMD and GDP [36-38]. Development economists have investigated multiple types of capital inflow for financial sector development, e.g., FDI [11], official aids [39] and portfolio investments [40]. Boutchkova and Megginson [15] examine the legal environment effect on stock market development, but no attention is paid on whether the corresponding investments promote FMD.

\subsection{A New Perspective: Sustainable Investments and Sustainable Development}

Estache [13] points out that a PPI policy is adopted in developing countries because there are outcomes expected as follows.

Contribution to fiscal stabilization, increased investments, improved efficiency from a more competitive environment, contribution to growth, better access and affordability for residential users and improved governance.

Where fiscal stabilization and growth are macroeconomic benefits and the other expected outcomes reflect the micro performance. Both of these expected outcomes expose the properties of PPI investments. Combining the properties with the historical background, the PPI policy should satisfy ESG criteria such that the PPI investments are sustainable investments. The criteria are examined as follows.

First, the PPI policy is initiated in the context of reforms that generate unemployment or other negative macro-economic effects [13]; hence, fiscal stabilization and growth mentioned above contribute to social stability. The social criterion is satisfied. Second, increased investments need to ensure improved efficiency and governance. In fact, PPI programs are launched in developing countries when the efficiency of public service is severally criticized [13]. Therefore, the governance criterion is satisfied. Third, "better access and affordability for residential users" actually require the investments to satisfy the basic needs of the public. To satisfy the basic needs, the PPI policy generates the positive macro performance, but PPI investments cannot be the driving force of economic growth. In other words, the increased and improved public service need to consume some natural resources, but it is difficult to imagine how the basic needs over-consume the natural resources such that the ability of the next generation to obtain their basic needs is compromised.

Recalling that PPI investments are attracted to address the poor service quality and service deterioration that are the norm in many developing countries [41], nobody will suspect that PPI investments may disobey the requirement of sustainable development. When the present generation may not meet the public services, the PPI policy almost has no possibility to compromise the future generation's ability to meet their basic needs. More practically and reasonably, the potential detriment of PPI investments on ecological systems should be reduced because the infrastructure industry before a PPI policy is operated by governments with the lack of transparency and damaging political interference [42]. Therefore, PPI investments at least have the relative advantage of satisfying the ecological criterion than the public funds.

Despite PPI investments, FMD satisfies ESG criteria suggested by sustainability literature [1-5]. Unlike real economy, the development of financial markets has no causal impact on ecological systems. Equity issuing and transactions in financial markets do not violate ESG criteria. Intrinsically, there is no reason to say that the present generation over-develops financial markets such that the future generation cannot develop financial markets any more. In fact, if a development indicator is measured for social behavior, it must consider the sustainability requirement; otherwise it measures growth instead of development. This paper uses standardized measures in the existing literature on the development of financial markets; the sustainability of FMD should be naturally satisfied. 


\subsection{Our Contribution}

To test the promotion effect of PPI policy on sustainable FMD, we include investments due to all types of private participation (The previous works only focus on one particular form of private participation). Moreover, considering that previous scholars measure the privatization policy by the number of privatized firm, ignoring (or overlooking) the scale difference across the firms. We measure the private participation by the investment size, avoiding the heterogeneity issue.

Our paper confirms the promotion effect of PPI investments on financial markets. For one thing, our work offers a first attempt to study the effect of sustainable investments on financial markets. For another, given that sustainable FMD is significant for macroeconomic performance, e.g., economic growth or development [36-38], the promotion effect explains why most developing countries actively attract PPI investments although the efficiency of private participation (In fact, the negative feedbacks can be found in any particular type of private participation (see [43] for privatization, see [44] for Public Private Partnerships and see [45-47] for concession))is controversial [14].Comparing with the traditional perspective for economic efficiency, the sustainability perspective for FMD conforms more closely to reality. Most relevantly, several scholars study the effect of privatization policies on FMD [16-19], but they explicitly or implicitly assume that the privatization policy improves industrial efficiency. Their findings are un-robust to the potential inefficiency of private participations.

FMD is measured in the dimension of size or liquidity. Despite confirming the promotion effect on financial market size and financial market liquidity, we uncover the mediation effect of financial market size for the relationship between PPI investments and financial market liquidity. The significance of mediation mechanism illustrates the PPI policy first enlarges financial market size and then fosters financial market liquidity as we expect.

\section{PPI Investments and FMD}

Before formulating hypotheses, the following model demonstrates why the PPI policy promotes the credibility of a government for PPI investments and then increases share prices of PPI programs over time.

\subsection{The Model}

Our model assumes the industrial efficiency is unchanged after introducing private participation. Thus, the promotion effect of PPI investments in this paper is not based on the potential improvement of industrial efficiency.

A government announces the policy of introducing private participation for $n$ infrastructure projects. For simplicity, we assume that every project requiring PPI investments, $I$, is completed in one period. The discount factor is $\delta<1$, whereas $\frac{1}{\delta}$ is the inflation factor. Moreover, we follow the assumptions provided by Perotti and Laeven [21] for the framework. First, if the government does not intervene ex post, investors will obtain normal profits. Otherwise, the investors will lose all investments. In other words, the investors will obtain the values of shares $I$ or 0 for investments.

Second, if the government reverses the policy with ex post intervention, despite the investment expropriation, $I$, the government will benefit from controlling the projects, $b$. The government requires state-owned-firms to complete the remaining projects for the control benefit, which depends on the size of control. On the other hand, the government will lose the reputation and undertake the financial cost to raise the public fund for the remaining projects. The financial cost for future investments is $f c$; the reputation loss leads to a political cost. As Perotti and Laeven [21] assume, the political cost is private information of government. Relative to the PPI investments, the political cost, $p c$, is distributed in the range $[0, \overline{p c}]$. The control benefit and financial cost satisfy the following relationship.

Proposition 1. b < fc for PPI programs.

Proof. A government has three optional strategies for infrastructure projects, (1) continuing to use public fund; (2) introducing private participation with no ex post intervention and (3) introducing 
private participation but reversing the policy in future periods. For convenience, let $X^{1}, X^{2}$ and $X^{3}$ to be these three optional strategies in order. Only when the ex post policy reversal leads to a negative payoff, the government will introduce private participation without ex post intervention. Therefore, investors require the government to promise no intervention in future such that a reputation constraint ensures $X^{2} \succ X^{3}$. Moreover, the government should obtain more from the strategy of introducing private participation than the strategy of using public fund; namely, $X^{2} \succ X^{1}$ and $X^{3} \succ X^{1}$. Otherwise, the government has no incentive to attract PPI investments for infrastructure programs. Combining the above conditions, the government effectively attracts PPI investments only when $X^{2} \succ X^{3} \succ X^{1}$ at the policy-decision stage. The condition of $\mathrm{X}^{2} \succ \mathrm{X}^{3} \succ \mathrm{X}^{1}$ is based on $b<f c$. By the way of contradiction, If $b \geq f c$, i.e., the benefit of controlling the project is not less than the cost-saving from attracting PPI investments such that $X^{1} \succcurlyeq X^{2}$ (whether $X^{1} \succcurlyeq X^{3}$ or not) or $X^{3} \succcurlyeq X^{2}$ (whether $X^{3} \succcurlyeq X^{1}$ or not), the government either drops attracting PPI investments or intervening private participation ex post. In anticipation of these government decisions, the investors will abandon investments for the PPI programs. Even when the government decides to introduce private participation in infrastructure projects, the government will fail to attract the PPI investments.

Due to the limited public fund and demands for the viable reform [13], the financial cost increases over time in developing countries and the political benefit decreases. Proposition 1 conforms to reality.

If the government adopts a policy reversal at period $t$, he will obtain the payoff as

$$
R_{t}^{g i}=\sum_{j=1}^{j=t}\left(\frac{1}{\delta}\right)^{j} * I+\sum_{j=t+1}^{j=n} \delta^{j-t} * b * I-\sum_{j=1}^{j=t}\left(\frac{1}{\delta}\right)^{j} * p c * I-\sum_{j=t+1}^{j=n} \delta^{j-t} * f c * I, t=1,2, \ldots, n
$$

where the superscript of gi refers to government intervention, which incurs when the government reverses the policy after introducing private participation.

Let $P r_{t}=\operatorname{Prob}\left\{R_{t}^{g i}<0\right\} ; P r_{t}$ is the probability that the government does not reverse his policy at period t. Investors pay shares (equities) for PPI investments as

$$
P_{t}=I * P r_{t}+0 *\left(1-P r_{t}\right)=I * P r_{t}
$$

Proposition 2. A government policy of attracting PPI investments fosters the share prices for the investments over time.

Proof. The government obtains the net payoff described by Equation (1) if he reverses the PPI policy. If the government waits one more period to adopt the policy reversal (i.e., at period $t+1$ ), he will obtain the following payoff

$$
\delta *\left[(1-p c) \sum_{j=1}^{j=t+1}\left(\frac{1}{\delta}\right)^{j} * I+(b-f c) \sum_{j=t+2}^{j=n} \delta^{j-t} * I\right]=(1-p c) \sum_{j=0}^{j=t}\left(\frac{1}{\delta}\right)^{j} * I+(b-f c) \sum_{j=t+3}^{j=n+1} \delta^{j-t} * I
$$

The government will continue encouraging private participation (without the policy reversal) at period $t$, if

$$
\begin{gathered}
\delta R_{t+1}^{g i}-R_{t}^{g i}=\left(1-p c_{t}\right) I+\left(\delta^{n+1-t}-\delta-\delta^{2}\right)(b-f c) I>0, \text { or } \\
p c_{t}<1-\left(\delta^{n+1-t}-\delta-\delta^{2}\right)(b-f c) \equiv p c_{t}^{*}
\end{gathered}
$$

Thus, Equation (2) is equivalent to the following equation.

$$
P_{t}=I * P r_{t}=I * \operatorname{Prob}\left\{p c<p c_{t}^{*} \mid p c<p c_{t-1}^{*}\right\}=I * \frac{\operatorname{Prob}\left\{p c<p c_{t}^{*}\right\}}{\operatorname{Prob}\left\{p c<p c_{t-1}^{*}\right\}}
$$

Because the decision at period $t$ is based on that the government does not reverse the policy at period $t-1, P_{t}$ is a function of $p c_{t}^{*}$ and $p c_{t-1}^{*}$, as shown by Equation (4). Considering the political 
cost of government is exogenous, the investors expect that $\operatorname{Prob}\left\{p c<p c_{t}^{*}\right\}$ is independent from $\operatorname{Prob}\left\{p c<p c_{t-1}^{*}\right\}$. Accordingly,

$$
P_{t}=I * \frac{\operatorname{Prob}\left\{p c<p c_{t}^{*}\right\}}{\operatorname{Prob}\left\{p c<p c_{t-1}^{*}\right\}}=I * \frac{\prod_{1}^{t} F\left(p c_{t}^{*}\right)}{\prod_{1}^{t-1} F\left(p c_{t}^{*}\right)}=I * F\left(p c_{t}^{*}\right)
$$

where $F\left(p c_{t}^{*}\right)$ is the probability for $p c_{t}<p c_{t}^{*}, p c_{t} \in[0, \overline{p c}]$. Correspondingly, $f\left(p c_{t}^{*}\right)$ in following inference is the probability density value.

$$
\left.\begin{array}{c}
\left.\begin{array}{c}
\text { Inequality }(3): p c_{t}^{*}=1-\left(\delta^{n+1-t}-\delta-\delta^{2}\right)(b-f c) \\
\text { Equation }(5): P_{t}=I * F\left(p c_{t}^{*}\right)
\end{array}\right\} \\
\rightarrow \frac{\partial P_{t}}{\partial t}=f\left(p c_{t}^{*}\right) \frac{\partial p c_{t}^{*}}{\partial t}=f\left(p c_{t}^{*}\right)(b-f c)\left(\delta^{n+1-t} l n^{\delta}\right) I \\
\text { Propostion } 1: b<f c \\
\delta \in(0,1) \rightarrow \ln \delta<0
\end{array}\right\} \rightarrow \frac{\partial P_{t}}{\partial t}>0
$$

Our model demonstrates $\frac{\partial P_{t}}{\partial t}>0$ for PPI investments, and it also shows that the positive derivative is not based on the industry-efficiency improvement.

\subsection{Hypotheses: Promotion Effects of PPI Investments}

In the existing literature, financial market size is measured by the ratio of market capitalization of listed companies expressed as a percentage of GDP $[15,17,48,49]$. Namely, Capital $=\frac{\sum P_{i, t} Q_{i, t}}{G D P_{i, t}}$, where $P_{i}$ is the share price level, $Q_{i}$ is the share quantity and GDP $P_{i}$ is the Gross Domestic Product at period $t$. Using this standard measure in the existing literature, we expect the promotion effect of PPI investments on financial market size because of the following reasons: First, unlike public funds, PPI investments go into financial markets as a new capital inflow such that they enlarge the financial market size. In other words, The PPI investments enlarge the value of capitalization by increasing $Q_{i, t}$. Second, PPI investments enlarge the capitalization value dynamically by increasing $P_{i, t}$. As our model demonstrates, the PPI investments build the confidence of shareholders and then increase the expected share prices for the investments. In fact, as the signal of government, the promotion effect is not restricted on PPI shares because the government credibility can ensure the sustainable development of the whole financial market.

Hypothesis 1. PPI investments in the developing countries are positively related to financial market size.

In the existing literature, financial market liquidity is measured by the percentage of total value of stocks traded relative to GDP [16,49]. Namely, Stocks $=\sum P_{i, t}^{t r} Q_{i, t}^{t r} / G D P_{i, t}$, where $P_{i, t}^{t r}$ and $Q_{i, t}^{t r}$ are the price and quantity of shares traded in the financial market. Unlike the public fund, PPI investments issue new shares in the financial market. Shareholders have more opportunities to improve their risk diversifications. Precisely, if the portfolio of shareholders is $\sum P_{i, j, 0}^{t r} Q_{i, j, 0}^{t r}, j \in[1, \ldots, N]$ at period 0 (i.e., before PPI investments), the shareholders have different share portfolios as $\sum P_{i, j^{\prime}, t}^{t r} Q_{i, j^{\prime}, t^{\prime}}^{t r} j^{\prime} \in$ $[1, \ldots, N, \ldots N+M], t \in[1, \ldots, n]$. Namely, after PPI investments, there are $M$ additional options for share portfolios. Transactions must incur except that the new shares $\left(P_{i, j^{\prime}, t}^{t r} Q_{i, j^{\prime}, t^{\prime}}^{t r} j^{\prime}=N+\right.$ $1, \ldots, N+m)$ cannot improve risk diversifications for all shareholders. This type of transaction is only based on the risk diversification improvement. Even when all the (potential) shareholders do not expect the share prices to increase, the financial market will become more liquid because of the transaction incurrence.

Moreover, financial market liquidity will be promoted dynamically. According to Equation (5), the share price level of PPI investments, $P_{i, t}$ depends on the expectations of shareholders on the political cost of the government. As long as the expectations are not common, some shareholders are willing to hold the shares of PPI programs via transaction to improve their risk portfolios. The expectation difference is satisfied because the political cost is the private information of the government. Therefore, 
transactions will not stop until all shares of PPI investments are held by the shareholders with the best expectations; all share prices of PPI programs converge to the highest prices, i.e., $P_{i, t+1}^{P P I} \rightarrow \overline{P_{i, t+1}^{P P I}}$.

Hypothesis 2. PPI investments in the developing countries are positively related to financial market liquidity.

As mentioned above, PPI investments issue new shares and then increase new share portfolios in financial markets. PPI investments either increase the share quantity or the expected share prices of shareholders, both of which will provide more options for risk diversification and then intrigue equity transactions. Consequently, when PPI investments enlarge financial market size, they also foster financial market liquidity. In other words, PPI investments are expected to positively affect the financial market liquidity by the mediator variable of financial market size.

Hypothesis 3. The mediator effect of financial capitalization is significant for the promotion effect of PPI investments on financial market liquidity.

\section{Empirical Methodology and Variables}

We empirically examine the relationship between PPI investmentsand FMD by estimating Equations (7) and (8).

$$
\begin{aligned}
& \text { Capital }_{i, t}=\beta_{1} \text { PPIG }_{i, t}+\beta_{2}^{\prime} X_{i, t}+\alpha_{i}+\gamma_{t}+\mu_{i, t} \\
& \text { stocks }_{i, t}=\beta_{3} P P I G_{i, t}+\beta_{4}^{\prime} X_{i, t}+\alpha_{i}+\gamma_{t}+\mu_{i, t}
\end{aligned}
$$

Using the data from 33 developing countries over the period 1997-2012, we measure financial market size by the percentage of market capitalization of listed companies to GDP, whereas we measure financial market liquidity by the percentage of stocks traded to GDP. Both of these percentages are standardized measures in the existing literature. Considering that a financial market tends to be more liquid when its size is enlarged [18,20], we also test the mediator effect of financial market size for the relationship between PPI investments and financial market liquidity. To test the promotion effect and mediator effect, we need to consider the endogeneity issue. First, our panel data may omit the properties related to FMD or measure the relevant properties imperfectly. Second, FMD decreases the financial cost of PPI investments, leading to reverse causality.

Theoretically, our data should include all countries such that our findings can be generalized to all the developing countries. However, some developing countries either have no PPI investments or have no data for the dependent variable or control variables. We take full use of all available data to investigate our research question. First, the data collection based on the data availability ensures that the data has no artificial selection bias. Thus, the findings conform more closely to reality. Second, the data collection method based on the data availability can lessen the potential endogenuity issue due to omitted variables. If we include some countries whose data is unavailable for some control variables, the corresponding regression results may be biased due to the variable omitting issue. In fact, this data collection strategy is the common method used in the relevant literature (e.g., Aggarwal et al. [39]).

We planned to collect the data in 2015. However, the newest data for PPI investments is only updated to 2012. Our findings are only based on the data from the period 1997-2012, but they are at least robust for the 15-year-period. More interesting, our findings are robust for the period over financial crises in 1998 and 2008. Our finding considers no situation in the last three years, but they are at least robust for those financial crises. This reflects that our findings are robust enough to the external shocks and then our findings are reliable.

As mentioned above, Capital is the percentage of market capitalization of listed companies to GDP, whereas Stocks is the percentage of stocks traded to GDP. The former percentage reflects financial market size; the latter one represents financial market liquidity (The turnover ratio in the literature [48, $50]$ is also used to measure the liquidity. According to the definition of turnover ratio, Turnover $=$ $\sum P_{i, t}^{t r} Q_{i, t}^{t r} / \sum P_{i, t} Q_{i, t}=$ Stocks $_{i, t} /$ Capital $_{i, t}$, its value reflects the financial market liquidity relative to the financial market size. In other words, the turnover ratio assumes that financial market liquidity 
is inversely related to financial market size $\left(\right.$ Capital $\left._{i, t}\right)$. This assumption is actually rejected by our evidence. Moreover, regressing Stocks $i_{i, t}$ but controlling for Capital $i_{, t}$ (our strategy) is better than regressing turnover ratio because the latter strategy does not really control for financial market size). PPIG refers to the percentage of PPI investments to GDP. In Equations (7) and (8), $i$ represents the country and $t$ indicates the time period from 1997 to 2012.

Table A1 list developing countries used in this research; Table A1 presents the variable descriptions and data sources. Table 1 reports descriptive statistics and Table 2 presents correlations for the variables used in this research.

Table 1. Descriptive statistics.

\begin{tabular}{lccccc}
\hline \multicolumn{1}{c}{ Variable } & Mean & Min & Max & Std.Dev & Obs \\
\hline Capitalization to GDP & 39.891 & 0.018 & 298.99 & 42.197 & 519 \\
\hline Stocks traded to GDP & 16.837 & 0 & 222.999 & 44.508 & 519 \\
\hline Turnover & 38.212 & 0 & 497.403 & 29.586 & 514 \\
\hline PPI investments to GDP & 1.277 & 0 & 15.966 & 58.576 & 528 \\
\hline Inflation & 4.452 & -14.8 & 33.736 & 1.646 & 528 \\
\hline GDP per capital & 3229.391 & 316.746 & $11,749.75$ & 3.919 & 522 \\
\hline Foreign trades to GDP & 77.392 & 15.841 & 220.407 & 2416.163 & 528 \\
\hline Remittances to GDP & 3.651 & 0.005 & 26.675 & 41.068 & 513 \\
\hline $\begin{array}{l}\text { S and P global equity } \\
\text { index }\end{array}$ & 14.462 & -82.25 & 189.23 & 4.871 & 475 \\
\hline Lending interest & 17.014 & 4.731 & 213.018 & 44.964 & 507 \\
\hline Legal origin & 4.212 & 2 & 7 & 14.743 & 528 \\
\hline
\end{tabular}

Table 2. Correlationmatrix.

\begin{tabular}{|c|c|c|c|c|c|c|c|c|c|c|c|c|}
\hline & & (1) & (2) & (3) & (4) & (5) & (6) & (7) & (8) & (9) & (10) & (11) \\
\hline (1) & $\begin{array}{l}\text { Capitalization } \\
\text { to GDP }\end{array}$ & 1 & & & & & & & & & & \\
\hline (2) & $\begin{array}{l}\text { Stocks Traded } \\
\text { to GDP }\end{array}$ & 0.724 & 1 & & & & & & & & & \\
\hline (3) & Turnover & 0.137 & 0.620 & 1 & & & & & & & & \\
\hline (4) & $\begin{array}{l}\text { PPI } \\
\text { Investments to } \\
\text { GDP }\end{array}$ & 0.160 & 0.111 & 0.010 & 1 & & & & & & & \\
\hline (5) & Inflation & 0.111 & 0.204 & 0.178 & 0.040 & 1 & & & & & & \\
\hline (6) & $\begin{array}{l}\text { GDP per } \\
\text { Capital }\end{array}$ & 0.129 & -0.001 & -0.133 & -0.210 & -0.171 & 1 & & & & & \\
\hline (7) & $\begin{array}{l}\text { Foreign Trades } \\
\text { to GDP }\end{array}$ & 0.281 & 0.120 & -0.114 & 0.017 & -0.007 & 0.327 & 1 & & & & \\
\hline (8) & $\begin{array}{l}\text { Remittances to } \\
\text { GDP }\end{array}$ & 0.039 & -0.071 & -0.092 & 0.148 & 0.078 & -0.219 & 0.114 & 1 & & & \\
\hline (9) & $\begin{array}{l}\text { S and PGlobal } \\
\text { Equity Index }\end{array}$ & 0.141 & 0.050 & 0.051 & -0.060 & 0.165 & 0.005 & -0.053 & 0.032 & 1 & & \\
\hline (10) & $\begin{array}{l}\text { Lending } \\
\text { Interest }\end{array}$ & -0.181 & -0.178 & -0.132 & 0.074 & -0.247 & -0.019 & -0.270 & -0.194 & -0.110 & 1 & \\
\hline (11) & Legal Origin & 0.285 & 0.158 & -0.001 & 0.043 & 0.092 & -0.312 & 0.043 & 0.344 & -0.019 & -0.289 & 1 \\
\hline
\end{tabular}

To test the mediator effect between PPI investments (PPIG) and financial market liquidity (Stocks), we especially control for financial market size (Capital) as in the following Equation (9). Intuitively, we will check whether if the coefficient of PPIG will decrease after controlling for Stocks.

$$
\text { Stocks }_{i, t}=\beta_{5} \text { PPIG }_{i, t}+\beta_{6} \text { Capital }_{i, t}+\beta_{7}^{\prime} X_{i, t}+\alpha_{i}+\gamma_{t}+\mu_{i, t}
$$


Formally, we will use z-test to judge whether the coefficient decrease is really significant. In particular, z-tests for mediator effect are suggested by Sobel [51], Baron and Kenny [52] and Goodman [53] as follows.

$$
\begin{gathered}
\mathrm{z}=\frac{\beta_{1} * \beta_{6}}{\sqrt{\left(\beta_{6}\right)^{2} *\left(S_{\beta_{1}}\right)^{2}+\left(\beta_{1}\right)^{2} *\left(S_{\beta_{6}}\right)^{2}}} \\
\mathrm{z}=\frac{\beta_{1} * \beta_{6}}{\sqrt{\left(\beta_{6}\right)^{2} *\left(S_{\beta_{1}}\right)^{2}+\left(\beta_{1}\right)^{2} *\left(S_{\beta_{6}}\right)^{2}+\left(S_{\beta_{1}}\right)^{2} *\left(S_{\beta_{6}}\right)^{2}}} \\
\mathrm{z}=\frac{\beta_{1} * \beta_{6}}{\sqrt{\left(\beta_{6}\right)^{2} *\left(S_{\beta_{1}}\right)^{2}+\left(\beta_{1}\right)^{2} *\left(S_{\beta_{6}}\right)^{2}-+\left(S_{\beta_{1}}\right)^{2} *\left(S_{\beta_{6}}\right)^{2}}}
\end{gathered}
$$

The matrix of $X$ in Equations (7) and (9) represents a group of traditional exogenous variables related to FMD in literature. In our estimations, we control for inflation and GDP per capital. Boyd et al. [12] provide evidence of a negative and significant link between inflation and FMD. The inflation indicator is defined by the annual percentage change in the GDP deflator. GDP per capital can proxy for the level of economic development; we control for the effect of economic development on financial market development.

The liberalization has also been shown to generate an impact on the size and liquidity of financial markets [48]. There are two categories of liberation indicators in the existing literature, de jure openness and de facto openness. The de jure openness is indicated by the restriction removals for capital account transactions. Because the regime is always adopted for months instead of years (see [54]), the de jure openness cannot be measured objectively (because it is unsuitable to define the dummy variable as either zero or one when the regime is adopted for several months). The de facto openness is indicated by the relevant inflow ratios. We control for the ratio of foreign trades (see [40]) to GDP (We do not control for FDI because it includes part of PPI investments).

Moreover, remittances are also controlled in this paper. Aggarwal et al. [39] shows that remittances become the second largest source of external finance for developing countries after FDI and they are twice as the amount of official aid received. For FMD, we cannot overlook this capital inflow.

Finally, we control for the lending interest rate and annual percentage change of $S$ and $P$ global equity indices. The former rate represents the domestic investment background in the developing country. A larger lending interest rate witnesses a higher cost of raising fund for investments, but it may also reflect a higher investment demand. The latter indices measure US dollar price changes in the international stock market, thereby reflecting the characteristics of the international financial market.

To examine the relationship between PPI investments and FMD, we first control the fixed effect of country for un-measurable country characteristics and the fixed effect of time for common shocks across countries. The fixed effects lessen the endogeneity bias due to omitted factors. Table 1 shows that the average percentage of PPI investments to GDP is $1.277 \%$, but the standard deviation is 58.576 , which indicates a significant heterogeneity across countries. To avoid the influence of heteroskedasticiy and autocorrelation, we run a second round of estimations with robust standard errors and test the mediator effect with the corresponding coefficients.

Third, we further conduct IV estimations and test the mediator effect. We admit that a country with a more developed financial market more likely attracts a larger amount of PPI investments. Moreover, we use foreign trades to GDP to measure the influence of liberalization policies, which may include some data noise. To settle the endogeneity problems, we net out the country-specific component to yield a measure of PPI investments that only depends on the underlying characteristics inherent to the particular time and legal origin. In particular, we keep the characteristics related to the particular legal origin because the legal origin effectively reflects the institution background $[38,55]$. As many empirical scholars (e.g., [56,57]) do, we use these two constraints (i.e., in the same year and 
with the same legal origin) to define the average value of the variable of interest, generating the IV for estimations. Specifically, our instrumental variable (PPIGiv) is obtained as the following equation.

$$
\operatorname{PPIGiv}_{i}=\frac{\sum_{j=1, \ldots, n, j \neq i} P P I G_{j}}{n-1}=\frac{\sum_{j=1}^{j=n} P P I G_{j}-P P I G_{i}}{n-1}, i, j \in I_{\text {legal origin-year }}
$$

Equation (13) shows the value of PPIGiv for a particular country equals the average value of PPIG within other similar countries $(I)$ in the same year. In particular, the similar countries are defined by the legal origin. For calculating the average value for each country, we abandon the country's value. In this way, we completely nets out the country-specific component. Considering that our IV may be still affected by the dependent variable $\left(F M D_{i, t}\right)$, we especially lag all independent variable in IV estimations one period. Before Z-test, the regression equations estimated are of the following equation:

$$
\begin{gathered}
\text { Capital }_{i, t}=\beta_{1} \hat{P P I} G_{i, t-1}+\beta_{2} X_{i, t-1}+a_{i}+\gamma_{t}+u_{i, t} \\
\text { stocks }_{i, t}=\beta_{1} P \hat{P I} G_{i, t-1}+\beta_{2} X_{i, t-1}+a_{i}+\gamma_{t}+u_{i, t} \\
\text { stocks }_{i, t}=\beta_{5} \hat{P P I G}_{i, t-1}+\beta_{6} \text { Capital }_{i, t-1}+\beta_{7} X_{i, t-1}+a_{i}+\gamma_{t}+u_{i, t}
\end{gathered}
$$

where $P \hat{P I G} G_{i, t-1}$ is obtained by estimating $P \hat{P I G} G_{i, t-1}=b_{1} P P I G i v_{i, t-1}+b_{2} X_{i, t-1}+a_{i}+\gamma_{t}+u_{i, t}$.

\section{Empirical Results}

Columns (1)-(3) in Table 3 report the estimation results of Equations (7)-(9). Table 3 shows that PPI investments have a positive relationship with FMD in the dimension of size or liquidity. A one percentage point increase in the share of PPI investments to GDP is related to 1.653 (2.053) one percentage point increase in the ratio of capitalization (stocks traded) to GDP. Moreover, Table 3 presents that the coefficient of PPI investments to GDP decrease (to only 1.076) after controlling for financial market size measured by the capitalization to GDP. The variable of interest is highly significant and the capitalization to GDP is also significant for explaining stocks traded to GDP.

As expected, the results show that FMD is promoted by the inflation and foreign trades. Moreover, the results confirm a negative effect of remittances and a positive effect of lending interest rate for FMD. The negative effect of remittances shows that remittance received from foreign countries decreases the participation willingness of individuals in their home country, whereas the positive effect of lending interest rate indicates that the lending interest rate mainly reflects the investment demand that fosters FMD. The effects of GDP per capital and S and P global equity indices are not robust, but they are (partially) significant for explaining FMD. 
Table 3. Fixed effects estimations with original standard errors.

\begin{tabular}{|c|c|c|c|}
\hline Method & & with Original Standard & \\
\hline \multirow{3}{*}{ Model for Variables } & Size & Liquidity & Mediator Effect \\
\hline & Capitalization to GDP & Stocks Traded to GDP & Stocks Traded to GDP \\
\hline & (1) & (2) & (3) \\
\hline Capitalization to GDP & & & $\begin{array}{c}0.591 \text { *** } \\
(0.037)\end{array}$ \\
\hline PPI investments to GDP & $\begin{array}{l}1.653 * * \\
(0.795)\end{array}$ & $\begin{array}{l}2.053 * * * \\
(0.755)\end{array}$ & $\begin{array}{l}1.076^{* *} \\
(0.595)\end{array}$ \\
\hline Inflation & $\begin{array}{l}0.616^{*} \\
(0.319)\end{array}$ & $\begin{array}{l}0.773^{* * *} \\
(0.302)\end{array}$ & $\begin{array}{l}0.409^{* *} \\
(0.239)\end{array}$ \\
\hline GDP per capital & $\begin{array}{l}-5.865 * \\
(3.019)\end{array}$ & $\begin{array}{c}0.480 \\
(2.869)\end{array}$ & $\begin{array}{l}3.945^{* *} \\
(2.26)\end{array}$ \\
\hline Foreign trades to GDP & $\begin{array}{l}0.312 * * * \\
(0.003)\end{array}$ & $\begin{array}{l}0.249 * * * \\
(0.087)\end{array}$ & $\begin{array}{l}0.065^{+} \\
(0.069)\end{array}$ \\
\hline Remittances to GDP & $\begin{array}{l}-1.876^{* * *} \\
(0.623)\end{array}$ & $\begin{array}{l}-1.230 * * * \\
(0.592)\end{array}$ & $\begin{array}{c}-0.101^{+} \\
(0.470)\end{array}$ \\
\hline $\begin{array}{l}\text { S and } P \text { global equity } \\
\text { indices }\end{array}$ & $\begin{array}{l}0.106^{* * *} \\
(0.029)\end{array}$ & $\begin{array}{l}0.024^{+} \\
(0.028)\end{array}$ & $\begin{array}{l}-0.038^{* *} \\
(0.022)\end{array}$ \\
\hline Lending interest & $\begin{array}{l}0.091^{+} \\
(0.099)\end{array}$ & $\begin{array}{l}0.077^{+} \\
(0.094)\end{array}$ & $\begin{array}{l}0.023^{+} \\
(0.073)\end{array}$ \\
\hline Constant & $\begin{array}{l}33.678^{* * * *} \\
(11.961)\end{array}$ & $\begin{array}{l}-11.288^{+} \\
(11.366)\end{array}$ & $\begin{array}{c}-31.126^{* * *} \\
(9.000)\end{array}$ \\
\hline$p$-value for F-statistics & 0.000 & 0.000 & 0.000 \\
\hline R-square & 0.0736 & 0.072 & 0.435 \\
\hline Observations & 460 & 460 & 460 \\
\hline Number of countries & 33 & 33 & 33 \\
\hline
\end{tabular}

To avoid the influence of heteroskedasticity and autocorrelation issue, we further conduct estimation with robust standard errors. Table 4 reports the estimation results and also confirm the positive and significant effect of PPI investments on FMD. Moreover, after controlling financial market size that is significant and positive, the coefficient of PPI investments decreases. 
Table 4. Fixed effects estimations with robust standard errors.

\begin{tabular}{|c|c|c|c|}
\hline \multirow{4}{*}{ Model for Variables } & \multicolumn{3}{|c|}{ OLS with Robust Standard Errors } \\
\hline & Size & Liquidity & Mediator effect \\
\hline & Capitalization to GDP & Stocks Traded to GDP & Stocks Traded to GDP \\
\hline & (1) & (2) & (3) \\
\hline Capitalization to GDP & & & $\begin{array}{l}0.591^{* * *} \\
(0.109)\end{array}$ \\
\hline PPI investments to GDP & $\begin{array}{l}1.653 * * \\
(0.793)\end{array}$ & $\begin{array}{l}2.053 * * * \\
(0.746)\end{array}$ & $\begin{array}{l}1.076^{* *} \\
(0.578)\end{array}$ \\
\hline Inflation & $\begin{array}{l}0.616^{+} \\
(0.527)\end{array}$ & $\begin{array}{l}0.773 * * \\
(0.370)\end{array}$ & $\begin{array}{l}0.409 * \\
(0.272)\end{array}$ \\
\hline GDP per capital & $\begin{array}{l}-5.865 * \\
(2.904)\end{array}$ & $\begin{array}{c}0.480 \\
(4.879)\end{array}$ & $\begin{array}{c}3.945 \\
(4.387)\end{array}$ \\
\hline Foreign trades to GDP & $\begin{array}{l}0.312 * * \\
(0.152)\end{array}$ & $\begin{array}{l}0.249 * * \\
(0.125)\end{array}$ & $\begin{array}{l}0.065^{+} \\
(0.075)\end{array}$ \\
\hline Remittances to GDP & $\begin{array}{l}-10876^{* * *} \\
(0.477)\end{array}$ & $\begin{array}{l}-1.210 * * \\
(0.454)\end{array}$ & $\begin{array}{c}-0.101^{+} \\
0.445\end{array}$ \\
\hline $\begin{array}{l}\text { S and } P \text { global equity } \\
\text { index }\end{array}$ & $\begin{array}{l}0.106^{* * *} \\
(0.030)\end{array}$ & $\begin{array}{l}0.024^{+} \\
(0.025)\end{array}$ & $\begin{array}{l}-0.038^{* *} \\
(0.022)\end{array}$ \\
\hline Lending interest rate & $\begin{array}{l}0.091^{+} \\
(0.088)\end{array}$ & $\begin{array}{l}0.075^{+} \\
(0.103)\end{array}$ & $\begin{array}{l}0.023^{+} \\
(0.077)\end{array}$ \\
\hline Constant & $\begin{array}{l}33.678 * \\
(20.264)\end{array}$ & $\begin{array}{l}-11.228^{+} \\
(24.077)\end{array}$ & $\begin{array}{l}-31.126 * * \\
(17.536)\end{array}$ \\
\hline$p$-value for F-statistics & 0.000 & 0.001 & 0.000 \\
\hline R-square & 0.074 & 0.072 & 0.435 \\
\hline Observations & 460 & 460 & 460 \\
\hline Number of countries & 33 & 33 & 33 \\
\hline
\end{tabular}

The following results are obtained by estimating $F M D_{i, t}=\beta_{1} P P I G_{i, t}+\beta_{2}^{\prime} X_{i, t}+a_{i}+\gamma_{t}+u_{i, t}$, where $F M D$ refers to financial market development measured by the size or liquidity of the financial market. The size is defined as the \% of market capitalization (of listed companies) to GDP, whereas the liquidity is measured by the stocks traded relative to GDP. PPIG is the \% of PPI investment to GDP. To test the mediator effect of financial market size between PPI investments and financial market liquidity, we control the market capitalization to estimate the effect of PPI investments on financial market liquidity (see Column 3). X, the matrix of control variables includes Inflation stated as the \% change of GDP each year, GDP per capital in thousands of dollars, foreign trades to GDP measured as $\%$ of total foreign trades to GDP, remittances to GDP measured as \% of remittances to GDP, lending interest rate and annual percentage change of $\mathrm{S}$ and $\mathrm{P}$ global equity indices.

In comparison with estimation results in Table 3, the following estimation results are obtained with robust standard errors. The following results are obtained by estimating $F M D_{i, t}=\beta_{1} P P I G_{i, t}+$ $\beta_{2}^{\prime} X_{i, t}+a_{i}+\gamma_{t}+u_{i, t}$, where $F M D$ refers to financial market development measured by the size or liquidity of the financial market. The size is defined as the \% of market capitalization (of listed companies) to GDP, whereas the liquidity is measured by the stocks traded relative to GDP. PPIG is the \% of PPI investment to GDP. To test the mediator effect of financial market size between PPI investments and financial market liquidity, we control the market capitalization to estimate the effect of PPI investments on financial market liquidity (see Column 3). $X$, the matrix of control variables includes Inflation stated as the \% change of GDP each year, GDP per capital in thousands of dollars, 
foreign trades to GDP measured as \% of total foreign trades to GDP, remittances to GDP measured as \% of remittances to GDP, lending interest rate and annual percentage change of S and P global equity indices.

Similar to Table 3, Table 4 also reflects the direct effect of PPI investments to financial market liquidity is less significant than the indirect effect of PPI investments through financial market size. Control variables obtain the same signals after including robust standard errors; all significant control variables in Table 3 are also significant in Table 4.

To address the concern due to the potential measurement errors and reverse causality, we further report the results of the IV estimations in Table 5 . Table 5 shows that the coefficient of PPI investments on financial market size or liquidity is positive and significant. Consequently, the promotion effect of PPI investments on FMD is confirmed in IV estimations. Moreover, Table 5 presents that the coefficient of PPI investments in the regression of financial market liquidity decrease (from 1.708 to 0.426 ) and the significance is not satisfied any more. The finding shows that the effect of PPI investments on financial market liquidity relies on financial market size such that the direct effect of PPI investments to financial market liquidity is insignificant.

Table 5. The results of IV estimations.

\begin{tabular}{|c|c|c|c|}
\hline Method & & 2SLS & \\
\hline \multirow{3}{*}{ Model for Variables } & Size & Liquidity & Mediator Effect \\
\hline & Capitalization to GDP & Stocks Traded to GDP & Stocks Traded to GDP \\
\hline & (1) & (2) & (3) \\
\hline Capitalization to GDP & & & $\begin{array}{c}0.530 * * * \\
(0.039)\end{array}$ \\
\hline PPI investments to GDP & $\begin{array}{l}1.708^{* * *} \\
(0.774)\end{array}$ & $\begin{array}{l}1.303 * * \\
(0.743)\end{array}$ & $\begin{array}{c}0.386 \\
(0.614)\end{array}$ \\
\hline Inflation & $\begin{array}{c}-0.285^{+} \\
(0.313)\end{array}$ & $\begin{array}{l}0.383^{+} \\
(0.301)\end{array}$ & $\begin{array}{c}0.139 \\
(0.248)\end{array}$ \\
\hline GDP per capital & $\begin{array}{l}-0.006 * * \\
(0.003)\end{array}$ & $\begin{array}{c}-0.001+ \\
(0.003)\end{array}$ & $\begin{array}{c}0.003 \\
(0.002)\end{array}$ \\
\hline Foreign trades to GDP & $\begin{array}{l}0.230 * * \\
(0.094)\end{array}$ & $\begin{array}{l}0.261^{* * *} \\
(0.091)\end{array}$ & $\begin{array}{c}0.064 \\
(0.076)\end{array}$ \\
\hline Remittances to GDP & $\begin{array}{l}-1.525^{* *} \\
(0.645)\end{array}$ & $\begin{array}{l}1.241 * * \\
(0.620)\end{array}$ & $\begin{array}{c}0.022 \\
(0.518) \\
\end{array}$ \\
\hline $\begin{array}{l}\text { S and } P \text { global equity } \\
\text { index }\end{array}$ & $\begin{array}{l}0.088^{* * *} \\
(0.028)\end{array}$ & $\begin{array}{l}0.088^{* * *} \\
(0.027)\end{array}$ & $\begin{array}{c}0.030 \\
(0.023)\end{array}$ \\
\hline Lending interest & $\begin{array}{l}0.067^{+} \\
(0.096)\end{array}$ & $\begin{array}{l}0.091^{+} \\
(0.092)\end{array}$ & $\begin{array}{c}0.054 \\
(0.076)\end{array}$ \\
\hline Constant & $\begin{array}{l}25.586 * * \\
(11.999)\end{array}$ & $\begin{array}{l}-4.877^{+} \\
(11.527)\end{array}$ & $\begin{array}{l}-23.051 \\
(9.565)\end{array}$ \\
\hline$p$-value for F-statistics & 0.000 & 0.000 & 0.000 \\
\hline R-square & 0.046 & 0.064 & 0.441 \\
\hline Observations & 431 & 431 & 431 \\
\hline Number of countries & 33 & 33 & 33 \\
\hline
\end{tabular}

The regression equation estimated is of the form of $F M D_{i, t}=b_{1} P P I G_{i, t-1}+b_{2} \hat{X}_{i, t-1}+a_{i}+\gamma_{t}+$ $u_{i, t}, \hat{X}_{i, t-1}$ is obtained by estimating $\hat{X}_{i, t-1}=b_{1} P P I G_{i, t-1}+b_{2} Z_{i, t-1}+a_{i}+\gamma_{t}+u_{i, t}$. We especially lag all independent variable in IV estimations one period because our instrument variable may be still affected by the time trend such that $F M D_{i, t}$ affects $Z_{i, t}$ or $\hat{X}_{i, t}$. FMD refers to financial market 
development measured by the size or liquidity of the financial market. The size is defined as the $\%$ of market capitalization (of listed companies) to GDP, whereas the liquidity is measured by the stocks traded relative to GDP. PPIG is the \% of PPI investment to GDP. To test the mediator effect of financial market size between PPI investments and financial market liquidity, we control the market capitalization to estimate the effect of PPI investments on financial market liquidity (see Column 3). X, the matrix of control variables includes Inflation stated as the \% change of GDP each year, GDP per capital in thousands of dollars, foreign trades to GDP measured as \% of total foreign trades to GDP, remittances to GDP measured as \% of remittances to GDP, lending interest rate and annual percentage change of $\mathrm{S}$ and $\mathrm{P}$ global equity indices. $\mathrm{Z}$ is the vector of instrumental variable, the average value of PPI investments within the other countries at the same year and with the same legal origin that approximates economic institutions.

All control variables in Columns (1)and (2) in Table 5 are significant and obtain the same signals as before, whereas all of them in Column (3) are positive and insignificant. The change in the signal and significance of control variables in Column (3) may reflect the fact that financial market size is much more important than other control variables for explaining financial market liquidity. Table 5 reports that the $p$-value for F-statistic is zero for IV estimations, which shows that our IV has appropriate explanatory power.

Table 6. Results of z-test for mediator effect.

\begin{tabular}{lccc}
\hline \multirow{2}{*}{ Model } & \multicolumn{3}{c}{ Z Test Results } \\
\cline { 2 - 4 } & Sobel [51]'s Model & $\begin{array}{c}\text { Baron and Kenny [52]'s } \\
\text { Model }\end{array}$ & Goodman [53]'s Model \\
\hline $\begin{array}{l}\text { OLS estimations (in } \\
\text { Table 3) }\end{array}$ & $2.062^{* *}$ & $2.058^{* *}$ & $2.066^{* *}$ \\
\hline $\begin{array}{l}\text { OLS estimations with } \\
\text { robust standard errors } \\
\text { (in Table 4) }\end{array}$ & $1.946^{*}$ & $1.917^{*}$ & $1.975^{* *}$ \\
\hline $\begin{array}{l}\text { IV estimations (in } \\
\text { Table 5) }\end{array}$ & $2.180^{* *}$ & $2.174^{* *}$ & $2.185^{* *}$ \\
\hline
\end{tabular}

Z-test for mediator effect can be obtained in three models. To ensure the robustness of mediator effect, we calculate the z-test results for all potential models, using estimations in Tables $3-5 .+, * * *$, or ${ }^{* * *}$ denotes the significance at $15 \%, 10 \%, 5 \%$, and $1 \%$ level, respectively.

Tables 3-5 intuitively show that the coefficient of PPI investments decreases after controlling the mediator variable, but, to formally test the significance of coefficient decreases, we use all optional Z-tests and report the results in Table 6 . Table 6 shows the coefficient decrease is significant, irrespective of different estimation methods and mediator models. Therefore, our results confirm PPI investments first promote the development of financial market size and then foster the development of financial market liquidity.

\section{Conclusions}

Since the late 1980s, most developing countries adopt a policy of attracting investments for Private Participation in Infrastructure (PPI) projects. Given the significance of PPI investments on financial markets, it is important to assess the promotion effect of PPI policy on financial market development. Referring to Environmental, Social and Governance (ESG) criteria, the PPI investments and financial market development (hereafter FMD) are sustainable. However, the existing literature does not explore or investigate whether the sustainable PPI investments promote the sustainable development of financial markets.

Our model demonstrates how PPI investments dynamically promote the expected prices of shares/equities for PPI programs by building the government creditability. Following the existing 
literature, we measure FMD in the dimension of size or liquidity. Financial market size is measured by the share of capitalization of listed companies to GDP, whereas financial market liquidity is measured by the share of stocks traded to GDP. Based on our model, we demonstrate the promotion effect of sustainable PPI investments on sustainable development of financial markets and also explain the mediation mechanism that the PPI investments enlarge financial market size, which, in turn, fosters financial market liquidity.

Using the data from developing countries, we provide evidence of a positive and significant relationship between PPI investment and FMD. Moreover, this paper confirms the significant mediator effect of financial market size for the relationship between PPI investments and financial market liquidity. These findings are robust to different control variables and estimation techniques. With the sustainability perspective, this paper contributes to the literature on transitional economy or industrial policy by providing a practical reason for the PPI policy prevalence in reality. Precisely, the promotion effect confirmed in this paper explains why the developing countries have been actively attracting PPI investments although the efficiency of PPI policy is controversial. Additionally, the promotion effect and the mediator effect are not based on endogenous mechanism designs; it can be generalized to all new capital inflows. It may have some limits due to the out-dated data and data collection based on the availability. Nonetheless, this paper contributes to financial economics and development economics in the perspectives of sustainable PPI promotion.

Author Contributions: Tong Fu designs the research and wrote the paper; whereas Hongzheng Chen partially undertook data analysis. Tong Fu and Yongrok Choi revise the paper after review. All authors read and approved the final manuscript.

Conflicts of Interest: The authors declare no conflict of interest.

\section{Appendix Appendix}

The data out of the period 1997-2012 are unavailable in developing countries. This Table A1 lists developing countries included in our estimations.

Table A1. Countries involved in our data.

\begin{tabular}{cccc}
\hline Argentina & Hungary & Morocco & Sri Lanka \\
Bangladesh & India & Namibia & Thailand \\
Botswana & Indonesia & Nigeria & Ukraine \\
Brazil & Jordan & Pakistan & Venezuela, RB \\
Bulgaria & Kenya & Panama & Vietnam \\
China & Lebanon & Peru & Zambia \\
Colombia & Malaysia & Philippines & \\
Ecuador & Mauritius & Romania & \\
Egypt, Arab Rep & Mexico & South Africa & \\
\hline
\end{tabular}

In Table A2, the variables marked by an asterisk are used to obtain instrumental variables. The variable market by + is the instrumental variable in this research. All following variables are collected from developing countries. 
Table A2. The definition and data source.

\begin{tabular}{|c|c|c|}
\hline Variable & Definition & Source \\
\hline Capitalization to GDP (\%) & $\begin{array}{l}\text { Market capitalization of listed } \\
\text { companies (\% of GDP). It } \\
\text { represents financial market size. }\end{array}$ & World Bank \\
\hline Stocks traded to GDP (\%) & $\begin{array}{l}\text { Total value of stocks traded (\% of } \\
\text { GDP). It represents financial } \\
\text { market liquidity. }\end{array}$ & World Bank \\
\hline PPI investments to GDP (\%) * & $\begin{array}{l}\text { Investments due to private } \\
\text { participation in infrastructure ( } \% \\
\text { of GDP). }\end{array}$ & World Bank \\
\hline Inflation $(\%)$ & $\begin{array}{l}\text { The annual percentage change in } \\
\text { the GDP deflator }(\%) \text {. It represents } \\
\text { economic growth. }\end{array}$ & World Bank \\
\hline $\begin{array}{l}\text { GDP per capital (in thousands of } \\
\text { US\$) }\end{array}$ & $\begin{array}{l}\text { GDP per capital in thousands of } \\
\text { constant } 2005 \text { US } \$ \text {. It represents } \\
\text { the economic development. }\end{array}$ & World Bank \\
\hline Foreign trades to GDP (\%) & $\begin{array}{l}\text { Total foreign trades (exports plus } \\
\text { imports, \% of GDP).It represents } \\
\text { de facto openness. }\end{array}$ & World Bank \\
\hline Remittances to GDP (\%) & $\begin{array}{l}\text { Remittances received ( } \% \text { of GDP), } \\
\text { as the } 2 \text { nd largest source of } \\
\text { external finance. }\end{array}$ & World Bank \\
\hline Lending interest rate (\%) & $\begin{array}{l}\text { The interest rate required by banks } \\
\text { from private sector. It reflects the } \\
\text { domestic investment background. }\end{array}$ & World Bank \\
\hline $\mathrm{S}$ and $\mathrm{P}$ global equity indices (\%) & $\begin{array}{l}\text { The annual percentage change in } \mathrm{S} \\
\text { and } \mathrm{P} \text { global equity indices. It } \\
\text { reflects the characteristics of the } \\
\text { international market. }\end{array}$ & World Bank \\
\hline Legal origin * & $\begin{array}{l}\text { There are three legal origins, } \\
\text { including common law, civil law } \\
\text { and religious law (also including } \\
\text { custom law / traditional thoughts). } \\
\text { Considering many countries' legal } \\
\text { systems are affected by more than } \\
\text { one legal origin. let legal = } 1,2,3 \text {, } \\
4,5,6 \text { or } 7 \text { if legal origin is } \\
\text { common law, civil law, religious } \\
\text { law, common law \& civil law, } \\
\text { common law \& religious law, civil } \\
\text { law \& religious law or the } \\
\text { combination of common law, civil } \\
\text { law \& religious law. }\end{array}$ & $\begin{array}{l}\text { Compiled from World Factbook, } \\
\text { Wikipedia, Globalex index. }\end{array}$ \\
\hline Averaged PPI investment to GDP+ & $\begin{array}{l}\text { The average value of "PPI } \\
\text { investments to GDP" within the } \\
\text { other countries at the same year } \\
\text { and with the same legal origin. } \\
\text { For each country, it reflects the PPI } \\
\text { investments (to GDP) that only } \\
\text { depend on the underlying } \\
\text { characteristics inherent to the } \\
\text { particular time and legal origin. }\end{array}$ & $\begin{array}{l}\text { Compiled from the variable of PPI } \\
\text { investments to GDP and the legal } \\
\text { origin variable. }\end{array}$ \\
\hline
\end{tabular}




\section{References}

1. Eurosif. European SRI Study 2010; European Sustainable Investment Forum: Paris, France, 2010.

2. Eurosif. Corporate Pension Funds \& Sustainable Investment Study; European Sustainable Investment Forum: Paris, France, 2011.

3. Hoffmann, J.; Scherhorn, G.; Busch, T. Darmstadt Definition of Sustainable Investments; Corporate Responsibility Interface Center/Wuppertal Institute: Wuppertal, Germany, 2004.

4. Juravle, C.; Lewis, A. The role of championship in the mainstreaming of sustainable investment (SI): What can we learn from SI pioneers in the United Kingdom? Organ. Environ. 2009, 22, 75-98. [CrossRef]

5. Sikken, B.J. Accelerating the Transition towards Sustainable Investing: Strategic Options for Investors, Corporations and Other Key Stakeholders; World Economic Forum: Geneva, Switzerland, 2011.

6. Martens, P.; Raza, M. Is globalisation sustainable? Sustainability 2010, 2, 281-293. [CrossRef]

7. Liu, Y.; Zhang, N. Sustainability of trade liberalization and antidumping: Evidence from Mexico's trade liberalization toward China. Sustainability 2015, 7, 11484-11503. [CrossRef]

8. Garzon, L. Globalization, Latin American migration and catalan: Closing the ring. Sustainability 2012, 4, 2498-2512. [CrossRef]

9. Busch, T.; Bauer, R.; Orlitzky, M. Sustainable development and financial markets: Old paths and new avenues. Bus. Soc. 2014. [CrossRef]

10. Fu, T. Does Private Partnership Promote Financial Sector Development in Developing Countries? Working Paper; Jiangxi University of Finance and Economics: Nanchang, China, 2015.

11. Alfaro, L.; Kalemli-Ozcan, S.; Selin, S. FDI, productivity and financial development. World Econ. 2009, 32, 111-135. [CrossRef]

12. Boyd, J.; Levine, R.; Smith, B. The impact of inflation on financial sector performance. J. Monet. Econ. 2001, 47, 221-248. [CrossRef]

13. Estache, A. PPI partnerships vs. PPI divorces in LDCs. Rev. Ind. Organ. 2006, 29, 3-26. [CrossRef]

14. Estache, A.; Philippe, C. The Impact of Private Participation in Infrastructure in Developing Countries: Taking Stock of about 20 Years of Experience; ECARES Working Papers; European Center for Advanced Research in Economics and Statistics: Brussels, Belgium, 2012.

15. Boutchkova, M.K.; Megginson, W.L. Privatization and the rise of global capital markets. Financ. Manag. 2000, 29, 31-75. [CrossRef]

16. Boubakri, N.; Hamza, O. The dynamics of privatization, the legal environment and stock market development. Int. Rev. Finance. Anal. 2007, 16, 304-331. [CrossRef]

17. Perotti, E.C.; van Oijen, P. Privatization, political risk and stock market development in emerging economies. J. Int. Money Financ. 2001, 20, 43-69. [CrossRef]

18. Bortolotti, B.; de Jong, F.; Nicodano, G.; Ibolya, S. Privatization and stock market liquidity. J. Bank. Financ. 2007, 31, 297-316. [CrossRef]

19. De la Torre, A.; Gozzi, J.C.; Schmukler, S.L. Stock market development under globalization: Whether the gains form reforms? J. Bank. Financ. 2007, 31, 1731-1754. [CrossRef]

20. Pagano, M. The floatation of companies and the stock market: A coordination failure model. Eur. Econ. Rev. 1993, 37, 1101-1125. [CrossRef]

21. Perotti, E.; Laeven, L. Confidence Building in Emerging Stock Markets; Working Paper; University of Amsterdam: Amsterdam, The Netherlands, 2002.

22. WWF; Zoological Society of London; Global Footprint Network. Living Planet Report 2010: Biodiversity, Biocapacity and Development; World Wide Fund for Nature: London, UK, 2010.

23. United Nations. The Millennium Development Goals Report; United Nations: New York, NY, USA, 2013.

24. Chertow, M.R. Industrial symbiosis: Literature and taxonomy. Annu. Rev. Energy Environ. 2000, 25, $313-337$. [CrossRef]

25. Jacobsen, N.B. Industrial symbiosis in Kalundborg, Denmark: A quantitative assessment of economic and environmental aspects. J. Ind. Ecol. 2006, 10, 239-255. [CrossRef]

26. Bauer, R.; Koedijk, K.; Otten, R. International evidence on ethical mutual fund performance and investment style. J. Bank. Financ. 2005, 29, 1751-1767. [CrossRef]

27. Galema, R.; Plantinga, A.; Scholtens, B. The stocks at stake: Return and risk in socially responsible investment. J. Bank. Financ. 2008, 32, 2646-2654. [CrossRef] 
28. Orlitzky, M. Does organizational size confound the relationship between corporate social performance and firm financial performance? J. Bus. Ethics 2001, 33, 167-180. [CrossRef]

29. Eurosif. European SRI Study 2012; Eurosif: Brussels, Belgium, 2012.

30. Novethic. European Asset Owners: ESG Perceptions and Integration Practices; Novethic SRI Research Centre: Paris, France, 2010.

31. Public Private Infrastructure Advisory Facility. Private Partnership in Infrastructure Datebase. Available online: http:/ / ppi.worldbank.org/ (accessed on 13 January 2015).

32. Bayliss, K. Private Sector Participation in African Infrastructure: Is It Worth the Risk? No. 55. Working Paper; International Policy Centre for Inclusive Growth: Brasilia, Brazil, 2009.

33. Jerome, A. Private Sector Participation in Infrastructure in Africa. In Proceedings of the Third African Economic Conference, Tunis, Tunisia, 12-14 November 2008.

34. Patel, U.; Bhattacharya, S. Infrastructure in India: The economics of transition from public to private provision. J. Comp. Econ. 2010, 38, 52-70. [CrossRef]

35. Andrade, S.C.; Bian, J.; Burch, T.R. Analyst coverage, information, and bubbles. J. Financ. Quant. Anal. 2012, 48, 1573-1605. [CrossRef]

36. Beck, T.; Demirgüç-Kunt, A.; Levine, R. Law, endowments, and finance. J. Financ. Econ. 2003, 70, $137-181$. [CrossRef]

37. La Porta, R.; Lopez-de Silanes, F.; Shleifer, A.; Vishny, R.W. Legal determinants of external finance. J. Financ. 1997, 52, 1131-1150. [CrossRef]

38. La Porta, R.; Lopez-de Silanes, F.; Shleifer, A.; Vishny, R.W. Law and finance. J. Polit. Econ. 1998, 106, 1113-1155. [CrossRef]

39. Aggarwal, R.; Demirgüç-Kunt, A.; Martínez, P.; Maria, S. Do remittances promote financial development? J. Dev. Econ. 2011, 96, 255-264. [CrossRef]

40. Bussiere, M.; Fratzscher, M. Financial openness and growth: Short-run gain, long-run pain? Rev. Int. Econ. 2008, 16, 69-95. [CrossRef]

41. World Bank. World Development Report (Infrastructure); World Bank: Washington, DC, USA, 1994.

42. World Bank. Reforming Infrastructure: Privatization, Regulation, and Competition; World Bank: Washington, DC, USA, 2004.

43. Parker, D.; Kirkpatrick, C. Privatization in developing countries: A review of the evidence and the policy lessons. J. Dev. Stud. 2005, 41, 513-541. [CrossRef]

44. Saussier, S. Public-private partnerships. J. Econ. Behav. Organ. 2013, 89, 143-144. [CrossRef]

45. Guasch, J.L. Granting and Renegotiating Infrastructure Concession: Doing It Right; The World Bank: Washington, DC, USA, 2004.

46. Guasch, J.L.; Laffont, J.-J.; Straub, S. Renegotiation of concession contracts: A theoretical approach. Rev. Ind. Organ. 2006, 29, 55-73. [CrossRef]

47. Guasch, J.L.; Laffont, J.-J.; Straub, S. Renegotiation of concession contracts in Latin America: Evidence from the water and transport sectors. Int. J. Ind. Organ. 2008, 26, 421-442. [CrossRef]

48. Levine, R.; Zervos, S. Capital control liberalization and stock market development. World Dev. 1998, 26, 1169-1183. [CrossRef]

49. Levine, R.; Zervos, S. Stock markets, banks, and economic growth. Am. Econ. Rev. 1998, 88, 537-558.

50. Levine, R. Financial development and economic growth: Views and agenda. J. Econ. Lit. 1997, 35, 688-726.

51. Sobel, M.E. Asymptotic confidence intervals for indirect effects in structural equation models. Sociol. Methodol. 1982, 13, 290-312. [CrossRef]

52. Baron, R.M.; Kenny, D.A. The moderator-mediator variable distinction in social psychological research-Conceptual, strategic, and statistical considerations. J. Personal. Soc. Psychol. 1986, 51, 1173-1182. [CrossRef]

53. Goodman, L. On the exact variance of products. J. Am. Stat. Assoc. 1960, 60, 272-286. [CrossRef]

54. Ilzetzki, E.; Mendoza, E.G.; Végh Gramont, C.A. How Big (Small?) Are Fiscal Multipliers? Working Paper, 11/52; International Monetary Fund: Washington, DC, USA, 2011.

55. La Porta, R.; Lopez-de Silanes, F.; Shleifer, A. The economic consequences of legal origins. J. Econ. Lit. 2008, 46, 285-332. [CrossRef] 
56. Reinnikka, R.; Svensson, J. Using micro-surveys to measure and explain corruption. World Dev. 2006, 34, 359-370. [CrossRef]

57. Fisman, R.; Svensson, J. Are corruption and taxation really harmful to growth? Firm level evidence. J. Dev. Econ. 2007, 83, 63-75. [CrossRef]

(c) 2016 by the authors. Licensee MDPI, Basel, Switzerland. This article is an open access article distributed under the terms and conditions of the Creative Commons Attribution (CC BY) license (http:/ / creativecommons.org/licenses/by/4.0/). 


\title{
Multi-Layered Capital Subsidy Policy for the PV Industry in China Considering Regional Differences
}

\author{
Lei $\mathrm{Li}^{1, *}$, Ting Chi ${ }^{1,+}$, Meng Zhang ${ }^{1,+}$ and Shi Wang ${ }^{2}$ \\ 1 School of Management and Economics, Tianjin University, 92, Wejin Road, Nankai District, Tianjin 300072, \\ China; yhhu@tju.edu.cn (T.C.); wushanshan533@tju.edu.cn (M.Z.) \\ 2 School of Computer Science, Carnegie Mellon University, Pittsburgh, PA 15213, USA; shiw@andrew.cmu.edu \\ * Correspondence: lilei@tju.edu.cn; Tel.: +86-138-2126-0061 \\ + These authors contributed equally to this work.
}

Academic Editors: Yongrok Choi, Malin Song and Seunghwan Myeong

Received: 30 November 2015; Accepted: 30 December 2015; Published: 5 January 2016

\begin{abstract}
As a country with huge energy consumption, China has been paying more and more attention to green growth in recent years. Several subsidy policies have been conducted to boost the photovoltaic (PV) industry so far. However, as a matter of fact, there are 31 provinces and municipalities (PM) in mainland China, and the economic condition, environmental resources and energy structure of each PM are all significantly different, which leads to a discrepancy of PV efficiency among regions. This paper proposes that the subsidies for the PV industry should be considered mainly from three aspects: the PM's economic condition, energy efficiency and environmental responsibility. We built 19 evaluation indicators involving economic, environmental and energy factors, allocated weight to each indicator using the entropy weight method and sorted the 31 evaluation objects by TOPSIS (Technique for Order of Preference by Similarity to the Ideal Solution) method. Additionally, through an empirical study, we obtained the subsidy proportion for each PM. The result could make much of a contribution to the green growth of different regions and to the whole country.
\end{abstract}

Keywords: PV industry; subsidy policy; regional difference; green growth

\section{Introduction}

With the recovery of the global economy and the constant development of industrialization, renewable energy has attracted increasing attention of the world. Traditional energy, such as fossil fuel energy, especially coal, will cause a greenhouse effect and air pollution. According to statistics from the Global Carbon Project, carbon dioxide emission from burning coal accounted for $43 \%$ of global emissions in 2013 [1]. China has the largest carbon dioxide emission, which occupies $29 \%$ of the world's total emissions. Meanwhile, fossil fuel as a non-clean energy will cause hazy weather and generate particulate matter during the burning process. According to the PM2.5 and PM10 monitoring report of the World Health Organization, only $12 \%$ of the residents of the world are living in a place that reaches the air quality standard set by the World Health Organization [2].

Compared to fuel energy, renewable energy is clean. Renewable energy includes solar energy, wind power, hydro power, tidal energy, biomass, etc. The paper will focus on solar energy.

With the technical improvement and wide application of silicon wafers, the PV industry has been growing very quickly in the past few decades [3]. This turns solar power into electricity with the advantages of being renewable, clean and easy to install. According to the European Photovoltaic Industry Association, global PV capacity reached 138.9 GW at the end of 2013 [4]. Compared to the capacity of $23 \mathrm{GW}$ in 2009, the growth rate is up to $500 \%$. From EPIA (European Photovoltaic Industry Association)'s analysis, a PV plant of this capacity can generate 160 terawatt hours of electricity, which 
is equal to the energy supply of 32 large fossil fuel power stations, and it can provide electricity to 45 million European residents.

From a global perspective, the European PV industry started earlier than the rest of the world. Spain's PV industry grew rapidly in the very beginning, and then was followed by Germany and Italy. The European PV industry reached its peak in 2011. In 2013, Europe reached a PV capacity of 81.5 GW and took first place in the world, and Germany has the biggest capacity among all European countries [4]. The PV industry in China grew quickly in recent years. In 2013, the new installation was $11,800 \mathrm{MW}$, which was the highest in the world. Figure 1 shows the accumulated capacity and incremental capacity of 2013 from a global view. For Mainland China, installed PV plants are mainly concentrated systems, but the government is also working on developing distributed ones. By the end of 2014, Gansu Province, Qinghai Province and Xinjiang Uygur Autonomous Region had the top three largest accumulated capacities, which are presented in Figure 2 [5].

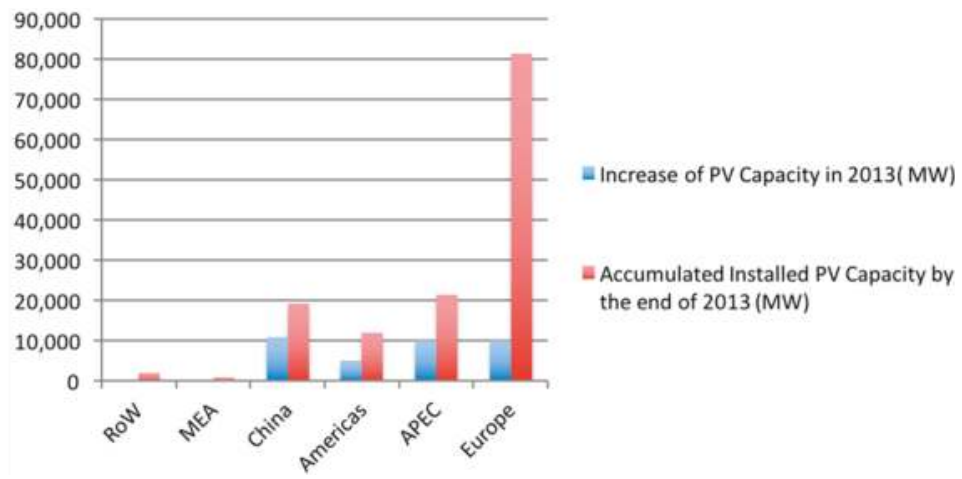

Figure 1. Distribution of PV capacity around the world in 2013 (RoW: Rest of the World, MEA: Middle-East Asia, APEC: Asia-Pacific Economic Cooperation).

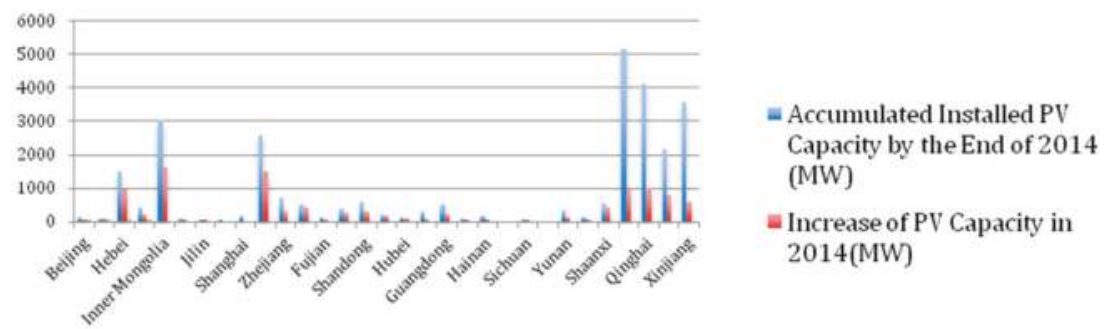

Figure 2. Distribution of PV capacity in Mainland China in 2014.

Sunlight has a huge impact on PV power generation, which could lead to the instability of electricity generation sometimes, and the cost of PV generation has remained high for a long time. Thus, it is hard for companies to profit [6]. The PV industry is still government driven [4]. In order to support PV companies, the government made a variety of financial subsidy policies, including capital subsidies, feed-in-tariff (FIT) subsidies, green certificate trading (GCT), etc. Countries should provide incentive polices based on each country's PV development phase [7]. In the early stage, the government is inclined to provide capital subsidies as a percentage of the companies' initial investment. At the time when connecting the PV systems to the electricity grid becomes possible, capital subsidies, FIT and other polices can be feasible. Subsidies are always given to the supply side first and then to the demand side.

Scholars did some remarkable research about countries' PV subsidy policies and their efficiency. 
Dusonchet and Telaretti [8,9] introduced Western and Eastern European countries' subsidy policies, including FIT, GCT and tax credits. Campoccia et al. [10] studied 27 European countries' subsidy policies and compared FIT and GCT of four representative countries based on payback period, ROI, IRR (Internal Rate of Return) and NPV. Menanteau et al. [11] compared the subsidy efficiency of the bidding system, FIT and GCT of European areas and pointed out that FIT is more efficient than bidding systems.

In Australia, the government ran the PV Rebate Program and Solar Homes and Communities Plan to support the PV industry. When residents purchase and install a PV system, they are able to obtain subsidies as a percentage of the purchase price [12]. However, this policy did not work well for improving environmental and economic efficiency. It was not significant for the reduction of $\mathrm{CO}_{2}$ emissions, nor fair for residents with low income, because successful applicants are mainly rated as having a medium or high income level. Jeon et al. [13] found that the current financial subsidy for the $\mathrm{PV}$ industry in Korean is not efficient. He analyzed the behaviors of investors, decision makers and customers, as well as external factors, including energy, the economy and environmental conditions, and implemented a real options dynamical model to simulate the interaction among those entities and factors. The result showed that Korea could still meet its target, even if it reduce financial subsidies by 669.9 USD and increased R \& D for PV by 310.4 USD. As a strong player in the Asian PV market, Japan's regional government was clearly helpful for promoting PV installation. Zhang et al. [14] analyzed panel data from 1996 to 2006 of 47 prefectures in Japan and found that both capital subsidies provided by the government and the decrease of installation cost have a significant positive impact on PV diffusion. Taiwan provided capital subsidies based on installed capacity by companies or individuals; Hsu [15] used a dynamical model to evaluate Taiwan's efficiency of FIT and capital subsidies. It was shown that when the upper limit of ROI is fixed, each single subsidy policy will be efficient, but the combination of two policies will not be. Avril et al. [7] believed that there should be a balance between the promotion of subsidy policies and the development speed of the PV industry. In the early phase of Spain's PV industry, PV demand grew rapidly, and the price increased in a short time due to the government's promotion policy. This resulted in turbulence in the job market when demand went down. Huo and Zhang [16] illustrated the PV market and subsidy policies in China, which include capital subsidies, FIT and a public bidding system. The research mentioned the problem of lacking R \& D programs and lacking a decreasing rate of capital subsidy to stimulate companies to lower production cost.

\section{Problems of PV Subsidy Policies in China}

The PV market in China is growing very quickly, which leads to a significant impact on the world's PV economy. In 2013, the incremental PV capacity of China was in first place in the world. The government launched the Golden-Sun Project in 2009 to provide capital subsidies. For a grid-connected PV system, the government provided a financial subsidy of $50 \%$ of the initial investment; for an independent PV system in remote areas without grid connection, the subsidy was $70 \%$ of the initial investment. Starting from March 2013, the MoF (Ministry of Finance of China)of China suspended approval of the Golden-Sun Project.

However, this incentive policy not only brought high-speed development of the PV industry, but also led to some issues.

In order to gain short-term profit, investors invested in excessive PV systems. The market was not able to react simultaneously, and the Matthew effect appeared. Installed capacity was much larger than power generation; the idle rate was up to $40 \%$ in 2012. Oversea markets, such as the U.S. and Europe, took anti-subsidy actions to limit the import of Chinese PV products due to unfair competition resulting from low prices [17] Hence, it is urgent for companies to adjust strategies for oversea markets. Capital subsidies are provided before the installation of systems, which leads to a lack of incentive for investors to maximize power generation; the digression rate of FIT and capital subsidies has not been settled [18]. When the cost decreasing rate is lower than the subsidy digression rate, owners of a PV plant are able to gain a huge profit through the gap [16]. Among the successful applicants for the 
Golden-Sun Project, several companies were not able to finish their installation on time. In June 2013, the National Audit Office of China audited approved companies of the Golden-Sun Project and found that several companies were trying to obtain subsidies with illegal application materials. The total subsidy they tried to get illegally was up to 210,000,000 RMB (about 33,894,000 USD) [19].

PV subsidy policies in China are still developing. During this phase, it is inevitable that unfairness and low efficiency appear. Previous scholars mainly focused on the evaluation of current incentive policies, including the impact on overseas and domestic markets, related social issues, environmental issues, etc. However, research focused on making subsidy policies for the PV industry is not enough. As a country with special conditions, China has large regional diversity. Environmental conditions, economic status and energy efficiency among provinces and municipalities are different. Imitating and learning from developed countries directly may not be wise. In contrast, considering the difference among each region and setting multi-layered subsidies are favorable for leading companies to invest in regions with better development conditions and building highly efficient PV systems.

\section{Evaluation Framework}

There are many factors contributing to PV efficiency. We will discuss these factors from three aspects considering the differences among regions. They are the ability to develop renewable energy, renewable energy efficiency and environmental responsibility. Table 1 illustrates the evaluation framework.

Table 1. PV subsidy efficiency evaluation framework.

\begin{tabular}{clc}
\hline Prime Indicators & \multicolumn{1}{c}{ Subsidiary Indicators } & Directions \\
\hline & Regional GDP & Positive \\
& GDP Per Capita & Positive \\
Ability to Develop & Investment in the Energy Industry & Positive \\
Renewable Energy & R \& D Funds in Industrial Enterprises above a & Positive \\
& Designated Size & Positive \\
& General Financial Revenue & Positive \\
\hline \multirow{2}{*}{ Renewable Energy } & Energy Consumption per Unit GDP & Negative \\
Efficiency & Electricity Consumption per Unit GDP & Negative \\
& Sunshine Duration & Positive \\
& Nitrogen Oxide Emission & Negative \\
& Dust Emission & Negative \\
\hline & Financial Expenditure for Environmental Protection & Positive \\
& Green Cover Rate for Built-Up Areas & Positive \\
& Thermal Power Generation Percentage & Negative \\
Environmental & Coal Consumption & Negative \\
& Sulfur Dioxide Emission & Negative \\
& Forest Coverage Rate & Positive \\
& Completed Investment for Treatment of Waste Gas & Positive \\
& Accumulated Installed PV Capacity & Positive \\
\hline
\end{tabular}

\subsection{Renewable Energy Efficiency}

We will discuss two aspects concerning PV efficiency. One is the efficiency of the supply side. Environmental conditions are some of the most important factors influencing PV generation efficiency. When the other conditions stay the same, the better the environmental conditions, the higher the generating/capacity rate, which means it is more productive. The other is the efficiency of the demand side, which could be explained by the economic value generated from unit energy consumption. The smaller the energy consumption per unit GDP, the larger the economic contribution from unit energy consumption. Hence, we pick sunshine duration and haze as the weather conditions to evaluate 
supply side efficiency and energy consumption per unit GDP and electricity consumption per unit GDP to evaluate the demand side efficiency of provinces and municipalities.

\subsubsection{Weather Conditions}

PV systems transform solar energy into electricity. The intensity of solar energy absorbed by silicon wafers directly affects the production rate of PV systems. Weather conditions play an important role in the intensity of sunshine reflecting off the silicon wafers, while sunshine duration and haze are two important weather factors.

Many scholars have verified the effect of sunshine hours on PV efficiency $[20,21]$. China is the third biggest country in the world, and it has a variety of weather conditions in 31 PMs, which is attributed to different sunshine hours among the areas. According to China Statistical Year Book, from 2007 to 2013, the province with the longest average sunshine duration is Tibet, with an average annual sunshine duration of $3120.6 \mathrm{~h}$, while the province with shortest sunshine duration is Sichuan Province, with an average $904.1 \mathrm{~h}$ a year, which is $2216.5 \mathrm{~h}$ less than Tibet and $6 \mathrm{~h}$ less per day [22]. With such a large national territorial area, China has diverse weather and geographical conditions, which contribute to significant differences in sunshine duration among regions and lead to different solar energy resources for PV systems from the environmental perspective.

Except for the huge difference in sunshine conditions among regions, haze is also an important factor that has affected PV efficiency in China in recent years. Haze is a kind of air pollution that consists of sulfur dioxide, nitrogen oxide and particulate matter. Particulate matter mainly comes from automobile exhaust, burning of coal, industrial waste gas, dust from construction sites, etc. In January 2013, serious hazy weather happened four times in 30 provinces and municipalities to varying degrees. In Beijing, only five days in January were not hazy. The National Disaster Management Office of China classified hazy weather as a natural disaster in January 2014.

Scholars proved that deposition from air pollution has a negative impact on PV generation efficiency, especially particulate matter, including dust from the burning process, coal ash from burning, clay, dust, red clay and lime [23-27]. Sanchez and Cheng studied the relation between PM2.5 and the PV output rate in Taipei [28]. It showed that the PV production rate decreased significantly in days with serious air pollution. In June 2013, terrible haze also appeared in Singapore. Liu et al. [29] analyzed data and found that the PV generation rate was clearly affected by hazy weather.

The degree of haze varies among regions. In China, heavily polluted areas are mostly cities with intensive industry development. North China has the severest pollution, followed by the Yangtze River Delta zone, while the western part and southern coastal cities are normally clean. According to the PM2.5 statistics for provinces and municipalities of China from 2011 to 2013, Hebei Province has the highest annual average nitrogen oxide emission and dust emission, which are 40-times and 165-times those of Tibet, respectively. Figure 3 illustrates the three-year annual average nitrogen oxide emission, dust emission and sulfur dioxide emission for mainland China from 2011 to 2013. Different economic status, population, industrial density, social conventions and other factors resulted in different environmental quality for regions, leading to differences in the supply side efficiency of PV systems ultimately.

In districts with severe haze, the PV generation rate is low, and the transfer of the energy structure from thermal power to PV power is slow, which leads to an inefficient response of haze. However, PV systems are more productive in places with better environmental conditions. Thus, the PV power generated could be connected to the grid and delivered to the rest of the country, which would help regions improve their energy structure, reduce air pollution and obtain a better external environment for the development of PV systems; this forms a virtuous cycle. 


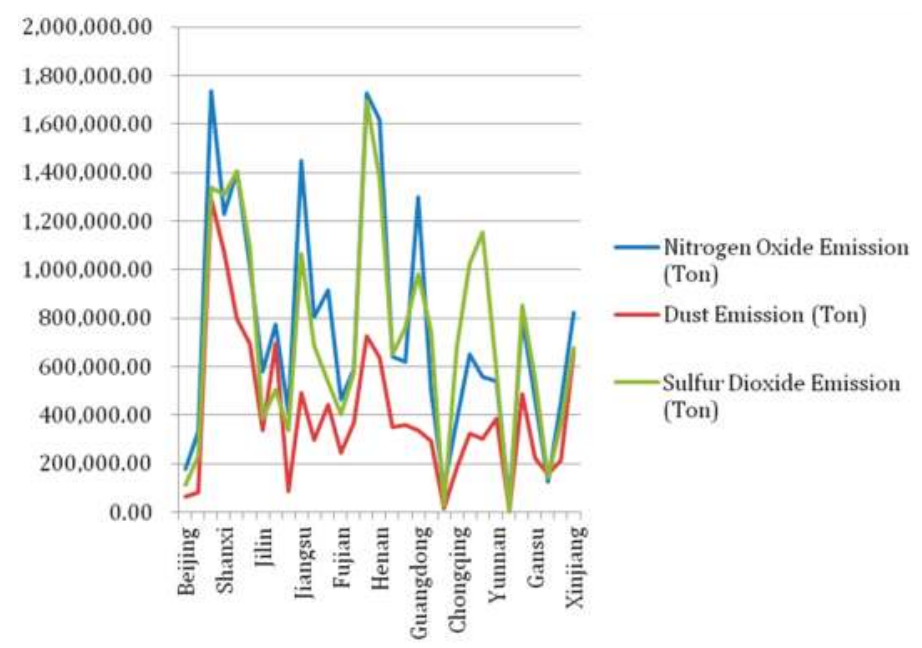

Figure 3. Three-year haze pollution for Mainland China starting from 2011.

\subsubsection{Energy Efficiency}

For demand side energy, we take energy consumption per unit GDP and electricity consumption per unit GDP into account. Developing the PV industry is not only for environmental benefit, but also for economic benefit. Due to the variation in production resources, local policies, industrial structure, etc., the GDP from unit energy consumption is different among the regions.

Energy consumption stands for energy intensity. In Nathan's research, he took energy consumption per unit GDP as an indicator of average energy intensity for his valuation model [30]. Other researchers discussed energy consumption per unit GDP, as well; they suggested that efficiency effects contributed to a majority of the decline of energy intensity [31]. In this paper, we mainly discuss electricity, which is one of the most important forms of energy, and electricity consumption per unit GDP has a similar calculation pattern as energy intensity; thus, we took electricity consumption per unit GDP as an indicator, as well. For regions with low energy consumption per unit GDP, they require less energy consumption for the increase of unit GDP, which means a higher utility rate for energy. When other conditions stay the same, those regions could gain more economic benefit with less energy consumption. Thus, these regions should be encouraged to develop renewable energy to gain economic and social benefits efficiently.

\subsection{Ability to Develop Renewable Energy}

Indicators in this sector stand for economic conditions in each area. Many scholars pointed out the bidirectional causal relationship between economic growth and energy use [32,33]. Thus, high GDP has a positive impact on energy. For indicators like investment in energy and R \& D funds in industrial enterprises, they are the cash flow for energy development. It is obvious that the higher these indicators are, the higher is the ability to develop renewable energy. For general financial revenue, this mainly comes from tax and flows to government expenditure or investment, which are highly relevant to renewable energy development. For electricity consumption, which is included in energy consumption, due to its causal relationship with economic growth, we see it as a positive indicator, as well.

Economic conditions are greatly different among the 31 provinces and municipalities. For general financial revenue from 2007 to 2013, the province with the highest annual average revenue is Guangdong with 472.69 billion RMB, while Tibet has the lowest revenue for the seven years, which is 
as low as 4.97 billion RMB. Meanwhile, there is a larger gap for R \& D funds in industrial enterprises above a designated size among the regions. Jiangsu has annual average industrial $\mathrm{R} \& \mathrm{D}$ funds of 85.4 billion RMB, which is 1900-times Tibet's 44.9 million RMB.

In order to improve the PV industry's efficiency, the government should subsidize places with better economic conditions. The main reason is that these places have more resources, including talent, capital, R \& D institutes, technology, education resources, highly efficient government departments, etc, as listed in Table 2 These factors are highly important for the development of an industry, especially for a high-tech industry, such as PV, which highly depends on technology, talent and capital. Better economic conditions are also favorable for the development of the PV industry due to economies of scale.

Table 2. Differences in the Ability to develop renewable energy among regions.

\begin{tabular}{|c|c|c|c|c|c|c|}
\hline \multirow[b]{2}{*}{ Peak } & \multicolumn{2}{|c|}{ GDP (100 Million Yuan) } & \multicolumn{2}{|c|}{$\begin{array}{l}\text { GDP Per Capita } \\
\text { (Yuan/Capita) }\end{array}$} & \multicolumn{2}{|c|}{$\begin{array}{c}\text { Investment in Energy } \\
\text { Industry (100 Million Yuan }\end{array}$} \\
\hline & GD & 46,689 & $\mathrm{SH}$ & 76,162 & NMG & 1826 \\
\hline Nadir & Tibet & 544 & GZ & 14,442 & Tibet & 66 \\
\hline Multiple & \multicolumn{2}{|c|}{86} & \multicolumn{2}{|c|}{5} & \multicolumn{2}{|c|}{28} \\
\hline & \multicolumn{2}{|c|}{$\begin{array}{c}\text { R \& D Funds in Industrial } \\
\text { Enterprises above a } \\
\text { Designated Size (10 } \\
\text { Thousands Yuan) }\end{array}$} & \multicolumn{2}{|c|}{$\begin{array}{c}\text { General Financial } \\
\text { Revenue (100 Million } \\
\text { Yuan) }\end{array}$} & \multicolumn{2}{|c|}{$\begin{array}{l}\text { Electricity Consumption } \\
\text { (100 Million KWh) }\end{array}$} \\
\hline Peak & JS & $8,542,638$ & GD & 4727 & GD & 4060 \\
\hline Nadir & Tibet & 4496 & Tibet & 50 & Tibet & 22 \\
\hline Multiple & \multicolumn{2}{|c|}{1900} & \multicolumn{2}{|c|}{95} & \multicolumn{2}{|c|}{188} \\
\hline
\end{tabular}

\subsection{Environmental Responsibility}

Scholars implemented a variety of indicators to evaluate social environmental responsibility. One of the most famous ones is the framework proposed by Global Reporting Initiative (GRI) [34]. It proposed economic, social and environmental indicators. Many researchers did empirical studies based on this framework [35]. In this valuation framework, energy and emissions and effluents and waste are two main aspects to be evaluated. Based on the idea of this authentic framework, we came up with a series of indicators to evaluate the environmental consciousness and responsibility of a local government. We also add a few valuable indicators based on the special conditions of China.

Environmental consciousness and responsibility of a local government can be reflected in several factors, including historical investment for environmental projects, the performance of historical and current environmental projects, etc. A government with a strong environmental consciousness and responsibility tends to have high promotion and efficiency for environmental projects, which lead to the better performance of those projects. In China, the efficiency of a government has a huge impact on the development of a certain industry, especially in a policy-driven industry. Hence, the country should provide better offers to such places.

Our research selected financial expenditure for environmental protection, the green coverage rate for built-up areas, thermal power generation percentage, coal consumption, sulfur dioxide emission, forest coverage rate, completed investment for treatment of waste gas and accumulated installed PV capacity as indicators for environmental consciousness and responsibility. These data were sourced from Status Statistics Bureau, and the indicators, such as green coverage rate for built-up areas, thermal power generation percentage, coal consumption, sulfur dioxide emission, forest coverage rate and accumulated installed PV capacity, reveal the current condition of the local government's achievement with respect to environmental projects, while financial expenditure for environmental protection and completed investment for treatment of waste gas present how much a government has done 
for environmental projects. Next, we calculated each indicator's entropy weight and found out the discrepancy of the regions for this indicator. Further, we sorted the evaluation objects based on TOPSIS and got the subsidy proportion for each province or municipality as references for the country's subsidy policy.

\section{Method}

The multiple-objective method is widely used in decision-making processes with multiple evaluation indicators, especially when some of the indicators conflict [36]. One of the most common evaluation methods for multiple-objective projects is the entropy weight TOPSIS method. We used the entropy weight method to allocate weight to indicators and sorted the evaluation objects with the TOPSIS method.

\subsection{Entropy Weight Method}

The theory of entropy originated from thermal dynamics and was introduced into informatics by Shannon [37]. In informatics, entropy reveals how much information the data provide [38]. For one indicator, the larger the difference among objectives, the smaller is the entropy, which means it provides more useful information and results for a larger weight. No subjective factor is involved in the above weight allocation process. Thus, compared to other weight allocation methods, the entropy weight method is objective. Meanwhile, this method helps simplify fuzzy decision-making processes, and it will not be affected by the correlation among indicators.

We calculated entropy for 19 evaluation indicators to obtain the degree of difference among 31 provinces and municipalities. The smaller the entropy of one indicator, the higher the discrepancy among the 31 provinces and municipalities under this indicator [39]. The calculation procedures are presented as follows.

Step 1. Normalization of the matrix:

For indicators with a positive direction,

$$
Y_{i j}=\frac{x_{i j}-\min \left(X_{j}\right)}{\max \left(X_{j}\right)-\min \left(X_{j}\right)}
$$

For indicators with a negative direction,

$$
Y_{i j}=\frac{\max \left(X_{j}\right)-x_{i j}}{\max \left(X_{j}\right)-\min \left(X_{j}\right)}
$$

where $Y_{i j}=$ the normalized value for the matrix, $X_{i j}=$ the original value for the matrix and $X_{i}=$ the original value of indicator $j$.

Step 2. Calculate the entropy value:

$$
I_{j}=-\ln (n)^{-1} \sum_{i=1}^{n} q_{i j} \ln q_{i j}
$$

where:

$$
q_{i j}=\frac{Y_{i j}}{\sum_{i=1}^{n} Y_{i j}}
$$

If $q_{i j}=0$, then $\lim _{q_{i j} \rightarrow 0} q_{i j} \ln q_{i j}=0$; where $I_{j}=$ the entropy value and $n=$ the number of evaluation objects. 
Step 3. Calculate the entropy weight:

$$
W_{j}=\frac{1-I_{j}}{\sum_{j=1}^{m}\left(1-I_{j}\right)}
$$

where $W_{j}=$ the entropy weight and $m=$ the number of evaluation indicators.

\subsection{TOPSIS Method}

TOPSIS stands for the Technique for Order of Preference by Similarity to the Ideal Solution [40]. Its principle is to get the ideal solution and the negative ideal solution and then to calculate the discrepancy between each evaluation object to both the ideal and negative ideal solution. The optimal evaluation object has the smallest discrepancy from the former and the biggest discrepancy from the latter.

TOPSIS has been widely used in a variety of multiple objective projects [41,42]. Allocating weight for indicators is a key procedure of the TOPSIS method, and the entropy weight method provides the objective weight. The procedures of TOPSIS can be presented as follows [41-45].

Step 1. Calculate the weighted evaluation matrix:

$$
Z_{i j}=W_{j} \times Y_{i j}
$$

where $W_{j}=$ the weighted value for the matrix, $Y_{i j}=$ the normalized decision matrix.

Step 2. Calculate the ideal solutions and the negative ideal solutions:

$$
\begin{aligned}
& {R_{j}}^{+}=\max \left(Z_{1 j}, Z_{2 j}, \ldots \ldots Z_{n j}\right) \\
& R_{j}{ }^{-}=\min \left(Z_{1 j}, Z_{2 j}, \ldots \ldots Z_{n j}\right)
\end{aligned}
$$

where $R_{j}^{+}$is the ideal solution for indicator $j$.

Step 3. Calculate the discrepancy with the ideal solutions and the negative ideal solutions:

$$
S_{i}^{+}=\sqrt{\sum_{j}^{m}\left(S_{j}^{+}-Z_{i j}\right)^{2}}
$$

where $S_{i}^{+}=$the discrepancy with the ideal solution for evaluation object $i$.

$$
S_{i}{ }^{-}=\sqrt{\sum_{j}^{m}\left(S_{j}^{-}-Z_{i j}\right)^{2}}
$$

where $S_{i}^{-}=$the discrepancy with the negative ideal solution for evaluation object $i$.

Step 4. Calculate the score for each evaluation object:

$$
C_{i}=\frac{S_{i}^{+}}{S_{i}^{+}+S_{i}^{-}}
$$

where $C_{i}=$ the score for evaluation object $i$ in TOPSIS.

The smaller the score, the higher the rank among evaluation objects. 


\section{Empirical Study}

China has diverse environmental conditions due to a vast national territory area. Moreover, economic inequality among regions in China has caused social problems for a long time; more developed cities are mainly in the east coastal areas. Environmental conditions, economic status and energy efficiency are diverse among regions. The diversity has a more significant impact on the development of the PV industry.

In order to understand the discrepancy in the ability to develop the PV industry, energy efficiency and environmental responsibility among regions, we built a criteria matrix of 19 evaluation indicators of 31 provinces and municipalities in Excel based on the framework presented in Table 1. The data are sourced from China Statistical Year Book of 2007 to 2013 [46], except for accumulated installed PV capacity, which is updated to 2014 by NEA (Natioanl Education Association) [5]. Missing data are filled based on the average method.

We calculate the entropy and the entropy weight for 19 indicators according to Equations (1) to (5) based on the entropy weight method, and we calculate evaluation scores $C_{i}$ for 31 provinces and municipalities according to Equations (6)-(11) based on the TOPSIS method. A lower $C_{i}$ stands for the larger competitiveness of energy efficiency, economic status and environmental conditions in developing the PV industry. To improve the efficiency of developing the PV industry, the government should provide higher subsidies for regions with a low $C_{i}$ score. The scores for 31 provinces and municipalities are presented in Table 3.

Table 3. Rank of the 31 provinces and municipalities (PM) of Mainland China in their efficiency for developing the PV industry.

\begin{tabular}{|c|c|c|c|c|c|}
\hline & $S_{i}^{+}$ & $S_{i}^{-}$ & $C_{i}$ & Rank & Subsidy Proportion \\
\hline Qinghai & 0.161 & 0.178 & 0.475 & 1 & $4.83 \%$ \\
\hline Jiangsu & 0.163 & 0.162 & 0.501 & 2 & $4.59 \%$ \\
\hline Gansu & 0.170 & 0.166 & 0.505 & 3 & $4.55 \%$ \\
\hline Guangdong & 0.174 & 0.157 & 0.526 & 4 & $4.36 \%$ \\
\hline Tibet & 0.208 & 0.161 & 0.564 & 5 & $4.01 \%$ \\
\hline Sichuan & 0.190 & 0.131 & 0.592 & 6 & $3.75 \%$ \\
\hline Hubei & 0.184 & 0.127 & 0.593 & 7 & $3.74 \%$ \\
\hline Zhejiang & 0.180 & 0.119 & 0.602 & 8 & $3.66 \%$ \\
\hline Xinjiang & 0.187 & 0.123 & 0.604 & 9 & $3.65 \%$ \\
\hline Shandong & 0.205 & 0.129 & 0.614 & 10 & $3.55 \%$ \\
\hline Yunan & 0.194 & 0.122 & 0.615 & 11 & $3.54 \%$ \\
\hline Inner Mongolia & 0.192 & 0.112 & 0.632 & 12 & $3.38 \%$ \\
\hline Guangxi & 0.203 & 0.112 & 0.645 & 13 & $3.27 \%$ \\
\hline Fujian & 0.199 & 0.109 & 0.646 & 14 & $3.26 \%$ \\
\hline Beijing & 0.220 & 0.118 & 0.650 & 15 & $3.22 \%$ \\
\hline Shanghai & 0.216 & 0.115 & 0.652 & 16 & $3.20 \%$ \\
\hline Hunan & 0.195 & 0.103 & 0.655 & 17 & $3.18 \%$ \\
\hline Tianjin & 0.223 & 0.108 & 0.675 & 18 & $2.99 \%$ \\
\hline Chongqing & 0.212 & 0.098 & 0.683 & 19 & $2.92 \%$ \\
\hline Hainan & 0.233 & 0.104 & 0.691 & 20 & $2.84 \%$ \\
\hline Ningxia & 0.216 & 0.095 & 0.694 & 21 & $2.82 \%$ \\
\hline Jiangxi & 0.217 & 0.092 & 0.701 & 22 & $2.75 \%$ \\
\hline Jilin & 0.219 & 0.090 & 0.709 & 23 & $2.68 \%$ \\
\hline Liaoning & 0.215 & 0.084 & 0.719 & 24 & $2.59 \%$ \\
\hline Hebei & 0.211 & 0.081 & 0.723 & 25 & $2.55 \%$ \\
\hline Shaanxi & 0.215 & 0.082 & 0.723 & 26 & $2.55 \%$ \\
\hline Anhui & 0.222 & 0.079 & 0.736 & 27 & $2.43 \%$ \\
\hline Heilongjiang & 0.229 & 0.081 & 0.740 & 28 & $2.39 \%$ \\
\hline Guizhou & 0.224 & 0.079 & 0.740 & 29 & $2.39 \%$ \\
\hline Henan & 0.223 & 0.074 & 0.752 & 30 & $2.28 \%$ \\
\hline Shanxin & 0.231 & 0.068 & 0.773 & 31 & $2.08 \%$ \\
\hline
\end{tabular}




\subsection{Analysis of Entropy and Weight}

Table 4 shows the entropy and weight for each indicator. The larger the weight, the larger the difference among the 31 provinces and municipalities for that indicator.

Table 4. Entropy and weights for the 19 evaluation indicators.

\begin{tabular}{clcc}
\hline Prime Indicators & \multicolumn{1}{c}{ Subsidiary Indicators } & Entropy & Weight \\
\hline & Regional GDP & 0.910 & 0.051 \\
& GDP Per Capita & 0.905 & 0.054 \\
Ability to Develop & Investment in Energy Industry & 0.929 & 0.040 \\
Renewable Energy & R \& D Funds in Industrial Enterprises above a Designated & 0.827 & 0.098 \\
& Size & 0.911 & 0.050 \\
& General Financial Revenue & 0.926 & 0.042 \\
\hline & Electricity Consumption & 0.939 & 0.035 \\
Renewable Energy & Energy Consumption per Unit GDP & 0.948 & 0.029 \\
Efficiency & Electricity Consumption per Unit GDP & 0.956 & 0.025 \\
& Sunshine Duration & 0.909 & 0.052 \\
& Nitrogen Oxide Emission & 0.936 & 0.036 \\
\hline & Dust Emission & 0.943 & 0.032 \\
& Financial Expenditure for Environmental Protection & 0.972 & 0.016 \\
& Green Coverage Rate for Built-Up Areas & 0.769 & 0.131 \\
Environmental & Thermal Power Generation Percentage & 0.930 & 0.039 \\
Responsibility & Coal Consumption & 0.919 & 0.046 \\
& Sulfur Dioxide Emission & 0.929 & 0.040 \\
& Forest Coverage Rate & 0.921 & 0.045 \\
& Completed Investment for Treatment of Waste Gas & 0.755 & 0.139 \\
\hline
\end{tabular}

Indicators with a weight over 0.1 are the thermal power generation percentage and accumulated installed PV capacity at the end of 2014. Indicators with a weight below 0.1 and over 0.05 are the regional GDP, GDP per capita, general financial revenue, R \& D funds in industrial enterprises above a designated size and nitrogen oxide emission. The differences among the regions fir the indicators above are relatively significant. However, the green coverage rate for built-up areas only accounts for 0.02, which means it has less variation among the regions.

\subsection{Analysis of Results in TOPSIS}

Based on the entropy weight method, we sort 31 provinces and municipalities in TOPSIS. The larger the discrepancy with the negative ideal solutions, the smaller the discrepancy with the ideal solutions and the higher rank of the evaluation object. The top five regions are Qinghai, Jiangsu, Gansu, Guangdong and Tibet; the bottom five regions are Anhui, Heilongjiang, Guizhou, Henan and Shanxi.

First is Qinghai Province, which has a high rank in several highly weighted indicators. Qinghai is in second place in thermal power generation percentage (negative) and accumulated installed PV capacity and in the third place in nitrogen oxide emission (negative). Qinghai Province is located in remote western China. It possesses superior environmental conditions to develop renewable energy. It has already attracted a large amount of renewable energy investments, including wind energy, solar energy, etc. It has a relatively advanced energy structure, consciousness and responsibility and also a highly efficient environment to develop renewable energy. With the national strategy of western China development, Qinghai is supposed to get high policy subsidies for PV development. Our result conforms to the subsidy policy in the Golden-Sun Project, which is that the government provides $70 \%$ of initial investment as the subsidy for independent PV systems in remote areas.

Jiangsu Province is the second, which is located in the Yangtze River Delta economic development zone. Jiangsu has preeminent economic conditions for industries. As for the indicators with a higher weight, Jiangsu ranks first place in R \& D funds in industrial enterprises above a designated size, second 
place in regional GDP and second place in general financial revenue. The well-developed economic environment brings more resources and opportunities for the PV industry. The rank conforms to the fact that Jiangsu is prioritized in developing distributed PV systems. Jiangsu ranks first place in accumulated installed distributed PV capacity and fifth place in total accumulated installed PV capacity.

Shanxi Province is at the bottom. Shanxi is famous for its coal. It highly depends on thermal power generation. Shanxi has the third highest thermal power generation percentage and ranks second place in dust emission. The traditional energy structure has a negative impact on environmental conditions, which is harmful for the efficiency of PV generation. This is one of the reasons that Shanxi has low accumulated installed PV capacity. For these kinds of places, we propose that the government should decrease PV subsidies and lead potential investment to places with higher development efficiency for the PV industry.

\section{Conclusions}

The global PV industry is still policy driven. In this paper, we discussed the differences in the ability to develop renewable energy, energy efficiency and environmental responsibility in 31 provinces and municipalities in China and proposed that the government should differentiate the amount of subsidies for the PV industry according to regional differences. We established 19 evaluation indicators, allocated weight to indicators through the entropy weight method, evaluated and sorted 31 provinces and municipalities through the TOPSIS method and obtained the subsidy proportion for each province or municipality. Through the multi-layer subsidy policy, the government could lead capital to places with higher development efficiency for the PV industry and increase PV generation with less capital and in a shorter time. It maximally avoids blind investment and waste of resources for PV installation, and it helps improve nationwide air quality, which could improve the energy structure, boost the PV industry from the national perspective and guarantee green growth.

It is more efficient than the Golden-Sun Project. The Golden-Sun Project only provided two layers of capital subsidies, which are $50 \%$ of the initial investment for distributed PV systems and $70 \%$ initial investment for remote, independent PV systems, respectively. This appealing policy made companies invest large amounts of money into the PV industry, which led to a high idle rate of PV capacity and a huge waste of money and installation resources. Even cheating on applying the subsidies happened. Compared to the two-layer capital subsidy policy, the paper proposed a 31-layer policy to differentiate subsidies for regions and controlled the upper limit of capital investment into each province or municipality accurately, which would lead to capital flow to places with better conditions for PV development.

We proposed a creative solution for PV subsidies considering the reality of China and for the green growth of each region, as well as the whole country. However, existing research concerning this area is not abundant. Hence, we could do more in the future. The selection of evaluation indicators could be more comprehensive; other factors affecting PV efficiency, such as cloud cover, can be included. Further, scholars can discuss the fairness of FIT or other subsidy methods in the future.

Acknowledgments: The authors gratefully acknowledge the support provided by the National Natural Science Foundation of China (Grant No. 71203153) the Independent Innovation Foundation of Tianjin University (Grant No. 2013XS-0039) and the Tianjin Municipal Science and Technology Commission (Grant No. 2014ZLZLZF00002).

Author Contributions: Lei Li conceived and designed the structure of paper; Ting Chi and Meng Zhang analyzed the data; and develop the analysis tools; Ting Chi, Meng Zhang and Shi Wang wrote the paper. Shi Wang revised the manuscript.

Conflicts of Interest: The authors declare no conflict of interest.

\section{Nomenclature}

$\begin{array}{ll}Y_{i j} & \text { Normalized decision matrix } \\ I_{j} & \text { Entropy } \\ W_{j} & \text { Entropy weight }\end{array}$




$\begin{array}{ll}Z_{i j} & \text { Weighted normalized matrix } \\ R_{j}^{+} & \text {Ideal solution in TOPSIS } \\ R_{j}^{-} & \text {Negative ideal solution in TOPSIS } \\ S_{i}^{+} & \text {Separation from ideal solution in TOPSIS } \\ S_{i}^{-} & \text {Separation from negative ideal solution in TOPSIS } \\ C_{i} & \text { Score for each evaluation object }\end{array}$

\section{References}

1. GCP. Fossil Fuel Emissions. Available online: http://www.globalcarbonatlas.org/?q=en/emissions (accessed on 2 December 2015).

2. WHO. Who's Ambient Air Pollution Database. Available online: http://www.who.int/phe/ health_topics/outdoorair/databases/AAP_database_results2014.pdf?ua=1 (accessed on 2 December 2015).

3. Dincer, I. Renewable energy and sustainable development: A crucial review. Renew. Sustain. Energy Rev. 2000, 4, 157-175. [CrossRef]

4. EPIA. Global Market Outlook for Photovoltaics 2014-2018. Available online: http://www.epia.org/ index.php?eID=tx_nawsecuredl\&u=0\&file=/uploads /tx_epiapublications $/ 44$ _epia_gmo_report_ver_17_mr. pdf\&t=1432808109\&hash=e64574ff7111896a0092f844dc530ae14fc1c3ac (accessed on 2 December 2015).

5. NEA. 2014 pv Industry Statistic. Available online: http://www.nea.gov.cn/2015-03/09/c_134049519.htm (accessed on 2 December 2015). (In Chinese)

6. IRENA. Renewable eNergy Cost Analysis-Solar Photovoltaics. Available online: http://www.irena.org/ menu/index.aspx?mnu=Subcat\&PriMenuID=36\&CatID=141\&SubcatID=231 (accessed on 2 December 2015).

7. Avril, S.; Mansilla, C.; Busson, M.; Lemaire, T. Photovoltaic energy policy: Financial estimation and performance comparison of the public support in five representative countries. Energy Policy 2012, 51, 244-258. [CrossRef]

8. Dusonchet, L.; Telaretti, E. Economic analysis of different supporting policies for the production of electrical energy by solar photovoltaics in eastern european union countries. Energy Policy 2010, 38, 4011-4020. [CrossRef]

9. Dusonchet, L.; Telaretti, E. Economic analysis of different supporting policies for the production of electrical energy by solar photovoltaics in western european union countries. Energy Policy 2010, 38, 3297-3308. [CrossRef]

10. Campoccia, A.; Dusonchet, L.; Telaretti, E.; Zizzo, G. Comparative analysis of different supporting measures for the production of electrical energy by solar pv and wind systems: Four representative european cases. Sol. Energy 2009, 83, 287-297. [CrossRef]

11. Menanteau, P.; Finon, D.; Lamy, M.-L. Prices versus quantities: Choosing policies for promoting the development of renewable energy. Energy Policy 2003, 31, 799-812. [CrossRef]

12. Macintosh, A.; Wilkinson, D. Searching for public benefits in solar subsidies: A case study on the australian government's residential photovoltaic rebate program. Energy Policy 2011, 39, 3199-3209. [CrossRef]

13. Jeon, C.; Lee, J.; Shin, J. Optimal subsidy estimation method using system dynamics and the real option model: Photovoltaic technology case. Appl. Energy 2015, 142, 33-43. [CrossRef]

14. Zhang, Y.; Song, J.; Hamori, S. Impact of subsidy policies on diffusion of photovoltaic power generation. Energy Policy 2011, 39, 1958-1964. [CrossRef]

15. Hsu, C.-W. Using a system dynamics model to assess the effects of capital subsidies and feed-in tariffs on solar pv installations. Appl. Energy 2012, 100, 205-217. [CrossRef]

16. Huo, M.-L.; Zhang, D.-W. Lessons from photovoltaic policies in china for future development. Energy Policy 2012, 51, 38-45. [CrossRef]

17. Sun, H.; Zhi, Q.; Wang, Y.; Yao, Q.; Su, J. China's solar photovoltaic industry development: The status quo, problems and approaches. Applied Energy 2014, 118, 221-230. [CrossRef]

18. Rigter, J.; Vidican, G. Cost and optimal feed-in tariff for small scale photovoltaic systems in China. Energy Policy 2010, 38, 6989-7000.

19. National Audit Office. Available online: https://www.nao.org.uk/ (accessed on 2 December 2015). 
20. Mondal, M.A.H.; Islam, A.S. Potential and viability of grid-connected solar pv system in bangladesh. Renew. Energy 2011, 36, 1869-1874. [CrossRef]

21. Sheikh, M.A. Renewable energy resource potential in pakistan. Renew. Sustain. Energy Rev. 2009, 13, 2696-2702. [CrossRef]

22. NBS. China Statistical Yearbook; China Statistical Press: Beijing, China, 2007-2013.

23. Kaldellis, J.K.; Kokala, A.; Kapsali, M. Natural air pollution deposition impact on the efficiency of pv panels in urban environment. Fresenius Environ. Bull. 2010, 19, 2864-2872.

24. Darwish, Z.A.; Kazem, H.A.; Sopian, K.; Al-Goul, M.; Alawadhi, H. Effect of dust pollutant type on photovoltaic performance. Renew. Sustain. Energy Rev. 2015, 41, 735-744. [CrossRef]

25. Kaldellis, J.; Fragos, P.; Kapsali, M. Systematic experimental study of the pollution deposition impact on the energy yield of photovoltaic installations. Renew. Energy 2011, 36, 2717-2724. [CrossRef]

26. Darwish, Z.A.; Kazem, H.A.; Sopian, K.; Alghoul, M.; Chaichan, M.T. Impact of some environmental variables with dust on solar photovoltaic (pv) performance: Review and research status. Int. J. Energy Environ. 2013, 7, 152-159.

27. Kaldellis, J.; Kapsali, M. Simulating the dust effect on the energy performance of photovoltaic generators based on experimental measurements. Energy 2011, 36, 5154-5161. [CrossRef]

28. Sanchez Jimenez, C.S.; Cheng, C.L. Effect of suspended particulate matter (PM2.5) on the performance of a bipv system in urban environments, a case study for Taipei city. In Proceedings of the Green Building towards Eco-City, Taipei, Taiwan, 11-14 October 2009; In-House Publishing: Rotterdam, The Netherlands, 2009.

29. Liu, H.; Nobre, A.M.; Yang, D.; Ye, J.Y.; Martins, F.R.; Ruther, R.; Reindl, T.; Aberle, A.G.; Peters, I.M. The impact of haze on performance ratio and short-circuit current of pv systems in singapore. In Proceedings of the 6th WCPEC, Kyoto, Japan, 24-27 November 2014.

30. Lewis, N.S.; Nocera, D.G. Powering the planet: Chemical challenges in solar energy utilization. Proc. Natl. Acad. Sci. USA 2006, 103, 15729-15735. [CrossRef] [PubMed]

31. Liao, H.; Fan, Y.; Wei, Y.-M. What induced China's energy intensity to fluctuate: 1997-2006? Energy Policy 2007, 35, 4640-4649. [CrossRef]

32. Stern, D.I. Energy and economic growth in the USA: A multivariate approach. Energy Econ. 1993, 15, 137-150. [CrossRef]

33. Yang, H.-Y. A note on the causal relationship between energy and gdp in taiwan. Energy Econ. 2000, 22, 309-317. [CrossRef]

34. Initiative, G.R. Sustainability Reporting Guidelines on Economic, Environmental, and Social Performance; Global Reporting Initiative: Amsterdam, The Netherland, 2000.

35. Gallego, I. The use of economic, social and environmental indicators as a measure of sustainable development in spain. Corp. Soc. Responsib. Environ. Manag. 2006, 13, 78-97. [CrossRef]

36. Ren, H.; Zhou, W.; Nakagami, K.i.; Gao, W.; Wu, Q. Multi-objective optimization for the operation of distributed energy systems considering economic and environmental aspects. Appl. Energy 2010, 87, 3642-3651. [CrossRef]

37. Shannon, C.E. A mathematical theory of communication. ACM SIGMOBILE Mob. Comput. Commun. Rev. 2001, 5, 3-55. [CrossRef]

38. Zou, Z.-H.; Yun, Y.; Sun, J.-N. Entropy method for determination of weight of evaluating indicators in fuzzy synthetic evaluation for water quality assessment. J. Environ. Sci. 2006, 18, 1020-1023. [CrossRef]

39. Qiu, W. Management Decision and Applied Entropy; China Machine Press: Beijing, China, 2002.

40. Yoon, K.P.; Hwang, C.-L. Multiple Attribute Decision Making: An Introduction; Sage Publications: Thousand Oaks, CA, USA, 1995; Volume 104.

41. Dong, J.; Chi, Y.; Zou, D.; Fu, C.; Huang, Q.; Ni, M. Energy-environment-economy assessment of waste management systems from a life cycle perspective: Model development and case study. Appl. Energy 2014, 114, 400-408. [CrossRef]

42. Cavallaro, F. Fuzzy topsis approach for assessing thermal-energy storage in concentrated solar power (CSP) systems. Appl. Energy 2010, 87, 496-503. [CrossRef]

43. Wang, T.-C.; Chang, T.-H. Application of topsis in evaluating initial training aircraft under a fuzzy environment. Expert Syst. Appl. 2007, 33, 870-880. [CrossRef] 
44. Jahanshahloo, G.R.; Lotfi, F.H.; Izadikhah, M. Extension of the topsis method for decision-making problems with fuzzy data. Appl. Math. Comput. 2006, 181, 1544-1551. [CrossRef]

45. Chen, C.-T. Extensions of the topsis for group decision-making under fuzzy environment. Fuzzy Sets Syst. 2000, 114, 1-9. [CrossRef]

46. National Bureau of Statistics of the People's Repubilc of China. China Statistical Year Book 2007-2013. Available online: http://www.stats.gov.cn/tjsj/ndsj/ (accessed on 2 December 2015). (In Chinese)

(C) 2016 by the authors. Licensee MDPI, Basel, Switzerland. This article is an open access article distributed under the terms and conditions of the Creative Commons Attribution (CC BY) license (http:/ / creativecommons.org/licenses/by/4.0/). 
Article

\title{
Which Subsidy Mode Improves the Financial Performance of Renewable Energy Firms? A Panel Data Analysis of Wind and Solar Energy Companies between 2009 and 2014
}

\author{
Huiming Zhang ${ }^{1,2, *}$, Yu Zheng ${ }^{2}$, Dequn Zhou ${ }^{3}$ and Peifeng Zhu ${ }^{4}$ \\ 1 China Institute of Manufacturing Development \& College of Economics and Management, \\ Nanjing University of Information Science \& Technology, Nanjing 210044, China \\ 2 College of Economics and Management, Nanjing University of Information Science\&Technology, \\ Nanjing 210044, China; ilovebzh@163.com \\ 3 Research Centre for Soft Energy Sciences, Nanjing University of Aeronautics and Astronautics, \\ Nanjing 211100, China; dqzhou88@163.com \\ 4 College of Economics and Management, Nanjing University of Chinese Medicine, Nanjing 210023, China; \\ zpf001511@126.com \\ * Correspondence: 002068@ nuist.edu.cn or hm.zhang_16@163.com; Tel.: +86-139-1474-1963
}

Academic Editors: Yongrok Choi, Malin Song and Seunghwan Myeong

Received: 22 September 2015; Accepted: 8 December 2015; Published: 15 December 2015

\begin{abstract}
The effectiveness of subsidies in improving the performance of renewable energy firms has aroused significant research attention in recent years. As subsidy modes may affect corporate financial performance,we have chosen companies specializing in wind and solar energy in the Shanghai and Shenzhen stock markets as samples.The relationships between the subsidy modes and financial performance of these two types of companies are investigated with a panel data model. Results of the total sample indicate that both indirect and non-innovative subsidy have significant effects on the financial performance of renewable energy companies. The regressive coefficient of the former,however, is a negative value, which illustrates that taxation, bonus, and other market-based mechanisms impair corporate profitability. Moreover, the influence of innovative subsidy is weak, which means that the subsidy used for research and development, technical demonstration, and other innovations of renewable energy enterprises have failed to effectively enhance corporate financial performance. In terms of sub-industries, the direct subsidy for wind energy companies has achieved a significant effect. Incomparison, the indirect subsidy and innovative subsidy acquired by solar energy companies have notably reduced corporate profitability. Thissuggests an urgent reform of subsidy policy for this industry is needed. The government should consider differences in the effects subsidies have for wind and solar energy companies when improving subsidy policy. In addition, market-based subsidy mechanisms should be perfected, and the structure of innovative subsidies should be ameliorated.
\end{abstract}

Keywords: renewable energy; subsidy mode; financial performance; panel data model

\section{Introduction}

The development of renewable energy in terms of energy production and consumption has become de rigeur among major countries; not only does it bring about a new point of economic growth but it can also alleviate climate change and energy safety to a certain extent. The US, UK, Japan, and other developed countries have established the role of subsidy policies in providing strong support. China similarly attaches great importance to renewable energy, especially for the wind and solar energy 
industries. Wind energy legislation includes the following: Renewable Energy Law (2005), Opinions of the State Council on Accelerating the Equipment Manufacturing Industry (2006), Implementation Measures for the Implementing Wind Power Industry (2006), Adjustment of Import Tax Preferential Policies for Large-scale Wind Energy Electricity Generator Equipment, Key Components and Raw Materials (2008), Interim Management Measures for Special-Project Funds of Wind Power Generation Equipment Industrialization (2008), Notice on the Improvement of Feed-tariff Policies of Wind Power (2009), On the Issue of Interim Measures for Additional Electricity Price Subsidy of Renewable Energy (2012), Notice on the Value-Added Tax of Wind Power (2015). As concerns the solar energy industry, subsidy policies include the following: Interim Management Measures for Financial Subsidies of PV Building (2009), Subsidies for Golden Sun Project (2010), Announcement on the Demonstration Project Directory of Golden Sun in 2012 and Notice on the Improvement of Photovoltaic Power Price Policies (2013), Notification on the Generating Capacity Subsidy for Distributive Photovoltaic Power (2013), Notice on the Value-Added Tax of Photovoltaic Power (2013), and other stipulations.

In relation to the above, the effect of subsidy has aroused the attention of governments and academic circles. Different subsidy modes used to stimulate the development of renewable energy may have varied influences on technical innovation and production cost, which, in turn, can affect corporate financial performance. Therefore, investigating subsidy modes may actually be more important than probing the entire subsidy. For example, the feed-in tariff can reduce the cost incurred by power-generation enterprises dealing with renewable energy. The expansion brought by employment subsidy may instead result in the rise of corporate operational costs, and the technical innovation spurred by the subsidy modes of R\&D andtechnology upgrading projectsmay enhance corporate competitiveness, avoid anti-subsidy trade disputes of the WTO to a certain extent, and enhance corporate financial performance. Therefore, the comprehensive effect of subsidy modes on the financial performance of renewable energy companies is complicated. Using this complexity and data availability, we select wind and solar energy companies as samples that account for a large proportion of listed companies of renewable energy, and explore the relationship between these two variables by establishing a panel data model. The main contributions of this paper are (1) to present an investigation into the relationship between subsidy modes and financial performance for the wind and solar companies and (2) to make a comparative study with a view to reforming subsidy policies.

\section{Literature Review}

Studies related to renewable energy subsidy can be grouped into two types: the selection and effects of subsidy modes and the influence of subsidies on corporate financial performance.

\subsection{Selection and Effects of Subsidy Modes}

Studies on the selection and effect of subsidy modes focus on three aspects.

(a) Selection of renewable energy subsidy modes in China with a review of international experience

Du et al. classified subsidies into four types: tax preference, fiscal subsidy, factor support, and preemption. Looking at the introduction of the US subsidy policies for the new energy industries and the analysis of existing flaws in Chinese policies, they proposed that China should encourage enterprises or individuals to build infrastructures for the new energy industry through either tax preference or tax reduction or exemption. In addition, China should both subsidize the individual purchases of new energy productsand incorporate a certain percentage of new energy products into governmental procurement. Finally, they maintained new energy companies could be subsidized through the addition of taxes on other traditional energy enterprises [1]. Focusing on Germany, Denmark, and some other European countries that are considered renewable energy powerhouses, Xie et al. analyzed their policy mechanisms and then proposed the direction Chinese reform could take regarding the types of subsidies, withaspectssuch as feed-in tariff, development foundation for renewable energy, and other financial support [2]. 


\section{(b) Effect of trade disputes on the choice of subsidy mode}

Disputes on international trade may affect the selection of subsidy modes, and such disputes have already aroused the attention of some scholars. For example, in their study,Xiong and Zhou pointed out that both ordinary competitive subsidy and R\&D subsidy were more compliant with the WTO regulations than prohibited subsidiessuch as export subsidy or import substitution subsidy [3]; furthermore, these subsidies can avoid the trade disputes of "anti-subsidy" to a certain extent. Sun and Tang argued that a system plight exists in the subsidy of renewable energy under the WTO framework, and that China needs to reform subsidy policy to fix the problem [4]. Such reforms should include using green governmental procurement to support the industry of renewable energy, using R\&D subsidy as much as possible, and changing direct subsidy into indirect subsidy. In contrast with China, as shown in the studies of Steve and Carolyn on Canadian Ontario, the feed-in tariff of Ontario was regarded as a challenge of prohibitive import substitution subsidy during the first round of debates over renewable energy at the WTO [5]. Therefore, the subsidy mode should also be improved.

\section{(c) Effectiveness of the subsidy mode choices}

Different subsidy modes indicate the varied influences of policy tools on the macro-economy, industrial or corporate production cost, technical innovation, and consumers. The results of the Grey prediction modelshow thatthe price subsidies of renewable energy in China can exert a noticeable positive influence on the macro-economy [6]. This viewpoint has also been supported by Ouyang and Lin, who pointed out that the diversion of subsidy from fossil energy to renewable energy may narrow the income gap [7].

Some scholars focused on the effect of subsidy modes on the downstream of the industry chain. For example, Lesserrevealed that the USwasbeing unreasonablypractical indirectlysubsidizing wind power generation because this subsidy mode aggravates market distortion [8]. Marco and Sánchez-Braza studied the influence of subsidy modes on solar energy $[9,10]$. The difference between the two lies in the fact thatthe former focused on capital subsidies whereas the latter emphasized property tax incentives.

With regards to the innovation subsidies, some findings indicate that modessuch as tax reduction or exemption [11], market and R\&D support [12], and the transfer payment of investment and development [13] may exert influence on the technology of renewable energy and therefore have an indirect influence on corporate financial performance. However, as pointed out by Shen and Luo, some modes, such as the transfer payment of investment and development, may instead result in low-level technology [13]. Analysis on the effect of subsidy modes from the perspectives of production and operation cost and the supply of finished products is a key topic of current studies found in the literature.

Orvika provided evidence showing that subsidies that separate wind power incentives from markets signal dramatically increased costs [14]; an inflexible power system should focus instead on investment subsidies rather than on production subsidies or fixed prices. In encouraging the development of renewable energy, the most common policy support includes the feed-in tariff of renewable energy (FIT) and the renewable portfolio standard (RPS), as reported by Keyuraphan et al. [15]. In Thailand, integrating these two ways has been a feasible approach in encouraging the power production of renewable energy. While studying the effect of subsidy on power generation of renewable energy, Zhang et al. argued that determining a moderate subsidy limit is important in increasing the power generation capacity of wind energy [16].

Cost-effectiveness is an important method in determining the choice ofwhich subsidy mode to use. Relevant studies generally compare either electricity price subsidy to capital subsidy [17], electricity price subsidy to license market system or feed-in tariff to the three-policy mix of feed-in tariff, investment subsidy, and soft loan [18]. In all these studies, the attention is focused on the downstream of the renewable energy industry chain. 


\subsection{Influence of Subsidy on Corporate Financial Performance}

Theoretically, viewpoints on subsidy performance may seem contradicting, as in the case of promotion vs. rent-seeking viewpoints. According to the former, subsidies promote R\&D and the investment in enterprises which enhance corporate performance in the current period. This view, however, has gained the support of only a few scholars, such as Kong and Li [19]. Instead, more scholars have pointed out that subsidy cannot necessarily be distributed effectively because of rent-seeking behavior. A subsidy may result in slow growth of profits or the reduction of return on asset. Beason, Bergstrom, Balsar and Ucdogruk, and Lu and Huang et al. all validated this argument through their empirical analyses of investment subsidy, fiscal subsidy, or food and beverage manufacturing companies [20-23]. Moreover, the influence of subsidy on corporate financial performance may also be uncertain and subject to some conditions, such as the period of influence [24], political relations, and others $[25,26]$.

Although previous studies on the subsidy issue have been worthwhile and beneficial, several shortcomings are observed:(1) Studies on the relationship between subsidy and corporate financial performance mainlyexamine agriculture or ordinary manufacturing and pay little attention to the industry of renewable energy.Afew studies consider the influence of subsidy modes on corporate financial performance; (2) The classification of subsidy modes is not yet unified. At present, some scholars classify the subsidy modes into direct and indirect, whereas others classify the subsidy modes into tax preference, fiscal subsidy, factor support and preemption, and so on. The difference in classification results in an uncertain research conclusion. Using the abovementioned analysis and the subsidy types acquired by renewable energy firms in China, we classify subsidy modes according to the two standards (i.e., whether they are fiscal direct subsidies or innovative subsidies), in order to explore the relationship of subsidies to corporate financial performance.

\section{Model and Hypotheses}

\subsection{Research Hypotheses}

A subsidy is generally considered to include direct fiscal input, tax reduction, financing preference, bonus, and other aspects. On the one hand, subsidy can be classified into two modes (direct subsidy and indirect subsidy) based on whether it is a fiscal direct subsidy. Alternatively, subsidiescan be used for the different purposes of R\&D, technology upgrading projects, technological application, employment, and others. Therefore, thesubsidy modes can be classified into innovative subsidies and non-innovative subsidies, whereinnovative subsidies refer to technological supply and diffusion.

Before proposing the hypotheses, we need to analyze how subsidy modes influence corporate financial performance. Direct subsidy refers to the direct appropriation of fiscal funds. Under current circumstances, which show that the market-based mechanism has not yet been fully established, direct subsidies may have a more conspicuous influence than indirect subsidies on corporate financial performance. Innovative subsidiesare used to promote corporate innovative capacity. Only innovative capacity has been promoted to a certain degree, leading to an effectiveincrease in the profitability of enterprises. Thus, theoretically speaking, an innovative subsidy given to enterprises is more likely to enhance corporate profitability than a non-innovative one. Based on the above,we put forward the following hypotheses:

- H1: A direct subsidy has asignificant positive effecton corporate financial performance under the circumstance ofimperfect market-based mechanisms.

- H2: An innovative subsidy can promote corporate profitability more conspicuously than a non-innovative subsidy. 


\subsection{Sample Selection and Data Source}

Enterprises listed in the Shanghai and Shenzhen stock exchanges, whose main business is renewable energy, include producers of wind energy, solar energy, bio-mass energy, and hydropower. Wind and solar energy companies figure predominantly and their subsidy issues have aroused the greatest attention. Therefore, these companies have been selected as samples. Considering that subsidiaryaccounts for subsidy in corporate annual reports began in 2009, we set the research period as 2009 to 2014. After the samples with negative net profit in this period are eliminated, the numbers of companies producing wind and solar energy are 26 and 21, respectively. The source for the data used in this study is the China Stock Market and Accounting ResearchDatabase. All estimations are obtained through the econometric software Stata.

\subsection{Variable Selection and Model Setup}

Two panel data models are established. The explanatory variables of the first model are direct subsidy and indirect subsidy. In accounting statements, a subsidy is recorded under the headings of "governmental subsidy" and "non-operating income". A direct subsidy includes special funds for industry development, direct funds of base construction and employee financial allocation. An indirect subsidy is taken to be the sum of tax reductions or exemptions, financing preferences, bonuses, and other market-based parameters, which equal total governmental subsidies minus direct subsidies. Innovative subsidies include research and development funds, techniques for the improvement of projects, special funds for science and technology infrastructure and other technical research and application subsidies. A non-innovative subsidy, therefore, equals total subsidies minus innovative subsidies. The subsidies for land evictions, heating, increasing employment and others are considered to be non-innovative ones.

The explained variable is corporate financial performance. Among numerous corporate profitability evaluation indices, netprofit is one of the most important indices; hence, it is used as the explained variable. Corporate age, capital intensity, and percentage of the largest shareholder serve as control variables.

(1) Corporate age. Theoretically, the net profit of an enterprise increases with the number of years it has existed. An enterprise with a longer period of existence may be more capable of making profit because it has accumulated market knowledge and experience. Therefore, corporate age is a variableaffecting corporate netprofit. The years of corporateexistence are taken asa measurement for this variable.

(2) Capital intensity. Increased capital intensity represents the higher proportion of materialized labor consumption in the production costs and the lower proportion of direct labor consumption. This function shows greater capital investment per unit labor than usualand enhances corporate profitability. Capital intensity is valued as the ratio of fixed assets to total employees.

(3) Percentage of the largest shareholder. The percentage of the largest shareholder reflects the distribution of control rights to a certain extent and determines the agency management between ownership and managerial authority. The relationship between the percentage of the largest shareholder and corporate financial performance is uncertain. A viewpoint shows that a positive relationship exists between the two variables because the governing power of the largest shareholder grows with his or her shareholding, thereby reducing the opportunist tendency of managers and promoting corporate value and profitability. An opposite viewpoint holds that the largest shareholder has the largest number of shares, which may enable him or her to infringe upon the interest of small and medium shareholders and the overall corporate interest. Based on the abovementioned analysis, the panel model is established and expressed as

$$
\operatorname{Ln}\left(\operatorname{Profit} t_{i t}\right)=\beta_{0}+\beta_{1} \operatorname{Ln}\left(\operatorname{Dsub}_{\mathrm{it}}\right)+\beta_{2} \operatorname{Ln}\left(N D s u b_{\mathrm{it}}\right)+\lambda_{1} \operatorname{Ln}\left(A \mathrm{~g} e_{\mathrm{it}}\right)+\lambda_{2} \operatorname{Ln}\left(\mathrm{Top}_{\mathrm{it}}\right)+\lambda_{3} \operatorname{Ln}\left(\mathrm{Cpl}_{\mathrm{it}}\right)+\varepsilon_{i t}
$$


where Profit $i_{i t}, D_{s u b}$ it, NDsub $i t, A g e_{i t}$, Top $_{i t}$, and $C p l_{i t}$ denote corporate netprofit, direct subsidy, indirect subsidy, corporate age, capital intensity and percentage of the largest shareholder, respectively.

The second model is the panel model of innovative subsidy and non-innovative subsidy, which is expressed as

$$
\mathrm{L} n\left(\operatorname{Profit}{ }_{i t}\right)=\beta_{0}+\beta_{1} \operatorname{Ln}\left(\operatorname{Isub}_{\mathrm{it}}\right)+\beta_{2} \operatorname{Ln}\left(\text { NIsub }_{\mathrm{it}}\right)+\lambda_{1} \operatorname{Ln}\left(A \mathrm{~g} e_{\mathrm{it}}\right)+\lambda_{2} \operatorname{Ln}\left(\mathrm{Top}_{\mathrm{it}}\right)+\lambda_{3} \operatorname{Ln}\left(\mathrm{Cpl}_{i t}\right)+\varepsilon_{i t}
$$

where $I s u b_{i t}$ and $N_{I s u b}$ it denote innovative subsidy and non-innovative subsidy, respectively. The symbols and definitions are shown in Table 1.

Table 1. Variable symbol and definition.

\begin{tabular}{ccc}
\hline Variable Classification & Variable Symbol & Variable Measurement \\
\hline Dependent variable & Profit & The net profits \\
\hline \multirow{3}{*}{ Explanatory variables } & Dsub & The direct fiscal appropriation \\
& NDsub & The sum of market-oriented subsidies \\
& Isub & The sum of technology supply and diffusion subsidies \\
& NIsub & The value of total subsidies minus the innovative ones \\
\hline \multirow{3}{*}{ Control variables } & Age & The number of years enterprise has existed \\
& Top & The proportion of the largest shareholder in total shares \\
& Cpl & The ratio of fixed assets to total employees
\end{tabular}

\section{EmpiricalResults}

\subsection{Descriptive Statistical Analysis}

Descriptive statistical analysis is presented in Tables 2 and 3. As shown in Figure 1, the netprofit of wind energy companies from 2009 to 2014 was higher than that of solar energy companiesas a whole. The average of the netprofit of windenergy companies declined for two consecutive years from 2009 to 2011 and began to rebound in 2012. The rebound is probably caused by the enacting of incentivepolicies such as the Twelfth Five-year Plan for Wind Power Technology and Twelfth Five-year Plan for Renewable Energy.The average of the netprofit of solar energy companies assumed a fluctuating trend from 2009 to 2012 and then gained 299.287 million yuan in 2009. Thereafter, the net profit increased to 584.069 million yuan in 2010, followed bya rebound in 2013 after a transient declining trend. Between 2009 and 2012, the solar industry experienced overcapacity and reorganized itself. Some firms subsequently shut down and quit the market, which led to an increase in earnings of other firmsin 2013.

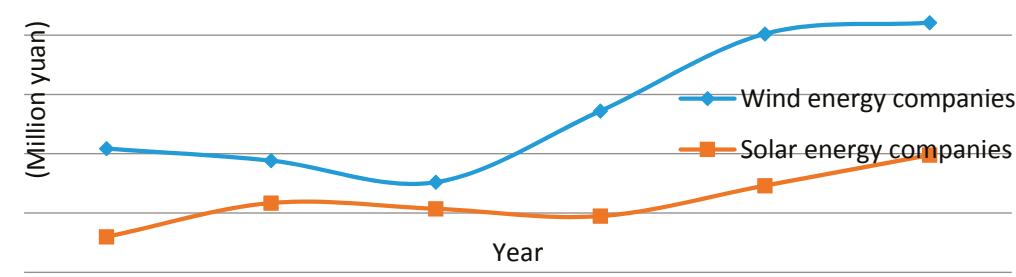

Figure 1. Net profits of renewable energy companies between 2009 and 2014. 
Table 2. The descriptive statistics (wind companies).

\begin{tabular}{|c|c|c|c|c|c|c|c|}
\hline Variables & Year & 2009 & 2010 & 2011 & 2012 & 2013 & 2014 \\
\hline \multirow{3}{*}{$\begin{array}{c}\text { Profit } \\
\text { (million yuan) }\end{array}$} & Mean & 1043.764 & 941.696 & 759.642 & 1359.855 & 2010.718 & 2105.544 \\
\hline & Min & 6.025 & 30.532 & 5.818 & 7.144 & 7.279 & 15.911 \\
\hline & Max & 5393.144 & 3739.722 & 4498.217 & 6852.454 & $12,900.02$ & $13,562.37$ \\
\hline \multirow{3}{*}{ Dsub (million yuan) } & Mean & 42.408 & 59.390 & 88.061 & 65.223 & 60.787 & 87.084 \\
\hline & Min & 0 & 0 & 0.337 & 0 & 0 & 0 \\
\hline & Max & 457.45 & 529.607 & 929.816 & 472.900 & 545.191 & 763.328 \\
\hline \multirow{3}{*}{$\begin{array}{c}\text { NDsub } \\
\text { (million yuan) }\end{array}$} & Mean & 30.249 & 27.050 & 26.936 & 31.734 & 19.763 & 106.936 \\
\hline & Min & 0 & 0 & 0 & 0 & 0 & 0 \\
\hline & Max & 191.543 & 192.718 & 208.888 & 311.754 & 138.789 & 1015.659 \\
\hline \multirow{3}{*}{ Isub (million yuan) } & Mean & 8.982 & 16.013 & 29.386 & 16.615 & 13.439 & 16.804 \\
\hline & Min & 0 & 0 & 0 & 0 & 0 & 0 \\
\hline & Max & 86.25 & 98.951 & 477.987 & 68.687 & 61.804 & 86.400 \\
\hline \multirow{3}{*}{$\begin{array}{c}\text { NIsub } \\
\text { (million yuan) }\end{array}$} & Mean & 63.674 & 70.427 & 85.611 & 80.333 & 67.144 & 142.065 \\
\hline & Min & 0 & 0 & 0.025 & 0.030 & 0 & 0.100 \\
\hline & Max & 459.627 & 545.472 & 660.384 & 552.669 & 556.818 & 834.92 \\
\hline \multirow{3}{*}{ Age (years) } & Mean & 12.231 & 13.231 & 14.231 & 15.231 & 16.231 & 17.231 \\
\hline & Min & 1 & 2 & 3 & 4 & 5 & 6 \\
\hline & Max & 21 & 22 & 23 & 24 & 25 & 26 \\
\hline \multirow{3}{*}{ Top (\%) } & Mean & 41.519 & 40.210 & 38.978 & 40.796 & 38.802 & 38.261 \\
\hline & Min & 18.270 & 8.910 & 8.980 & 8.980 & 8.98 & 8.98 \\
\hline & Max & 70.540 & 70.540 & 66.39 & 73.670 & 67.39 & 67.39 \\
\hline \multirow{3}{*}{$\begin{array}{c}\text { Cpl (million } \\
\text { yuan/per capita) }\end{array}$} & Mean & 6.698 & 6.375 & 2.770 & 3.409 & 2.966 & 2.913 \\
\hline & Min & 0.068 & 0.078 & 0.088 & 0.099 & 0.116 & 0.127 \\
\hline & Max & 98.708 & 109.410 & 18.978 & 27.250 & 14.504 & 16.561 \\
\hline
\end{tabular}

Table 3. The descriptive statistics(solar companies).

\begin{tabular}{cccccccc}
\hline Variables & Year & $\mathbf{2 0 0 9}$ & $\mathbf{2 0 1 0}$ & $\mathbf{2 0 1 1}$ & $\mathbf{2 0 1 2}$ & $\mathbf{2 0 1 3}$ & $\mathbf{2 0 1 4}$ \\
\hline \multirow{2}{*}{ Profit } & Mean & 299.286 & 584.069 & 535.731 & 473.818 & 731.002 & 988.946 \\
(million yuan) & Min & 2.710 & 31.720 & 0.230 & 5.320 & 0.670 & 0 \\
& Max & 1579.310 & 3868.160 & 3282 & 3252.260 & 4280.990 & 8119.020 \\
\hline \multirow{2}{*}{ Dsub (million yuan) } & Mean & 27.828 & 31.918 & 52.080 & 44.918 & 48.152 & 84.458 \\
& Min & 0 & 1.350 & 2.170 & 2.520 & 2.320 & 0.860 \\
& Max & 219.850 & 155.340 & 380.770 & 189.700 & 226.410 & 418.230 \\
\hline \multirow{2}{*}{ NDsub } & Mean & 5.446 & 6.312 & 5.020 & 6.462 & 10.650 & 9.159 \\
(million yuan) & Min & 0 & 0 & 0 & 0 & 0 & 0 \\
& Max & 50.000 & 52.780 & 19.400 & 24.220 & 54.880 & 66.039 \\
\hline \multirow{3}{*}{ Isub (million yuan) } & Mean & 1.140 & 1.905 & 1.458 & 5.142 & 4.724 & 10.212 \\
& Min & 0 & 0 & 0 & 0 & 0 & 0 \\
& Max & 8.940 & 14.787 & 5.980 & 56.000 & 52.030 & 70.890 \\
\hline \multirow{2}{*}{ NIsub } & Mean & 32.134 & 34.918 & 55.642 & 47.244 & 54.078 & 83.406 \\
(million yuan) & Min & 1.160 & 1.350 & 1.220 & 0.640 & 3.710 & 1.34 \\
& Max & 219.850 & 155.340 & 381.660 & 199.700 & 220.260 & 440.320 \\
\hline \multirow{2}{*}{ Age (years) } & Mean & 14.524 & 15.524 & 16.524 & 17.524 & 18.524 & 19.524 \\
& Min & 2 & 3 & 4 & 5 & 6 & 7 \\
& Max & 39 & 40 & 41 & 42 & 43 & 44 \\
\hline Top (\%) & Mean & 57.004 & 54.270 & 52.859 & 51.933 & 52.948 & 37.919 \\
& Min & 32.71 & 21.97 & 14.82 & 15.670 & 14.790 & 3.620 \\
Cpl (million & Max & 76 & 76 & 74 & 77 & 74 & 57.350 \\
\hline \multirow{2}{*}{ yuan/per capita) } & Mean & 1.463 & 1.827 & 1.696 & 1.624 & 1.622 & 2.510 \\
& Min & 0.150 & 0.010 & 0.080 & 0.050 & 0.060 & 0.080 \\
& 10.340 & 14.230 & 13.280 & 9.830 & 9.020 & 19.400 \\
\hline
\end{tabular}


Figures 2 and 3 present the characteristics of subsidy modes for the two types of companies. Both the direct and non-innovative subsidies of windand solar energy companies from 2009 to 2014 were obviously higher than their indirect and innovative subsidies. Innovative subsidieshad the lowest showing of the four subsidy modes at 16.804 million yuan in 2014. This figure is significantly lower than the 142.065 million yuan for non-innovative subsidized companies, the 87.084 million yuanof direct subsidies, and the 71.779 million yuan for indirect subsidized companies in the same year.

Forsub-industries, wind energy companies are higher than solar energy enterprises. The direct subsidy and non-innovative subsidy of solar energy companies have similar trends, and these two types of subsidies are significantly higher thanthe direct and innovative subsidies. All four types of subsidies for wind energy companies went through a fluctuant trend from 2009 to 2013 and rebounded in 2014. The accruement of innovative subsidy was relatively small, from 13.438 million yuan to 16.804 million yuan, whereas the three other types of subsidies increased dramatically. Similarly, the four types of subsidies for solar energy companies fluctuated from 2009 to 2013, and indirect subsidy declined slightly in 2013 from 10.65 million yuan to 9.16 million yuan, whereas direct, innovative, and non-innovative subsidies increased considerably.

Obviously, Figures 1-3 provide evidence showing that the financial performance of renewable energy companies improved markedly in the lasttwo years. Of the various types of subsidies, indirect subsidies and innovative subsidies account for a relatively small share of the total subsidy. From 2009 to 2013 , the various subsidiesfor these two types of companies fluctuated, but in 2014, all three types of subsidies increased considerably.

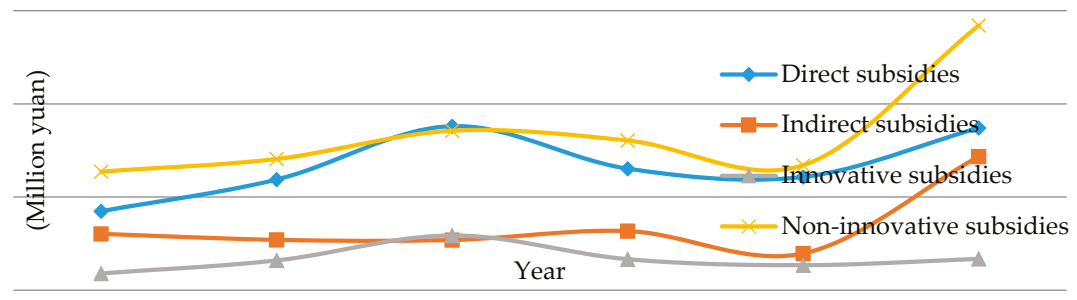

Figure 2. Subsidy modes for wind energy companies between 2009 and 2014.

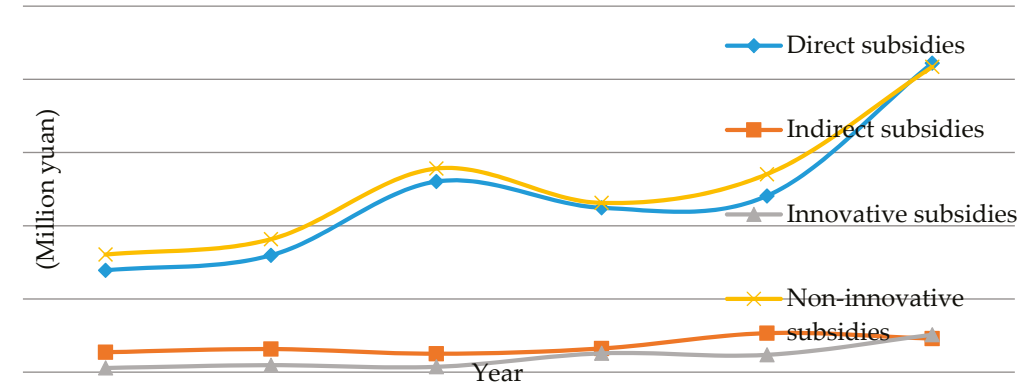

Figure 3. Subsidy modes for solar energy companies between 2009 and 2014

\subsection{The RegressionAnalysis of Total Samples}

A correlation test must be conducted before empirical analysis is undertaken. If correlation coefficients are both less than 0.5 , various explanatory variables and control variables are weakly correlated. The absolute values of correlation coefficients have a maximum value of 0.3230 and a minimum value of 0.0140 ; so, as both are less than 0.5 , weak correlation is evident. 
First, the estimation result for the entire sample is presented (see Table 4). The Hausman test value of 0.0000 shows thatthe fixed effect model is selected for both Formulas (1) and (2). Looking at the explanatory variables, the influence of direct subsidy on corporate financial performance is insignificant, but indirect subsidy mode and corporate net profit are negatively correlated at the $10 \%$ significance level. When the indirect subsidy increases by $1 \%$, corporate net profit decreases to $0.0227 \%$. Obviously, the direct subsidy fails to significantly improve the profitability of renewable energy companies. A higher indirect subsidy characterized by taxes and incentives may actually impair corporate financial subsidies, indicating that Chinese market-based subsidy mechanisms need to be urgently improved. With regards to research hypothesis $\mathrm{H} 2$, the innovative subsidies of both the current period and the two lag periods do not significantly influence the financial performance of renewable energy companies, whereas the non-innovative subsidies of the two lag periods obviously enhance corporate financial performance. This finding impliesthat there is a time-lag in the functioning of non-innovative subsidies. When non-innovative subsidy increases by $1 \%$, corporate net profit also increases by $0.0737 \%$. Of the control variables, corporate history, largest shareholder, and capital intensity insignificantly influence corporate financial performance.

Table 4. Estimation results of total samples.

\begin{tabular}{cccccc}
\hline \multicolumn{3}{c}{ Direct and Indirect Subsidy Modes } & \multicolumn{3}{c}{ Innovativeand Non-Innovative Subsidy Modes } \\
\hline Explanatory & Fixed Effects & Random Effects & Explanatory & Fixed Effects & Random Effects \\
\hline Cons & $17.3028^{* * *}(9.76)$ & $17.1614^{* * *}(13.48)$ & Cons & $17.6254^{* * *}(7.75)$ & $17.2036^{* * *}(11.25)$ \\
Age & $0.0784(1.45)$ & $0.0055(0.27)$ & Age & $0.1088(1.10)$ & $-0.0006(-0.02)$ \\
Top & $0.0586(0.16)$ & $-0.1266(-0.47)$ & Top & $-0.1658(-0.39)$ & $-0.1724(-0.56)$ \\
Cpl & $0.0701(1.42)$ & $0.1307^{* *}(2.72)$ & Cpl & $0.0360(0.64)$ & $0.0979^{*}(1.89)$ \\
Dsub & $0.0298(1.14)$ & $0.0583^{* *}(2.28)$ & Isub -2 & $-0.0263(-1.42)$ & $-0.0093(-0.57)$ \\
NDsub & $-0.0227^{*}(-1.69)$ & $-0.0101(-0.75)$ & NIsub -2 & $0.0737^{*}(2.13)$ & $0.0973^{* *}(2.92)$ \\
\hline \multirow{2}{*}{0.0000} & Hausman & & 0.0000 \\
Hausman & \multicolumn{2}{c}{ value } \\
\hline
\end{tabular}

Note: the figures in brackets are $T$ test results; $* * *$ and ${ }^{* * *}$ represent $10 \%, 5 \%$ and $1 \%$ significance level. Isub $_{-2}$ and NIsub $_{-2}$ are innovative and non-innovative subsidy lagging for two periods, respectively.

\subsection{Regressive Analysis of Sub-Industries}

The estimation results of sub-industries are compared. With regards to the direct subsidy and indirect subsidy effects of wind energy companies, the Hausman test value is 0.5797 . The original hypothesis should not be rejected, and the random effect should be selected. In contrast to the regressionresults of the entire sample, among the explainable variables, the influence of direct subsidy on corporate financial performance is significant at the $10 \%$ significance level;this coincides with $\mathrm{H} 1$. When direct subsidy increases by $1 \%$, corporate net profit also increases by $0.0460 \%$. Indirect subsidy has a weak influence. Of the various control variables, capital intensity has a greater effect on corporate financial performance, with a $1 \%$ significance level. Looking at innovative and non-innovative subsidy modes, the Hausman test value is 0.0000 , and the fixed effect model is adopted. As indicated by Table 5, both types of subsidies do not significantly influence corporate financial performance. Promoting corporate innovative capacity, the subsidies for R\&D, technological demonstration, old project renovation, and other recipients fails to achieve the expected effect. Hence, the technological innovative capacity of wind energy companies needs to be promoted.

The empirical result of solar energy companies is different from that of wind energyfirms. The finding can be inferred from the Hausman test value in Table 6, where both Formulas (1) and (2) select the fixed effect model. Direct subsidies acquired by solar energy companies fail to enhance their financial performance, unlike the results achieved by wind energy companies.Furthermore, a weak negative correlation exists between these two variables, rejecting H1. Indirect subsidies remarkably impair corporate profitability, and the regressive coefficient $-0.0474 \%$ passes the $5 \%$ significance level test. Corporate history, largest shareholder, and other control variables all have a weak influence on 
corporate netprofit. The innovative subsidies granted to solar energy companies actually reduced corporate netprofit, thus rejecting $\mathrm{H} 2$. When innovative subsidies increase by $1 \%$, corporate net profit declines by $-0.0484 \%$, but the negative effect of innovative subsidy lags for two periods. Empirical tests of the current period and the one-lag period demonstrate that innovative subsidies do not have a significant influence on corporate performance. According to the sub-industry findings, solar energy companies need subsidy policy reform more urgently than wind energy companies because the regressive coefficients of indirect and innovative subsidies of solar energy companies reject the hypotheses.

Table 5. Estimation results of sub-industry(wind energy companies).

\begin{tabular}{cccccc}
\hline \multicolumn{3}{c}{ Direct and Indirect Subsidy Modes } & \multicolumn{2}{c}{ Innovativeand Non-Innovative Subsidy Modes } \\
\hline Explanatory & Fixed Effects & Random Effects & Explanatory & Fixed Effects & Random Effects \\
\hline Cons & $10.9574^{* * *}(4.29)$ & $9.7463^{* * *}(6.16)$ & Cons & $10.9475^{* * *}(4.27)$ & $9.7827^{* * *}(6.21)$ \\
Age & $0.2435(0.59)$ & $0.2184(0.69)$ & Age & $0.3303(0.82)$ & $0.3157(1.03)$ \\
Top & $1.0016^{*}(1.67)$ & $0.5581(1.51)$ & Top & $1.0129^{*}(1.69)$ & $0.5112(1.39)$ \\
Cpl & $0.2774^{* *}(2.53)$ & $0.4573^{* * *}(5.12)$ & Cpl & $0.2992^{* *}(2.71)$ & $0.4811^{* * *}(5.34)$ \\
Dsub & $0.0293(1.22)$ & $0.0460^{*}(1.96)$ & Isub & $-0.01950(-1.15)$ & $-0.0069(-0.40)$ \\
NDsub & $0.0111(0.59)$ & $0.0177(0.94)$ & NIsub & $0.0205(0.76)$ & $0.0386(1.47)$ \\
\hline Hausman & \multicolumn{3}{c}{ Hausman } \\
value & \multicolumn{3}{c}{0.5797} & value & 0.0000 \\
\hline
\end{tabular}

Note: the figures in brackets are $T$ test results; ${ }^{* * *}$ and ${ }^{* * *}$ represent $10 \%, 5 \%$ and $1 \%$ significance level.

Table 6. Estimation results of sub-industry (solar energy companies).

\begin{tabular}{cccccc}
\hline \multicolumn{3}{c}{ Direct and Indirect Subsidy Modes } & \multicolumn{3}{c}{ Innovativeand Non-Innovative Subsidy Modes } \\
\hline Explanatory & Fixed Effects & Random Effects & Explanatory & Fixed Effects & Random Effects \\
\hline Cons & $19.76339^{* * *}(7.01)$ & $20.07996^{* * *}(8.70)$ & Cons & $17.0767^{* * *}(4.77)$ & $17.1926^{* * *}(6.19)$ \\
Age & $0.0705(1.07)$ & $0.0288(0.91)$ & Age & $0.1502(1.39)$ & $0.0564(1.58)$ \\
Top & $-0.2355(-0.49)$ & $-0.4942(-1.24)$ & Top & $-0.2702(-0.55)$ & $-0.5373(-1.36)$ \\
Capital & $0.0171697(0.29)$ & $0.0283(0.48)$ & Capital & $0.0132(0.22)$ & $0.0003(0.01)$ \\
Dsub & $-0.0400(-0.63)$ & $0.0250(0.41)$ & Isub -2 & $-0.0484^{* *}(-2.16)$ & $-0.0524^{* *}(-2.55)$ \\
NDsub & $-0.0474^{* *}(-2.47)$ & $-0.0361^{*}(-1.95)$ & N Isub -2 & $0.0362(0.33)$ & $0.1996^{*}(1.92)$ \\
\hline Hausman & \multicolumn{3}{c}{0.0011} & Hausman & \multicolumn{2}{c}{0.0036} \\
value & \multicolumn{3}{c}{ value } \\
\hline
\end{tabular}

Note: the figures in brackets are $T$ test results; ${ }^{* * *}$ and ${ }^{* * *}$ represent $10 \%, 5 \%$ and $1 \%$ significance level. Isub $_{-2}$ and NIsub $_{-2}$ are innovative and non-innovative subsidy lagging for two periods, respectively.

The reasons for the weak or negative impact of indirect and innovative subsidies on the financial performance of both types of companies include information asymmetry, less detailed subsidy standards and unreasonable innovative subsidy structure. The information asymmetry in the subsidizing process implies that senior managers probably seek unjustified rents, thus resulting in the abuse of subsidies. With regard to the allocation of indirect subsidies, there is a lack of detailed standards relating to grants, such as technological level, corporate scale and financial performance evaluation. Innovative subsidy can be subdivided into two subsidy modes, namely technological supply and diffusion. The unreasonable innovative subsidy structure illustrates that China attaches more importance to technological supply subsidies than technological diffusion ones. Furthermore, for technological diffusion subsidies, feed-in tariffs fail to stimulate renewable energy companies because of grid connection, power priority purchase and cross-regional transmission.Thus, unreasonable innovative subsidy structures can improve neither innovation capability nor application of renewable energy companies notably. 
In addition to information asymmetry and subsidy methods, excessive subsidies in periods of weak domestic market demand enhance overcapacity risks, thus reducing profitability of renewable energy companies.

\subsection{Robust Test}

To validate the reliability of the empirical analysis result, we employ different measurements of corporate financial performance and capital intensity for a re-test. Based on the replacement of net profit with the proportion of net profit to main business income, results illustrate that the regressive coefficient of direct subsidy for the wind energy companies is 0.0295 , passing the $10 \%$ significance level test.Similar tothe former studies, indirect subsidy showsaweak impact, and the $p$-value is 0.449 . As for solar companies, both the indirect and innovative subsidies reduce the profitability notably, and the regressive coefficients are -0.0463 and -0.0363 , respectively.

Based on the substitutionof the ratio of inventory to total assets for capital intensity, the results are the same as those obtained previously. Therefore, the result of variable inspection is robust.

\section{Conclusions}

This study employs the panel model to examine the correlation between subsidy modes andfinancial performanceforrenewable energy companies. Indirect subsidy and non-innovative subsidy obviously have a significant influence on the financial performance of the entire sample. However, because the coefficient of the former subsidy is a negative value, tax, bonus, and other market-based mechanisms impair corporate profitability, failing to achieve the government-desired goals. The result of the re-test shows that direct and innovative subsidies are inconsistent with $\mathrm{H} 1$ and H2. In terms of sub-industries, the subsidy effect of wind energy companies is slightly better than that of solar energy companies. The direct subsidy for wind energy companies achieves a considerable effect, thus supporting H1. By comparison, indirect, innovative, and non-innovative subsidies all have non-significant effects. Both indirect and innovative subsidies acquired by solar energy companies remarkably reduce corporate profitability, indicating that the subsidy policy of this industry sector needs to be discussed again. The policy implications are statedbelow.

(1) Perfecting market-based subsidy mechanisms such as tax, bonus, etc. Tax, bonus, and other subsidy mechanisms granted to renewable energy companies must be detailed according to set standards, such as scale, technological level, and financial performance of renewable energy companies; this strengthens the auditing process prior to the granting of subsidies and increases supervision of the use of subsidies. The enforcement of market-based subsidy mechanisms is more likely to be effective when guaranteed by institutions.Moreover, a reward and punishment system should be established by which the indirect subsidy amount and the type of next year's subsidy will be determined by the previous year'sperformance. For energy companies that perform better, more funds can be granted; for companies with lower performance after subsidies, subsidies should be reduced or even eliminated.

(2) Increasing the subsidies for technological diffusion.As indicated by previous analysis, technological supply and diffusionsubsidiesare two types of innovative subsidy. The former mainly refers to subsidizing technological R\&D, whereas the latter emphasizes technological promotion and demonstration. As revealed by the analysis of annual corporate reports, the $R \& D$ subsidies of renewable energy companies account for a considerate percentage, whereas the subsidies used for technological diffusion are insufficient.This weakens the transformation of technological achievements to a certain extent. Therefore, the government should increase the percentage of innovative subsidies such as technique improvement projects, government rewards for demonstration projects and project soft loans allotted for technological diffusion while reinforcing the audit and supervision of subsidies. 
(3) Subsidy policies should be reformed to vary from wind energy companies to solar ones. Compared with the policies for wind energy companies, the subsidy policies for solar energy companiesrequiremore urgent improvements.Direct, indirect and innovative subsidies for these types of companies all need reformation. In contrast to direct subsidies, the latter two forms of subsidy should be of particular concern because of their notable negative impact on corporate financial performance.

While perfecting the mechanism of indirect and innovative subsidies for wind energy companies, we can continue to increase the amount of direct subsidies in a way that does not conflict with current WTO trade disputes.

Acknowledgments: Acknowledgments: This study is funded by National Natural Science Foundation of China (No. 71173116; 71573121; 71203100), Jiangsu Natural Science Foundation (No. BK20151527), National Social Science Foundation of China (No. 13CGL094; 11BGL038), Jiangsu Social Science Funding Program (No. 12EYD015), Six Talents Peaks Project in Jiangsu Province (2015-XNY-008), 2015 Open Project of Jiangsu Engineering Research Center on Meteorological Energy Using and Control (KCMEIC05), Philosophy and Social Science Development ReportProjects of Ministry of Education in China (China Manufacturing Development Research Report. No. 13JBG004), Jiangsu Qinglan Project, Jiangsu Provincial Government Scholarship for Overseas Studies, and A Project Funded by the Priority Academic Program Development of Jiangsu Higher Education Institutions.

Author Contributions: Author Contributions: HuimingZhang came up the original idea for the manuscript. Yu Zheng was responsible for data collection. Huiming Zhang, Yu Zheng, and Peifeng Zhu carried out the analyses. Dequn Zhou put forward valuable suggestions for the policy implications. All authors read and approved the final version.

Conflicts of Interest: Conflicts of Interest: The authors declare that they have no conflict of interest.

\section{References}

1. Du, W.J.; Chen, G.; Gao, Y. Analysis of Subsidy Modes for Developing New Energy Industry. Econ. Forum 2011, 11, 99-102. (in Chinese)

2. Xie, X.X.; Wang, Z.Y.; Gao, H. Renewable Energy Subsidy Policy Trends of Developed Countries and the Enlightenment for China. Energy China 2013, 8, 15-19. (in Chinese)

3. Xiong, L.; Zhou, M.R. A Comparison of Renewable Energy Subsidy Policies between China and US from the Perspective of WTO. Int. Bus. Res. 2011, 5, 13-23. (in Chinese)

4. Sun, F.B.; Tang, H.X. Institutional Predicament of Renewable Energy Subsidies within the WTO Framework and Solution. J. Kunming Univ. Sci. Technol. Soc. Sci. Ed. 2015, 15, 30-36. (in Chinese)

5. Steve, C.; Carolyn, F. Canada-Renewable Energy: Implications for WTO Law on Green and Not-So-Green Subsidies. World Trade Rev. 2015, 14, 177-210.

6. Yan, J.; Zhang, Q.H. Feed-in Tariff of Renewable Energy in China and Its Impact on Macro-economy. Statist. Inf. Forum 2014, 29, 46-51.

7. Ouyang, X.L.; Lin, B.Q. Impacts of increasing renewable energy subsidies and phasing out fossil fuel subsidies in China. Renew. Sustain. Energy Rev. 2014, 37, 933-942. [CrossRef]

8. Lesser, J.A. Wind Generation Patterns andthe Economics of WindSubsidies. Electr. J. 2013, 26, 8-16.

9. Marco, A.D.; Cagliano, A.D.; Nervo, M.L.; Rafele, C. Using System Dynamics to assess the impact of RFID technology on retail operations. Int. J. Prod. Econ. 2012, 135, 333-344.

10. Sánchez-Braza, A.; Pablo-Romero, M.P. Evaluation of property tax bonus to promote solar thermal systems in Andalusia (Spain). Energy Policy 2014, 67, 832-843. [CrossRef]

11. Daniel, S. Financing US Renewable Energy Projects in a Post-Subsidy World. Nat. Gas Electr. 2013, 29, 7-10.

12. Koseoglu, N.M.; van den Bergh, J.C.J.M.; Lacerda, J.S. Allocating subsidies to R\&D or to market applications of renewableenergy? Balance and geographical relevance. Energy Sustain. Dev. 2013, 17, 536-545.

13. Shen, J.F.; Luo, C. Overall review of renewable energy subsidy policies in China-Contradictions of intentions and effects. Renew. Sustain. Energy Rev. 2015, 41, 1478-1488. [CrossRef]

14. Orvika, R. Subsidies for renewable energy in inflexible power markets. J. Regul. Econ. 2014, 46, 318-343.

15. Keyuraphan, S.; Thanarak, P.; Ketjoy, N.; Rakwichian, W. Subsidy schemes of renewable energy policy for electricity generation in Thailand. Procedia Eng. 2012, 32, 440-448. [CrossRef] 
16. Zhang, D.; Xiong, W.M.; Tang, C.; Liu, Z.; Zhang, X.L. Determining the appropriate amount of subsidies for wind power: The integrated renewable power planning (IRPP) model and its application in China. Sustain. Energy Technol. Assess. 2014, 6, 141-148. [CrossRef]

17. Hsu, C.W. Using a system dynamics model to assess the effects of capital subsidies and feed-in tariffs on solar PV installations. Appl. Energy 2012, 100, 205-217. [CrossRef]

18. Fagiani, R.; Barquín, J.; Hakvoort, R. Risk-based assessment of the cost-efficiency and the effectivity of renewable energy support schemes: Certificate markets versus feed-in tariffs. Energy Policy 2013, 55, 648-661. [CrossRef]

19. Kong, D.M.; Li, T.S. Whether government subsidies improved firms' performance and social responsibility? Secur. Mar. Her. 2014, 6, 26-31. (in Chinese)

20. Beason, R.; Weinstein, D.E. Growth,Economies of Scale, and Targeting in Japan (1955-1990). Rev. Econ. Statist. 1996, 78, 286-295. [CrossRef]

21. Bergstorm, F. Capital Subsidies and the Performance of Firms. Small Bus. Econ. 2000, 14, 183-193. [CrossRef]

22. Balsar, C.; Ucdogruk, Y. The Impact of Investment and R\&D Subsidieson Firm Performance: Evidence from IstanbulStock Exchange. MIBES Trans. 2008, 2, 1-12.

23. Lu, A.M.; Huang, D.H. Impact of financial subsidies on the performance of "ST" firms. Oper. Manag. 2015, 5, 102-104. (in Chinese)

24. Leng, J.F.; Wang, K. The impact of subsidies on the agriculture listed companies' profitability: An analysis of panel data. J. Jiangxi Agric. 2007, 19, 134-137. (in Chinese)

25. Faccio, M.; Masulis, R.W.; McConnell, J.J. Political Connections and Corporate Bailouts. J. Financ. 2006, 61, 2597-2635. [CrossRef]

26. Pan, Y.; Dai, Y.Y.; Li, C.X. Political connections and government subsidies of companies in financial distress: Empirical evidence from Chinese ST listed companies. Nankai Bus. Rev. 2009, 12, 6-17. (in Chinese)

(C) 2015 by the authors. Licensee MDPI, Basel, Switzerland. This article is an open access article distributed under the terms and conditions of the Creative Commons Attribution (CC BY) license (http:/ / creativecommons.org/licenses/by/4.0/). 


\title{
Regional Water Footprint Assessment: A Case Study of Leshan City
}

\author{
Rui Zhao ${ }^{1,2}$, Hualing $\mathrm{He}^{1}$ and Ning Zhang ${ }^{3,4, *}$ \\ 1 Faculty of Geosciences and Environmental Engineering, Southwest Jiaotong University, Chengdu 611756, \\ China; ruizhaoswjtu@hotmail.com (R.Z.); robotnik@yeah.net (H.H) \\ 2 State-Province Joint Engineering Research Lab in Geospatial Information Technology for High Speed \\ Railway Safety, Southwest Jiaotong University, Chengdu 611756, China \\ 3 Department of Economics, Jinan University, Guangzhou 510632, China \\ 4 Institute of Resource, Environment and Sustainable Development Research, Jinan University, \\ Guangzhou 510632, China \\ * Correspondence: zn928@naver.com or zhangn@jnu.edu; Tel.: +86-20-8522-0811; Fax: +86-20-8522-8489
}

Academic Editors: Yongrok Choi, Malin Song and Seunghwan Myeong Received: 26 September 2015; Accepted: 10 December 2015; Published: 15 December 2015

\begin{abstract}
This paper presents an assessment of urban water footprint in the period of 2001 to 2012 by taking Leshan City, China as a typical case study. The water footprint is calculated by the sum of the water footprints of various sectors, i.e., crop production, animal products, industrial processes, domestic waster, eco-environment, and virtual water trade. Results show that the water footprints of the various sectors rose by degrees varying from $19 \%$ to $55 \%$, which gave rise to an increase of the total water footprint of $43.13 \%$ from 2001 to 2012 . Crop production and animal products are identified as the major water intensive sectors, accounting for about $68.97 \%$ of the total water footprint. The water footprint in the Northeastern area of Leshan City is greater than that of the Southwestern area in the period 1992-2012, resulted in an expansion of water footprint in the Sha Wan and Wu Tongqiao Districts due to the development of urbanization. The application of water footprint assessment is expected to provide insight into the improvement of urban water efficiency, and thus aid in better water resources management.
\end{abstract}

Keywords: water footprint; water footprint assessment; Leshan City; water resources management

\section{Introduction}

With the development of urbanization, water scarcity has become more and more prominent [1-3]. In particular, the shortage of water resources has had a great impact on China's economic and social development, i.e., whether sufficient food can be provided to feed such a large and growing population [4-8]. To promote water conservation, secure water efficiency corresponding to urban growth is an increasing challenge for China's policy makers [6,9].

The water footprint, as a comprehensive indicator for water resources management, is interpreted as the total amount of freshwater use to measure water consumption and pollution [10-13]. Proposed by Hoekstra in 2003, assessment of water footprint has been widely applied to various categories in the past decade, e.g., products, business services, geographical areas, etc. [7,12,14].

In the field of product assessment, Chapagain et al. [15] assessed its associated impacts on the water resources based upon the water footprint of cotton consumption, which were transitional. Ridoutt et al. [16] applied a LCA-based methodology to water footprint accounting of agricultural food products, by which the farming stage was identified as the major sector of water consumption, and was strongly influenced by the downstream food manufacturers. Similar results were found by Ercin et al. [17], Gerbens-Leenes and Hoekstra [18], Ridoutt et al. [19], Van Oel and Hoekstra [20], Chico et 
al. [21], Herath et al. [22], Ene et al. [23], who extended water footprint assessment to wider application for products, such as soy milk and soy burgers, sweeteners and bio-ethanol, paper, livestock, jeans and wines. Mekonnen and Hoekstra [24] measured the water footprint of crops and derived crop products in the period of 1996-2005. Three components of water footprints were assessed, i.e., green, blue and grey, to indicate consumption of rainwater, surface and groundwater, and freshwater assimilating water with pollutants, in contrast to natural background concentration. On this basis, Mekonnen and Hoekstra [25] found that the blue and grey water footprint of the animal products derived from grazing were smaller than those from industrial manufacturing. Since a key issue has come up throughout the assessment of water footprint, namely the lack of a unified and well recognized evaluating principle and methodology, ISO 14046 is proposed to fill this gap by taking a life cycle perspective to assess water footprint, including scope division, inventory analysis, impact assessment, result interpretation etc [26,27]. For instance, Manzardo et al. [28] applied water footprint assessment based on the methodology of ISO14067 to a tomato sauce produced in U.S, and drew a comparison with the result obtained by conventional water footprint network accounting. The result showed that the consistent results were provided by the two methods, except for application to degradative water use.

With regard to the assessment of business water footprint, Ercin et al. [29] took a hypothetical factory of sugar-containing carbonated beverages as an example to examine freshwater use along the supply chain. Similarly, Ruini et al. [30], applied water footprint assessment to a pasta company, in order to measure the sustainability of the related manufacturing process. Li and Chen [31] applied water footprint evaluation to gaming service, which reflected that direct water consumption only accounted for a small proportion.

In applications of different geographic dimensions, a number of studies on national, regional water footprint assessment were proposed. For instance, each country's water footprint was calculated by Hoekstra and Chapagain [32], whilst the major influencing factors were identified as consumption volume, patter, growth conditions and water efficiency. A water footprint derived from the LCA is usually determined by a functional unit, which may result in lower comparability when applying to accounting of different sectors in a designated geographic area [33]. The input-output (I-O) method is thus recommended to provide a holistic assessment in a unified functional unit. For example, Zhao et al. [34] used the input-output method to assess China's water footprint in 2002, by which China was verified as a virtual water exporter. The result was validated by Chen and Chen [35], who indicated that China was the world largest exporter and deficit receiver according to the virtual water trade. Zhang and Anadon [36] further identified that China's domestically virtual water trade was twice than that embodied in exports in terms of a multi-regional input-output analysis. In the regional sector, Zhang et al. [37,38], Wang et al. [39] took Beijing as a typical case study, to evaluate the water footprint based on an input-output framework, through which Beijing was found to be a virtual water importer, i.e., dependence on external water resources. In addition to the I-O application, Fiałkiewicz et al. [40] established Urban Water Footprint Labs in the towns of Vicenza, Innsbruck and Wroclaw, including a common water technology and management database available on the project web-site, through which policies were made to support better water management.

The previous studies regarding water footprint assessment are useful in identification of the most water-intensive sector, thus to provide insight into better policy or decision-making on water saving and improvement of water efficiency. However, the variation of water footprint in a specific region is difficult to investigate. The spatial representation provides an opportunity not only to demonstrate the spatial-temporal evolution of the regional water footprint distribution, but also to identify the area with the greatest change of the water footprint in a certain temporal range, ultimately to promote the regional water resources management and allocation [41,42].

This study provides a holistic assessment for urban water footprint by using Leshan City, Sichuan Province as a case study, to measure the freshwater consumption of various sectors. Leshan City, because of its rapid urbanization and industrialization, is similar to the development of other cities in 
China. In this context, the area with the largest water consumption as well as the time variation of the utilization of water resources of a specific area can be identified, in order to lay out reasonable policy mechanisms for water resource allocation. In addition, a computational tool has been devised to help policy makers better understand and employ the method of water footprint assessment.

\section{Methodology and Data}

The total water footprint in a geographically delineated area is seen as a sum of the water footprint accounting process [12]. The actual water consumption of one region equals to the local demand of water resources and imported virtual water, in which the former is mainly divided into the demand for crop production, animal products, industrial processes, domestic water and eco-environment, as shown in Figure 1. Other sectors related to the water consumption are omitted in the system boundary. For example, water withdrawal and purification for domestic use are incorporated into the water footprint of domestic water, which is measured as direct water consumption. This is because the domestic sewage should be treated to discharge into nearby rivers, according to the National Standard of the second-class water quality [43].

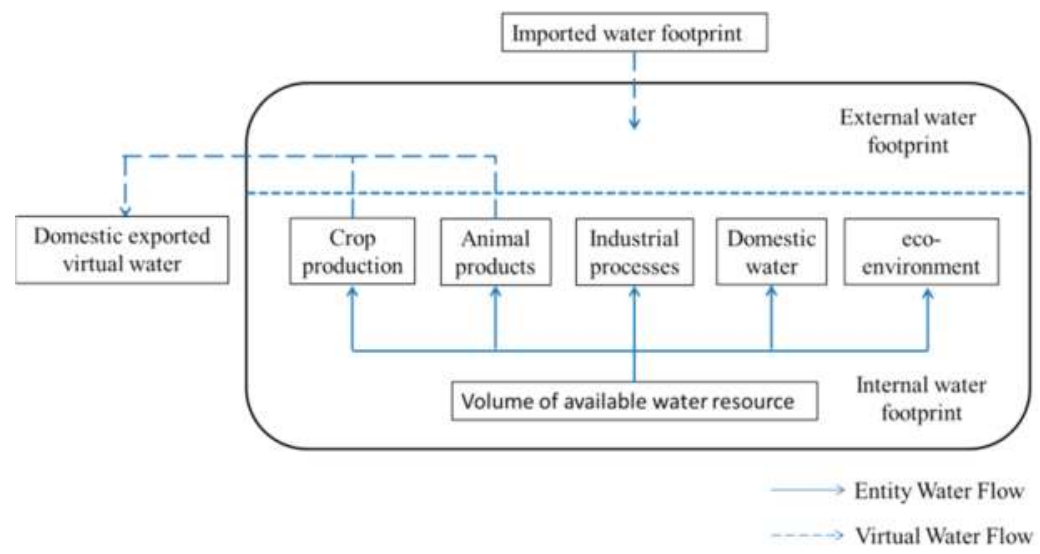

Figure 1. System boundary of regional water footprint assessment.

\subsection{Water Footprint of Crop Production}

The average water demand of crop production mainly depends on the types of crops, the region of growth, and the mode of irrigation system. For a specific crop, the average water demand is calculated per district, given as follows [44]:

$$
A W D_{c d}=\frac{C W R_{c d}}{A_{c d}}
$$

where $A W D_{c d}$ is the average water demand ( $\mathrm{m}^{3}$ per tonne) of crop $c$ in district $d$ of a specific urban area, $C W R_{c d}$ the water requirement of crop production ( $\mathrm{m}^{3}$ per ha), and $A_{c d}$ the crop yield (tonne per ha).

Here, $\mathrm{CWR}_{\mathrm{cd}}$ can be approximately substituted by the accumulated crop evapo-transpiration $\mathrm{ET}_{\mathrm{C}}$ (in $\mathrm{mm} /$ day), given as follows [45]:

$$
\mathrm{ET}_{\mathrm{c}}=\mathrm{K}_{\mathrm{c}} \times \mathrm{ET}_{0}
$$


where $K_{c}$ is the crop coefficient, and $E T_{0}$ is the crop evapotranspiration in an ideal environment of growth $(\mathrm{mm} / \mathrm{d})$, which is calculated by using the Food and Agriculture Organization (FAO) Penman-Monteith equation [44,46,47]:

$$
\mathrm{ET}_{0}=\frac{0.408 \Delta\left(\mathrm{R}_{\mathrm{n}}-\mathrm{G}\right)+\gamma \frac{900}{\mathrm{~T}+273} \mathrm{u}_{2}\left(\mathrm{e}_{\mathrm{s}}-\mathrm{e}_{\mathrm{a}}\right)}{\Delta+\gamma\left(1+0.34 \mathrm{u}_{2}\right)}
$$

where:

$R_{n}=$ net radiation at the crop surface, $M J /\left(m^{2} d\right) ;$

$G=$ flux of soil heat, $M J /\left(m^{2} d\right)$;

$\mathrm{T}=$ average temperature, ${ }^{\circ} \mathrm{C}$;

$u_{2}=$ wind speed while measuring at 2 meters height, $\mathrm{m} / \mathrm{s}$;

$e_{S}=$ pressure of saturation vapour, $k P a$;

$e_{a}=$ actual vapour pressure, $k P a$;

$\Delta=$ slope of the curve between saturation vapour pressure and temperature, $\mathrm{kPa} /{ }^{\circ} \mathrm{C}$;

$\gamma=$ psychrometric constant, $\mathrm{kPa} /{ }^{\circ} \mathrm{C}$.

\subsection{Water Footprint of Animal Products}

The water footprint of animal products is composed of the virtual water content of a live animal during its entire lifespan, and the water consumption while distributing various meat products from the animals [45]. The virtual water contains the water use of feeding, drinking water and servicing, calculated as follows [48]:

$$
\mathrm{VWC}=\mathrm{VWC}_{\text {feed }}+\mathrm{VWC}_{\text {drink }}+\mathrm{VWC}_{\text {servicing }}
$$

where $\mathrm{VWC}_{\text {feed }}, \mathrm{VWC}_{\text {drink}}$, and $\mathrm{VWC}_{\text {servicing }}$ denote the virtual water contents corresponding to feeding, drinking and servicing respectively, $\mathrm{m}^{3}$ per tonne.

$\mathrm{VWC}_{\text {feed }}$ can be measured as the sum of the water requirement of the prepared feed mix and the virtual water of various feed ingredients contained, shown as follows:

$$
\mathrm{VWC}_{\text {feed }}=\frac{\int_{\text {birth }}^{\text {death }}\left(\mathrm{Q}_{\text {mix }}+\sum_{\mathrm{i}=1}^{\mathrm{N}} \mathrm{VWC}_{\mathrm{i}} \times \mathrm{C}_{\mathrm{i}}\right) \mathrm{dt}}{\mathrm{W}}
$$

where:

$\mathrm{Q}_{\text {mix }}=$ water demand of mixing the feed, $\mathrm{m}^{3} / \mathrm{d}$;

$\mathrm{VWC}_{\mathrm{i}}=$ virtual water content of the ith feed crop, $\mathrm{m}^{3} / \mathrm{t}$;

$\mathrm{C}_{\mathrm{i}}=$ quantity of feed crop consumed by the animal daily, $\mathrm{t} / \mathrm{d}$;

$\mathrm{W}=$ average live weight of the animal at the end of its lifespan, $\mathrm{t}$;

The virtual water content from drinking water $\mathrm{VWC}_{\text {drink }}$ can be calculated by:

$$
\mathrm{VWC}_{\text {drink }}=\frac{\int_{\text {birth }}^{\text {death }} \mathrm{Q}_{\mathrm{d}} \mathrm{dt}}{\mathrm{W}}
$$

where:

$\mathrm{Q}_{\mathrm{d}}=$ the daily drinking water consumed by the animal, $\mathrm{m}^{3} / \mathrm{d}$;

$\mathrm{W}=$ average live weight of the animal at the end of its lifespan, $t$;

The virtual water content from service water is deemed as the water consumed by the farmyard cleaning and maintaining, animal washing during the entire lifespan of the live animal, which is calculated by:

$$
\mathrm{VWC}_{\text {servicing }}=\frac{\int_{\text {birth }}^{\text {death }} \mathrm{Q}_{\mathrm{s}} \mathrm{dt}}{\mathrm{W}}
$$


where:

$\mathrm{Q}_{\mathrm{S}}=$ the daily service water requirement of the animal, $\mathrm{m}^{3} / \mathrm{d}$;

$\mathrm{W}=$ average live weight of the animal at the end of its lifespan, $\mathrm{t}$;

\subsection{Water Footprint of Industrial Processes}

The crop and animal products as raw or auxiliary materials for industrial processes have not been taken into account in the calculation of water footprint of industrial sector, except for direct freshwater use, virtual water content, and water pollution [49]. Thus, the water footprint of the industrial sector can be measured by:

$$
\mathrm{V}_{\text {Itotal }}=\mathrm{V}_{\text {Iblue }}+\mathrm{V}_{\text {Igrey }}+\mathrm{V}_{\text {Ivirtual }}
$$

where $\mathrm{V}_{\text {Iblue }}, \mathrm{V}_{\text {Igrey }}, \mathrm{V}_{\text {Ivirtual }}$ represent the blue, grey and virtual water footprint of the industrial processes.

The blue water footprint is regarded as the direct freshwater use in the industrial processes, calculated by [49]:

$$
\mathrm{V}_{\text {Iblue }}=\mathrm{V}_{\text {draft }}-\mathrm{V}_{\text {effluent }}
$$

where $V_{\text {draft }}$ indicates the water withdrawn by the stages related to production, transportation etc., $\mathrm{m}^{3} / \mathrm{y} ; V_{\text {effluent }}$ the waste water emissions, $\mathrm{m}^{3} / \mathrm{y}$.

The grey water footprint is used to indicate the degree of water pollution, defined as the volume of freshwater which is required to dilute pollutants, calculated by [12]:

$$
\mathrm{V}_{\text {Igrey }}=\frac{\mathrm{W}_{1}}{\mathrm{C}_{\max }-\mathrm{C}_{\text {nat }}}
$$

where $\mathrm{W}_{1}$ is the load of pollutant, tonne $/ \mathrm{y} ; \mathrm{C}_{\max }$ the maximum acceptable concentration, tonne/y; $\mathrm{C}_{\text {nat }}$ the natural concentration in the receiving water body, tonne/y. In its real application, the industrial waste water is treated by compliance with the National Standard of the third-class water quality standard, and then discharged into nearby rivers, no matter what treatment process is implemented [50]. Thus, different cases can be only reflected by selecting the most typical pollutants of one industry, or the pollutants which have the most impact on the local water quality, to calculate the $\mathrm{C}_{\max }$ and $\mathrm{C}_{\text {nat }}$.

In the industrial sector, the most typical pollutants, e.g., $\mathrm{COD}, \mathrm{BOD}_{5}$, ammonia nitrogen etc., are selected to reflect the degree of water pollution in the delineated region [49]. Thus, Equation (10) is transformed as:

$$
\mathrm{V}_{\text {Igrey }}=\frac{\mathrm{V}_{\text {effl }} \times\left(\mathrm{C}_{\text {effl }}-\mathrm{C}_{\text {nat }}\right)}{\mathrm{C}_{\max }-\mathrm{C}_{\text {nat }}}
$$

where:

$\mathrm{V}_{\text {effl }}=$ the waste water emissions, $\mathrm{m}^{3} / \mathrm{y}$;

$\mathrm{C}_{\mathrm{effl}}=$ the concentration of the typical pollutants, tonne $/ \mathrm{y}$;

$\mathrm{C}_{\max }=$ the maximum acceptable concentration, tonne/y;

$\mathrm{C}_{\text {nat }}=$ the natural concentration in the receiving water body, tonne $/ \mathrm{y}$.

The virtual water footprint of the industrial sector is incorporated into the water required by the raw and auxiliary materials, fuels consumption [49], which is measured as follows:

$$
\mathrm{V}_{\text {Ivirtual }}=\sum_{\mathrm{i}=1}^{\mathrm{n}} \mathrm{M}_{\mathrm{i}} \mathrm{k}_{\mathrm{i}}
$$

where $\mathrm{M}_{\mathrm{i}}$ represents the consumption of the ith materials or fuels and $\mathrm{k}_{\mathrm{i}}$ the water footprint coefficient of the ith materials or fuels. 


\subsection{Water Footprint of Domestic Water}

The urban domestic water is regarded as a fundamental source for provision of goods and services consumed by the inhabitants' daily life, including the water demand for household use, personal hygiene, drinking, washing clothes and dishes, flushing toilets, etc. [11,12]. The water footprint of urban domestic water is measured as the direct water consumption in this study, by which the water withdrawal and purification for domestic use are incorporated.

\subsection{Water Footprint of Eco-Environment}

The eco-environmental water demand is defined as the amount of water used by the ecosystem to maintain the water balance of the living beings and improve the water environment as well as the environment in which human lives [51-53]. In this paper, the water footprint of urban eco-environment comprises the ecological water use of urban green spaces, water use of rivers and lakes, and water use of urban sanitation, aiming at the improvement of water quality, ecological environment, and urban landscape etc., shown as follows [51]:

$$
\mathrm{W}_{\text {etotal }}=\mathrm{W}_{\mathrm{gr}}+\mathrm{W}_{\mathrm{rl}}+\mathrm{W}_{\mathrm{sa}}
$$

where $W_{\text {gr }}$ indicates the water footprint of urban green spaces, $\mathrm{m}^{3} / \mathrm{y} ; \mathrm{W}_{\mathrm{rl}}$ the water footprint of urban rivers and lakes, $\mathrm{m}^{3} / \mathrm{y} ; \mathrm{W}_{\mathrm{sa}}$ the water footprint of the urban sanitation, $\mathrm{m}^{3} / \mathrm{y}$.

The water footprint of urban green spaces $W_{\text {gr }}$ is calculated by the quota method, shown as follows [52]:

$$
\mathrm{W}_{\mathrm{gr}}=\mathrm{q}_{\mathrm{gr}} \times \mathrm{c} g r_{\mathrm{gr}}
$$

where:

$\mathrm{q}_{\mathrm{gr}}=$ the water quota of urban green spaces, $\mathrm{m}^{3} /\left(\mathrm{ym}^{2}\right)$;

$\mathrm{c}_{\mathrm{gr}}=$ the urban green coverage, $\mathrm{m}^{2}$.

The water footprint of urban rivers and lakes $W_{\mathrm{rl}}$ is calculated by the water budget method, shown as follows [54]:

$$
\mathrm{W}_{\mathrm{rl}}=\mathrm{V}_{\mathrm{ep}}+\mathrm{V}_{\mathrm{sp}}+\mathrm{V}_{\mathrm{rl}} \times \mathrm{f}_{\mathrm{c}}
$$

where $V_{e}$ is the volume of evaporation from urban water surface, $\mathrm{m}^{3} ; \mathrm{V}_{\mathrm{s}}$ the volume of seepage from urban water body, $\mathrm{m}^{3} ; \mathrm{V}_{\mathrm{rl}}$ the volume of urban rivers and lakes, $\mathrm{m}^{3} ; \mathrm{f}_{\mathrm{c}}$ the period of water replacement.

The evaporation from urban water surface $V_{\text {ep }}$ is calculated by the following equation [54]:

$$
\mathrm{V}_{\mathrm{ep}}=10 \times \mathrm{A}_{\mathrm{S}} \times \mathrm{E}_{\mathrm{urb}}
$$

where:

$\mathrm{A}_{\mathrm{S}}=$ area of urban water surface, $\mathrm{hm}^{2}$;

$\mathrm{E}_{\mathrm{urb}}=$ urban evaporation potential, $\mathrm{mm}$;

The seepage from urban water body $V_{\text {sp }}$ is calculated by the following equation [54]:

$$
\mathrm{V}_{\mathrm{sp}}=10 \times \mathrm{A}_{\mathrm{S}} \times \mathrm{D}_{\mathrm{sp}}
$$

where:

$\mathrm{A}_{\mathrm{S}}=$ area of urban water surface, $\mathrm{hm}^{2}$;

$\mathrm{D}_{\mathrm{sp}}=$ depth of seepage, $\mathrm{mm}$;

The water footprint of the urban sanitation $W_{\mathrm{sa}}$ is calculated by the quota method, given as follows [54]:

$$
\mathrm{W}_{\mathrm{sa}}=\mathrm{q}_{\mathrm{sa}} \times \mathrm{c}_{\mathrm{sa}}
$$


where:

$\mathrm{q}_{\mathrm{sa}}=$ the water quota of urban sanitation, $\mathrm{m}^{3} / \mathrm{hm}^{2}$;

$\mathrm{c}_{\mathrm{sa}}=$ the urban area, $\mathrm{hm}^{2}$.

All of these coefficients, such as $D_{s p}, E_{u r b}, f_{c}$, are derived from the local statistical data. For example, the $D_{\text {sp }}$ represents the depth of seepage, which can be calculated by the permeability of sediment on the riverbed [54,55]. According to the local standard of hydrogeology and engineering geology, the permeability of sediment in Southwestern China is approximately $0.6 \mathrm{~m} / \mathrm{d}$. Other empirical values of the coefficients can be determined in a similar way.

\subsection{Water Footprint of Virtual Water Trade}

Virtual water trade is used to indicate the water embedded in traded water intensive products, aiming at improvement of water use efficiency and mitigation of water crisis [10,34]. Especially in China, there is a closer connection between commodities trade among different regions or cities, which may result in virtual water trade. The water footprint of urban virtual water trade $V_{\text {trade }}$ is calculated by the difference between the gross virtual water export $V_{\text {exp }}$ and the gross virtual water import $V_{\text {imp }}$, shown as follows $[10,12]$ :

$$
\mathrm{V}_{\text {trade }}=\mathrm{V}_{\mathrm{imp}}-\mathrm{V}_{\mathrm{exp}}
$$

\subsection{Case Background and Data Source}

Leshan was selected as a typical case study city to assess its associated water footprint. It is a city with a history of more than 3,000 years, located in the southern part of Sichuan Province $\left(102^{\circ} 15^{\prime}-104^{\circ} 15^{\prime} \mathrm{E}, 28^{\circ} 28^{\prime}-29^{\circ} 56^{\prime} \mathrm{N}\right)$. The administrative area's population is 12,827 including 4 districts, 7 country towns, and 211 village towns, with a total population of 3.56 million in 2013. Leshan's gross domestic production (GDP) has reached 113.479 billion Chinese Yuan, ranked as the 9th in Sichuan Province. As one of the most significant agricultural bases in Sichuan, Leshan City plays an important role in crop and livestock production, ranked the first based on the sales of farm products. In addition, the government of Leshan City pays greater attention to accelerating industrial development, by which a number of high-tech zones have been established in relation to electronics, poly-silicons, pharmaceutical etc [56,57]. Leshan city is abundant with water resources with 11.52 billion cubic meters, and located at the confluence of Minjing, Dadu and Qhing Yijiang rivers [58]. In this context, the dominant industries are water intensive [59].

The corresponding data for calculation of water footprint of crop production, animal products, industrial processes, domestic water, eco-environment and virtual water trade are mainly sourced from: FAO Statistical Database [60], Sichuan Water Resources Bulletin (2001-2012) [61], Leshan Statistical Year Book (2001-2012) [62], Thematic Database for Human-earth System [63], China Meteorological Data Sharing Service System [64], China Crop Database by Ministry of Agriculture [65], China Soil Scientific Database [66], Discharge Standard of Pollutants for Municipal Wastewater Treatment Plant (GB18918-2002) [43].

In order to assist policy makers in the application of the above methodology for water footprint assessment, as well as to simplify the computational complexity, a calculation tool was developed using the $C$ programming language. Figure 2 shows the user log-in interface of the developed tool. When a user has registered by filling out the request form and agreed on use for academic purposes, the log-on account and the corresponding password are provided by sending them to the user's email address. 


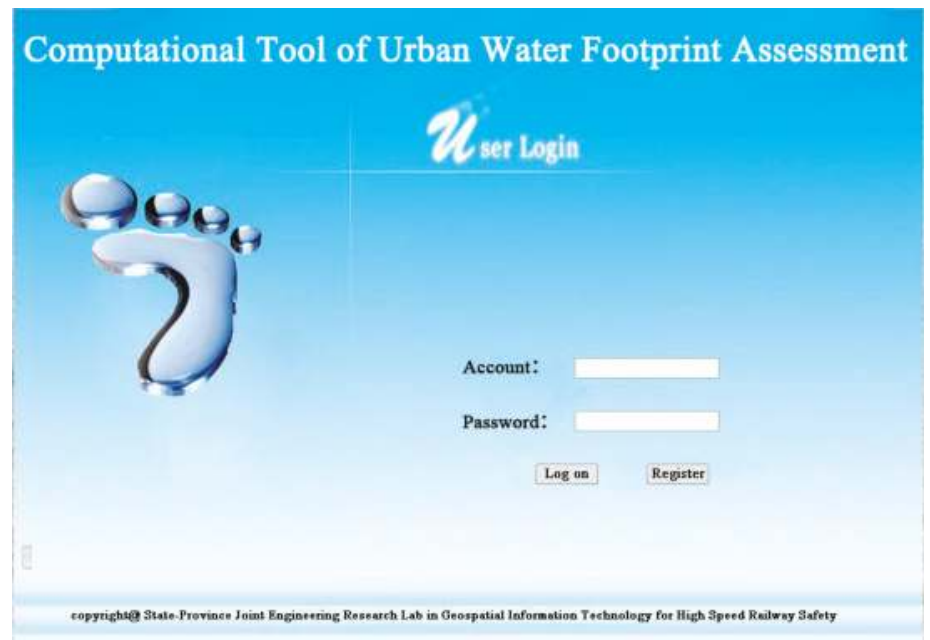

Figure 2. Log-on interface of the calculation tool.

Once the tool is logged on successfully, calculation of the water footprint of all the above mentioned sectors can be implemented, e.g., on submitting the corresponding data to climate, soil, crops, respectively, the water footprint of crop production can be calculated, as shown in Figure 3.

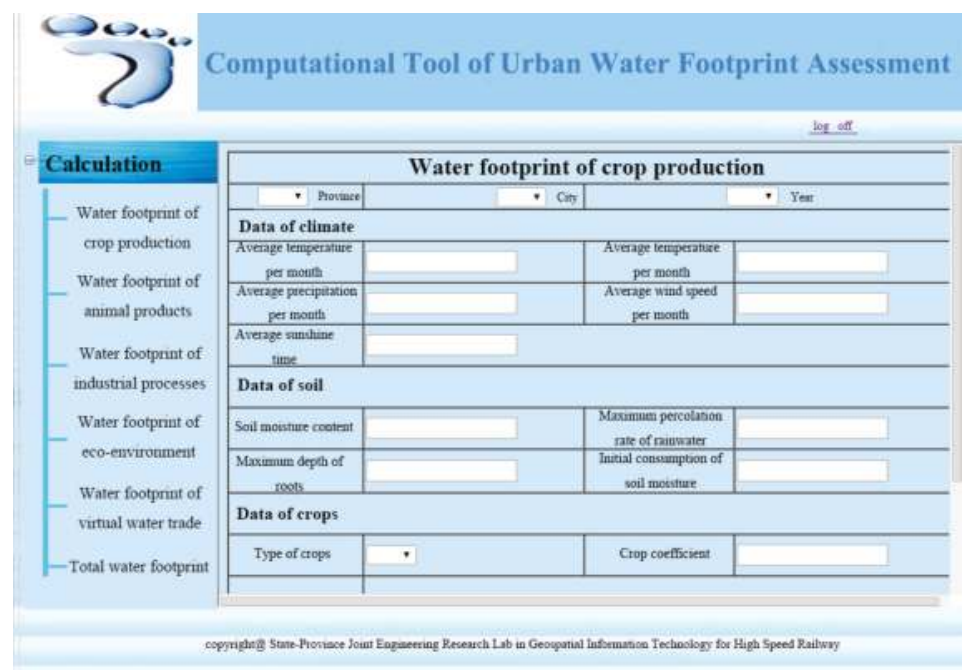

Figure 3. Water footprint calculation of crop production by using the calculation tool.

\section{Results and Discussion}

\subsection{Results}

Table 1 shows the water footprint of each sector in the period 2001-2012, in which the total water footprint of 2012 is 7.79 billion $\mathrm{m}^{3}$, increased by $43.13 \%$ in contrast to 2001 . Crop production accounts for the most at $41.53 \%$ on average, animal products $27.44 \%$, virtual water trade $11.74 \%$, industrial processes $7.71 \%$, domestic water $6.75 \%$, and eco-environment the least, at $4.82 \%$. This indicates that 
crop production and animal products are the major water consumed sectors, which highlights Leshan City in its advantage of agricultural production within Sichuan Province [67]. Thus, it is suggested that advanced technologies of water-saving irrigation should be developed to enhance the water productivity of crops and minimize loss of water delivery.

Table 1. Water footprint of Leshan City in the period 2001-2012 (billion cubic meters).

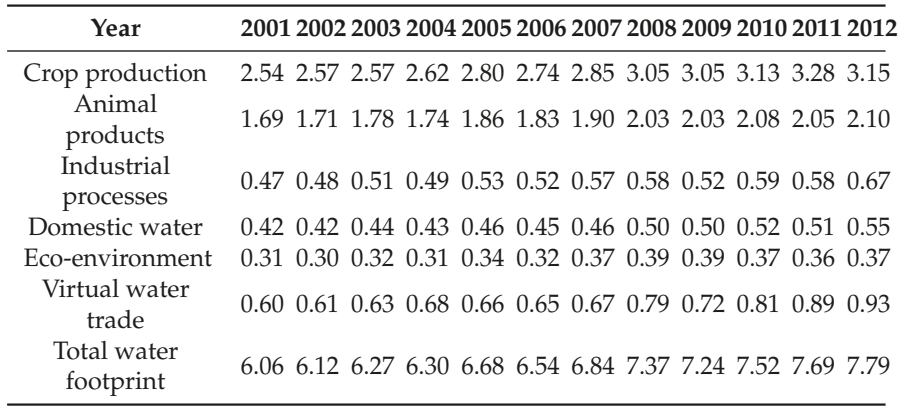

In spite of the minor fluctuation, the water footprint of each sector presents an underlying trend of growth in the period 2001-2012, as shown in Figure 4. The water footprint of virtual water trade increases substantially, by approximately 55\%, followed by industrial processes as $43 \%$, domestic water as $31 \%$, crop production and animal products as $24 \%$. The water footprint of eco-environment is slightly changed, with its increase of $19 \%$ up to 2012 . For Leshan city, the per capita water resource is $3326 \mathrm{~m}^{3}$, which is far greater than the water stress indicator, as the annual water supplies below 1700 $\mathrm{m}^{3}$ per person $[58,68]$. Since Leshan is rich in water resources, it is targeted to export water intensive products to other cities or regions, such as ceramic and pottery, stainless steel, phosphorus chemical products, etc. $[59,69]$.

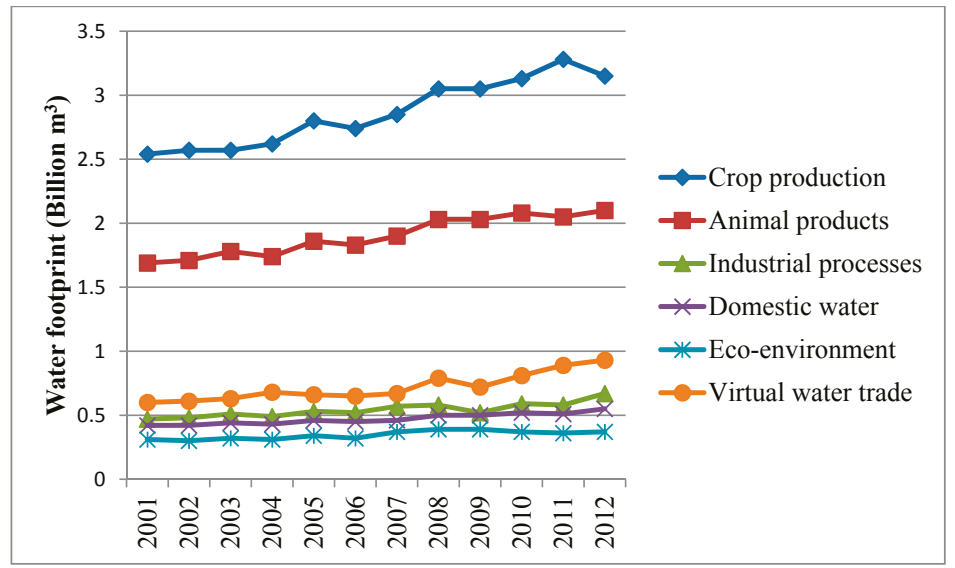

Figure 4. Variation trend of water footprint for each sector in the period 2001-2012.

Dividing the total water footprint by the urban acreage, water footprint intensity (WFI) is thus calculated by using the ArcGIS software to create a water footprint map (WFM). The WFM is intended to visualize the water footprint intensity in order to reflect its variation in a determined spatial and temporal distribution, e.g., the spatial distribution is limited to the administrative area of Leshan City, whilst the temporal ranges from 2001 to 2012. The WFM is based on the "Three Elements of map 
design", which involves mathematical element, geographic elements and decorative elements [70]. The satellite imagery of Leshan City is rasterized to create the basic elements layers, such as administrative division, rivers, etc. Related data, e.g., regional area, water footprints of different sectors etc., are input into the database. By using the anti-gravity weighting method and interpolation, the preliminary WFM is generated through further colour rendering. The annotation is labeled on the map, such as legend, plotting scale, etc.

Figure 5 shows the WFI variation of Leshan City in the period 2001-2012. The ranges are highlighted using a background colour which gradually changes from blue to red, indicated that the water footprint intensity increased from 100 to 120,000. Accordingly, the features of water resources utilization in Leshan City can be summarized as follows from the figure:

(1) Variation of spatial distribution: The spatial representation of water usage is helpful in identifying the water scarce area. For instance, the WFI of the Northeastern area is apparently larger than that of the Southwestern area, which is consistent with the regional characteristics of demographic and geographic distribution, i.e., the Northeastern area is the comparatively economic developed area in Leshan City, with dense population and water intensive industries.

(2) Variation of temporal distribution: the distribution of total water footprint has led to an expansion during the period of 2001 to 2012, e.g., the water footprint intensity in Sha Wan and Wu Tongqiao Districts is increased, as shown in Figure 4. This situation is resulted from the development of urbanization, as these districts are gradually incorporated into the central urban areas, which can be verified by "Leshan City Planning in the period 2010-2030", indicated that Sha Wan and Wu Tongqiao Districts are merged as the central urban areas, with the urban land-use reaching 100 square kilometers in the year of 2020 [62].

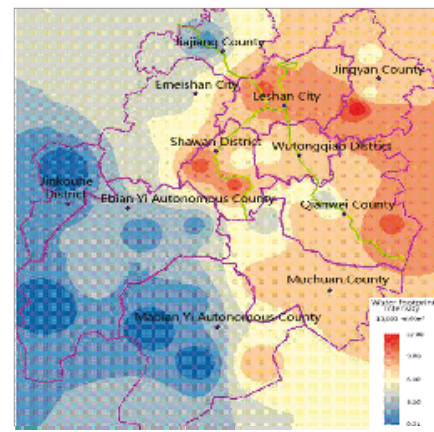

a. Water footprint intensily in the year of 2001

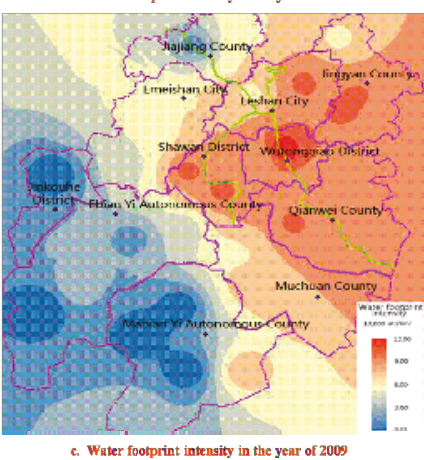

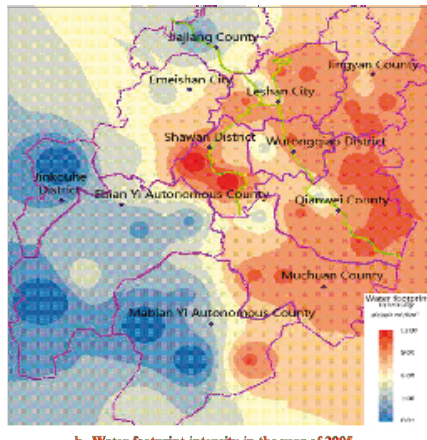

b. Water footprint intensity in the year of 2005

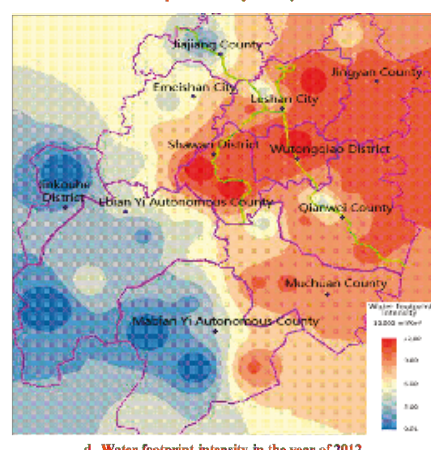

1. Woter fotorint intensity in the year of 2012

Figure 5. Variation of water footprint intensity of Leshan City in the period 2001-2012. 


\subsection{Discussion}

In this study, the sectors division is similar to that has been proposed by Aldaya et al. (2010) and Rui et al. (2011), who place emphasis on evaluating regional water resources utilization from the perspective of factors of production [71,72]. From the decomposition of water footprint, the sector of crop production accounts for the largest proportion, at $41.53 \%$ averagely. This has been validated by a number of similar studies using different accounting methods, to indicate that the agricultural sector consumes a large amount of freshwater, and contributes to the largest water footprint $[7,37,73,74]$. At the same time, it has great potential to enhance agricultural water efficiency, by which water saving irrigation is thus strongly encouraged [75]. For instance, drip irrigation is proposed by using networks of pipes to water the soil surface or root zone of plants directly, which is a management option to reduce water consumption and maintain agricultural production and productivity [76]. Compared with the conventional surface flooding irrigation commonly used in China, drip irrigation is more efficient in reduction of energy consumption and carbon emissions [77]. Significant efforts should be also made by policy makers regarding identification of advanced water resource management to promote water saving irrigation, e.g., remote sensing and satellite imagery are useful to identify losses in agricultural productivity by assessing agricultural water use, which supports better agricultural planning [78]. Besides, a number of policy instruments, such as pricing strategy, economic sanctions, financial subsidies, etc., may give rise to internalization of the external cost of water, thus to drive development of less water intensive industries and services [7,79].

Water footprint accounting provides better implications to illustrate the potential links among human demand, water consumption and global trade, in order to improve water resource management $[40,80]$. However, the accounting methods of water footprint are still in progress, which may result in uncertainties of the associated results, e.g., lack of a unified methodology for the accounting $[81,82]$. The accounting methods can be mainly divided into the bottom-up and top-down methods in general, in which the former focuses on water footprint assessment in the process of manufacture, whilst the latter emphasizes the product consumption process [12,83]. The incomparability of the final accounting result thus gives rise to a variety of data demands and division of systems boundary. In our study, water footprint is calculated by the sum of the water footprints of various sectors, which can be attributed to a typical application of the top-down method, to evaluate regional water resources utilization in a perspective of factors of production. It is expected to confirm the validity and sensitivity of this approach by applying it to a wider range of case scenarios.

Apart from that, it is noteworthy that no water footprints can completely enhance the understanding of water resource issues and contribute to policy analysis, except for bringing increased attention to discussions on water scarcity [84-86]. A single indicator like a water footprint is not sufficient to provide policy guidance, but more information that involves variables regarding physical, social and economic dimensions should be taken into account in order to determine an optimal framework of policy making related to water resources management $[86,87]$.

\section{Conclusions}

This study applies water footprint assessment to measuring the water consumption of Leshan City in the period 1992-2012. The water footprints of various sectors show an increasing trend to varying degrees, in which the virtual water trade increases substantially by approximately $55 \%$ up to 2012 , followed by the industrial processes at $43 \%$, domestic water at $31 \%$, crop production and animal products at $24 \%$, and eco-environment at $19 \%$. In contrast to 2001 , the total water footprint of 2012 increased by $43.13 \%$. Crop production and animal products are identified as the major water consumption sectors, accounting for about $41.53 \%$ and $27.44 \%$ of the total water footprint.

From the perspective of the geographic distribution of Leshan City, the water footprint in the Northeastern area is greater than that of the Southwestern area in the period 1992-2012. In particular, the distribution of total water footprint has led to an expansion in Sha Wan and Wu Tongqiao Districts in the Northeastern area, with the development of urbanization. 
It is expected that the water footprint assessment can provide insight into the improvement of urban water management. For example, crop production and animal products are identified as the major water consumed sectors in the study. Water saving irrigation is thus recommended to enhance the water productivity of crops and minimize loss of water delivery, in order to ultimately reduce the associated water footprint.

However, there are some limitations in this study. First, the specific water requirement from different sources in a designated sector, e.g., the origin of that water, has not been taken into account. Second, the internal structure of water footprint accounting, such as the water balance between blue and green water, has been omitted in this study. Further study will center on improvement of the assessment, in order to examine the internal structure and establish a more precise system boundary for the accounting, to promote sustainable water management.

Acknowledgments: Acknowledgments: This study is sponsored by the National Natural Science Foundation of China (No.41301639; 41571520; 41461118), Guangxi Key Laboratory of Spatial Information and Geomatics (No. 14-045-24-12), the Fundamental Research Funds for the Central Universities (No. 2682014RC04), the National Social Science Foundation of China (15ZDA054) and the Ministry of Education Innovation Team (No. IRT13092).

Author Contributions: Author Contributions: Rui Zhao was involved in conceptualizing the whole study, proposing the assessment sectors and writing the whole paper. Hualing He conducted the case study to collect the data and implemented the calculation of the water footprint. Ning Zhang improved the whole structure of the paper.

Conflicts of Interest: Conflicts of Interest: The authors declare no conflict of interest.

\section{References}

1. Otero, I.; Kallis, G.; Aguilar, R.; Ruiz, V. Water scarcity, social power and the production of an elite suburb: The political ecology of water in Matadepera, Catalonia. Ecol. Econ. 2011, 70, 1297-1308.

2. Bogardi, J.J.; Dudgeon, D.; Lawford, R.; Flinkerbusch, E.; Meyn, A.; Pahl-Wostl, C.; Viehlhauer, K.; Vörösmarty, C. Water security for a planet under pressure: Interconnected challenges of a changing world call for sustainable solutions. Curr. Opin. Env. Sust. 2012, 4, 35-43. [CrossRef]

3. Trenberth, K.E.; Dai, A.; van der Schrier, G.; Jones, P.D.; Barichivich, J.; Briffa, K.R.; Sheffield, J. Global warming and changes in drought. Nat. Clim. Chang. 2014, 4, 17-22. [CrossRef]

4. Jiang, Y. China's water scarcity. J. Environ. Manag. 2009, 90, 3185-3196. [CrossRef] [PubMed]

5. Ge, L.; Xie, G.; Zhang, C.; Li, S.; Qi, Y.; Cao, S.; He, T. An evaluation of China's water footprint. Water Resour. Manag. 2011, 25, 2633-2647. [CrossRef]

6. Gong, P.; Liang, S.; Carlton, E.; Jiang, Q.; Wu, J.; Wang, L.; Remais, J.V. Urbanisation and health in China. Lancet 2012, 379, 843-852. [CrossRef]

7. Dong, H.; Geng, Y.; Sarkis, J.; Fujita, T.; Okadera, T.; Xue, B. Regional water footprint evaluation in China: A case of Liaoning. Sci. Total Environ. 2013, 442, 215-224. [CrossRef] [PubMed]

8. Mao, X.; Yuan, D.; Wei, X.; Chen, Q.; Yan, C.; He, L. Network Analysis for a Better Water Use Configuration in the Baiyangdian Basin, China. Sustainability 2015, 7, 1730-1741. [CrossRef]

9. Liu, J.; Zang, C.; Tian, S.; Liu, J.; Yang, H.; Jia, S.; You, L.; Liu, B.; Zhang, M. Water conservancy projects in China: Achievements, challenges and way forward. Global Environ. Chang. 2013, 23, 633-643. [CrossRef]

10. Hoekstra, A.Y.; Hung, P. Virtual Water Trade: A Quantification of Virtual Water flows Between Nations in Relation to International Crop Trade; UNESCO-IHE: Delft, The Netherlands, 2003.

11. Hubacek, K.; Guan, D.; Barrett, J.; Wiedmann, T. Environmental implications of urbanization and lifestyle change in China: Ecological and Water Footprints. J. Clean. Prod. 2009, 17, 1241-1248. [CrossRef]

12. Hoekstra, A.Y.; Chapagain, A.K.; Aldaya, M.M.; Mekonnen, M.M. The Water Footprint Assessment Manual: Setting the Global Standard; Earthscan: London, UK, 2011.

13. Paterson, W.; Rushforth, R.; Ruddell, B.L.; Konar, M.; Ahams, I.C.; Gironás, J.; Mijic, A.; Mejia, A. Water Footprint of Cities: A Review and Suggestions for Future Research. Sustainability 2015, 7, 8461-8490. [CrossRef]

14. Hoekstra, A.Y.; Chapagain, A.K. Globalization of Water: Sharing the Planet's Freshwater Resources; Blackwell Publishing: Hoboken, NJ, USA, 2008. 
15. Chapagain, A.K.; Hoekstra, A.Y.; Savenije, H.H.G.; Gautam, R. The water footprint of cotton consumption: An assessment of the impact of worldwide consumption of cotton products on the water resources in the cotton producing countries. Ecol. Econ. 2006, 60, 186-203. [CrossRef]

16. Ridoutt, B.G.; Eady, S.J.; Sellahewa, J.; Simons, L.; Bektash, R. Water footprinting at the product brand level: Case study and future challenges. J. Clean. Prod. 2009, 17, 1228-1235. [CrossRef]

17. Mekonnen, M.M.; Hoekstra, A.Y. The green, blue and grey water footprint of crops and derived crop products. Hydrol. Earth Syst. Sci. 2011, 15, 1577-1600. [CrossRef]

18. Mekonnen, M.M.; Hoekstra, A.Y. A Global Assessment of the Water Footprint of Farm Animal Products. Ecosystems 2012, 15, 401-415. [CrossRef]

19. Ercin, A.E.; Aldaya, M.M.; Hoekstra, A.Y. The water footprint of soy milk and soy burger and equivalent animal products. Ecol. Indic. 2012, 18, 392-402. [CrossRef]

20. Gerbens-Leenes, W.; Mekonnen, M.M.; Hoekstra, A.Y. The water footprint of poultry, pork and beef: A comparative study in different countries and production systems. Water Resour. Ind. 2013, 1-2, 25-36. [CrossRef]

21. Ridoutt, B.G.; Sanguansri, P.; Freer, M.; Harper, G.S. Water footprint of livestock: Comparison of six geographically defined beef production systems. Int. J. Life Cycle Ass. 2012, 17, 165-175. [CrossRef]

22. Van Oel, P.R.; Hoekstra, A.Y. Towards Quantification of the Water Footprint of Paper: A First Estimate of its Consumptive Component. Water Resour. Manag. 2012, 26, 733-749. [CrossRef]

23. Chico, D.; Aldaya, M.M.; Garrido, A. A water footprint assessment of a pair of jeans: The influence of agricultural policies on the sustainability of consumer products. J. Clean. Prod. 2013, 57, 238-248. [CrossRef]

24. Herath, I.; Green, S.; Singh, R.; Horne, D.; van der Zijpp, S.; Clothier, B. Water footprinting of agricultural products: A hydrological assessment for the water footprint of New Zealand's wines. J. Clean. Prod. 2013, 41, 232-243. [CrossRef]

25. Ene, S.A.; Teodosiu, C.; Robu, B.; Volf, I. Water footprint assessment in the winemaking industry: A case study for a Romanian medium size production plant. J. Clean. Prod. 2013, 43, 122-135. [CrossRef]

26. ISO (The International Organization for Standardization). ISO 14046 Water Footprint-Principles, Requirements and Guidelines; ISO: Geneva, Switzerland, 2014.

27. Pfister, S.; Vionnet, S.; Levova, T.; Humbert, S. Ecoinvent 3: Assessing water use in LCA and facilitating water footprinting. Int. J. Life Cycle Assess. 2015. [CrossRef]

28. Manzardo, A.; Mazzi, A.; Loss, A.; Butler, M.; Williamson, A.; Scipioni, A. Lessons learned from the application of different water footprint approaches to compare different food packaging alternatives. J. Clean. Prod. 2015. [CrossRef]

29. Ercin, A.E.; Aldaya, M.M.; Hoekstra, A.Y. Corporate Water Footprint Accounting and Impact Assessment: The Case of the Water Footprint of a Sugar-Containing Carbonated Beverage. Water Resour. Manag. 2011, 25, 721-741. [CrossRef]

30. Ruini, L.; Marino, M.; Pignatelli, S.; Laio, F.; Ridolfi, L. Water footprint of a large-sized food company: The case of Barilla pasta production. Water Resour. Ind. 2013, 1-2, 7-24. [CrossRef]

31. Li, J.S.; Chen, G.Q. Water footprint assessment for service sector: A case study of gaming industry in water scarce Macao. Ecol. Indic. 2014, 47, 164-170. [CrossRef]

32. Hoekstra, A.Y.; Chapagain, A.K. Water footprints of nations: Water use by people as a function of their consumption pattern. Water Resour. Manag. 2007, 21, 35-48. [CrossRef]

33. Turconi, R.; Boldrin, A.; Astrup, T. Life cycle assessment (LCA) of electricity generation technologies: Overview, comparability and limitations. Renew. Sust. Ener. Rev. 2013, 28, 555-565. [CrossRef]

34. Zhao, X.; Chen, B.; Yang, Z.F. National water footprint in an input-output framework-A case study of China 2002. Ecol. Model. 2009, 220, 245-253. [CrossRef]

35. Chen, Z.M.; Chen, G.Q. Virtual water accounting for the globalized world economy: National water footprint and international virtual water trade. Ecol. Indic. 2013, 28, 142-149. [CrossRef]

36. Zhang, C.; Anadon, L.D. A multi-regional input-output analysis of domestic virtual water trade and provincial water footprint in China. Ecol. Econ. 2014, 100, 159-172. [CrossRef]

37. Zhang, Z.; Shi, M.; Yang, H.; Chapagan, A. An input-output analysis of trends in virtual water trade and the impact on water resources and uses in China. Econ. Syst. Res. 2011, 23, 431-446. [CrossRef] 
38. Zhang, Z.; Shi, M.; Yang, H. Understanding Beijing's Water Challenge: A Decomposition Analysis of Changes in Beijing's Water Footprint between 1997 and 2007. Environ. Sci. Technol. 2012, 46, 12373-12380. [CrossRef] [PubMed]

39. Wang, Z.; Huang, K.; Yang, S.; Yu, Y. An input-output approach to evaluate the water footprint and virtual water trade of Beijing, China. J. Clean. Prod. 2013, 42, 172-179. [CrossRef]

40. Fiałkiewicz, W.; Czaban, S.; Kolonko, A.; Konieczny, T.; Malinowski, P.; Manzardo, A.; Loss, A.; Scipioni, A.; Leonhardt, G.; Rauch, W.; et al. Water footprint as a new approach to water management in the urban areas. Available online: http://www.researchgate.net/publication/265636445 _WATER_FOOTPRINT_AS_A_NEW_APPROACH_TO_WATER_MANAGEMENT_IN_THE_URBAN_AR EAS (accessed on 20 November 2015)

41. Tague, C.L.; Band, L.E. RHESSys: Regional hydro-ecologic simulation system-an object-oriented approach to spatially distributed modeling of carbon, water, and nutrient cycling. Earth Interact. 2004, 8, 1-42. [CrossRef]

42. Wardropper, C.B.; Chang, C.; Rissman, A.R. Fragmented water quality governance: Constraints to spatial targeting for nutrient reduction in a Midwestern USA watershed. Landsc. Urban Plan. 2015, 137, 64-75. [CrossRef]

43. China NPC (National People's Congress). Discharge Standard of pollutants for municipal wastewater treatment plant. Available online: http://kjs.mep.gov.cn/hjbhbz/bzwb/shjbh/swrwpfbz/ 200307/W020061027518964575034.pdf (accessed on 24 November 2015). (In Chinese).

44. Hoekstra, A.Y.; Hung, P. Globalisation of water resources: international virtual water flows inrelation to crop trade. Global Environ. Chang. 2005, 15, 45-56. [CrossRef]

45. Chapagain, A.K.; Hoekstra, A.Y. Virtual Water Flows Between Nations in Relation to Trade in Livestock and Livestock Products; UNESCO-IHE: Delft, The Netherlands, 2003.

46. Allen, R.G.; Smith, M.; Perrier, A.; Pereira, L.S. An Update for the Calculation of Reference Evapotranspiration. ICID Bulletin 1994, 43, 35-92.

47. Allen, R.G.; Pereira, L.S.; Raes, D.; Smith, M. Crop Evapotranspiration: Guidelines for Computing Crop Water Requirements-FAO Irrigation and Drainage Paper 56; Food and Agriculture Organization of the United Nations: Rome, Italy, 1998.

48. Chapagain, A.; Orr, S. UK Water Footprint: the impact of the UK's food and fibre consumption on global water resources. Volume two: appendices. Available online: http://www.waterfootprint.org (accessed on 15 January 2015)

49. Jia, J.; Yan, Y.; Wang, C.; Liang, Y.; Zhang, Y.; Wu, G.; Liu, X.; Wang, L.; Du, C. The estimation and application of the water footprint in industrial processes. Acta Ecol. Sin. 2012, 32, 6558-6565. (In Chinese). [CrossRef]

50. China NPC (National People's Congress). Environment quality standards for surface water. Available online: http:/ / kjs.mep.gov.cn/hjbhbz/bzwb/shjbh/shjzlbz/200206/W020061027509896672057.pdf (accessed on 24 November 2015). (In Chinese).

51. Yang, Z.; Cui, B.; Liu, J. Estimation methods of eco-environmental water requirements: Case study. Sci. China Ser. D 2005, 48, 1280-1292. [CrossRef]

52. Miao, H.; Wei, Y.; Jiang, L.; Ouyang, Z.; Shi, J.; Wang, X.; Zhao, J. Ecological water use and the estimate method. Acta Ecol. Sin. 2003, 23, 1156-1164. (In Chinese).

53. Ying, X.; Zeng, G.M.; Chen, G.Q.; Tang, L.; Wang, K.L.; Huang, D.Y. Combining AHP with GIS in synthetic evaluation of eco-environment quality-A case study of Hunan Province, China. Ecol. Model. 2007, 209, 97-109. [CrossRef]

54. Yang, A.; Tang, K.; Wang, H.; Liu, X. Theory and calculation method of ecological water use. J. Hydraul. Eng-Asce. 2004, 12, 39-44. (In Chinese).

55. Veličković, B. Colmation as one of the processes in interaction between the groundwater and surface water. Facta universitatis-series 2005, 3, 165-172. [CrossRef]

56. The Peoples' Government of Leshan. Overview of Leshan City. Available online: http:/ / www.leshan.gov.cn/LSSQ.aspx (accessed on 15 January 2015). (In Chinese).

57. Yao, L.; Xu, J.; Li, Y. Evaluation of the Efficiency of Low Carbon Industrialization in Cultural and Natural Heritage: Taking Leshan as an Example. Sustainability 2014, 6, 3825-3842. [CrossRef]

58. Zhu, Z.; Hou, L. Shortage appraisal and sustainable utilization of water resource in Sichuan Province. Sci. Soil Water Conserv. 2006, 4, 92-95. (In Chinese). 
59. Wang, W.; He, M.; Pan, K.; Zhu, Q.; Zhou, Y.; Fan, Y.; Hu, Q. Analysis of spatio-temporal characteristics of water resources ecological footprint and ecological carrying capacity in Sichuan province. J. Nat. Resour. 2011, 26, 1555-1565. (In Chinese).

60. Food and Agriculture Organization (FAO). FAO Statistical Database. Available online: http://faostat.fao.org/ (accessed on 20 November 2014).

61. Sichuan Provincial Water Resources Department. Sichuan Water Resources Bulletin; Sichuan Provincial Water Resources Department: Chengdu, China, 2012. (In Chinese)

62. Leshan Statistical Bureau. Leshan Statistical Year Book; Leshan Statistical Bureau: Leshan, China, 2012. (In Chinese).

63. Institute of Geographic Sciences and Natural Resources Research, CAS. Thematic Database for Human-earth System. Available online: http:/ / www.data.ac.cn/ (accessed on 20 November 2014). (In Chinese).

64. National Meteorological Information Center. China Meteorological Data Sharing Service System. Available online: http:/ /cdc.cma.gov.cn/ (accessed on 20 November 2014). (In Chinese).

65. Department of Plantation Management of Ministry of Agriculture. China Crop Database by Ministry of Agriculture. Available online: http:/ / zzys.agri.gov.cn/nongqing.aspx (accessed on 20 November 2014). (In Chinese).

66. Institute of Soil Science, Chinese Academy of Sciences. China Soil Scientific Database. Available online: http:/ /www.soil.csdb.cn/ (accessed on 20 November 2014). (In Chinese).

67. Deng, X.; Xie, S.; Qin, T.; Sun, Z.; He, D. Assessment of water resources utilization in Sichuan Province based on water footprint analysis. Yangtze River 2007, 38, 61-63. (In Chinese).

68. McCarty, J.J. Climate Change 2001: Impacts, Adaptation, and Vulnerability: Contribution of Working Group II to the Third Assessment Report of the Intergovernmental Panel on Climate Change; Cambridge University Press: Cambridge, UK, 2001.

69. The Peoples' Government of Leshan. Leshan City Planning in the period 2011-2030. Available online: http:/ / www.leshan.gov.cn/NewsInfo.aspx?id=974E2E332822CBD0 (accessed on 23 January 2015). (In Chinese).

70. DiBiase, D.; MacEachren, A.M.; Krygier, J.B.; Reeves, C. Animation and the role of map design in scientific visualization. Cartography Geogr. Inform. Syst. 1992, 19, 201-214. [CrossRef]

71. Aldaya, M.M.; Garrido, A.; Llamas, M.R.; Varela-Ortega, C.; Novo, P.; Casado, R.R. Water footprint and virtual water trade in Spain. Water policy. 2010, 35, 49-59.

72. Rui, Q.I.; Geng, Y.; Zhu, Q.H. Evaluation of regional water resources utilization based on water footprint method. J. Nat. Resour. 2011, 26, 486-495. (In Chinese).

73. Feng, K.; Chapagain, A.; Suh, S.; Pfister, S.; Hubacek, K. Comparison of bottom-up and top-down approaches to calculating the water footprints of nations. Econ. Syst. Res. 2011, 23, 371-385. [CrossRef]

74. Zhang, Z.; Yang, H.; Shi, M. Analyses of water footprint of Beijing in an interregional input-output framework. Ecol. Econ. 2011, 70, 2494-2502. [CrossRef]

75. Yang, Y.; Moiwo, J.P.; Hu, Y. Estimation of irrigation requirement for sustainable water resources reallocation in North China. Agr. Water Manag. 2010, 97, 1711-1721. [CrossRef]

76. Jobbins, G.; Kalpakian, J.; Chriyaa, A.; Legrouri, A.; El Mzouri, E.H. To what end? Drip irrigation and the water-energy-food nexus in Morocco. Int. J. Water Resour. Dev. 2015, 31, 393-460. [CrossRef]

77. Wang, J.; Rothausen, S.G.S.A.; Conway, D.; Zhang, L.; Xiong, W.; Holman, I.P.; Li, Y. China's water-energy nexus: Greenhouse-gas emissions from groundwater use for agriculture. Environ. Res. Lett. 2012, 7, 14-35. [CrossRef]

78. Jaafar, H.H.; Zurayk, R.; King, C.; Ahmad, F.; Al-Outa, R. Impact of the Syrian conflict on irrigated agriculture in the Orontes Basin. Int. J. Water Resour. Dev. 2015, 31. [CrossRef]

79. Keulertz, M.; Woertz, E. Financial challenges of the nexus: Pathways for investment in water, energy and agriculture in the Arab world. Int. J. Water Resour. Dev. 2015, 31, 312-325. [CrossRef]

80. Galli, A.; Wiedmann, T.; Ercin, E.; Knoblauch, D.; Ewing, B.; Giljum, S. Integrating ecological, carbon and water footprint into a "footprint family" of indicators: Definition and role in tracking human pressure on the planet. Ecol. Indic. 2012, 16, 100-112. [CrossRef]

81. Zhang, Y.; Singh, S.; Bakshi, B.R. Accounting for ecosystem services in life cycle assessment, Part I: A critical review. Environ. Sci. Technol. 2010, 44, 2232-2242. [CrossRef] [PubMed] 
82. Zhuo, L.; Mekonnen, M.M.; Hoekstra, A.Y. Sensitivity and uncertainty in crop water footprint accounting: A case study for the Yellow River Basin. Hydrol. Earth. Syst. Sci. 2014, 18, 2219-2234. [CrossRef]

83. Wang, X.H.; Xu, Z.M.; Li, Y.H. A rough estimate of water footprint of Gansu province in 2003. J. Nat. Resour. 2005, 20, 115-121. (In Chinese).

84. Wichelns, D. Virtual water and water footprints offer limited insight regarding important policy questions. Int. J. Water Resour. Dev. 2010, 26, 639-651. [CrossRef]

85. Wichelns, D. Virtual water and water footprints: policy relevant or simply descriptive? Int. J. Water Resour. Dev. 2010, 26, 689-695. [CrossRef]

86. Wichelns, D. Assessing water footprints will not be helpful in improving water management or ensuring food security. Int. J. Water Resour. Dev. 2011, 27, 607-619. [CrossRef]

87. Wichelns, D. Do the virtual water and water footprint perspectives enhance policy discussions? Int. J. Water Resour. Dev. 2011, 27, 633-645.

(C) 2015 by the authors. Licensee MDPI, Basel, Switzerland. This article is an open access article distributed under the terms and conditions of the Creative Commons Attribution (CC BY) license (http:/ / creativecommons.org/licenses/by/4.0/). 
Article

\title{
Sustainable Lake Basin Water Resource Governance in China: The Case of Tai Lake
}

\author{
Zhengning $\mathrm{Pu}^{1}$, Hui Wang ${ }^{2, *}$, Haili Bian ${ }^{1}$ and Jiasha $\mathrm{Fu}^{3}$ \\ 1 School of Economics and Management, Southeast University, 2 Si Pai Lou, Nanjing 210000, China; \\ puzhengning@seu.edu.cn (Z.P.); 220131760@seu.edu.cn (H.B.) \\ 2 WHU otto Beisheim School of Management, Burgplatz 2, 56179 Vallendar, Germany \\ 3 Academy of Development and Strategy, Renmin University of China, Zhong Guan Cun Rd. 59, \\ Beijing 100872, China; jiasha0512@ruc.edu.cn \\ * Correspondence: hui.wang@whu.edu; Tel.: +86-158-9594-8024; Fax: +86-25-5209-0719
}

Academic Editors: Yongrok Choi, Malin Song and Seunghwan Myeong

Received: 30 September 2015; Accepted: 9 December 2015; Published: 11 December 2015

\begin{abstract}
China's water pollution is severe and has a negative impact on its residents. Establishing an emissions trading mechanism will be helpful for reducing the pollution. However, the government in China controls the emission rights market. The "GDP Only" preference blocks equitable rules to address the externalities. To modify this distortion, we develop a multi-objective primary distribution model that optimizes economic efficiency, environmental contribution, and fairness. In addition, the geographical location of a company and the industry differential are two key factors that would affect the local government's decision. According to the simulation results using data from Tai Lake in China, this model can effectively help to meet the political expectation that large-scale manufacturers with poor technology can take the initiative to reduce emissions through emission-rights distribution.
\end{abstract}

Keywords: water pollution; emission right initial allocation; China; Tai Lake

\section{Introduction}

In modern society, human development and the sustainable consumption of environmental resources present a paradox. This is particularly true for developing countries. The two conflicting goals generate a tug-of-war for these countries. Although developed countries have established a pattern of economic growth with an increasing awareness of global environmental protection, policy makers from developing countries face an increasingly difficult dilemma.

The primary environmental challenges faced by China relate to air pollution issues, such as carbon emissions and particle pollutants and water pollution issues, such as water recycling, excessive chemical emissions, and solid pollutant emissions. Carbon emissions and particle pollutant emissions have drawn widespread attention due to their global influence and frequent occurrence (Persson [1], Liao [2]). Meanwhile, China's water pollution is severe and has a negative impact on its residents (Zhang [3]). Therefore, it is important to study the sustainable utilization of water resources and water pollution control.

Tai Lake, located in Jiangsu Province, China, experienced an explosive growth of algae bloom in the early summer of 2007, disrupting the tap water for over 10 million residents living in the six cities near Tai Lake. This issue has raised public concern about the sustainable use and management of water resources in China. The Tai Lake problem forced the local government to improve water environmental protection policies and develop appropriate management tools.

In many developed countries, emissions trading systems have been proven to be effective for water pollution control, but adopting this tool may not exert the desired effect in developing countries due to different institutional factors. For example, in China, local governments have the ability to 
establish such a market. The decision to adopt strategies that control water quality in regional lakes requires further research.

Despite having huge influence over emissions trading markets, local governments in China have not been enthusiastic about using them to improve environmental quality. This is because economic growth has always been the priority of regional administrative departments and local government officers in China. Such economy-oriented regional governance policies have caused regional administrative officials to be less than enthusiastic about environmental policy. Even when a pilot environmental program was established (e.g., the pilot emission trade market system setup for Tai Lake area in 2011), it will be described by the local government as a new tool for regional economic development rather than as an environmental improvement instrument.

The establishment of an emissions trading market to combat water pollution often involves inter-regional issues. The relevant administrative bodies tend to lack interest in these issues due to the many administrative procedures involved and the cost of environmental strategies (Xia [4], Zhao [5]), which is contrary to their political objectives. Therefore, incorporating objectives and preferences of local governments is the key to optimizing the effect of the emissions trading market in China. In this paper, we developed a primary distribution model for emissions rights that could meet the local administrative department's demands regarding the region's industrial management and help control the total amount of water pollution in an area. This paper contributes to the literature through establishing a non-linear programming distribution model for water pollution emissions trading based on the local government's industrial preferences and enterprise location. We complement empirical emissions trading research through simulations using corporate data from Tai Lake basin. The combination of our theoretical model and simulation results helps fill the gap in the water pollution emissions trading literature since previous studies are more focused on carbon emissions.

Our results show that, by considering the physical characteristics of the rivers and lakes, emission rights distribution and future trading can effectively control the total pollutant amount while improving the industrial structure of the region, and potentially satisfy the local government. The application of this strategy could contribute to the sustainable utilization of water and to local economic development. The remainder of this paper is organized as follows: Section 2 reviews the previous studies; Section 3 establishes the theoretical model; and Section 4 includes a simulation. Finally, Section 5 concludes the paper.

\section{Literature Review}

Researchers (Dales [6], Brady [7], Brill [8]) have conducted systematic and in-depth theoretical studies of the primary distribution of emission rights. The work of Tientenberg [9] is regarded as the foundation for modern emission rights studies. Montgomery [10] introduced mathematical analysis into emission rights trading and proved that competitive markets achieve cost-effective pollution reductions. O'Neill [11] noted that for water environments with verification and supervision by basin regulators, optimizing emission rights trading with total amount distribution, water quality evaluation, and the simulation of sources (when a source is treated as a single pollution emission agent or a single pollution point for the estimation area), trading can effectively reduce the negative effects of emissions. Three means of primary emission rights distribution-free distribution, public auction, and sale with the bid price pre-established-are the standard emission rights distribution means under the United States Clean Air Act, as amended in 1990 for air resource governance. Rose and Stevens [12] showed that public auction and sale with bid prices are better than free distribution. However, due to the resistance encountered in the United States and other countries, free distribution is regarded as more practical.

In addition to theoretical analysis, scholars have also examined emission rights empirically, focusing mainly on carbon emissions. For example, Beckerman et al. [13] studied the international fairness distribution of carbon emissions. Park et al. [14] developed a new method for emission rights distribution with a Boltzmann distribution and guided the distribution among countries with the 
principle of maximum entropy. Ahn [15] adopted an MCP model to quantify the primary emission-right distribution's influence on the emission amount, emission rights price, and social welfare in Korea's electricity power market.

In China, the emission rights pilot program was first implemented in the 1980s. Since then, scholars have conducted studies on water pollution emission rights. Li et al. [16-19] had the most consistent ongoing involvement in all of these studies. They analyzed the importance of primary emission rights in theory and noted that, compared with paid distribution, free distribution is more practical. They also noted that the country should conduct detailed research on emission rights distribution to establish China's emission rights trading market. Later, they adopted an objective method of establishing a multi-goal decision-making model for primary emission rights distribution based on economic optimization, fairness, and production consistency. In 2005, they built a free distribution model to maximize expected social welfare in trading cost conditions with a mechanism design principle. By 2013, they had built a primary distribution model for the basin based on the economic optimization and fairness principles and conducted an empirical analysis of the Tai Lake case. The results show that the primary distribution model can help Tai Lake emission rights management institutions to better balance economic optimization and distribution fairness.

Apart from Li's group, other Chinese researchers have also performed considerable research on building models for emission rights distribution. For example, Shang [20] built a dynamic data model for primary emission rights distribution. By comparing emission standards, emission taxes, and emission rights trading, Zhou [21] stated that emission rights trading has its own advantages in terms of water pollution regulation. He developed a basin emission rights trading model to determine the advantages and disadvantages of the three types of primary distribution and the characteristics of emission rights auctions and emission rights banks. Tao [22] chose GDP, population, and water environmental volume and amount to build a multi-principle model based on an information entropy method. China's basin emission rights are distributed based on a total control objective and a maximum entropy method. Tao's [22] case study was conducted using the Chemical Oxygen Demand (COD) of China's seven basins.

To meet the requirements of local administrative departments, studies of China's emission rights have focused on solutions for severely polluted areas. Zhou [23] designed a specific method for emission rights trading in the printing and dyeing industry, explored the total amount determination and primary distribution and analyzed the corporate economic burden. Based on the status quo of emission rights distribution and its problems, Huang et al. [24] took the pollutants' density control and total control as the limitation and built a multi-goal economic and water quality optimal distribution model by considering fairness and the discharger's production sustainability. He also developed a better distribution method based on the Jushui River simulation. With Nanputi Qingshan as the example, Li [25] established a multi-goal distribution model to reduce pollutant costs and to optimize environmental risks. He found that water emissions trading technology provided the necessary means to measure the improvement in water environment quality based on empirical analysis. Xiao [26] simulated the carbon emissions permission distribution of three factories in the Pudong district of Shanghai with a Shapley value, benchmark, and grandfather systems. He compared these three methods with the Shapely value as the parameter and made suggestions for primary distribution in the carbon emissions trading system in Shanghai.

Until now, most research has focused on economic efficiency (which is usually measured by the total utility gain of a single firm) and fairness (removing the discrimination of firm size, industry, etc.) but has given little consideration to the environmental consequences of the geographic location of sources or the government's preferences for certain industries.

However, the government's preferences are a kind of discrimination due to the "GDP Only" philosophy. When regulating the initial allocation of emission allowances, in order to maintain high economic growth, the government often gives large enterprises more pollution emission permits. Many of these companies have serious negative environmental impacts. In addition, some technologically 
advanced firms do not get sufficient emission permits due to the small volume of their economic contributions. The policy that aimed to let backward enterprises pay more has led the advanced firms to purchase emission rights from the laggards in the process of actual execution. This arrangement on one hand leads to an inactive emission trading market; on the other hand, it is in breach of the fair principle that might hurt the firms' enthusiasm to develop new technologies and eventually hinder development sustainability. The government in China controls the emission rights market. It has the responsibility to build fair and equitable discriminatory rules to reflect the externalities and conserve the sustainability.

The existing research does not capture such initial pollution right distribution discrimination against small companies. Therefore, we try to solve this unfair treatment and build a primary distribution model for pollution emission rights that balances three goals: economic efficiency, environmental contribution (positive or negative), and fairness optimization. This model also considers the geographical location and different types of industries. We then conduct a simulation using the corporate data for the Wujin District of Lake Tai in China.

\section{Theoretical Model for Water Pollution Right Distribution}

For water pollution, extensive research (Sun [27], Cui [28], Zhang [29]) has focused on the lake itself. Little work has been performed on the tributaries surrounding the lake, despite their role as the sources of lake water pollution. Therefore, for seriously polluted tributaries, there has been a continuous effort to prevent and control industrial-sourced pollution and to pilot an emission trading system. Meanwhile, many problems remain in the theoretical study of lake basin emission rights distribution and in actual practice. There is much room for improvement, especially in water resource governance using tools such as emission rights distribution and trading.

For China's local government officers, there are two main aspects of water pollution management. First, current emission rights distribution often aims to control the pollutant density instead of considering the strong impact of the physical features of a self-cleaning pollutant, such as the flow rate, on water pollution control. Second, for emission rights distribution model design (Shang [20], Li [16], and $\mathrm{Li}$ [25]), production sustainability is taken into consideration, but the anti-discrimination of initial pollution rights distribution has not yet been used. The primary emission rights distribution design in practice encourages the development of high-pollution and low-effect sources. This research tries to introduce the source's location and anti-discrimination of initial pollution right distribution into the traditional emission rights model. The new river emission rights model is essentially a multi-goal distribution model that focuses on the economy, the environment, and fairness. We believe that this research can complement the current distribution method.

\subsection{Non-Linear Model for the Initial Allocation of Pollution Permits}

\subsubsection{Economic Optimization}

In the process of primary emission rights distribution, the environmental regulator prioritizes economic development, which enables drain manufacturers with the biggest economic contribution in the region to obtain emission rights sufficient for their needs. Under the condition that the environment in the region is protected, economic efficiency can be maximized. However, in reality, the source of lake water pollution is often industrial pollution or diffused agricultural pollution in tributaries. If the industrial source pollution is severe, the different geographic locations of the polluters affect the environment to various degrees. For example, due to the self-cleaning ability of flowing water, the pollution of a large-scale polluter upstream is sometimes smaller than that of a middle-scale or small-scale polluter downstream in the same river. In other words, the location of the polluter matters as much as the scale of the polluter.

As a result, from the viewpoint of total volume control, this study adopts the following assumptions in terms of the establishment of a primary distribution model for emission rights. 
Assumption I

There are $n$ major polluters (drain manufacturers) in the area supervised by the environmental regulator, which specifies an upper limit $E^{*}$ for the total pollution amount according to the environmental capacity. Each drain manufacturer $i$ has a full right of use of the primary emission right distributed to itself and thereby earns utilities. The utility function between the pollution $x$ that firm $i$ emitted could be denoted as $f_{i}\left(x_{i}\right), i=1,2, \ldots, n$, and meets the following conditions:

(1) $f_{i}\left(x_{i}\right)$ has a sequential second derivative, and when $x_{i}>0, f_{i}^{\prime}\left(x_{i}\right)>0$;

(2) $f_{i}\left(x_{i}\right)$ is a strictly concave function that equals $f_{i}^{\prime \prime}\left(x_{i}\right)<0$.

It should be noted that the assimilative capacity of the river (represented by $E^{*}$ ) is closely related to the water features, water quality goals, and pollutant characteristics. Therefore, when calculating the assimilative capacity, we adopt the water transport function from environmental science to calculate and control the pollutant density of a cross-section of the river. The dilution and mixture function of the river water and polluted water is as follows:

$$
C=\frac{C_{p} Q_{p}+C_{e} Q_{e}}{Q_{p}+Q_{e}}
$$

where $C$ is the density of the completely mixed water quality $(\mathrm{mg} / \mathrm{L}) ; Q_{p}$ and $C_{p}$ stand for the upstream designated water amount $\left(\mathrm{m}^{3} / \mathrm{s}\right)$ and the designed water density $(\mathrm{mg} / \mathrm{L})$, respectively; and $Q$ and $C_{e}$ are the designed flow rate of the polluted water and the designed emission density ( $\mathrm{mg} / \mathrm{L})$, respectively. Because the influence of the pollution source can be superimposed linearly, the impact of several polluted source emissions on the controlling point or cross-section equals the sum of each polluted point, which conforms to linear superimposition. The calculation of each source can be superimposed to measure the source point conditions. The restrictions of a single section or single point can recur in multi-section or multi-point restrictions based on node balance.

The emission can be summarized as the full mixture; the equation for calculating the acceptable assimilative capacity in the water area between the drain outlet and the controlling section is as follows:

Single-source emission:

$$
E^{*}=S\left(Q_{p}+Q_{E}\right)-Q_{p} C_{p}
$$

Multi-source emission:

$$
E^{*}=S\left(Q_{p}+\sum_{i=1}^{n} Q_{E i}\right)-Q_{p} \cdot C_{p}, i=1,2, \ldots, n
$$

In Equations (2) and (3), S represents the water quality standard of the controlling section (mg/L), $Q_{E i}$ is the emission flow rate of the $\mathrm{i}^{\text {th }}$ drain outlet, and $\mathrm{n}$ represents the number of drain outlets.

Meanwhile, to maximize the economic efficiency of the pollution control area, a second assumption is adopted for this study.

\section{Assumption II}

To maximize the total economic effectiveness of the pollution control area $\alpha_{i}$, $\alpha_{i}$ stands for the environment regulator's preference for the emission drain manufacturer with a large marginal contribution. $\alpha_{i} \geqslant 0, i=1,2, \ldots, n$, and $\alpha_{i}$ is a standard unit in the current regional pollution industry. 
According to Assumptions I and II, a free emission rights distribution decision-making model based on economic optimization in the control area could be established as follows:

$$
\begin{gathered}
\max \sum_{i=1}^{n} \alpha_{i} f_{i}\left(x_{i}\right) \\
\text { s.t. }\left\{\begin{array}{c}
\sum_{i=1}^{n} x_{i} \leqslant E^{*} \\
x_{i} \geqslant 0, i=1,2, \ldots, n
\end{array}\right.
\end{gathered}
$$

\subsubsection{Environmental Optimization and Fairness}

Apart from economic considerations, there is no doubt that the implementation of an environmental policy improves an area's total utility, especially when the given area had been through rapid economic growth and local citizens require environment improvement. This improvement is called environmental optimization. In this research, environmental optimization refers to the smallest total amount of pollution emission in the entire area, especially the smallest pollution amount that flows to the control section of the lake. Moreover, in actual emission rights distribution situations, the fair distribution of emission rights among drain manufacturers cannot be neglected; this fair distribution is often referred to as fairness optimization.

With regard to fairness, $\mathrm{Li}$ [16] defined it as the need for each drain manufacturer to have an equal right in the primary emission rights distribution. The distribution result is a good way to motivate drain manufacturers to cleanly produce and to be active in preventing pollution. Therefore, with the condition that the environment regulator ensures that each drain manufacturer enjoys an equal right, the distribution should also take into consideration factors such as development, production technology, pollution control, and future planning. It should not protect a backward manufacturer nor limit its development. To achieve these two goals, we make assumptions III and IV, respectively.

We hold that the contribution of manufacturers can be reflected in the amount of polluted water disposed of. In this regard, assumption III is as follows:

\section{Assumption III}

The contribution of drain manufacturer $i$ to the environment of the control area is an important reference index that determines whether the regulator will allow the manufacturer to continue to exist, and the environment contribution index $\lambda_{i}$ conforms to the following function:

$$
\lambda_{i}=\frac{w t_{i}}{W T}
$$

where $w t_{i}$ refers to the amount of wastewater disposed of by manufacturer $i$ in the control area, and WT refers to the total amount of water disposed of by manufacturers in the control area.

By referring to Li's idea that the contribution of a manufacturer to the regional economy is determined by the output value (count as GDP) of one company, the job opportunity that one company created, and the profit and tax in equal proportions, the economic contribution can be regarded as an important index for the local government when evaluating fairness for companies that need a pollution rights allocation. Therefore, we adopt the following assumption:

\section{Assumption IV}

The economic contribution index $\gamma_{i}$ by the drain manufacturer in the pollution control area is as follows:

$$
\gamma_{i}=\frac{1}{3}\left(\frac{g_{i}}{G}+\frac{p_{i}}{P}+\frac{z_{i}}{Z}\right)
$$

In this index, $\mathrm{g}_{\mathrm{i}}$ represents the total output value calculated under GDP achieved by drain manufacturer $i$ in normal conditions in the pollution control area; $p_{i}$ refers to the job opportunities 
created by drain manufacturer $i$ in normal conditions in the pollution control area; $z_{i}$ is the sum of the profit and tax realized by drain manufacturer i in normal conditions in the pollution control area; $G$ is the total output value of all of the drain manufacturers in the pollution control area; P refers to all of the job opportunities created by drain manufacturers; and $\mathrm{Z}$ refers to the total profit and tax realized by drain manufacturers.

According to the above assumption, we can build a primary free emission-rights distribution decision-making model based on water quality optimization in the control area as follows:

$$
\begin{gathered}
\min \sum \frac{2}{\left(\gamma_{i}+\lambda_{i}\right)} \beta_{i} x_{i} \quad(i=1,2,3 \ldots, n) \\
\text { s.t. }\left\{\begin{array}{c}
C_{i} \leqslant C_{i \max }, i=1,2,3 \ldots, n \\
x_{i}^{\prime} \geqslant 0, i=1,2,3 \ldots, n
\end{array}\right.
\end{gathered}
$$

where $C_{i}$ stands for the actual pollution amount in point $C_{i}$, which can be gained from Equations (1) and (5). $C_{i \max }$ represents the assimilative capability in $C_{i}$, which can be derived based on Equations (2) and (3). Moreover, $\beta_{i}$ is the geographic preference (which depends on whether the company is at the upstream or downstream of a river) of manufacturers in the same industry. When the drain discharger has the same level of technology, due to the attention given to the final emission into the lake cross-section, the regulator will give a smaller geographical preferred coefficient to manufacturers that are further from the final section to encourage them to move further away from the final lake emission section.

\subsection{Simulation Agent Category}

Based on the distribution model and the current realities of China's lake basin industry, we classify enterprises in the same key pollution industry in one pollution basin into four categories according to their corporate scale and their wastewater treatment technology. Type A are highly polluting large-scale enterprises with low levels of technology. In China, these are mainly traditional state-owned enterprises (SOEs) and local large-scale collectively owned enterprises. These companies are major players for China's economy, and have been protected by the local administrators because of their current economic growth ability. Type B are leading large-scale enterprises with high pollution treatment technology. In China's regional economy, these agents are mainly represented by foreign enterprises and large-scale SOEs with relative advanced technology (compared with Type A agent). They were welcomed by the local government, but usually could provide less economic contribution compared with Type A agents in the meantime. Type $C$ agents are developing small-scale companies with high levels of technology. These are mainly innovative companies with new industrial technologies. They are interactive and full of future possibility but contribute least to the local economy at the current moment. Finally, Type D agents are small-scale companies with low technology, mainly small local private companies. In modern China's economy, these companies usually provide the most job opportunities in one region, which leads to some special protection by the local governments. The typical classification of enterprises is shown in Table 1.

Table 1. Type classification of enterprises.

\begin{tabular}{lll}
\hline Agent Type & Size & Technology \\
\hline A & Large & Low \\
B & Large & High \\
C & Small & High \\
D & Small & Low \\
\hline
\end{tabular}


For one polluted lake basin area, the objective function of economic optimization is as follows:

$$
\begin{gathered}
\min \sum_{i=1}^{n} \alpha_{i} \times f\left(x_{i}\right) \\
\text { s.t. }\left\{\begin{array}{c}
\sum_{i=1}^{n} x_{i}=E \\
x_{i} \geqslant 0, i=1,2,3, \ldots, \mathrm{n}
\end{array}\right.
\end{gathered}
$$

For the same area, when economic optimization is determined and the water quality requirements of the lake section are considered, the objective function of the local environment and fairness is as follows:

$$
\begin{gathered}
\min \sum_{i=1}^{n} \frac{2}{\lambda_{i}+\gamma_{i}} \beta_{i} x_{i} \\
\text { s.t. }\left\{\begin{array}{c}
\sum_{i=1}^{n} x_{i}=E \\
x_{i} \geqslant 0, i=1,2,3, \ldots, \mathrm{n}
\end{array}\right.
\end{gathered}
$$

To obtain the optimal solution for the multi-goal planning objective, we adopt an objective planning model to give the two objective functions the same weight. As a result, solving the multi-objective planning model is transformed into solving the single objective model:

$$
\begin{gathered}
\min \sqrt{\left(\sum_{i=1}^{n} \alpha_{i} f\left(x_{i}\right)-A\right)^{2}+\left(\sum_{i=1}^{n} \frac{2}{\lambda_{i}+\gamma_{i}} \beta_{i} x_{i}-B\right)^{2}} \\
\text { s.t. }\left\{\begin{array}{c}
\sum_{i=1}^{n} x_{i}=E \\
x_{i} \geqslant 0, i=1,2,3, \ldots, \mathrm{n}
\end{array}\right.
\end{gathered}
$$

Constants A and B in Equation (10) are the optimal solutions for the economic optimization objective function and the environment and fairness optimization objective function, respectively.

\section{Data Simulation for Lake Tai of China}

We conduct a simulation using data from the Tai Lake tributary in the Jiangsu Wujin area to test the theoretical model in Section 3. Tai Lake is China's third-largest freshwater lake, with a water area of 2338 square kilometers. It is located in the center of the Tai Lake Valley and is the major water source in the valley. Because Tai Lake is one of the three largest freshwater lakes in China, since the blue-green algae outbreak in 2007 the Tai Lake valley has become the key valley for China's water pollution control.

The area around the Tai Lake Valley is in the Wujin district, which is south of Jiangsu province. Since the 1980s, the economy in Wujin has developed rapidly. Printing, dyeing, and brewing have become the pillar industries. Because the core industries in the area are also the major sources of pollution of Tai Lake, we chose corporate data in Wujin to conduct the simulation for the model. A map of Tai Lake and the location of the selected companies is in Figure 1.

To investigate the industrial preferences and the impact of geographic location on primary emission distribution rights, we choose six typical enterprises in Wujin as examples. Summary statistics are shown in Table 2. Agents labeled A-D denote the types of companies we have classified in Table 1 based on enterprise scale and waste treatment ability. Agents E and F are the comparatives introduced into the investigation for A with respect to geographic location and industry (agents A and $\mathrm{E}$ are similar companies in the same industry but one is located the upstream of the river and one downstream; agents $\mathrm{A}$ and $\mathrm{F}$ are of the same economic scale and are located similarly but belong to different industries), respectively.

Table 2 shows the six companies selected as simulation agents from the printing, dyeing, and brewing industries. According to the "Study on price systems for compensated use of water pollution 
emission rights in Tai Lake valley", printing, dyeing, and brewing are major industries for COD emissions and therefore require special attention (Zhang [30], Yao [31]). Because the unit emissions of the brewing industry are low, we assume the preferred coefficient $\alpha$ in the printing and dyeing industry. The textile industry is 1.0 and the preferred coefficient $\alpha$ in the brewing industry is 1.2, because the pollution from the brewing industry is lower. The geographic location coefficient can be obtained from the balance between the COD river discharge amount and the COD emissions.

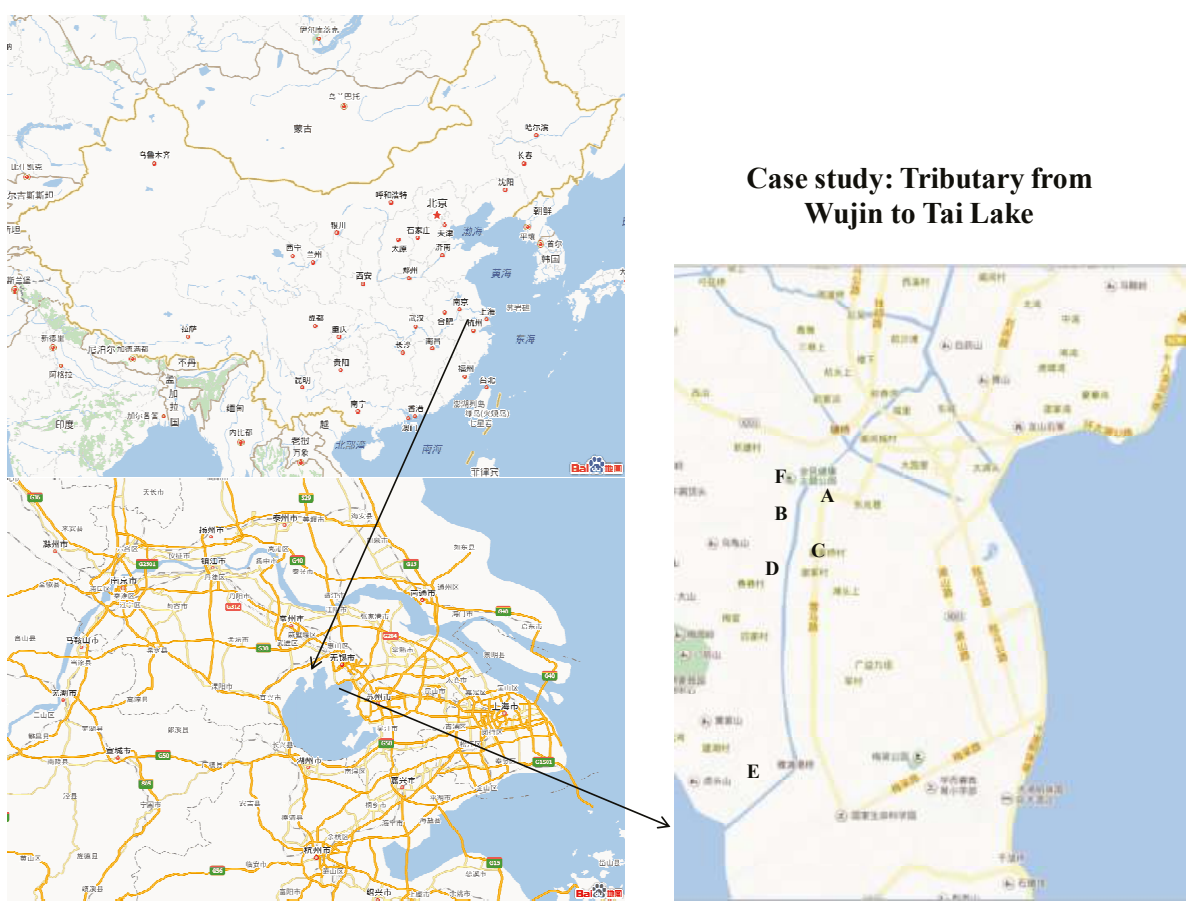

Figure 1. Agent location map. Date Source: ditu.baidu.com.

Table 2. COD production and to the river

\begin{tabular}{|c|c|c|c|c|}
\hline $\begin{array}{l}\text { Agent } \\
\text { Code }\end{array}$ & Company Name & $\begin{array}{l}\text { COD } \\
\text { Produced } \\
\text { (Ton) }\end{array}$ & $\begin{array}{l}\text { COD Emission } \\
\text { (Ton) }\end{array}$ & $\begin{array}{l}\text { COD To the } \\
\text { River (Ton) }\end{array}$ \\
\hline $\mathrm{A}$ & PINYTEX & 917.54 & 917.54 & 357.84 \\
\hline B & $\begin{array}{l}\text { Wuxi Liansheng Dyeing and } \\
\text { Printing }\end{array}$ & 1066.92 & 71.04 & 27.71 \\
\hline $\mathrm{C}$ & Changzhou Jinghua Dyeing & 220.96 & 19.64 & 7.66 \\
\hline $\mathrm{D}$ & Changzhou Jiada Dyeing & 165.35 & 165.35 & 64.49 \\
\hline E & Jiangsu Huasheng & 286.05 & 33.21 & 33.21 \\
\hline $\mathrm{F}$ & Snowbeer Wuxi & 1016.70 & 50.80 & 19.81 \\
\hline
\end{tabular}

Because the COD of the river is detected at the lake cross section of the river, it can be easily seen from Table 2 that, with the exception of the COD river discharge amount of agent $\mathrm{E}$, which is equal to the emission amount, the other companies' COD river discharge amount is one-third of the emission amount. We conclude that $\mathrm{E}$ is a downstream agent and the other companies are upstream agents and are close to each other. Therefore, this study assumes that $\beta$, the geographic location coefficient of 
agent $\mathrm{E}$, is 0.3 and the geographic location coefficient of the other companies $\beta$ is 0.1 . Additionally, because $\lambda_{i}$, the environment contribution index, is positively correlated with the amount of disposed wastewater, and $\gamma_{i}$, the economic contribution index, positively correlates with the enterprise size, we use the wastewater disposed (company value) for each agent we picked divided by the total value of the selected agent group to represent the $\lambda_{i}\left(\gamma_{i}\right)$ for one agent. The coefficients of the six typical companies are included in Table 3.

Table 3. Coefficient for companies.

\begin{tabular}{llllll}
\hline Agent Code & Company Name & $\alpha$ & $\boldsymbol{\beta}$ & $\gamma$ & $\boldsymbol{\Lambda}$ \\
\hline $\mathrm{A}$ & PINYTEX & 1.0 & 0.1 & 0.25 & 0.001 \\
$\mathrm{~B}$ & Wuxi Liansheng Dyeing and Printing & 1.0 & 0.1 & 0.29 & 0.41 \\
$\mathrm{C}$ & Changzhou Jinghua Dyeing & 1.0 & 0.1 & 0.06 & 0.08 \\
$\mathrm{D}$ & Changzhou Jiada Dyeing & 1.0 & 0.1 & 0.05 & 0.001 \\
$\mathrm{E}$ & Jiangsu Huasheng & 1.0 & 0.3 & 0.08 & 0.10 \\
$\mathrm{~F}$ & Snowbeer Wuxi & 1.2 & 0.1 & 0.28 & 0.40 \\
\hline
\end{tabular}

Based on Zhang's [32] findings of the emission rights in Wujin, the required amount of emission rights for the six companies selected by this study is 353.35 tons. To control the total amount, the regulator set the distribution amount of emission rights at $90 \%$ of the demand amount, which is $\mathrm{E}=318.02$ tons. Assuming that the discharges are homogenous, the earnings function based on pollutant emissions is likely similar. Assuming that the enterprise utility function is $f\left(x_{i}\right)=A x_{i}^{k}+C$, among which $\mathrm{A}$ and $\mathrm{C}$ are constants and $0<\mathrm{k} \leqslant 1$, the COD and revenue of the six companies are shown in Table 4.

Table 4. COD production and company revenue. ${ }^{1}$

\begin{tabular}{llll}
\hline $\begin{array}{l}\text { Agent } \\
\text { Code }\end{array}$ & Company Name & COD Produced (Ton) & $\begin{array}{l}\text { Revenue (Million } \\
\text { RMB) }\end{array}$ \\
\hline A & PINYTEX & 917.54 & 121 \\
B & Wuxi Liansheng Dyeing and & 1066.92 & 132 \\
C & Printing & 220.96 & 50 \\
D & Changzhou Jinghua Dyeing & 165.35 & 30 \\
E & Changzhou Jiada Dyeing & 286.05 & 80 \\
F & Jiangsu Huasheng & 1016.70 & 211 \\
\hline
\end{tabular}

${ }^{1}$ Revenue data from: http://company.ch.gongchang.com/.

According to the COD volume and the companies' revenues, we use SPSS software for fitting and obtain the earnings function for the selected companies selected as follows: $f\left(x_{i}\right)=72.1 x^{0.778}$. Here, Equation (8) shows the optimal economic objective of the area. For the same area, under the condition of economic optimization, Equation (9) only addresses the water quality at the lake section, the local environment, and the fairness optimization.

When we look for an optimal solution to the multi-goal planning model, we adopt an objective planning model and give the same weight to the two objective functions. As a result, solving the multi-objective model is transformed into solving the single-objective model of Equation (10). This study adopts Lingo11 to seek the optimal solution for the multi-objective model, and the results are shown in Table 5. 
Table 5. Primary pollution rights allocation.

\begin{tabular}{llll}
\hline $\begin{array}{l}\text { Agent } \\
\text { Code }\end{array}$ & Company Name & $\begin{array}{l}\text { Initial Pollution Rights } \\
\text { Allocated (Ton) }\end{array}$ & $\begin{array}{l}\text { Initial Pollution } \\
\text { Rights Demand (Ton) }\end{array}$ \\
\hline A & PINYTEX & 6.61 & 303.64 \\
B & Wuxi Liansheng Dyeing and & 163.6117 & 1.76 \\
C & Printing & 0.83 & -3.84 \\
D & Changzhou Jinghua Dyeing & 0.01 & 45.35 \\
E & Changzhou Jiada Dyeing & 0.02 & 22.19 \\
F & Jiangsu Huasheng & 146.94 & -16.19 \\
\hline
\end{tabular}

In Table 5, row three describes the initial pollution rights allocated to different agents by the model simulation, and row four describes the requirements for each agent based on Zhang's [32] findings for the six agents' initial pollution rights demands, which follows the basic government requirement-fixed total amount of pollution, and maximizing the total economic gain. The simulation result shows that the distribution amount of emission rights of agent $\mathrm{A}$ is extremely low; it needs to buy emission rights or improve its technology to meet pollution discharge requirements. The agent type A represented is a to-be-improved company that has large-scale production and poor pollution treatment technology; the new design would conform to the political expectation that large-scale manufacturers with poor technology can take the initiative to reduce emissions through emission-rights distribution. In other words, the actual cost for agent A's production, including its environmental cost, was finally accurately discovered. At the same time, as a leading large-scale enterprise with high pollution treatment technology, agent B can create economic value and make a contribution by refusing special treatment as a star enterprise for its emission-rights distribution. This is consistent with the actual situation in the pilot areas. As an innovative and developing company in the industry, agent $C$ is under little pressure for emission rights and will be encouraged to expand its production scale. Agent $\mathrm{D}$ is a small-scale workshop with poor technology and will be severely restricted under the emission-rights distribution pattern. This type of enterprise will be eliminated as a result of the anti-discrimination of initial pollution right distribution.

As a downstream manufacturer that is similar to agent $\mathrm{A}$, agent $\mathrm{E}^{\prime}$ s pollutant level in the control section is the most severe, and it will be discriminated against in the emission-rights distribution. This type of prejudice will force those manufacturers that discharge growing amounts of pollutants and that are located in special locations to finally take action, such as by moving away from the lake cross section. In the end, as the type of industry preferred by the government and the one that could most effectively contribute to the economy and environment at the same time, agent $\mathrm{F}$ will receive the most distribution rights. The simulation confirms that the emission-rights distribution and trading in the market based on both the manufacturer's geographic location and the government's preference can help facilitate industrial structure optimization toward the local regulator's preference.

\section{Conclusions}

The diffusion feature of water means that geographic location is an important factor when considering the distribution rights of any valley-type pollution emissions, especially for areas of major pollution focus such as lakes. Thus, a primary pollution rights decision that combined a company's geographic location differences with the consideration of industry differences could help China's central government and local public administrators to strike a balance between economic development, industrial transformation, and environmental protection to achieve sustainable development. In terms of the market's primary distribution of emission rights, this study establishes a multi-goal and non-linear planning distribution model for lake-water pollution by introducing geographic location, industrial preference, and anti-discrimination of initial pollution right distribution. 
Based on the simulation, which uses data from typical corporate agents of the Tai Lake basin in Wujin, we can see that in terms of the primary emission distribution pattern, manufacturers who have advanced wastewater treatment technology, a favorable geographic location, and high levels of production technology in the industry can win the recognition of distributors. Meanwhile, the results of the emission-rights distribution of manufacturer's wastewater could be more reasonable after giving consideration to factors such as industrial differences and geographic locations. A reasonable primary distribution would also benefit trading in the secondary market and the sustainable utilization of water resources in the areas concerned.

It should also be noted that the distribution of emission rights is just a step towards establishing an emission trade market. Reasonable primary rights distribution can help to effectively distinguish key polluters, which is valuable because it helps the administration to achieve the unified deployment of the local industry and water pollution control. After the primary distribution of emission rights is determined, it is necessary to establish various prices for different pollutants based on the treatment costs. To determine the price in the primary market and conduct effective supervision of the following emission rights, there must be supervision of the trading market to ensure successful trading implementation. In this way, we can ensure that the emission rights trading mechanism can effectively control pollutant emissions.

Acknowledgments: Acknowledgments: This research was funded by the China Social Science Fund (fund number 15CJL048) and Jiangsu Social Science Fund (fund number 13GLB004). We want to thank $\mathrm{Xu} \mathrm{Xu}$ and Markum Reed from the School of Economics and Management, Southeast University for their delightful suggestions and comments on an early version of this paper. Special thanks go to Markum Reed for the language polishing of this final version. We also want to thank three of our anonymous reviewers and our external editors for their useful suggestions during the review process. All remaining errors are ours.

Author Contributions: Author Contributions: Zhengning Pu came up with the original idea for this article; Zhengning Pu and Hui Wang co-designed the theoretical model; Hui Wang collected the data and ran the simulation for the research; Haili Bian helped do the literature review for the article; Zhengning Pu and Jiasha Fu wrote the paper. All authors read and approved this version.

Conflicts of Interest: Conflicts of Interest: The authors declare that they have no conflict of interest.

\section{References}

1. Persson, T.A.; Azar, C.; Lindgren, K. Allocation of $\mathrm{CO}_{2}$ emission permits-Economic incentives for emission reductions in developing countries. Energy Policy 2006, 34, 1889-1899. [CrossRef]

2. Liao, Z.; Zhu, X.; Shi, J. Case study on initial allocation of Shanghai carbon emission trading based on Shapley value. J. Clean. Prod. 2014, 103, 338-344. [CrossRef]

3. Zhang, X. The overall assessment of China's environmental policies. Soc. Sci. China 1999, 3, 88-99.

4. Xia, D.; Sun, R.; Ren, Y. Study on evolutionary stable strategy of government and enterprise in emission right pricing. Technol. Econ. 2010, 29, 23-27.

5. Zhao, W. Pricing of Initial Emission Permits. Ph.D. Thesis, Jilin University, Changchun, China, 2013.

6. Dales, J.H. Pollution, Property and Prices; University of Toronto Press: Toronto, ON, Canada, 1968.

7. Brady, G.L.; Morrison, R.E. Emissions trading: An overview of the EPA policy statement. Int. J. Environ. Stud. 1984, 23, 19-40. [CrossRef]

8. Brill, E.D.; Eheart, J.W.; Kshirsagar, S.R.; Lence, B.J. Water quality impacts of biochemical oxygen demand under transferable discharge permit programs. Water Resour. Res. 1984, 20, 445-455. [CrossRef]

9. Tietenberg, T.H. Emissions Trading: An Exercise in Reforming Pollution Policy; Resources for the Future: Washington, DC, USA, 1985.

10. Montgomery, W.D. Markets in licenses and efficient pollution control programs. J. Econ. Theory 1972, 5, 395-418. [CrossRef]

11. O'Neill, W.B. Pollution Permits and Markets for Water Quality. Ph.D. Thesis, University of Wisconsin, Madison, WI, USA, 1980.

12. Rose, A.; Stevens, B. The efficiency and equity of marketable permits for $\mathrm{CO}_{2}$ emissions. Resour. Energy Econ. 1993, 15, 117-146. [CrossRef] 
13. Beckerman, W.; Pasek, J. The equitable international allocation of tradable carbon emission permits. Glob. Environ. Change 1995, 5, 405-413. [CrossRef]

14. Park, J.; Kim, C.U.; Isard, W. Permit allocation in emissions trading using the Boltzmann distribution. Physica A 2012, 20, 4883-4890. [CrossRef]

15. Ahn, J. Assessment of initial emission allowance allocation methods in the Korean electricity market. Energy Econ. 2014, 43, 244-255. [CrossRef]

16. Li, S.; Huang, T. Free allocation mechanism of initial emissions permits in the condition of transaction cost. Syst. Eng. Theory Method. Appl. 2006, 15, 318-322.

17. Li, S.; Huang, T. Allocation model of initial emission permits in the condition of economy optimization and fair principles. Syst. Eng. Theory Method. Appl. 2004, 3, 282-285.

18. Li, S.; Huang, T. A Multi-Objectives Decision Model of Initial Emission Permits Allocation. Chin. J. Manag. Sci. 2003, 11, 40-44.

19. Wan, S.; Li, S.; Ma, L. The initial allocation of emission permits in river basins. J. Syst. Manag. 2013, 2, 278-281.

20. Shang, J. Application of dynamic planning in river primary blowdowon right allocation. Water Resour. Hydropower Northeast China 2006, 24, 9-10.

21. Zhou, N.; Ji, C. Research on Initial allocation model for regional water right. Water Resour. Power 2007, 3, 6-8.

22. Pang, A.; Li, C.; Sun, T.; Yang, Z. An improved ET control method to determine the water-saving potential for farmland in Baiyangdian Watershed, China. Front. Earth Sci. 2013, 7, 151-158. [CrossRef]

23. Zhou, H.; Huang, X. Research on Fee Allocation and Transaction Price of Taihu Basin COD Emission Based on the emission Performance: Taking Zhangjiagang City Printing and Dyeing Industry for Example. In Proceedings of the Conference for Lake Tai Governance; 2004. Available online: http:/ / cpfd.cnki.com.cn/Article/CPFDTOTAL-ZGSL200412002084.htm (accessed on 10 December 2015).

24. Huang, X.; Shao, D.; Gu, W. Multi-objective optimal allocation model of river emission rights. J. Hydraul. Eng. 2008, 39, 73-78.

25. Li, D. Research on Trading Technology of Water Pollution Discharge Permits for Small Watershed Based on Multi-Objective Optimization Theory. Master's Thesis, Zhejiang University, Hangzhou, China, 2010.

26. Xiao, J.; Luo, Y.; Zhao, Y.; Yue, C. Game analysis on selling initial permits by auction. J. Huazhong Univ. Sci. Technol. 2001, 9, 37-39.

27. Sun, T.; Zhang, H.; Wang, Y. The application of information entropy in basin level water waste permits allocation in China. Resour. Conserv. Recycl. 2013, 70, 50-54. [CrossRef]

28. Cui, Z.; Meng, W.; Liu, J. Pricing model of pollutant emission for small-and-medium-size enterprises under centralized pollution control mode. Ind. Eng. J. 2011, 14, 28-32.

29. Zhang, P.; Zhang, X.; Yu, L. The study on stepped pricing for paid use of emission permits: Taking COD for example. Ecol. Econ. 2012, 8, 60-62.

30. Zhang, S.; Xu, P.; Lu, Y.; Li, Y. Superficial view of cost accounting of pollution control base on emission right transaction price. Environ. Pollut. Control 2010, 7, 96-99.

31. Yao, E.; Rao, Y.; Li, Z. Costing studies of emission rights based on the replacement cost method-A case study of Shenyang COD emissions. J. Liaoning Norm. Univ. 2013, 35, 557-562.

32. Zhang, Y. Research on the Design of Watershed-Based Water Pollution Trading Policy and its Water Environmental Quality Impacts-A Case Study in Tai Lake Basin. Ph.D. Thesis, Nanjing University, Nanjing, China, 2012. 


\title{
Location Planning Problem of Service Centers for Sustainable Home Healthcare: Evidence from the Empirical Analysis of Shanghai
}

\author{
Gang $\mathrm{Du}^{1}$ and Chuanwang Sun ${ }^{2,3, *}$ \\ 1 Department of Business Management, School of Business Administration, Faculty of Economics and \\ Management, East China Normal University, Shanghai 200062, China; gdu@dbm.ecnu.edu.cn \\ 2 Collaborative Innovation Center for Energy Economics and Energy Policy, China Institute for Studies in \\ Energy Policy, School of Economics, Xiamen University, Xiamen 361005, China \\ 3 Department of Economics, College of Arts \& Sciences, Cornell University, Ithaca, NY 14850, USA \\ * Correspondence: scw@xmu.edu.cn; Tel.: +86-59-2218-6076; Fax: +86-59-2218-6075
}

Academic Editors: Yongrok Choi, Malin Song and Seunghwan Myeong

Received: 4 October 2015; Accepted: 23 November 2015; Published: 27 November 2015

\begin{abstract}
It is of theoretical and practical significance to understand what factors influence the sustainable development of home healthcare services in China. Based on a face-to-face survey, we find that the location planning, which is decisive for the improvement of patient satisfaction, can effectively reduce the risks, as well as the costs of redundant construction and re-construction of service centers for home healthcare and, thus, helps ensure the sustainability of health and the environment. The purposes of this paper are to investigate the existing problem of home healthcare in Shanghai and to find the optimum location planning scheme under several realistic constraints. By considering differentiated services provided by the medical staff at different levels and the degrees of patient satisfaction, a mixed integer programming model is built to minimize the total medical cost. The IBM ILOGCPLEX is used to solve the above model. Finally, a case study of Putuo district in Shanghai is conducted to validate the proposed model and methodology. Results indicate that the model used in this paper can effectively reduce the total medical cost and enhance the medical sustainability, and therefore, the results of the model can be used as a reference for decision makers on the location planning problem of home healthcare services in China.
\end{abstract}

Keywords: location planning problem; home healthcare; mixed integer programming; sustainability

\section{Introduction}

The problems of medical resource shortages and an aging population have become increasingly prominent in China. The number of elderly people aged over 60 years in China is more than 200 million, accounting for $14.9 \%$ of the total population in China [1]. This figure was significantly higher than the traditional aging society standard (10\%) set by the United Nations. In particular, about $80 \% \sim 90 \%$ of old people suffered from various chronic diseases and faced the corresponding pressures from home healthcare problems. According to the forecasting from the National Aging Committee of China, in the next 20 years, China would enter the period of its aging peak, and the old population (According to the China Report of the Development on Aging Cause 2013, the population aged 60 and over is counted as the old population. This statistical principle is based on the regulations on retirement age. In China, men currently can retire at the age of 60 years, while women who work in factories can retire as early as 50 years old. Additionally, women who work in public sectors can retire at the age of 55 . Therefore, people aged 60 and over are regarded as the elderly.) is expected to increase at a sustained amount of 10 million per annum. In a word, the problem of "getting old before getting rich" has become more severe in China [2]. 
As a new mode of health services, home healthcare service is more efficient, flexible and convenient, which can effectively alleviate the problem of medical resource shortages. Especially, it can reduce the medical cost and improve the service quality at the same time [3,4]. "Home healthcare" can be defined as home-visiting medical services provided by general practitioner service teams based on online and/or phone-call reservation systems. The patients include the elderly population (people aged 60 and over), families that have lost their only child, the disabled and other special populations. In developed countries, such as European countries (especially France), Australia and Canada [5], home healthcare has played an increasingly important role in the healthcare systems. In recent years, some healthcare services in the U.S. have been transferred from hospitals to patient's homes [6]. Additionally, the demand for home healthcare services has shown an increasing trend in many developed countries over the years. The market for home healthcare in the U.S. exceeded $\$ 7.7$ billion in 2012 [7]. The development of home healthcare in developed countries has proven that it is conducive to alleviating medical resource imbalances, reducing the costs of healthcare systems, increasing the life quality of patients and improving the degree of patient satisfaction [8].

In order to cope with the medical problems resulting from an aging population, the Chinese government has paid more attention to the promotion of home healthcare services in recent years. Take Shanghai as an example. In order to explore the service mode of "developing community health services provided by healthcare teams dominated by general practitioners" (in the medical profession, a general practitioner (GP) is a medical doctor who treats acute and chronic illnesses and provides preventive care and health education to patients), 11 pilots of community health centers have been set up in Changning, Putuo and other districts in Shanghai since 2003. As of 2014, the system of family doctors or nurse practitioners was established for all community health centers in Shanghai, and about $1 / 6$ of the residents signed home care nursing service contracts with family doctors.

As China's most populous city, Shanghai is facing a serious challenge of aging population. Therefore, the investigation of Shanghai on the barriers, as well as decisive factors of the development of home healthcare services can be a good reference for other regions in China. Based on this concern, we conducted a face-to-face survey in several districts in Shanghai to explore the influencing factors of the development of home healthcare services. The results indicate that the location of service centers for home healthcare is decisive for the improvement of patient satisfaction, which is of paramount importance for medical service providers. However, although many scholars have conducted research on the determinants of patient satisfaction [9], there is no agreed definition of the concept of patient satisfaction, because satisfaction is multi-dimensional $[10,11]$. According to the results from the face-to-face survey in China [12], there are four indexes for measuring patient satisfaction in home healthcare: first, response time; second, patient wait time; third, service quality; fourth, service price. In general, response time is affected by factors, such as the level of convenience in contacting, as well as the number of medical staff. Patient wait time, a quality indicator of home healthcare services, is influenced by location planning of service centers for home healthcare, as well as the scheduling and dispatching of medical staff. Service quality in home healthcare is affected by the levels of healthcare workers and the degree of advancement of medical equipment. Service price is influenced by the pricing scheme or the price specifications regulated by the government. Particularly, the inappropriate location of service centers for home healthcare, which is a decisive factor influencing whether medical staff are able to provide timely and convenient services for patients, is the major determinant of patient satisfaction. Therefore, the location planning problem of service centers for home healthcare becomes particularly important.

The contributions of this study are summarized as follows: (1) we investigate the current situation of home healthcare in Shanghai, so as to explore the influencing factors of the development of home healthcare services, which can provide a valuable reference for the location planning of service centers for home healthcare in other regions in China; (2) we propose a location planning model that considers the actual constraints and then conduct a sensitivity analysis to optimize the current layout of the service centers for home health to a certain extent; (3) based on the empirical analysis of Shanghai, 
we provide some policy implications for the decision makers to build an effective location plan and promote the sustainable development of China's home healthcare.

The rest of this paper will be organized as follows. A concise literature review is presented in Section 2. Section 3 discusses the data collection and presentation. Section 4 constructs the location optimization model. Section 5 provides the empirical analysis and relevant results in this study. Finally, the conclusion will be given in Section 6 .

\section{Literature Review}

Many scholars have conducted research on the application of home healthcare [13-15]. In addition, in recent years, the sustainability of healthcare has also attracted increasing attention from researchers and policy makers [16-18].

The location planning problem is a classical problem in the field of operations research. In other words, the solution to the problem aims to maximally meet the resource demand by a given number of facilities. Specifically, the intermediate value problem, the maximal covering location problem and the center problem are the three classical models of the location problem. The solution to the intermediate value problem, which could provide the shortest distances from service requiring places to the destinations, was posed by Hakimi in 1964 [19]. The covering location problem can be divided into the maximal covering location problem and the set covering location problem. Church and ReVelle [20] posed the maximal covering location problem by restricting the optimal location sites of the service centers to the network nodes. The set covering location problem was first posed by Roth [21], who resolved the location problem of fire centers, the optimal ambulance location and other emergency service facilities. Different from the set covering the location problem, the center problem is the minimax problem, which calculates the minimax distance from any service requiring places to the nearest facilities under the constraint of a fixed number of facilities.

As of now, much research has been done to solve the location problem in the medical field. In order to optimize the location of hospitals, Liu and Li [22] built a Pareto multi-objective generic algorithm location model. Diao and Jiang [23] not only introduced factors, such as customer preference and traffic weight, but also simulated the monthly number of hospital visits using the Monte Carlo method. Vahidnia et al. [24] utilized a fuzzy analytic hierarchy process to optimize the hospital location by combining a geographic information system (GIS). Soltani and Marandi [25] studied the potential location for hospitals based on fuzzy multiple criteria decision making (MCDM). Varnakovida and Messina [26] performed an empirical analysis for the location of community hospitals in Michigan, U.S. Kim et al. [27] adopt branch and bound algorithms to determine the location for long-term care facilities. Toregas et al. [28] presented the emergency facilities as a set covering problem and solved this problem using linear programming. To optimize the location approaches, the problems of location and capability deployment were also considered by Cong et al. [29] in the study of the network location problem of home healthcare centers under a certain demand.

Research on the problem of the location planning of service centers for home healthcare is still relatively scarce [30-32]. Compared to the traditional healthcare service, home healthcare is special considering that the medical staff needs to offer visiting services, and patient satisfaction drops with longer waiting time [33-36]. However, if the waiting time exceeds the acceptable and tolerable limit, there would be an exponential plummet in patient satisfaction, and patient satisfaction could even drop to zero when patients terminate a service request for home healthcare and choose other kinds of medical services [12]. Meanwhile, the number of medical staff of different levels also has an impact on the capabilities of each service center. Based on the above analysis, this paper tries to build a location model of service centers for home healthcare to reduce medical cost and improve medical efficiency.

In this paper, two versions of questionnaires (questionnaires for individuals and medical staff) are designed to investigate the current situation and problems of home healthcare in Shanghai. The results indicate that unreasonable location planning is a crucial factor for patient dissatisfaction. Therefore, we build a mixed integer programming model that considers various actual constraints. In order to 
validate the effectiveness of the proposed model and methodology, we conduct a case study of Putuo district in Shanghai and the sensitivity analysis of the proposed optimization model. Results indicate that the proposed model can provide a reference for decision makers to solve the location planning problem of service centers for home healthcare, so as to improve the efficiency, as well as the levels of home healthcare services in China.

\section{Data Collection and Presentation}

\subsection{Variables and Data Collection}

According to the data from the Chinese Health and Family Planning Statistical Yearbook [37], we can see that the number of patients visiting community health centers increased greatly during 2003-2012, while the number of patients visiting hospitals and other medical institutions decreased correspondingly (See Figure 1). Specifically, the number of patients visiting hospitals dropped from 143.34 thousand persons in 2003 to 62.89 thousand persons in 2012, and the average annual decrease rate was $7 \%$. Comparatively, the number of patients visiting community health centers increased from 564.84 thousand persons in 2003 to 1155.17 thousand persons in 2012, which was equivalent to a growth of $104.5 \%$.

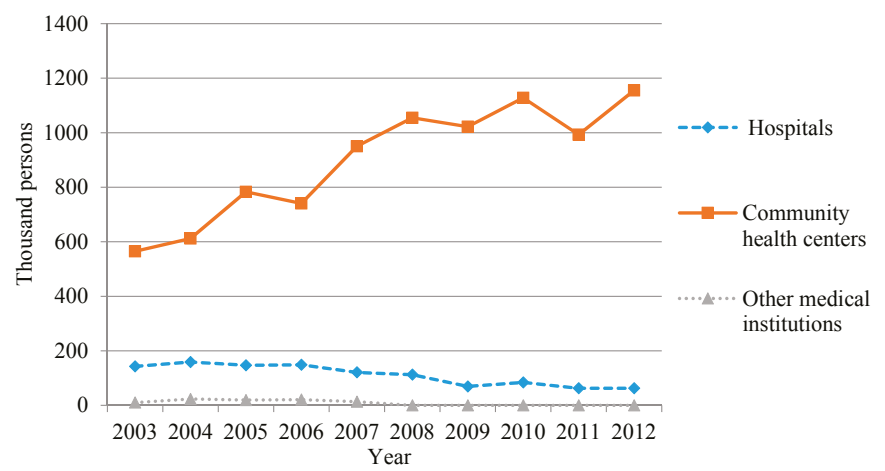

Figure 1. Number of patients visiting different types of medical institutions in Shanghai. Data source: Chinese Health and Family Planning Statistical Yearbook [37].

In order to do further research on home healthcare services, we conducted an in-depth survey on the major challenges, as well as obstacles for the sustainable development of home healthcare in Shanghai, China. Variables and data of the following part used in this paper are based on the face-to-face survey. The survey was launched by the Business School of East China Normal University in the first half of 2015. We designed two kinds of questionnaires: questionnaires for medical staff and questionnaires for individuals. Medical staff include doctors, nurses and administrative staff of hospitals. Individuals are mainly residents in Shanghai. The respondents (individuals) in our survey include patients in the hospitals, patients in the community health centers, home care patients and households in communities in various districts in Shanghai. Therefore, individuals in this paper refer to the broader community. Much effort has been made to improve the design of the questionnaires. For instance, we gathered advice from medical staff in relative departments of hospitals to improve the questionnaire design and to ensure the scientificity and effectiveness of the questionnaires. In addition, in order to guarantee the validity of the survey, we adjusted and amended the questionnaires several times after interviewing administrative staff and staff members of home health centers. Especially, aiming at redesigning and improving the quality of the survey, the pre-test survey were conducted twice to identify problems related to questionnaire design. It is important to test the effectiveness of the survey questionnaire before actually using it to collect data. In other words, pretesting and piloting 
help identify questions that do not make any sense to participants or problems that might lead to biased answers.

We experienced several problems related to the question and questionnaire design during the pre-test of the questionnaire. For example, some respondents could not completely and accurately fill out the forms because of the unclear classification of hospitals in the previous questionnaire. Generally, hospitals in China are organized according to a three-tier system, and hospitals are designated as primary, secondary or tertiary institutions. Therefore, in the pre-test questionnaire, we only provided the above three options for respondents to choose. However, hospitals in different districts in Shanghai have a more detailed subdivision, and therefore, the related questions and answer options for survey questions should be designed more precisely. Another problem is that the demographics of families, including nuptiality, family structure, living arrangements, and so on, are diversified and complicated, and the answer options for survey questions in the previous questionnaire cannot fully cover the various situations. Other problems include: (1) some respondents are still unfamiliar with the definition, as well as the scope of home healthcare services; (2) some respondents have never used home healthcare services, the answers of whom might influence the effectiveness of the questionnaires; (3) some respondents cannot give accurate answers to questions due to the lack of medical knowledge. Therefore, in order to obtain more accurate answers, on the one hand, we revised and improved the design of specific questions; on the other hand, we trained the investigators to provide more detailed explanations to respondents on several questions during the actual face-to-face survey.

Questionnaires for individuals are designed to investigate the expectations and the degrees of urgency of demand for home healthcare of households at different ages, with different income levels and living situations. The urgency of home healthcare in our survey is measured by the degree of urgency of demand in home healthcare services at different ages. In general, we could expect that there would be more people requiring home healthcare in China, and the degree of urgency of demand for home healthcare services would increase with age. First, there would be more people suffering from chronic illnesses or physical disabilities due to the aging population. Second, the number of frail elderly people would rise due to a higher life expectancy. Third, specific healthcare conditions, such as recovering from surgery or acute illnesses, often need consistent and further medical treatment at home. Based on the above analysis, we set the specific question in the questionnaire as follows:

Would you please describe the degree of urgency of demand for home healthcare services?

A. I am in urgent need.

B. I am in need of home healthcare, but it is not urgent.

C. I do not need them.

The top three reasons for respondents who are in urgent need of home healthcare are summarized as follows: (1) the respondent is a chronic disease patient or physically-disabled patient; (2) the respondent cannot stand the long waiting times, as well as the high-cost health expenses for receiving treatment at hospitals; (3) the respondent prefers to receive medical treatment at home because he/she is unsatisfied with the treatment environment of hospitals.

Questionnaires for staff in hospitals mainly focus on their attitudes towards home healthcare services and their expectations of possible medical-supporting funds, facilities and payment for medical staff.

The data processing and expected objectives of the questionnaires on home healthcare (overview) are as follows:

\section{Questionnaires for individuals:}

(1) Demands for home healthcare among different groups (indexes of analysis: age, income level, living conditions, etc.).

(2) Understanding levels of the system of family doctors or nurse practitioners among different groups (indexes of analysis: age, educational level, etc.). 
(3) The degrees of familiarity with healthcare institutions around the accommodations or work places among different groups (indexes of analysis: age, income level, etc.).

(4) The degrees of familiarity with commercial health insurance or medical insurance among different groups (results from the survey on commercial insurance are used for comparison).

2. Questionnaires for staff working in hospitals:

(1) The attitudes of doctors and nurses toward home healthcare services.

(2) The current or expected ways of providing home health services by hospitals.

(3) The expected facilities and possible medical-supporting funds provided by hospitals for home healthcare services.

The survey is aimed at not only learning about the general situation of home healthcare in Shanghai city, but also analyzing the influencing factors of the sustainable development of home healthcare at the micro-level. Considering that there is a large number of health centers in Shanghai, we only selected a few representative districts (Putuo, Xuhui, Minghang, Changning, etc.) for our investigation (see Figure 2). The most prestigious medical centers in Shanghai, including Shanghai Sixth People's Hospital, Shanghai Putuo District Central Hospital, Shanghai Minhang District Central Hospital and several hospitals in the Caoyang district, are investigated in our survey. In addition, we conducted an in-depth study on home healthcare by doing face-to-face interviews with doctors, nurses and administrative staff in the above-mentioned hospitals. The total number of questionnaires is 511, for which the number of valid questionnaires is 493 , and the number of questionnaires for individuals is 319 .

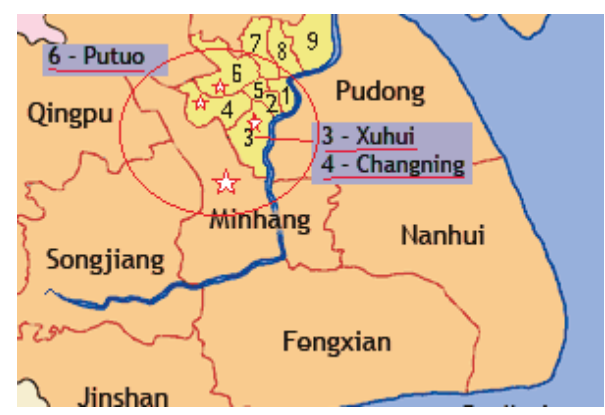

Figure 2. The representative districts of Shanghai for the survey.

\subsection{Data Presentation}

Some investigation results are presented as follows:

Figure 3 shows that $62 \%$ of respondents are in need of home healthcare services, but the need is not urgent; $9 \%$ of respondents are in urgent need of home healthcare services; and $29 \%$ of respondents do not need home healthcare services.

We further investigate the urgency of demand for home healthcare at different ages. As shown in Figure 4, residents aged below 45 showed the lowest demand for home healthcare, for which about 35 percent of respondents do not need home health services. However, the demand for home healthcare services rises gradually with age, and the share of "in urgent need" is the highest for residents aged over 75 (35.5\%).

Further, we investigated the satisfaction degree of respondents who received healthcare services at home. Results show that the overall satisfaction rate is $79.8 \%$. Specifically, the share of high ratings for home healthcare services is $2.5 \%$; the share of middle-high ratings for home healthcare services is $25.8 \%$; and the share of moderate ratings is $51.5 \%$ (see Figure 5 ). 


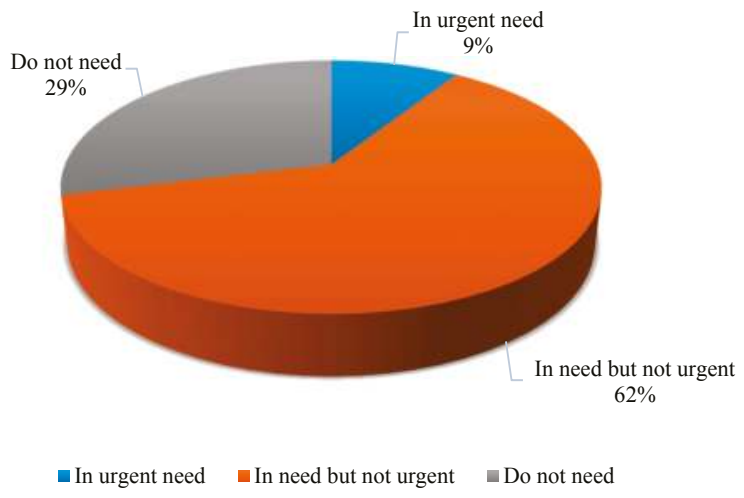

Figure 3. The demand for home healthcare.

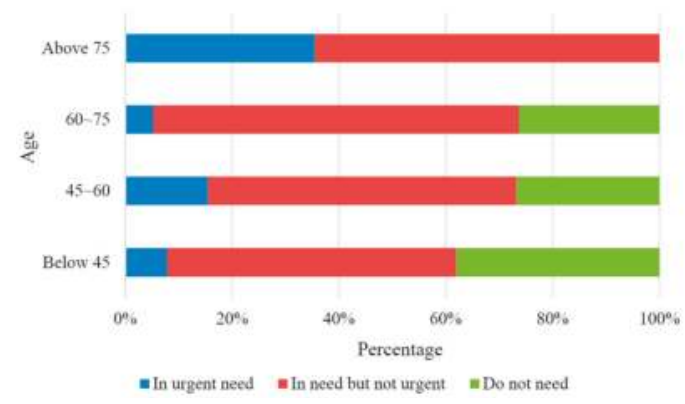

Figure 4. Demands for home healthcare of respondents at different ages.

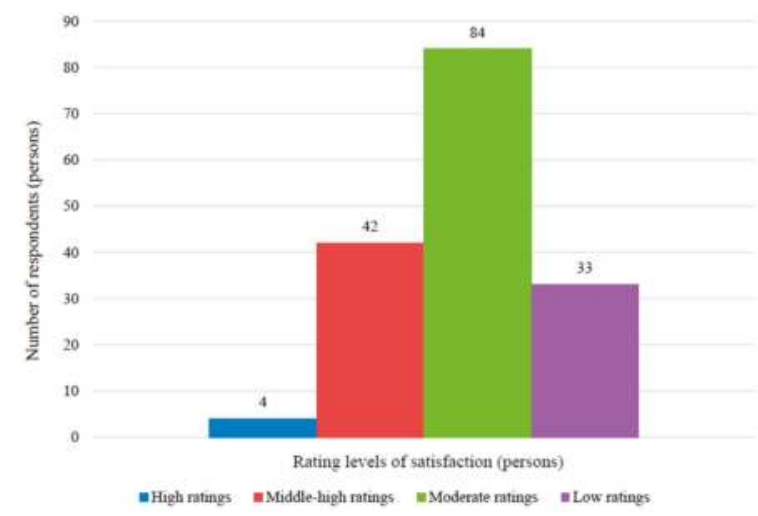

Figure 5. The degrees of satisfaction of respondents on home healthcare services.

We further investigate the reasons behind patient dissatisfaction, and the results are shown in Figure 6: 


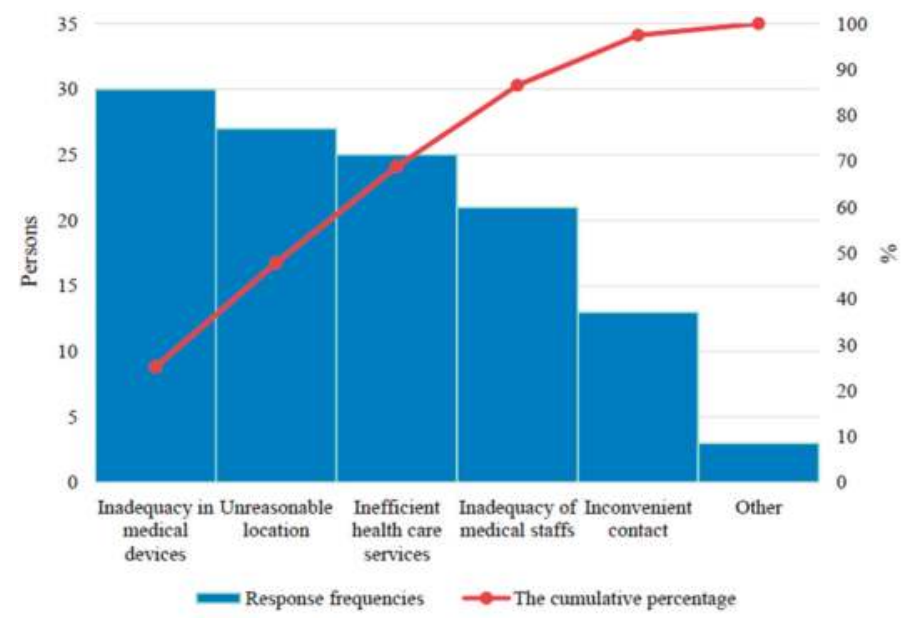

Figure 6. Reasons for not choosing home healthcare services.

As shown in Figure 6, one of the major reasons for patient dissatisfaction is that the requirements of patients cannot be met by medical staff in a timely manner. Additionally, the limited capability of home healthcare services that could not meet patients' expectations is another reason for patient dissatisfaction.

According to the results of the questionnaires, the inappropriate location of service centers for home healthcare was an important obstacle for the further promotion and development of home healthcare in China. In summary, the major reasons for residents who are unwilling to choose home healthcare services are: (1) the inadequacy of the local healthcare infrastructure and medical devices, (2) inefficient healthcare services; (3) the inadequacy of the capabilities of medical staff; (4) inconvenient contact methods. We should note that some of the above problems, such as inefficient healthcare services and inconvenient contact methods, could be addressed through process improvement initiatives, known as Kaizen events (Kaizen means "improvement" in Japanese, and Kaizen events focus on implementing improvements to the process of meeting customer demands) [38]. Therefore, we undertake a root cause analysis to alleviate or even eliminate the above problems.

(1) "The inadequacy in the local healthcare infrastructure and medical devices" is mainly caused by the lack of funding to support home care services. The solutions could be: first, seeking to optimize investments in home healthcare; second, looking for financial assistance to increase medical devices; third, seeking government financial support to the home healthcare industry.

(2) Reasons for "inefficient healthcare services" are as follows: first, there is not enough staff to pick up telephone calls; second, the imperfect customer service response mechanism; third, ineffective communication; fourth, long wait times for health services. Possible solutions could be: first, increasing medical staff; second, optimizing the dispatch and scheduling of healthcare staff; third, creating a reasonable location plan of service centers for home healthcare; fourth, under the constraint of limited medical resources, further optimizing the allocation of medical staff in the aspects of workload assignment and minimizing the traveling time of nurse practitioners.

(3) The main reason for "the inadequacy in the capabilities of medical staff" is that there is not enough medical staff, especially senior doctors and skilled medical staff. Possible solutions could be: first, conducting medical staff training; second, attracting more skilled medical staff to join the home healthcare industry.

(4) The main reason for "inconvenient contact method" is the inadequacy of modern communication services. The problem can be solved by providing better online customer support and online 
reservation services, developing customized telephone booking services, providing reservation services based on mobile application system, etc.

In conclusion, home healthcare services in China still have shortcomings in terms of management and operational efficiency. The delayed or late responses of medical staff to the patients' demands are the major reasons for patient dissatisfaction. Due to this reason, the inefficient services have resulted in the distrust of patients for home healthcare. Therefore, in order to improve the operational efficiency and to achieve the effective allocation of medical resources, it is necessary to build an optimized model to solve the location planning problem of service centers for home healthcare [39].

\section{Construction of the Optimization Model}

This paper focuses on how to resolve the location planning problem of home health centers with the unknown candidate service centers for home healthcare and service-requiring places (considering the constraints of the capabilities of service facilities and differentiated service competencies). The model is based on the following basic assumptions:

(1) The service demands in each phase are certain;

(2) The existing health centers shall not be closed, and the size of the health centers can be expanded in the next phase;

(3) Healthcare services of the existing centers shall not be stopped, and we do not consider the situation of firing employees;

(4) Wages and unit travel cost of medical staff would not change with time.

The model in this paper uses the following subscripts, parameters and variables:

Subscripts:

$i$ represents the $i$-th service center $(i=1, \ldots, I)$;

$j$ represents the $j$-th destination $(j=1, \ldots, J)$;

$k$ represents the $k$-th type of service $(k=1, \ldots, K)$;

$l$ represents the services provided by the $l$-th grade medical staff $(l=1, \ldots, L)$;

$t$ represents the $t$-th time phase $(t=1, \ldots, T)$.

Parameters:

$c_{i}$ represents the investment cost of building the $i$-th service center, which is related to the geographic location;

$c_{k}$ represents the investment cost to open the $k$-th type of service (namely the professional equipment cost), which is related to the service type;

$c_{k}{ }^{\prime}$ represents the hourly wage of the medical staff providing the $k$-th type of service;

$c_{i j}$ represents the transportation cost of providing one service from the $i$-th service center to the $j$-th service-requiring place;

$d_{j k t}$ represents the demand of the $k$-th type of service for the $j$-th service-requiring place in the $t$-th time phase;

$\tau_{k}$ represents the execution time of the $k$-th type of service;

$t_{i j}$ represents the transportation time from the $i$-th service center to the $j$-th service-requiring place (namely response time of demand); therefore, the total time for the $i$-th service center to provide the $k$-th type of service for the $j$-th service-requiring place is $\tau_{\mathrm{k}}+2 \mathrm{t}_{\mathrm{ij}}$;

$\alpha$ represents the time value of money;

$\alpha^{t-1}$ represents the time value coefficient of capital in the $t$-th time phase; the time value of money means a certain amount of currency held at present will have a higher value in the future;

$F_{i}$ represents the maximum size of the $i$-th service center, and it is related to the floor area and other factors of the service center;

$H_{l t}$ represents the maximum number of the $l$-th grade of medical staff in the $t$-th time phase;

$P$ represents the minimum satisfactory rate of the service-requiring place; 
$U_{k}$ represents the maximum response time of the $k$-th type of service (maximum transportation time from service centers to service-requiring places);

$E_{k}$ represents the customer expected response time of the $k$-th type of service.

Decision variables:

$x_{i t}$ is a binary variable and represents whether the $i$-th service center is built in the $t$-th time phase (one: yes; zero: no);

$y_{i k t}$ is a binary variable and represents whether the $k$-th type of service is launched by the $i$-th service center in the $t$-th time phase (one: yes; zero: no);

$n_{i l k t}$ represents the capability to provide the $k$-th type of service by the $l$-th grade of medical staff from the $i$-th service center in the $t$-th time phase;

$z_{i j k t}$ is a binary variable and represents the percentage for the $i$-th service center to meet the demands from the $j$-th service-requiring place while providing the $k$-th type of service in the $t$-th time phase.

The mathematic model is as follows:

$$
\begin{aligned}
& \min \sum_{\mathrm{t}=1}^{\mathrm{T}} \sum_{\mathrm{i}=1}^{\mathrm{I}} \alpha^{\mathrm{t}-1} \mathrm{c}_{\mathrm{i}} \mathrm{x}_{\mathrm{it}}+\sum_{\mathrm{t}=1}^{\mathrm{T}} \sum_{\mathrm{i}=1}^{\mathrm{I}} \sum_{\mathrm{k}=1}^{\mathrm{K}} \alpha^{\mathrm{t}-1} \mathrm{c}_{\mathrm{k}} \mathrm{y}_{\mathrm{ikt}}+ \\
& \sum_{\mathrm{t}=1}^{\mathrm{T}} \sum_{\mathrm{i}=1}^{\mathrm{I}} \sum_{\mathrm{l}=1}^{\mathrm{L}} \sum_{\mathrm{k}=1}^{\mathrm{K}} \mathrm{c}_{\mathrm{k}}{ }^{\prime} \mathrm{n}_{\mathrm{ilkt}}+\sum_{\mathrm{t}=1}^{\mathrm{T}} \sum_{\mathrm{i}=1}^{\mathrm{I}} \sum_{\mathrm{j}=1}^{\mathrm{J}} \sum_{\mathrm{k}=1}^{\mathrm{K}} \mathrm{c}_{\mathrm{ij}} \mathrm{z}_{\mathrm{ijkt}} \mathrm{d}_{\mathrm{jkt}}
\end{aligned}
$$

The constraints are as follows:

$$
\begin{gathered}
\mathrm{y}_{\mathrm{ikt}} \leqslant \mathrm{x}_{\mathrm{it}} \forall i, k, t \\
\mathrm{z}_{\mathrm{ijkt}} \leqslant \mathrm{y}_{\mathrm{ikt}} \forall i, j, k, t \\
\mathrm{n}_{\mathrm{ilkt}} \leqslant \mathrm{y}_{\mathrm{ikt}} \mathrm{M} \forall i, l, k, t \text { (M is the maximal number) } \\
\sum_{\mathrm{l}=1}^{\mathrm{L}} \sum_{\mathrm{k}=1}^{\mathrm{K}} \mathrm{n}_{\mathrm{ilkt}} \leqslant \mathrm{F}_{\mathrm{i}} \forall i, l, k, t \\
\sum_{\mathrm{j}=1}^{\mathrm{J}}\left(\tau_{\mathrm{k}}+2 \mathrm{t}_{\mathrm{ij}}\right) \mathrm{z}_{\mathrm{ijkt}} \mathrm{d}_{\mathrm{jkt}} \leqslant \sum_{\mathrm{l}=1}^{\mathrm{L}} \mathrm{n}_{\mathrm{ilkt}} \forall i, j, l, k, t \\
\sum_{\mathrm{i}=1}^{\mathrm{I}} \sum_{\mathrm{k}=1}^{\mathrm{K}} \mathrm{n}_{\mathrm{ilkt}} \leqslant \mathrm{H}_{\mathrm{lt}} \forall i, l, k, t \\
\mathrm{P} \leqslant \sum_{\mathrm{i}=1}^{\mathrm{I}} \mathrm{z}_{\mathrm{ijkt}} \leqslant 1 \forall i, j, k, t \\
\mathrm{z}_{\mathrm{ijkt}} \leqslant \frac{\mathrm{t}_{\mathrm{ij}}-\mathrm{U}_{\mathrm{k}}}{\mathrm{E}_{k}-\mathrm{U}_{k}} \forall i, j, k, t \\
\mathrm{x}_{\mathrm{i}(\mathrm{t}+1)} \geqslant \mathrm{x}_{\mathrm{it}} \forall i, t \\
\mathrm{y}_{\mathrm{ik}(\mathrm{t}+1)} \geqslant \mathrm{y}_{\mathrm{ikt}} \forall i, k, t \\
\mathrm{x}_{\mathrm{it}}, \mathrm{y}_{\mathrm{ikt}} \in\{0,1\} \forall i, k, t \\
\mathrm{n}_{\mathrm{ilkt}} \geqslant 0 \forall i, l, k, t \\
0 \leqslant \mathrm{z}_{\mathrm{ijkt}} \leqslant 1 \forall i, j, k, t
\end{gathered}
$$

Objective Equation (1) represents the model with the lowest total cost and includes four items. The first item represents the total investment cost of building the service center, while the second item represents the total investment cost of starting the business. Both of the items have considered the 
time value of money. The third item represents the total labor cost of the service center, and the fourth item represents the total transportation cost of providing the service.

Constraint Equation (2) denotes that services can be provided for customers only if the service center has already been built;

Constraints Equations (3) and (4) represent that a particular service can be provided only if the service has been launched by the service center;

Constraint Equation (5) represents that the capacity of the service center cannot exceed its limits;

Constraint Equation (6) represents that the total services provided by each service center shall meet the restrictions of the service capacity of each service center;

Constraint Equation (7) represents that there is a maximum number of medical staff of each grade;

Constraint Equation (8) represents that the demands of each service-requiring place shall be met proportionally;

Constraint Equation (9) represents that the degree of satisfaction will decrease with the increasing waiting times; once the response time of the medical staff has exceeded the expectations of the customers, especially, the healthcare services will become invalid after exceeding the maximum response time;

Constraints Equations (10) and (11) represent that the existing service centers or services cannot be closed or terminated;

Constraints Equations (12)-(14) represent the value range of the variables.

\section{Empirical Analysis}

We take service centers for home healthcare in Putuo district in Shanghai as an example for the empirical analysis in this paper. There are eight sub-districts and two towns in Putuo district, namely the sub-districts of Changshou Road, Yichuan Road, Ganquan Road, Shiquan Road, Changfeng Xincun, Caoyang Xincun, Wanli, Zhenru, as well as the towns of Taopu and Changzhen. The population of this district is about 1.3 million. Calculated from the research data, there are about 0.85 million people in the potential target market of home healthcare. In this paper, we try to verify the effectiveness of the model through the research on the location problem of the home health centers in Putuo district at Shanghai, China. The following numerical calculation is achieved by running IBM ILOGCPLEX Program 12.6 under the Windows 7 operating system.

\subsection{Existing Condition of Service Point Location}

Firstly, we can check whether the existing service centers for home healthcare can meet the requirements of the residents using the location model in this paper. Home healthcare services of Putuo district are mainly provided by the community health centers of Changshou Sub-district, Yichuan Sub-district, Ganquan Sub-district, Shiquan Sub-district, Changfeng, Baiyu, Caoyang, Zhenru Town, Taopu Town and Changzheng Town. Relevant data of these ten main service centers are shown in Table 1.

The opportunity cost for building a community health center can be calculated by the area of a service center multiplied by the rent level in the community. The number of maximum members determines the maximum annual capability of each service center (the number of maximum members $\times$ the annual workload). Taking the current data as the data in the first year, the maximum capacity of the second year will increase proportionally with the increase in the planned area (shown in Table 2).

At present, healthcare services provided by each service center can be classified into "hospital bed at home" and "health record establishment". The former means that patients can receive medical treatment and care in a familiar environment by transferring the treatment places from hospitals to homes, and the latter means that family doctors or nurse practitioners will create and maintain the authoritative records of physical and psychological health for community residents by providing visiting services. Relevant data of these two services and other relevant data are shown in Table 3. 
Table 1. Relevant data of community health centers.

\begin{tabular}{|c|c|c|c|c|c|c|c|}
\hline \multirow{2}{*}{$\begin{array}{l}\text { Community } \\
\text { Health Centers }\end{array}$} & \multirow{2}{*}{$\begin{array}{l}\text { Total Area } \\
\left(\mathrm{m}^{2}\right)\end{array}$} & \multirow{2}{*}{$\begin{array}{c}\text { Planned } \\
\text { Increased Area } \\
\left(\mathrm{m}^{2}\right)\end{array}$} & \multirow{2}{*}{$\begin{array}{l}\text { Nearby Rent } \\
\left(\mathrm{RMB} / \mathrm{m}^{2}\right)\end{array}$} & \multirow{2}{*}{$\begin{array}{l}\text { Max Members of the } \\
\text { Service Center } \\
\text { (Persons) }\end{array}$} & \multicolumn{3}{|c|}{$\begin{array}{l}\text { Total Number of Medical Staff at } \\
\text { Different Levels (Persons) }\end{array}$} \\
\hline & & & & & Primary & Intermediate & Advanced \\
\hline $\begin{array}{c}\text { Changshou } \\
\text { Sub-district }\left(i_{1}\right)\end{array}$ & 1978 & 514 & 3100 & 20 & 8 & 10 & 2 \\
\hline $\begin{array}{c}\text { Yichuan } \\
\text { Sub-district }\left(i_{2}\right)\end{array}$ & 6024 & 489 & 2200 & 40 & 15 & 18 & 7 \\
\hline $\begin{array}{c}\text { Ganquan } \\
\text { Sub-district }\left(i_{3}\right)\end{array}$ & 2236 & 218 & 2200 & 25 & 10 & 12 & 3 \\
\hline $\begin{array}{c}\text { Shiquan } \\
\text { Sub-district }\left(i_{4}\right)\end{array}$ & 2647 & 345 & 2000 & 20 & 6 & 12 & 2 \\
\hline $\begin{array}{c}\text { Changfeng } \\
\text { Community }\left(i_{5}\right)\end{array}$ & 4987 & 678 & 3200 & 35 & 15 & 15 & 5 \\
\hline $\begin{array}{l}\text { Baiyu Community } \\
\qquad\left(i_{6}\right)\end{array}$ & 1616 & 1000 & 3000 & 15 & 8 & 4 & 3 \\
\hline $\begin{array}{c}\text { Caoyang } \\
\text { Community }\left(i_{7}\right)\end{array}$ & 6074 & 845 & 2100 & 50 & 21 & 20 & 9 \\
\hline Zhenru Town $\left(i_{8}\right)$ & 3961 & 987 & 2200 & 30 & 10 & 15 & 5 \\
\hline Taopu Town $\left(i_{9}\right)$ & 6280 & 879 & 1000 & 50 & 18 & 24 & 8 \\
\hline $\begin{array}{l}\text { Changzheng } \\
\text { Town }\left(i_{10}\right)\end{array}$ & 4600 & 678 & 2000 & 35 & 15 & 15 & 5 \\
\hline
\end{tabular}

Table 2. Input data of community health centers.

\begin{tabular}{cccc}
\hline $\begin{array}{c}\text { Community Health } \\
\text { Centers }\end{array}$ & $\begin{array}{c}\text { Annual Investment } \\
\text { Cost (Million RMB) }\end{array}$ & $\begin{array}{c}\text { Service Capacity of } \\
\text { the 1st Year } \\
\text { (Thousand Hours) }\end{array}$ & $\begin{array}{c}\text { Service Capacity of } \\
\text { the 2nd Year } \\
\text { (Thousand Hours) }\end{array}$ \\
\hline $\begin{array}{c}\text { Changshou Sub-district } \\
\text { Yichuan Sub-district }\end{array}$ & 6.13 & 40 & 50.39 \\
Ganquan Sub-district & 13.25 & 80 & 86.49 \\
Shiquan Sub-district & 4.91 & 50 & 54.88 \\
Changfeng Community & 5.29 & 40 & 45.21 \\
Baiyu Community & 15.95 & 70 & 79.52 \\
Caoyang Community & 4.84 & 30 & 48.56 \\
Zhenru Town & 12.75 & 100 & 113.91 \\
Taopu Town & 8.71 & 60 & 74.95 \\
Changzheng Town & 6.28 & 100 & 114.00 \\
\hline
\end{tabular}

The settlements of residents are randomly distributed; therefore, the service-requiring places input into this model are also randomly generated (shown in Table 4). In addition, the demand data are randomly generated after determining the threshold in accordance with the research results. Additionally, the demand of the second year is calculated by the $10 \%$ increase compared to that of the first year.

However, after inputting these data into the proposed model, an infeasible solution results. After debugging, we find that a feasible solution can be obtained only by decreasing the minimum satisfactory rate of demand to $74 \%$, which means that those 10 candidate service centers need to be opened in the first year. This also indicates that even if all service centers are operated completely at present, only about $74 \%$ of the demands can be met. In this case, the optimal configuration is shown in Table 5 . 
Table 3. Relevant data in this paper.

\begin{tabular}{|c|c|c|c|c|}
\hline \multicolumn{5}{|c|}{ Relevant Data of Service } \\
\hline Services & $\begin{array}{c}\text { Annual Investment } \\
\text { Cost (RMB) }\end{array}$ & $\begin{array}{l}\text { Service Payment } \\
\text { (RMB/Hour) }\end{array}$ & $\begin{array}{l}\text { Execution Time } \\
\text { (Hour) }\end{array}$ & $\begin{array}{l}\text { Maximum } \\
\text { Response Time } \\
\text { (Hour) }\end{array}$ \\
\hline $\begin{array}{l}\text { Hospital bed at } \\
\text { home }\left(k_{1}\right)\end{array}$ & 20,000 & 30 & 1 & 0.5 \\
\hline $\begin{array}{c}\text { Health records } \\
\text { establishment } \\
\left(k_{2}\right)\end{array}$ & 10,000 & 15 & 0.5 & 0.5 \\
\hline \multicolumn{5}{|c|}{ Other Relevant Data } \\
\hline Parameters & $\begin{array}{c}\text { Minimum } \\
\text { percentage of } \\
\text { demand satisfied for } \\
\text { each } \\
\text { service-requiring } \\
\text { place }\end{array}$ & $\begin{array}{l}\text { Annual workload } \\
\text { of medical staff } \\
\text { providing home } \\
\text { healthcare services } \\
\text { (hours) }\end{array}$ & $\begin{array}{l}\text { Unit transportation } \\
\text { speed (km/hour) }\end{array}$ & $\begin{array}{l}\text { Unit transportation } \\
\text { cost }(\mathrm{RMB} / \mathrm{km})\end{array}$ \\
\hline Values & $90 \%$ & 2000 & 10 & 2 \\
\hline
\end{tabular}

Table 4. Results of randomly-generated demands.

\begin{tabular}{ccccc}
\hline \multirow{2}{*}{ Service } & Demand & \multicolumn{2}{c}{ Hospital Bed at Home (Hours) } & \multicolumn{2}{c}{ Health Records Establishment (Hours) } \\
\cline { 2 - 5 } & The 1st year & The 2nd year & The 1st year & The 2nd year \\
\hline$j_{1}$ & 5543 & 6098 & 1679 & 1847 \\
$j_{2}$ & 5020 & 5522 & 1427 & 1569 \\
$j_{3}$ & 4054 & 4459 & 1188 & 1306 \\
$j_{4}$ & 4451 & 4896 & 1959 & 2155 \\
$j_{5}$ & 4224 & 4647 & 1221 & 1344 \\
$j_{6}$ & 5572 & 6129 & 1343 & 1477 \\
$j_{100}$ & 6404 & 7045 & 1057 & 1163 \\
\hline
\end{tabular}

It can be seen from Table 5 that the service of the hospital bed at home cannot be met. Therefore, the results need to be further optimized.

Table 5. The optimal configuration of service capacity under the present situation.

\begin{tabular}{|c|c|c|c|c|}
\hline \multirow[t]{2}{*}{$\begin{array}{c}\text { Community Health } \\
\text { Centers }\end{array}$} & \multicolumn{2}{|c|}{$\begin{array}{c}\text { Number of Persons in } \\
\text { the 1st Year }\end{array}$} & \multicolumn{2}{|c|}{$\begin{array}{l}\text { Number of Persons in } \\
\text { the 2nd Year }\end{array}$} \\
\hline & $\begin{array}{l}\text { Hospital bed } \\
\text { at Home }\end{array}$ & $\begin{array}{c}\text { Health Records } \\
\text { Establishment }\end{array}$ & $\begin{array}{c}\text { Hospital Bed } \\
\text { at Home }\end{array}$ & $\begin{array}{c}\text { Health Records } \\
\text { Establishment }\end{array}$ \\
\hline Changshou Sub-district $\left(i_{1}\right)$ & 17 & 3 & 22 & 4 \\
\hline Yichuan Sub-district $\left(i_{2}\right)$ & 34 & 6 & 37 & 6 \\
\hline Ganquan Sub-district $\left(i_{3}\right)$ & 21 & 4 & 23 & 4 \\
\hline Shiquan Sub-district $\left(i_{4}\right)$ & 20 & & 23 & \\
\hline Changfeng Community $\left(i_{5}\right)$ & 29 & 6 & 32 & 8 \\
\hline Baiyu Community $\left(i_{6}\right)$ & 12 & 3 & 19 & 5 \\
\hline Caoyang Community $\left(i_{7}\right)$ & 41 & 9 & 51 & 6 \\
\hline Zhenru Town $\left(i_{8}\right)$ & 30 & & 30 & 7 \\
\hline Taopu Town $\left(i_{9}\right)$ & 39 & 10 & 26 & 4 \\
\hline Changzheng Town $\left(i_{10}\right)$ & 30 & 5 & 35 & 5 \\
\hline
\end{tabular}




\subsection{Service Point Location Optimization}

In order to resolve the problem of unmet demands, it is possible to better meet the needs of the residents by building some new home health centers in the populated areas or improving the service efficiency. The service efficiency could be improved by the following methods: first, minimize the idle time by scheduling and dispatching medical staff; second, minimize the routes, as well as transportation time from service centers to targeted locations by optimizing the route arrangement; third, conduct customer training for medical staff. This paper mainly adopts the location model to optimize the re-layout of the home health centers. According to the above results, three candidate service centers should be built respectively in Wanli Sub-district, Changzheng Town and Taopu Town. Based on the above analysis, there would be 13 candidate service centers. The distribution of the service centers can be referred to in Figure 7 and Table 6.

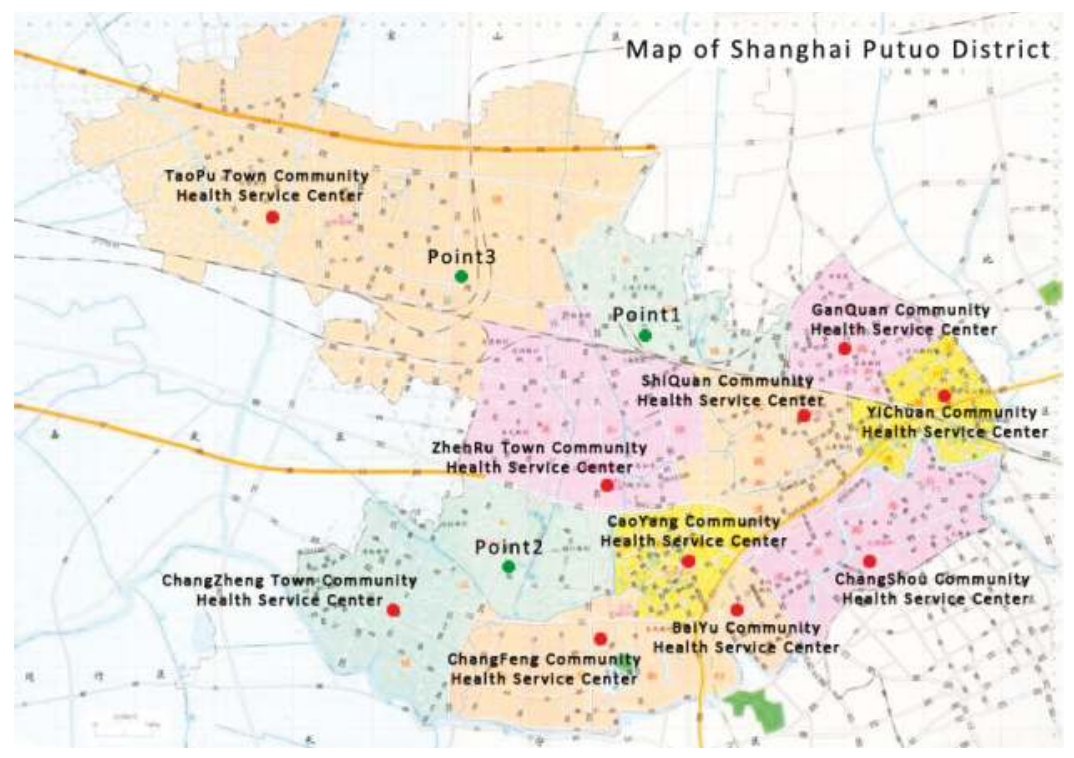

Figure 7. Candidate community health centers of Putuo district in Shanghai.

Table 6. Relevant data of the new service centers of three candidate points.

\begin{tabular}{ccccc}
\hline $\begin{array}{c}\text { Community } \\
\text { Health Centers }\end{array}$ & $\begin{array}{c}\text { Required Area } \\
\left(\mathbf{m}^{\mathbf{2}}\right)\end{array}$ & $\begin{array}{c}\text { Increased Area in } \\
\text { the 2nd Year } \mathbf{( m}^{\mathbf{2}} \mathbf{)}\end{array}$ & $\begin{array}{c}\text { Max Members } \\
\text { (Persons) }\end{array}$ & $\begin{array}{c}\text { Investment Cost } \\
\text { (Million RMB) }\end{array}$ \\
\hline Candidate 1 & 4000 & 700 & 35 & 8 \\
Candidate 2 & 4000 & 700 & 35 & 7.2 \\
Candidate 3 & 4000 & 700 & 35 & 4 \\
\hline
\end{tabular}

If the minimum satisfactory rate of demand is $90 \%$, inputting the relevant data of these 13 service centers and the original service-requiring places into this model would obtain the following results (shown in Table 7).

Compared to the previous results, home healthcare services will be launched in the three new candidate service centers based on the new location results by cancelling the Changshou Road and Changfeng Xincun community health centers (Shown in Figure 8). A comparison of the results (shown in Table 8) indicates that the new layout of the service centers can not only improve the demand 
satisfaction rate from $70 \%$ to $90 \%$, but also can decrease the total cost by 0.44 million RMB in two years. Therefore, this optimization scheme is effective and feasible.

Table 7. Computational results of service centers that should be opened.

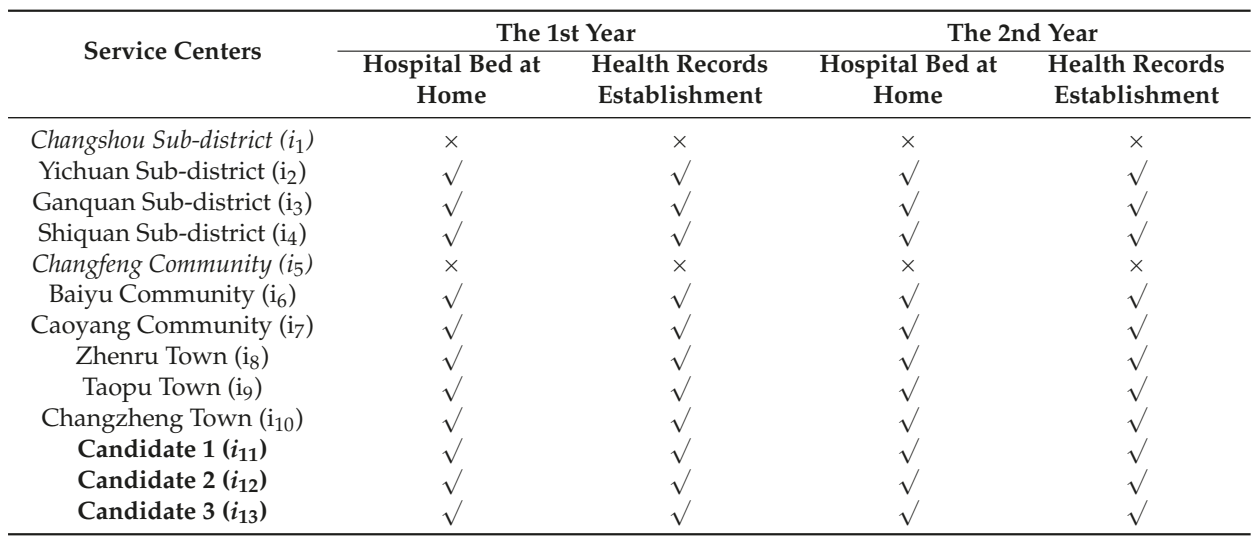

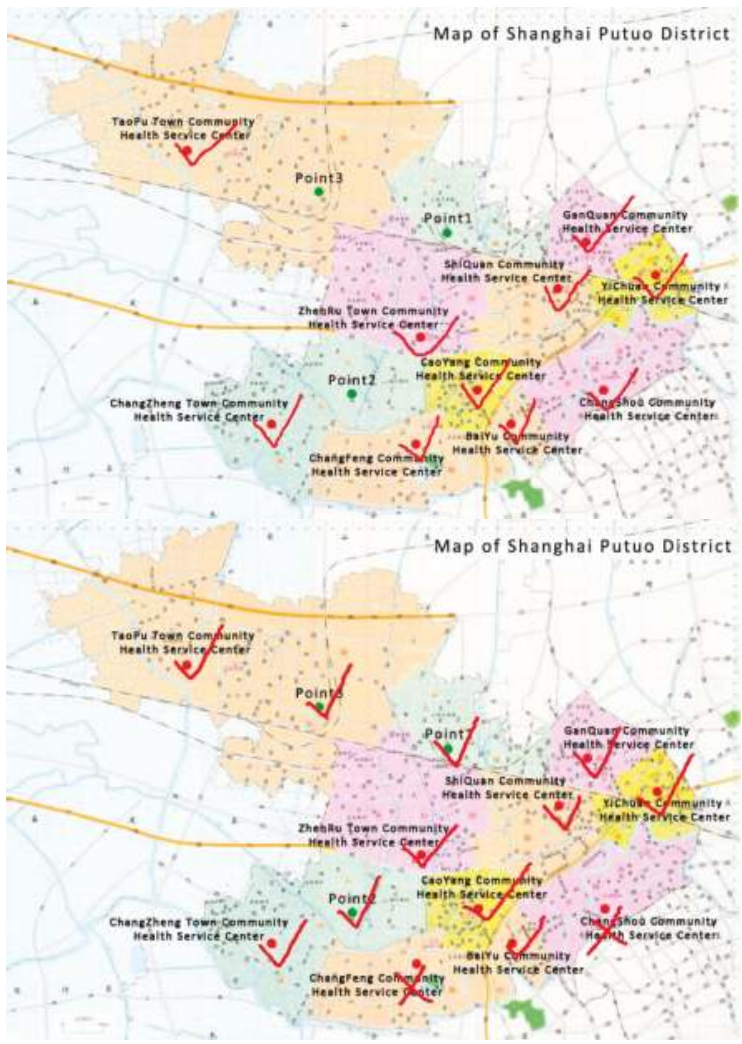

Figure 8. The comparative diagram of opening community health centers with two schemes. 
Table 8. Comparison between the current condition and the optimized scheme.

\begin{tabular}{lll}
\hline & Current Condition & Optimized Scheme \\
\hline & Changshou Sub-district, Yichuan & Yichuan Sub-district, Ganquan \\
& Sub-district, Ganquan Sub-district, & Sub-district, Shiquan Sub-district, \\
Service centers & $\begin{array}{l}\text { Baiyuan Sub-district, Changfeng, } \\
\text { Town, Changzheng Town community } \\
\text { health centers }\end{array}$ & $\begin{array}{l}\text { Baiyu, Caoyang, Zhenru Town, } \\
\text { Taopu Town, Changzheng Town } \\
\text { community health centers as well } \\
\text { as candidates 1, 2 and 3 }\end{array}$ \\
\hline Quantity of service centers & 10 & 11 \\
\hline Total cost & 207.15 million RMB & 206.71 million RMB \\
\hline Satisfactory rate of demand & More than $74 \%$ & More than 90\% \\
\hline
\end{tabular}

\subsection{Sensitivity Analysis of the Optimization Model}

We conducted a sensitivity analysis of the demands based on the decision making model. In this process, we assume the number of demand points to be unchanged, while the demand at each demand point changes over time. In this paper, a demand point stands for a household that needs home healthcare. The demand change at each demand point represents the increase or decrease of different types of home healthcare services.

As shown in Figure 9, the total system cost increases linearly with an upsurge in demand, while the average time of responses showed a stepwise reduction with the growth of demand. When the demand expanded, decision makers would increase service centers for home healthcare and adjust the arrangement of workers, so that the average time of response would be reduced.

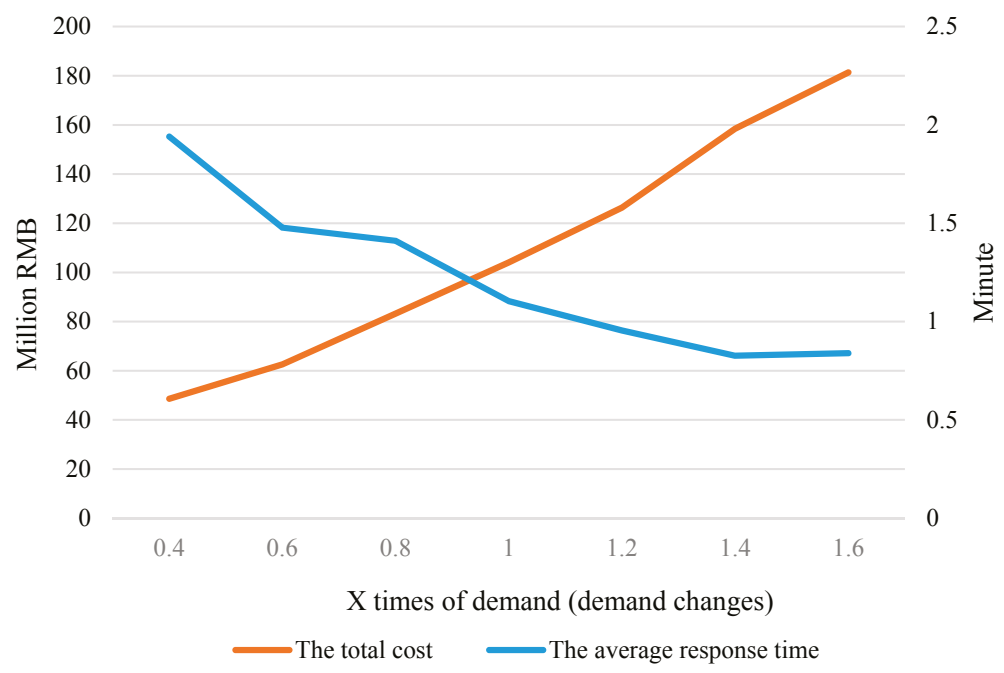

Figure 9. The impact of demand changes on the total cost and the average response time.

When the demand changes ( $x$ times of demand) reached over 1.4, the average time of response would reach a minimum value and remain constant. Meanwhile, when all of the service centers are opened, the increase of the overall cost would only be affected by labor cost and transportation cost.

For the case of 26 demand points, it takes about 2 min for the CPLEX program to identify an optimal solution to the location-allocation problem. However, with the increased quantity of demand points, there would be a rapid rise in computing time. 
The sensitivity analysis evaluates the impacts of the change in the upper limit of response time $\left(\mathrm{U}_{\mathrm{k}}\right)$ on the average response time and the total cost. In this paper, we consider the upper bounds of different response times: the minimum $U_{k}$ is set as 0.4 -times the original value of $U_{k}$, and the maximum $U_{k}$ is set as 1.6-times the original value of $U_{k}$. In the numerical experiment, the interval of times of $U_{k}$ is set as 0.2 . With the change of $U_{k}$, we could obtain its impact on the average response time and the total cost (see Figure 10).

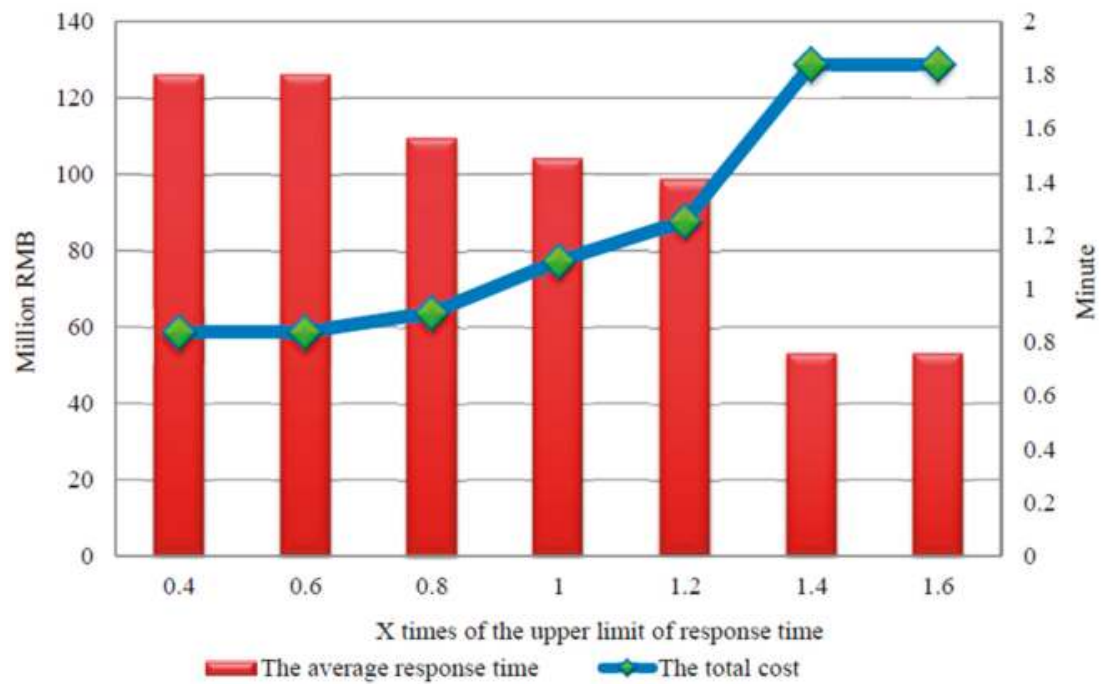

Figure 10. The impact of changes in the upper limit of response time on the total cost and the average response time.

As shown in Figure 10, the total cost of home health centers demonstrates a decreasing trend with the increase of the upper limit of response time $\left(\mathrm{U}_{\mathrm{k}}\right)$. This indicates that when patients do not require being served within a short time, the constraint of response time could be relaxed. Accordingly, the number of healthcare centers could be reduced during the location planning process, and the total cost of healthcare centers could also be reduced. In summary, with the increase of the upper limit of response time $\left(\mathrm{U}_{\mathrm{k}}\right)$, the average response time could be increased, the number of service points could be decreased and the total cost of health service centers could be reduced accordingly.

When the upper limit of response time is increased large enough, the corresponding constraint would no longer have any effects. In other words, the increase of $U_{k}$ would not affect any decisions in location planning. When the $U_{k}$ is increased by 1.4 times, the total cost, as well as the average response time would not change any more. When the $U_{k}$ is increased by less than 0.6 times, the system would achieve the fastest response speed.

Figure 10 shows that there exists an inverse relationship between the total cost and the average response time. Therefore, the decision makers in the home healthcare industry are recommended to comprehensively consider the investment cost and patient satisfaction and to set a reasonable upper limit of response time to achieve the long-term benefit based on their strategic positioning.

Our particular investigation extends the field's body of knowledge in the following aspects:

(1) The proposed model in this paper verifies whether the location of current home health centers is reasonable. There are four evaluation indexes: the minimum total cost for building health centers, the minimum investment cost for starting the business, the minimum labor cost and the minimum transportation cost. This paper investigates the following important issues: where to 
locate service centers for home healthcare, how to arrange the route to minimize the total cost and how to achieve the highest degree of fulfillment for demand with the fastest response time.

(2) Based on the on-site survey, we find that location planning has an important impact on patient satisfaction. The problem identified by the face-to-face survey provides a realistic basis for the research on location planning, and therefore, the results in this paper have higher reference values for policy makers.

(3) The model used in this paper considers more realistic constraints, such as the classification of medical staff, multiple types of services provided by health centers and the time window during the service delivery process (or the response time of demand) in the model. The above factors have not been comprehensively considered in the previous studies. Therefore, the results in this paper are more reliable and useful.

(4) Results in this paper are based on the two-stage continuous optimization. In the first stage, based on the on-site survey and the verification of the model, we find that the existing ten service centers for home healthcare cannot fully meet the demand. In the second stage, we first set the corresponding candidates for the location planning of service centers based on the on-site survey and then identify the suitable three candidates that have the minimum cost, and the fastest response time should be opened. Meanwhile, two of the existing service centers should be closed.

The theoretical contributions of this paper lie in two aspects. First, from the perspective of the generalization of the model, the model used in this paper can be extended and applied to solve the location planning problems of other industries (e.g., the location planning of Shanghai Disneyland Park, the location planning of distribution centers of logistics systems, etc.). However, we should note that the objective function and constraints need to be revised according to the different characteristics of industries. In summary, the research ideas and the framework construction of the model can provide a reference for the location planning problems of other industries. Second, this paper constructed a mathematical model to solve the location problem of health service centers and obtained the optimal solutions to site selection by computer programming. In other words, different from the traditional qualitative analysis of the location planning problem, this paper provides a theoretical reference for the quantitative analysis of location planning. Based on the mathematical modelling, the estimated results are more scientific and, thus, have higher reference values.

\section{Conclusions and Implications}

Population ageing is increasingly becoming an issue of concern throughout China. Currently, China's public healthcare system, as well as pension system are fiscally unsustainable. As a new mode of service, home healthcare service, which contributes to health promotion and disease prevention by establishing a personal health record (PHR) system, providing health information, promoting healthier lifestyles, etc., is crucial for sustainable development in public health. In addition, home healthcare services can effectively alleviate the problem of medical resource shortages especially in large cities in China with a critical shortage of medical resources. In particular, home healthcare services can provide convenient healthcare services to the elderly and other special populations with lower investment cost. Therefore, investigating the systemic challenges of home healthcare, challenges related to the institutional and professional competencies of home healthcare centers, the demands, expectations and degrees of patient satisfaction are of great significance. According to the analysis of survey data, location planning is the key element for reducing the investment cost, as well as avoiding the unnecessary construction of service centers for home healthcare. Therefore, the empirical study of this paper can contribute to the literature in terms of promoting sustainable healthcare in China.

The proper layout of the service centers for home healthcare not only can decrease the investment cost and avoid redundant construction, but also can improve the degree of patient satisfaction, so as to realize sustainable development of home healthcare. The face-to-face survey data show that the location planning is highly important for optimizing the distribution of medical resources, which is therefore conducive for improving the utilization of resources and enhancing the patient satisfaction. 
To validate the proposed methodology, a location planning model is built and the sensitivity analysis is conducted in this paper, which can optimize the current layout of the home healthcare centers to a certain extent.

Although the proposed optimization model is a common method for the location planning problem, it has distinguished advantages in obtaining reasonable results by considering various actual constraints with limited time. It can be used to solve most of the location planning problems. At present, the Chinese government promotes establishing the home healthcare system, while reasonable location methods, as well as empirical studies based on face-to-face surveys on home healthcare are still scarce. Although only a case study of Shanghai is conducted based on this model, the method can be extended to other regions and, thus, can be a reference for promoting the sustainable development of home healthcare in China.

Considering that medical demands are uncertain, how to establish a stochastic programming model that takes actual constraints into account for a solution will be an important topic for future research. Especially, the integration of the location planning and the personal scheduling is also an interesting research topic.

Acknowledgments: Acknowledgments: We would like to express our sincere gratitude to the editors and the anonymous referees for exceptionally helpful comments and suggestions. This work was supported by the Research Grant from the National Natural Science Foundation of China (Funding Nos: 71472065, 71303199), the Research Projects of the Social Science and Humanities of the Young Fund of the Ministry of Education (Funding Nos: 14YJC630026, 13YJC790123), the Shanghai Pujiang Program (14PJC027), the Key Projects of Shanghai Soft Science Research Program (15692104700) and the Overseas Published Project for Humanities and Social Science of East China Normal University (2014HW027), Soft Science Plan Funded Project of Fujian Province, China (2014R0088), Natural Science Foundation of Fujian Province, China (2014J01269). Moreover, we would like to thank the whole medical staff of Shanghai No. 6 People's Hospital for real data collecting and providing valuable suggestions. Especially, we would like to thank the experts who participated in the evaluation and improvement of this manuscript.

Author Contributions: Author Contributions: Both of the authors have contributed to the idea of the survey, as well as to the proposed optimization model. Gang Du wrote the whole manuscript and solved the model using CPLEX. Chuanwang Sun provided some core advice and checked through the whole paper.

Conflicts of Interest: Conflicts of Interest: The authors declare no conflicts of interest.

\section{References}

1. The China Statistical Yearbook. Available online: http://www.stats.gov.cn/ (accessed on 24 November 2015).

2. The National Aging Committee of China. Available online: http://www.cncaprc.gov.cn/ (accessed on 24 November 2015).

3. Chahed, S.; Marcon, E.; Sahin, E.; Feillet, D.; Dallery, Y. Exploring new operational research opportunities within the home care context: The chemotherapy at home. Health Care Manag. Sci. 2009, 12, 179-191. [PubMed]

4. Davies, C.; Dale, J. Paediatric home care for acute illness: I. GPs' and hospitalat-home staff views. Int. J. Health Care Qual. Assur. 2003, 16, 361-366. [CrossRef]

5. Chevreul, K.; Com-Ruelle, L.; Midy, F.; Paris, V. The Development of Hospital Care at Home: An investigation of Australian, British and Canadian Experiences. Available online: http://www.irdes.fr/ EspaceAnglais/Publications/IrdesPublications/QES091.pdf (accessed on 24 November 2015).

6. AHIP Center for Policy and Research. Innovations in Reducing Preventable Hospital Admissions, Readmissions, and Emergency Room Use. Available online: https://www.ahip.org/Innovations-2010Report/ (accessed on 24 November 2015).

7. King, C. To Your Health: Intel and GE's Joint Venture. Available online: http:/ /www.ecommercetimes.com/ (accessed on 24 November 2015).

8. Medicare Payment Advisory Commission (MEDPAC). Home Health Care Services (Chapter 8). Available online: http://www.medpac.gov/documents/reports/mar12_ch08.pdf?sfvrsn=0 (accessed on 24 November 2015). 
9. Mourad, S.M.; Nelen, W.L.; Akkermans, R.P.; Vollebergh, J.H.; Grol, R.P.; Hermens, R.P.; Kremer, J.A. Determinants of patients' experiences and satisfaction with fertility care. Fertil. Steril. 2010, 94, 1254-1260. [CrossRef] [PubMed]

10. Batchelor, C.; Owens, D.J.; Read, M.; Bloor, M. Patient satisfaction studies: Methodology, management and consumer evaluation. Int. J. Health Care Qual. Assur. 1994, 7, 22-30. [CrossRef] [PubMed]

11. Tam, J. Linking quality improvement with patient satisfaction: A study of a health service centre. Mark. Intell. Plan. 2007, 25, 732-745. [CrossRef]

12. Du, G. Scheduling Optimization of Home Health Care Service considering Patients' Priorities and Time Windows; Working Paper; Bussiness School, East China Normal University: Shanghai, China, 2015.

13. Lanzarone, E.; Matta, A. Robust nurse-to-patient assignment in home care services to minimize overtimes under continuity of care. Oper. Res. Health Care 2014, 3, 48-58. [CrossRef]

14. Milburn, A.B. Operations research applications in home healthcare. In Handbook of Healthcare System Scheduling; Springer US: New York, NY, USA, 2012; pp. 281-302.

15. Lanzarone, E.; Matta, A.; Scaccabarozzi, G. A patient stochastic model to support human resource planning in home care. Prod. Plan. Control 2010, 21, 3-25. [CrossRef]

16. Carmen Carnero, M. Assessment of Environmental Sustainability in Health Care Organizations. Sustainability 2015, 7, 8270-8291. [CrossRef]

17. Kim, J.I.; Senaratna, D.M.; Ruza, J.; Kam, C.; Ng, S. Feasibility Study on an Evidence-Based Decision-Support System for Hospital Site Selection for an Aging Population. Sustainability 2015, 7, 2730-2744. [CrossRef]

18. Fischer, M. Fit for the Future? A new approach in the debate about what makes healthcare systems really sustainable. Sustainability 2014, 7, 294-312. [CrossRef]

19. Hakimi, S.L. Optimum Locations of Switching Centers and the Absolute Centers and Medians of a Graph. Oper. Res. 1964, 12, 450-459. [CrossRef]

20. Church, R.L.; ReVelle, C.S. Theoretical and Computational Links between the p-Median, Location Set-covering, and the Maximal Covering Location Problem. Geogr. Anal. 1976, 8, 406-415. [CrossRef]

21. Roth, R. Computer solutions to minimum-cover problems. Oper. Res. 1969, 17, 455-465. [CrossRef]

22. Liu, M.W.; Li, X. A Pareto Genetic Algorithm for Multi-objective Site Search Problem: A Case Study on Hospital Location in Shenzhen City. Trop. Geogr. 2010, 30, 650-655.

23. Diao, Y.H.; Jiang, Z.B. A Stochastic Programming Based Method for Hospital Site Select ion. J. Shanghai Jiaotong Univ. 2010, 44, 433-436.

24. Vahidnia, M.H.; Alesheikh, A.A.; Alimohammadi, A. Hospital site selection using fuzzy AHP and its derivatives. J. Environ. Manag. 2009, 90, 3048-3056. [CrossRef] [PubMed]

25. Soltani, A.; Marandi, I.Z. Hospital site selection using two-stage fuzzy multi-criteria decision making process. J. Urban Environ. Eng. 2011, 5, 32-43. [CrossRef]

26. Pariwate, V.; Joseph, P.M. Hospital Site Selection Analysis. Available online: http://citeseerx.ist.psu.edu/ viewdoc/download?doi=10.1.1.121.4330\&rep=rep1\&type=pdf (accessed on 24 November 2015).

27. Dong-Guen, K.; Yeong-Dae, K. A branch and bound algorithm for determining locations of long-term care facilities. Eur. J. Oper. Res. 2010, 206, 168-177.

28. Toregas, C.; Swain, R.; ReVelle, C.; Bergman, L. The location of emergency service facilities. Oper. Res. 1971, 19, 1363-1373. [CrossRef]

29. Cong, F.; Geng, N.; Gu, Y.; Jiang, Z. An approach for community care centre location planning under certainty. Ind. Eng. Manag. 2013, 18, 41-45.

30. Evren, S.; Andrea, M. A contribution to operations management-related issues and models for home care structures. Int. J. Logist. Res. Appl. 2014, 18, 1-31.

31. Gupta, D.; Denton, B. Appointment scheduling in health care: Challenges and opportunities. IEEE Trans. 2008, 40, 800-819. [CrossRef]

32. Noha, M.G.; Ahmed, F.A.M. A Mathematical Programming Approach to the Optimal Sustainable Product Mix for the Process Industry. Sustainability 2015, 7, 13085-13103.

33. Hiermann, G.; Prandtstetter, M.; Rendl, A.; Puchinger, J.; Raidl, G.R. Metaheuristics for solving a multimodal home-healthcare scheduling problem. Cent. Eur. J. Oper. Res. 2013, 23, 89-113. [CrossRef]

34. Bertels, S.; Fahle, T. A hybrid setup for a hybrid scenario: Combining heuristics for the home health care problem. Comput. Oper. Res. 2006, 33, 2866-2890. [CrossRef] 
35. Trautsamwieser, A.; Hirsch, P. Optimization of daily scheduling for home health care services. J. Appl. Oper. Res. 2011, 3, 124-136.

36. Rasmussen, M.S.; Justesen, T.; Dohn, A.; Larsen, J. The home care crew scheduling problem: Preference-based visit clustering and temporal dependencies. Eur. J. Oper. Res. 2012, 219, 598-610. [CrossRef]

37. National Health and Family Planning Commission of the People's Republic of China. China's Health and Family Planning Yearbook 2013; Peking Union Medical College Press: Beijing, China, 2014.

38. Melanson, S.E.F.; Goonan, E.M.; Lobo, M.M.; Baum, J.M.; Paredes, J.D.; Santos, K.S.; Gustafson, M.L.; Tanasijevic, M.J. Applying Lean/Toyota production system principles to improve phlebotomy patient satisfaction and workflow. Am. J. Clin. Pathol. 2009, 132, 914-919. [PubMed]

39. Wei, T.; Geng, N.; Jiang, Z.; Cong, F. Multi-service Multi-facility Location Problem under Deterministic Demand. Ind. Eng. Manag. 2014, 19, 47-52.

(C) 2015 by the authors. Licensee MDPI, Basel, Switzerland. This article is an open access article distributed under the terms and conditions of the Creative Commons Attribution (CC BY) license (http:/ / creativecommons.org/licenses/by/4.0/). 


\title{
Dynamic Factor Analysis of Trends in Temporal-Spatial Patterns of China's Coal Consumption
}

\author{
Yuhuan Sun ${ }^{1, *}$, Qian $\mathrm{Li}^{1}$, Ting Chen ${ }^{1}$ and Xiaoai Jia ${ }^{2}$ \\ 1 School of Statistics, Dongbei University of Finance and Economics, Dalian 116025, China; \\ liqian03067@163.com (Q.L.); chentingtongji@163.com (T.C.) \\ 2 School of Statistics, Shandong Institute of Business and Technology, Yantai 264005, China; \\ jxiaoai@sdibt.edu.cn \\ * Author to whom correspondence should be addressed; yhsun@dufe.edu.cn or yhsun602@163.com; \\ Tel.: +86-137-0426-3150.
}

Academic Editors: Yongrok Choi, Malin Song and Seunghwan Myeong

Received: 23 September 2015; Accepted: 11 November 2015; Published: 13 November 2015

\begin{abstract}
This paper analyzes coal consumption in the 31 provinces and regions of China from 1995 to 2012. Using spatial analysis in Arc geographical information systems (ArcGIS) and the concept of the center of gravity in physics, we explore the regional differences in temporal-spatial coal consumption and the factors influencing them. The results show that China's coal consumption increased yearly, especially after 2003. It exhibits a marked spatial clustering phenomenon; consumption in the south and east exceeded that in the north and west respectively. Moreover, the center of gravity of consumption gradually moved toward the southwest, indicating reducing gaps in coal consumption between the north-south and the east-west regions. Both the level of economic development and coal consumption are positively related with regional coal production. Promoting urbanization and increasing the proportion of the tertiary industry can effectively reduce coal consumption and help readjust coal consumption patterns to sustainable levels.
\end{abstract}

Keywords: coal consumption; temporal and spatial patterns; ArcGIS; barycenter model; spatial econometrics

\section{Introduction}

Energy forms the material basis for a country's economic development. A country cannot develop and prosper without adequate energy resources. Energy consumption is known to increase sharply with economic development. Thus, the lack of energy resources can be a bottleneck to economic development and restrict economic growth [1,2]. In this context, while the impact of coal consumption on economic development has received extensive attention from scholars, their conclusions, which could be roughly divided into the following three categories, tend to differ. Some scholars note that there is a unidirectional causal relationship between coal consumption and economic growth. Thus, any reduction in coal consumption could lead to a fall in economic growth. Using the Toda-Yamamoto method, for instance, Bhattacharya et al. [3] confirmed that a causal relationship runs from coal consumption to economic growth. Bloch et al. [4] used data of production and consumption of coal resources and came to the same conclusion. Some scholars think that there is bidirectional causality between coal consumption and economic growth. Zhang and Yang [5] revealed the negative bidirectional causality between China's coal consumption and economic growth, using the data of China's coal consumption and GDP from 1978 to 2009. Moreover, they pointed out that the negative relationship between coal consumption and economic growth might be attributed to the shift in 
economic development toward less energy intensive sectors. However, Gurgul and Lach [6] thought that there is no causal relationship between coal consumption and economic growth, which means that coal consumption does not affect economic growth. Li et al. [7] showed that the relationship between coal consumption and economic growth may differ across countries: they found evidence of a bidirectional causal relationship between coal consumption and economic growth for Germany, Russia, and Japan; a unidirectional causality from economic growth to coal consumption for China; and no causal relationships between coal consumption and economic growth for the USA and India. Scholars have also focused on the relationship between coal resource utilization and society and between coal resource utilization and the environment. Shahbaz et al. [8] used the error correction model to investigate the effects of South Africa's coal consumption on the country's environmental performance and showed a strong positive correlation between coal consumption and environmental degradation. Tiwari et al. [9] reached similar conclusions in the Indian context. Besides, Shan et al. [10] provided evidence of an upward trend in the use of coal, which is a significant source of air pollution, for space heating and cooking.

Different areas own different resource endowments and have varying levels of economic development. Both factors impact coal consumption. Chen et al. [11] analyzed the differences in coal consumption across various regions in the Chinese cement industry and found that the eastern region has the highest energy costs. Liu et al. [12] analyzed the relationship between coal consumption and economic growth by constructing a panel data model of China's eastern, central, and western areas. A comparative analysis indicated that economic growth in the central region had a greater impact on coal consumption than economic growth in other regions, and the industrial structure in the eastern part of the country significantly impacted coal consumption compared to the other regions. Guo et al. [13] used cluster analysis to divide China's provinces into four zones: high economic growth and high energy consumption zone, low economic growth and high energy consumption zone, low economic growth and low energy consumption zone, and high economic growth and low energy consumption zone. They established an error correction model showing that when investment in fixed assets and proportion of heavy industry increase, regional energy consumption intensity also increases; however, the extent of the impact on the energy consumption intensity varies among regions.

In recent years, geographical information systems (GIS), spatial analysis techniques, and spatial econometric models have become popular, as they allow analyses at the province level and also provide technical support for analyzing the spatial distribution of energy consumption. Chuai et al. [14] and Herrerias et al. [15] used ArcGIS spatial analysis to study the spatial distribution of energy consumption and carbon emissions and the spatial distribution of energy consumption intensity respectively for China's provinces and regions. In addition, center of gravity models are advantageous as they can demonstrate development trajectories visually and quantitatively. Ren and Li [16] analyzed changing trends in China's energy consumption. They concluded that the center of gravity of China's energy consumption was gradually moving toward the southwest, and the gap in energy consumption between the east-west and north-south directions had reduced. Using the same idea of center of gravity and ArcGIS, Zhang et al. [17] showed that coal continued to be the main energy source in the central and western regions of China and that the regions consuming the majority of coal were mainly distributed in developed provinces such as Beijing and Tianjin.

The reviewed research indicates that a detailed analysis of China's coal consumption is important to understand and predict China's economic transition. The diverse geography and culture of China's provinces leads to regional differences in coal consumption. Thus, it is important to conduct a representative analysis of the spatial and temporal distribution of coal consumption. This paper attempts to do this systematically using ArcGIS spatial analysis and the center of gravity calculation method. It also uses space measurement methods to quantitatively analyze the factors influencing coal consumption. In doing so, it hopes to contribute knowledge toward improving the distribution patterns of China's coal consumption, reducing its overall coal consumption, and promoting the efficient use of coal resources. 


\section{Materials and Methods}

\subsection{Methods of Spatial Analysis}

Spatial analysis combines the spatial location with attributes of geographical objects, the purpose being the extraction and scientific communication of spatial information, thus solving the practical problems of geographical space. The primary methods of spatial analysis comprise (i) dynamic analysis of space as in the hydrology model, spatial price rivalry model, alternative spaces model, and so on; (ii) spatial analysis of maps, such as the buffer in GIS and overlay analysis; and (iii) spatial analysis based on geographical information, namely, spatial information analysis. This paper utilizes the ArcGIS spatial analysis module to match China's social and economic attributes pertaining to coal consumption to its geographical attributes [18]. It then analyzes the characteristics of the temporal and spatial evolution of China's coal consumption.

\subsection{Barycenter Model}

The concept of the center of gravity originates from physics. It refers to the centralized point of gravitational force generated by various parts of a body. According to the center of gravity model, there is a point in the geographical space where all forces are relatively balanced. The barycenter concept provides a more intuitive depiction of the development path in quantitative and visual terms. Accordingly, it has been widely applied in research pertaining to temporal and spatial distributions. The Americans have used this concept since the 1970s to study geographic distribution in the social and economic context, as well as the field of natural resources, among others. Thereafter, Chinese scholars tried to use the same method to analyze spatial distributions in social and economic areas. For example, Buch et al. [19] used the barycenter model to investigate the foreign investments flowing among European regions. They concluded that these investments were not redirected between regions. Jin et al. [20] used GIS technology and the concept of the barycenter to analyze the environmental effects of foreign trade and its spatial variations in the eastern regions of China. Assuming an area consisting of $N$ secondary regions, the concept of the center of gravity can be used to calculate the attribute of the area as follows:

$$
X=\frac{\sum M_{i} X_{i}}{\sum M_{i}} \text { and } Y=\frac{\sum M_{i} Y_{i}}{\sum M_{i}}
$$

In Equation (1), $X$ represents the longitude of the center of gravity for the region, and $Y$ represents the latitude. $X_{i}$ and $Y_{i}$ respectively represent the longitude and latitude of the center of gravity in the No.i secondary region. $M_{i}$ represents the attribute value of the No.i secondary region. This paper regards China as a whole, and its 31 provinces as second-level regions. The capitals of the provinces are selected as the second-area centers, and the attribute values are coal consumption and coal production of the 31 provinces.

\subsection{Spatial Econometric Model}

The term spatial econometric model mainly refers to the spatial lag model (SLM) and the spatial error model (SEM).

(1) The SLM is mainly used to analyze whether a variable has a diffusion effect in one interval. It is expressed as

$$
Y=\rho W y+X \beta+\varepsilon
$$

$Y$ is the dependent variable, $X$ is the $n \times k$ matrix of exogenous variables, $\rho$ refers to the coefficient of spatial regression, $W$ is the $n \times n$ spatial weight matrix, $W y$ is the spatial lag dependent variable, and $\varepsilon$ denotes the stochastic error vector. 
(2) According to the SEM, spatial dependence exists not only in the dependent variable but also in the stochastic error. Therefore,

$$
\left\{\begin{array}{c}
Y=X \beta+\varepsilon \\
\varepsilon=\lambda W \varepsilon+\mu
\end{array}\right.
$$

In Equation (3), $\varepsilon$ presents the stochastic error vector, $\lambda$ is the spatial error coefficient of the $n \times 1$ section-dependent variable vector, and $\mu$ is the stochastic error vector with a normal distribution.

\subsection{Theoretical Hypothesis}

(1) Hypothesis of the barycenter model

The hypothesis of the barycenter model states that if the geographic coordinates of a central city remain unchanged, the barycenter of coal consumption will change as coal consumption changes. In addition, if the proportion of one region's consumption is large and grows fast, the barycenter of consumption will move toward that region.

(2) Hypothesis of the SEM

According to spatial econometrics, an economic geographic phenomenon observed in one unit regional space is correlated with the same phenomenon in a neighboring space unit. Over the years, the classic econometrics model has assumed that space is homogeneous by ignoring the spatial effect. The latter generates deviation in the model setting and makes the ordinary least squares estimation invalid [21]. However, spatial autocorrelation is an objective reality, and thus, an SEM must be established to overcome the space dependency that cannot be resolved by the ordinary least squares method.

\subsection{Data Sources}

This paper uses the coal consumption data of 31 provinces and regions in China during 1995 to 2012 to track the changing temporal and spatial distribution patterns of China's coal consumption and to study the factors influencing the temporal and spatial distributions. Energy data are mainly sourced from the "China Energy Statistical Yearbook (2013) [22]" and "China Compendium of Statistics 1949-2009 [23]." The economic data are primarily sourced from the "China Statistical Yearbook (2013) [24]", while data pertaining to the Tibet autonomous region come from the "Development Status and Future Trends Survey of Tibet Energy Industry 2014-2018 (http:/ / www.askci.com)" and "Tibet Statistical Yearbook (2013) [25]". Since Chongqing was not classified as a municipality until 1997, the data before 1997 are calculated via interpolation, which is based on the average growth rate for many years.

\section{Temporal Evolution of China's Coal Consumption}

There are significant regional differences in China's coal consumption. Further, differences in the levels of economic and technology development among provinces in different periods caused coal consumption patterns to change over time. The following subsections discuss the temporal and spatial characteristics of China's coal consumption patterns.

\subsection{Characteristics of Temporal Evolution}

\subsubsection{Upward Trends of China's Total Coal Consumption and Per Capita Consumption}

Figure 1 presents line charts of coal consumption and per capita coal consumption in China from 1995 to 2012. 


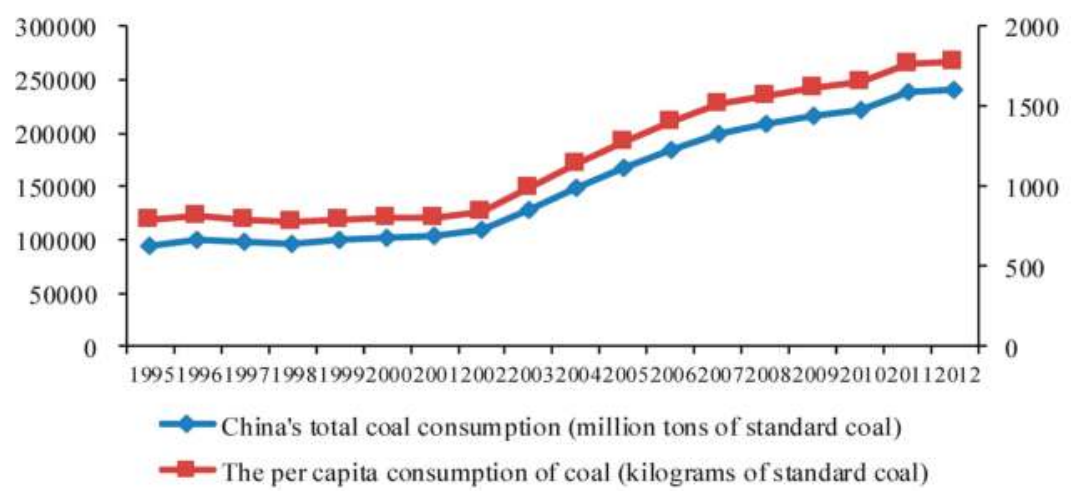

Figure 1. Changes in China's coal production and per capita coal consumption from 1995 to 2012.

The changing trends of China's total coal consumption and per capita coal consumption are quite similar. From 1995 to 2002, the total coal consumption and per capita coal consumption remained mostly unchanged, showing a slightly declining trend. Notably, total coal consumption reduced between 1996 and 1998, from 994.4 million tons to 966.92 million tons of standard coal. Coal consumption per capita reduced from 812 kilograms to 775 kilograms of standard coal. However, both types of consumption have increased rapidly since 2003. Coal consumption in 2003 was $128,640.67$ million tons of standard coal. The figure reached 240,846.36 million tons of standard coal in 2012, which is 1.87 times of that in 2003, showing an annual average growth rate of $7.20 \%$. Thus, the year 2003 marked an important turning point in terms of coal consumption for China.

\subsubsection{Significant Spatial Clustering with Regard to China's Coal Consumption}

Moran's I is an important index used to test whether the attribute value of one element is correlated to that of the neighboring space. It contains three categories: positive correlation, negative correlation, and noncorrelation. When Moran's I is greater than 0 , the elements are positively correlated, suggesting that the same changing trend exists between the attribute value of one unit and that of the neighboring space unit. When Moran's I is equal to 0 , the elements are not correlated, indicating that there is no interaction between two neighboring regions. When Moran's I is less than 0 , they are negatively correlated, indicating opposing trends between two neighboring regions. Table 1 lists Moran's I values of coal consumption in China's provinces from 1995 to 2012, which are calculated using the software GeoDa.

Table 1. Moran's I values of China's provincial coal consumption.

\begin{tabular}{|c|c|c|c|c|c|c|c|c|c|}
\hline Years & 1995 & 1996 & 1997 & 1998 & 1999 & 2000 & 2001 & 2002 & 2003 \\
\hline $\begin{array}{l}\text { Moran's } \\
\text { I }\end{array}$ & 0.2153 & 0.2040 & 0.2231 & 0.2019 & 0.2268 & 0.2303 & 0.2415 & 0.2147 & 0.1938 \\
\hline Z-value & 3.1078 & 3.0213 & 3.1498 & 2.9031 & 3.4278 & 3.3327 & 3.6560 & 3.1782 & 2.8771 \\
\hline$P$-value & 0.010 & 0.005 & 0.008 & 0.010 & 0.006 & 0.006 & 0.005 & 0.006 & 0.012 \\
\hline Years & 2004 & 2005 & 2006 & 2007 & 2008 & 2009 & 2010 & 2011 & 2012 \\
\hline $\begin{array}{c}\text { Moran's } \\
\text { I }\end{array}$ & 0.1954 & 0.1986 & 0.1969 & 0.1912 & 0.1933 & 0.1921 & 0.1918 & 0.1878 & 0.1779 \\
\hline$Z$-value & 2.7281 & 2.8622 & 2.9847 & 2.8734 & 2.9031 & 2.9421 & 2.9678 & 2.9132 & 2.8662 \\
\hline$P$-value & 0.014 & 0.014 & 0.012 & 0.011 & 0.016 & 0.014 & 0.012 & 0.012 & 0.011 \\
\hline
\end{tabular}

From 1995 to 2012, Moran's I values of coal consumption in China's provinces were positive and passed the significance test at the $95 \%$ confidence interval. This shows that China's coal consumption 
has been in a state of accumulated development and that neighboring provinces show the same changing trends. Moran's I values from 1995 to 2002 are greater than 0.2, indicating that there are significant spatial agglomeration effects. After 2003, Moran's I values decreased continuously, reaching a minimum value of 0.1179 in 2012; however, the spatial agglomeration effects were still significant. Overall, China's coal consumption shows an unbalanced development trend that has weakened slightly over time, but the spatial agglomeration effects still remain significant.

\subsection{Characteristics of Space Pattern Evolution}

\subsubsection{Coal Consumption in Different Provinces and Regions of the Country}

Different provinces and regions have their own characteristics of coal consumption, and the differences between them are quite significant. In 1995, the northern region of China (including Shanxi, Hebei, and Inner Mongolia) consumed the majority of the country's coal, as did northeast China (including Heilongjiang and Liaoning). The top five provinces in terms of coal consumption in 1995 were Shanxi, Hebei, Shandong, Liaoning, and Jiangsu. The total coal consumption of these five provinces reached $386,127,600$ tons of standard coal, accounting for $37.34 \%$ of the national total consumption (Figure 2a). Compared with 1995, China's coal consumption patterns for 2000 remained almost unchanged; coal consumption of all provinces grew slightly and even decreased for some provinces such as Shanxi and Heilongjiang (Figure $2 b$ ). To some extent, coal consumption of all the provinces in China increased from 2000 to 2005. The consumption of Shandong, Sichuan, and Jiangsu increased rapidly, and thus, increasing coal consumption patterns gradually moved toward the southwest. Initially, Shanxi, Henan, and Hebei were the major centers of coal consumption. Meanwhile, developed provinces in the southern region, like Guangdong and Zhejiang, experienced a rapid increase in coal consumption (Figure 2c). From 2005 to 2012, China's coal consumption patterns remained stable while the scale of coal consumption continued to increase for each province. By 2012, China's coal consumption had reached 2,408,463,600 tons of standard coal, an increase of $43.90 \%$ over 2005. Accordingly, Shandong, Inner Mongolia, Shanxi, Hebei, and Jiangsu became the top five provinces in terms of coal consumption. The accompanying coal consumption patterns revealed Shanxi, Inner Mongolia, and Henan as the areas where coal consumption is predominantly concentrated in central China. The corresponding areas in the Bohai Coastal Region and the Yangtze Delta Area were Liaoning, Beijing-Tianjin-Hebei, and Shandong, and Jiangsu, Zhejiang, and Shanghai, respectively (Figure 2d). 


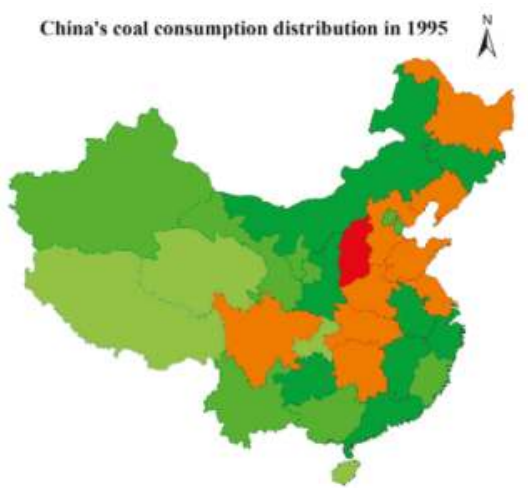

(a)

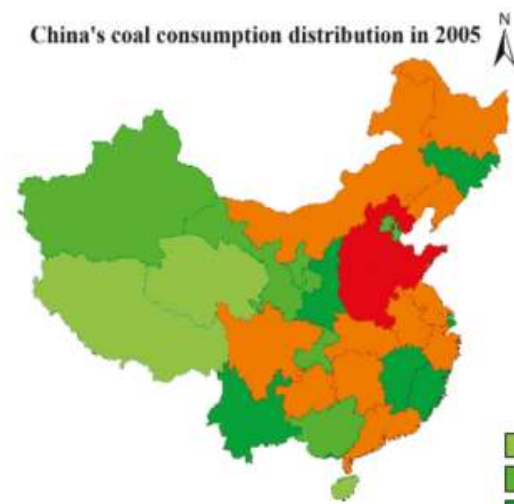

(c)

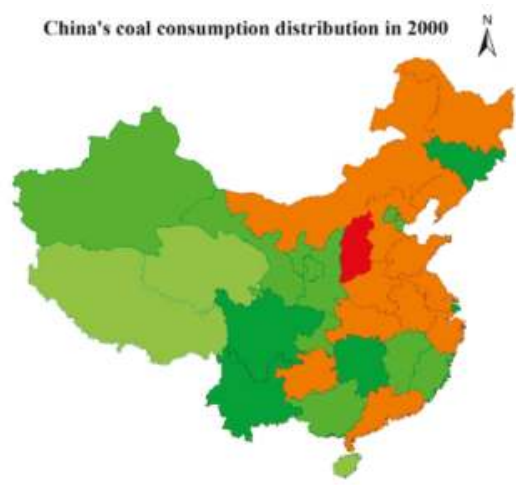

(b)

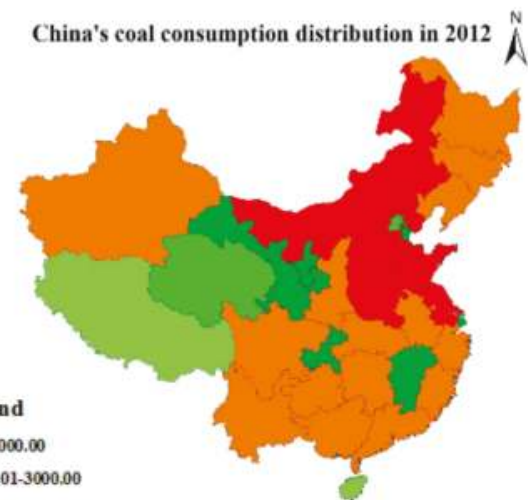

(d)
3000.01-5000.00

\$000.01-13000.00

13000.01-37328.00

Units:million tons of standard

coal

Figure 2. Regional differences in coal consumption across China's provinces and regions from 1995 to 2012.

\subsubsection{Change in the Center of Gravity of China's Coal Consumption}

Figure 3 is the trajectory map of the barycenter of China's coal consumption, which is plotted according to the barycenter model and data of coal consumption by China's provinces and regions from 1995 to 2012. 


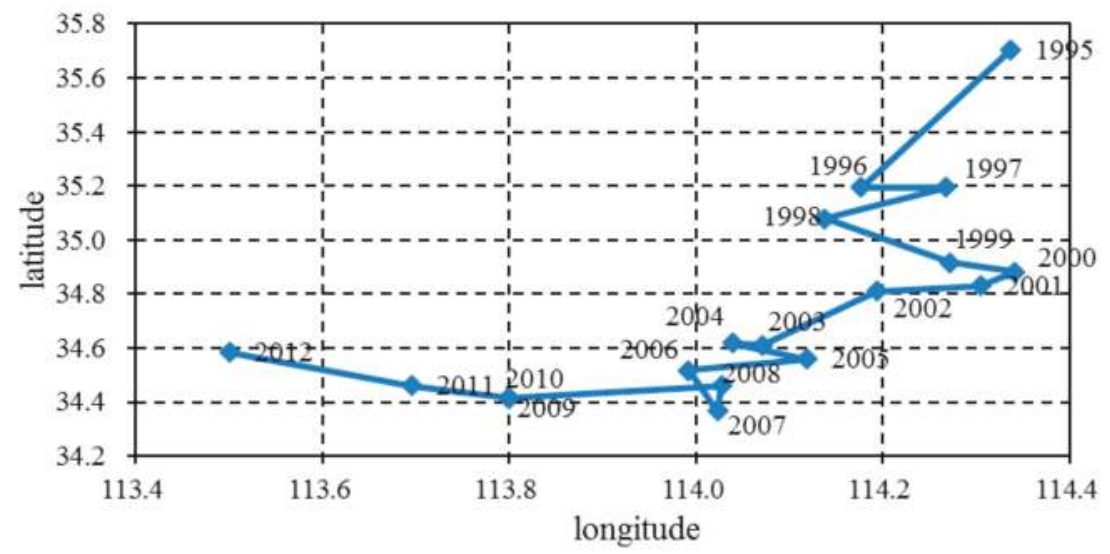

Figure 3. Tracking the path of the center of gravity of coal consumption in China from 1995 to 2012.

Figure 3 shows that the barycenter of China's coal consumption is moving toward the west-south part of the country. It moved from $\left(114.34^{\circ} \mathrm{E}, 35.10^{\circ} \mathrm{N}\right)$ to $\left(113.50^{\circ} \mathrm{E}, 34.58^{\circ} \mathrm{N}\right)$, shifting westward by $0.84^{\circ}$ and southward by $1.12^{\circ}$, thus revealing the significant reduction in the gaps between coal consumption in the east-west and north-south parts of the country. However, the gap in the north-south direction reduced much faster. This result regarding the changing trends in China's barycenter of energy consumption is quite consistent with that of Ren and $\operatorname{Li}(2008)$ [16]. This phenomenon may be correlated with the fact that coal is the dominant energy resource in China, and thus, the evolution of coal consumption patterns plays an important role in the evolution of energy consumption patterns.

The trajectory of the center of gravity of China's coal consumption can be roughly divided into three stages. The first stage is from 1995 to 2002, during which the center of gravity of coal consumption moved toward the southwest. The move toward the south is more obvious, with the change in the center of gravity by $0.84^{\circ}$. Northeast China's total energy consumption (e.g., in Liaoning and Heilongjiang) grew very slowly; some may say it even stagnated. However, it increased in the southern provinces such as Shanghai and Zhejiang. The second stage of the trajectory of the center of gravity of China's coal consumption is from 2003 to 2008. The center of gravity moved in a disorderly fashion, but its position remained relatively stable on an annual basis. The third stage is from 2009 to 2012 , when the center of gravity rapidly moved westward at an average annual pace of up to $0.10^{\circ}$. This phenomenon resulted in the rapid increase of coal consumption in Shanxi and Ningxia.

\section{Analysis of Influencing Factors}

In order to study the characteristics of the temporal evolution of China's coal consumption, this paper uses econometric models to quantitatively analyze the factors influencing the temporal changes in the country's coal consumption patterns.

\subsection{Index Selection}

China's coal consumption is influenced by many direct and indirect factors, such as coal resource endowments, the level of economic development, technology changes, and characteristics of industry development. After conducting a literature review, China's coal consumption (MC) was selected as the dependent variable. The following were selected as independent variables.

(1) Endowment of coal resources

Geological circumstances ensure that the distribution of coal resources in China is extremely uneven. These resources are concentrated in the northern regions of the Kunlun-Qinling-Dabie Mountains. North China contains the majority of the country's coal resources, accounting for $49.5 \%$ of 
national reserves, followed by Northwest China (30.39\%). Coal production and consumption were mainly concentrated in these areas during the early stages of the country's economic development. For example, the Shanxi and Hebei provinces in North China were the two of the country's biggest coal producers and consumers in 1995. Therefore, natural endowment of coal resources is the most basic factor influencing coal production and consumption, and it determines the direction of regional development, especially at the early stages of development. Therefore, endowment of coal resources, which is represented by coal production (MP), was selected as one of the independent variables.

(2) Level of economic development

China's current economic development mainly relies on coal consumption, and the relationship between economic development and coal consumption has aroused much interest in academic circles [35]. It is essential to analyze the level of economic development when studying coal consumption. In this paper, the gross regional product (GRP) represents the level of economic development.

(3) Urbanization level

Shan et al. showed that China's rural population of 600 million consumes about 192 million tons of raw coal each year [10]. The rural population directly affects coal consumption, and the urbanization level, in turn, can reflect the changes in China's rural population. In this paper, the urbanization level is measured in terms of the proportion of the urban population $(\mathrm{CP})$.

(4) Industrial structure

The country's industrial structure has a direct bearing on its coal consumption. The higher the proportion of the tertiary industry, the lower the coal consumption. In addition, even if the gross regional product remains unchanged, different industrial structures entail varying amounts of coal consumption [12]. Therefore, industrial structure was selected as one of the independent variables, and it is represented by the proportion of tertiary industry output (TE).

In addition, in order to further test for multicollinearity, this paper uses SPSS 19.0 software to calculate the tolerances and variables inflation factors (VIFs) of the four explanatory variables. The results are detailed in Table 2. The tolerances and VIFs are both less than five, and therefore, multicollinearity among the explanatory variables has been eliminated.

Table 2. Test results of multicollinearity among independent variables.

\begin{tabular}{ccccc}
\hline $\begin{array}{c}\text { Independent } \\
\text { Variable }\end{array}$ & MP & GRP & CP & TE \\
\hline Tolerance & 0.877 & 0.806 & 0.604 & 0.643 \\
VIF & 1.140 & 1.241 & 1.655 & 1.554 \\
\hline
\end{tabular}

\subsection{Empirical Process}

Table 3 presents the results of the Lagrange multipliers estimated by the least squares method, which could be used as criteria for judging the manner of selection of the space model. The Lagrange multiplier (lag) passes the test at the significance level, but the Lagrange multiplier (error) fails to do so. Thus, compared to the SEM, the SLM is more appropriate. 
Table 3. Results of the Lagrange multiplier judgment.

\begin{tabular}{cccc}
\hline TEST & MT/DF & VALUE & PROB \\
\hline $\begin{array}{c}\text { Moran's I (error) } \\
\text { Lagrange Multiplier (lag) }\end{array}$ & 0.2135 & 4.1579 & 0.0327 \\
$\begin{array}{c}\text { Robust Lagrange } \\
\text { Multiplier (lag) } \\
\text { Lagrange Multiplier } \\
\quad(\text { error) }\end{array}$ & 1 & 4.6864 & 0.0367 \\
$\begin{array}{c}\text { Robust Lagrange } \\
\text { Multiplier (error) } \\
\text { Lagrange Multiplier } \\
\text { (SARMA) }\end{array}$ & 1 & 3.5206 & 0.0320 \\
\hline
\end{tabular}

According to Table 4, compared with the results by the least squares method, the regression coefficients of the SLM are corrected, and the goodness of fit increases from 0.85 to 0.87 . Thus, the explanatory ability is enhanced. Furthermore, the value of the log likelihood significantly increases to some extent, the Akaike information criterion (AIC) and Schwarz criterion (SC) decrease, and the estimated result of the SLM is thus more stable.

Table 4. Maximum likelihood estimation results of the econometric model.

\begin{tabular}{ccccc}
\hline \multirow{2}{*}{ Variable } & \multicolumn{2}{c}{ OLS } & \multicolumn{2}{c}{ SLM } \\
\cline { 2 - 5 } & Coefficient & $\boldsymbol{P}$-Value & Coefficient & $\boldsymbol{P}$-Value \\
\hline C & 8111.0 & 0.0062 & 6642.4 & 0.0045 \\
MP & 1.1744 & 0.0000 & 1.0966 & 0.0000 \\
GRP & 0.2989 & 0.0000 & 0.2900 & 0.0000 \\
CP & 38.861 & 0.1247 & -69.808 & 0.0768 \\
TE & -123.04 & -0.0902 & -95.977 & 0.0861 \\
$\rho$ & - & - & 0.3159 & 0.0149 \\
$R^{2}$ & 0.8516 & & 0.8735 & \\
Log likelihood & -297.07 & & -273.73 & \\
AIC & 584.13 & 571.47 & \\
SC & 591.30 & & 583.07 & \\
\hline
\end{tabular}

The value of $\rho$ in the SLM is 0.3159 , and the corresponding $P$-value is $1.49 \%$, which means that the SLM passes the test at the $5 \%$ significance level, and the model is appropriate in the given context. Since the coal production (MP) and gross regional production (GRP) of the model also pass the test at the $1 \%$ significance level, and the proportion of urban population (CP) and the proportion of tertiary industry output (TE) pass the test at the 10\% significance level, it can be concluded that the model fits well.

Additionally, the Breusch-Pagan test was used to test heteroscedasticity for the spatial lag model. The results provide a test value of 3.6598 , and the $P$-value is 0.4540 , indicating that there is no heteroscedasticity in the spatial lag model and that the fitting model coincides well with the theoretical assumption.

\subsection{Main Conclusion}

(1) There is a significant spatial clustering effect of coal consumption among provinces. The value of $\rho$ in the SLM is 0.3159 , which means that the coal consumption of two adjacent provinces follows the same trend; in other words, provinces with high coal consumption cluster together as do those with low coal consumption. Factors such as geographical position, resource endowment, and transportation costs may be attributed to this phenomenon. 
(2) The increase in coal production drastically increases coal consumption. There is a significant positive correlation between coal production and coal consumption for all provinces, and the correlation passes the test at the $1 \%$ significance level. The regression coefficient of the model is 1.0966 , which means that when regional coal production increases by 10,000 tons of standard coal, coal consumption will increase by 10,966 tons of standard coal. The fact that coal consumption is higher than production suggests that a gap exists between the supply and demand of China's current coal consumption. It is still necessary to import coal, especially in the southeast coastal areas, to completely meet consumption needs. China's coal imports increased rapidly from 126 million tons in 2009 to 327 million tons in 2013 and increased by $160 \%$ in four years since China's change in role from a net exporter to a net importer of coal. In addition, Wang et al. (2013) predicted that China's coal production will peak in 2025, its coal demand will reach 612 million tons according to conservative estimates, and imports will rise to 222 million tons, accounting for $36.27 \%$ of the coal demand. It is thus increasingly urgent to adjust the structure of China's energy consumption and reduce its coal consumption.

(3) Some provinces suffer from resource depletion and environmental pollution, which are masked by economic development. Here, the correlation between the level of economic development and coal consumption is positive and significant at the $1 \%$ level. In the SLM, the regression coefficient of GRP is 0.2900 ; thus, when the GRP increases by 100 million yuan, coal consumption will increase by 0.2900 tons of standard coal. However, China's energy consumption intensity in 2012 was 0.8012 tons of standard $\mathrm{coal} / \mathrm{ten}$ thousand yuan, which is 3.3 times that of the United States and 2.5 times that of the world average. This result also indirectly confirms that China's energy consumption is still largely dependent on coal. Rapid economic growth across the country has dramatically increased the consumption of energy resources, particularly coal, which shows that China's economic development comes at the expense of high energy costs, environmental pollution, and ecological imbalance. Therefore, scholars increasingly focus on advocating a sustainable and environmentally friendly pattern of economic development, and provinces of high-energy consumption should focus on these aspects in particular.

(4) The urbanization level is an important factor affecting coal consumption. To some extent, the proportion of the urban population reflects the level of urbanization, and it is negatively related to coal consumption. In the SLM, the regression coefficient of the proportion of urban population is -69.808 and is significant at the $10 \%$ level, showing that when the proportion of the urban population is increased by $1 \%$, coal consumption will reduce by 698,080 tons of standard coal. Coal consumption mainly includes industrial coal and residential coal. Moreover, the use of coal for space heating and cooking in China's rural areas is increasing [10]. Compared with the urban population, the rural population consumes more coal, thus indicating why the urbanization level affects coal consumption.

(5) There is negative correlation between the proportion of tertiary industry output and coal consumption. In the SLM, the regression coefficient of the proportion of tertiary industry output is -95.977 , and it is significant at the $1 \%$ level; if the proportion of tertiary industry output is increased by $1 \%$, coal consumption will reduce by 959,770 tons of standard coal. The secondary industry mainly includes the industrial sector and the construction industry, whose energy consumption is very high, especially the heavy industry. In contrast, the tertiary industry consumes less energy. In 2013, China's first, second, and third industry proportions were 15\%,52\%, and 33\% respectively, and the corresponding world averages are $5 \%, 31 \%$, and $64 \%$. These results indicate that China should be proactive in adjusting its industrial structure by promoting the development of the tertiary industry, and reducing energy consumption effectively.

\section{Recommendations}

The distribution patterns of China's coal consumption have changed over time. The coal consumption of China's provinces and regions is increasing, but its growth rates differ across provinces. Thus, the regional differences are narrowing. In addition, the empirical results show that coal production, level of economic development, industrial structure, and other factors have an effect on the distribution patterns of China's coal consumption. Therefore, after uncovering the characteristics 
of the temporal and spatial patterns of China's coal consumption, the results of this paper drive us to make the following recommendations.

\subsection{Management of Coal Resources by Regional Differentiation and Improving Interaction among Provinces} and Regions

Coal resource endowments obviously differ among China's provinces and regions. Thus, it is necessary to devise and implement customized management policies concerning coal resources. The northern regions, which are rich in coal resources, should tap them strategically. The manner of utilization of the existing coal resources (e.g., conversion rate) should be improved, and clean energy options should be explored simultaneously. Efforts should be made to conserve coal resources and ensure that sustainable utilization patterns are achieved and maintained. In addition, areas with poor coal resources can tap into other local resources like wind and solar energy. Energy-saving mechanisms and technological advancements can help provinces conserve, develop, and expand their renewable energy resources.

The obvious spatial correlations in China's coal consumption mean that coal consumption will be affected by that of the neighboring provinces. Thus, policy makers should consider not only the energy environment in the given region but also the influences of neighboring provinces on the coal consumption of that region. Besides, coordinated regional development, strengthened communication between neighboring provinces and regions, and improved technology and skill sets can help overcome the barriers inherent between areas of high-energy consumption and low-energy consumption.

\subsection{Improving Coal Transportation Capacity and Alleviating the Imbalance between Coal Supply and Demand}

The empirical results show increasing coal production can promote coal consumption on the whole, but the degree to which coal production affects coal consumption varies among the provinces and regions. Comparing coal production and coal consumption among China's provinces and regions shows that the trends in China's coal supply and demand are reverse of those indicated by the geographical distribution. Provinces with higher coal production usually have lower coal consumption, such as in Shanxi province and Inner Mongolia, whose coal consumption is far less than the production. Further, provinces with lower coal production usually have higher coal consumption, as in the case of Guangdong province and Jiangsu province, whose coal consumption is significantly greater than their production. The huge spatial mismatch between coal production and consumption is one of the most important causes of the imbalanced distribution patterns of coal consumption.

In order to maintain the balance between coal supply and demand, China has resorted to long-distance coal transportation, which, however, is plagued by various problems such as high cost and low transport efficiency. The government should thus actively improve its coal transportation network and introduce advanced equipment and technology to enhance the efficiency of coal transportation. Such initiatives would ensure the stable development of the coal transportation industry, easing the contradictions between coal supply and demand across China's provinces and regions.

\subsection{Speeding up the Process of Urbanization and Promoting Clean Energy}

As stated previously, certain provinces and regions of China have sacrificed the environment and ecological balance in the pursuit of economic development. One of the key reforms of China's government, urbanization has a decisive influence on the creation of a harmonious society and optimal allocation of resources. Besides, the results of the above analysis show that increasing urbanization is beneficial to reducing coal consumption. Therefore, in order to realign coal consumption patterns, the government should actively promote the urbanization process. Moreover, urbanization should be pursued in a planned scientific manner based on local realities such as resource availability, the level of industrial development, resource consumption, state of the environment, and available scientific 
knowledge and technology. Additionally, the proportion of coal usage may be reduced significantly by improving coal usage efficiency and promoting clean energy resources such as solar and wind energy.

\subsection{Adjusting the Industrial Structure and Raising the Proportion of the Tertiary Industry}

Currently, China's secondary industry accounts for a bigger proportion of its total industry, and the growth in the heavy industry further increases this proportion. Therefore, it is necessary to control the speed and scale of the development of the secondary industry and heavy industry sectors. Industrial applications that require excessive use of iron, steel, and cement require novel technologies to optimize their coal consumption. Simultaneously, the industrial structure should be adjusted reasonably in order to actively promote its transformation into a structure dominated by the tertiary industry. These efforts would help create a "low investment, low consumption, high efficiency" pattern of economic development. It is also necessary to improve industrial productivity and support investment to new industries that can promote economic growth and reduce coal consumption, and realign the regional industry layout.

\section{Conclusions}

Some scholars, such as Elliott et al. [26], have analyzed economic issues at the city level. However, the manner and type of data collection for coal consumption differ among cities. Moreover, many a time, the data are incomplete, which may influence the accuracy and reasonableness of the model. Improvements in China's energy data collection will help researchers conduct more detailed analyses on coal consumption at the city level in the near future.

Acknowledgments: This research is supported by the Supporting Project for Characteristic Subject Construction at Dongbei University of Finance and Economics (No: XKT-201413) and the Collaborative Innovation Project for Energy Economics of Shandong Province (No: 2014SDXT013).

Author Contributions: Yuhuan Sun had the original idea for the study. Qian Li was responsible for data collection. Yuhuan Sun, Qian Li, and Ting Chen carried out the analyses. All authors drafted the manuscript and have read and approved the final version.

Conflicts of Interest: The authors declare no conflict of interest.

\section{References}

1. Shahbaz, M.; Hye, Q.M.A.; Tiwari, A.K.; Leitão, N.C. Economic growth, energy consumption, financial development, international trade and $\mathrm{CO}_{2}$ emissions in Indonesia. Renew. Sustain. Enery Rev. 2013, 25, 109-121. [CrossRef]

2. Song, M.L.; Wang, S.H.; Yu, H.Y.; Yang, L.; Wu, L. To reduce energy consumption and to maintain rapid economic growth :Analysis of the condition in China based on expended IPAT model. Renew. Sustain. Enery Rev. 2011, 15, 5129-5234. [CrossRef]

3. Bhattacharya, M.; Rafiq, S.; Bhattacharya, S. The role of technology on the dynamics of coal consumption-economic growth: New evidence from China. Appl. Energy 2015, 154, 686-695. [CrossRef]

4. Bloch, H.; Rafiq, S.; Salim, R. Coal consumption, $\mathrm{CO}_{2}$ emission and economic growth in China: Empirical evidence and policy responses. Energ. Econ. 2012, 34, 518-528. [CrossRef]

5. Zhang, W.; Yang, S. The influence of energy consumption of China on its real GDP from aggregated and disaggregated viewpoints. Enery Policy 2013, 57, 76-81. [CrossRef]

6. Gurgul, H.; Lach, L. The role of coal consumption in the economic growth of the Polish economy in transition. Enery Policy 2011, 39, 2088-2099. [CrossRef]

7. Lei, Y.; Li, L.; Pan, D. Study on the relationships between coal consumption and economic growth of the six biggest coal consumption countries: With coal price as a third variable. Energy Procedia 2014, 61, 624-634. [CrossRef]

8. Shahbaz, M.; Kumar, T.A.; Nasir, M. The effects of financial development, economic growth, coal consumption and trade openness on $\mathrm{CO}_{2}$ emissions in South Africa. Enery Policy 2013, 61, 1452-1459. [CrossRef] 
9. Tiwari, A.K.; Shahbaz, M.; Hye, Q.M.A. The environmental Kuznets curve and the role of coal consumption in India: Cointegration and causality analysis in an open economy. Renew. Sust. Energy Rev. 2013, 18, 519-527. [CrossRef]

10. Shan, M.; Wang, P.S.; Li, J.R.; Yue, G.X.; Yang, X.D. Energy and environment in Chinese rural buildings: Situations, challenges, and intervention strategies. Build. Environ. 2015, 31, 271-282. [CrossRef]

11. Chen, F.; Shen, L.; Liu, L.; Gao, T.M. Spatial differences of exergy use of cement manufacturing industry in China based on extended exergy accounting method. J. Geogr. Sci. 2015, 25, 1393-1407. [CrossRef]

12. Liu, M.Z.; Wang, R.; Zhou, M.H.; Zhang, J. The comparative analysis of regional coal consumption effect in China-empirical evidence based on panel data model. Resour. Sci. 2011, 39, 1641-1649. (In Chinese)

13. Guo, J.; Wang, L.; Sun, P. The analysis of influencing factors of Chinese regional energy consumption intensity. Resour. Sci. 2009, 31, 205-213. (In Chinese)

14. Chuai, X.W.; Huang, X.J.; Wang, W.J.; Wen, J.Q.; Chen, Q.; Peng, J.W. Spatial econometric analysis of carbon emissions from energy consumption in China. J. Geogr. Sci. 2012, 22, 630-642. [CrossRef]

15. Herrerias, M.J.; Cuadros, A.; Orts, V. Energy intensity and investment ownership across Chinese provinces. Energ. Econ. 2013, 36, 286-298. [CrossRef]

16. Ren, Z.Y.; Li, Q. The temporal and spatial differences of China's energy production and consumption since 1978. Acta Geogr. Sin. 2008, 12, 1318-1326. (In Chinese)

17. Zhang, L.X.; Yang, Z.F.; Liang, J.; Cai, Y.P. Spatial variation and distribution of urban energy consumption from cities in China. Energies 2011, 4, 26-38. [CrossRef]

18. Gao, C.; Wang, X.Y.; Jiang, T.; Jin, G. Spatial distribution of archaeological sites in lakeshore of Chaohu Lake in China based on GIS. Chin. Geogr. Sci. 2009, 19, 333-340. [CrossRef]

19. Buch, C.; Kokta, R.; Piazoloc, D. Foreign direct investment in Europe: Is there redirection form the south to the east? J. Comp. Econ. 2003, 31, 94-109. [CrossRef]

20. Jin, X.; Dong, S.; Luo, L.; Li, Y.; Yuan, C.; Shu, K.; Chen, J. Environment effects of foreign trade and its spatial variations in mid-eastern provinces and cities in China. Chin. Geogr. Sci. 2012, 22, 626-636. [CrossRef]

21. Anselin, L. A test for spatial autocorrelation in seemingly unrelated regressions. Econ. Lett. 1988, 28, 335-341. [CrossRef]

22. National Bureau of Energy Statistics Division. China Energy Statistical Yearbook; China Statistics Press: Beijing, China, 2013. (In Chinese)

23. Department of Comprehensive Statistics of National Bureau of Statistics. China Compendium of Statistics 1949-2009; China Statistics Press: Beijing, China, 2009. (In Chinese)

24. Department of Comprehensive Statistics of National Bureau of Statistics. China Statistical Yearbook; China Statistics Press: Beijing, China, 2013. (In Chinese)

25. Bureau of Tibet Autonomous Region. Tibet Statistical Yearbook; China Statistics Press: Beijing, China, 2013. (In Chinese)

26. Elliott, R.J.R.; Sun, P.Y.; Chen, S.Y. Energy intensity and foreign direct investment: A Chinese city-level study. Energy Econ. 2013, 40, 484-494. [CrossRef]

(C) 2015 by the authors. Licensee MDPI, Basel, Switzerland. This article is an open access article distributed under the terms and conditions of the Creative Commons Attribution (CC BY) license (http:/ / creativecommons.org/licenses/by/4.0/). 
Article

\title{
Intermediary Propositions for Green Growth with Sustainable Governance
}

\author{
Yongrok Choi \\ Department of International Trade and Regional Studies, Inha University, 100 Inha-ro, Nam-gu, Incheon 402-751, \\ Korea; yrchoi@inha.ac.kr; Tel.: +86-791-8381-0553; Fax: +86-791-8381-0892
}

Academic Editors: Giuseppe Ioppolo, Malin Song and Seunghwan Myeong Received: 24 September 2015; Accepted: 3 November 2015; Published: 5 November 2015

\begin{abstract}
This article gives an overview of the conceptual characteristics of sustainable development by searching the governance-oriented intermediaries. It shows how the new paradigm of green growth evolved through international consensus and how this paradigm of the public-private partnership (PPP) could work with the new propositions of intermediation. The historical context in the latter half of the 20th century is outlined, in which a paradigm shift toward PPP was caused by green growth policies. It emphasizes the governance, resulting in the propositions of the intermediary role of PPP by the SWOT matrix: facilitator, collaborator, network manager and service provider.
\end{abstract}

Keywords: public-private partnership (PPP); intermediary propositions; facilitator; SWOT matrix; green growth

\section{Introduction}

Within the turn of the 21st century, humankind in the world has been experiencing rapidly-changing environmental conditions, resulting in the turmoil of a paradigm shift. Global warming and the environmental crisis worldwide are some of the phenomena of the fourth revolution of the green wave. For example, China faces huge environmental and air-cleanup challenges and costs, which it is undertaking on its own. The country estimates that pollution cost it roughly $3.5 \%$ of GDP in 2010, and life expectancy in the Northern provinces has decreased by about 5.5 years due to air pollution [1]. Almost 75 percent of China's biggest cities failed to meet the country's environmental protection standards, and only 19 of China's 74 larger cities met the standards. It is not uncommon for air pollution in most parts of China to breach levels considered by some experts to be hazardous. That has drawn much public ire and is a worry for the government, which fears any discontent that might compromise stability. At last, China declared a "war on pollution" at the opening of the annual meeting of parliament on March 2014. The government unveiled detailed measures to tackle what has become a hot-button social issue. Curbing pollution has become a key part of efforts to upgrade the economy, shift the focus away from heavy industry and tackle the perennial problem of overcapacity, describing smog as "nature's red-light warning against inefficient and blind development" [2]. China should get rid of the so-called global factory and instead take a new step toward qualitative selection to curb its growth potential. China will cut outdated steel production capacity by a total of 27 million tonnes in the year 2015, slash cement production by 42 million tones and also shut down 50,000 small coal-fired furnaces across the country. It is a huge loss serving as a bottleneck for growth potential.

By the same token, Korea and Japan have been experiencing the challenging issues of environmental disasters and, thus, strongly promoted eco-friendly sustainable economic development policies, so-called green growth. Now, green growth is not just an optional alternative, but the survival kit to overcome the environmental crisis across the world. Here, green growth means fostering economic growth and development while ensuring that natural assets continue to provide 
the resources and environmental services on which our well-being relies. To do this, it must catalyze investment and innovation, which will underpin sustainable growth and give rise to new economic opportunities. Sustainable development provides an important context for green growth. Here, sustainable development is defined, in general, as the development that meets the needs of the present without compromising the ability of future generations to meet their own needs [3]. Green growth is not an alternative way of sustainable development, but rather should be considered a subset of it, entailing an operational policy agenda that can help achieve concrete, measurable progress at the interface between economic needs and the environment [4]. That is the reason for this research in examining the feasibility of green growth policies in Northeast Asian countries.

Green growth is based on the theory of green economics, or greenomics in short, and it represents the fourth wave followed by the agricultural, industrial and IT industrial (or Internet-oriented) revolutions in world history. Greenomics is not just based on economics and interdisciplinary study, but is based on innovative or even creative multi-disciplinary studies, because greenomics, as a core of sustainable development, resulted from revolutionary technological innovation, likewise proceeding from the other three revolutions. From the perspective of sustainable development, economic growth and environmental protection cannot be integrated easily (coupling issue), and thus, it should be multi-dimensional and interdisciplinary at its core. However, the technical revolution has filled this missing link between economic demands and environmental protection, resulting in the feasibility of decoupling great potential for higher economic development and a better quality of life [5]. The reduction of greenhouse gases (GHG) may result in increased cost and/or productivity loss by traditional measures, while it creates new frontiers for renewable energy industries, green financing, etc. Moreover, green growth policies even increase the performance of the traditional "brick" industries by the creation of value: invisible long-term profits coming from the loyalty of huge interest groups. Global warming and the environmental crisis are no longer threats, but challenging opportunities for all countries, regardless of their economic level and/or cultural differences [6] (p. 7). Thus, we can call this phenomenon the new green wave, consisting of green growth policies and strategies, as the fourth revolutionary paradigm shift in human history.

Green growth is a much more practical concept in its details, compared to the more abstract terms and conditions of sustainable development, because it is based on practical, as well as feasible policies of governments and strategies of the private sector [7]. This brings the background of this research. The research shall overview most of the revolutionary factors of green growth in terms of a comparison of different policies and business strategies and examine their feasibility using the theoretical modeling of SWOT analysis. Based on the SWOT matrix, the research shall propose the feasible role and functions of the public-private partnership (PPP) as the best alternative intermediary to fill the missing link of the paradigm shift of green growth.

The remainder of this paper is organized as follows. In Section 2, the background of the green growth paradigm shall be examined. Section 3 shall analyze the paradigm shift of green growth by a comparative analysis in major countries, utilizing the SWOT matrix for the feasibility of the intermediation of the PPP. Section 4 shall conclude with the limits of this research and future prospects of green growth.

\section{Paradigm Shift to Green Growth}

\subsection{Historical Background of the Paradigm Shift}

The interrelationship between technology, productivity and growth has long been discussed along the history of human civilization. The importance of technological innovation cannot be overestimated with relation to the paradigm shift over time. It is the central determinant of the long-term success or failure of organizations [8]. Based on this technological innovation in history, the first agricultural revolution in the pre-history era was a great stepping stone for mankind to take off toward civilization for thousands of years. It is called the "classical economy" based on the self-sufficiency paradigm, 
represented by the famous Say's law; supply creates its own demand. The second industrial revolution, symbolized by steam and railroads in Britain during 1780-1860 and then in the following 300 years over the world, brought mass-production, mass-media and mass-consumption by the new paradigm of economies of scale; the more you produce, the higher the productivity you get. After World War I and II, the innovative inauguration of the computer and its consecutive ICT (information and communication technology) enhancement successfully transformed the whole of society with the new paradigm of economies of networking, serving as a new economic engine and for better life quality for 30 years. This new paradigm of economies of networking changed the mass-quantity-based economies into the quality-oriented smart revolution; the more you share information and experiences, the better you "create" values by group intelligence. Especially, the Internet has accelerated the new era of "knowledge" since the year 2000. The popular slogan in the industrial revolution era, stating that "information is power and money", has been changed, by the flood of information on the Internet, into the new slogan of "knowledge allows you to make smart decisions and perform smart activities". Here, new knowledge is defined as the information to select the best alternative [9].

The quality-oriented paradigm shift caused a diverse innovative way of thinking, and it caused the fourth revolution of the green wave, as well. The industrial revolution caused energy-intensive industries to dominate all of the economic development processes in every country. It caused too much environmental problems, such as deforestation, greenhouse gas emission, water pollution, etc., resulting in too frequent, unforeseeable disasters, such as floods, droughts, earthquakes, toxic air and water and melting down of glaciers. Every country should face the challenges of sustainable development under this unforeseeable disaster, and at last, sustainable development should became the core of qualitatively-enhanced economic policies.

In order to understand the historical background of the green wave, we need to systematically organize the trend of sustainable development first. Sustainable development, a concept that emerged in the context of a growing awareness of an imminent ecological crisis, could be more seriously addressed from the 1980s onward. From the perspective of policy-oriented practical terms, the United Nations Conference on the Human Environment (UNCHE) held in Stockholm, Sweden, in 1972 should be recorded as the first cornerstone toward the green wave, because it was the first major international gathering focused on human activities in relationship to the environment. The conference acknowledged that the goal of reducing human impact on the environment would require extensive international cooperation, as many of the problems affecting the environment are global in nature; caused by one country locally, while affecting other countries. Following this conference, the United Nations Environmental Program (UNEP) was launched in order to encourage United Nations agencies to integrate environmental measures into their programs in 1972. Following UNCHE and UNEP, the United Nations commissioned a group of 22 people from developed and developing countries to identify long-term environmental strategies for the international community. This World Commission on Environment and Development (WCED), better known as the Brundtland Commission, submitted their report, entitled "Our common future", to the UN in 1987 (WCED 1987). The Brundtland Report focused primarily on the needs and interests of humans and was concerned with securing global equity for future generations by redistributing resources towards poorer nations to encourage their economic growth in order to enable all human beings to achieve their basic needs (see Figure 1). The basic paradigm of the Brundtland Report became the platform for all of the following international action plans [10]. The green growth paradigm can be summarized by the triple bottom line (TBL) as an accounting framework with three parts of social, environmental (or ecological) and economic sustainability in Figure 1. Sustainable development policies should be socially equitable, economically viable and environmentally bearable. Unfortunately, it is not easy to find the best solution, but at the same time, it is not impossible to find the optimal path to control for all of these criteria.

Based on the Brundtland Report, the United Nations Conference on Environment and Development (UNCED), also known as the Rio Summit, Rio Conference or Earth Summit, was held to obtain a more systematic action plan to initiate sustainable development worldwide at Rio de 
Janeiro in 1992. An important achievement was an agreement on the Climate Change Convention (UNFCCC), which, in turn, led to the Kyoto Protocol. UNFCCC is an international environmental treaty and currently the only international climate policy venue with broad legitimacy, due in part to its virtually universal membership negotiated at the UNCED. The objective of the treaty is to "stabilize greenhouse gas concentrations in the atmosphere at a level that would prevent dangerous anthropogenic interference with the climate system" [8]. The treaty is considered legally non-binding, but provides a framework for negotiating specific international treaties (called "protocols") that may set binding limits on greenhouse gases (GHG). The UNFCCC was adopted in 1992 and entered into force in 1994 with 196 member parties as of March 2014. The parties to the convention have met annually from 1995 in Conferences of the Parties (COP) to assess progress in dealing with climate change.

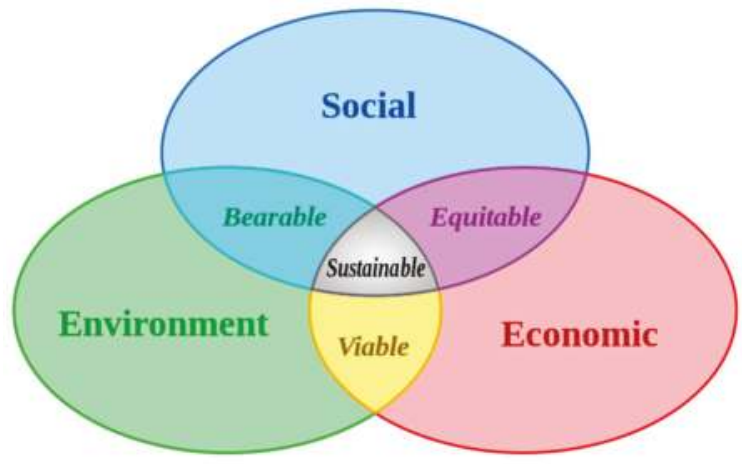

Figure 1. Paradigms of sustainable development (tree polar layer, TPL). Source: sustainable development from Wikipedia [11].

In 1997, the Kyoto Protocol was concluded and established legally-binding obligations for developed countries to reduce their six GHG emissions of $\mathrm{CO}_{2}, \mathrm{CH}_{4}, \mathrm{~N}_{2} \mathrm{O}, \mathrm{HFC}, \mathrm{PFC}_{\mathrm{S}}$ and $\mathrm{SF}_{6}$. The Kyoto Protocol has had two commitment periods, the first of which lasted from 2005-2012 and the second 2012-2020. It made flexible mechanism for the successful governance of performance, such as Joint Implementation (JI), the Clean Development Mechanism (CDM) and the Emission Trading System (ETS). One of the first tasks set by the UNFCCC was for signatory nations to establish national greenhouse gas inventories of greenhouse gas (GHG) emissions and removals, which were used to create the 1990 benchmark levels for accession of Annex I countries to the Kyoto Protocol and for the commitment of those countries to GHG reductions. Updated inventories must be regularly submitted by Annex I countries. The Kyoto Protocol has been ratified by all of the other Annex I Parties. All Annex I Parties, excluding the U.S., have participated in the first Kyoto commitment period. Thirty seven Annex I countries and the EU have agreed to second-round Kyoto targets. Unfortunately, the U.S. has not ratified the Kyoto Protocol, and thus, it created a great bottleneck for all of the other parties to move toward the post Kyoto Protocol regime. Following the Kyoto Protocol, parties to the Convention (COP) have agreed to further commitments. These include the Bali Action Plan (2007), the Copenhagen Accord (2009), the Cancún agreements (2010) and the Durban Platform for Enhanced Action (2012). The 2010 Cancún agreements state that future global warming should be limited to below $2.0^{\circ} \mathrm{C}\left(3.6^{\circ} \mathrm{F}\right)$ relative to the pre-industrial level. The Copenhagen Accord by COP-15 mentioned the "Copenhagen Green Climate Fund", and via Cancún agreements (2010), its governing instrument was adopted at the COP 17 (2012) in Durban.

The Green Climate Fund (GCF) is a fund within this framework of the UNFCCC founded as a mechanism to redistribute money from the developed to the developing world, in order to assist the developing countries with adaptation and mitigation practices to counter climate change. The GCF is based on the new Songdo district of Incheon, Korea. It is governed by a board of 24 members and 
initially supported by an interim secretariat. GCF will support projects, programs, policies and other activities for developing country parties using thematic funding windows [12]. It is intended to be the centerpiece of efforts to raise climate financing of $\$ 100$ billion a year by 2020 . This is not an official figure for the size of the fund itself, however. Disputes also remain as to whether the funding target will be based on public sources or whether "leveraged" private finance will be counted towards the total amount [13].

Over time, sustainable development has transformed into green growth, as the latter emphasizes more the fact that it is essential to "decouple" economic growth from unsustainable environmental pressures, such as those leading to global climate change. Decoupling of economic development from the pressure of environmental protection gave great opportunities for governments and companies to create values in an innovative way through technological development, and it was a great, imperative stepping stone to proliferate the green wave [14]. For example, under the sustainable development perspectives, it has been said that shifting the energy mix towards cleaner sources of energy and cleaning up polluting sources of energy, such as with carbon capture and sequestration, will also tend to raise energy costs, at least for a period of time. By contrast, under the green growth perspective, investments in energy-efficient "new" technology in industries can be cost effective, with benefits cumulating over time. Unfortunately, there is no automatic link between cleaner energy and better market performance, but these goals can often be made to be complementary.

This is the basic paradigm of green growth; the better the life quality, the healthier the economy and the more equitable is society due to the innovative way of decoupling. However, the green wave as the fourth revolution may have a flexible and diverse means of complementary promotion depending on the circumstances and cultural background of the countries. Every country should choose its own differentiated policies for its own green growth. There is no universally agreed-upon political paradigm. Nonetheless, the most important mission at this moment is to set up the global standards for this green wave, because "new" technology, "new" product and "new" green business affect not only the green growth economy, but also the whole of society, as the Internet revolution made a great impact on the daily life of all economic entities, as well as society itself. Unfortunately, the global standards as the cornerstone for the world to take off toward the next generation of the green wave are still in their midst. All of the new global standards should be defined in terms of new technology as the basic engine, new financing to boost this new innovative phenomenon and changing the way of thinking to maintain and expand the new phenomena. All of these three facets are related to the global standards, and thus, the competition for the global standards is rather fierce, even if it is invisible. All of the governments and global companies take these global standards to lead the global wave with their individual strategies or policy paradigms. Therefore, it is really important to compare these paradigms of countries to green growth in the next section.

\subsection{Comparison of the Green Growth Paradigms}

The global economy has been slowly recovering from the economic crisis in 2007. However, the speed and performances are different from one country to another due to the surrounding circumstances and differences in the policy paradigm. This is especially true from the perspective of green growth. Most of the developing countries cannot emphasize the importance of environmental issues. Rather, these countries should put more efforts toward the rapid recovery of the ever-slowly-growing economies. Even so, their individual policy mechanisms and social paradigms are different from each other. Moreover, even one country may change its emphasis or paradigm over time. China has been called "the global factory", and "made-in-China" has meant the lowest price in the world. However, this is not so anymore, because recently, the Chinese government has become intensively aware of air pollution and the natural disasters arising from environmental aggravation. Since 2006, the Chinese 12th five-year economic development plan has begun to put more effort toward the feasibility of decoupling in major industries and, thus, investing more in technological innovation to decrease energy intensiveness and increase eco-friendly productivity. For this purpose, 
the Chinese government set up new rules and regulations with many more subsidies and promotional policies. It is quite clear that the Chinese government set up the new paradigm on green growth with government-led, regulatory-oriented policies [15].

Compared to China, the Korean government has taken a more rigid regulatory regime with the belief that the government-led policies shall result in much faster performance and higher efficiency to lead the global green growth [16]. This government-led paradigm on economic development has been successful, at least in the past, but no longer in Korea, because the economy has been enormously expanded with respect to its volume, and thus, it became much more complicated than before. Especially, the Korean economy has suffered from sluggish growth of the labor force and capital investment into its economy, thus experiencing an about $0 \%$ growth era at present. The input-promoted quantitative economic growth in Korea cannot no longer be sustained. Instead, innovation-oriented qualitative economic development is necessary with an aging society [17]. Moreover, the major companies in Korea, such as Samsung and Hyundai cars, are more aware of global competitiveness than local political pressure, because the Korean economy is based on international trade with an export-oriented economic structure. Therefore, the regulatory regime toward green growth is no longer efficient and effective in this innovation-oriented and very complicated economy.

Nonetheless, the Korean government hosted the Green Climate Fund (GCF) at Incheon in 2012. Thus, it has strongly promoted green growth policies since 2008. Based on the Framework Act on Low Carbon, Green Growth, the Korean government inaugurated the greenhouse gas and energy target management system (TMS) for the 470 largest companies since 2012 and carbon emission trading system (ETS) nationwide in 2015. The political paradigm for green growth is so firm in Korea, that the market should follow the optimal path toward green growth. It is noteworthy that most of the Korean companies and the public are very adaptive to the new trend and/or policies, and thus, there is optimism that the Korean economy will promote green growth strategies in a more pro-active way [18].

Compared to the other two Northeast Asian countries, Japan has taken the highest level of the government-led paradigm on green growth. It comes from the cultural background. Most of the private sector in Japanese tends to harmonize itself with the networking society, and thus, the social leaders of government and some intermediaries of business associations may have a strong impact on social activities and economic decisions. Even if the Japanese government does not clearly regulate much of the details of the green growth strategies, as long as the government propagates the objective goal of green growth, most companies and the public may follow without much reluctance [19]. Specifically, the Japanese government led the Kyoto Protocol, one of the strongest measures to curb $\mathrm{CO}_{2}$ emissions worldwide; thus, without many visible regulatory measures, the Japanese economy has been transforming slowly, but effectively toward green growth. However, the Japanese government may face the dilemma for green growth between normative leadership and the practical burden of green growth. This set off the Kyoto Protocol, and it successfully performed its commitment to decrease $6 \%$ of carbon emissions compared to the basic year of 1990, as the leading Annex I country. However, the dropping of the USA and the passive attitudes of many other major countries with respect to the Commitment, such as China, made the Japanese government hold back from a more active role toward the post-Kyoto regime. Now, the Japanese government faces the utmost fatigue from the Kyoto Protocol regime and thus needs more strong leadership for more voluntary partnerships, not only from the outside of the country, but also from local companies and the public to re-take the challenging path of green growth [20].

As Northeast Asian countries take the government-led regulatory regime toward green growth, the opposite extreme case could be found in the United States. The basic paradigm of the United States may come from the passive intervention of the market by the government with the more market-friendly promotion of green technologies. The diverse economic policies related to green growth are not exceptional. Thus, the United States could not enter the Kyoto Protocol due to the strong opposition of the private sector against the government decision for green growth. Nonetheless, some local governments and global companies, such as California and Wal-Mart, have taken strong 
measures to utilize the new opportunities of green growth more aggressively with a regulatory frame, while most of the economy is experiencing the slow, but steady steps toward green growth. Even if there are several environmentally-friendly protective measures on the government side, still most of the green growth strategies are not yet ready for a market- and eco-friendly platform. Unfortunately, the market cannot respond effectively to the green growth paradigm, and it takes too much time for the market to find the right way toward global standards. Therefore, it is a great task for the government to lead the market more efficiently and effectively toward global green standards. Otherwise, it is afraid of the potential huge loss when it loses the leadership of the fifth green growth revolution worldwide. For this purpose, it may need to consider the strong connection to the private sector to actively lead the global trend of green growth.

On the contrary, the European Union (EU) takes another extreme paradigm on the spectrum of the government's role. With the successful implementation of the Kyoto Protocol, the EU Commission set up the Directorate-General for Climate Action (DG CLIMA) to lead the European Commission's efforts to fight climate change at the EU and international level. It runs the European EMS (Environmental Management System) with the mission to formulate and implement climate policies and strategies, to take a leading role in international negotiations on climate, to implement the EU's Emissions Trading System (EU ETS), to monitor national emissions by EU member countries and to promote low-carbon technologies and adaptation measures in 2010. EU is at the front in dealing with green growth activities with diverse efforts to promote the development of low-carbon technologies and adaptation measures, especially by creating regulatory frameworks to guide the deployment of these technologies and by providing diverse financial support. However, their regulatory platform is rather passive and related to many more promotional policies toward the incentive areas of green growth by green financing. Therefore, the paradigm of the EU could be promotional, even somewhat government led, and the financing approach by the EU is noteworthy. It introduced the carbon Emission Trading System (ETS), the first in the world, and expanded it much more aggressively than any other part of the world, even under the global economic crisis. The strong support of the ETS turned the environmental issues into purely internalized economies outside of external factors. Even if the ETS has had fluctuating prices, as well as concerns for the future of the ETS itself, it still covers almost all of the economic decisions, as well as the daily life of all of the public in the EU. Their positive reinforcement by green financing and government-led indirect suggestions to try to achieve non-forced compliance can influence the motives, incentives and decision making of companies and individuals, at least as effectively, if not more effectively, than direct enforcement of green growth. Moreover, the financing Nudge paradigm brought a strong partnership between the local government and the private companies in diverse projects for the enhanced adaptation toward green growth. This public-private partnership (PPP) is the core paradigm of the OECD, and thus, it sheds light on the future direction of the green wave for all of the countries.

The OECD has taken the lead in the international cooperation for green growth, since sustainable development has transformed into green growth with much more emphasis on decoupling the feasibility between urgent economic needs and long-term environmental protectionism. They published a series of green growth strategies and best alternative policies for the optimal path toward green growth. Especially, their emphasis on the PPP regime cannot be overestimated in the area of green growth. The government should provide the seed money and strategic platform for the public, which is afraid of the investment in green business, the invention of new technology or even the adoption of new technologies. Private companies might be aware of these new challenging initiatives of the government and participate in the new frontier of green growth more pro-actively (pumping policy). The feedback from these economic entities should guarantee the innovation of new standards, new platforms and new ways of life by government concession. This PPP requires no helper, but partners to enlarge their piece of the pie for all of the partners in the challenging future. Specifically, the government should not lead without the consideration of partners, and the private sector should 
provide more feedback for the market-oriented and performance-oriented paradigm of green growth under this PPP mechanism.

Based on all of the comparative analyses of the government policy paradigms on sustainable development, we need some harmonized new paradigm of sustainable development on behalf of the role of the government and the private sector together. As shown in Figure 2, the highly-regulated government-led paradigm of green growth policies in Northeast Asian countries should decrease the leading role of the government, while increasing the partnership with the private sector. Otherwise, the governments in the Northeast Asian countries may face strong antipathy from the private sector due to the over-emphasized regulation and the interventions of the government. On the contrary, the government of the United States should provide more regulatory enforcement of green growth and promote active participation by the private sector more effectively in a short amount of time. In this way, the new PPP paradigm could work effectively to create new global standards for green growth, and every economic entity is willing to participate in these new standards to create value by the pro-active adaptation of these new global standards. Based on Figure 2, it is quite safe to conclude that the new paradigm for green growth should be based on the active partnership between the public and the private sector for sustainable governance $[14,18]$. Even so, there is too diverse of a spectrum of this PPP mechanism, from the loose, indirect Nudge strategies of the government, to the strong, direct intervention of the government with the "help" of private partners. Therefore, the PPP is not the only solution for a harmonized paradigm of sustainable development. The organization and its surrounding conditions of the PPP are much more important for efficient and effective performance. In the one extreme of the Korean PPP, it may incur a moral hazard in the private sector due to the strong support of the government, while the other extreme case of the United States type of PPP may result in the laissez-faire non-obligation on the performance, because everybody's work is nobody's work. That is the reason for the research to complement the contents of the PPP in terms of a feasibility study in the following chapter.

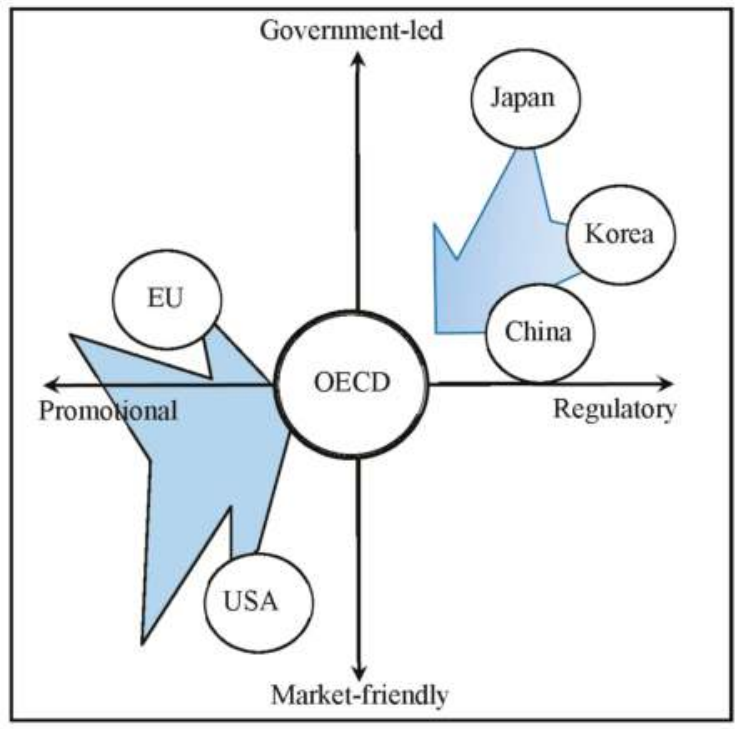

Figure 2. Paradigms of the government policies.

We examined the comparative analysis on the policy paradigm from the global perspective to the country by country cases. Since we conclude that the PPP is not optional, but necessary for all of the 
countries to promote green growth, it is time to examine more in-depth the contents of the role and functions of the PPP mechanism for green growth. Because the most important issues for green growth are categorized by the harmonized, yet more pro-active partnership between the PPP, we shall use the well-known SWOT matrix approach in the next section in order to find out the optimal propositions for the role and functions of the PPP mechanism in more detail.

\section{SOWT Matrix and the Propositions of the PPP Mechanism}

\subsection{Consultocracy in the Green Growth Economy}

There are many theories about how to use public resources to combat climate change, but most of the research concluded that there is somewhat a missing link between the implementation of these theoretical suggestions and the resulting performance because of the lack of a harmonized partnership in the process. Since the green growth policies result in invisible values most of the time in the long-term via very complicated and complex processes with the involvement of diverse interest groups, these policies easily fall into pit-falls, for which the policies "effectively" achieve the quantitative objectives of green growth, but still, it is clear that many of the achieved outputs are instantaneous and show up only with misused or wasted resources [21].

Nobody wants the achieved outputs and/or there to be no guarantee that this performance could be maintained over time. Therefore, sustainable performance over time is the key for the governance in green growth. There are many exemplary case studies for which policies are implemented successfully, but nobody wants them due to the one-way operation of the government [14,21]. Therefore, it is also necessary to organize an efficient and policy-effective intermediary for the harmonized PPP system to promote the feedback between the government and the private sector, resulting in sustainable value creation. Specifically, it is really difficult to develop or even to innovate new green technologies under a government-led economy. Moreover, most of the newly-developed technologies are rather inventor-oriented, and thus, it is quite difficult to match them with the right demanding partners, even under a market-friendly economy. Small and medium companies, which make up more than 60 percent in all of the countries, could not easily find where and how to get the best support that is already provided by the government and/or the right technologies that are newly-developed in the market. Thus, the intermediation of this match-making for the new challenging frontier of green growth is the core of successful and sustainable governance. By the same token, for the feasibility analysis and following the long- and short-term plan, the third party with the new challenging green growth project is definitely required to search for the right information, to evaluate the information and to finalize it for public fund-raising.

Unfortunately, there are too many operational missing links to obtain sustainable performance. For example, the government creates a project for the PPP, such as a forest business association to plant trees to protect deforestation. This policy could be "effectively" implemented by the PPP in the short term only. There is no guarantee that these newly-planted trees will grow well, because the PPP has no concern for these services in the long-term. All of these operational missing links between public policy and market performance require a survival kit for the intermediation under the green growth regime, but unfortunately, it is really difficult for companies, even for governments to find a solution by themselves and/or a cooperative solution with the potentially best partners. Therefore, it is quite necessary to find the role and functions of these intermediaries to fill the missing link between the cooperative networking partners for the governance of sustainable performance [22]. It is especially true that in our research, as the OECD pointed out, the PPP system is crucial as the best intermediary for the internalization of all externalities of the interested groups and of their related future challenges.

Most of the countries do utilize an intermediary for the implementation of government policies on green growth. In Korea, for example, there are several voluntary schemes for PPP projects toward green growth: the agreement on energy savings, certification for environmentally-friendly agricultural products, certification for use of the environmental seal, designation of environmentally-friendly 
companies, green building certification and voluntary environmental management agreements. However, most of these intermediaries have serious "consultocracy" problems, and thus, most of these programs and projects just have showing-off effects in many cases. Here, consultocracy means that the supplier-, developer- or policy maker-oriented intermediaries argue over and confirm the feasibility of new systems, new methods and new strategies for the market without enough consideration of market factors and, thus, resulting in the lack of economic efficiency, company capacity and the technical interface with the legacy system, due to its autocracy on the decision [21] (p. 38). Thus, the consultocracy causes enormous waste of resources and time, due to the lack of a governance-oriented mediating role. Unfortunately, this comes from the inefficiency of a large organization, such as government-led policy implementation [23]. In the following section, we shall try to examine the role and functions of these intermediaries in terms of their appropriate role and functions among the partners of all economic entities on the complicated, and yet complex, implementation process of green growth policies.

\subsection{Environmental Conditions for Green Growth Intermediation}

As shown in Figure 2, most of the Asian countries are promoting government-led green growth policies, because there are some conflicts of interest between the public and businesses, at least in the initial stage of green growth. Since the government could not intervene in the market in a direct way effectively, most of the government-led projects could be implemented by intermediaries, such as the independent official authorities (public companies), business associations, academic third parties, etc. The PPP is the best platform of this kind of third sector of the economy to handle cooperative challenges in general. When the government cannot perform effectively, but wants to intervene in the private economy with the indirect Nudge strategy, it may use a diverse PPP as the third part of the economy, and this PPP could gain a diverse spectrum from the government-owned operating public companies to the negligible portion of ownership on the stock market with the majority shares operated by private companies.

The motivation of these diverse PPP could be found from the political strategic consideration. Since the green wave requires the utmost participation of almost all of the economic entities, it is not easy to convey the right signal by policies only. Fortunately, there is global consensus on the pressure for green growth, and this may require the public and private sectors to cooperate with highly motivated global consensus. Due to the complicated, complex process with very vague performance, which in general cannot be measured easily and effectively, green growth should be supported by the strong participation of all. The public should be aware of the long-term effect of the eco-friendly strategies and, thus, be keen to provide invisible pressure on companies for their transformation to the green platform, and this may result in unexpected new business opportunities. POSCO, a steel-manufacturing company, has great pressure from the government and the public, and thus, it concentrated on greening strategies of the entire manufacturing process. They noticed that there are is too much steel scrap thrown out from the manufacturing process as waste and, thus, invested to decrease and collect all of these steel scraps, and finally, this waste of steel scraps brought much extra profit, as well as brand loyalty as an eco-friendly company. When the company found that the new efforts toward green growth do not have costs, but investment results in visible and invisible values, they could participate more aggressively in a proactive partnership with the government. They have to harmonize short-term profits and long-term values created by the loyalty of the interest groups. Additionally, the government should utilize this PPP as the flagship to initiate new challenges of innovation, new technology adoption and new green strategies and to get feedback and the voluntary, but necessary, participation of companies.

There are many opportunities for these PPPs to be handled more effectively to create values on the cooperative network. Since they get indirect support from the government, it is easy to enter a new market, with new innovative technology and a new field of projects. Moreover, the private partners may provide better resources to examine the feasibility, providing more efficient solutions 
for possible bottlenecks and implementing a green mission more effectively. Most of all, this PPP could be a third part of the project, which means that it can avoid any subjective mistake, either by the government or by the private sector. It also provides a very flexible approach to handle the projects that all of the participants could contribute to their strategic strength. It could obtain strong indirect guarantees from government participation, while it could recruit the best partners to mobilize their best resources. Specifically, green growth is an area for international cooperation, and thus, government participation is very important for the other project partners to obtain a transparent and predictable mechanism for their major tasks, to harmonize with the global standards, as well as the concession of the other countries.

However, the surrounding condition of PPPs does not seem to be very effective for the sustainable operation of a cooperative network by all of the participants, mainly due to the uncertainty regarding the policies or policy risks. The mission of PPPs requires quantitative performance, in the short term in general, and thus, it does not care about the future feedback from the users and the markets. If the policies give a good signal of the predictable, transparent operation of PPPs, it will be very beneficial for private companies to participate in this guaranteed opportunity. Unfortunately, government policies tend to be short term oriented, and thus, private partners could not invest more for this unsustainable partner of the government. Instead, they may take a more passive position to take advantage without much contribution. Especially, when there is some conflict of the interest between the partners, the third party of the PPP could not effectively harmonize the interest and, thus, chooses the second best on behalf of the government, as the political situation changes, which could result in worse performance than the private competitors. Unfortunately, there are many diverse conflicts of interest, and thus, it is not easy for all partners to participate in this collaboration network voluntarily and pro-actively to create values for all. Thus, the voluntarily, pro-active partnership for all of the members in the collaboration network is required among the interest groups, and only when the government can adopt market-oriented strategies, can the PPP, as the network manager of the collaboration network, fill the missing link.

\subsection{Internal Capacity of the Green Growth Intermediaries}

The strongest factor for the PPP, as an intermediary to find and fill the missing link of the collaboration network, could be found in that it is supported and thus has guaranteed performance at least in quantitative terms in the short run. The government participation makes the PPP more active to promote the policy goal. It could bring the best combination of partners, as well, in the field, due to the strong incentives and support of the government. For example, Korea was far short of enough telecommunications in the 1980s. It also had great challenges in its research and development capacity in the field, as well. When the Korean government set up the new entity of Korea Telecom (KT), as a kind of PPP strongly supported by the government, KT created a time division exchange (TDX) system as the fourth new innovation in the world. Moreover, the efficient installation of the telecommunication network nationwide by KT made Korea one of the top leading countries of IT in the Internet era. This kind of PPP could easily access diverse resources with dynamic flexibility and the best partners in their collaboration network, thus reducing any procedural cost.

However, the weakest factor of the PPP may come from the consultocracy. Since most of the PPPs are based on a certain project with a political mission, they tend to stick to the goal of the policy mission and, thus, easily forget the results of it. Instead, they emphasize short-term achievement, because most of the policies require short-term benchmarks. For example, in order to prevent deforestation, they just plant the same kind of trees, in general efficiently and especially "effectively", but one kind of tree could be in danger of attack by injurious insects and even susceptible to fire. The more government controls the management, the higher the consultocracy that could result. By contrast, if there are certain guarantees by the government with very flexible operation of the mission, then the moral hazard of non-responsible decision makers could be easily identified. In 2004, the Korean government pronounced its regional economic development five-year plan, promoting the development of selective 
regions with a total budget of 66.6 billion dollars through 2008. The core project for the policies is based on the Regional Innovation System (RIS). To promote RIS, the government set up 14 RIS boards nationwide. As PPP-based intermediaries of RIS, the 14 regional boards are made up of 725 people in Korea. Unfortunately, most board members are from universities. Moreover, 11 of 14 chairpersons of these boards come from universities, as well. Moreover, most of these intermediaries from universities and faculties are not active in participating in commercial activities, because they do not have any obligation. Some RISs in Korea are just renamed as the traditional brick and mortal industry complex, such as Kumi, whereas others are newly made in the green fields of mountain regions without any infrastructure at all. Because there are no performance-based incentives or obligations for financing of the strategic fields, most RIS boards do not consider much their selection or management of RIS. These missing links between these 14 RIS boards and their regional operations prohibits continuing their mission, and when the new President is elected, all of these PPPs will be gone with much waste of national resources [24].

\subsection{SWOT Matrix and the Proposed Paradigm for Green Growth}

Based on the above surrounding environmental conditions and the internal capacity analyses of the PPP as an intermediary, we can integrate its strengths (S) and weaknesses (W), its opportunities $(\mathrm{O})$ and the threats $(\mathrm{T})$, resulting in the SWOT matrix model. As shown in Table 1, the internal capacity analysis gives the facts about the strengths and weaknesses of the PPP as an intermediary, while the external surrounding environment analysis brings the opportunity and threat factors. From this summary of the facts, we can draw the future strategies for market- and performance-oriented governance. It should be called a strategy, because it comes from the current situation and the internal facts, resulting in more dependable, feasible scenarios of the strategic alternatives [10].

First of all, the PPP should increase the role of the facilitator (SO strategy, facilitator proposition). Based on the strong support of the government and the global consensus toward green growth, the PPP intermediary should make an effort to innovate new technology, to transform its business into the green growth platform with more eco-friendly strategies and to create new products and new businesses. As an early adopter of green growth, it should shed light for all of the interest groups on understand this new direction as being much more valuable than any other traditional legacy system. This requires a pro-active role to invite the potential partners to enter the collaboration network in a more voluntary manner with their own contribution to value sharing.

Table 1. SWOT matrix strategies.

\begin{tabular}{|c|c|c|c|c|}
\hline & & Internal Capacity & Strength & Weakness \\
\hline External Environment & & & $\begin{array}{ll}\text { - } & \text { Government Support } \\
\text { - } & \text { Best Private Partner } \\
\text { Flexible Management }\end{array}$ & $\begin{array}{ll}\text { - } & \text { Consultocracy } \\
\text { (Moral Hazard) } \\
\text { - } \\
\text { Low Motivation }\end{array}$ \\
\hline Opportunity & $\bullet$ & $\begin{array}{l}\text { Global Consensus } \\
\text { New } \\
\text { Biz. Opportunities }\end{array}$ & $\begin{array}{l}\text { Increasing Role for Facilitator } \\
\text { (SO Strategy) }\end{array}$ & $\begin{array}{l}\text { Increasing Role for Network } \\
\text { Manager (OW Strategy) }\end{array}$ \\
\hline Threat & $\bullet$ & $\begin{array}{l}\text { Low Partnership } \\
\text { Policy Risk }\end{array}$ & $\begin{array}{l}\text { Increasing Role for Collaborator } \\
\text { (ST Strategy) }\end{array}$ & $\begin{array}{l}\text { Increasing Role for Service } \\
\text { Provider (TW Strategy) }\end{array}$ \\
\hline
\end{tabular}

The second strategy coming from the weakness and opportunity factors should be based on the increased role as the network manager (OW strategy, network manager proposition). As green growth requires complicated and complex processes from the input to the finally-created values in the long term, there are conflicts from diverse interest groups. The most important role for the PPP intermediary should be networking with them more effectively for cooperation and to harmonize their 
conflicting interests in terms of bearable, equitable and viable cooperation, as shown in the Figure 1. Networking and its operation for all of the interest groups are crucial for the sustainable performance of green growth.

The third strategy to utilize the strengths and to overcome the threats should be based on the enhanced role as the collaborator (ST strategy, collaborator proposition). There are too many helpers in government-led projects, but no partners at all, in general. The helpers are not responsible for the performance and, thus, just provide consulting under too abstract and ideal conditions. Neither can they give any proactive contribution, because of the lack of any practical incentives. Therefore, in order to continuously promote the green growth collaboration, all of the interest groups should not just be outsiders, but inside partners with a proactive contribution with appropriate rights and responsibilities to share with each other. This collaborator proposition expels the consultocracy, because those that act only as helpers can no longer contribute with lip service alone, while partners participate with a strong motivation from the value sharing system.

The last strategy coming from the weakness and opportunity factors should be based on the increased role as the service provider (TW strategy, service provider proposition). The PPP intermediary should provide all of the necessary information and potential resources for the participants. The diverse background of the partners in the collaboration networking may lack exact requirements or future challenges in detail, and the network manager should give all possible support to the participants to communicate more effectively and find their needs. For example, a technician only develops new innovation by his or her own idea, and this green technology may not match the demand of companies due to the lack of market information, time and funding. In this case, the network manager should provide diverse options to match this new green technology with the demanding partners.

\section{Conclusions}

The green growth policies worldwide have been promoted by new challenges to protect the environment, to find and develop new green technologies and businesses and to integrate all of the possible interest groups for equitable, viable and bearable development. Followed by the third revolution of the Internet, this fourth revolution of green growth clearly makes all of the economic entities become aware of the environmental impact and sustainable resource utilization. However, there is still a high level of doubt regarding green growth, especially from the companies' perspectives. Most companies regard this new green growth paradigm as an additional burden with much cost, resulting in the weakening of international competitiveness. In order to transform this passive attitude of the private sector into more proactive partnerships in the new frontier of green growth, the public-private partnership (PPP) could be the best alternative as an intermediary to fill the missing link in collaboration networking.

However, the PPP, as the harmonized third party, could not achieve successful governance due to internal bottlenecks, as well as external surrounding difficulties. In order to utilize the opportunities and strengths and to overcome the threats and weakness, this paper suggested four propositions as the appropriate intermediary: facilitator proposition, network manager proposition, collaborator proposition and service provider proposition. Even if these propositions better explain the role and functions of the PPP, still, the paper could not deliver more details about these propositions with comparative case studies. This will be the tasks for future extensions of this research.

Acknowledgments: This work was supported by the National Research Foundation of Korea Grant funded by the Korean Government (NRF-2014S1A5B1011422).

Conflicts of Interest: The author declares no conflict of interest. 


\section{References}

1. Lerner, M. Yellow Dust Storm Carries Chinese Pollutants to Korea. Available online: http: //blogs.blouinnews.com/blouinbeatsciencehealth/2015/02/24/yellow-dust-storm-carries-chinesepollutants-to-korea/ (accessed on 24 February 2015).

2. Reuters News. China to "Declare War" on Pollution, Premier Says. Available online: http://www.reuters. com/article/2014/03/05/us-china-parliament-pollution-idUSBREA2405W20140305 (accessed on 4 March 2014).

3. World Commission on Environment and Development (WCED). Our Common Future; Oxford University Press: Oxford, UK, 1987; p. 43.

4. OECD. Towards Green Growth. Available online: http://www.keepeek.com/Digital-Asset-Management/ oecd/environment/towards-green-growth_9789264111318-en\#page4 (accessed on 24 September 2015).

5. Chen, S.Y.; Xie, Z. Is China's e-governance sustainable? Testing Solow IT productivity paradox in China's context. Technol. Forecast. Soc. Chang. 2015, 96, 51-61. [CrossRef]

6. Fankhauser, S.; Bowen, A.; Calel, R.; Dechezleprêtre, A.; Grover, D.; Rydge, J.; Sato, M. Who will win the green race? In search of environmental competitiveness and innovation. Cent. Clim. Chang. Econ. Policy Work. Pap. 2013, 23, 902-913. [CrossRef]

7. Du Pisani, J.A. Sustainable development-historical roots of the concept. Environ. Sci. 2006, 3, 83-96. [CrossRef]

8. Munir, K.A. Competitive dynamics in face of technological discontinuity: A framework for action. J. High Technol. Manag. Res. 2003, 14, 93-109. [CrossRef]

9. Yongrok, C. Global e-Business Management: Theory and Practice; Bomyeong Books: Seoul, Korea, 2014; p. 14.

10. UNFCC Report. Available online: http://report.mitigation2014.org/drafts/final-draft-postplenary/ipcc wg3_ar5_final-draft_postplenary_chapter13.pdf (accessed on 24 September 2015).

11. Sustainable Development: Wikipedia. Available online: https://en.wikipedia.org/wiki/File:Sustainable development.svg (accessed on 1 November 2015).

12. United Nations Framework Convention on Climate Change (UNFCCC). Transitional Committee for the Design of the Green Climate Fund. Available online: http://unfccc.int/cooperation_and_support/financial_ mechanism/green_climate_fund/items/6902.php (accessed on 23 November 2011).

13. Institute for Policy Studies, Green Climate Fund, A Glossary of Climate Finance Terms. Available online: http:/ / climatemarkets.org/glossary/green-climate-fund.html (accessed on 23 July 2013).

14. Choi, Y.; Ning, Z. Introduction to the Special Issue on "the Sustainable Asia Conference 2014". Sustainability 2015, 7, 1502-1695. [CrossRef]

15. Gao, P. Government in the catching-up of technology innovation: Case of administrative intervention in China. Technol. Forcast. Soc. Chang. 2015, 96, 4-14. [CrossRef]

16. Kim, K.; Leipziger, D.M. Korea: A Case of Government-Led Development; World Bank: Washington, DC, USA, 1993.

17. Rim, C. Korea's Age Boom: How South Korea is Addressing the Reality of Low Fertility and a Rapidly Aging Society. Available online: http://journal.aarpinternational.org/a/b/2013/02/Koreas-Age-BoomHow-South-Korea-is-Addressing-the-Reality-of-Low-Fertility-and-a-Rapidly-Aging-Society (accessed on 24 July 2015).

18. Choi, Y. Introduction to the special Issue on "Sustainable e-Governance in Northeast Asia: Challenges for Sustainable Innovation". Technol. Forcast. Soc. Chang. 2015, 96, 1-3. [CrossRef]

19. Hideyo, K. Corporation Japan; Ihlsin Sa Publishing Co.: Seoul, Korea, 1998. (In Korean)

20. Light, A. Has Japan Killed the Kyoto Protocol? Even If It Has There's Still Hope for a Climate Agreement (web-article). Available online: https://www.americanprogress.org/issues/green/news/2010/12/08/8733/ has-japan-killed-the-kyoto-protocol/ (accessed on 8 December 2010).

21. Choi, Y. The role of intermediation on the international aid for the governance of technical training program. Technol. Forcast. Soc. Chang. 2015, 96, 32-39. [CrossRef]

22. Choi, Y.; Yu, Y. The influence of perceived corporate sustainability practices on employees and organizational performance. Sustainability 2014, 6, 348-365. [CrossRef] 
23. Harvey, L. X-efficiency. In The New Palgrave Dictionary of Economics, 2nd ed.; Palgrave MacMilan: London, UK, 2008.

24. Choi, Y. Optimizing risk management for the sustainable performance of the regional innovation system in Korea through met mediation. Hum. Ecol. Risk Assess. 2009, 15, 270-280. [CrossRef]

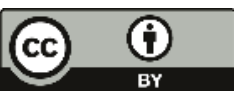

(C) 2015 by the author. Licensee MDPI, Basel, Switzerland. This article is an open access article distributed under the terms and conditions of the Creative Commons Attribution (CC BY) license (http:/ / creativecommons.org/licenses/by/4.0/). 


\title{
The Efficiency and Its Determinants for China's Medical Care System: Some Policy Implications for Northeast Asia
}

\author{
Kejia Chu ${ }^{1}$, Ning Zhang ${ }^{2, *}$ and Zhongfei Chen ${ }^{2, *}$ \\ 1 Department of Insurance, Guangdong University of Finance, Guangzhou 510521, China; \\ kejiachu@gduf.edu.cn \\ 2 Department of Economics; Institute of Resource, Environment and Sustainable Development, School of \\ Economics, Jinan University, Guangzhou 510632, China \\ * Authors to whom correspondence should be addressed; zn928@naver.com or zhangn@jnu.edu.cn (N.Z.); \\ chenzf@jnu.edu.cn (Z.C.); Tel.: +86-791-8381-0553 (N.Z.); +86-159-1319-7920 (Z.C.).
}

Academic Editor: Marc A. Rosen

Received: 4 July 2015; Accepted: 14 October 2015; Published: 20 October 2015

\begin{abstract}
The medical care system in China has experienced significant changes during three decades of reform, and thus result in a need to investigate the effects of medical reform. This paper investigates the technical efficiency of Chinese hospitals in 31 provinces during the period from 2002 to 2013 by proposing a new global generalized directional distance function (GGDDF) approach taking account of undesirable output, i.e., mortality. Results show that despite the technical efficiency had being improved with time trend, most Chinese provinces are not performing well on hospitals' technical efficiency and leave a large potential to improve. Some provinces display better performance compared to other provinces of China. We further investigate the factors that affect the technical efficiency of Chinese hospitals with Tobit models. It concludes that the medical insurance reforms have improved the performance of Chinese hospitals, while public subsidies have decreased it. The provinces with higher GDP per capital and population density, the performance of their hospitals is better. The related policy implications for Northeast Asia are derived, including encouraging the development of private hospitals, enlarging the coverage of medical services, and pursuing different policies for the provinces with higher GDP per capital and population density.
\end{abstract}

Keywords: global generalized directional distance function approach (GGDDF); Chinese hospitals; technical efficiency

\section{Introduction}

Since reform and opening up to the outside world in 1978, health status and outcome in China has been significantly improved. According to the World Development Indicators (WDI) published by the World Bank, life expectancy in China increased from 66.5 years in 1978 to 75.0 years in 2013, and the infant mortality rate decreased from $5.3 \%$ to $1.1 \%$ during the same period. However, the medical care sector in China has still been severely criticized for the high price and low quality of medical service since the market-orientated reform of 1985. It has even been judged as a failure by some researchers in China [1]. In addition, these challenges facing China's medical system make the government authorities need to find new solutions and correct the distortions when pushing the reform forward. The government approved a new scheme for medical care reform in 2009 and significantly increased the fiscal budget in the medical care, so that to establish a universal coverage of medical care system that efficiently and conveniently provide the affordable and safe medical services in 2020. However, the ongoing reform still needs evaluation and correction. China is the most 
populated country in the world and has entered into the era of ageing society [2,3]. How to efficiently deliver enough medical service to people is a vitally important problem for the government authorities. Meanwhile, monitoring the efficiency performance of Chinese hospitals can provide useful information for assessing the effectiveness of health policies and measures, and also as a means to improve hospital efficiency and productivity in the most cost-effective way. As most of Chinese hospitals are public hospitals as non-profit enterprises and the price data is missing, we focus on the technical efficiency, which evaluates the ability of a DMU (Decision-making Unit) to produce the current outputs at the minimal amounts of inputs, rather than cost-effectiveness, which assesses the ability of a DMU to produce outputs at the minimum cost by simultaneously adjusting the output levels at the current revenue expressed in terms of the assessed DMU's own prices and quantities $[4,5]$.

Greater attention has been given to hospital's technical efficiency and a growing number of studies in recent decades, so that to compare the relative performance given the need to ensure the best use of scarce resources [6], especially when facing the challenges in demands for high quality medical services over the long term in an ageing society $[7,8]$. The efficiency concept used is that of technical efficiency. A hospital is said to be technically efficient if an increase in an output requires a decrease in at least one other output, or an increase in at least one input. Alternatively, a reduction in any input must require an increase in at least one other input or a decrease in at least one output $[9,10]$. In the literature, there are two main approaches are employed to evaluate the technical efficiency of hospitals, including the DEA (Data Envelop Analysis) and SFA (Stochastic Frontier Analysis) [6,11-17]. As mentioned above and the contextual setting that will be introduced later, the medical sector of China is still in transition and facing great challenges. However, focus on the technical efficiency of Chinese hospitals has not been well discussed in the literature. This is the first motivation of present research to fill in this gap. Moreover, other important questions are proposed to address in this paper are as follows:

i. What are the technical efficiency scores and the dynamics for the hospitals in different provinces of China during the period of 2002-2013?

ii. How the external environmental factors affect the technical efficiency of Chinese hospitals? Have the medical reform improve the technical efficiency of Chinese hospitals?

Comparing to other various technical efficiency methods, the directional distance function (DDF) approach has gained much attentions and allows for incorporating both desirable outputs and undesirable outputs (pollutant). Generally, there are two kinds of distance functions that are widely used in the literature, including the Shephard distance function and the DDF. More details are introduced by Zhang and Choi [18]. The undesirable outputs are by-products in the production that are typically ignored and may yield biased measured of technical efficiency [19-21]. Moreover, a major advantage of the DDF is that it is capable of expanding desirable outputs and contracting inputs or bad outputs simultaneously [18]. The DDF was first introduced by Chambers et al. [22,23] and later has been widely applied to studies in field of Environment Economics and Energy Economics [18,19]. Despite these distinguished features and advantages, the DDF has rarely been applied to analyze the sustainable performance of hospitals. Hence, it is the second motivation for this research.

The basic DDF model that proposed by proposed by Chambers et al. [22,23] has several restrictions. The basic DDF function generalizes radial measures of technical efficiency since it allows for radial expansion of outputs and contraction of inputs as well as a non-radial expansion of outputs and contraction of inputs [24]. It does not provide technical efficiency information for specific inputs or outputs as it adjusts all inputs and outputs by the same proportion to the efficient targets. Moreover, the radial efficiency measures overestimate technical efficiency when there is slack [24]. Therefore, recent research has been developed to modify these drawbacks. Fukuyama and Weber [24] propose a slack-based inefficiency measure by extending the basic DDF model. Meanwhile, Färe and Grosskopf [25,26] propose a generalized non-radial DDF. Yu et al. [18], Zhang et al. [27] and Mei et al. [28] incorporate the meta-frontier approach into a non-radial DDF. In addition, Zhou et al. [29] 
design a non-radial DDF following an axiomatic approach, while Zhang et al. [19] develop a sequential generalized directional distance function approach to calculate the efficiency. We extend the work of Färe and Grosskopf $[25,26]$, and use an innovative global benchmark technology in the generalized non-radial DDF that envelopes all contemporaneous benchmark technologies by establishing a single reference PPS (production possibility set) from a panel data on inputs and outputs of relevant DMUs, i.e., the global generalized directional distance function [30], so that to improve the discriminating power and comparability of intertemporal observations and analyze the sustainable performance of Chinese hospitals.

With respect to factors that have influences on the technical efficiency of Chinese hospitals, Eggleston et al. [31] and Wagstaff et al. [32] have concluded that the Chinese hospital is quite inefficient after a comprehensive review of Chinese health care system. Hu et al. [14] use the Tobit model to analyze the effects of some factors on the technical efficiency of Chinese hospitals, including the coastal location, public subsidies, the social medical insurance reform, the ratio of third-class hospitals to total hospitals and population characteristics. In addition, they conclude that the former two have insignificant effect on improving the technical efficiency, while the latter two significantly promote the technical efficiency. However, they use the traditional DEA to estimate the technical efficiency score in the first step. Therefore, it still needs more rigorous research to act as robust check.

The remainder of this paper is organized as follows: Section 2 briefly introduces the background of this paper. Then the methodology specification is presented in Section 3. In Section 4, we analyze the empirical results of global generalized directional distance function (GGDDF) approach. In Section 5, it continues to detect the factors that affect the sustainable performance of Chinese hospitals with Tobit models. The Section 6 concludes and provides some policy implications of this research.

\section{The Medical Care System of China}

In the period 1949 to 1978, the medical care system of China was characterized by "prevention first", community organization and cooperative financing. In this stage, the price of medical service was kept low by the Central Price Commission. People's needs for basic medical service had been satisfied, which helped to improve their health status [33]. As the economic reform moved forward, the government put first priority on economic development when the local government was given more autonomy and competed for economic growth, rather than public services like medical care [34,35]. As a result, the development of the medical care system was challenged by limited public funds and the rapid expansion of medical expenditures [36].

Reform in the medical care system was not implemented until 1985, when the State Council approved the plan proposed by the Ministry of Health (MOH) of China, which intended to encourage the establishment of more hospitals in urban and rural areas. This gave existing hospitals more autonomy and raised the price of medical service, reducing the restrictions on the supply of medical service [37]. Meanwhile, the $\mathrm{MOH}$ of China also strengthened the quality of medical service through stipulating a regulation on hospital grading in late of 1989, namely certificating hospitals in China every three year in different grade according to their capacity to supply high-quality medical service. Later in 1992, the MOH of China granted further substantial financial autonomy to hospitals, encouraging the hospitals to increase their revenue by offering higher quality service and allowing hospitals to transform to modern companies and set joint ventures. After these reforms, new hospitals began to spring up and the supply of medical service largely increased [38]. As the regulation and entry barriers, the number of private hospitals had not increased a lot until 2001 when the government abolished some limitations. According to the latest China's Health Statistical Yearbook, up to the end of 2013, there are 11313 private hospitals in China, while there are 13396 public hospitals. However, the public hospitals still maintain the dominant position in the healthcare sector of China [39]. At the same time, China began market and commercialization reform in the medical care system. Negative side-effects quickly began to emerge, including the poor access and high costs of medical service [31,35]. In 
addition, the average growth of health expenditure per capita has reached 16.02\% during 2001-2013 (See Figure 1). The government just undertook $23.31 \%$ of it.

Responding to the rapid increase of costs and the reduction of medical care affordability, the government launched a series of reforms in 1994. The State Council implemented the pilot reform of basic social medical insurance scheme (BSMIS) for urban employees in Jiangsu and Jiangxi province. This was applied to the whole country in 1998. In 2003, the new rural cooperative medical system (NRCMS) was implemented in the four provinces by the State Council. For more details, see Dong [36]. With the outbreak of SARS (Severe Acute Respiratory Syndromes) in 2003 and the scandal of high expenses in medical services, i.e., an inpatient was charged 5.5 million yuan ( 0.67 million USD) by the hospital in 2005 and the $\mathrm{MOH}$ found there existed arbitrage charge and forged diagnosis report in the hospital after investigation, the $\mathrm{MOH}$ finally made a prudent review on the medical care system in China and admitted the low coverage of the medical insurance and the failure of market-orientation reform in medical care industry.

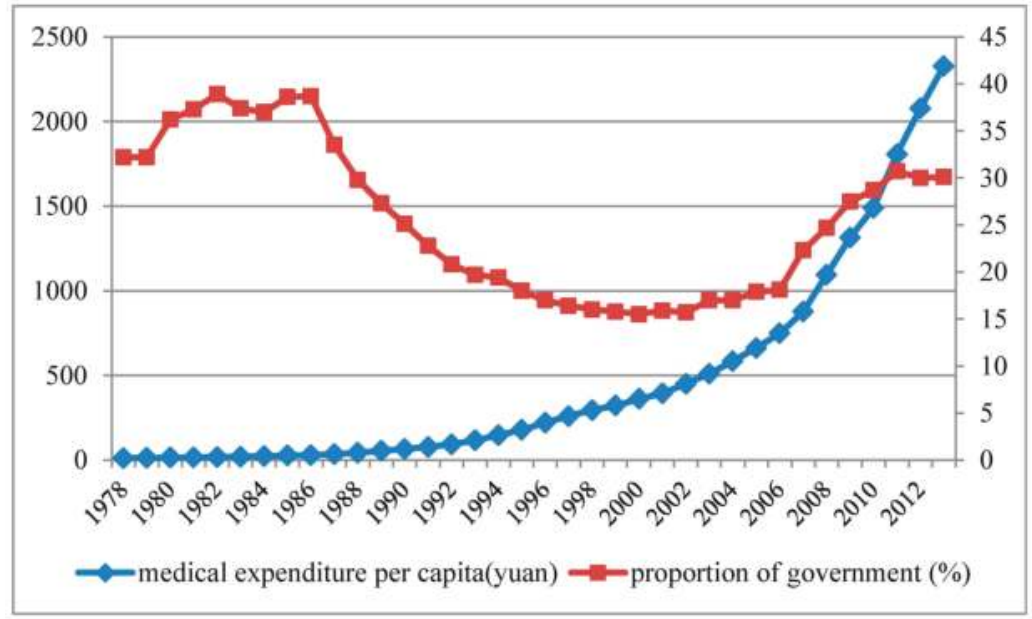

Figure 1. Trend of medical expenditure per capita (left) and the share of government medical expenditure (right) in China. Sources: China's Health and Family Planning Yearbook 2014 [40].

After 2005, the government took measures to increase the coverage of medical insurance. The milestone in this period is the publication of new scheme for medical care reform in 2009. The government promised to increase the fiscal subsidies rather than rely on market to sufficiently satisfy people's needs for basic medical services. Meanwhile, it would invest 850 million yuan (about 124.43 million USD) in the next two years to deepen the reform, including accelerating the establishment of basic medical care insurance system and essential drug system, improving the community-level medical service system, increasing the equalization in the public medical services and the pilot experiments on public hospital reforms. Reform will never cease until people can access to more affordable, accessible and equal medical service in this first largest populated country.

\section{Methodology}

\subsection{Global Generalized Directional Distance Function}

In order to introduce the generalized directional distance function, firstly we need to explain the term "production technology with undesirable outputs". Assume that there are $j=1, \ldots, N$ DMUs. 
These can be hospitals. Suppose that each DMU uses inputs vector $x \in \Re_{+}^{M}$ to jointly produce good output vector $y \in \Re_{+}^{S}$ and bad output vector $b \in \Re_{+}^{J}$. The production technology is expressed as:

$$
T=\{(x, y, b): x \text { can produce }(y, b)\}
$$

where $T$ is often assumed to satisfy the standard axioms of production theory, such as inactivity is always possible, and finite amounts of input can produce only finite amounts of output. In addition, inputs and desirable outputs are often assumed to be strongly or freely disposable. In the presence of undesirable output, a weak disposability needs to be imposed on $T$. The weak-disposability assumption implies that reducing bad outputs, such as mortality rate, are costly in terms of proportional reductions in hospital production. The DEA piecewise linear production frontier is used to construct the production technology. Then, production technology $T$ for $N$ DMUs exhibiting constant returns to scale can be expressed as follows:

$$
\begin{gathered}
T=\left\{(x, y, b): \sum_{n=1}^{N} z_{n} x_{m n} \leq x_{m}, m=1, \ldots, M,\right. \\
\sum_{n=1}^{N} z_{n} y_{s n} \geq y_{s}, s=1, \ldots, S, \\
\sum_{n=1}^{N} z_{n} b_{j n}=b_{j}, j=1, \ldots, J, \\
\left.z_{n} \geq 0, n=1, \ldots, N\right\} .
\end{gathered}
$$

A formal definition of the generalized DDF is proposed in Yu et al. [18] and Zhang et al. [19] with undesirable outputs. Following Yu et al. [18], the generalized DDF is defined as:

$$
\vec{D}(x, y, b ; g)=\sup \left\{\mathbf{w}^{T} \boldsymbol{\beta}:((x, y, b)+g \cdot \operatorname{diag}(\boldsymbol{\beta})) \in T\right\}
$$

where $\mathbf{w}=\left(w_{m}^{x}, w_{s}^{y}, w_{j}^{b}\right)^{T}$ denotes a normalized weight vector relevant to numbers of inputs and outputs, $g=\left(-g_{x}, g_{y},-g_{b}\right)$ is an explicit directional vector, and $\beta=\left(\beta_{m}^{x}, \beta_{s}^{y}, \beta_{j}^{b}\right)^{T} \geq 0$ denotes the scaler of scaling factors. We also incorporate global production technology into the GDDF model to improve the discriminating power and comparability of intertemporal observations.

The value of $\vec{D}(x, y, b ; g)$ under the global production technology can be calculated by solving the following DEA-type model:

$$
\begin{gathered}
\vec{D}^{r}(x, y, b ; g)=\max w_{m}^{x} \beta_{m}^{x}+w_{s}^{y} \beta_{s}^{y}+w_{j}^{b} \beta_{j}^{b} \\
\text { s.t. } \sum_{t=1}^{T} \sum_{n=1}^{N} z_{n} x^{t}{ }_{m n} \leq x_{m}-\beta_{m}^{x} g_{x m}, m=1, \ldots, M, \\
\sum_{t=1}^{T} \sum_{n=1}^{N} z_{n} y^{t}{ }_{s n} \geq y_{s}+\beta_{s}^{y} g_{y s}, s=1, \ldots S, \\
\sum_{t=1}^{T} \sum_{n=1}^{N} z_{n} b_{j n}^{t}=b_{j}-\beta_{j}^{b} g_{b j}, j=1, \ldots J, \\
z_{n} \geq 0, n=1,2, \cdots, N \\
\beta_{m}^{x}, \beta_{s}^{y}, \beta_{j}^{b} \geq 0 .
\end{gathered}
$$

The directional vector $g$ can be set up in different ways, based on given policy goals. If $\vec{D}(x, y, b ; g)=0$, then the specific unit to be evaluated is located on the frontier of best practices in the direction of $g$.

The technical efficiency can be defined based on the generalized DDF. As there are three kinds of variables, three inputs, two desirable outputs, and one undesirable output, we set the weight vector as $(1 / 3 M, 1 / 3 S, 1 / 3 J)$ and the directional vectors as $g=(-x, y,-b)$, based on Equation (3). 
The overall technical efficiency (OTE) for a hospital is defined as the average technical efficiency of each factor. Suppose that $\beta_{x}^{*}, \beta_{y}^{*}$, and $\beta_{b}^{*}$ represent the optimal solutions to Equation (4), then the OTE can be formulated as:

$$
\text { OTE }=1-\frac{1}{M+S+J}\left(\sum_{m=1}^{M} \beta_{x m}^{*}+\sum_{s=1}^{S} \beta_{y s}^{*}+\sum_{j=1}^{J} \beta_{b j}^{*}\right)
$$

\subsection{Tobit Model}

After the technical efficiency scores generated from GGDDF, we further regress it on the environmental variables, so that to check the effects of these exogenous on the difference technical efficiency of Chinese hospitals. As the technical efficiency scores must lie between 0 and 1 , we adopt the censored (Tobit) regression model. The unobservable latent regression is specified as follows:

$$
O T E_{i t}^{*}=x_{i t}^{\prime} \beta+\varepsilon_{i t}
$$

where $x_{i t}$ is a vector of exogenous environmental variables, and $\beta$ is a vector of parameters to be estimated. $\varepsilon_{i t}$ is the error term and distributed as $N\left(0, \sigma^{2}\right)$.

The observed technical efficiency scores, OTE $E_{i t}$, are the censored values of OTE $E_{i t}^{*}$. It is defined as follows:

$$
O T E_{i t}=\left\{\begin{array}{ccc}
0, & \text { if } & O T E_{i t}^{*}<0 \\
O T E_{i t}^{*}, & \text { if } & \text { OTE }_{i t}^{*} \in[0,1] \\
1, & \text { if } & \text { OTE }_{i t}^{*}>1
\end{array}\right.
$$

The Tobit model structured in the Equations (6) and (7) are finally estimated by the maximum likelihood method (MLE).

\subsection{Background Literature and Descriptive Data}

Our analysis includes the province-level data of Chinese hospitals available over the period 2002 to 2013 (372 observations) due to the hospital-level data being rarely disclosed, which cover much longer period than previous research on China, like Ng [13] and Hu et al. [14]. This province-level data was obtained from China's Health Statistical Yearbook that published by $\mathrm{MOH}$ of China during 2003-2014. We have obtained approval from the Ethics Board to use data. It covers all the hospitals in different provinces of China. The overwhelming majority of Chinese hospitals are public hospitals. According to the data of China's Health Statistical Yearbook, the proportion of total assets of private hospitals just account for $4.07 \%$ at end of 2013 in China. The criteria used for adopting the inputs and the outputs variables are the practices according to the previous research on hospital efficiency, which include Jacobs [6], Hu et al. [14], Barros et al. [15,16], Koop et al. [41], Rosko and Mutter [42], Varabyova and Schreyögg [43], Li et al. [10], and the accessibility of the data of Chinese hospitals, so that to rigorously estimate the technical efficiency [10]. For the inputs, we choose the total staff, the total assets and the number of beds, which stands for the labor, the capital and the capacity, respectively. For the curse of dimensionality is always present in nonparametric estimation, we adopt the total staff as a whole instead of physicians, nurses and technicians, to represent labor input $[10,13,14]$. Meanwhile, for the outputs, there is still no established consensus on how to accurately measure the outputs of hospital production. Some researchers use the number of outpatient and inpatient to measure the outputs of hospitals [10,13,14]. However, according to Biørn et al. [44] and Ozcan [45], it is more appropriate to adopt the total revenue and the number of surgery as output variables. Furthermore, except for these desirable outputs, we also focus on the bad outputs "mortality rate" under GGDDF method, which has not been paid much attention in the literature of hospital efficiency. It is measured by the morality rate of different provinces in China. We recognize that it is significant to distinguish the death due to the mistakes in the medical services and the natural death. However, according to present literature, Zuckerman et al. [46] and Hu et al. [14] also used this indicator to measure the undesirable outputs. 
Moreover, as the detailed information of mortality in China is not disclosed [47], we simply use the single indicator "mortality rate". We also try to find some other alternative indicators to replace it, but we failed at last. If we acquire the more details in the future, we will use more accurate variables to improve present research. By the way, we believe that the simple indicator "mortality rate" could reflect the death due to the mistakes in the medical services to some degree. We just focus on the hospitals in China, and there will be no significant differences in the natural death rate for these domestic areas of China. The detailed definition and descriptive statistics of these inputs and outputs variables are presented in Table 1.

Table 1. The definition and descriptive statistics of input and output variables.

\begin{tabular}{|c|c|c|c|c|c|c|}
\hline Variable & Definition & Observation & Mean & Std. Dev. & Min & Max \\
\hline total staff & $\begin{array}{l}\text { the number } \\
\text { of total staff } \\
\text { in the } \\
\text { hospitals }\end{array}$ & 372 & $207,046.2$ & $130,728.4$ & 10,058 & 684,976 \\
\hline total assets & $\begin{array}{l}\text { the total } \\
\text { assets of } \\
\text { hospitals } \\
\text { (million } \\
\text { yuan) }\end{array}$ & 372 & $43,800.00$ & $39,800.00$ & 717.00 & $216,000.00$ \\
\hline beds & $\begin{array}{l}\text { the number } \\
\text { of beds in } \\
\text { the hospitals }\end{array}$ & 372 & $100,245.90$ & $79,129.75$ & 4238.00 & $1,027,919.00$ \\
\hline total revenue & $\begin{array}{l}\text { the total } \\
\text { revenue of } \\
\text { hospitals } \\
\text { (million } \\
\text { yuan) }\end{array}$ & 372 & $34,200.00$ & $34,500.00$ & 588.00 & $214,000.00$ \\
\hline surgery & $\begin{array}{l}\text { the total } \\
\text { number of } \\
\text { surgeries }\end{array}$ & 372 & $748,730.00$ & $997,765.20$ & 6230.00 & $16,000,000.00$ \\
\hline mortality & $\begin{array}{l}\text { the mortality } \\
\text { ratio in } \\
\text { different } \\
\text { provinces }\end{array}$ & 372 & 5.96 & 0.67 & 4.21 & 7.30 \\
\hline
\end{tabular}

Sources: China's Health Statistical Yearbook 2003-2013 [48-58], China's Health and Family Planning Yearbook 2014 [40].

We utilize the Lingo package to estimate the technical efficiency of Chinese hospitals with the mentioned data. Thereafter, we adopt the Stata software (StataCorp LP, College Station, TX, USA) to analyze how these environmental variables affect the technical efficiency scores in the second stage.

\section{Technical Efficiency Estimation}

The proposed technical score is applied to hospitals in 31 provinces of China. It is calculated from the GGDDF of Equation (5) and takes values of between 0 and 1. According to this definition, the closer the technical efficiency measure is to 1 , the more efficient the hospitals can be considered to be in providing medical services.

The hospital's overall technical efficiency scores are presented in Table 2. According to Table 2, the overall technical efficiency varies from different provinces and different years. In 2003, the technical efficiency scores of Beijing, Hainan and Tibet all equal to 1, inferring that the hospitals in these three provinces are the most efficient and lie on the frontier. Meanwhile, the overall technical efficiency scores of Beijing, Shanghai and Guangdong also equal to 1 in 2013. However, from the estimated technical efficiency scores of Table 2, most of the Chinese hospitals are inefficient and far from the technical frontier. When the SARS broke out in 2003, it had caused the panic among people as well as 
the government intervention at that time. Therefore, the technical efficiency of Chinese hospitals also had been affected and showed oscillations. Some provinces, like Beijing, Hainan, Tibet and Qinghai, experienced the sharply increase of technical efficiency, while others, including Guangdong, Hebei, Shandong and Shaanxi undergone large decrease of technical efficiency.

Table 2. The technical efficiency scores of Chinese hospitals in different provinces and years.

\begin{tabular}{|c|c|c|c|c|c|c|c|c|c|c|c|c|}
\hline Province & 2002 & 2003 & 2004 & 2005 & 2006 & 2007 & 2008 & 2009 & 2010 & 2011 & 2012 & 2013 \\
\hline Anhui & 0.181 & 0.166 & 0.358 & 0.285 & 0.271 & 0.519 & 0.354 & 0.402 & 0.415 & 0.444 & 0.512 & 0.522 \\
\hline Beijing & 0.368 & 1.000 & 0.393 & 0.396 & 0.518 & 0.451 & 0.547 & 0.594 & 0.644 & 0.730 & 0.968 & 1.000 \\
\hline Chongqing & 0.196 & 0.315 & 0.222 & 0.246 & 0.254 & 0.323 & 0.626 & 0.404 & 0.424 & 0.443 & 0.549 & 0.574 \\
\hline Fujian & 0.267 & 0.344 & 0.306 & 0.320 & 0.326 & 0.934 & 0.364 & 0.332 & 0.418 & 0.389 & 0.579 & 0.602 \\
\hline Gansu & 0.159 & 0.196 & 0.181 & 0.164 & 0.164 & 0.500 & 0.241 & 0.200 & 0.359 & 0.370 & 0.425 & 0.460 \\
\hline Guangdong & 0.337 & 0.249 & 0.497 & 0.463 & 0.450 & 0.492 & 0.569 & 0.625 & 0.690 & 0.807 & 0.952 & 1.000 \\
\hline Guangxi & 0.146 & 0.183 & 0.261 & 0.275 & 0.280 & 0.339 & 0.354 & 0.406 & 0.446 & 0.492 & 0.599 & 0.636 \\
\hline Guizhou & 0.177 & 0.264 & 0.203 & 0.237 & 0.274 & 0.412 & 0.347 & 0.446 & 0.452 & 0.478 & 0.536 & 0.565 \\
\hline Hainan & 0.213 & 1.000 & 0.166 & 0.197 & 0.189 & 0.252 & 0.270 & 0.316 & 0.360 & 0.381 & 0.450 & 0.473 \\
\hline Hebei & 0.534 & 0.118 & 0.278 & 0.291 & 0.289 & 0.374 & 0.405 & 0.486 & 0.487 & 0.468 & 0.606 & 0.595 \\
\hline Heilongjiang & 0.167 & 0.190 & 0.275 & 0.299 & 0.300 & 0.407 & 0.414 & 0.477 & 0.438 & 0.463 & 0.533 & 0.544 \\
\hline Henan & 0.217 & 0.092 & 0.284 & 0.311 & 0.310 & 0.363 & 0.415 & 0.472 & 0.496 & 0.514 & 0.622 & 0.618 \\
\hline Hubei & 0.242 & 0.180 & 0.353 & 0.307 & 0.308 & 0.386 & 0.512 & 0.455 & 0.462 & 0.472 & 0.566 & 0.573 \\
\hline Hunan & 0.233 & 0.155 & 0.289 & 0.282 & 0.295 & 0.616 & 0.379 & 0.320 & 0.458 & 0.479 & 0.589 & 0.641 \\
\hline $\begin{array}{c}\text { Inner } \\
\text { Mongolia }\end{array}$ & 0.141 & 0.158 & 0.207 & 0.210 & 38 & 89 & 98 & 79 & 0.390 & 0.424 & 0.491 & 0.490 \\
\hline Jiangsu & 0.357 & 0.232 & 0.589 & 0.394 & 0.405 & 0.445 & 0.460 & 0.495 & 0.521 & 0.555 & 0.690 & 0.726 \\
\hline Jiangxi & 0.223 & 0.172 & 0.321 & 0.260 & 0.264 & 0.627 & 0.342 & 0.340 & 0.442 & 0.467 & 0.546 & 0.550 \\
\hline Jilin & 0.221 & 0.196 & 0.271 & 0.226 & 0.244 & 0.323 & 0.416 & 0.449 & 0.420 & 0.420 & 0.524 & 0.575 \\
\hline Liaoning & 0.073 & 0.135 & 0.285 & 0.295 & 0.314 & 0.471 & 0.407 & 0.449 & 0.476 & 0.502 & 0.637 & 0.652 \\
\hline Ningxia & 0.070 & 1.000 & 0.172 & 0.191 & 0.185 & 0.222 & 0.265 & 0.303 & 0.337 & 0.359 & 0.419 & 0.461 \\
\hline Qinghai & 0.072 & 0.984 & 0.129 & 0.141 & 0.152 & 0.283 & 0.212 & 0.267 & 0.296 & 0.346 & 0.432 & 0.477 \\
\hline Shaanxi & 0.352 & 0.179 & 0.212 & 0.207 & 0.225 & 0.270 & 0.320 & 0.354 & 0.412 & 0.454 & 0.553 & 0.564 \\
\hline Shandong & 0.417 & 0.113 & 0.383 & 0.317 & 0.342 & 0.429 & 0.448 & 0.485 & 0.511 & 0.552 & 0.661 & 0.681 \\
\hline Shanghai & 0.419 & 0.578 & 0.576 & 0.490 & 0.492 & 0.522 & 0.613 & 0.640 & 0.675 & 0.801 & 0.966 & 1.000 \\
\hline Shanxi & 0.221 & 0.146 & 0.327 & 0.213 & 0.249 & 0.630 & 0.283 & 0.255 & 0.383 & 0.398 & 0.522 & 0.561 \\
\hline Sichuan & 0.250 & 0.140 & 0.277 & 0.308 & 0.299 & 0.448 & 0.417 & 0.495 & 0.510 & 0.535 & 0.636 & 0.653 \\
\hline Tianjin & 0.310 & 0.864 & 0.338 & 0.351 & 0.338 & 0.453 & 0.410 & 0.490 & 0.525 & 0.598 & 0.659 & 0.732 \\
\hline Tibet & 0.097 & 1.000 & 0.243 & 0.088 & 0.121 & 0.473 & 0.201 & 0.263 & 0.207 & 0.259 & 0.349 & 0.300 \\
\hline Xinjiang & 0.209 & 0.213 & 0.274 & 0.280 & 0.246 & 0.392 & 0.323 & 0.351 & 0.429 & 0.463 & 0.547 & 0.550 \\
\hline Yunnan & 0.077 & 0.217 & 0.226 & 0.236 & 0.255 & 0.299 & 0.394 & 0.396 & 0.418 & 0.451 & 0.517 & 0.513 \\
\hline Zhejiang & 0.357 & 0.316 & 0.544 & 0.419 & 0.440 & 0.520 & 0.584 & 0.579 & 0.620 & 0.657 & 0.839 & 0.878 \\
\hline
\end{tabular}

With regard to overall average technical efficiency of hospitals in individual provinces, Shanghai shows the best performance among all the counterpart provinces for highest averaged technical efficiency score 0.648 (See Figure 2, with standard deviation of 0.185). The hospitals in Beijing rank the second place, with averaged technical efficiency score of 0.634 (with standard deviation of 0.239 ). The hospitals in Guangdong rank the third place for averaged technical efficiency score of 0.594 (with standard deviation of 0.232). Despite the averaged overall technical efficiency scores of hospitals in these three provinces are still much less than 1, they seems much better comparing to other provinces, which also indicates the technical efficiency of hospitals in developed regions will be more excellent. Shanghai, Beijing and Guangdong are provinces with higher level of economic development in the passing decades. Beijing is the capital of China as well as political and cultural center in China. Meanwhile, the Shanghai is the municipality directly under the central government and financial center in China. Guangdong has first experienced the "Open and Reform" policy since 1978 in China and witnessed the sharp expansion of FDI and international trade. 


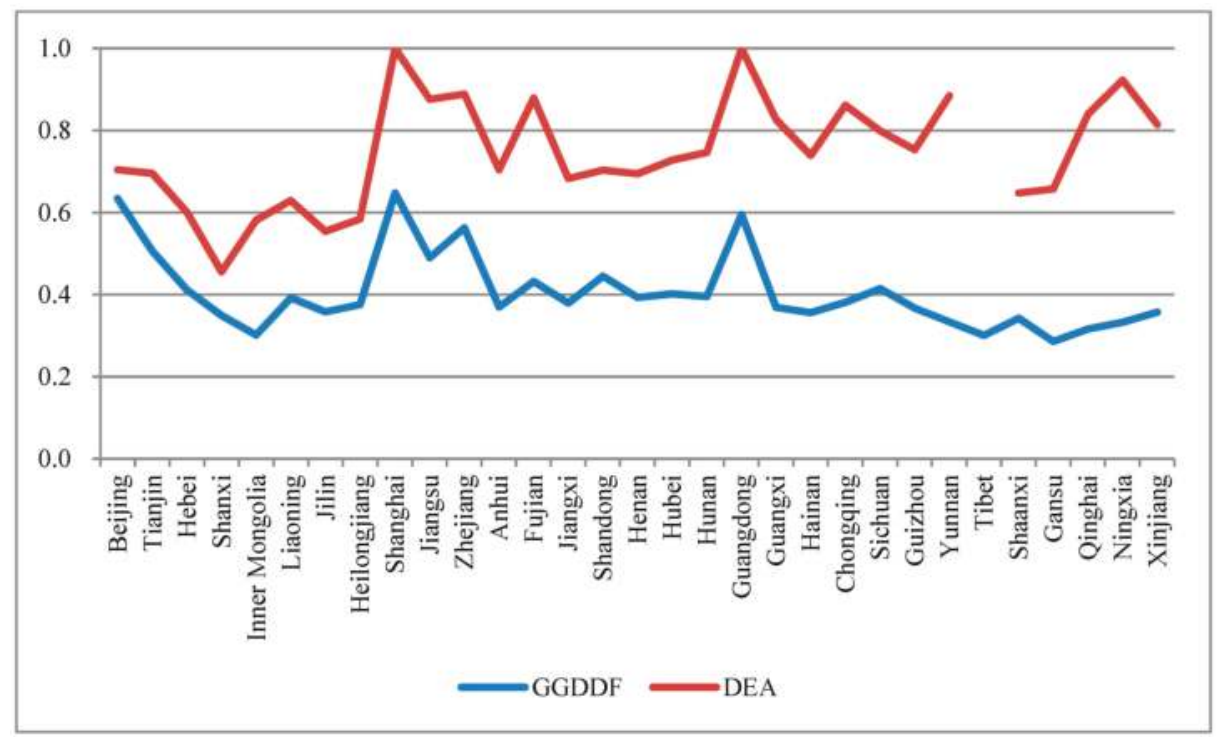

Figure 2. Technical efficiency scores of hospitals in different provinces (Sources: the technical efficiency score estimate with DEA is obtained from Hu et al. [14] "Analysis of hospital technical efficiency in China: Effect of health insurance reform", China Economic Review).

The trends of relative technical efficiency performance of all the hospitals in 31 provinces of China are shown in Figure 3. Although the overall technical efficiency score temporally declined during the period of 2004-2006 and 2008-2009, the long-term technical efficiency is still in an upwards trend. Therefore, the overall technical efficiency of hospitals in China has been improved in the last decade. The fluctuation of the overall technical efficiency score may be due to the rapid increase of medical fees for inpatient and outpatient as well as the outbreak of financial crisis since 2008. As the statistics of China's Health Statistical Yearbook indicated, the average inpatient medical charge and outpatient medical charge both had increased about $7.5 \%-11.0 \%$ during the period of 2004-2006 and 2008-2009, which is much higher than other period. 


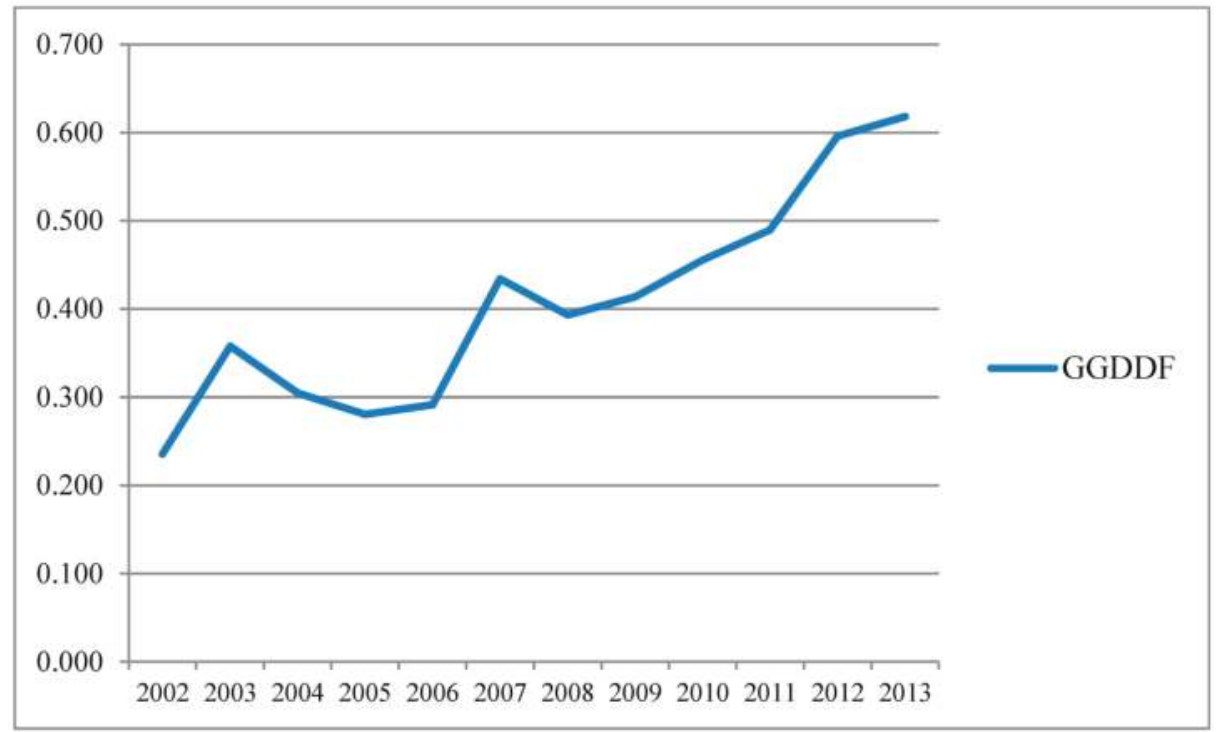

Figure 3. Trend of technical efficiency score.

\section{Determinants of Technical Efficiency for Chinese Hospitals}

\subsection{Model and Variables Specification}

From the information of contextual setting part of this paper, the medical sector of China had underwent profound reform in the passing three decades. The social and economic environment was also in rapid transition for emerging of "China's miracle". Meanwhile, we need to further investigate the deep reasons for the changes of technical efficiency of Chinese hospitals, so that to acquire more insights on hospital management and public policy implications for further reform in the medical sector of China. Therefore, following the literature on two-stage DEA $[14,59,60]$, we adopts a Tobit model to exam how these exogenous environmental variables affects the technical efficiency for Chinese hospitals.

Based on the literature survey, contextual setting of China and the available data, the independent variables are selected as follows, i.e., we will examine the relationship between hospital's overall technical efficiency and the following covariates: 3A class (San Ji Jia Deng) hospital proportion (best), public subsidies (suby), medical insurance reforms (reform 1 ) and (reform 2 ). The justification for the selection of these covariates is provided in the following subsections.

The 3A class hospital proportion in the total number of public hospitals indicates the supervision as well as the medical services quality. In China, the hospitals have been divided into three grades according to their capability to supply high-quality medical service. There are three subclasses in each grade. The top is labeled as 3A hospital. They could offer specialized medical service, medical research and tertiary medical education. However, the technological advantage and accumulation of human resources is costly to improve the medical services of hospitals.

The public subsidies are the amount of funds transferred to the hospitals, which could increase the hospitals' budget for more professional personnel and advanced equipment, as well as induce moral hazard or shirking behavior. The net effects of public subsidy are not clear. Public hospitals in China always hold the major share of the medical market despite flourishing private hospitals since 2001. Furthermore, price regulation on medical service makes the public subsidies very significant to cover expenses for public hospitals. 
The social medical insurance reform is measured with two dummy variables. As the contextual setting part indicates, China initiated the NRCMS in 2003. The government launched the basic social medical insurance for urban residents program (BSMIP) in 2007, which is different from BSMIS and covers the elderly, students, children and unemployed. Then the three-tier social medical insurance schemes finally established and increase the affordability of medical service. Follow the research of Hu et al. [14], we also examine whether the introduction of NRCMS and BSMIP have increased the technical efficiency of hospitals. We define that these binary dummy variables equal 1 for post-reform period after 2003 and 2007, respectively.

Moreover, to control the heterogeneity of different provinces, we further introduce explanatory variables of the characteristics of provinces in China, including the GDP per capita $(g d p p)$, the population density (popd) and the geography location (area). According to the China Statistical Yearbook, the eastern area includes 12 provinces like Beijing, Tianjin, Hebei, Liaoning, Jiangsu, Shandong, Shanghai, Zhejiang, Fujian, Guangdong, Guangxi and Hainan. The middle area includes nine provinces, such as Shanxi, Inner Mongolia, Jilin, Heilongjiang, Anhui, Jiangxi, Henan, Hubei and Hunan. The western area includes the rest 10 provinces, i.e., Chongqing, Sichuan, Guizhou, Yunnan, Tibet, Shaanxi, Gansu, Qinghai, Ningxia and Xinjiang. The variable area is a dummy variable. When the province is in the east area, area is labelled 0 , and equals 1 for the middle area, 2 for the west area.

The detailed definition and descriptive statistics of these independent variables are presented in Table 3.

Table 3. The definition and descriptive statistics of independent variables.

\begin{tabular}{|c|c|c|c|c|c|c|}
\hline Variable & Description & Observations & Mean & Std. Dev. & Min & Max \\
\hline gdpp & $\begin{array}{l}\text { GDP per } \\
\text { capita }\end{array}$ & 372 & 9.766 & 0.648 & 8.089 & 11.228 \\
\hline popd & $\begin{array}{l}\text { population } \\
\text { density }\end{array}$ & 372 & 0.413 & 0.598 & 0.002 & 3.833 \\
\hline suby & $\begin{array}{c}\text { government } \\
\text { subsidy }\end{array}$ & 372 & 14.937 & 8.122 & 3.037 & 59.232 \\
\hline best & $\begin{array}{l}\text { ratio of 3A } \\
\text { hospitals }\end{array}$ & 372 & 4.180 & 2.431 & 0.792 & 13.143 \\
\hline reform1 & $\begin{array}{l}\text { NRCMS } \\
\text { reform }\end{array}$ & 372 & 0.833 & 0.373 & 0 & 1 \\
\hline reform2 & $\begin{array}{l}\text { BSMIS } \\
\text { reform }\end{array}$ & 372 & 0.500 & 0.501 & 0 & 1 \\
\hline area & location & 372 & 0.935 & 0.841 & 0 & 2 \\
\hline
\end{tabular}

From the correlation matrix reported in Table 4, the adopted explanatory variables are all significantly related with the technical efficiency of the Chinese hospitals in different provinces. Moreover, most correlation coefficients of these explanatory variables are much lower than 0.5 . In addition, the possibility of multi-collinearity problem can be eliminated with further check on VIF (variance inflation factor), which is smaller than 5 . 
Table 4. The correlation matrix between technical efficiency (TE) and explanatory variables.

\begin{tabular}{cccccccc}
\hline & TE & gdpp & popd & suby & best & reform1 & reform2 \\
\hline TE & 1 & & & & & & \\
gdpp & $0.663^{* * *}$ & 1 & & & & & \\
popd & $0.401^{* * *}$ & $0.529^{* * *}$ & 1 & & & & \\
suby & $-0.304^{* * *}$ & $-0.172^{* * *}$ & $-0.272^{* * *}$ & 1 & & & \\
best & $0.370^{* * *}$ & $0.499^{* * *}$ & $0.588^{* * *}$ & $-0.303 * * *$ & 1 & & \\
reform1 & $0.260^{* * *}$ & $0.433^{* * *}$ & 0.026 & -0.049 & 0.05 & 1 \\
reform2 & $0.472^{* * *}$ & $0.554^{* * *}$ & 0.039 & 0.069 & 0.06 & $0.447^{* * *}$ & 1 \\
\hline
\end{tabular}

Note: The symbols *,***** indicate significance at $10 \%, 5 \%$ and $1 \%$ levels, respectively.

\subsection{Empirical Results}

Table 5 reports the empirical results of Tobit model regressed on the explanatory variables mentioned above. It starts from a limited set of regressors and gradually adds in more controls. The column (1) of Table 5 is the baseline results. In the continued columns, we further add more new variables to check the effects of different factors as well as the robustness of the empirical models. The time trends are captured and controlled through year dummy in the models.

Table 5. The results of Tobit models.

\begin{tabular}{|c|c|c|c|c|c|}
\hline & (1) & (2) & (3) & (4) & (5) \\
\hline gdpp & $\begin{array}{c}0.100 * * * \\
(5.79)\end{array}$ & $\begin{array}{c}0.075^{* * *} \\
(4.54)\end{array}$ & $\begin{array}{c}0.073^{* * *} \\
(4.74)\end{array}$ & $\begin{array}{c}0.073^{* * *} \\
(4.74)\end{array}$ & $\begin{array}{c}0.083^{* * *} \\
(4.50)\end{array}$ \\
\hline popd & $\begin{array}{c}0.066^{* * *} \\
(5.16)\end{array}$ & $\begin{array}{c}0.052 * * * \\
(4.01)\end{array}$ & $\begin{array}{c}0.050 * * * \\
(3.65)\end{array}$ & $\begin{array}{c}0.050 * * * \\
(3.65)\end{array}$ & $\begin{array}{c}0.049^{* * *} \\
(3.48)\end{array}$ \\
\hline suby & & $\begin{array}{c}-0.007^{* * *} \\
(-5.47)\end{array}$ & $\begin{array}{c}-0.007^{* * *} \\
(-5.39)\end{array}$ & $\begin{array}{c}-0.007^{* * *} \\
(-5.39)\end{array}$ & $\begin{array}{c}-0.007^{* * *} \\
(-4.96)\end{array}$ \\
\hline best & & & $\begin{array}{l}0.001 \\
(0.34)\end{array}$ & $\begin{array}{l}0.001 \\
(0.34)\end{array}$ & $\begin{array}{l}0.002 \\
(0.53)\end{array}$ \\
\hline reform1 & & & & $\begin{array}{c}0.173^{* * * *} \\
(5.06)\end{array}$ & $\begin{array}{c}0.168^{* * *} \\
(4.84)\end{array}$ \\
\hline reform2 & & & & $\begin{array}{c}0.137^{* * *} \\
(3.81)\end{array}$ & $\begin{array}{c}0.131^{* * *} \\
(3.57)\end{array}$ \\
\hline area & & & & & $\begin{array}{l}0.010 \\
(0.75)\end{array}$ \\
\hline _cons & $\begin{array}{c}-0.694^{* * *} \\
(-4.51)\end{array}$ & $\begin{array}{c}-0.370 * * \\
(-2.43)\end{array}$ & $\begin{array}{c}-0.359 * * \\
(-2.49)\end{array}$ & $\begin{array}{c}-0.359 * * \\
(-2.49)\end{array}$ & $\begin{array}{c}-0.452 * * * \\
(-2.64)\end{array}$ \\
\hline sigma & & & & & \\
\hline _cons & $\begin{array}{c}0.126^{* * *} \\
(10.61)\end{array}$ & $\begin{array}{c}0.113^{* * *} \\
(11.63)\end{array}$ & $\begin{array}{c}0.113^{* * *} \\
(11.63)\end{array}$ & $\begin{array}{c}0.113^{* * *} \\
(11.63)\end{array}$ & $\begin{array}{c}0.113^{* * *} \\
(11.78)\end{array}$ \\
\hline Year effects & Yes & Yes & Yes & Yes & Yes \\
\hline Log pseudolikelihood & 265.97 & 265.53 & 265.53 & 265.49 & 227.14 \\
\hline $\mathrm{F}$ & 55.09 & 59.66 & 59.65 & 63.51 & 58.61 \\
\hline$N$ & 372 & 372 & 372 & 372 & 372 \\
\hline
\end{tabular}

Note: The $t$ value in parentheses (based on robust standard error). The symbols ${ }^{*}{ }^{* *},{ }^{* * *}$ indicate significance at $10 \%$, $5 \%$ and $1 \%$ levels, respectively.

According to column (1) of Table 5, the variable gdpp and popd are both significant at $1 \%$ and positive with the overall technical efficiency of Chinese hospitals. In column (2) of Table 5, we further investigate the effects of government subsidies (suby) on the sustainable performance of hospitals on the basis of the model of column (1). The results shows that the coefficient of public subsidies is negative at 1-percent significant level, which means that the subsidies make negative impacts on the Chinese hospitals to improve technical efficiency. According to column (3) in Table 5, the coefficient of the $3 \mathrm{~A}$ class hospital proportion is not significant, implying that it has no effects on technical efficiency of Chinese hospitals. As the definition in Table 3, the binary dummy variables Reform 1 and Reform 2 are designed to analyze the effects when introducing the social medical insurance reform in 2003 and 2007. 
Referring to column (4) in Table 5, both coefficients of Reform 1 and Reform 2 are significantly positive at 1 percent level.

In order to further control the location heterogeneity, an area dummy variable is added into model and the regression results is showed in column (5) of Table 5. The estimated coefficient of area is statistically insignificant, implying there is no apparent difference among eastern, middle and western provinces, after controlling for other factors.

Furthermore, comparing the results of different columns in the Table 5, we find that the estimated results are very robust for each regressor, for example, the variable " $g d p p$ " is statistically significant at $1 \%$ in model 1-model 5 , and its coefficients fluctuate in small range.

\section{Discussion}

The results reveal that technical efficiency of Chinese hospitals varies among different provinces and time. Despite the trend of technical efficiency being improved with time, most Chinese provinces are not performing well leave a large potential to improve. Beijing, Shanghai and Guangdong display better performance comparing to other provinces of China. Later, we further investigate the factors that may affect the technical efficiency of Chinese hospitals, which also shed lights on the effects of reforms undergone. It concludes that the social medical insurance reforms that launched in 2003 and 2007 both have promoted the technical efficiency of Chinese hospitals. Meanwhile, the government subsidies have negative influence on the technical efficiency of Chinese hospitals. The proportion of 3A hospitals and the area dummy variable is not statistically significant. With higher GDP per capital and population density, which means greater medical services demand potentials, the technical efficiency scores is higher in China.

\subsection{Technical Efficiency Estimation Compared with Other Research}

For comparison purposes, we also provide the technical efficiency estimated by Hu et al. [14] in Figure 2, who also make a research on the technical efficiency of Chinese hospital with province level data during 2002-2008. They employed the output-oriented CCR DEA model and considered both desirable and undesirable outputs in hospital production. The outputs variables are the total number of outpatient and emergency room visits, the total number of inpatient days and patient mortality, while the inputs variables are the number of doctors, medical technicians, other staff and beds as well as the fixed assets. According to the existing research, including Jacobs [6], Barros et al. [16], Koop et al. [41], Rosko and Mutter [42], we add the total revenue as an output of hospitals. As the contextual setting part indicates, after years of medical reforms during the period of 2002-2013, the hospitals in China began to rely more on market and revenue collected from the medical services rather than the government subsidies. For most provinces of China, the proportion of the government subsidies in the total revenue is less than $16 \%$ at present. Comparing to our estimation of overall technical efficiency scores, the results of Hu et al. [14] has much higher values (The Tibet's efficiency score had not been estimated for missing data in Hu et al. [14]), implying an overestimated technical efficiency performance. However, our results and the results of $\mathrm{Hu}$ et al. [14] shows similar patterns for different provinces, for example, the technical efficiency scores of Shanghai, Beijing and Guangdong were also much higher than other provinces in Hu et al. [14].

\subsection{Discussion on Determinants of Sustainability Technical Efficiency for Chinese Hospitals}

As the coefficients of GDP per capita and population density are all positive, it implies that when the economic development and population density is higher, there will be more demands for medical services, and the overall technical efficiency will be pushed to a higher level. This is also confirmed by the facts that hospitals in Beijing, Shanghai and Guangdong display better performance.

Public subsidies may increase the hospitals' budget for more professional personnel and advanced equipment, as well as induce moral hazard or shirking behavior. Our results indicate that pubic subsidies to hospitals are an incentive to induce moral hazards rather than improve on technical 
efficiency. In contrast, Hu et al. [14] argued that the government subsidy has ambiguous and insignificant effects on the Chinese hospital efficiency.

The 3A class hospital proportion has positive but not significant effects on Chinese hospital's technical efficiency, suggesting its limited influences on the performance of Chinese hospitals. The supervising authorities will grade the hospitals according to several standards every three years. Hence, the $3 \mathrm{~A}$ hospital rating is also a signal for great technology advantage and high quality of medical service. However, without a sound pre-triage system, the $3 \mathrm{~A}$ hospitals just attract crowded patients for signals and take advantage of the monopoly power in the medical market. Therefore, the net effects are ambiguous and the coefficient of variable "best" is not significant despite it is still positive.

The social medical insurance reforms have a positive influence on the overall technical efficiency of Chinese hospitals, which is consistent with the empirical results of $\mathrm{Hu}$ et al. [14]. The medical insurance reforms of the NRCMS and BSMIP has increase the opportunity of the poor to acquire the medical service, namely the government subsidy people to get the basic medical service and therefore increasing the demand for medical service as well as the output of the hospitals. Wagstaff and Lindelow [61] and Wagstaff et al. [62] also witnessed the increase in the medical service utilization after the reform. Moreover, as the column (1) in Table 2 indicates, the absolute value of the coefficients of Reform 1 is much larger than the Reform 2 . It implies that the coverage of social medical insurance in the rural is more effectively lower the cost of Chinese hospitals than that in the urban.

Reform was first initiated in eastern provinces of China, which may enhance the management and incentives in the medical care industry through deregulation. Moreover, the eastern area is much richer and more developed than western and central area of China [63]. The more favorable environment and diversified medical demand of people will drive the hospitals to be more efficient. However, most private hospitals in China were also set up there for deregulation. According to the latest China's Health and Family Planning Yearbook [40], up to the end of 2013, there are 11,313 private hospitals in China. Therefore, the overall technical efficiency of hospitals may be lowered down mainly for the market share nibbled away by the private hospitals. Therefore, it may be underlying reasons for the insignificancy of variable "area", despite the results still need further research and tests.

Based on the analysis mentioned above, the policy implications are derived as follows: Firstly, it needs to encourage the development of private hospitals for the government. Meanwhile, the government should cut down the fiscal subsidies on the hospitals and switch from relying on the government to the market. Secondly, a sound pre-triage system is necessary when the pushing the reform of big public hospitals and community-level hospitals. When $3 \mathrm{~A}$ hospital is evaluated without it, the effects of this monitoring mechanism will be limited. Thirdly, the coverage of medical services should be enlarged, especially for the treatment of critical diseases as well as the essential drugs. Meanwhile, the medical insurance for the rural and urban should be unified an integrated to offer people equal insurance for basic medical service. The present medical insurance in China is in a high degree of fragmentation for different provinces or counties. Finally, the government needs to pursue different policies to improve the technical efficiency of Chinese hospitals for the province with higher GDP per capital and population density having better performance.

As this empirical study just focuses on the Chinese hospitals with province-level data, the further research could try to collect and utilize the hospital-level data to check the robustness of the conclusions and provide more policy implications. Meanwhile, a comparative study can be conducted on the technical efficiency of China, Korea, Japan, etc. Such a benchmarking comparison among the Northeast Asian countries could provide much more comprehensive implications. Moreover, some scholars argue that it should adopt alternative methods to analyze the determinants of technical efficiency of Chinese hospitals. Therefore, we plan to use double-bootstrapped truncated regression [64] and the conditional nonparametric approach [65] to replace the present Tobit model in the second stage and try to check the robustness of results in this paper. 


\section{Conclusions}

In the background of the New Normal, which does not had a clear definition at present and usually refers to a significant regime change of economic growth that display an obvious slow-down, it is significant to quantify its technical efficiency in different sectors for China. The medical sector of China has undergone decades of reform, despite still being criticized for the problems of "poor access and high fee". As a new round of reform are approaching and its critical importance for the welfare of whole society, this study is the first to analyze the technical efficiency of province-level of Chinese hospitals in the period 2002 to 2013 using a new global generalized directional distance function approach taking account of undesirable output. Meanwhile, this research fills the gap in the literature on the hospital's technical efficiency in different area of China.

This study shows that the technical efficiency of Chinese hospitals has been improved with time trend. However, most Chinese provinces still do not perform well and have large potentials to improve. Meanwhile, some factors improve the technical efficiency of Chinese hospitals, including economic development, population density and social medical insurance reforms. In contrast, the government subsidies to hospitals reduce the technical efficiency of Chinese hospitals. The proportion of 3A hospitals display limited positive effects on the technical efficiency of Chinese hospitals. These indicate that not all the medical reforms have successfully raised the hospital efficiency in China, and leave clues for future reform.

The present research offers a comprehensive evaluation of Chinese hospitals. This study also proposes suggestions for further medical reform in China. China is the largest Northeast Asian country. The research may shed lights on medical reforms or hospital management in other Northeast Asian countries for the similar culture and contiguity to each other, for example, the medical insurance as well as the government subsidies on public hospitals. Moreover, China has played a significantly important role in the Northeast Asian area. It has the largest land area, population and GDP. The reform and improvement on the technical efficiency for the Chinese medical system will promote the overall welfare in this region as well as boost the economic integration in the medical sector.

Acknowledgments: We thank the financial support provided by the National Science Foundation of China (41461118), Humanities and Social Science Fund of Jiangxi (JJ1420), Philosophy and Social Science fund of Jiangxi (15SKJD21) and the China Postdoctoral Foundation (2014M551849, 2014KY55).

Author Contributions: Kejia Chu designed research; Ning Zhang performed research and analyzed the data; Ning Zhang and Zhongfei Chen wrote and revised the paper. All authors read and approved the final manuscript.

Conflicts of Interest: The authors declare no conflict of interest.

\section{References}

1. State Council DRC Research Project. Assessment of China's medical and health system reform and suggestions. China Health Policy 2005, 9, 4-7.

2. Flaherty, J.H.; Liu, M.L.; Ding, L.; Dong, B.; Ding, Q.; Li, X.; Xiao, S. China: The aging giant. J. Am. Geriatr. Soc. 2007, 55, 1295-1300. [CrossRef] [PubMed]

3. World Bank. World Development Report 2007: Development and the Next Generation; World Bank Publications: Washington, DC, USA, 2006.

4. Arah, O.A.; Klazinga, N.S.; Delnoij, D.M.J.; Ten Asbroek, A.H.A.; Custers, T. Conceptual frameworks for health systems performance: A quest for effectiveness, quality, and improvement. Int. J. Qual. Health Care 2003, 15, 377-398. [CrossRef] [PubMed]

5. Fukuyama, H.; Shiraz, R.K. Cost-effectiveness measures on convex and nonconvex technologies. Eur. J. Oper. Res. 2015, 246, 307-319. [CrossRef]

6. Jacobs, R. Alternative methods to examine hospital efficiency: Data envelopment analysis and stochastic frontier analysis. Health Care Manag. Sci. 2001, 4, 103-115. [CrossRef] [PubMed]

7. Docherty, P.; Kira, M.; Shani, A.R. Creating Sustainable Work Systems (2nd Ed): Developing Social Sustainability; Routledge: London, UK, 2008. 
8. Rosenberg-Yunger, Z.R.; Daar, A.S.; Singer, P.A.; Martin, D.K. Healthcare sustainability and the challenges of innovation to biopharmaceuticals in Canada. Health Policy 2008, 87, 359-368. [CrossRef] [PubMed]

9. Magnussen, J. Efficiency measurement and the operationalization of hospital production. Health Serv. Res. 1996, 31, 21-37. [PubMed]

10. Li, H.; Dong, S.; Liu, T. Relative efficiency and productivity: A preliminary exploration of public hospitals in Beijing, China. BMC Health Serv. Res. 2014. [CrossRef] [PubMed]

11. Hollingsworth, B. The measurement of efficiency and productivity of health care delivery. Health Econ. 2008, 17, 1107-1128. [CrossRef] [PubMed]

12. Hwang, J.; Akdede, S.H. The influence of governance on public sector efficiency: A cross-country analysis. Soc. Sci. J. 2011, 48, 735-738. [CrossRef]

13. Ng, Y.C. The productive efficiency of Chinese hospitals. China Econ. Rev. 2011, 22, 428-439. [CrossRef]

14. Hu, H.H.; Qi, Q.; Yang, C.H. Analysis of hospital technical efficiency in China: Effect of health insurance reform. China Econ. Rev. 2012, 23, 865-877. [CrossRef]

15. Barros, C.P.; de Menezes, A.G.; Vieira, J.C. Measurement of hospital efficiency, using a latent class stochastic frontier model. Appl. Econ. 2013, 45, 47-54. [CrossRef]

16. Barros, C.P.; de Menezes, A.G.; Peypoch, N.; Solonandrasana, B.; Vieira, J.C. An analysis of hospital efficiency and productivity growth using the Luenberger indicator. Health Care Manag. Sci. 2008, 11, 373-381. [CrossRef] [PubMed]

17. Hsu, Y.C. The efficiency of government spending on health: Evidence from Europe and Central Asia. Soc. Sci. J. 2013, 50, 665-673. [CrossRef]

18. Zhang, N.; Choi, Y. A note on the evolution of directional distance function and its development in energy and environmental studies 1997-2013. Renew. Sustain. Energy Rev. 2014, 33, 50-59. [CrossRef]

19. Yu, Y.; Choi, Y.; Zhang, N. Strategic corporate sustainability performance of Chinese state-owned listed firms: A meta-frontier generalized directional distance function approach. Soc. Sci. J. 2014, 52, 300-310. [CrossRef]

20. Zhang, N.; Kong, F.; Choi, Y. Measuring sustainability performance for China: A sequential generalized directional distance function approach. Econ. Model. 2014, 41, 392-397. [CrossRef]

21. Chung, Y.H.; Färe, R.; Grosskopf, S. Productivity and undesirable outputs: A directional distance function approach. J. Environ. Manag. 1997, 51, 229-240. [CrossRef]

22. Chambers, R.G.; Chung, Y.; Färe, R. Benefit and distance functions. J. Econ. Theory 1996, 70, 407-419. [CrossRef]

23. Chambers, R.G.; Chung, Y.; Färe, R. Profit, directional distance functions, and Nerlovian efficiency. J. Optimiz. Theory Appl. 1998, 98, 351-364. [CrossRef]

24. Fukuyama, H.; Weber, W.L. A directional slacks-based measure of technical inefficiency. Socio-Econ. Plan. Sci. 2009, 43, 274-287. [CrossRef]

25. Färe, R.; Grosskopf, S. Directional distance functions and slacks-based measures of efficiency. Eur. J. Oper. Res. 2010, 200, 320-322. [CrossRef]

26. Färe, R.; Grosskopf, S. Directional distance functions and slacks-based measures of efficiency: Some clarifications. Eur. J. Oper. Res. 2010, 206, 702. [CrossRef]

27. Zhang, N.; Zhou, P.; Choi, Y. Energy efficiency, $\mathrm{CO}_{2}$ emission performance and technology gaps in fossil fuel electricity generation in Korea: A meta-frontier non-radial directional distance functionanalysis. Energy Policy 2013, 56, 653-662. [CrossRef]

28. Mei, G.; Gan, J.; Zhang, N. Metafrontier environmental efficiency for China's regions: A slack-based efficiency measure. Sustainability 2015, 7, 4004-4021. [CrossRef]

29. Zhou, P.; Ang, B.W.; Wang, H. Energy and $\mathrm{CO}_{2}$ emission performance in electricity generation: A non-radial directional distance function approach. Eur. J. Oper. Res. 2012, 221, 625-635. [CrossRef]

30. Oh, D.H. A global Malmquist-Luenberger productivity index. J. Product. Anal. 2010, 34, 183-197. [CrossRef]

31. Eggleston, K.; Ling, L.; Qingyue, M.; Lindelow, M.; Wagstaff, A. Health service delivery in China: A literature review. Health Econ. 2008, 17, 149-165. [CrossRef] [PubMed]

32. Wagstaff, A.; Yip, W.; Lindelow, M.; Hsiao, W.C. China's health system and its reform: A review of recent studies. Health Econ. 2009, 18, 7-23. [CrossRef] [PubMed]

33. Hsiao, W.C. The Chinese health care system: Lessons for other nations. Soc. Sci. Med. 1995, 41, 1047-1055. [CrossRef] 
34. Dong, W. Health Care Reform in Urban China. Available online: Munkschool.utoronto.ca/cphs/wp-content/ uploads/2012/03/Weizhen_Dong-2001-02.pdf (accessed on 8 June 2015).

35. Audibert, M.; Mathonnat, J.; Pelissier, A.; Huang, X.X.; Ma, A. Health insurance reform and efficiency of township hospitals in rural China: An analysis from survey data. China Econ. Rev. 2013, 27, 326-338. [CrossRef]

36. Dong, K. Medical insurance system evolution in China. China Econ. Rev. 2009, 20, 591-597. [CrossRef]

37. Yip, W.; Hsiao, W. China's health care reform: A tentative assessment. China Econ. Rev. 2009, 20, 613-619. [CrossRef]

38. World Bank. Fixing the Public Hospital System in China: China Health Policy Notes No.2; World Bank Publications: Washington, DC, USA, 2010.

39. Gu, E.; Zhang, J. Health care regime change in urban China: Unmanaged marketization and reluctant privatization. Pac. Aff. 2006, 79, 49-71. [CrossRef]

40. National Health and Family Planning Commission of the People's Republic of China. China's Health and Family Planning Yearbook 2014; Peking Union Medical College Press: Beijing, China, 2015.

41. Koop, G.; Osiewalski, J.; Steel, M.F. Bayesian efficiency analysis through individual effects: Hospital cost frontiers. J. Econom. 1997, 76, 77-105. [CrossRef]

42. Rosko, M.D.; Mutter, R.L. Stochastic frontier analysis of hospital inefficiency: A review of empirical issues and an assessment of robustness. Med. Care Res. Rev. 2008, 65, 131-166. [CrossRef] [PubMed]

43. Varabyova, Y.; Schreyögg, J. International comparisons of the technical efficiency of the hospital sector: Panel data analysis of OECD countries using parametric and non-parametric approaches. Health Policy 2013, 112, 70-79. [CrossRef] [PubMed]

44. Biørn, E.; Hagen, T.P.; Iversen, T.; Magnussen, J. The effect of activity-based financing on hospital efficiency: A panel data analysis of DEA efficiency scores 1992-2000. Health Care Manag. Sci. 2003, 6, 271-283. [CrossRef] [PubMed]

45. Ozcan, Y.A. Sensitivity analysis of hospital efficiency under alternative output/input and peer groups: A review. Knowl. Technol. Policy 1992, 5, 1-29. [CrossRef]

46. Zuckerman, S.; Hadley, J.; Iezzoni, L. Measuring hospital efficiency with frontier cost functions. J. Health Econ. 1994, 13, 255-280. [CrossRef]

47. Xue, Y.; Liang, H.; Wu, X.; Gong, H.; Li, B.; Zhang, Y. Effects of electronic medical record in a Chinese hospital: A time series study. Int. J. Med. Inform. 2012, 81, 683-689. [CrossRef] [PubMed]

48. Ministry of Health of the People's Republic of China. China's Health Statistical Yearbook 2003; Peking Union Medical College Press: Beijing, China, 2004.

49. Ministry of Health of the People's Republic of China. China's Health Statistical Yearbook 2004; Peking Union Medical College Press: Beijing, China, 2005.

50. Ministry of Health of the People's Republic of China. China's Health Statistical Yearbook 2005; Peking Union Medical College Press: Beijing, China, 2006.

51. Ministry of Health of the People's Republic of China. China's Health Statistical Yearbook 2006; Peking Union Medical College Press: Beijing, China, 2007.

52. Ministry of Health of the People's Republic of China. China's Health Statistical Yearbook 2007; Peking Union Medical College Press: Beijing, China, 2008.

53. Ministry of Health of the People's Republic of China. China's Health Statistical Yearbook 2008; Peking Union Medical College Press: Beijing, China, 2009.

54. Ministry of Health of the People's Republic of China. China's Health Statistical Yearbook 2009; Peking Union Medical College Press: Beijing, China, 2010.

55. Ministry of Health of the People's Republic of China. China's Health Statistical Yearbook 2010; Peking Union Medical College Press: Beijing, China, 2011.

56. Ministry of Health of the People's Republic of China. China's Health Statistical Yearbook 2011; Peking Union Medical College Press: Beijing, China, 2012.

57. Ministry of Health of the People's Republic of China. China's Health Statistical Yearbook 2012; Peking Union Medical College Press: Beijing, China, 2013.

58. Ministry of Health of the People's Republic of China. China's Health Statistical Yearbook 2013; Peking Union Medical College Press: Beijing, China, 2014. 
59. Araújo, C.; Barros, C.P.; Wanke, P. Efficiency determinants and capacity issues in Brazilian for-profit hospitals. Health Care Manag. Sci. 2014, 17, 126-138. [CrossRef] [PubMed]

60. Dutta, A.; Bandyopadhyay, S.; Ghose, A. Measurement and determinants of public hospital efficiency in West Bengal, India. J. Asian Public Policy 2014, 7, 231-244. [CrossRef]

61. Wagstaff, A.; Lindelow, M. Can insurance increase financial risk? The curious case of health insurance in China. J. Health Econ. 2008, 27, 990-1005. [CrossRef] [PubMed]

62. Wagstaff, A.; Lindelow, M.; Jun, G.; Ling, X.; Juncheng, Q. Extending health insurance to the rural population: An impact evaluation of China's new cooperative medical scheme. J. Health Econ. 2009, 28, 1-19. [CrossRef] [PubMed]

63. Jian, T.; Sachs, J.D.; Warner, A.M. Trends in regional inequality in China. China Econ. Rev. 1996, 7, 1-21. [CrossRef]

64. Simar, L.; Wilson, P.W. Estimation and inference in two-stage, semi-parametric models of production processes. J. Econom. 2007, 136, 31-64. [CrossRef]

65. Bădin, L.; Daraio, C.; Simar, L. Optimal bandwidth selection for conditional efficiency measures: A data-driven approach. Eur. J. Oper. Res. 2010, 201, 633-640. [CrossRef]

(C) 2015 by the authors. Licensee MDPI, Basel, Switzerland. This article is an open access article distributed under the terms and conditions of the Creative Commons Attribution (CC BY) license (http:/ / creativecommons.org/licenses/by/4.0/). 
Article

\title{
Exploring the Spatial-Temporal Disparities of Urban Land Use Economic Efficiency in China and Its Influencing Factors under Environmental Constraints Based on a Sequential Slacks-Based Model
}

\author{
Hualin Xie ${ }^{1,2, *}$ and Wei Wang ${ }^{1,2, *}$ \\ 1 Research Center of Land Management, Jiangxi University of Finance and Economics, \\ Nanchang 330013, China \\ 2 Institute of Poyang Lake Eco-economics, Jiangxi University of Finance and Economics, \\ Nanchang 330013, China \\ * Authors to whom correspondence should be addressed; xiehualin@jxufe.edu.cn (H.X.); \\ phx0502066@163.com (W.W.); Tel./Fax: +86-791-8381-0267 (H.X.).
}

Academic Editors: Yongrok Choi, Malin Song and Seunghwan Myeong

Received: 15 June 2015; Accepted: 23 July 2015; Published: 31 July 2015

\begin{abstract}
Using a sequential slack-based measure (SSBM) model, this paper analyzes the spatiotemporal disparities of urban land use economic efficiency (ULUEE) under environmental constraints, and its influencing factors in 270 cities across China from 2003-2012. The main results are as follows: (1) The average ULUEE for Chinese cities is only 0.411 , and out of the 270 cities, only six cities are always efficient in urban land use in the study period. Most cities have a lot of room to improve the economic output of secondary and tertiary industries, as well as environmental protection work; (2) The eastern region of China enjoys the highest ULUEE, followed by the western and central regions. Super-scale cities show the best performance of all four city scales, followed by large-scale, small-scale and medium-scale cities. Cities with relatively developed economies and less pollutant discharge always have better ULUEE; (3) The results of slack variables analysis show that most cities have problems such as the labor surplus, over-development, excessive pollutant discharge, economic output shortage, and unreasonable use of funds is the most serious one; (4) The regression results of the influencing factors show that improvements of the per capita GDP and land use intensity are helpful to raise ULUEE. The urbanization rate and the proportion of foreign enterprises' output account for the total output in the secondary and tertiary industries only have the same effect in some regions and city scales. The land management policy and land leasing policy have negative impact on the ULUEE in all the three regions and four city scales; (5) Some targeted policy goals are proposed, including the reduction of surplus labor, and pay more attention to environmental protection. Most importantly, effective implementation of land management policies from the central government, and stopping blind leasing of land to make up the local government's financial deficit would be very helpful to improve the ULUEE of Chinese cities.
\end{abstract}

Keywords: urban land use; economic efficiency; sequential SBM model; China; environmental constraints

\section{Introduction}

Urban land use is an important topic in the development of Chinese cities, and effective use of urban land is very important for sustainable city management [1]. According to China City Statistical Yearbook, the urban land refers to urban built-up area from the perspective of urban production. This is construction area for non-agricultural production, which accounts for most of the output 
of Chinese secondary and tertiary industries, and unfortunately, most of the industrial pollutant discharge [2]. Land is an important input in the production process, and it is the main carrier of production activities and the main bearing of pollutants caused by the production activities. With rapid economic development, the scale of Chinese urban development is growing rapidly [3]. The total urban built-up area in 2012 was as high as 45.57 thousand square kilometers, which is approximately 2.1 times of that in 2000, indicating an alarming average annual growth rate of $8.58 \%$ [2]. Massive urban expansion has occupied a great deal of arable land and forestland resources, exacerbating the problem of food security in China [4]. On the other hand, many regions in China have large areas of idle land, causing a serious waste of land resources [5]. It is reported that over four percent of urban land is idle in China, and approximately 40 percent is used inefficiently [6]. Such mismanagement has aggravated the Marxist dialectical contradiction between people and land, threatening sustainable urban management and development in China [7]. In addition, land for production, especially for industrial production, has the fastest growth rate of all types of built-up land, producing huge pollutant discharges and causing great damage to the environment [2]. Urban land use in China is now facing the problems of relatively low economic efficiency and excessive pollutant emissions [8]. Therefore, analyzing urban land use economic efficiency (ULUEE) under the environment constraints is a meaningful work for the future development of Chinese cities.

The Chinese government has paid attention to the problem of urban land use for a long time. To tackle the problem of unreasonable occupation of arable land, a series of land planning programs were launched in 1985, and the land management law was amended in 1998, effectively curbing the large-scale expropriation of arable land brought about by rapid urbanization and industrialization [9]. To improve the ULUEE, the Ministry of Land Resources and many relevant departments in China have provided guidance and planning to enhance the intensity of urban land use [10]. As for environmental protection, the central government has issued a series of laws and regulations, such as the Water Pollution Control Act, to limit industrial pollutant emissions and improve the ecological environment [11]. However, the problems of inefficient urban land use and serious environmental pollution have not yet been fundamentally solved. From the economic perspective, the supply of land is inelastic. Because we can save a large amount of land when achieving the same economic output by raising land use efficiency, which helps slow down the unreasonable occupation of arable land for economic production purposes. This means that improving ULUEE has been proven to be the best way to alleviate food security issues and realize sustainable urban management.

The problem of ULUEE was first studied in the early 20th century by describing the external form and spatial distribution of urban land use. This approach was mainly based on the historical experiences of urban land use development and gave rise to models such as the axial growth model, the concentric growth model, the sector growth model, and the multi-core growth model [12]. Then, the economic location school introduced spatial economics research methods, which assumed that land users were rational economic actors whose pursuits were the maximization of economic interests and the minimization of cost. This school held that optimal allocation of land resources could be achieved through regulation of the land market [13], which is good guidance for the improvement of ULUEE. Moreover, the social behavior school introduced humanistic ideas into studies of urban land use, emphasizing the importance of human values and other non-economic factors in the distribution of urban land resources [14]. The political economy school emphasizes the important effects of political power on urban land use and trying to reveal the driving factors behind urban land use modes, which made great contributions to improve ULUEE $[15,16]$, and some other studies have also discussed the concept of landscape efficiency and land sustainability $[17,18]$. In recent years, the research focus has shifted to the optimal allocation, intensive utilization and efficiency evaluation of urban land [19], and domestic scholars have carried out extensive studies on ULUEE in China from multiple aspects, including basic theory, using evaluation indexes, refining methodology, examining driving factors and improving management approaches. Regarding evaluation indexes, multiple-index systems including social, economic and environmental factors have already been adopted in many studies [20,21]. 
Many methods have been applied to the studies of ULUEE, such as the analytic hierarchy process (AHP) [20,22], the principal component analysis (PCA) [23] and the data envelopment analysis (DEA) [21]. Considering the defects of subjectivity and information compression, AHP and PCA are not suitable for efficiency evaluation. Data envelopment analysis (DEA) has a significant advantage of not needing to set any prior functions or parameter weights. However, many studies have adopted radial DEA models, which neglect the slack variables, leading to biased results. To overcome this problem, a new approach named non-radial and nonparametric (SBM) model was proposed, which incorporates the slack variables directly into the objective function, making evaluation more accurate $[24,25]$. Because many studies only consider economic output, while ignoring the pollutants caused by production, leading overestimates of ULUEE and incorrect policy recommendations, some suggest that the environmental pollution should be incorporated into the evaluation indicator system as an undesirable output [8]. However, the results based on data in different periods cannot be compared with each other, this paper will apply a sequential slack-based measure (SSBM) model, which extends the SBM approach by taking changing production technology into account [26].

Considering the fact that few past studies have covered the ULUEE of Chinese cities at the prefecture level, this paper will explore the spatial and temporal disparities of ULUEE in China during 2003-2012, reveal the mechanisms of influencing factors, and present corresponding countermeasures to improve ULUEE. In addition, due to some reasons such as economic policy and urban development habits, cities of different scales show huge gaps in economic development levels and industrial structures. Thus, we will make comparisons of ULUEE among different city scales.

This paper will make three main contributions to the studies on China's ULUEE. First, this paper is the first to analyze the dynamic changes of ULUEE in China at the prefecture level by using an SBM model. Second, this paper explores the factors influencing ULUEE in China. Third, this paper proposes some effective countermeasures to improve the ULUEE and realize sustainable urban management. Therefore, the following questions will be addressed in this paper.

(1) What is the general ULUEE in China? Which are the top or bottom performers?

(2) What are the regional and size disparities of ULUEE among China's cities?

(3) Which factors influence ULUEE and what are the influencing mechanisms?

The remainder of this paper is organized as follows. Section 2 introduces the methods, indicators and data used in this paper. Section 3 shows the empirical results. Section 4 concludes with some suggestions for future studies.

\section{Methods and Data}

\subsection{SBM-Undesirable Model}

A meaningful assumption of DEA models is that there always be a certain gap between actual resource allocation and the optimal one, which can be called the slack variable and expressed as input excess or output shortage of the observation. One problem of traditional radial DEA models is that the slack variables are not considered in the objective function, which can lead to inaccurate results in efficiency evaluations. To overcome this problem, a new approach named non-radial and nonparametric (SBM) model was proposed, which incorporates the slack variables directly into the objective function. Considering the changing production technology in the study period, we apply a relatively new model named sequential slack-based measure (SSBM) model, which combine the concept of sequential production technology. The SSBM model is described as follows [26]:

Suppose that there are $N$ DMUs, and each DMU requires $M$ inputs (x) to produce $J$ desirable outputs (y) and $K$ undesirable outputs (b). In this paper, they can be denoted by the vectors $\mathrm{x} \in R^{M}$, $y \in R^{J}, b \in R^{K}$; then we can define the matrixes $\mathrm{X}, \mathrm{Y}, \mathrm{B}$ as $X=\left[x_{11}, \ldots, x_{M N}\right] \in R^{M \times N}, Y=$ $\left[y_{11}, \ldots, y_{M N}\right] \in R^{J \times N}, B=\left[b_{11}, \ldots, b_{M N}\right] \in R^{K \times N}$, with $X>0, Y>0, B>0$. 
In this way, the production technology can be expressed as:

$$
\mathrm{P}=\{(\mathrm{x}, \mathrm{y}, \mathrm{b}) \mathrm{x} \text { can produce }(\mathrm{y}, \mathrm{b}), \mathrm{x} \geq \mathrm{X} \lambda, \mathrm{y} \leq \mathrm{Y} \lambda, \mathrm{b} \geq \mathrm{B} \lambda, \lambda \geq 0\}
$$

where $\mathrm{P}$ is always assumed to satisfy the production theory [25], Considering that production technology will change during the study period, we impose the constraints of $\sum_{n=1}^{N} \lambda_{n}=1$ into the function for the variable returns to scale (VRS). Thus, the optimization problem of sequential SBM (SSBM) can be expressed as:

$$
\begin{aligned}
& \rho *=\min \frac{1-\frac{1}{M} \sum_{m=1}^{M}\left(\frac{s_{m 0}^{x}}{x_{m 0}}\right)}{1+\frac{1}{J+K}\left(\sum_{j=1}^{J} \frac{s_{j 0}^{y}}{y_{j 0}}+\sum_{k=1}^{K} \frac{s_{k 0}^{b}}{b_{k 0}}\right)} \\
& \text { S.T. }\left\{\begin{array}{c}
x_{0}=\sum_{t=1}^{T} \mathrm{X}^{\mathrm{t}} \lambda_{n}{ }^{\mathrm{t}}+s_{0}^{x} \\
y_{0}=\sum_{t=1}^{T} \mathrm{Y}^{\mathrm{t}} \lambda_{n}{ }^{\mathrm{t}}-s_{0}^{y} \\
b_{0}=\sum_{t=1}^{T} \mathrm{~B}^{\mathrm{t}} \lambda_{n}{ }^{\mathrm{t}}+s_{0}^{b} \\
\sum_{n=1}^{N} \lambda_{n}=1, s_{0}^{x} \geq 0, s_{0}^{y} \geq 0, s_{0}^{b} \geq 0
\end{array}\right.
\end{aligned}
$$

where $m, j$, and $k$ represent the indexes of inputs, desirable outputs and undesirable outputs; $M, J$, $K$ is the number of inputs, desirable outputs and undesirable outputs, respectively; $t(t=2003, \ldots$, 2012) represent year $t$, and the subscript 0 represents the DMU which is under estimated in this model. $s_{x} *, s_{y} *$ and $s_{b} *$ represents the slack variables of inputs, desirable outputs and undesirable outputs, respectively; $\rho$ represents the efficiency of the DMU which is estimated in the model; $\lambda$ represents the nonnegative multiple vector.

When $\rho^{*}=1$, the DMU is efficient. When $\rho^{*}<1$, the DMU is inefficient, and it is necessary to adjust the input-output structure. In order to make this DMU efficient in the optimality, we should make adjustments of the form $x *=X \lambda+s_{x} *, y *=Y \lambda-s_{y} *$, and $b *=B \lambda+s_{b} *$. Thus altered, the SBM model can do efficiency evaluations in the presence of undesirable outputs.

On the other hand, we can know how to improve the input-output efficiency by analyzing the slack variable ratios of inputs, desirable outputs and undesirable outputs, respectively.

The input excess ratio is the proportion of input reduction:

$$
\bar{X}=\frac{1}{M} \sum_{m=1}^{M}\left(\frac{s_{m}^{x}}{x_{m}}\right)
$$

The desirable output shortage ratio is proportion of desirable output increase:

$$
\bar{Y}=\frac{1}{J} \sum_{j=1}^{J}\left(\frac{s_{j}^{y}}{y_{j}}\right)
$$

The undesirable output shortage ratio is proportion of undesirable output increase:

$$
\bar{B}=\frac{1}{K} \sum_{k=1}^{K}\left(\frac{s_{k}^{b}}{b_{k}}\right)
$$




\subsection{Selection of Input and Output Indicators}

Land use efficiency is affected by economic, social and environmental factors [26-28], so we should consider environmental outputs as well as economic outputs. This study constructed an indicator system for land use efficiency evaluation (see Table 1), using the following input and output indicators.

(1) Input indicators. The input factors mainly include land, capital, and labor. Because the objects of study are urban areas, we chose the built-up area as land input. We chose the total investment in fixed assets as the capital inputs. The numbers of secondary industry and tertiary industry employees were selected as the labor inputs.

(2) Output indicators. We chose the value added in secondary and tertiary industry as the desirable outputs, and industrial sulfur dioxide, industrial wastewater, and industrial soot emissions as undesirable outputs.

Table 1. Input and output indicators.

\begin{tabular}{|c|c|c|c|}
\hline Variable Category & Variable Name & Description & Units \\
\hline \multirow{5}{*}{ Inputs } & AREA & Built area & $\mathrm{km}^{2}$ \\
\hline & FIX & $\begin{array}{c}\text { Total investment in fixed } \\
\text { assets }\end{array}$ & $10^{8}$ Yuan \\
\hline & INV & $\begin{array}{l}\text { investment in } \\
\text { environmental } \\
\text { management }\end{array}$ & $10^{4}$ Yuan \\
\hline & EM2 & $\begin{array}{l}\text { Number of secondary } \\
\text { industry employees }\end{array}$ & $10^{4}$ Persons \\
\hline & EM3 & $\begin{array}{l}\text { Number of tertiary } \\
\text { industry employees }\end{array}$ & $10^{4}$ Persons \\
\hline \multirow[t]{2}{*}{ Desirable outputs } & P2 & $\begin{array}{l}\text { Value added in } \\
\text { secondary industry }\end{array}$ & $10^{8}$ Yuan \\
\hline & P3 & $\begin{array}{c}\text { Value added in tertiary } \\
\text { industry }\end{array}$ & $10^{8}$ Yuan \\
\hline \multirow{3}{*}{ Undesirable outputs } & $\mathrm{SO}_{2}$ & Industrial sulfur dioxide & $\mathrm{t}$ \\
\hline & WA & Industrial wastewater & $\mathrm{t}$ \\
\hline & DU & Industrial soot & $\mathrm{t}$ \\
\hline
\end{tabular}

\subsection{Econometric Model}

In this paper, we establish an empirical model to explore the factors influencing ULUEE in China's cities. The econometric model is as follows:

$$
y_{i t}=\alpha_{i t}+\beta_{1} P G D P_{i t}+\beta_{2} L U I_{i t}+\beta_{3} U R B_{i t}+\beta_{4} P O L_{i t}+\beta_{5} L L P_{i t}+\beta_{6} F D I_{i t}+\mu_{i t}
$$

where $i(i=1, \ldots, 270)$ and $t(t=2003, \ldots, 2012)$ represent city $i$ and year $t$, respectively. The term, $\alpha_{i t}$ is a constant, and $\mu_{i t}$ is the random error term. $y_{i t}$ is the ULUEE for city $i$. PGDP is the per capita GDP. LUI is land use intensity, which is represented by economic output per square kilometer of urban construction land. URB is the urbanization rate, which is expressed as the proportion of population in the municipal district of the total population of the city. $P O L$ represents the land management policy. $L L P$ refers to land leasing policy for financing local governments, which is very popular in the cities with fiscal problems, and it is expressed as fiscal gap ratio. FDI refers to the proportion of foreign enterprises' output account for the total output in the secondary and tertiary industries.

Generally speaking, a higher level of GDP per capita leads to the higher resource efficiency. Because a region with relatively higher GDP per capita always pays more attention to the quality of economic development, which leads to relatively higher resource use efficiency [29].Therefore, we hypothesize that there might be a positive correlation between GDP per capita and ULUEE. In addition, 
the greater the land use intensity, the higher the economic value per square kilometer. Therefore, we hypothesize that there might be a positive correlation between land use intensity and ULUEE. As is well known, the higher the urbanization rate, the higher the levels of economic development and technology, which easily lead to relatively high resource use efficiency [30]. Thus, we hypothesize that there might be a positive correlation between urbanization rate and ULUEE.

The implementation of land management policy has promoted the optimization of urban land layout and improved land use efficiency, so there may be a positive correlation between land management policy and ULUEE. Considering that the Notice of the relevant issues concerning the adjustment for approval of urban construction land from the State Council, which was implemented by the Ministry of land and resources in 2007 was the most comprehensive and clear document on land resources management in recent years [31], therefore, the policy variable is assigned the value of 1 from 2007 on, and the value of 0 before 2007.

After the reform of tax system in 1994, the central government occupies most of the taxes, making local governments face serious financial difficulties. Therefore, they have to look for effective ways to make up for the fiscal deficit such as revenue from land leasing. Almost every city actively introduces investment through lowering the land price, in order to promote economic development. However, the pursuit of short-term interests obviously lacks scientific planning of land use, leading to inefficient land use [32]. Therefore, we hypothesize that the land leasing policy might have a negative impact on the ULUEE. In addition, because Chinese market economy is still less than 40 years old since the reform and opening up in 1978, the foreign capital enterprises have better production and management technology than the domestic ones [33]. Thus, we hypothesize that the proportion of foreign enterprises' output account for the total output in the secondary and tertiary industries might have a positive impact on the ULUEE.

\subsection{Data}

In this paper, the data are sourced from the China City Statistical Yearbook (2003-2013), Regional Economic Statistical Yearbook (2003-2013) and China Statistical Yearbook (2003-2013). Because data are missing from some cities, the results of this study are based on data from 270 cities, which account for more than 95 percent of the total number of Chinese cities. To eliminate the effects of price factors, urban investment in fixed assets and values added in secondary and tertiary industry are converted to 2000 constant prices with fixed asset and GDP deflectors, respectively.

\section{Empirical Results}

\subsection{Overall Analysis of Land Use Efficiency}

According to regional distribution and disparities of economic development, we divide Chinese cities into three groups [8]: the eastern region, central region, and western region. The eastern region contained 11 coastal provinces or municipalities (Beijing, Tianjin, Hebei, Liaoning, Shanghai, Jiangsu, Zhejiang, Fujian, Shandong, Guangdong and Hainan), economic development in this region is much better than that in the other two regions. The central region contained eight inland provinces (Shanxi, Jilin, Heilongiang, Anhui, Jiangxi, Henan, Hubei, Hunan). This region has a large population and is famous for agricultural production. The western region contained the remaining 12 provinces, municipalities and autonomous regions (Sichuan, Chongqing, Inner Mongolia, Guangxi, Guizhou, Yunnan, Tibet, Shaanxi, Gansu, Qinghai, Ningxia, Xinjiang). This region covers more than half of China's territory, but population density and economic development levels are the lowest in China's three regions. According to the latest standard for categorizing groups of city by scale from the Green Book of Small and Medium-sized Cities (2014), the cities in China can also be divided into five types of scales (huge, very large, large, medium, and small). We treat huge and very large cities together as super cities, due to the cities of these two types being few in number, and their common feature that the population and economy in any one of them is oversized. 
Based on the SSBM model, we computed the ULUEEs for 270 cities in China during 2003-2012 (see Figure 1). Also shown in Figure 1 for comparison is the trend of the ULUEE computed without considering undesirable outputs, and the trend of the ULUEE based on the SBM model considering undesirable outputs. As expected, in most of the study period, the ULUEE values based on the SSBM model computed with consideration of undesirable outputs is lower than that computed ignoring undesirable outputs throughout the research period, whose average scores are 0.411 and 0.441 , respectively. Therefore, undesirable outputs have obvious influence on ULUEE, and ignoring undesirable outputs could lead to overestimating ULUEE. Moreover, the results based on the SBM model considering undesirable outputs are higher than those based on the SSBM model, this may be because the results based on SBM model have not included the concept of sequential production technology. Therefore, the following analysis will adopt results based on SSBM model considering undesirable outputs.

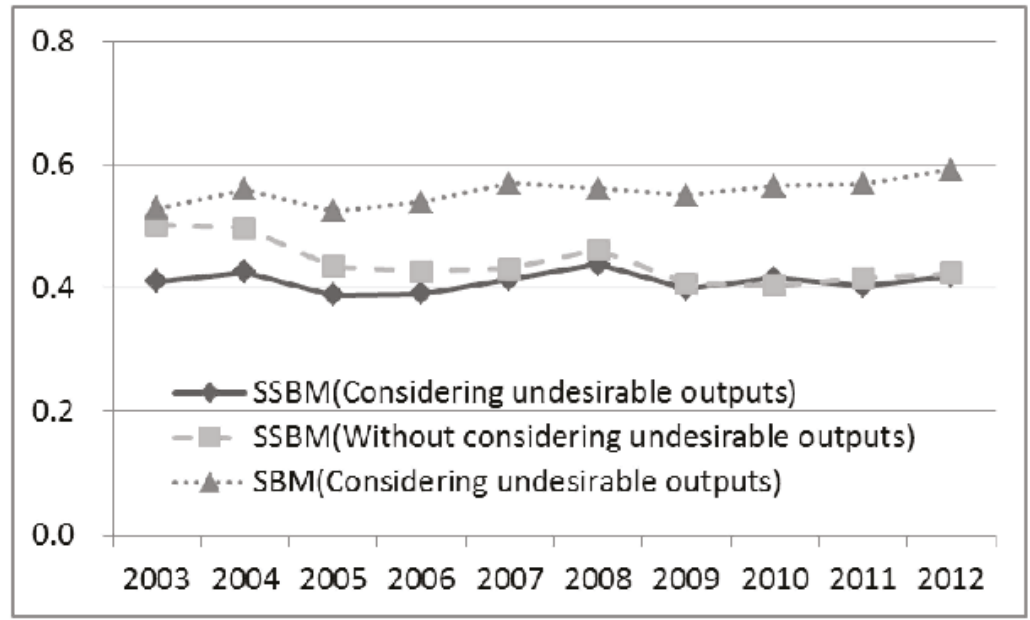

Figure 1. Trends of ULUEE in China during 2003-2012.

Figure 1 shows that ULUEE in China has always been very low during the study period without obvious changes. One possible interpretation is that weak land management systems and imperfect land markets have contributed greatly to severe land waste and low ULUEE [28]. On the other hand, the singular pursuit of economic growth while neglecting environmental protection is also an important reason. In addition, the ULUEE based on the SSBM model without considering undesirable outputs have come close to those based on the SSBM model considering undesirable outputs. This may because there are more environmental protection laws that have been issued in the second half of the study period than ever before, such as Water Pollution Prevention and Control Law of the People's Republic of China [34], thus, China has made great achievements in environmental protection work.

In addition, as shown in Figure 2, the ULUEE of the eastern region shows a slight downward trend in the study period, however, it is much higher than in the other two regions. The ULUEE of the western region shows a slight upward trend, and the ULUEE of the central does not change much. It is worth noting that the ULUEE of the western region has exceeded that of the central region since 2005, therefore, cities from the central region should do their best to improve their ULUEE. 


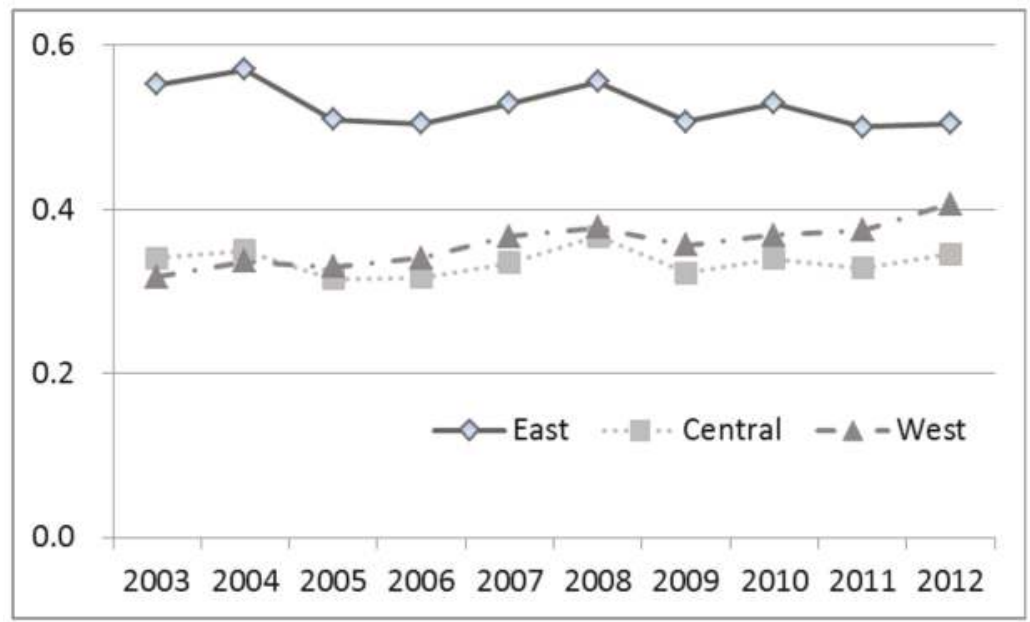

Figure 2. Trends of ULUEE in three regions of China during 2003-2012.

\subsection{Disparity of the ULUEE at Regional and Scale Levels}

In order to show a more detailed condition for the ULUEE during the study period, we divide the cities into three groups according to their ULUEEs (see Table 2). The perfect group contains six cities (e.g., Wuxi, Suzhou, Ningde, Shenzhen, Foshan, and Zhongshan) which are efficient during 2003-2012, indicating that land use in these cities has always been in the best condition, with the environment improving concurrently with economic development. We divide the rest of the cities into two groups on average, and they are called good group and bad group. The good group contains 132 cities whose ULUEE is between 0.34 and 1 , and the bad group contains the remaining 132 cities whose ULUEE is below 0.34 [35]. We can note that most cities show relatively poor performance in urban land use, which suggests that some countermeasures should be taken to improve the input-output allocation. In sum, the conditions of ULUEE are not ideal, and as many as $97.78 \%$ of China's cities are inefficient in their use of land. This result indicates that most cities still have much room to improve their ULUEEs.

Table 2. Clusters of ULUEEs for 270 cities in China.

\begin{tabular}{cccc}
\hline Efficiency & Grade & Number of cities & Proportion (\%) \\
\hline 1 & Perfect & 6 & 2.22 \\
0.34 & Good & 132 & 48.89 \\
$<0.34$ & Bad & 132 & 48.89 \\
Total & & 270 & 100 \\
\hline
\end{tabular}

Figure 3 shows the disparities of the ULUEE in the three regions of China. The six cities belongs to the perfect group are all located in the eastern region. In addition, the eastern region enjoys the highest proportion of good cities $(74.49 \%)$, and the lowest proportion of bad cities $(19.39 \%)$. However, the central and western regions suffer the highest proportion of bad cities ( $65.98 \%$ and $65.33 \%$, respectively), and neither of the two regions have perfect cities.

Figure 4 shows the disparities of the ULUEE within the four city scale categories. Only large-scale and small-scale city group have perfect cities. Out of the six perfect cities, five cities belongs to large-scale city group (e.g., Wuxi, Suzhou, Shenzhen, Foshan and Zhongshan), and the rest of the city named Ningde belongs to small-scale city group. Besides, the proportion of good cities in the super-scale city group rank first $(81.82 \%)$, followed by the small-scale city group cities $(56.82 \%)$, and 
the large-scale and medium-scale city groups show relatively low proportions of $50.91 \%$ and $40 \%$. The medium-scale city group suffers the highest proportion of bad cities $(60 \%)$, followed by the large-scale city group $(44.55 \%)$, and the small-scale and super-scale city groups show relatively low proportions of $40.91 \%$ and $18.18 \%$.

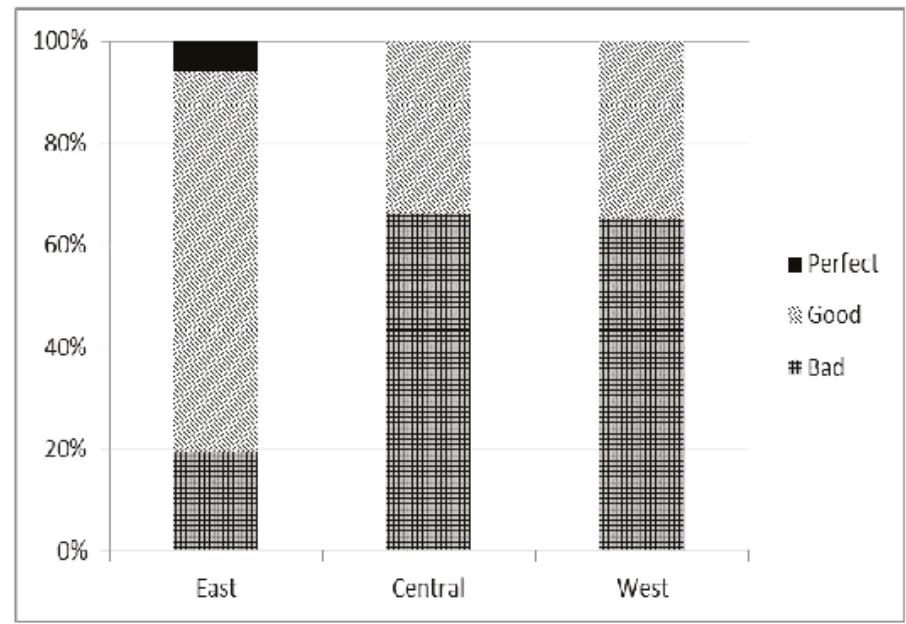

Figure 3. Disparity of the ULUEE in different regions of China.

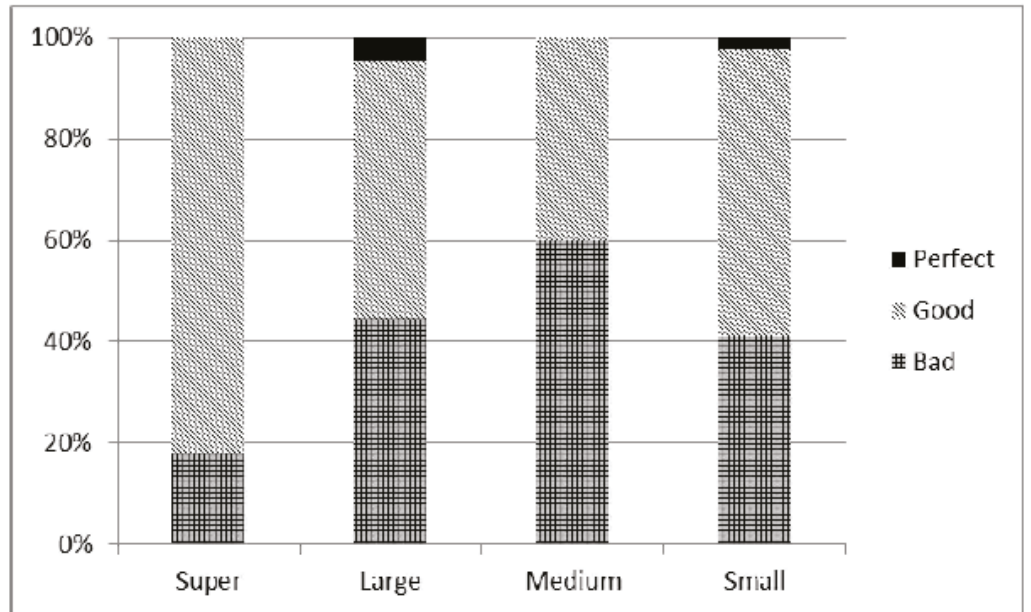

Figure 4. Disparity of the ULUEE in different city scales.

\subsection{Disparity of the ULUEE at Regional and Scale Levels}

In order to show a more detailed condition for the ULUEE during the study period, we divide the cities into three groups according to their ULUEEs. The perfect group contains six cities (e.g., Wuxi, Suzhou, Ningde, Shenzhen, Foshan, and Zhongshan) which are efficient during 2003-2012, indicating that land use in these cities has always been in the best condition, with the environment improving concurrently with economic development. We divide the rest of the cities into two groups on average, and they are called good group and bad group. The good group contains 132 cities whose ULUEE 
is between 0.34 and 1 , and the bad group contains the remaining 132 cities whose ULUEE is below 0.34 [35]. We can note that most cities show relatively poor performance in urban land use, which suggests that some countermeasures should be taken to improve the input-output allocation. In sum, the conditions of ULUEE are not ideal, and as many as $97.78 \%$ of China's cities are inefficient in their use of land. This result indicates that most cities still have much room to improve their ULUEEs.

Figure 3 shows the disparities of the ULUEE in the three regions of China. The six cities belongs to the perfect group are all located in the eastern region. In addition, the eastern region enjoys the highest proportion of good cities $(74.49 \%)$, and the lowest proportion of bad cities $(19.39 \%)$. However, the central and western regions suffer higher proportions of bad cities (65.98\% and $65.33 \%$, respectively), and neither of the two regions have perfect cities.

Figure 4 shows the disparities of the ULUEE within the four city scale categories. Only large-scale and small-scale city group have perfect cities. Out of the six perfect cities, five cities belongs to the large-scale city group (e.g., Wuxi, Suzhou, Shenzhen, Foshan, and Zhongshan), and the other city (Ningde) belongs to small-scale city group. Besides, the proportion of good cities in the super-scale city group rank first $(81.82 \%)$, followed by the small-scale city group cities $(56.82 \%)$, and the large-scale and medium-scale city groups show relatively low proportions of $50.91 \%$ and $40 \%$. The medium-scale city group suffers the highest proportion of bad cities $(60 \%)$, followed by the large-scale city group cities $(44.55 \%)$, and the small-scale and super-scale city groups show relatively low proportions of $40.91 \%$ and $18.18 \%$.

As is shown in Table 3, cities in the eastern region are more efficient, with an average efficiency of 0.526 , followed by the western region (0.357). The efficiency in the central region $(0.336)$ is the lowest. Considering the fact that the eastern region enjoys the most developed economy while the western region suffers the worst economic conditions, and the central region lies between the eastern and western regions in this respect, this result also provides evidence in favor of the environmental Kuznets curve hypothesis, which posits that environmental improvements do not occur until after economic development reaches a certain level, while environmental damage becomes more severe with economic development before reaching that level.

Table 3 also shows that the small-scale city group enjoys the highest ULUEE with an average score of 0.514 , followed by the large-scale city group (0.44) and small-scale city group (0.426). In addition, the medium-scale cities have the lowest ULUEE of 0.364. In summary, cities in eastern China show better performance than those in central and western China as a whole, and the average ULUEE of the super-scale city group is higher than that of the other three scale groups. One possible explanation is that the urban economy in the eastern region is the most developed, leading to the greater economic output and investment in environmental protection, which helps to improve the ULUEE. Another possible reason may be that the super cities have large capital and talent advantages due to supported policies and their good location [36]. Therefore, they can obtain higher economic output as well as better environmental protection. 
Table 3. Disparity of ULUEE in different scales and regions.

\begin{tabular}{cccc}
\hline $\begin{array}{c}\text { Region or Whole } \\
\text { County }\end{array}$ & Level & $\begin{array}{c}\text { Average Value at } \\
\text { Different Levels }\end{array}$ & $\begin{array}{c}\text { Average Value at } \\
\text { Different Regions }\end{array}$ \\
\hline \multirow{2}{*}{ East } & Super & 0.639 & 0.526 \\
& Large & 0.575 & \\
& Medium & 0.462 & 0.336 \\
Sentral & Super & 0.452 & \\
& Large & 0.417 & 0.357 \\
\hline \multirow{2}{*}{ West } & Medium & 0.344 & \\
& Small & 0.317 & \\
& Super & 0.363 & 0.411 \\
& Large & 0.329 & \\
\hline & Medium & 0.333 & \\
\hline
\end{tabular}

\subsection{Spatio-Temporal Pattern of ULUEE in China}

To supplement the general trend of ULUEE in China during 2003-2012 (see Figure 1), this study explored the spatio-temporal pattern of ULUEE in the four years of 2003, 2006, 2009, and 2012. As shown in Figure 5, most perfect cities are located in the eastern region with relatively developed economies. This may because most Chinese famous economic zones are located in this region, such as the Yangtze River Delta and Pearl River Delta. However, there are also some cities located in the underdeveloped inland provinces (e.g., Kunming and Zhangjiajie), and the common point of these cities is that industrial layout is mostly focused on tertiary industry, with relatively high economic output and less environmental pollution. Therefore, we can conclude that a higher level of economic development and a reasonable industrial layout contribute to the improvement of ULUEE in China. 

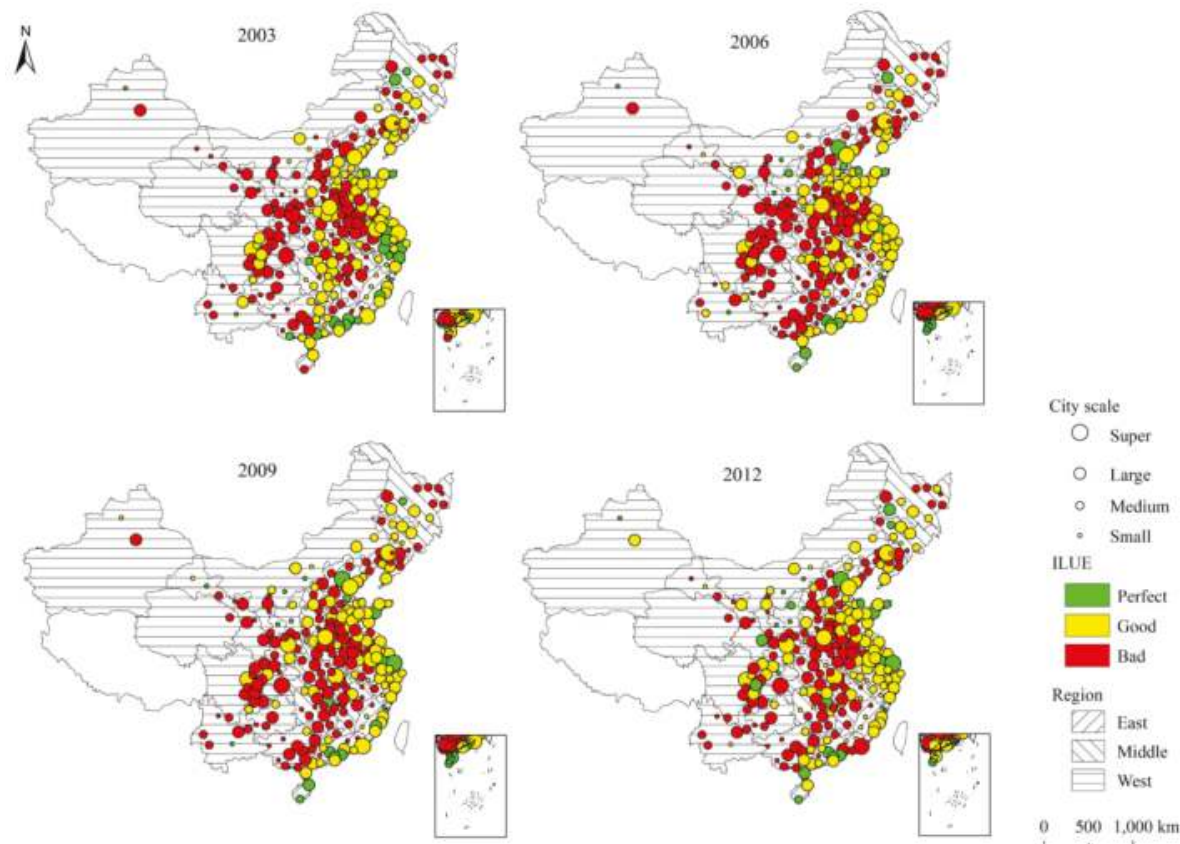

Figure 5. Patterns of ULUEE of China in 2003, 2006, 2009 and 2012.

In terms of individual years, the most efficient cities are located in the eastern region in 2003, whose average ULUEE is 0.438 , whereas those in the central and western regions are 0.422 and 0.417 , respectively. Therefore, the cities in the eastern region were more efficient than those in the other two regions. The number of efficient cities in China is 26 , which only accounts for $9.63 \%$ of all the cities. Worse performances are found in the three regions, and the number of efficient cities in China is 21, many cities show lower than those in 2003. However, some cities soon turned into efficient cities in 2009 (e.g., Qingdao and Shanghai), and the three regions show increases in average ULUEEs. Better performances in the three regions could be found in 2012. The average ULUEEs of the eastern, central, and western regions are $0.426,0.418$, and 0.423 , respectively. The number of efficient cities in China climbs back to 29 , which accounts for $10.74 \%$ of all the cities.

In summary, the regions with more developed economies have better performance in urban land use (e.g., Beijing, Shanghai, and Shenzhen). One possible explanation of this result is that advantages of capital, technology and talent are obvious in these cities, which can help effectively solve the bottleneck problems in the process of resource allocation and utilization, such as the balance between economic development and environmental protection, which need huge investment of capital and technology [37]. Moreover, they can bring positive influence on the social and economic developments of surrounding cities, which is beneficial for improving the overall status of the whole region. On the contrary, the cities with less developed economies always show poorer ULUEEs because development goals in these cities blindly focus on scale expansions of economic development, causing the wasteful use of urban land resources and the sidelining of environmental protection. On the other hand, reasonable industrial layout is also an important factor in improving land use efficiency. The cities that focus on the development of industries with high economic output and low pollution find it easier to achieve the goal of efficiency in urban land use. For instance, the cities Zhangjiajie, Huangshan, and Sanya are famous tourist cities in China, which focus on the tourism development rather than industry with heavy pollutions, and their ULUEE is relatively high during the study period. 
In addition, the cities focused on industries that produce higher economic output and less environmental pollution can successfully avoid the dangerous mode of bad land use. Such as introducing a large number of heavy polluted enterprises just for short-term economic interests, which can easily lead to vast waste of land resources and great damage to the local ecological environment [38].

\subsection{Optimization of ULUEE}

According to the assumptions of the SSBM model, we can conclude that if the ULUEE is less than 1, then the DMU is inefficient, and we can find the reasons for inefficient land use and ways to achieve improvements by analyzing the slack variables from the model. Table 4 shows the excesses of inputs and undesirable outputs and shortages of desirable outputs, from which we can achieve the optimization direction of the ULUEE.

Table 4. Optimization of ULUEE for cities in China in 2012.

\begin{tabular}{cccccccccc}
\hline & \multicolumn{3}{c}{ Inputs Excess (\%) } & & \multicolumn{3}{c}{$\begin{array}{c}\text { Undesirable Output Excess } \\
\mathbf{( \% )}\end{array}$} & $\begin{array}{c}\text { Desirable Output } \\
\text { Shortage (\%) }\end{array}$ \\
\cline { 2 - 10 } & AREA & FIX & EM2 & EM3 & WA & SO $_{2}$ & DU & P2 & P3 \\
\hline East & 26.55 & 40.54 & 37.14 & 27.24 & 29.95 & 62.21 & 58.37 & 10.36 & 0.56 \\
Central & 51.63 & 57.42 & 52.55 & 59.19 & 41.25 & 73.87 & 89.82 & 7.57 & 4.70 \\
West & 50.56 & 56.27 & 55.41 & 62.75 & 38.13 & 63.62 & 51.97 & 5.47 & 4.84 \\
Super & 23.48 & 52.04 & 34.39 & 29.47 & 14.16 & 54.42 & 43.87 & 2.32 & 0.00 \\
Large & 37.35 & 47.51 & 44.66 & 43.80 & 30.39 & 65.45 & 62.74 & 9.40 & 1.48 \\
Medium & 55.32 & 51.17 & 55.54 & 61.83 & 41.71 & 72.71 & 87.71 & 12.12 & 5.23 \\
Small & 47.14 & 43.74 & 41.10 & 52.59 & 54.82 & 59.79 & 48.36 & 6.98 & 8.49 \\
China & 38.93 & 48.89 & 44.65 & 44.54 & 34.53 & 66.00 & 75.75 & 8.71 & 2.16 \\
\hline
\end{tabular}

Note: AREA: Built-up area; FIX: Total investment in fixed asset; EM2: Number of secondary industry employees; EM3: Number of tertiary industry employees; WA: Industrial wastewater; $\mathrm{SO}_{2}$ : Industrial sulfur dioxide; DU: Industrial soot; P2: Value added in secondary industry; P3: Value added in tertiary industry.

From a national perspective, the excess ratio of total investment in fixed assets ranks first in all four inputs, which means that investment in environmental management can be reduced by $48.89 \%$ under the condition of the same level of output. This calls for more reasonable use of capital investment during secondary and tertiary industry production processes in Chinese cities. The excess ratios of the number of workers employed in secondary and tertiary industries are, respectively as high as $44.65 \%$ and $44.54 \%$, which indicates that severe labor surplus is an urgent issue in these two industries. The excess ratio of urban built-up area is $38.93 \%$, which shows evidence for curbing the unreasonable use of land resources. As for undesirable outputs, the excess ratio of industrial soot ranks first with a score of $68.26 \%$, which implies that the industrial soot can be cut by $75.75 \%$ while maintaining the same level of inputs. Industrial wastewater discharge and the industrial sulfur dioxide emissions have excess ratios of $34.53 \%$ and $66 \%$, respectively, which indicates that the great benefits of industrial production in China are accompanied by serious environmental pollution. The shortage ratios of the desirable outputs are relatively small, only $8.71 \%$ and $2.16 \%$ in the secondary and tertiary industries, respectively, which implies that the outputs in these two industries can increase by $8.71 \%$ and $2.16 \%$, respectively, in the realization of optimal production.

From a regional perspective, the cities in eastern region show the best performance in all three regions. From the city scale perspective, the super cities are more efficient than the other city scales. Although a few disparities exist in cities from different regions and city scales, most of them have problems in the unreasonable use of land, funds, labor surplus, excessive discharge of pollutants, and economic output shortage. Therefore, a series of targeted policies should be introduced to improve the ULUEE in China. 


\subsection{Influencing Factors of the ULUEE}

The results of a Hausman test showed that the fixed effect model was better than the random effect model. This study uses the fixed effect model to investigate how the different explanatory factors influence ULUEE. Table 5 shows the estimation results of the panel data model regression at a regional level, and Table 6 the shows estimation results of the panel data model regression for different city scales.

As Table 5 shown, Per capita GDP (PGDP) and land use intensity (LUI) have significant positive impacts on ULUEE in all the three regions and four types of city scale groups, which are consistent with the hypotheses. This means we can improve the ULUEE by increasing Per capita GDP and land use intensity in Chinese cities. The urbanization rate (URB) and the proportion of foreign enterprises' output account for the total output in the secondary and tertiary industries (FDI) have significant positive impacts on ULUEE in the eastern and central regions, which are also consistent with the hypotheses. However, land management policy (POL) has negative impacts on ULUEE in all the three regions and four types of city scale groups, which is inconsistent with the hypotheses. This may because the central land policies have not been effectively implemented in Chinese cities [39]. In addition, the urbanization rate (URB) has significant positive impacts on ULUEE in the eastern region, while it has an opposite effect in the central region. This may due to the rapidly increasing population and the gradually slowdown of labor transfer speed in the central region, which lead to severe population burden and labor surplus problems. Moreover, the urbanization rate (URB) has significant positive impacts on ULUEE in the super city group, while it has opposite effect in the medium city group.

Table 5. Results of the panel data model regression for different regions.

\begin{tabular}{|c|c|c|c|}
\hline Variables & East & Central & West \\
\hline PGDP & $\begin{array}{l}0.04037^{* * *} \\
(12.84563)\end{array}$ & $\begin{array}{l}0.04704^{* * *} \\
(15.98672)\end{array}$ & $\begin{array}{l}0.04698^{* * *} \\
(14.61161)\end{array}$ \\
\hline LUI & $\begin{array}{l}0.01664 * * * \\
(19.99913)\end{array}$ & $\begin{array}{l}0.01117^{* * * *} \\
(14.89497)\end{array}$ & $\begin{array}{l}0.01829 * * * \\
(17.01049)\end{array}$ \\
\hline POL & $\begin{array}{l}-0.20301 \text { *** } \\
(-18.56826)\end{array}$ & $\begin{array}{l}-0.12314 \text { *** } \\
(-14.24576)\end{array}$ & $\begin{array}{l}-0.12962 * * * \\
(-13.25553)\end{array}$ \\
\hline URB & $\begin{array}{c}0.14689 * * * \\
(5.79202)\end{array}$ & $\begin{array}{c}-0.09111 \text { *** } \\
(-5.54864)\end{array}$ & $\begin{array}{c}0.01133 \\
(0.52791)\end{array}$ \\
\hline LLP & $\begin{array}{l}-0.00003 \\
(0.60169)\end{array}$ & $\begin{array}{l}-0.00019 * * \\
(-2.00119)\end{array}$ & $\begin{array}{c}-0.00015^{* * *} \\
(-3.45475)\end{array}$ \\
\hline FDI & $\begin{array}{c}0.00061^{* * *} \\
(2.95261)\end{array}$ & $\begin{array}{l}0.00043 \text { * } \\
(1.86889) \\
\end{array}$ & $\begin{array}{c}0.00011 \\
(0.50279) \\
\end{array}$ \\
\hline Constant & $\begin{array}{l}0.17406^{* * *} \\
(14.08999)\end{array}$ & $\begin{array}{l}0.21703^{* * *} \\
(28.79594)\end{array}$ & $\begin{array}{l}0.14958^{* * *} \\
(13.89071)\end{array}$ \\
\hline $\mathrm{R}^{2}$ & 0.60144 & 0.46702 & 0.58148 \\
\hline Adjusted-R ${ }^{2}$ & 0.59898 & 0.46369 & 0.57807 \\
\hline F-statistic & 244.71080 & 140.48980 & 170.88940 \\
\hline Prob. & 0.00000 & 0.00000 & 0.00000 \\
\hline
\end{tabular}


Table 6. Results of the panel data model regression for different city scales.

\begin{tabular}{|c|c|c|c|c|}
\hline Variables & Super & Large & Medium & Small \\
\hline PGDP & $\begin{array}{l}0.03457^{* *} \\
(2.84485)\end{array}$ & $\begin{array}{l}0.05042^{* * *} \\
(18.34933)\end{array}$ & $\begin{array}{l}0.04568^{* * *} \\
(16.03002)\end{array}$ & $\begin{array}{c}0.03419^{* * * *} \\
(7.08167)\end{array}$ \\
\hline LUI & $\begin{array}{c}0.01767^{* *} \\
(2.93964)\end{array}$ & $\begin{array}{l}0.01306^{* * *} \\
(14.73244)\end{array}$ & $\begin{array}{l}0.01454^{* * * *} \\
(20.52423)\end{array}$ & $\begin{array}{c}0.02121^{* * * *} \\
(16.03803)\end{array}$ \\
\hline POL & $\begin{array}{l}-0.08726 * \\
(-1.9837)\end{array}$ & $\begin{array}{l}-0.15637^{* * *} \\
(-16.84201)\end{array}$ & $\begin{array}{l}-0.12486^{* * *} \\
(-12.81364)\end{array}$ & $\begin{array}{c}-0.13124^{* * *} \\
(-5.42657)\end{array}$ \\
\hline URB & $\begin{array}{c}0.26486^{* *} \\
(2.72825)\end{array}$ & $\begin{array}{l}-0.02016 \\
(-1.0294)\end{array}$ & $\begin{array}{c}-0.05199^{* * * *} \\
(-2.67407)\end{array}$ & $\begin{array}{c}0.09233 \\
(1.80282)\end{array}$ \\
\hline LLP & $\begin{array}{l}-0.00006 \\
(-0.7452)\end{array}$ & $\begin{array}{c}-0.00003 \\
(-0.74724)\end{array}$ & $\begin{array}{c}-0.00058^{* * *} \\
(-4.98737)\end{array}$ & $\begin{array}{c}-0.00099 * * * \\
(-2.98753)\end{array}$ \\
\hline FDI & $\begin{array}{c}0.00317 \\
(1.84166)\end{array}$ & $\begin{array}{c}0.00179 * * * \\
(7.14713)\end{array}$ & $\begin{array}{l}0.00027^{* *} \\
(2.09296)\end{array}$ & $\begin{array}{l}-0.00141 * * \\
(-2.25177)\end{array}$ \\
\hline Constant & $\begin{array}{c}-0.03534 \\
(-0.58574)\end{array}$ & $\begin{array}{c}0.18827 * * * \\
(19.34132)\end{array}$ & $\begin{array}{c}0.19836^{* * * *} \\
(22.51948)\end{array}$ & $\begin{array}{c}0.17421^{* * *} \\
(8.69024)\end{array}$ \\
\hline$R^{2}$ & 0.63134 & 0.65951 & 0.60613 & 0.53565 \\
\hline Adjusted-R ${ }^{2}$ & 0.60986 & 0.65764 & 0.60386 & 0.52918 \\
\hline F-statistic & 29.39783 & 352.52980 & 266.74590 & 82.86234 \\
\hline Prob. & 0.00000 & 0.00000 & 0.00000 & 0.00000 \\
\hline
\end{tabular}

As for the land leasing policy (LLP), it has negative impacts on ULUEE in all the three regions and four types of city scale groups, which is consistent with the hypotheses. This may indicate that making up for the deficit by selling land resources is not a wise choice. In addition, the proportion of foreign enterprises' output account for the total output in the secondary and tertiary industries (FDI) has positive impacts on ULUEE in all the three regions and four types of city scale groups except small-scale cities, this may imply that small-scale cities should attract more foreign investment and expand the scale of economic development.

\section{Conclusions and Discussion}

\subsection{Conclusions}

Based on the SSBM model, this paper analyzes the spatial and temporal disparities and influencing factors of ULUEE for 270 cities in China during 2003-2012. The main conclusions are as follows.

(1) Undesirable outputs such as industrial pollutants have obvious negative effects on the ULUEE, and it is necessary to take undesirable outputs into account in order to make a precise evaluation of ULUEE. Out of 270 cities, there are only six cities that were always efficient in urban land use in the study period, and the average ULUEE for the cities considered is only 0.411. It is worth noting that all the six cities are located in the eastern region. In addition, poor modes of land use still exist in most cities in China, and their ULUEEs have much room to improve.

(2) The eastern region of China enjoys the highest ULUEE, followed by the western and central regions. The cities that have relatively high ULUEEs are mainly located in areas with relatively developed economies, such as the Yangtze River Delta and the Pearl River Delta. Super-scale cities show the best ULUEE out of all four scales, followed by large-scale, small-scale and medium-scale cities. The level of economic development and industrial layout play important roles on the ULUEE. Cities with developed economies, high economic output, and low pollution perform 
better in land use, while others suffer from poor land use efficiency due to less developed economies and more heavily polluting industries.

(3) The results of slack variables analysis show that most cities have problems in the unreasonable use of funds, labor surplus, over-development, the excessive discharge of pollutants, and economic output shortage. Therefore, a series of targeted policies should be introduced to improve ULUEE in China.

(4) Increases in the per capita GDP (PGDP) and land use intensity (LUI) are helpful to raise the ULUEE of cities in all the three regions and four city scales, which is consistent with our hypotheses. The urbanization rate (URB) has the same effect only in the eastern region and super-scale cities, and the proportion of foreign enterprises' output account for the total output in the secondary and tertiary industries (FDI) has the same effect only in the central and western regions, and large-scale and medium-scale cities. However, both the land management policy (POL) and land leasing policy (LLP) have negative impact on the ULUEE in all the three regions and four city scales, indicating that the ineffective implementation of central government land management policies and unsustainable land leasing methods are not good for local governments to improve their ULUEE.

(5) Some measures are suggested to improve ULUEE, including the reduction of surplus labor, and paying more attention to environmental protection. It is worth noting that policy factors are more critical, we can realize obvious improvement in the ULUEE of Chinese cities by effectively implementing the central government's land management policies, and stopping blindly leasing land to make up for the local government's financial deficit.

\subsection{Discussion}

This study incorporates environmentally undesirable outputs into the SSBM framework to evaluate ULUEE, yielding results that are more consistent with actual conditions. However, there are still some limitations. For instance, only three industrial pollutants are selected to represent environmentally undesirable outputs, and the pollutants from industrial wastewater such as chemical oxygen demand and ammoniacal nitrogen are not considered due to the unavailability of data. Additionally, humanistic factors such as human capital are not considered in this paper for the same reason, which is to be improved in further work.

Acknowledgments: This study was supported by the National Natural Science Foundation of China (No. 41361111) and the Natural Science Foundation of Jiangxi Province (No. 20143ACB21023 and No. 20142BAB203028), the Fok Ying Tung Foundation (No. 141084), the Technology Foundation of Jiangxi Education Department of China (No. KJLD14033), and the Social Science Foundation of Jiangxi Province (No. 13GL05).

Author Contributions: Hualin Xie and Wei Wang had the original idea for the study. Wei Wang was responsible for data collecting. Hualin Xie and Wei Wang carried out the analyses. Both authors drafted the manuscript, and approved the final one. Both authors have read and approved the final manuscript.

Conflicts of Interest: The authors declare no conflict of interest.

\section{References}

1. Halleux, J.M.; Marcinczak, S.; Krabben, E. The adaptive efficiency of land use planning measured by the control of urban sprawl. The cases of the Netherlands, Belgium and Poland. Land Use Policy 2012, 29, 887-898. [CrossRef]

2. Ministry of Housing and Urban-Rural Construction of the People's Republic of China. China Urban Construction Statistical Yearbook; China Planning Press: Beijing, China, 2013. (In Chinese)

3. Li, J.; Deng, J.; Wang, K.; Li, J.; Huang, T.; Lin, Y.; Yu, H. Spatiotemporal Patterns of Urbanization in a Developed Region of Eastern Coastal China. Sustainability 2014, 6, 4042-4058. [CrossRef]

4. Long, H.L.; Liu, Y.S.; Wu, X.Q.; Dong, G.H. Spatio-temporal dynamic patterns of farmland and rural settlements in Su-Xi-Chang region: Implications for building a new countryside in coastal China. Land Use Policy 2009, 26, 322-333. [CrossRef] 
5. Gong, J.; Chen, W.; Liu, Y.; Wang, J. The intensity change of urban development land: Implications for the city master plan of Guangzhou, China. Land Use Policy 2014, 40, 91-100. [CrossRef]

6. Wu, Y.L.; Qu, F.T. Mechanism of intensive urban land use in China: Theoretical and practical study. Resour. Sci. 2007, 29, 106-113. (In Chinese)

7. Wang, J.; Chen, Y.; Shao, X.; Zhang, Y.; Cao, Y. Land-use changes and policy dimension driving forces in China: Present, trend and future. Land Use Policy 2012, 29, 737-749. [CrossRef]

8. Zhang, N.; Kong, F.; Yu, Y. Measuring ecological total-factor energy efficiency incorporating regional heterogeneities in China. Ecol. Indic. 2015, 51, 165-172. [CrossRef]

9. Li, X.; Yeh, A.G.O. Analyzing spatial restructuring of land use patterns in a fast growing region using remote sensing and GIS. Landsc. Urban Plan. 2004, 69, 335-354. [CrossRef]

10. Meng, Y.; Zhang, F.R.; An, P.L.; Dong, M.L.; Wang, Z.Y.; Zhao, T. Industrial land-use efficiency and planning in Shunyi, Beijing. Landsc. Urban Plan. 2008, 85, 40-48. [CrossRef]

11. Xinhua News Agency. Water pollution control law of the People's Republic of China. Available online: http:/ / www.gov.cn/flfg/2008-02/28/content_905050.htm (accessed on 28 February 2008). (In Chinese)

12. Chapin, F.S.; Kaiser, E.J. Urban Land Use Planning, 3rd ed.; University of Illinois Press: Champaign, IL, USA, 1967.

13. Koopmans, T.C.; Beckman, M.J. Assignment Problems and the Location of Economic Activities. Econometrica 1957, 25, 53-76. [CrossRef]

14. Webber, M.M. Explorations into Urban Structure; Philadelphia University Press: Philadelphia, PA, USA, 1964.

15. Harvey, D. The Urban Process under Capitalism. Int. J. Urban Reg. Res. 1978, 2, 101-131. [CrossRef]

16. Fisch, O. Optimal allocation of land to transportation in a non-optimal urban structure. Reg. Sci. Urban Econ. 1982, 12, 235-246. [CrossRef]

17. Marull, J.; Pino, J.; Tello, E.; Cordobilla, M.J. Social metabolism, landscape change and land-use planning in the Barcelona Metropolitan Region. Land Use Policy 2010, 27, 497-510. [CrossRef]

18. Hartmann, T.; Spit, T. Dilemmas of involvement in land management-Comparing an active (Dutch) and a passive (German) approach. Land Use Policy 2015, 42, 729-737. [CrossRef]

19. Sui, D.Z. GIS-based urban modeling: Practices, problems and prospects. Int. J. Geogr. Inf. Sci. 1998, 12, 651-671. [CrossRef] [PubMed]

20. Yang, Q.; Wan, X.; Ma, H. Assessing Green Development Efficiency of Municipalities and Provinces in China Integrating Models of Super-Efficiency DEA and Malmquist Index. Sustainability 2015, 7, 4492-4510. [CrossRef]

21. Lin, W.; Chen, B.; Xie, L.; Pan, H. Estimating Energy Consumption of Transport Modes in China Using DEA. Sustainability 2015, 7, 4225-4239. [CrossRef]

22. Huang, M.; Wang, B. Evaluating green performance of building products based on gray relational analysis and analytic hierarchy process. Environ. Prog. Sustain. Energy 2014, 33, 1389-1395. [CrossRef]

23. Zhou, S.; Feng, J. University Teachers' Performance Comprehensive Evaluation Based on Principal Component Analysis. High. Educ. Soc. Sci. 2015, 8, 34-39.

24. Xie, H.; Wang, W. Spatiotemporal differences and convergence of urban industrial land use efficiency for China's major economic zones. J. Geogr. Sci. 2015, 25, 1183-1198.

25. Tone, K. A slacks-based measure of efficiency in data envelopment analysis. Eur. J. Oper. Res. 2001, 130, 498-509. [CrossRef]

26. Zhang, N.; Kim, J.D. Measuring sustainability by Energy Efficiency Analysis for Korean Power Companies: A Sequential Slacks-Based Efficiency Measure. Sustainability 2014, 6, 1414-1426. [CrossRef]

27. Färe, R.; Grosskopf, S.; Fukuyama, H. New Directions: Efficiency and Productivity; Springer: New York, NY, USA, 2005.

28. Wang, H.; Wang, L.; Su, F.; Tao, R. Rural residential properties in China: Land use patterns, efficiency and prospects for reform. Habitat Int. 2011, 36, 201-209. [CrossRef]

29. Wang, Q.; Zhao, Z.; Shen, N.; Liu, T. Have Chinese cities achieved the win-win between environmental protection and economic development? From the perspective of environmental efficiency. Ecol. Indic. 2015, 51, 151-158. [CrossRef]

30. Wang, K.; Zhang, P. The Research on Impact Factors and Characteristic of Cultivated Land Resources Use Efficiency-take Henan Province, China as a Case Study. IERI Procedia 2013, 5, 2-9. [CrossRef] 
31. Ministry of Land and Resources of the People's Republic of China. Notice of the relevant issues concerning the adjustment for approval of urban construction land from the State Council. Available online: http: //www.mlr.gov.cn/zwgk/zytz/200701/t20070123_79059.htm (accessed on 23 January 2007). (In Chinese)

32. Zhang, Z. Study of Chinese urban land use efficiency. J. Quant. Tech. Econ. 2014, 7, 134-149. (In Chinese)

33. Jiang, X.; Zhu, K.; Green, C. The energy efficiency advantage of foreign-invested enterprises in China and the role of structural differences. China Econ. Rev. 2015, 34, 225-235. [CrossRef]

34. The Central People's Government of the People's Republic of China. Water pollution prevention and control law of the People's Republic of China. Available online: http://www.zswj3fj.com/newsinfo.aspx?NId= 12995\&NodeID=165 (accessed on 28 February 2008). (In Chinese)

35. Choi, Y.; Zhang, Y.; Zhou, P. Efficiency and abatement costs of energy-related $\mathrm{CO}_{2}$ emissions in China: A slacks-based efficiency measure. Appl. Energy 2012, 98, 198-208. [CrossRef]

36. Wan, Z.; Zhang, Y.; Wang, X.; Chen, J. Policy and politics behind Shanghai's Free Trade Zone Program. J. Transp. Geogr. 2014, 34, 1-6. [CrossRef]

37. Cai, Z.; Song, Y. Environmental Protection Investment and Sustainable Development-Policy Simulation Based on Nonlinear Dynamics. Energy Procedia 2011, 5, 467-471.

38. Xiao, Q.; Zong, Y.; Lu, S. Assessment of heavy metal pollution and human health risk in urban soils of steel industrial city (Anshan), Liaoning, Northeast China. Ecotoxicol. Environ. Saf. 2015, 120, 377-385.

39. 21st Century Economic Report. Strict land policy and ineffective implementation. Available online: http:/ / www.nctudi.com/news_show.php/id-21849 (accessed on 28 February 2012). (In Chinese)

(C) 2015 by the authors. Licensee MDPI, Basel, Switzerland. This article is an open access article distributed under the terms and conditions of the Creative Commons Attribution (CC BY) license (http:/ / creativecommons.org/licenses/by/4.0/). 



\section{MDPI}

St. Alban-Anlage 66

4052 Basel

Switzerland

Tel. +41 616837734

Fax +41 613028918

www.mdpi.com

Sustainability Editorial Office

E-mail: Sustainability@mdpi.com www.mdpi.com/journal/sustainability

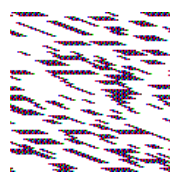





\section{MDPI}

St. Alban-Anlage 66

4052 Basel

Switzerland

Tel: +41 616837734

Fax: +41 613028918 